\author{
UNIVERSIDADE ESTADUAL PAULISTA \\ Instituto de Geociências e Ciências Exatas \\ Campus de Rio Claro
}

\title{
ANÁLISE COMBINATÓRIA NO ENSINO MÉDIO APOIADA NA METODOLOGIA DE ENSINO-APRENDIZAGEM- AVALIAÇÃO DE MATEMÁTICA ATRAVÉS DA RESOLUÇÃO DE PROBLEMAS
}

Analucia Castro Pimenta de Souza

Orientadora: Profa. Dra. Lourdes de la Rosa Onuchic

Dissertação de Mestrado elaborada junto ao Curso de Pós-Graduação em Educação Matemática - Área de Ensino e Aprendizagem da Matemática e seus Fundamentos Filosófico-Científicos, para obtenção do Título de Mestre em Educação Matemática. 
510.07 Souza, Analucia Castro Pimenta de Análise combinatória no ensino médio apoiada na metodologia de ensino-aprendizagem-avaliação de matemática através da resolução de problemas / Analucia Castro Pimenta de Souza. - Rio Claro : [s.n.], 2010

343 f. : il., figs., tabs., quadros

Dissertação (mestrado) - Universidade Estadual Paulista, Instituto de Geociências e Ciências Exatas

Orientador: Lourdes de la Rosa Onuchic

1. Matemática - Estudo e ensino. 2. Matemática discreta. 3. Educação matemática. I. Título.

Ficha Catalográfica elaborada pela STATI - Biblioteca da UNESP

Campus de Rio Claro/SP 


\section{Comissão Examinadora}

$\overline{\text { Profa. Dra. Rosana Giaretta Sguerra Miskulin }}$

Profa. Dra. Raquel Normandia Moreira Brumatti

Profa. Dra. Lourdes de la Rosa Onuchic

Analucia Castro Pimenta de Souza

(Aluna)

Rio Claro, 24 de fevereiro de 2010

Resultado: Aprovada. 


\section{DEDICATÓRIA}

Aos meus pais, Maria Teresa e Sérgio, que sempre estiveram presentes, com amor incondicional, me incentivando e me apoiando em todos os momentos. São meus exemplos de vida, de trilhar um caminho com coragem, fé e ideal. Sem eles não seria possível chegar até aqui. 


\section{AGRADECIMENTOS}

A Deus, pela minha vida, pela minha família, pela proteção, por ter me dado força nos momentos difíceis e por me abençoar com tantas pessoas que contribuíram para a realização deste trabalho.

Aos meus pais, Maria Teresa e Sérgio, por terem me concedido a vida, pelo amor, pela dedicação, pela segurança, pela confiança, por me mostrarem o valor do estudo e por entenderem e suportarem minha ausência. Esta conquista também é de vocês.

Aos meus irmãos, Eduardo e Sérgio, e às minhas cunhadas, Andrea e Fabiana, que sempre me incentivaram durante este trabalho. Obrigada pelo amor e por compreenderem minha ausência em diversos momentos.

Ao meu sobrinho Arthur, pela alegria que irradia e me faz mais feliz.

Ao Rodrigo, meu amor, que sempre esteve ao meu lado, tendo paciência nas minhas ausências, me apoiando com compreensão, carinho e amor. Agradeço também aos seus pais, Carla e Antônio Flávio, que me acolheram com carinho aqui em Rio Claro.

À Dona Lourdes, pela dedicação, pela paciência, pela confiança, pela amizade e que me proporcionou, em inúmeras orientações, mais do que momentos de aprendizagem, mas aprender 'ver com os olhos da mente' o que é ser um pesquisador. Mais uma vez, muito obrigada.

Aos professores Dra. Rosana Giaretta Sguerra Miskulin e Dr. Sérgio Lorenzato, membros da comissão examinadora, pelas valiosas contribuições no Exame de Qualificação.

Aos colegas do Programa de Pós-Graduação em Educação Matemática, pela amizade e pelos momentos de alegria e de estudo.

Aos professores e funcionários da PGEM, pelos momentos de convivência durante este período de Mestrado.

À secretária da Pós-Graduação, Inajara, e às secretárias do departamento de Matemática, Ana e Elisa, pela disponibilidade e atenção no atendimento.

Aos membros do Grupo de Trabalho e Estudos em Resolução de Problemas - GTERP, Raquel A., Malu, Graci, Raquel B., Célia, Marcos, Eliane, Paulo, Norma, Tatiane e Miriam, pelo estudo, pelas sugestões dadas sobre minha pesquisa e pelas comemorações, proporcionando valiosos momentos de descontração. Enfim, pelas amizades que conquistei.

Aos meus irmãos de orientação, Célia e Marcos, pela amizade, pela paciência e por dividir os desabafos nos momentos de desânimo. 
Aos meus amigos, de perto e de longe, que souberam entender os momentos de ausência, mas que sempre me incentivaram.

À Secretaria da Educação do Estado de São Paulo pelo apoio financeiro. 
A Palavra Mágica

Certa palavra dorme na sombra de um livro raro

Como desencantá-la?

É a senha da vida

a senha do mundo.

Vou procurá-la.

Vou procurá-la a vida inteira

no mundo todo.

Se tarda o encontro, se não a encontro, não desanimo,

procuro sempre.

Procuro sempre, e minha procura ficará sendo minha palavra.

Carlos Drummond de Andrade 


\section{RESUMO}

Esta pesquisa tem como objetivo trabalhar a Análise Combinatória, fazendo uso da Metodologia de Ensino-Aprendizagem-Avaliação de Matemática através da Resolução de Problemas. Abordamos, em nossa fundamentação teórica, a Análise Combinatória contida na Matemática Discreta, iniciando a pesquisa com uma introdução histórica da Análise Combinatória, seguida por uma análise de livros didáticos e pela busca de trabalhos de outros autores que se referiam ao ensino e à aprendizagem desse conteúdo. Criamos três projetos para trabalhar com a metodologia de ensino adotada por nós, em três cenários diferentes, onde a pesquisadora assumiu três posturas diferentes frente ao problema da pesquisa: como uma professora-pesquisadora, com seus próprios alunos, em sua sala de aula; como uma pesquisadora, ministrando uma oficina de trabalho, em um encontro de Educação Matemática, tendo como participantes, professores, educadores matemáticos e até alunos da Licenciatura em Matemática; e, como uma pesquisadora, em Encontros em Educação Matemática, divulgando sua pesquisa. Através da análise dos dados, obtidos nas aplicações dos três projetos, pudemos mostrar como os participantes desses projetos se envolveram ao fazer uso da metodologia de ensino adotada e relatamos as contribuições que trouxeram para nossa pesquisa. Verificamos que houve envolvimento ativo dos participantes na construção de novos conceitos e conteúdos, através da resolução dos problemas propostos, por meio de um trabalho investigativo, que proporcionou uma aprendizagem com compreensão e significado, com resultados importantes para a prática docente. Esta pesquisa foi desenvolvida seguindo a Metodologia de Pesquisa apresentada por Thomas A. Romberg.

Palavras-chave: Resolução de Problemas. Ensino-Aprendizagem-Avaliação de Matemática através da Resolução de Problemas. Matemática Discreta. Análise Combinatória. Educação Matemática. 


\begin{abstract}
This paper has the objective to study the Combinatory Analysis using Methodology of Teaching-Learning-Assessment of Mathematics through Problem Solving. In our theoretical fundamentation we address the Combinatory Analysis contained in the Discrete Mathematics, starting the research with a historical introduction of the Combinatory Analysis followed by a review of textbooks and the search for other author's articles concerning this content's teaching and learning. We have developed three projects to apply the teaching methodology we adopted in three different settings, where the researcher played three distinct roles facing the research's problem: a) as a teacher-researcher, with her own students in her own classroom; b) as a researcher, conducting a workshop in a Mathematical Education conference, with teachers, mathematics educators and graduate students; c) as a researcher, in Mathematics Education Conferences divulgating her research. By analyzing all the data obtained in the application of the three projects we could show how the participants were engaged in using the adopted teaching methodology and we also reported the contributions they have brought to our research. We could verify that there was significant involvement from all the participants in the construction of new concepts and contents by solving the proposed problems in an investigative way, providing a different learning, full of understanding and meaning, with very significant results in terms of teaching practice. This research was developed following the Research Methodology presented by Thomas A. Romberg.
\end{abstract}

Key words: Problem Solving. Methodology of Teaching-Learning-Assessment of Mathematics through Problem Solving. Discrete Mathematics. Combinatory Analysis. Mathematics Education. 


\section{ÍNDICE DE ILUSTRAÇÕES}

Página

Figura 1 - A relação de sociedade, matemática, alunos, professores e escolarização............. 24

Figura 2 - Relações entre sociedade, escola, aluno, professor e saber................................... 25

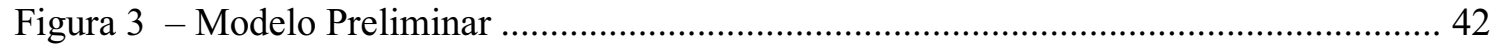

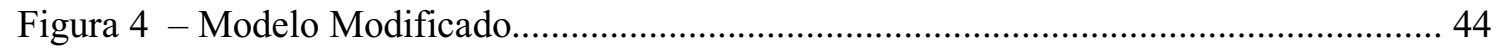

Figura 5 - Triângulo Aritmético apresentado por Pascal....................................................... 62

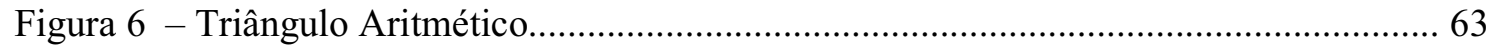

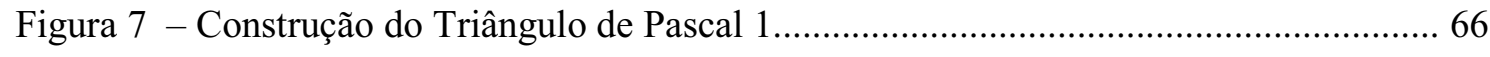

Figura 8 - Construção do Triângulo de Pascal 2 .................................................................... 66

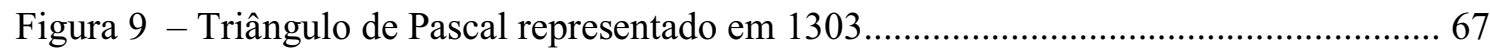

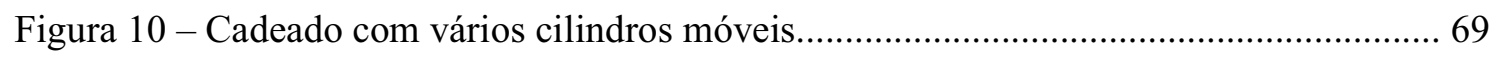

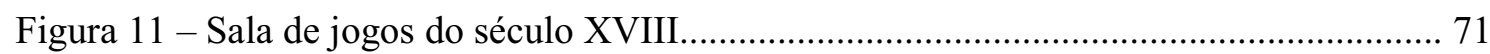

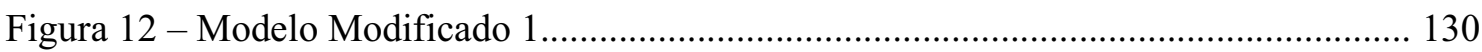

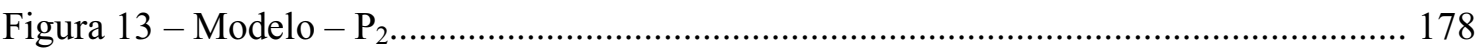

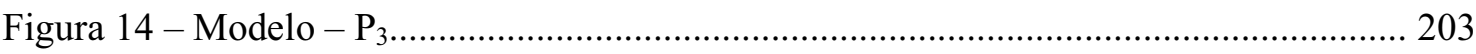


1.1 - Visão dos pesquisadores sobre pesquisa................................................ 20

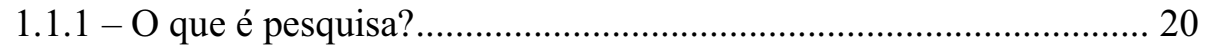

1.1.2 - Pesquisa em Educação Matemática................................................. 21

1.2 - Metodologia de Pesquisa.................................................................... 23

1.3 - Metodologia de Thomas A. Romberg................................................... 23

1.3.1 - Educação Matemática como um campo de estudo........................... 24

1.3.2 - As atividades dos pesquisadores (Fluxograma de Romberg)......... 26

1.3.3 - Os métodos de pesquisa usados pelos pesquisadores.................... 31

\section{CAPÍTULO 2 - Identificação do Problema da Pesquisa - Iniciando a pesquisa (1ํㅡㄹ bloco}

de Romberg)__ 34

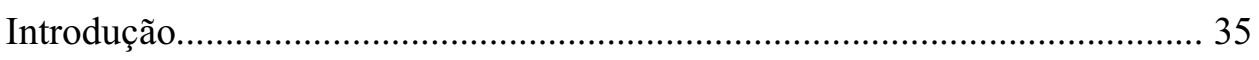

2.1 - Fenômeno de Interesse................................................................. 36

2.1.1 - Minha trajetória pessoal e profissional........................................ 36

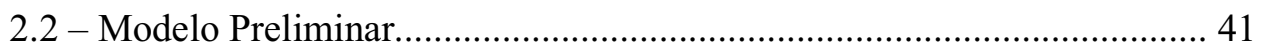

2.2.1 - Modelo Modificado........................................................................... 43

2.3 - Relacionar o Fenômeno de Interesse e o Modelo Modificado com ideias

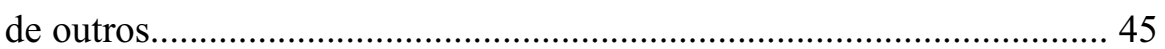

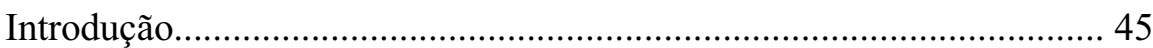

2.3.1 - Matemática Discreta...................................................................... 45

2.3.2 - A História da Análise Combinatória............................................. 58

2.3.3 - Análise Combinatória............................................................. 72

2.3.3.1 - Análise do tópico Análise Combinatória, nos livros

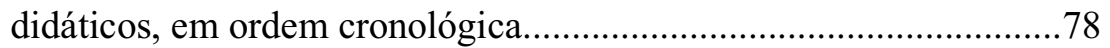

2.3.3.2 - Documentos Legais: A visão do ensino de Análise Combinatória ao longo das reformas ocorridas no ensino de

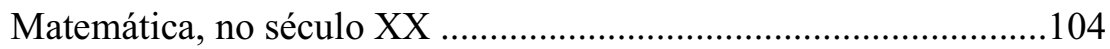

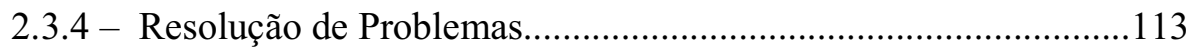

2.3.4.1 - História da Pesquisa em Resolução de Problemas.............114 
3.1 - Selecionar Estratégias e Procedimentos de Pesquisa

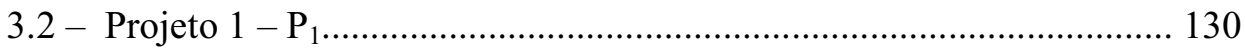

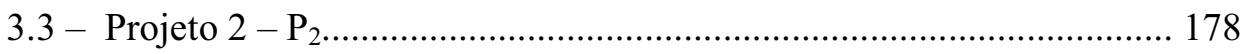

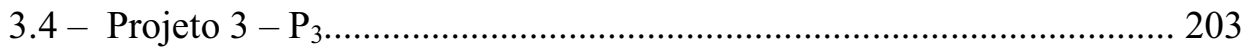

CAPÍTULO 4 - Procedimento Geral em ação - Aplicação dos três projetos 218

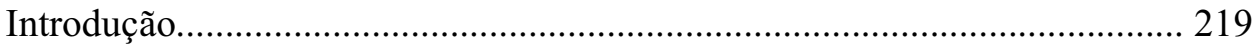

4.1 - A aplicação do Projeto 1........................................................................ 222

4.2 - A aplicação do Projeto 2 2...................................................................... 269

4.3 - A aplicação do Projeto 3....................................................................... 282

CAPÍTULO 5 - Resultados e Reflexões ( $3^{0}$ bloco de Romberg)

5.1 - Coletar, Interpretar e Relatar as evidências coletadas diante do Problema da Pesquisa 290

5.1.1 - Projeto 1 291

5.1.2 - Projeto 2. 293

5.1.3 - Entrevista.. 296

5.1.4 - Projeto 3. 301

5.2 - Antecipar as Ações de Outros 304

5.2.1 - Reflexões e posições da professora-pesquisadora pós-pesquisa. 


\section{INTRODUÇÃO}

Esta pesquisa abrange dois eixos temáticos: Análise Combinatória, contida na Matemática Discreta, e Resolução de Problemas.

A escolha do tema, Análise Combinatória, para este trabalho decorreu das minhas experiências vividas enquanto estudante, professora e pesquisadora.

Durante os ensinos Fundamental e Médio, a minha aptidão e o interesse pela Matemática sempre estiveram presentes. Realizava as atividades, propostas pelo professor, sem apresentar muitas dificuldades. Eu tinha uma dedicação maior a essa disciplina e, também, às outras disciplinas da área de exatas. Diante das dificuldades, não desanimava, mesmo ouvindo comentários dos colegas que não gostavam de Matemática. Ao cursar Bacharelado e Licenciatura em Matemática, aprofundou-se mais meu conhecimento matemático.

O interesse em pesquisar na área de Educação Matemática surgiu com as dificuldades encontradas ao ministrar minhas primeiras aulas. Senti a necessidade de um respaldo teórico e metodológico que, de fato, pudessem contribuir para minha formação de professor e, consequentemente, proporcionar aos alunos uma aprendizagem com significado e, ao profissional, uma metodologia de ensino diferente da tradicional.

Desse modo, fiz o Curso de Especialização em Educação Matemática, em que tive meu primeiro contato com os fundamentos em Educação Matemática. Nessa mesma época, participei do GTERP (Grupo de Trabalho e Estudos em Resolução de Problemas) do 
Programa de Pós-Graduação em Educação Matemática, da UNESP de Rio Claro/SP, onde conheci uma metodologia de ensino alternativa.

Decidi escolher, como tema para a monografia desse curso, Análise Combinatória, pois este sempre fora um conteúdo em que encontrava dificuldade, não conseguindo associar as fórmulas que se lhe apresentavam com os conceitos pertinentes a esse tópico matemático. Nesse trabalho foi feito um levantamento bibliográfico do tema.

Desse modo, atuar como professora, abordando esse conteúdo, era-me um desafio. Assim, desenvolver o tema desta pesquisa, adotando como metodologia de trabalho para a sala de aula, a Metodologia de Ensino-Aprendizagem-Avaliação de Matemática através da Resolução de Problemas, surgiu naturalmente do interesse em dar continuidade a esse trabalho. Sendo que esta forma de trabalhar Matemática com Resolução de Problemas é bastante diferente da forma de trabalhar com heurísticas ou estratégias, segundo Polya. Na metodologia adotada para este trabalho, em sala de aula, o problema é ponto de partida e, durante sua resolução, são construídos conceitos e conteúdos novos com a participação ativa dos alunos.

Apresentamos, como objetivo principal desta pesquisa, criar uma proposta de trabalho para abordar Análise Combinatória em sala de aula, utilizando a Metodologia de EnsinoAprendizagem-Avaliação de Matemática através da Resolução de Problemas.

Ao fazer a apresentação deste nosso trabalho de pesquisa, procuramos seguir os passos trabalhados ao longo de seu desenvolvimento.

No Capítulo 1 - Metodologia de Pesquisa - apresentamos um suporte teórico sobre metodologias de pesquisa. Descrevemos a visão de alguns autores sobre o que vem a ser pesquisa de um modo geral e, em particular, a pesquisa em Educação Matemática. Descrevemos a metodologia de pesquisa adotada para desenvolver este trabalho, apresentada por Thomas A. Romberg em seu artigo, de 1992, intitulado Perspectives on Scholarship and Research Methods. Essa metodologia é composta por uma sequência de dez atividades, descritas por Romberg, num fluxograma, que orientarão os novos pesquisadores e explicitam o transcorrer da pesquisa. Ao conjunto dessas atividades denominamos Metodologia de Thomas A. Romberg. Essas dez atividades estão distribuídas em três blocos: o primeiro bloco trata da identificação do problema (atividades 1, 2, 3 e 4); o segundo bloco apresenta uma proposta de resolução desse problema, no qual estratégias e procedimentos de trabalho são levantados e selecionados (atividades 5 e 6); e o terceiro e último bloco que, após o procedimento geral ser posto em ação, trata da análise das informações obtidas, buscando tudo o que ficou evidente diante da questão ou conjectura levantada (atividades 7, 8, 9 e 10). 
No Capítulo 2 - Identificação do Problema de Pesquisa - Iniciando a Pesquisa, $1^{\underline{o}}$ bloco de Romberg, demos início à nossa pesquisa trabalhando sobre as quatro primeiras atividades: identificar um Fenômeno de Interesse; construir um Modelo Preliminar; relacionar o Fenômeno de Interesse e o Modelo Preliminar com ideias de outros pesquisadores; levantar questões específicas ou fazer uma conjectura plausível, levando à identificação do problema de pesquisa.

Descrevi, a partir da minha trajetória pessoal e profissional, como cheguei ao Fenômeno de Interesse, mostrando que havia um envolvimento com um tópico matemático e a preocupação com seu ensino. Decorrente dessa trajetória, definimos o Fenômeno de Interesse a ser pesquisado: Trabalhar Análise Combinatória, em sala de aula do Ensino Médio, a partir da Metodologia de ensino-aprendizagem-avaliação de Matemática através da resolução de problemas.

Para delinearmos um caminho a ser seguido durante a pesquisa, construímos, dentro da Metodologia de Romberg, um Modelo Preliminar que apresentava uma sequência de passos organizados a serem seguidos, envolvendo variáveis relativas ao fenômeno de interesse e às relações implícitas entre elas.

$\mathrm{Na}$ sequência, trabalhamos sobre a fundamentação teórica necessária à nossa pesquisa. Relacionamos com ideias de outros, ou seja, o que outros pesquisadores pensam sobre o nosso fenômeno de interesse criado e, também, como essas ideias podem explicar, ampliar ou até modificar o modelo preliminar proposto. Nossa pesquisa está fundamentada em dois eixos: Análise Combinatória, contida na Matemática Discreta, e Resolução de Problemas, vista como uma metodologia de ensino. O fato de conhecer como outros autores abordam esses eixos, trouxe-nos referências teóricas relevantes para este trabalho, pois possibilitaram a ampliação das investigações durante o seu transcorrer.

As principais fontes de pesquisa das quais fizemos uso foram: livros didáticos e acadêmicos, os PCN-EM (Parâmetros Curriculares Nacionais - Ensino Médio - Matemática); as Propostas Curriculares do Estado de São Paulo, de 1989 (2ª edição) e de 2008; artigos em revistas; teses e dissertações. Ainda foi aplicada uma entrevista a um professor de Matemática, do Ensino Médio, que trabalhava, na ocasião, Análise Combinatória em sua sala de aula. Também, fizemos uso de documentos do NCTM - National Council of Teachers of Mathematics - USA (Conselho Nacional de Professores de Matemática dos Estados Unidos). Tratamos a Matemática Discreta como um ramo da Matemática, da qual a Análise Combinatória faz parte. Descrevemos o que é Matemática Discreta, falamos sobre sua 
aplicabilidade, sua forma de ensino e de quando se deu sua inserção no currículo da matemática escolar americana.

A investigação sobre Matemática Discreta foi, para nós, nova e a consideramos relevante para esta pesquisa, pois percebemos o desconhecimento desse ramo matemático no nosso meio acadêmico. Em relação à Análise Combinatória, iniciamos o trabalho relatando sobre sua gênese no contexto histórico. Nos livros de História da Matemática, a localização desse conteúdo foi, por nós, detectada de forma esparsa. Percebemos então que, ao longo da história, a partir do trabalho feito com Probabilidade, a história da Análise Combinatória foi sistematizada.

Ainda, neste capítulo, analisamos doze livros didáticos, dispostos em ordem cronológica - livros das décadas de 40, 50, 60, 70, 90 e anos 2000. Estabelecemos alguns critérios para analisar os livros didáticos selecionados, com o objetivo de saber como a Análise Combinatória é neles abordada. Pudemos concluir que a maioria desses livros apresenta Análise Combinatória nos moldes do ensino tradicional.

Para o segundo eixo temático de nossa fundamentação teórica - Resolução de Problemas -, investigamos a história da pesquisa em resolução de problemas, mostramos as diferentes concepções assumidas sobre resolução de problemas no processo de ensinoaprendizagem de Matemática; e a resolução de problemas vista como uma metodologia de ensino. Assim, apoiadas nesse estudo feito, pudemos sentir, justificar, mostrar a aceitação da resolução de problemas para esta pesquisa e deixar clara a concepção, defendida por nós, ao ver a resolução de problemas como uma forte aliada no processo de ensino-aprendizagem.

Adotamos para o trabalho em sala de aula, dentro desta pesquisa, a Metodologia de Ensino-Aprendizagem-Avaliação de Matemática através da Resolução de Problemas. A palavra composta ensino-aprendizagem-avaliação significa que o ensino e a aprendizagem devem ocorrer simultaneamente, durante o processo de construção de um determinado conceito ou conteúdo. E a avaliação, integrada ao ensino, contribui para a melhora da aprendizagem.

A partir daí, definimos nosso problema de pesquisa: Qual é a contribuição da Metodologia de Ensino-Aprendizagem-Avaliação de Matemática através da Resolução de Problemas em uma nova abordagem, em sala de aula, da Análise Combinatória? Mas, também, com ela aparecia uma outra forte questão: Como se desenvolve a formação de conceitos de Análise Combinatória, adotando-se a Resolução de Problemas como uma metodologia de ensino? de aprendizagem? e de avaliação? 
Parecia-nos que essas duas perguntas tinham algo em comum e eram complementares. Mas, questionando-nos, ainda, perguntávamos: há alguma diferença essencial entre as duas? Com a primeira, envolvendo mais a força da metodologia adotada, poderíamos contribuir para a construção de uma nova abordagem para trabalhar Análise Combinatória, uma linha de trabalho para o professor. Com a segunda, mostrando mais preocupação com a aprendizagem dos alunos, buscaríamos um caminho para a construção de novos conceitos e novos conteúdos, tendo os alunos como coconstrutores desse conhecimento e o professor como um veículo para conduzir essa construção. Como essas duas colocações parecem se ajustar uma à outra, decidimos que a pergunta diretriz de nossa pesquisa poderia surgir numa sequência em que a primeira, quando respondida, poderia levar à resposta da segunda.

No Capítulo 3 - Dando continuidade à pesquisa - $2^{\underline{o}}$ bloco de Romberg, refletimos sobre as muitas contribuições que recebemos de nossos "outros" ao percebermos que ela, a nossa pesquisa, pedia mais. Decidimos que eu assumiria três posturas diferentes diante do problema da pesquisa: como uma professora-pesquisadora, trabalhando em sua própria sala de aula, com seus próprios alunos; como uma pesquisadora, ministrando minicursos e oficinas de trabalho, em encontros de Educação Matemática, com professores, educadores matemáticos e até alunos da Licenciatura em Matemática; e como uma pesquisadora que se apresentasse em Congressos e Encontros de Educação Matemática, oferecendo suas próprias pesquisas, para conhecimento e divulgação delas a outros pesquisadores e para discussão e análise.

Para prosseguir nossa pesquisa, nosso modelo foi modificado, e definimos um novo modelo constituído por três diferentes partes: o Projeto 1 - $\mathbf{P}_{\mathbf{1}}$, o Projeto 2- $\mathbf{P}_{\mathbf{2}}$ e o Projeto 3- $\mathbf{P}_{\mathbf{3}}$, cada um deles destinado a atender, respectivamente, à postura da pesquisadora em cada uma das visões acima. Assim, como Estratégia Geral de nossa Pesquisa, criamos os três projetos $\mathbf{P}_{1}, \mathbf{P}_{2}$ e $\mathbf{P}_{3}$, adotando, para os três, a Metodologia de Ensino-Aprendizagem-Avaliação de Matemática através da Resolução de Problemas, com o objetivo de responder à Pergunta da Pesquisa segundo três visões diferentes. Como Procedimento Geral, elaboramos a criação desses três projetos, que foram aplicados separadamente.

No Capítulo 4 - Procedimento Geral em ação - Aplicação dos três projetos, descrevemos o que ocorreu quando o Procedimento Geral foi posto em ação, ou seja, o que aconteceu nas aplicações dos projetos $\mathrm{P}_{1}, \mathrm{P}_{2}$ e $\mathrm{P}_{3}$. Nos três projetos evidenciamos o trabalho em sala de aula, adotando a Metodologia de Ensino-Aprendizagem-Avaliação de Matemática através da Resolução de Problemas, proporcionando aos alunos uma aprendizagem com significado e compreensão. O problema é o ponto de partida no processo de ensino- 
aprendizagem-avaliação de Matemática. Assim, temos que essa metodologia é um meio de se aprender Matemática ao longo da resolução de problemas.

No Capítulo 5 - Reflexões e Resultados - $3^{-}$bloco de Romberg - Dar sentido às evidências coletadas e relatar os resultados para outros, apresentamos nossa visão dos dados obtidos, daquilo que nos ficou evidente nas aplicações dos projetos. Neste capítulo, fizemos uma análise das informações obtidas após o Procedimento Geral ser posto em ação, para os projetos $\mathrm{P}_{1}$ e $\mathrm{P}_{2}$, buscando tudo o que ficou evidente diante das questões levantadas em nossa pesquisa. Realizamos reflexão sobre as ações feitas durante essas aplicações e interpretamos as evidências obtidas. Nesse ínterim, decidimos entrevistar um professor do Ensino Médio com o objetivo de conhecer outro ponto de vista sobre o tema proposto em nossa pesquisa. Deveria ser um professor que não conhecesse a metodologia adotada por nós, que não tivesse participado da aplicação dos Projetos 1 e 2 e que estivesse atuante na $2^{\underline{a}}$ série do Ensino Médio, em que a Análise Combinatória é trabalhada. Ainda neste capítulo foi feita a análise do Projeto 3.

Nas análises feitas, buscamos mostrar o que havia em comum aos três projetos: a importância do tema da pesquisa - Análise Combinatória contida na Matemática Discreta; a importância da Metodologia de Ensino-Aprendizagem-Avaliação de Matemática através da Resolução de Problemas; o envolvimento, cada um a seu modo, dos participantes de cada projeto; e a importância da pesquisadora no desenvolvimento de cada projeto e sua reflexão na ação e sobre a ação realizada.

Por fim, apresentamos as conclusões e sugestões a fim de antecipar as ações de outros pesquisadores, de modo que esta pesquisa possa trazer contribuições à Educação Matemática.

Consideramos importante um trabalho diferenciado, ao adotar a Metodologia de Ensino-Aprendizagem-Avaliação de Matemática através da Resolução de Problemas, por propiciar aos alunos a participação na construção dos conceitos de Análise Combinatória ao resolver um problema. Podemos afirmar que a metodologia de ensino adotada proporcionou, aos participantes, crescimento na aprendizagem.

Percebemos também a importância de se trabalhar com as grandes ideias dos conceitos envolvidos na Análise Combinatória: raciocínio combinatório; explorar o processo de contagem; e o conceito de padrão, pois os participantes dos projetos desenvolvidos puderam construir seus conceitos sem precisar fazer o uso mecânico de fórmulas, como é abordado no modo tradicional.

Apresentamos, também, nossas reflexões feitas sobre a minha prática como professora, professora-pesquisadora e pesquisadora, ao inter-relacionar as conclusões obtidas 
nas aplicações dos três projetos. Como fruto dessas reflexões e atendendo ao objetivo desta pesquisa, pudemos considerar as importantes contribuições para a formação do professor que, ao ler este trabalho, pode refletir sobre o que ocorreu, além da sala de aula, ao trabalharmos com Análise Combinatória e, com sua prática, buscar um trabalho diferenciado.

Assim, respondendo à nossa pergunta de pesquisa, podemos concluir que a Metodologia de Ensino-Aprendizagem-Avaliação de Matemática através da Resolução de Problemas, trabalhando Análise Combinatória, contribuiu para um trabalho significativo tanto para os alunos como para o professor. 


\section{CAPÍTULO 1 - Metodologia de Pesquisa}

1.1 - Visão dos pesquisadores sobre pesquisa

1.1.1 - O que é pesquisa?

1.1.2 - Pesquisa em Educação Matemática

1.2 - Metodologia de Pesquisa

1.3 - Metodologia de Thomas A. Romberg

1.3.1 - Educação Matemática como um campo de estudo

1.3.2 - As atividades dos pesquisadores (Fluxograma de Romberg)

1.3.3 - Os métodos de pesquisa usados pelos pesquisadores 


\section{CAPÍTULO 1 - Metodologia de Pesquisa}

Apresentamos neste capítulo um suporte teórico sobre Metodologia de Pesquisa. Descrevemos a visão de alguns autores sobre o que vem a ser pesquisa de um modo geral e, em particular, a pesquisa em Educação Matemática. A seguir, descrevemos a metodologia escolhida para desenvolver este trabalho de pesquisa.

\subsection{Visão dos pesquisadores sobre pesquisa}

\subsubsection{O que é pesquisa?}

$\mathrm{Na}$ etimologia da palavra, pesquisa está ligada à investigação, à busca e a idéia, sempre a mesma, é a de mergulhar na busca de explicações dos porquês e dos comos, com foco em uma prática. (D'AMBRÓSIO, 1996, p.94)

D’Ambrósio (1996, p.79) diz que pesquisa é o que permite a interface interativa entre teoria e prática e partir para a prática é como um mergulho no desconhecido.

Ainda, D’Ambrósio (1996, p.80), conceitua pesquisa, dizendo que

$\mathrm{O}$ elo entre passado e futuro é o que conceituamos como presente. Se as teorias vêm do conhecimento acumulado ao longo do passado e os efeitos da prática vão se manifestar no futuro, o elo entre teoria e prática deve se dar no presente, na ação, na própria prática. E isso nos permite conceituar pesquisa como elo entre teoria e prática.

Pode-se encontrar no Dicionário Houaiss vários verbetes para a palavra pesquisa: pesquisa é o conjunto de atividades que têm por finalidade a descoberta de novos conhecimentos no domínio científico, literário, artístico, etc.; é uma investigação ou indagação minuciosa. 
Pesquisa também se define como o estudo dos métodos da ciência, sendo o método o caminho pelo qual se atinge um objetivo ou um modo de proceder.

Para Romberg (1992), pesquisa refere-se a processos, as coisas que se faz, não os objetos que alguém pode tocar e ver. (2007, p.97)

Pode-se encontrar, na literatura, diferentes modos de definir pesquisa. Cada autor, ao definir pesquisa, segundo sua própria concepção, a situa dentro de seu campo de estudo, gerando então, diferentes linhas de pesquisa.

Segundo D’Ambrósio (2006, p.10) há duas vertentes para pesquisa: a pesquisa quantitativa e a pesquisa qualitativa.

A primeira delas lida com grande número de indivíduos e recorre aos métodos estatísticos para coletar e analisar os dados obtidos. Não há preocupação em se relacionar os dados coletados com o pesquisador ou com o ambiente de pesquisa. É comum chamá-la de pesquisa estatística ou pesquisa positivista. Nesse mesmo livro e na mesma página D’Ambrósio diz que pesquisa qualitativa, também chamada pesquisa naturalística, tem, em sua essência, a interação do pesquisador com a interpretação dos dados e discursos, mesmo quando ela envolve grupos de participantes.

Falando sobre pesquisa qualitativa, D’Ambrósio (1996, p.103) diz que:

[...] pesquisa focalizada no indivíduo, com toda a sua complexidade, e na sua inserção e interação com o ambiente sociocultural e natural. $\mathrm{O}$ referencial teórico, que resulta de uma filosofia do pesquisador, é intrínseco ao processo. (D’AMBRÓSIO, 1996, p.103)

e descreve algumas etapas relacionadas a pesquisa:

1) Formulação das questões a serem investigadas com base no referencial teórico do pesquisador;

2) Seleção de locais, sujeitos e objetos que constituirão o foco da investigação;

3) Identificação das relações entre esses elementos;

4) Definição de estratégias de coleção e análise de dados;

5) Coleção de dados sobre os elementos selecionados no item 2 e sobre as relações identificadas no item 3;

6) Análise desses dados e refinamento das questões formuladas no item 1 e da seleção proposta no item 2 ;

7) Redefinição de estratégias definidas no item 4;

8) Coleta e análise dos dados

\subsubsection{Pesquisa em Educação Matemática}

A história da pesquisa em Educação Matemática é parte da história de um campo - Educação Matemática - que tem se desenvolvido nos últimos dois séculos, quando matemáticos e educadores voltaram sua atenção ao que é e 
a como é, ou deveria ser, ensinada e aprendida a Matemática na escola. Desde o início, pesquisa em educação matemática tem sido moldada por forças dentro da grande área da pesquisa educacional, que abandonou, há cerca de um século atrás, a especulação filosófica, por uma abordagem mais científica. Mas, como a educação matemática propriamente dita, a pesquisa em educação matemática tem sofrido para atingir sua própria identidade. Ela tem tentado formular suas próprias decisões e seus próprios caminhos para atingi-la. Ela tem tentado definir-se e desenvolver um grupo de pessoas que se identifiquem como pesquisadores em Educação Matemática. (KILPATRICK, 1992, p.01)

A pesquisa em Educação Matemática começa nas universidades no final do século XIX, na Europa, com o objetivo de que os professores, além de ensinar, também orientassem pesquisas. A Educação Matemática veio a ser reconhecida como disciplina de universidade. A necessidade de mais e melhores professores, começou-se a expandir em universidades nos programas em educação de professores.

A pesquisa em Educação Matemática teve a influência de duas disciplinas: a Matemática e a Psicologia.

Como a educação matemática era desenvolvida na universidade, ela tendia a atrair pessoas cujo interesse primário era a Matemática e que pensavam a si mesmos como matemáticos. Estes educadores matemáticos conduziram estudos filosóficos e históricos, pesquisas e eventualmente outros tipos de pesquisa empírica. Seus trabalhos e aquele dos matemáticos levantaram muitos dos aspectos que os pesquisadores estão estudando hoje. (KILPATRICK, 1992, p.05)

No artigo intitulado Fincando estacas: uma tentativa de demarcar a Educação Matemática como campo profissional e cientifico, de Jeremy Kilpatrick (1996), traduzido por Miskulin et al, pode-se ler que

O campo da Educação Matemática tem aspectos profissionais e acadêmicos. Do lado acadêmico, a questão do que é considerado pesquisa está ainda sendo debatida. Um exame de dois conjuntos de critérios propostos para avaliar a qualidade da pesquisa em Educação Matemática revela que, apropriadamente interpretados, os critérios emprestados das ciências naturais e sociais são relevantes para um campo que está tentando ser científico. Do lado profissional, a Educação Matemática deve inevitavelmente preocupar-se com a aplicação do conhecimento especializado para auxiliar os estudantes e os professores que são seus clientes. A formação de professores continua sendo a função maior da Educação Matemática, paralelamente à busca do conhecimento sólido para ser aplicado. Os educadores matemáticos universitários precisam trabalhar junto com matemáticos e com professores em sala de aula no desenvolvimento da teoria e da prática. A Educação Matemática tem se desenvolvido bem em países nos quais as estruturas institucionais a apóiam como um campo acadêmico identificável. (KILPATRICK, 1996, p.99)

Sobre a Educação Matemática no Brasil, Fiorentini e Lorenzato (2006) citam que 
O surgimento da Educação Matemática no Brasil, como mostraremos mais adiante, também teve início a partir do MMM, mais precisamente no final dos anos de 1970 e durante a década de 1980. É nesse período que surge a Sociedade Brasileira de Educação Matemática (SBEM) e os primeiro programas de pós-graduação em Educação Matemática. (...) Podemos afirmar que, no início do século XXI, havia no Brasil uma comunidade de educadores matemáticos que contava com uma associação própria (SBEM congregando cerca de 12 mil associados. (FIORENTINI; LORENZATO, 2006, p.07)

\subsection{Metodologia de pesquisa}

O termo metodologia refere-se ao corpo de regras e diligências estabelecidas para realizar uma pesquisa. Também, esse termo é entendido como método ou ramo da lógica que se ocupa dos métodos das diferentes ciências.

Adotar uma metodologia de pesquisa depende do tipo do trabalho e o que se objetiva com ele. Utilizar uma metodologia adequada é fundamental, pois serve de guia para o pesquisador durante todo o desenvolvimento do trabalho. Ela possibilita tratar do tema proposto dentro de limites fixos, tomando cuidado para que o pesquisador não perca o foco da pesquisa, isto é, dirigindo-se a caminhos que não se referem ao tema a ser pesquisado. Os métodos utilizados pelo pesquisador garantem a fidedignidade e a qualidade da pesquisa. Porém, não há uma única metodologia de pesquisa correta a ser adotada para um trabalho. A escolha da metodologia depende do tipo de estudo, do objetivo da pesquisa e da crença e conhecimento do pesquisador.

A estrutura de um trabalho está baseada em uma metodologia de pesquisa. Neste nosso trabalho, a metodologia de pesquisa a ser utilizada está fundamentada na sequência apresentada em 1992 por Thomas A. Romberg.

\subsection{Metodologia de Thomas A. Romberg.}

O objetivo da pesquisa em educação matemática deveria produzir novo conhecimento sobre o ensino e a aprendizagem de matemática. Porque os alunos aprendem a maior parte de sua matemática nas salas de aula da escola, acredito que a principal missão de um programa de pesquisa seria a de identificar as componentes principais das salas de aula que promovem compreensão matemática e esclareçam algumas das características organizacionais que contribuem ou impedem a operação de tais salas de aula. (ROMBERG, 1997, p. 379)

Neste trabalho será adotada uma Metodologia de Pesquisa, fundamentada na sequência de dez atividades que os pesquisadores devem desenvolver ao realizá-la, atividades essas descritas por Thomas A. Romberg em um fluxograma. Ao conjunto dessas atividades denominamos Metodologia de Thomas A. Romberg. 
Thomas A. Romberg (1992), matemático e professor da Universidade de WisconsinMadison-USA, descreve, no artigo intitulado "Perspectives on Scholarship and Research Methods" (Perspectivas sobre o Conhecimento e Métodos de Pesquisa), a Educação Matemática como um campo de estudo, as atividades dos pesquisadores e os métodos de pesquisa usados por eles, visando identificar as amplas tendências de pesquisa que estão relacionadas ao estudo do ensino e da aprendizagem nos ambientes escolares. Romberg disse, em 1992, que acreditava que pelo menos cinco amplas tendências nas ciências sociais pudessem ser descritas: Crescimento de Pesquisa; Crescente diversidade em métodos de pesquisa; Uma mudança na epistemologia; Uma mudança na psicologia da aprendizagem; $\mathrm{O}$ crescimento da consciência política, sendo que elas são interrelacionadas e não verdadeiramente independentes.

\subsubsection{Educação Matemática como um campo de estudo.}

Romberg (1992) considera a Educação Matemática como um campo de estudo no qual se investigam questões relacionadas aos processos envolvidos no ensino e na aprendizagem de Matemática nas escolas, e, ainda, as perspectivas e os procedimentos de investigação escolar. O diagrama abaixo (de E.G. Begle, apud Romberg, 1992, p.95) elucida como os componentes do processo da educação escolar (escola, professores, alunos, Matemática) estão interrelacionados, dentro da sociedade.

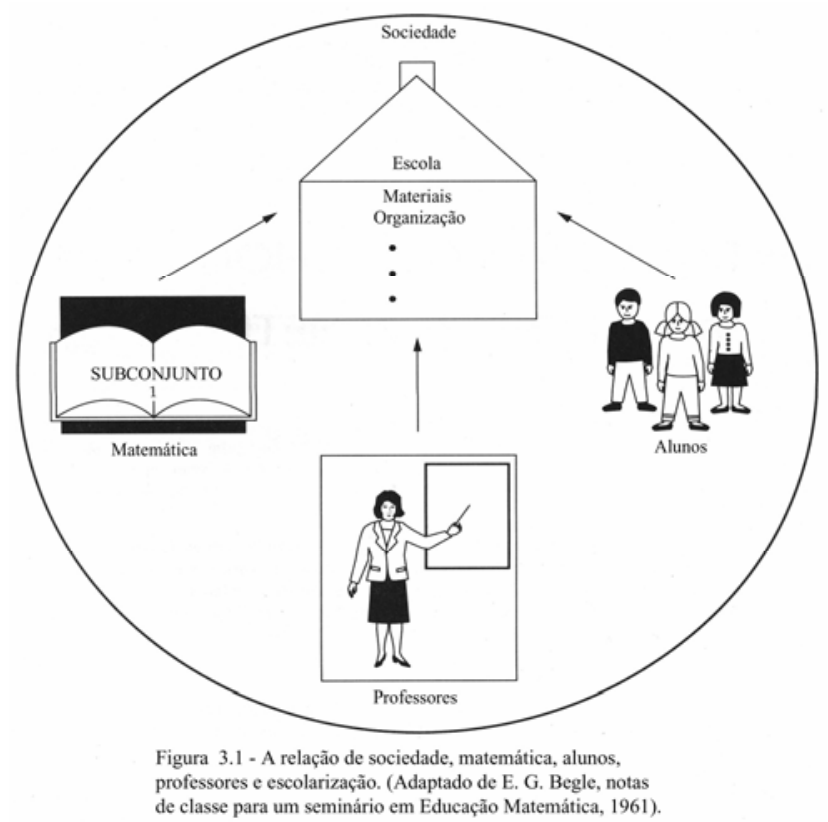

Figura 1: A relação de sociedade, matemática, alunos, professores e escolarização. (Adaptado de E.G. Begle, notas de classe para um seminário em Educação Matemática, 1961) (apud Romberg, 1992, p.95) 
Nesse sentido, Tinoco (1991) define e representa, de modo semelhante, a Educação Matemática: "visa à compreensão dos fenômenos que ocorrem nas ligações entre os três vértices do triângulo e as influências que estas ligações sofrem do sistema escolar e da estrutura social em geral" (TINOCO, 1991, p.69)

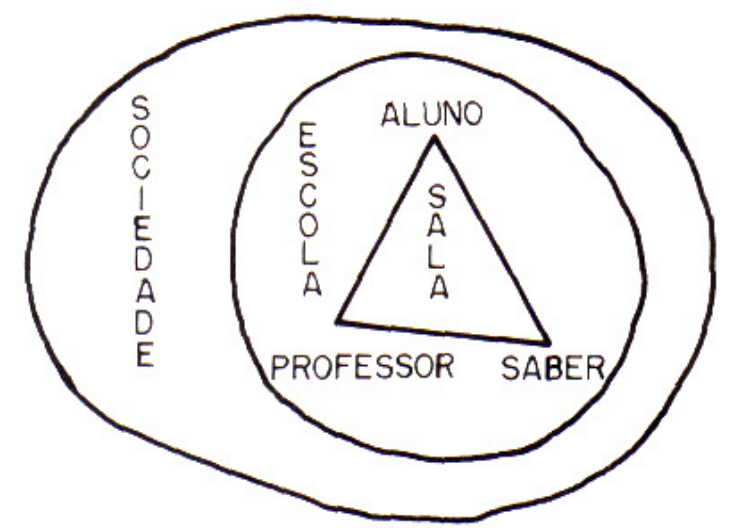

Figura 2: Relações entre sociedade, escola, aluno, professor e saber. (Tinoco, 1991, p.69)

Tinoco explicita que, na pesquisa em Educação Matemática, procuram-se conhecer os fenômenos envolvidos:

E também,

- no trabalho dos alunos: relações do aluno com o saber, com os outros alunos e com o professor;

- no trabalho do professor ao planejar e avaliar as atividades para a sala de aula. Incluem-se nisto a transposição didática e a "leitura" dos tipos de procedimentos dos alunos;

- no funcionamento da escola e suas relações com a sociedade. (p.70)

Em relação ao aluno: é preciso valorizar nele a capacidade de colocar questões, a coragem de propor soluções, o gosto pelo saber; enfim, o espírito crítico e a criatividade voltados para o coletivo.

Em relação ao professor: é de fato o condutor e o responsável pelo processo ensino-aprendizagem. Não vai moldar alunos e, sim, respeitá-los, valorizar o conhecimento que esses alunos adquirem na vida, ampliar e sistematizar este conhecimento, por meio de atividades planejadas para esse fim. Para tal, é importante o seu papel na "transposição didática" do saber, o que pressupõe o domínio do mesmo.

Em relação à Matemática: ela está no mundo, nas relações entre as pessoas, no espaço físico em que vivemos [...]. O papel da Matemática na escola deve atender a esses dois aspectos: preparar melhor o aluno para o exercício da cidadania e propiciar a ele o acesso à cultura matemática acumulada pela humanidade. Sempre que possível, o aluno deve construir o conhecimento por si, trabalhando assim para a sua autonomia intelectual. (TINOCO, 1991, p.70) 


\subsubsection{As atividades dos pesquisadores (Fluxograma de Romberg)}

O termo pesquisa refere-se a processos, a coisas que se faz, não a objetos que se pode tocar e ver. Além disso, fazer pesquisa não pode ser visto como uma ação mecânica ou como um conjunto de atividades que os indivíduos seguem de uma maneira prescrita ou predeterminada. (ROMBERG, 2007, p.97)

Romberg ressalta que as atividades envolvidas em fazer pesquisa incorporam mais características de uma arte do que de uma disciplina puramente técnica, atividades estas que dão respaldo aos pesquisadores e explicitam o desenvolvimento da pesquisa.

Desse modo, Romberg descreve dez atividades, organizadas em um fluxograma, que são distribuídas em três blocos: o primeiro bloco trata da identificação do problema (atividades 1, 2, 3, e 4); o segundo bloco se propõe a resolver esse problema, onde estratégias e procedimentos de trabalho são levantados e selecionados (atividades 5 e 6); e o terceiro e último bloco, após o Procedimento geral ser posto em ação, trata da análise das informações obtidas, buscando tudo o que ficou evidente frente à questão ou conjectura levantada. Romberg justifica esse modelo dizendo que essas atividades são importantes pois esclarecem alguns problemas comuns que pessoas, não familiarizadas com pesquisa, enfrentam na compreensão do processo. Ainda o autor ressalta que as atividades descritas não precisam ser seguidas necessariamente na ordem apresentada, e afirma que a interação entre fatores como a intenção do pesquisador, as suposições, as conjecturas, a disponibilidade de informações, os métodos e, assim por diante, não podem ser separados na prática tão nitidamente. (ROMBERG, 2007, p.98) 
Metodologia de Romberg

As atividades dos pesquisadores

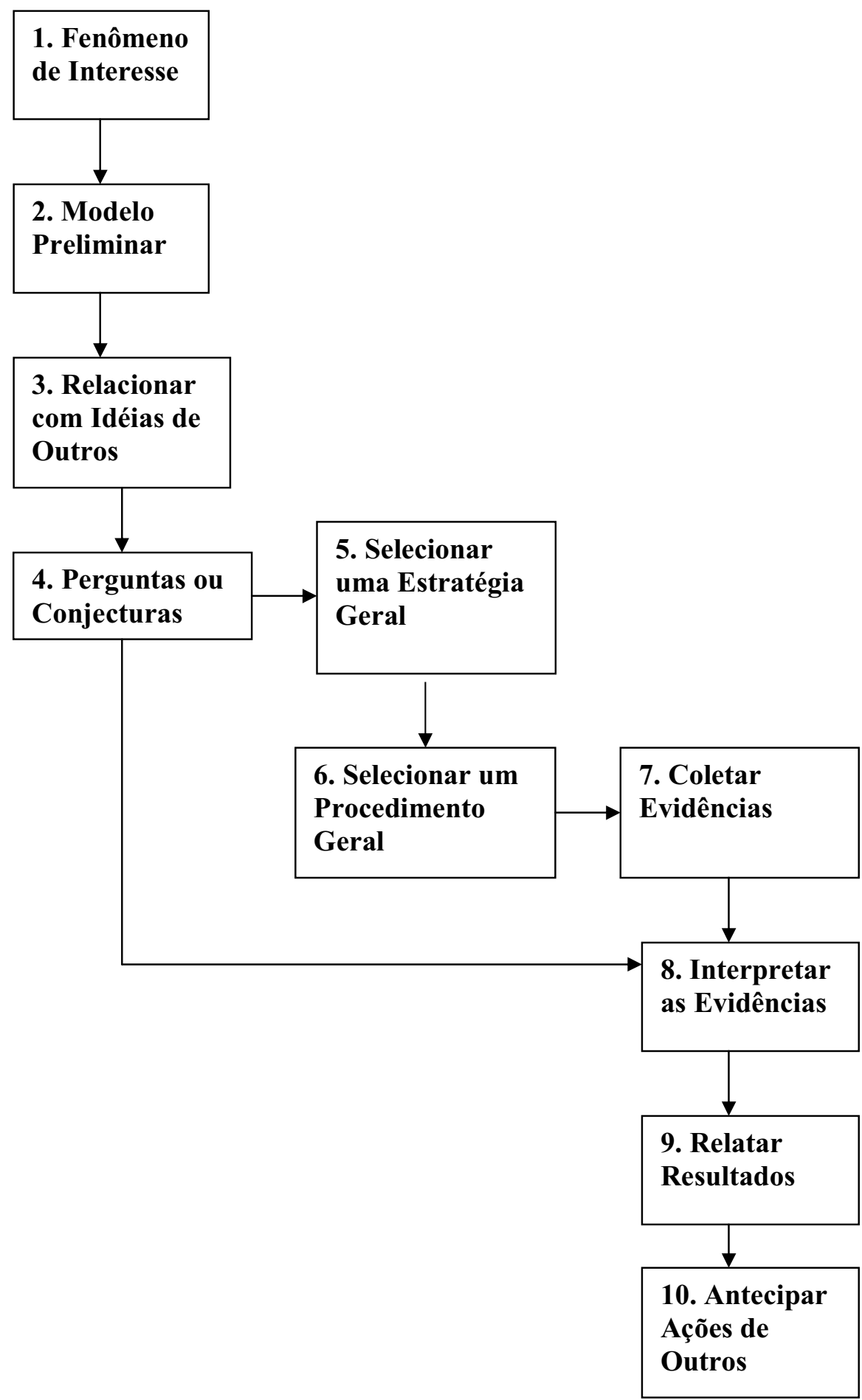




\section{$1^{\circ}$ bloco: Identificação do problema}

As quatro primeiras atividades são as mais importantes, pois elas estão envolvidas com o situar as idéias de alguém sobre um particular problema no trabalho de outros estudiosos e decidir o que se quer investigar. (ROMBERG, 2007, p.98)

$\underline{1^{\mathrm{a}} \text { atividade: Identificar um fenômeno de interesse }}$

Romberg diz que o fenômeno de interesse de toda pesquisa começa com uma curiosidade sobre um fenômeno particular do mundo real. Entendendo-se fenômeno como um fato de interesse científico que pode ser descrito e explicado cientificamente.

\section{$\underline{2^{\mathrm{a}} \text { atividade: Construir um modelo preliminar }}$}

Nesta atividade é construído um modelo formado pelas variáveis-chave do fenômeno de interesse e as relações implícitas entre elas.

O modelo preliminar serve como um ponto de partida para a pesquisa e mostra como as variáveis identificadas pelo pesquisador possivelmente estão operando.

$\underline{3^{\mathrm{a}} \text { atividade: Relacionar o Fenômeno de Interesse e o Modelo Preliminar com ideias de outros }}$ pesquisadores.

Esta atividade consiste em examinar o que outros pensam sobre o fenômeno de interesse e também em determinar se suas ideias podem explicar, ampliar ou modificar o modelo proposto. Romberg ressalta que o pesquisador deve reconhecer que cada investigador é um membro de um particular grupo de pesquisa que defende uma determinada "visão de mundo" (2007, p.100). Desse modo, o pesquisador deve tomar cuidado para não optar por um autor que não esteja trabalhando sobre a linha de interesse do fenômeno escolhido.

\section{$\underline{4^{\mathrm{a}} \text { atividade: Levantar questões específicas ou fazer uma conjectura plausível }}$}

Romberg considera esta atividade como um passo decisivo para a pesquisa, porque uma grande quantidade de perguntas possíveis aparece ao examinar-se um fenômeno particular e decidir que perguntas examinar não é fácil (2007, p.100). O autor diz que as perguntas podem assumir uma das seguintes formas: caráter descritivo: quando orientadas no passado, questiona-se "Como as coisas chegaram a ser dessa maneira?" e, quando orientadas no presente, “Qual é o status das coisas?”; caráter preditivo: quando orientadas no futuro, “O que posso prever para o que vai acontecer no futuro?" 
Romberg prefere as conjecturas às perguntas. As conjecturas estão baseadas em algumas relações entre as variáveis que caracterizam o fenômeno e nas idéias sobre aquelas variáveis-chave e suas relações com o esboçado no modelo (2007, p.100). As conjecturas pra ficarem válidas precisam ser demonstradas e as perguntas devem ser respondidas e justificadas. Comprovar a conjectura ou responder a pergunta levantada constitui-se no problema de pesquisa.

\section{$2^{\circ}$ bloco: Resolução do problema levantado}

$\underline{5^{a} \text { atividade: Selecionar uma Estratégia Geral de pesquisa em busca de evidências que levem a }}$ resolver o problema levantado.

Nesta atividade, o pesquisador deve decidir o quê fazer para responder as questões levantadas ou defender sua conjectura. Para decidir que métodos serão utilizados, Romberg diz que a estratégia geral selecionada deve estar relacionada às questões ou às conjecturas levantadas a partir da visão de mundo que ele, pesquisador, tem e do modelo preliminar construído que explica o fenômeno de interesse selecionado.

Para definir a Estratégia Geral selecionada, torna-se necessário levantar estratégias auxiliares apoiadas nas variáveis no Modelo Preliminar para sua concepção.

$6^{\mathrm{a}}$ atividade: Selecionar um Procedimento Geral de pesquisa, correspondente à Estratégia Geral selecionada, que conduza o pesquisador durante toda investigação.

Esta atividade mostra como fazer para coletar os dados, como selecionar uma amostra, como coletar uma informação (entrevista, pergunta, observação, teste), como organizar a informação uma vez que ela tenha sido coletada, etc. (2007, p.102)

Há muitos procedimentos específicos que podem ser seguidos para diferentes tipos de questões. É preciso ter cuidado ao selecionar procedimentos que ponham luz sobre as questões levantadas.

Tendo se tornado evidentes os procedimentos auxiliares selecionados e postos em ação, como consequência o procedimento geral será posto em ação. 


\section{$3^{\circ}$ bloco: Dar sentido às informações coletadas na aplicação do procedimento geral e relatar os resultados para outros.}

\section{$\underline{7^{\mathrm{a}} \text { atividade: Coletar informações. }}$}

Quando colocados os procedimentos em ação, obtêm-se informações que serão importantes para responder às perguntas ou às conjecturas levantadas. Os procedimentos podem ser totalmente planejados ou até serem redefinidos durante a coleta. Isso depende do modo com que se conduz a pesquisa.

\section{$\underline{8^{\mathrm{a}} \text { atividade: Interpretar as informações coletadas. }}$}

Nesta atividade as informações coletadas são analisadas e interpretadas em função do problema identificado na pesquisa. O pesquisador pode se utilizar de métodos quantitativos, no caso em que se atribui números às informações, e de métodos qualitativos, métodos de análise utilizados quando os números não forem necessariamente utilizados. Dentre as informações coletadas, parte delas é relevante, parte é irrelevante e parte é até não compreensível. Cabe ao pesquisador, então, selecionar aquelas que sejam importantes para a pesquisa e que ajudam a responder às perguntas ou às conjecturas levantadas. Romberg ressalta que tentar encontrar informação importante dentre todas as que estejam disponíveis é uma arte na qual certas pessoas são melhores do que outras.(2007, p.103)

\section{$\underline{9^{a}}$ atividade: Transmitir os resultados para outros.}

Romberg fala da importância de relatar aos outros membros de sua comunidade de pesquisa sobre uma investigação terminada e buscar por seus comentários e críticas. Além dessa responsabilidade, é importante que o pesquisador situe em seu trabalho sua própria visão de mundo, pois suas descobertas serão interpretadas segundo essa visão, caso contrário, os leitores desse relatório usarão suas próprias noções para poder interpretar o estudo feito.

$\underline{10^{\mathrm{a}} \text { atividade: Antecipar a ação de outros. }}$

Romberg afirma que os pesquisadores tentam situar cada estudo em uma cadeia de investigações. Coisas que vieram antes e coisas que vêm após qualquer particular estudo são importantes. (2007, p.103)

O pesquisador, nessa atividade, está interessado no que acontecerá depois e deveria antecipar ações posteriores. Desse modo, membros de uma comunidade científica discutem 
ideias entre si, dão sugestões para novos passos, modificações de estudos anteriores, elaboração de propostas, etc.

\subsubsection{Os métodos de pesquisa usados pelos pesquisadores.}

Sabe-se que as estratégias pertencem ao mundo das ideias e os procedimentos ao mundo das ações. Para colocar o Procedimento Geral em ação, há diferentes métodos a serem usados.

Para Romberg, as decisões sobre métodos são tomadas como uma consequência das atividades 1 a 4 . Nos segundo e terceiro blocos apresentam-se as atividades 5 a 10 nas quais, o pesquisador deve decidir:

1) que evidência é necessária para dirigir as perguntas ou conjecturas levantadas.

2) como coletar, analisar e interpretar aquela evidência.

3) como relatar as descobertas obtidas na pesquisa para outros pesquisadores.

Os pesquisadores raramente começam uma investigação com uma estratégia fixada para coletar dados ou com um método específico de análise em mente. Assim, Romberg diz que há dois aspectos para o uso do termo métodos de pesquisa que precisam ser compreendidos:

$1^{\circ}$ ) os métodos específicos discutidos na literatura de pesquisa podem incluir a maneira na qual a informação é coletada e o modo como ela é agregada e analisada ou, às vezes, como é relatada.

$2^{\circ}$ ) os métodos que um pesquisador usa para coletar evidências dependem de pelo menos cinco fatores: a visão de mundo; a orientação do tempo em que as perguntas foram feitas; se a situação atualmente existe ou não; a fonte de informação prevista e o julgamento do produto. A visão de mundo situa os métodos usados dentro das crenças de uma particular comunidade de estudo. A orientação do tempo considera se as perguntas que estão sendo levantadas são dirigidas ao passado, ao presente ou ao futuro. Em relação às situações, é preciso saber se elas existem ou ainda precisam ser criadas. A fonte de informação prevista precisa ser artefatos (livros, falas e coisas semelhantes), respostas às questões, ou observação de ações. O julgamento do produto refere-se a estudos de avaliação como uma categoria distinta de métodos de pesquisa. Grande número de métodos específicos que existem na literatura estão baseados ou usam esses cinco fatores. 
- Métodos usados com uma evidência existente: O pesquisador encontra o que já existe e não pode alterar a forma na qual os dados aparecem. Para esse caso há três métodos diferentes:

Historiografia: Nessa abordagem, um esforço é feito para lançar luz sobre condições e problemas atuais por meio de uma compreensão mais profunda e mais completa do que o que foi feito ou do que ocorreu no passado.

Análise de conteúdo: Este método é usado para investigar questões orientadas no presente quando artefatos atuais podem ser examinados.

Análises de tendência: Este método é usado para ir além da informação sobre o passado ou o presente a fim de fazer predições sobre o futuro.

- Métodos usados quando uma situação existe e a evidência deve ser desenvolvida: A situação existe e dados específicos devem ser colocados; o pesquisador tem controle sobre a forma pela qual a informação é coletada e agregada.

Alguns deles são:

Pesquisa retrospectiva: Este método é usado para estudar questões que são orientadas no passado - a situação existiu uma vez e os indivíduos que foram participantes dessa situação passada podem ser entrevistados usando este método.

Pesquisa de massa descritiva: Este método muito comum é usado para estudar questões orientadas no presente. O procedimento consiste em pedir a uma amostra de participantes, cuidadosamente retirados da situação, para responder a um conjunto de questões prédeterminadas e estruturadas.

Entrevistas estruturadas: Este método é semelhante ao da pesquisa de massa descritiva, exceto que é assumido que ao ouvir (e codificar) respostas, os pesquisadores podem encontrar informação mais esclarecedora do que ao usar pesquisas de massa.

Observações estruturadas: Este método é usado para estudar grupos nos quais as ações de diferentes membros possam ser vistas. Por exemplo, documentar os tipos de interações de professor e aluno que acontecem durante uma aula de matemática e determinar até que ponto os alunos se comprometem com a aprendizagem.

Estudos de caso: Este método é usado para organizar e relatar informação sobre as ações, percepções e crenças de um indivíduo ou de um grupo sob condições ou circunstâncias específicas. O pesquisador está interessado em contar uma história detalhada sobre um caso particular. O que distingue um estudo de caso de outros campos de métodos de estudo é que o pesquisador não está interessado em fazer julgamentos sobre um programa ou em testar uma hipótese teórica, apenas estão escrevendo uma história natural de uma situação particular. 
Pesquisa-ação: Este termo se refere a uma estratégia de pesquisa usada para investigar situações de escolaridade onde o pesquisador assume "prática inteligente", que precisa ser documentada e entendida, derivada de experiências nas escolas ou nas salas de aula. A documentação é geralmente feita pelo praticante.

Etnografia: O termo etnografia vem da antropologia e significa um retrato do modo de vida de algum grupo identificável de pessoas. O rótulo é usado para referir-se tanto à combinação de processos usados quando os antropólogos fazem um trabalho de campo quanto ao produto daquele esforço - o relato etnográfico escrito. É um método usado para estudar a cultura complexa das escolas. Esta abordagem usualmente requer um observador participante altamente treinado para examinar artefatos, conduzir entrevistas clínicas e fazer observações clínicas. Ela difere de outros métodos em que o pesquisador tenta interpretar as ações das pessoas de acordo com a cultura na qual elas vivem.

Dentre esses métodos apresentados, este trabalho se identifica com o método de pesquisa-ação. Será realizado um trabalho na sala de aula, tendo o pesquisador atuando como docente.

Thiollent coloca que

uma pesquisa pode ser qualificada de pesquisa-ação quando houver realmente uma ação por parte das pessoas ou grupos implicados no problema sob observação. Além disso, é preciso que a ação seja uma ação não-trivial, o que quer dizer uma ação problemática merecendo investigação

E ainda para ser elaborada. (apud Rodrigues, 1992, p.66)

a pesquisa-ação não é apenas constituída pela ação ou participação. Com ela é necessário produzir conhecimentos, adquirir experiência, contribuir para a discussão ou fazer avançar o debate acerca das questões abordadas. Parte da informação gerada é divulgada, sob formas e meios apropriados, no seio da população. Outra parte da informação, cotejada com resultados de pesquisas anteriores, é estruturada em conhecimentos. Estes são divulgados pelos canais próprios às ciências sociais (revistas, congressos, etc.) e também próprios a esta linha de pesquisa. (RODRIGUES, 1992, p.68)

Acreditamos que, com a pesquisa-ação, teremos uma participação efetiva nas situações observadas no trabalho. Desencadeando uma discussão sobre os fatos abordados, adquirindo experiência e produção de conhecimento e dando melhores condições para respondermos aos questionamentos da realidade a ser investigada. 


\section{CAPÍTULO 2 - Identificação do Problema da Pesquisa - Iniciando a pesquisa

\author{
(1ํㅡㅁ bloco de Romberg)
}

Introdução

2.1 - Fenômeno de Interesse

2.1.1 - Minha trajetória pessoal e profissional

2.2 - Modelo Preliminar

2.2.1 - Modelo Modificado

2.3 - Relacionar o Fenômeno de Interesse e o Modelo Modificado com ideias de outros

Introdução

2.3.1 - Matemática Discreta

2.3.2 - A História da Análise Combinatória

2.3.3 - Análise Combinatória

2.3.3.1 - Análise do tópico Análise Combinatória, nos livros didáticos, em ordem cronológica

2.3.3.2 - Documentos Legais: A visão do ensino de Análise Combinatória ao longo das reformas ocorridas no ensino de Matemática, no século XX

\subsection{4 - Resolução de Problemas}

2.3.4.1 - História da Pesquisa em Resolução de Problemas

2.3.4.2 - Metodologia de Ensino-Aprendizagem-Avaliação de Matemática através da Resolução de Problemas

2.4 - A identificação do Problema da Pesquisa 


\section{CAPÍTULO 2 - Identificação do Problema de Pesquisa - Iniciando a Pesquisa (1ํㅡㅁoco de Romberg)}

\section{Introdução}

Kilpatrick (1992, p.03) apresenta no artigo intitulado A History of Research in Mathematics Education que os propósitos da pesquisa em Educação Matemática são variados. Se se vê tal pesquisa como parecida à aquela das ciências naturais seguindo a tradição empírico-analítica, adotam-se os fins tradicionais das ciências: explicar, predizer ou controlar. Se se vê a pesquisa em Educação Matemática sendo mais parecida a compreensão interpretativa de uma cultura que um antropólogo poderia buscar, tenta-se ao invés disto, compreender os significados que a aprendizagem e o ensino de matemática têm para aqueles que estão engajados na atividade. Se se toma a abordagem da sociologia crítica e considera "pesquisa-ação" projetada para ajudar os professores e os alunos a ganhar uma maior liberdade e autonomia em seu trabalho, a pesquisa é feita tanto para melhorar a prática tanto para envolver os participantes naquela melhora. Um movimento de pesquisa em Educação Matemática ao longo da década passada (dito em 1992) tem se afastado da tradição empíricoanalítico e, mais vacilantemente para abordagens interpretativas e críticas.

Embora os métodos da tradição empírico-analítica tenham dominado a pesquisa em Educação Matemática na maior parte deste século, as aspirações científicas de explicação, predição e controle parecem nunca ter tido como predominante uma motivação desejada a compreensão e, especialmente, da melhoria tanto da aprendizagem como o ensino da Matemática. A despeito desse desejo, entretanto, compreensão e melhora não têm 
ordinariamente significado a adoção das visões dos participantes ou considerado o contexto institucional como problemático. A pesquisa em Educação Matemática tem tratado primeiramente problemas de aprendizagem e ensino como definido pelos pesquisadores. Eles consideram estudos de pesquisa porque eles conhecem as práticas que devem ser melhoradas e têm uma visão de como esse melhoramento pode ser realizado. Eles tentam fazer pesquisa que seja mais aplicada do que pura.

Foram apresentadas, por Romberg, no capítulo 1, as dez atividades de pesquisa e a forma como estão relacionadas. Decidimos denominar e adotar essa sequência de atividades como Metodologia de Pesquisa de Romberg.

No capítulo 2, dando início a nossa pesquisa, trabalharemos sobre as quatro primeiras atividades: identificar um Fenômeno de Interesse, construir um Modelo Preliminar, Relacionar o Fenômeno de Interesse e o Modelo Preliminar com ideias de outros pesquisadores, levantar questões específicas ou fazer uma conjectura plausível, levando à identificação do problema de pesquisa.

\subsection{Fenômeno de Interesse}

\subsubsection{Minha trajetória pessoal e profissional}

\section{Meu envolvimento com a Matemática e a preocupação com seu ensino}

Desde as séries iniciais do Ensino Fundamental sempre tive uma aptidão maior pela Matemática. Obtinha boas notas nas tarefas, trabalhos e avaliações. Quando questionada por que gostava de Matemática, dizia que era devido aos bons professores que tinha, as aulas eram organizadas, explicavam de modo claro e eram exigentes quanto à organização dos cadernos e disciplina na sala de aula. Mesmo com o rigor exigido pelos professores, me envolvia e me dedicava no estudo da Matemática.

Quando iniciei o $2^{0}$ grau, atual Ensino Médio, percebi que, além da Matemática, havia outras disciplinas da área de exatas que me interessavam: Física e Química. Tinha maior facilidade em assimilar os conteúdos dessas disciplinas. E, também, alguns tópicos da disciplina de Biologia, como Genética, e na de Geografia, com escala e mapas, o que deixava claro um interesse maior pela Matemática.

Fiz o Ensino Médio em escola particular, mas as aulas nessa escola continuavam sendo dadas na forma tradicional. O que diferenciava era o material didático e o domínio do conteúdo pelo professor. Percebia que nela o objetivo principal para a aprendizagem era o de "passar no vestibular". Dessa forma, a memorização de regras e certos artifícios (truques) se 
tornavam habilidades e não uma aprendizagem com compreensão e significado naqueles conteúdos matemáticos trabalhados. Estes estiveram camuflados diante do método de ensino empregado pelos professores durante esses vários anos.

Tanto no Ensino Fundamental como no Ensino Médio, as aulas eram tradicionais, com aulas expositivas, exercícios de fixação, uso de apostilas, livros didáticos e provas escrita e individual bimestrais e semestrais.

Terminei o Ensino Médio decidida a prestar vestibular em um dos Cursos da Área de Exatas: engenharia, computação, matemática, química entre outros. Mas mesmo tendo uma área definida, tive dificuldade em escolher o curso que iria definir minha profissão. Prestei vestibular para Ciência da Computação, mas não fui aprovada. Então fiz um ano de cursinho para me preparar melhor para o vestibular. Nesse curso, os conteúdos eram apresentados pelos professores de modo mais sintetizado ainda, e as aulas continuavam sendo tradicionais.

Durante o cursinho, o interesse pela Matemática crescia, ao contrário de muitos da turma que a abominavam. Questionava-me sobre o que fazia gostar tanto de Matemática e como trabalhar com ela profissionalmente me impulsionava mais ainda pelo seu estudo.

Optei então em fazer o vestibular para o curso de Matemática (UNESP e USP) e Matemática Aplicada Computacional (UNICAMP). Fui aprovada, em 1993, na UNESP Campus de São José do Rio Preto-SP, no Instituto de Biociências, Letras e Ciências Exatas (IBILCE), no curso de Bacharelado em Matemática.

A escolha do curso por Bacharelado ou Licenciatura em Matemática era feita no ato da inscrição para o vestibular (atualmente se opta a partir do segundo ano do curso). Procurei informações com alguns alunos que já cursavam Matemática para saber a diferença entre essas duas opções e na época, o que as diferenciava eram as disciplinas pedagógicas. Em sua maioria, os alunos não se encontravam muito animados com essas disciplinas, no curso de Licenciatura, mas o curso de Bacharelado era voltado mais para pesquisa. Optei por bacharelado em Matemática visando à pesquisa acadêmica no meu campo profissional.

No primeiro ano do curso tínhamos aulas todos juntos, bacharelandos e licenciandos. A partir do segundo ano, as turmas se separavam.

Durante o curso tive contato com disciplinas que ajudaram no enriquecimento e aprofundamento de conceitos matemáticos vistos até o Ensino Médio e, também, adquiri novos conceitos. Essas disciplinas eram voltadas para a Matemática Pura ou Aplicada.

Os professores ministravam as aulas com rigor acadêmico (preocupações excessivas com notações e demonstrações), não dando margem a discussão sobre o processo de ensinoaprendizagem de Matemática. Mas, até então, isso não me incomodava, pois estava ciente de 
que o curso de Bacharelado tinha caráter teórico e voltado para a pesquisa. Não havia uma relação com o ensino na sala de aula de Matemática. Na maioria das aulas, os conteúdos eram demonstrados por meio de teoremas e propriedades, o que, para mim, se mostravam importantes para poder justificar e esclarecer tantas dúvidas e inquietações encontradas até o término do Ensino Médio.

Quando tinha contato com os alunos do curso de Licenciatura, estes não discutiam sobre o ensino e comentavam que as disciplinas pedagógicas eram chatas, monótonas e realizavam trabalhos sem discuti-los com os professores. O Estágio obrigatório, realizado nas escolas que consistia em observar um determinado número de aulas, nem sempre acontecia, pois conseguiam a assinatura do professor da classe em que estavam estagiando e concluíam (pelo menos burocraticamente) a disciplina. Assim não tinham uma preocupação com sua formação profissional. Talvez a falta de interesse demonstrado não fosse somente dos alunos mas, também, dos professores que ministravam essas disciplinas.

Desse modo, percebi que não havia muita distinção entre o Bacharelado e Licenciatura, pois as disciplinas de Matemática Pura ou Aplicada eram vistas com o mesmo enfoque e as disciplinas pedagógicas eram abordadas sem a devida preocupação.

Visando à carreira acadêmica, quando concluí a graduação (em 1996), iniciei o curso de mestrado em Matemática Pura na mesma Universidade, como aluna especial. Como não estava regularizada no curso, precisava custear meus estudos e estadia. Desse modo, comecei a trabalhar em uma escola voltada para acompanhamento escolar, atendendo alunos para ter aulas de reforço, fazer tarefas, trabalhos e aulas particulares. Os alunos eram, em sua maioria, de diferentes escolas privadas.

Foi minha primeira experiência profissional. Observando o material (apostilas e livros didáticos) trazidos pelos alunos e as dúvidas que apresentavam, comecei a me preocupar com e como os conteúdos matemáticos estavam sendo trabalhados nas escolas e de que maneira eram transmitidos. O que realmente sentia era frustração, pois a Matemática que eu estudava, no Curso de Mestrado estava muito além daquela que meus alunos estavam aprendendo na escola. Conceitos considerados simples e básicos, que serviam de respaldo para outros conteúdos, não estavam sendo compreendidos por esses alunos.

Esse contato, com os alunos, que não havia tido até meu curso de Bacharelado, foi relevante para meu amadurecimento profissional pois, foi durante esse período, que percebi o quanto era importante discutir problemas sobre o processo de ensino-aprendizagem de Matemática, sobre a aprendizagem dos alunos e a formação dos professores. Tudo isso me inquietava. Até no trabalho com um conceito matemático, por mais simples que fosse, ficava 
preocupada e procurava saber se os alunos estavam realmente entendendo o que eu dizia e fazia.

Desse modo, no Mestrado em Matemática Pura, não conseguia ver mais sentido em estudar os inúmeros teoremas e suas demonstrações. Embora reconhecendo sua importância, era frustrante, para mim, discutir toda essa matemática feita uma vez que seu objetivo era o de desenvolver pesquisas de caráter teórico, voltadas para a Academia. Sentia, como professora de sala de aula do Ensino Básico, a necessidade de conhecer novas formas de ensinar matemática e que, no mestrado em Matemática Pura, não poderia desenvolver pesquisas destinadas ao processo de ensino-aprendizagem de matemática.

Diante dessa situação, não dei continuidade ao mestrado e continuei trabalhando na mesma escola. Minha preocupação então era a de contribuir para um melhor aprendizado em Matemática, sanando as dúvidas dos alunos e possibilitando-lhes novas maneiras de resolver seus problemas a fim de obterem um melhor desempenho escolar.

Durante o ano em que ministrei aulas nesta escola, aprendi muito com os alunos e creio que mais do que eles comigo. No término de um ano, minha preocupação não era apenas com o conteúdo matemático. A inquietação e a dificuldade maior era como transmiti-lo da melhor forma. Então buscava conhecer diferentes metodologias de ensino que pudessem contribuir nas minhas aulas, pois sentia a necessidade de ministrar aulas diferentes, motivar os alunos e encoraja-los par progredir nos estudos e compreender com significado os conteúdos matemáticos.

Amenizar as dificuldades encontradas pelos alunos era um desafio para mim, e meu questionamento era como fazer isso. Desse modo, obter informações sobre o ensino de Matemática e me dedicar a ele passou a ser minha meta, meu principal objetivo.

Em meados de 1999, iniciei o Curso de Pós Graduação Lato-Sensu em Educação Matemática no Centro Universitário do Norte Paulista - UNORP, em São José do Rio PretoSP, com carga horária de 360 horas. As aulas eram realizadas aos sábados, distribuídas nos seguintes módulos: Educação Matemática; Aritmética-Álgebra-Geometria e suas aplicações no ensino; Metodologia da Resolução de Problemas, onde foi abordada a metodologia de ensino-aprendizagem de Matemática através da resolução de problemas; Informática Aplicada na Educação Matemática; História da Matemática e Metodologia da Pesquisa Científica.

Nesse curso tive a oportunidade de ter contato com textos voltados para a Educação Matemática que permitiram o acesso à Matemática voltada para a sala de aula. A convivência com outros professores que freqüentavam o curso também foi importante no sentido de trocar experiências, identificar as mesmas dificuldades, buscar inovações e enriquecer 
profissionalmente. Dentre os módulos estudados interessei-me em pesquisar sobre o processo de ensino-aprendizagem, objetivando explorar metodologias que contribuíssem para minha formação e conseqüentemente para a aprendizagem do aluno.

O último módulo visto foi a disciplina Metodologia da Pesquisa Científica, que contribuiu para o início do exercício de pesquisar e, também, elaborar a monografia exigida no final do curso. Escolhi a Metodologia de Ensino-Aprendizagem de Matemática através da Resolução de Problemas como metodologia de trabalho para a sala de aula e a Análise Combinatória foi o conteúdo escolhido para ser abordado. Nessa monografia descrevi os seguintes tópicos: uma breve abordagem histórica sobre a Análise Combinatória; análise de alguns livros didáticos (dos mais antigos até os adotados atualmente); da Proposta Curricular do Ensino de Matemática do Estado de São Paulo e dos Parâmetros Curriculares Nacionais, referentes ao Ensino Médio; descrição sobre a Metodologia de Ensino-Aprendizagem de Matemática através da Resolução de Problemas ao longo das reformas de ensino de Matemática e da forma como se trabalha com essa metodologia. Deixei também algumas sugestões a fim de propor um trabalho diferenciado em sala de aula.

No ano 2000, ingressei no Programa de Pós-Graduação em Educação Matemática da UNESP de Rio Claro, como aluna especial do Mestrado. Cursei algumas disciplinas e participei do Grupo de Trabalho e Estudos em Resolução de Problemas (GTERP), coordenado pela professora Dra Lourdes de la Rosa Onuchic.

No ano de 2003 reingressei na Universidade Estadual Paulista - IBILCE, em São José do Rio Preto, para cursar algumas disciplinas ministradas em 2003 e 2004 a fim de obter o título de licenciada em Matemática. No ano em que conclui esse curso, 2004, participei do concurso público do estado de São Paulo e ingressei, como professora efetiva na rede estadual de ensino, nos Ensinos Fundamental e Médio. Também, nesse mesmo período, ministrei aulas em Faculdades particulares.

Foi através do Curso de Especialização em Educação Matemática, da participação no GTERP e também da reflexão sobre a prática na sala de aula, que se fundamentou meu projeto para ingressar no mestrado.

A inquietação diante das dúvidas apresentadas pelos alunos e a busca para aperfeiçoar a formação do professor levou-me a elaborar uma proposta para trabalhar na sala de aula.

Durante o levantamento de dados para a elaboração da Monografia, pude constatar que os livros didáticos apresentam semelhança na maneira com que abordam os conceitos da Análise Combinatória. Esta é geralmente trabalhada através de "fórmula-aplicação", deixando lacunas na compreensão desse objeto matemático. Desse modo, a Análise Combinatória é 
considerada um tema de difícil operacionalização em sala de aula e o aluno tem difículdade em encontrar a fórmula adequada para solucionar um problema. Nos PCNs e na Proposta Curricular do Estado de São Paulo, são apresentadas sugestões inovadoras, mas pouco aplicadas pelos professores em sala de aula e sem conexão com os livros didáticos adotados atualmente.

$\mathrm{Na}$ literatura levantada, encontramos poucos textos sobre Análise Combinatória, apenas dois trabalhos aplicados em sala de aula mas nenhum utilizando a metodologia que pretendemos abordar na pesquisa.

Desse modo, refletindo sobre nossa experiência profissional, a preocupação por um ensino voltado à aprendizagem, com significado e compreensão, definimos o fenômeno de interesse a ser pesquisado: Trabalhar Análise Combinatória, em sala de aula do Ensino Médio, a partir da Metodologia de ensino-aprendizagem-avaliação de Matemática através da resolução de problemas.

\section{2 - Modelo Preliminar}

Ao recomendar a construção de um modelo preliminar como uma das atividades (atividade 2) que os pesquisadores devem realizar, Romberg (1992) se distingue de outros autores que tratam do assunto, tornando seu trabalho, neste aspecto, original.

[...] consiste num esquema onde se indicam as variáveis componentes do fenômeno e as relações entre elas. Variáveis são os elementos que compõem e interferem no fenômeno de interesse. (ALLEVATO, 2005, p.20)

O Modelo Preliminar apresenta uma sequência de passos organizados a serem seguidos para o desenvolvimento da pesquisa pretendida. Construído o Modelo Preliminar, percebemos que, relacionando-o com o Fenômeno de Interesse, poderíamos trabalhar Análise Combinatória, em sala de aula do Ensino Médio, a partir da agora chamada Metodologia de Ensino-Aprendizagem-Avaliação de Matemática através da Resolução de Problemas, de modo a visualizar o percurso do trabalho desta pesquisa.

Esse Modelo Preliminar apresenta um modo de organizar o desenvolvimento de nossa pesquisa, trilhando os seguintes passos: definição de uma escola para trabalhar o fenômeno de interesse; entrar em contato com a direção e a coordenação dessa escola para obter permissão de aplicar um projeto alternativo de trabalho; entrar em contato com professores dessa escola interessados nessa proposta; apresentar a Metodologia de Ensino-Aprendizagem-Avaliação de Matemática através da Resolução de Problemas; escolha de uma sala de aula para aplicação 
do projeto; disponibilidade de aulas para a execução do trabalho; análise da proposta pedagógica e do conteúdo programático da Escola escolhida; localização do conteúdo Análise Combinatória dentro do planejamento escolar; a criação de um projeto para trabalhar Análise Combinatória nessa sala de aula; aplicação desse projeto; analisar o que ficou evidente durante sua aplicação; e tirar conclusões.

Em um fluxograma o Modelo Preliminar mostra-se assim:

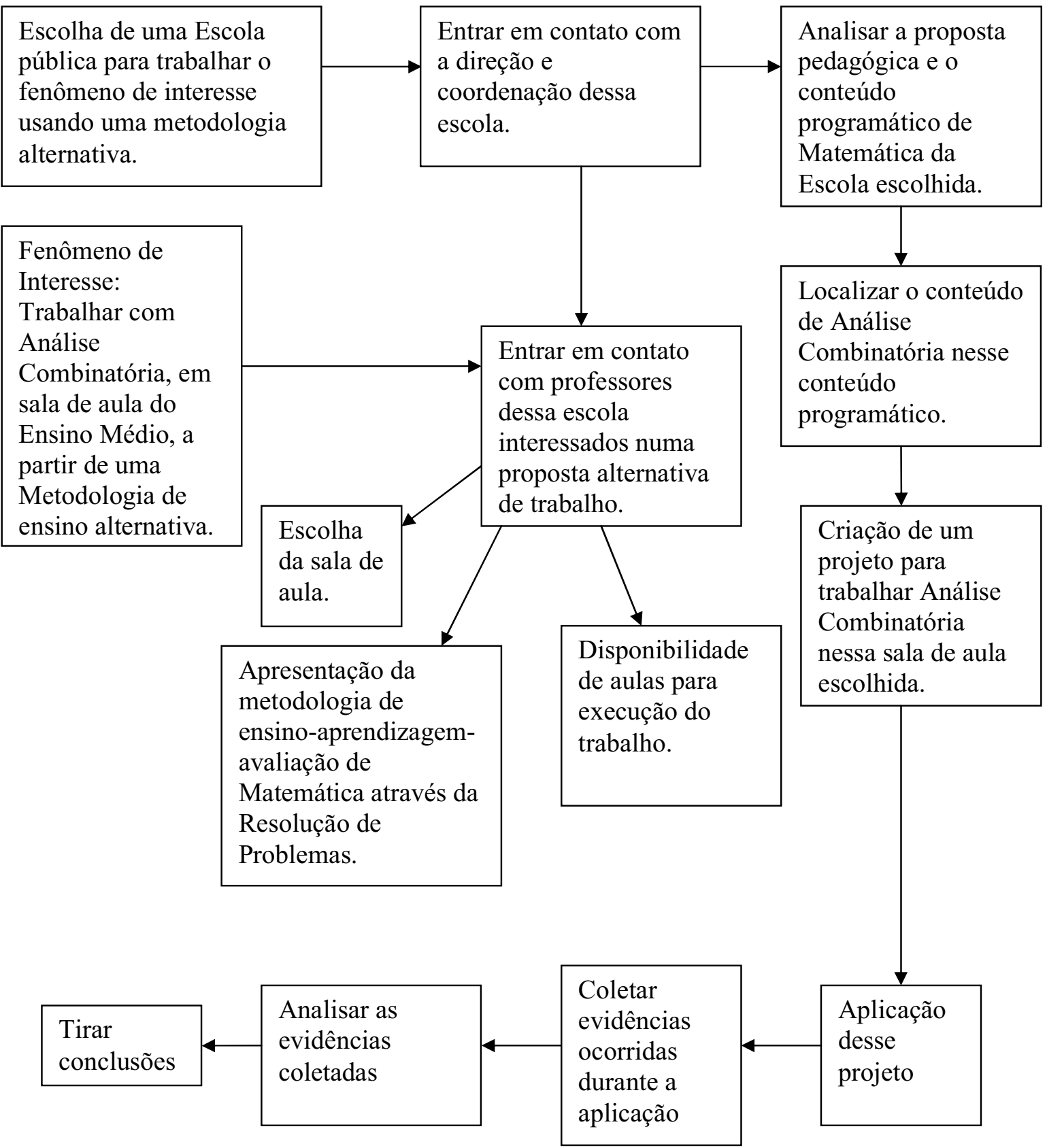

Figura 3: Modelo Preliminar 


\subsection{1 - Modelo Modificado}

Antes de iniciar esta pesquisa, estava atuando como professora efetiva da rede estadual de ensino do Estado de São Paulo com cargo na cidade de Olímpia - SP. Como ingressei no Mestrado, fiz a inscrição para concorrer a um cargo substituto, em Rio Claro, para poder cursar o Mestrado e desenvolver esta pesquisa. O artigo 22 da Lei Complementar $n^{0}$ 444/85, regulamentado pelo Decreto 24.948 de 03/04/1986, permite ao professor ocupar um cargo em outra escola, assumindo aulas livres ou aulas de um professor em afastamento. Desse modo, fui transferida para uma escola em Rio Claro, a Escola Professora Oscália Góes Correa Santos que, na ocasião, tinha algumas salas da $2^{\underline{a}}$ série do Ensino Médio, turma que interessava à minha pesquisa.

Uma das variáveis do Modelo Preliminar foi, então, modificada. Ao invés de procurar um professor da escola para aplicar a pesquisa, passamos a ser a própria professora da $2^{\mathrm{a}}$ série do Ensino Médio, sala pretendida para desenvolver a pesquisa. Assim, o Modelo Preliminar sofreu uma importante mudança e passou a ser chamado por nós Modelo Modificado e a aplicação desse projeto seria realizada por nós. 


\section{Modelo Modificado}

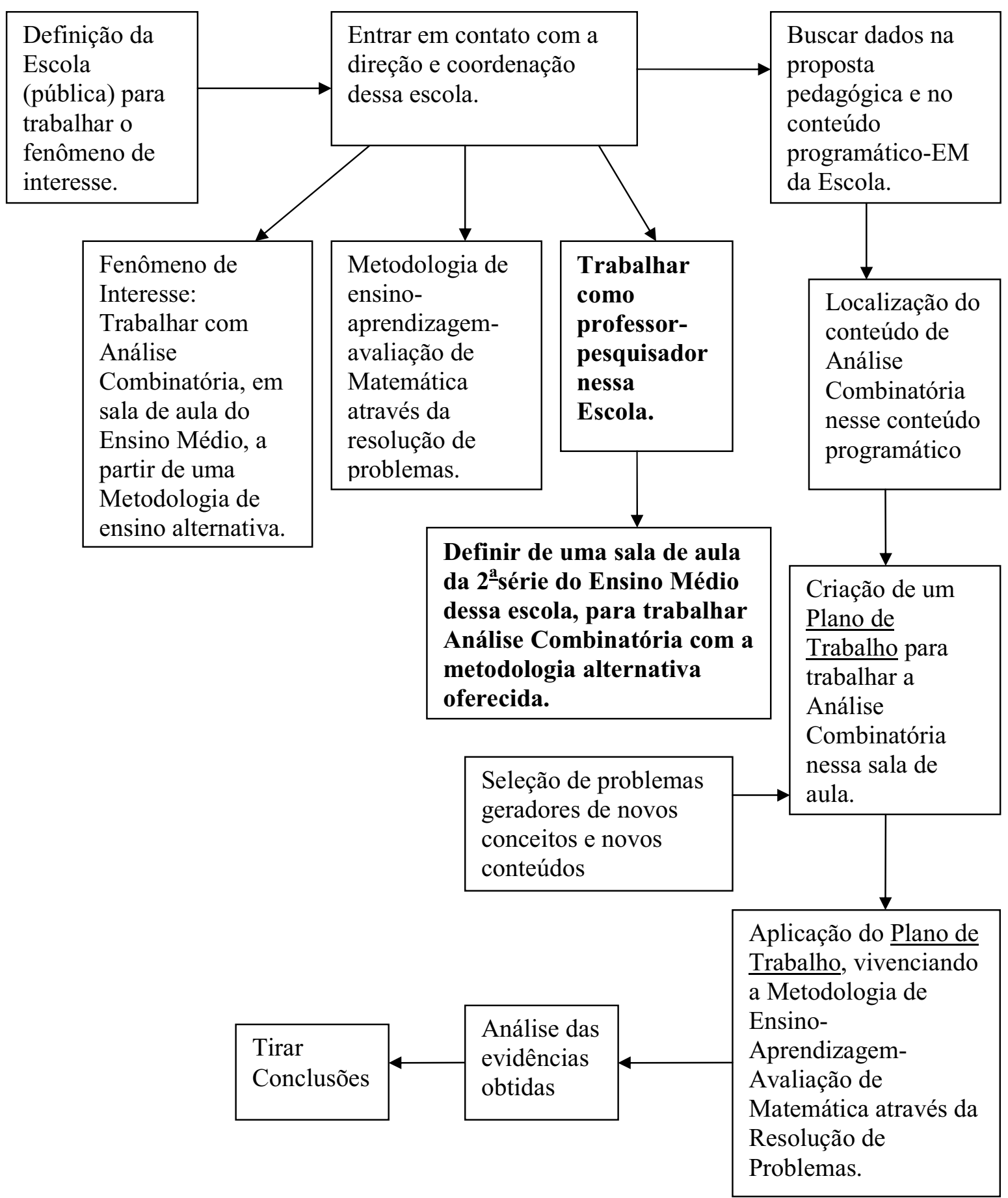

Figura 4: Modelo Modificado 


\subsection{Relacionar o Fenômeno de Interesse e o Modelo Modificado com ideias de outros.}

\section{Introdução}

Definido nosso Fenômeno de Interesse e construído o Modelo Modificado, serão realizadas leituras relacionadas a eles, ou seja, queremos saber o que outros autores escreveram sobre Matemática Discreta e Análise Combinatória; Resolução de Problemas. Conhecer o que outros autores pensam e quais são suas ideias, relativas a pesquisas desenvolvidas, relacionadas ao tema, pode proporcionar referências teóricas relevantes para o trabalho, pois nos dá a possibilidade de se ampliarem as investigações durante o seu transcorrer. Como afirma Allevato, 2005, p.22, um vasto conhecimento de estudos relacionados ao seu tema de investigação, permitirá ao pesquisador ter parâmetros para o estudo do fenômeno e, particularmente, para a interpretação das evidências.

Nesta atividade, trabalhamos sobre a fundamentação teórica necessária à nossa pesquisa. As principais fontes de pesquisa, das quais faremos uso, serão livros didáticos e acadêmicos, os PCN-EM (Parâmetros Curriculares Nacionais - Ensino Médio - de Matemática); as Propostas Curriculares do Estado de São Paulo, de 1989 (2 edição) e de 2008; artigos em revistas; teses e dissertações. Ainda será aplicada entrevista a um professor de Matemática do Ensino Médio e, em particular, aos que trabalham ou deveriam trabalhar Análise Combinatória em suas salas de aula.

Nossa pesquisa estará fundamentada sobre dois eixos: Matemática Discreta; Resolução de Problemas.

\subsubsection{Matemática Discreta}

Ao relacionar com ideias de outros, no eixo Matemática Discreta, conseguimos coletar, em diferentes publicações, dados a respeito de Matemática Discreta. Depois, resolvemos organizá-los cronologicamente. Mas, antes, sentimo-nos motivada a ver que essa "nova matemática", "a matemática para nosso tempo", se colocava como uma grande mudança que afeta tanto o currículo quanto a forma de trabalhar a Matemática, pois 
Os NCTM $M^{1}$ Curriculum and Evaluation Standards for School Mathematics (1989) (Padrões de Currículo e Avaliação para a Matemática Escolar - NCTM) é uma estrutura para criar e implementar mudança no ensino e na aprendizagem de Matemática em todos os níveis, K-12 (pré - Ensino Médio).

A publicação Professional Standards for Teaching Mathematics (1991) (Padrões Profissonais para o ensino de Matemática - NCTM) foi projetada, junto com a publicação Curriculum and Evaluation Standards for School Mathematics, para estabelecer uma estrutura ampla que guiasse a reforma na matemática escolar na década seguinte. Em particular, esses padrões apresentam uma visão de que ensino viria vinculada para apoiar as mudanças no currículo apresentado no Curriculum and Evaluation Standards. Esse documento explica em detalhes o que os professores precisam saber para ensinar visando os novos objetivos da Educação Matemática e como o ensino deveria ser avaliado para o propósito de melhora.

Nessas duas publicações foi introduzida a Matemática Discreta, como podemos notar em Abrantes (1994, p.17)

Para os Standards (1989/1991), a Matemática Discreta diz respeito às propriedades matemáticas de conjuntos e sistemas numeráveis, e o seu estudo é indispensável no mundo do processamento da informação e na resolução de problemas que envolvam métodos computacionais. O NCTM argumenta que "os computadores são essencialmente máquinas finitas e discretas" que vêm exercendo uma influência crescente nos modos de criar e usar a Matemática.

Robinson, (Yearbook 2000 - NCTM, p.112), discute em seu artigo o impacto dos Standards na matemática escolar e comenta que os Standards sugerem profunda mudança em quase todos os aspectos do ensino e da aprendizagem de matemática. E ainda diz que os professores precisam saber não apenas quais são as mudanças mas, também por que essas mudanças são apresentadas e como elas afetam o ensino e a aprendizagem de Matemática.

Os "Standards", como documento, são de fato uma lente através da qual professores, escolas e sistemas, olhando para o currículo de matemática atual, veem como esse currículo se posiciona contra as necessidades de nossa sociedade crescentemente tecnológica. Um ramo particular nos "Standards" que exemplifica essa necessidade de mudança é a Matemática Discreta.

No livro Discrete Mathematics across the Curriculum, K-12, 1991 Yearbook do NCTM, Margaret J. Kenney e Christian R. Hirsch (NCTM) apresentam, em seus capítulos,

\footnotetext{
${ }^{1}$ NCTM: National Council of Mathematics of Teacher (Conselho Nacional de Professores de Matemática).
} 
relevâncias sobre a Matemática Discreta, tais como: por que ela é importante; o que ela compreende nos vários níveis escolares; onde ela aparece no currículo; e algumas ideias sobre o seu ensino. A Matemática Discreta, como linha unificadora, permeando várias ideias, incorpora muitas das recomendações apresentadas nos Standards, tais como: a Matemática Discreta promove a elaboração de conexões matemáticas; a Matemática Discreta dá um cenário para a resolução de problemas com aplicações no mundo real; a Matemática Discreta aproveita-se de cenários tecnológicos; a Matemática Discreta favorece o pensamento crítico e o raciocínio matemático.

Mas, o que é Matemática Discreta?

Dossey (1991, p.3), no que se refere à gênese do currículo de Matemática Discreta, diz que

A Matemática Discreta cresceu muito da resposta das ciências matemáticas para a necessidade de uma melhor compreensão das bases combinatórias da matemática usada no desenvolvimento de algoritmos computacionais eficientes, a criação de novas abordagens para problemas de pesquisa operacionais, e os estudo das heurísticas subjacentes às abordagens de tais problemas. A existência da Matemática Discreta como uma área separada de estudo teve seu início nos anos 60. E, no início da década de 70, muitos textos influentes apareceram no nível superior da graduação.

No capítulo 1 desse livro, Dossey (1991) apresenta a Matemática Discreta como a Matemática para o nosso tempo, dizendo que ela é um ramo da Matemática que cresceu rapidamente em importância na década passada. Este crescimento é devido em grande parte às muitas aplicações de seus princípios em negócios e para seus vínculos próximos à ciência da computação. Os teoremas e as estratégias de resolução de problemas centrais à Matemática Discreta, combinados com o crescente poder computacional dos computadores, abriram áreas de investigação e aplicações inteiramente novas. Entretanto, cidadãos comuns e muitos professores de Matemática nunca ouviram falar sobre ela. O que é isso, perguntam?

Ainda Dossey (1991) diz que o dicionário define discreto como "distinto de outros; separado; consistindo de partes distintas; descontínuas”. Matemática Discreta, então, envolve o estudo de objetos e de ideias que podem ser divididos em partes "separadas" ou "descontínuas". Assim, a Matemática Discreta pode ser contrastada com a noção clássica da Matemática Contínua, que é a matemática subjacente à maioria dos problemas de Álgebra e do Cálculo. Esses dois tópicos tipicamente usam números reais ou complexos como um domínio para suas funções. A Matemática Discreta, por contraste, é necessária para a 
investigação de cenários onde as funções são definidas sobre conjuntos de números discretos ou finitos tais como os inteiros positivos.

A Matemática Contínua é bem apropriada a situações cujo principal objetivo é a medida de uma quantidade. Em cenários de Matemática Discreta, o foco está em determinar uma contagem. Embora alguns coloquem os dois ramos de Matemática, Contínua e Discreta, numa competição frente a frente, realmente pode se mostrar que as duas abordagens complementam-se nas aplicações do mundo real. Por exemplo, abordagens discretas dão aproximações para o tamanho de algumas medidas, enquanto que métodos contínuos permitem o estabelecimento de alguns limites para o número de passos ao calcular algoritmos que são finitos na natureza.

Os problemas de Matemática Discreta podem ser classificados em três amplas categorias:

$1^{\text {a) }}$ Problemas de existência: trata de reconhecer se um dado problema tem uma solução ou não;

$2^{\mathrm{a}}$ ) Problemas de contagem: investiga quantas soluções podem existir para problemas com soluções conhecidas; e

$3^{\text {a }) ~ P r o b l e m a s ~ d e ~ o t i m i z a c ̧ a ̃ o: ~ f o c a l i z a ~ s o b r e ~ a ~ d e s c o b e r t a ~ d e ~ u m a ~ m e l h o r ~ s o l u c ̧ a ̃ o ~ p a r a ~}$ um problema particular.

O documento Mathematics Framework for Califórnia Public Schools, 1985, identificou sete ramos de conteúdo matemático: número, medida, geometria, padrões e funções, estatística e probabilidade, lógica e álgebra. Em 1992, ecoando o “1985 Framework”, num novo documento foram endossados esses ramos e adicionado um novo: a Matemática Discreta. Esse título, não muito familiar inclui assuntos que professores, em todos os níveis, têm trabalhado por anos. Discreta põe ênfase sobre entidades separadas (discretas) mais do que sobre medidas de quantidades contínuas - sobre questões como how many (quantos? quantidades discretas) mais do que questões como how much (quanto? - quantidades contínuas). Na terceira série, por exemplo, podia-se perguntar a Boris (how many) de quantos modos diferentes ele poderia se vestir se tivesse três camisas e duas calças (seis); e, na sétima série, podia-se pedir para os alunos programarem um torneio. Essa Matemática Discreta inclui tópicos tais como o princípio de contagem combinatorial (como contar permutações e combinações para problemas de probabilidade) e estruturas discretas (como as redes de trabalho ou árvores).

Na Matemática Discreta há uma grande quantidade de ideias relacionadas tais como princípios para contar arranjos de objetos discretos (permutações, combinações, seleções); 
outros princípios de contagem (o princípio da inclusão/exclusão e o princípio da casa dos pombos $^{2}$ ); algumas ideias básicas e úteis da teoria dos conjuntos (uniões e interseções); o estudo de estruturas discretas (redes de comunicação, grafos e estruturas de árvore); relações de recorrência (tais como a relação de Fibonacci, $F_{n}=F_{n-1}+F_{n-2}$ ); e a análise de algoritmos.

Desde que discreto significa enfocar sobre entidades discretas e separadas mais do que sobre medidas de quantidades contínuas; isso não significa que tudo que não é contínuo deva ser considerado matemática discreta. A aritmética com inteiros, por exemplo, é tratada no padrão número, não na matemática discreta, pois o conjunto dos inteiros é infinito. (Mathematics Framework, 1992, p.84)

Ainda, no Framework (1992, p.149),

destaca-se a Matemática Discreta como importante nas ciências da informação e outras situações nas quais as relações entre conjuntos finitos de elementos são de interesse. Gráficos finitos e suas representações matriciais associadas são importantes adições ao repertório de ferramentas para resolução de problemas nos estudantes. Os diagramas, as redes e os fluxogramas que estudantes constroem para modelar situações ou usam para planejar, esquematizar e tomar decisões podem ser explorados por suas propriedades matemáticas. Os estudantes precisam experimentar desenvolvendo e analisando algoritmos em uma variedade de situações: na prática (instruções, jogos, procedimentos); no computador (programação, aplicações); e na matemática (fatoração em números primos). Além disso, eles deveriam investigar técnicas de contagem e organização e compreender como estas técnicas são usadas na probabilidade. Muitas dessas idéias da Matemática Discreta servem para projetos práticos e para a integração com tópicos de outras áreas do currículo, especialmente as ciências sociais.

Ainda no Mathematics Framework podemos ver o tratamento dado a Matemática Discreta no núcleo do currículo: Situações realísticas frequentemente têm características discretas que podem ser representadas por estruturas matemáticas apropriadas para os alunos da high school ${ }^{3}$, particularmente os gráficos e suas matrizes associadas. Os alunos podem usar estas ideias para dar sentido em esquematizar, rotacionar, e trabalhar com redes; empregar métodos de caminhos críticos nos contextos práticos, e usar métodos simples para organizar

\footnotetext{
${ }^{2}$ Princípio da casa dos pombos ou Princípio das gavetas de Dirichlet: Se forem dados $n$ objetos, a serem colocados em, no máximo, $(n-1)$ gavetas, então uma delas conterá necessariamente mais do que um objeto. Ou, equivalentemente, se forem dados $n$ objetos, a serem colocados em, no máximo, (n - 1) gavetas, então uma delas conterá pelo menos dois objetos. A demonstração e aplicações desse princípio podem ser encontradas no Revista do Professor de Matemática n ${ }^{\circ} 08$, p.21-26, $1^{\circ}$ semestre de 1986.

${ }^{3}$ Ensino Médio.
} 
classificações como hierarquias ou classificação cruzada. A ideia de recorrência é desenvolvida como um meio de reduzir situações complicadas a outras mais simples. Alunos constroem, analisam e comparam algoritmos e usam métodos gráficos de programação linear e suas analogias discretas como uma técnica de tomada de decisão. Métodos combinatórios são usados para analisar situações envolvendo probabilidades.

Matemática Discreta no currículo posterior: Os alunos se tornam familiares com operações matriciais elementares e as implicações destas operações em diferentes situações. A Indução Matemática é desenvolvida como uma técnica de prova formal com uma variedade de aplicações. (Framework, 1992, p.149)

Gardiner (1991, p.10), no artigo intitulado A Cautionary Note ("Uma Nota Cautelosa"), afirma que Matemática Discreta não é nova. Muitas de suas ideias fundamentais e técnicas emergiram no século dezoito, especialmente com Euler. Mas elas não foram reconhecidas como um ramo separado da matemática até muito recentemente. Somente durante os últimos quarenta anos foi que a Matemática Discreta ganhou sua independência e se tornou cada vez mais importante tanto na matemática como na vida cotidiana. Isto é parcialmente devido aos desenvolvimentos dentro da matemática, mas o fator decisivo foi o surgimento meteórico dos computadores. Sem dúvida, uma outra definição de Matemática Discreta deve ser "aquelas partes da matemática que são mais obviamente relevantes para calcular."

Esse autor também diz que a interação da Matemática Discreta e os computadores têm tornado possível novas aplicações poderosas, tem posto a atenção sobre novos tipos de problemas, e tem nos forçado a olhar para a matemática tradicional de novos modos. Enquanto estas mudanças têm acontecido e, embora elas permitam nossas sérias considerações, elas não deveriam ser usadas para justificar uma rejeição precipitada da matemática tradicional em favor daquilo que imaginamos ser um material mais relevante.

Ainda, Gardiner (1991, p.10), falando de Lováz e de Poincaré, diz que

A ciência computacional penetra a matemática clássica colocando velhas questões em uma nova perspectiva ... Esta nova perspectiva sobre a matemática clássica é de fato um desafio para os educadores matemáticos. A introdução dos computadores (em qualquer nível) é somente uma resposta parcial ... muito mais trabalho terá que ser feito - experimental e teórico - antes que os contornos da resposta fiquem claros. (Lovász, 1988, p.69)

$\mathrm{O}$ ensino não deveria estar submetido a mudanças rápidas sob caprichosas rajadas de modas efêmeras. (Poincaré, 1914, p.151) 
Poucos matemáticos clássicos estavam mais ligados ao espírito moderno do que Poincaré e poucos matemáticos modernos contribuíram de mais impressivamente para os desenvolvimentos recentes do que Lovász. Ainda, quando vem a ideia de rever a matemática com os estudantes comuns, ambos saem de seus caminhos e recomendam cautela. Antes de olhar mais de perto para a questão da matemática discreta no nível escolar, Gardiner disse que se deveria tentar explicar por que seria necessário considerar suas recomendações seriamente, pois a educação é um longo período de preparação. A matemática escolar tem que evoluir num modo controlado. Nunca se deveria permitir que ela perdesse o controle para a recente "moda efêmera", mesmo que se isso significasse continuar, por um certo tempo, a ensinar a matéria à moda antiga.

O que isso tem a nos contar sobre a possível introdução da Matemática Discreta no nível escolar?

Toda a matemática escolar também facilmente se degenera numa sucessão de rotinas sem sentido. E a Matemática Discreta tem características que a tornam vulnerável a tal degeneração.

Quais são, então, as implicações para a Matemática Discreta no nível escolar?

Seguindo as ideias de Gardiner, 1991, p.22, são aqui transcritas essas implicações:

- Antes de tudo se os problemas matemáticos na matemática discreta são dados em seu cenário natural, eles tendem a ser mais difíceis - mesmo para aqueles que sentem que saberiam como resolvê-los.

O valor educacional de Matemática Discreta encontra-se precisamente no fato de que ela força os alunos a pensarem sobre coisas muito elementares, tais como contagem sistemática. Entretanto, essa ideia pode ser facilmente enfraquecida pelo fato de que a maioria professores de matemática sentem-se obrigados a "ajudar" os alunos a resolver problemas difíceis reduzindo as resoluções a um número de passos manejáveis e predizíveis ou regras, requerendo um mínimo absoluto de pensar. Seu valor educacional, assim, estará perdido.

- Embora o trabalho com Matemática Discreta seja elementar no sentido de que ela tem poucos pré-requisitos técnicos, muito dele é intrinsecamente não natural para o adolescente médio, por exemplo, o princípio de Pigeonhole ${ }^{4}$; as árvores e gráficos ponderados ou dirigidos; e as limitações da "ganância" quando se buscam soluções ótimas. Muito do que pode se tornar acessível requer um ensino muito cuidadoso se se

\footnotetext{
${ }^{4}$ Princípio de Pigeonhole ou Princípio da casa dos pombos. Tradução de Pigeonhole: o buraco do pombal.
} 
quer que ele se torne natural, por exemplo, a regra do produto para a contagem; a habilidade em contar um conjunto maior por dois caminhos diferentes; matrizes; a diferença entre e a relativa importância das relações de recorrência e as fórmulas fechadas; a diferença entre um algoritmo aparentemente correto e um provado corretamente.

- É frequentemente dito que Matemática Discreta tem a vantagem de ter muitas aplicações aparentemente acessíveis no mundo real. Estas são acessíveis somente no sentido de que o problema que se está tentando resolver pode ser entendido (em alguma forma convenientemente simplificada) e que uma solução pode ser efetuada usando-se algum simples algoritmo dado. $\mathrm{O}$ algoritmo relevante pode ser implementado por alunos da high school (Ensino Médio), embora as ideias matemáticas por atrás dela estejam fora de seu alcance.

Continua Gardiner, 1991, p.13, dizendo que, no nível introdutório, a Matemática Discreta deveria estar baseada sobre muitas ideias importantes, não sobre teorias ou algoritmos padronizados. Ela deveria concentrar-se sobre problemas que requerem que os alunos pensem em contextos que lhes sejam familiares e naturais, e não deveria recorrer a rotinas pobremente compreendidas. Os problemas estudados deveriam ser escolhidos de modo que deles se pudesse extrair um pequeno número de técnicas centrais. Engel (1983, p.313, apud Gardiner, 1991, p.13) disse a esse respeito que Se você ensina geometria, você não prova uma amostra aleatória de teoremas. Você seleciona aqueles teoremas dos quais você pode dominar o assunto). Sim. Ai é que está o problema! Identificar técnicas centrais apropriadas pode ser complicado.

Esta é provavelmente uma razão porque Lovász, na citação da página 35, esperava que houvesse muito mais trabalho antes de que se pudesse esperar atingir um consenso nas técnicas centrais apropriadas no nível escolar.

Ainda, se desejarmos explorar as vantagens educacionais de problemas compreendidos facilmente que forçam os estudantes a pensar, então devemos produzir um currículo revisado que não tente fazer tanta mudança. Devemos também desenvolver paradigmas de aprendizagem regulares para ajudar os professores a ensinar os novos tópicos com sucesso.

Se se quer explorar a arte de contar no Ensino Médio, então os estudantes precisam já ter tido experiência com muita contagem estruturada intuitivamente, por exemplo, olhando os oito vértices de um cubo como "quatro superiores e quatro inferiores" e as doze arestas como "quatro superiores, quatro inferiores" e outras quatro unindo-as. 
Gardiner apresenta ainda possíveis mudanças curriculares que considera importantes para trabalhar com os estudantes: Contagem (1-12); Inteiros (6-12); Seqüências (6-12); Geometria (4-12), Recorrência (6-12); Algoritmos (8-12); e Probabilidade (7-12)5.

Os livros-texto foram logo seguidos por recomendações para a inclusão de programas de estudo no currículo universitário com ênfase em matemática. A maioria dos Programas, como o Programa Geral de Ciências Matemáticas do MAA - The Mathematical Association of America, recomendava a inclusão de um trabalho em Matemática Discreta. Pedia-se por um conteúdo: teoria dos grafos (propriedades, árvores, coberturas gráficas, circuitos e modelos gráficos) e combinatória (princípios de contagem, permutações e combinações, inclusão/exclusão e relações de recorrência). Essas recomendações davam ênfase à necessidade e posteriormente especificado o conteúdo de ofertas em Matemática Discreta, com ênfase em Matemática.

As conexões com o currículo da escola secundária foram rapidamente seguidas por recomendações adicionais sobre a necessidade de desenvolver ideias de Matemática Discreta logo no começo do currículo de matemática.

O apoio desses relatos e outras sugestões para reforma no currículo de matemática escolar deu base para muitos projetos patrocinados pelo $\mathrm{NSF}^{6}$ para os professores, para conduzir os professores à atualização em Matemática Discreta e suas aplicações. Este crescimento no conhecimento dos professores, o surgimento de tópicos discretos em livrostexto comerciais e a publicação de artigos tratando de Matemática Discreta na revista Mathematics Teacher promoveu a causa da Matemática Discreta.

A inclusão da Matemática Discreta como um padrão de nível secundário nos Standards $^{7}$ (1989) deu o ímpeto final para uma série de considerações do tópico em todos os programas da matemática escolar.

A declaração sobre Matemática Discreta nos Standards prevê, em parte, como segue: (NCTM, 1989, p.176)

\footnotetext{
${ }^{5}$ Kindergarden (pré): 5 anos

Elementary School (1-5): $1^{\underline{0}}$ ano ( 6 anos), $2^{\underline{0}}$ ano ( 7 anos), $3^{\circ}$ ano ( 8 anos), $4^{\circ}$ ano ( 9 anos) e $5^{\circ}$ ano $(10$ anos).

Middle School (6-8): $6^{\circ}$ ano (11 anos), $7^{\circ}$ ano (12 anos) e $8^{\circ}$ ano (13 anos).

High School (9-12): $9^{\circ}$ ano- Freshman (14 anos), $10^{\circ}$ ano- Sophomore (15 anos), $11^{\circ}$ ano-Jr. high school (16 anos) e $12^{\circ}$ ano-Senior high school (17 anos).

${ }^{6}$ National Science Foundation (Fundação da Ciência Nacional)

${ }^{7}$ Standards (1989): documento norte-americano Curriculum and Evaluation Standards for School Mathematics (Padrões de Currículo e Avaliação para matemática escolar), organizado pelo NCTM National Council of Teachers of Mathematics (Conselho Nacional de Professores de Matemática).
} 
Nas séries de 9-12, a matemática deveria incluir tópicos de matemática discreta para que todos os estudantes pudessem:

- representar situações problema usando estruturas discretas tais como grafos finitos, matrizes, seqüências e relações de recorrência;

- representar e analisar grafos finitos usando matrizes;

- desenvolver e analisar algoritmos;

- resolver problemas com enumeração e probabilidade finita;

E ainda em adição, estudantes que pretendem ir para universidade possam

- representar e resolver problemas usando programação linear e equações diferença;

- investigar situações problema que surgem em conexão com a validação computacional e a aplicação de algoritmos.

Ainda nos Standards, comenta-se sobre o foco em 1991, apresentado por Dossey ao abordar a Matemática Discreta:

Quando nós movemos para o século vinte e um, informação e sua comunicação tem se tornado pelo menos tão importantes quanto a produção de bens materiais. Enquanto o mundo físico ou material está mais freqüentemente modelado pela matemática contínua, isto é, o cálculo de idéias prévias de álgebra, geometria, e trigonometria, o mundo não material do processamento da informação requer o uso da matemática discreta (descontínua). A tecnologia computacional, também, exerce uma influência bastante crescente na forma como a matemática é criada e usada. Computadores são essencialmente, máquinas finitas e discretas, e assim tópicos de matemática discreta são essenciais para resolver problemas que usam métodos computacionais. À luz destes fatos, é crucial que todos os estudantes tenham experiências com os conceitos e métodos da matemática discreta. (1991, p.05)

E concluindo, Dossey diz:

A Matemática Discreta permite aos alunos explorarem situações problema únicas que não são diretamente abordáveis através da escrita de uma equação ou da aplicação de uma fórmula comum. Pede-se aos alunos que frequentemente visualizem a situação através do desenvolvimento de um modelo ou qualquer outra forma de representação. Outros cenários pedem por analisar casos especiais ou desenvolver uma solução ao considerar um problema mais simples envolvendo poucos casos. A teoria não requer aprender um grande número de definições e teoremas, mas realmente requer uma mente afiada e inquisitiva (perspicaz e curiosa). Um desenvolvimento cuidadoso do conteúdo de Matemática Discreta, construir suas ligações ao programa escolar atual, e intensificar as conexões entre abordagens contínua e discreta para tópicos, podem dar aos estudantes as oportunidades pretendidas pelos Standards e necessárias aos jovens adultos que se preparam para entrar no mundo do trabalho no século vinte e um. (1991, p.08) 
Veloso (1997, p.44) apresenta

Dois problemas que são exemplos de situações em que os alunos têm de criar modelos eficazes de contagem sistemática. Esses modelos requerem raciocínio crítico mas não exigem muitos conhecimentos de matemática formal, o que, segundo Gardiner (1991), é frequente em muitos problemas que envolvem processos de Matemática Discreta.

Nesses problemas: “o jogo das torres de Hanói” e "qual é o número máximo de regiões definidas?", Veloso analisou estratégias de resolução de problemas, aspectos experimentais nos processos argumentativos e o uso das relações de recorrência.

O primeiro, uma das versões do jogo das Torres de Hanói, utiliza de uma placa de madeira, com três hastes metálicas (ou de madeira) e três "discos" de madeira, de diâmetros diferentes $\left(d_{1}, d_{2}\right.$ e $\left.d_{3}\right)$. O objetivo desse jogo consiste em deslocar para uma das hastes (por exemplo, a haste 3) a torre de três discos colocada em uma delas (por exemplo, na haste 1), com o número mínimo de movimentos. Há duas regras a seguir: só pode ser colocado um disco de cada vez e não se pode sobrepor um disco de maior diâmetro a um disco de diâmetro menor. Veloso descreve que o objetivo ao trabalhar com esse jogo é o de valorizar matematicamente as relações de recorrência em processos de resolução de problemas e também permite trabalhar "boas" estratégias de resolução de problemas envolvendo poucos conhecimentos de matemática formal.

Nesta figura

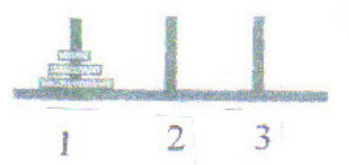

A primeira parte do deslocamento dos discos, realizando um número mínimo de movimentos, é feita do seguinte modo:

Mantendo o disco 3 na haste 1, desloca-se, em três movimentos, a torre com os discos 1 e 2 , da haste 1 para a haste 2 . A haste 3 está agora vazia e o disco 3 continua na haste 1 . Só então desloca-se o disco 3 para a haste 3 .
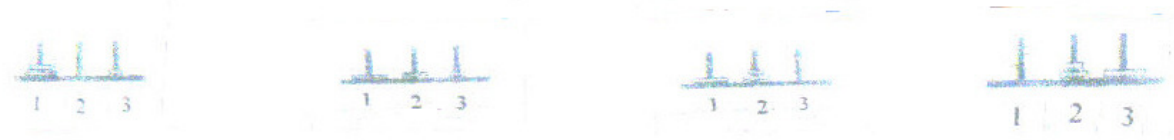
Finalmente, repete-se o processo de deslocamento com os discos 1 e 2, da haste 2 para a haste 3.
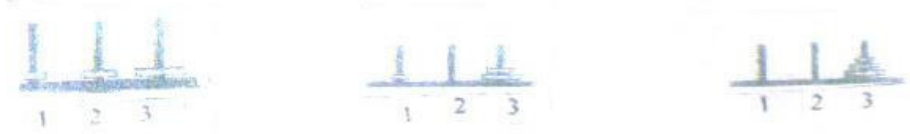

Para o deslocamento de três discos temos sete como o número mínimo de movimentos. Se fizermos o mesmo processo com quatro discos, teremos pelo menos 15 movimentos. Desse modo, podemos organizar uma tabela, iniciando com 1 disco e o respectivo número mínimo de movimentos:

\begin{tabular}{|ll|l|l|l|l|l|c|}
\hline $\mathrm{n}^{\mathrm{o}}$ de discos $(\mathrm{n})$ & 1 & 2 & 3 & 4 & $\cdots$ & $\mathrm{n}$ \\
\hline $\begin{array}{l}\text { número mínimo de } \\
\text { movimentos }\left(\mathrm{m}_{\mathrm{n}}\right)\end{array}$ & 1 & 3 & 7 & 15 & $\cdots$ & $2 \mathrm{~m}_{\mathrm{n}-1}+1$ \\
\hline
\end{tabular}

Consideremos uma torre com $\mathrm{n}$ discos e o número mínimo de movimentos $\mathrm{m}_{\mathrm{n}} \mathrm{em}$ função de $n$. Para $n=1$ temos $m_{1}=1$; Para $n=2$, temos $m_{2}=2 \cdot 1+1=3$; Para $n=3$, temos $\mathrm{m}_{3}=2 \cdot 3+1$ e Para $\mathrm{n}=4$ teremos 15 movimentos, ou seja, 2 x $7+1$. Pode-se então conjecturar a seguinte relação de recorrência: $\mathrm{m}_{\mathrm{n}}=2 \mathrm{~m}_{\mathrm{n}-1}+1$, para $\mathrm{n} \geq 1, n \in \mathrm{N}$. Outra conjectura que expressa a mesma quantidade de movimentos poderia ser: $m_{n}=m_{n-1}+2^{n-1}$, para $\mathrm{n} \geq 1, n \in \mathrm{N}$.

Uma outra relação de recorrência que exprime o número de movimentos $\mathrm{m}_{\mathrm{n}}$ em função do número de discos $n$ é: $\mathrm{m}_{\mathrm{n}}=2^{\mathrm{n}}-1, \mathrm{n} \geq 1, n \in \mathrm{N}$.

As três fórmulas $\mathrm{m}_{\mathrm{n}}=2 \mathrm{~m}_{\mathrm{n}-1}+1, \mathrm{~m}_{\mathrm{n}}=\mathrm{m}_{\mathrm{n}-1}+2^{\mathrm{n}-1} \mathrm{e} \mathrm{m}_{\mathrm{n}}=2^{\mathrm{n}}-1, \mathrm{n} \geq 1, n \in \mathrm{N}$, são equivalentes pois representam o mesmo número mínimo de movimentos.

Essas conjecturas poderiam tornar-se uma fórmula que vale sempre, são demonstráveis a partir de condições de equivalência.

O outro problema é "Qual é o número máximo de regiões definidas?”, cujo enunciado é: Qual é o número máximo de regiões definidas no plano por $\mathrm{n}$ retas, não paralelas duas a duas, e que se intersectam em pontos diferentes?

Os objetivos desse problema são: dar importância a aspectos experimentais nos processos argumentativos e compreender o processo gerador de novas regiões utilizando a relação de recorrência como um modelo adequado. 
Se considerarmos uma reta, o plano fica "dividido" em duas regiões:

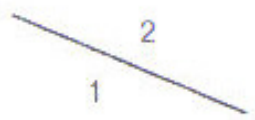

Se considerarmos duas retas, o plano fica "dividido" em quatro regiões:

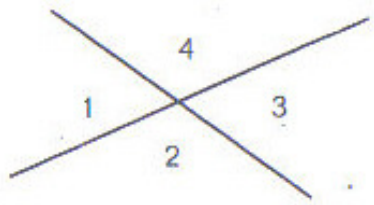

Se considerarmos três retas, o plano fica "dividido" em sete regiões:

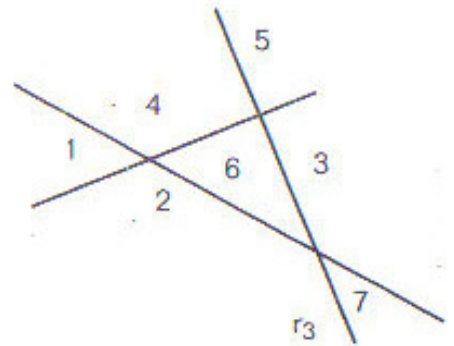

Observa-se que o fato de se pensar em zero retas nos leva a apenas uma região, o plano.

Essas contagens podem ser registradas na tabela a seguir:

\begin{tabular}{|l|l|l|l|l|l|}
\hline $\mathrm{n}^{\mathrm{o}}$ de retas $(\mathrm{n})$ & 0 & 1 & 2 & 3 & $\cdots$ \\
\hline $\begin{array}{l}\mathrm{n}^{\mathrm{o}}(\text { máximo) de regiões definidas } \\
\text { pelas retas }\left(\mathrm{r}_{\mathrm{n}}\right)\end{array}$ & 1 & 2 & 4 & 7 & $\cdots$ \\
\hline
\end{tabular}

Seja $r_{n}$ o número de regiões definidas por $n$ retas nas condições do problema. Pode-se conjecturar a seguinte relação de recorrência: o número de regiões obtidas com $\mathrm{n}$ retas é igual à soma de $\mathrm{n}$ com o número de regiões definidas por $(\mathrm{n}-1)$ retas.

Desse modo, temos: $r_{n}=n+r_{n-1}$.

Esses dois problemas podem facilmente mostrar que, dentro do processo de contagem, como parte da Matemática Discreta, trabalhando no conjunto dos números naturais não é necessário muito conhecimento matemático formal e que os conceitos novos construídos são bastante fortes em si mesmos. Também, o que se observa é que durante a contagem o aluno pode apreciar o processo de recorrência que o leva a construir uma conjectura e depois até prová-la. 


\subsubsection{A História da Análise Combinatória}

Tratamos a Matemática Discreta como um ramo da matemática do qual a Análise Combinatória faz parte. Descrevemos o que é Matemática Discreta, falamos sobre sua importância, sua forma de ensino e de quando se deu sua inserção no currículo da matemática escolar. Como forma de ver a Análise Combinatória fazendo parte da Matemática Discreta, propomos ao leitor o seguinte problema:

"Quantos números de dois algarismos distintos podemos formar com os algarismos $1,2,3,4,5,6,7,8$, e 9?"

O objetivo desse problema é o de determinar a quantidade de números de dois algarismos distintos formados apenas com os algarismos dados.

Suponhamos que o leitor pudesse iniciar sua resolução, por exemplo, do seguinte modo: começando com o algarismo 1 para dezena, poderia ter como algarismo das unidades, 2, 3, 4, 5, 6, 7, 8 e 9. Então, como resposta haveria somente 8 números possíveis. Começando com o algarismo 2 para a dezena, haveria também 8 números. Assim por diante, seguindo o mesmo raciocínio, chegar-se-ia a um total de 72 números, isto é, 9 × 8 números.

E se um dos leitores respondesse: “encontrei 71 números e meio!” Seria isso possível? Sabe-se que não, pois estamos tratando com entes discretos, ou seja, objetos separados, numa quantidade discreta de números descontínuos, consistindo de partes distintas e, assim, se está trabalhando com um conjunto finito de números. Logo, seria absurdo considerar-se que um dos leitores pudesse encontrar 71 números e meio pois, na Matemática Discreta, seus elementos são números naturais.

Outros exemplos de situações de Matemática Discreta que poderiam ser apresentadas são: a tela de uma televisão ou de um computador, formados por milhares de linhas e colunas (matriz) definindo uma coleção de muitos pontos isolados que não formam um conjunto contínuo. As situações acima retratam exemplos da Matemática Discreta e seu estudo tem grande destaque na área da Informática. Temos que a tela do computador é uma estrutura com um número finito de pontos e muitas de suas propriedades podem ser entendidas dentro do universo da Matemática Discreta.

Durante o trabalho em sala de aula, o professor de matemática é frequentemente abordado pelos alunos, que os questionam sobre o uso da Matemática no seu cotidiano. Perguntas como "Para que eu preciso estudar a matemática que estou aprendendo?" ou "Onde eu vou usar essa matemática?" ou, ainda, "Para que é que eu preciso saber isso?" são inevitáveis e, muitas vezes, ficam sem respostas. 
$\mathrm{Na}$ verdade, o que ocorre, muitas vezes, é que os alunos não conseguem relacionar aquilo que aprendem na escola com as ações de seu dia a dia ou com as demais disciplinas escolares. Uma possível razão para isso poderia estar no modo como o professor conduz sua aula. No entanto, no intento de responder aos questionamentos dos alunos, acreditamos que o professor poderia, muitas vezes, recorrer à História da Matemática. Esse é um recurso que pode motivar os alunos no início de cada novo conteúdo trabalhado, favorecendo um melhor aprendizado. Essa é, também, uma maneira para se poder esclarecer e compreender como um determinado conteúdo matemático foi construído, evoluindo e chegando a resolver novos problemas que surgem no mundo, atenuando as dúvidas dos alunos ou até mesmo eliminandoas.

O que dizer de um professor de matemática que, numa sala de segundo ano de Ensino Médio diga: - Hoje vamos começar um tópico novo. Vamos estudar Análise Combinatória.

Que possíveis perguntas esse professor poderia ouvir:

— Que é que é isso professor? Nunca ouvi falar disso. Para que isso serve?...

Como recurso motivador, esse professor poderia começar seu trabalho com alguns problemas de Análise Combinatória pertinentes à sua história, desde que, preparado para isso, tivesse feito uma pesquisa bibliográfica para saber como se deu o desenvolvimento da Análise Combinatória. Dessa maneira, procuramos investigar o que vem a ser esse ramo da Matemática que, muitas vezes, aterroriza alguns alunos, mas que, também, chega a despertar a curiosidade em muitos outros.

Sabe-se que as origens da Análise Combinatória são remotas. Datam dos primeiros estudos sobre números figurados, feitos pelos geômetras gregos entre os quais alguns da escola pitagórica. O homem iniciou o processo de contagem devido à necessidade de controlar a quantidade de coisas que possuía, como os animais e os alimentos. Eles contavam as coisas uma a uma e, para isso, utilizavam pedras, nós em cordas e, mais tarde, os números naturais. Mas alguns problemas do seu dia a dia não eram solucionados quando envolviam, por exemplo, grandes quantidades, pois só sabiam contar um a um os seus objetos. Surgiu então a necessidade de um outro método de contagem. Assim, esse progresso exigiu um novo tipo de contagem que superou a simples enumeração dos objetos (ROSA, 1998, p.03). Aparece então a noção de agrupamento de objetos de um conjunto, utilizando-se de certas técnicas, não tendo assim a necessidade de contá-los um a um.

Levando-se em conta o fascínio que os jogos de azar sempre exerceram sobre os homens, estimulando-os a achar maneiras mais segura de ganhar, não é de se espantar que, desde há muito, problemas relativos a jogos de cartas ou de dados tenham atraído a atenção de 
pessoas com mentes mais especulativas. Em verdade, o desenvolvimento da Análise Combinatória deve-se, em grande parte, à necessidade de se resolver problemas de contagem originados na teoria das probabilidades.

Combinatória é o ramo da matemática preocupado com contagem, arranjamento e ordem. Embora contemplado pela riqueza dos primeiros contribuintes, já que há referências para problemas combinatórios no Velho Testamento, sua emergência como uma disciplina separada é frequentemente creditada ao matemático e filósofo alemão Gottfried Wilhelm Leibniz (1646-1716), em cujo tratado de 1666, "Dissertatio", de arte combinatória, foi talvez a primeira monografia escrita sobre o assunto.

Ao iniciar o levantamento sobre o aspecto histórico da Análise Combinatória, não encontramos muito material, a não ser na introdução de alguns livros, acadêmicos e didáticos, que apresentam somente um breve tratamento histórico sobre Combinatória. Nos livros de História da Matemática, a localização desse conteúdo foi, por nós, detectada de forma esparsa. Nesses livros, ela é, geralmente, abordada associada a outro conteúdo da Matemática Discreta - a Probabilidade - que didaticamente é trabalhada depois da Análise Combinatória.

Procurando seguir, de perto, uma breve sequência cronológica de fatos históricos, podemos encontrar no livro History of Mathematics, de David Eugene Smith (1958, p.524), o seguinte:

- Na Grécia antiga, esse assunto foi abordado com pouca atenção pelos escritores gregos. Plutarco (séc. I), um desses escritores, contou que Xenócrates, o filósofo, por volta de 350 a.C., calculou o número de possíveis sílabas, 1002000000000, mas não parece muito provável que esse cálculo represente um cálculo real de combinação. Plutarco também declarou que Chrysippus, filósofo estóico, por volta de 207 a.C., encontrou o número de combinações de dez axiomas, chegando a mais do que 1000000. Na verdade, não se tem nenhuma evidência de teoria de combinações entre os gregos.

- Os escritores romanos, tendo pouco interesse em qualquer aspecto da Matemática, exceto no prático, puseram quase nenhuma atenção à teoria das combinações. A exceção principal foi Boethius que, por volta de 510, deu uma regra para encontrar as combinações de $n$ coisas tomadas duas a duas, que poderiam se expressar por $\frac{1}{2} n(n-1)$.

- Parece que os hindus também não tenham dado atenção a esse assunto, até que Bháskara, (1114-1185), referiu-se ao assunto duas vezes em sua obra Lilavati. Ele afirmou que uma ideia de permutações servia à métrica, dizendo: utiliza-se em métrica (...) para achar as variações do metro; nas artes (como na arquitetura) para calcular as mudanças 
nas aberturas (de um edifício); e na música, o esquema de permutações musicais; na medicina, as combinações de diferentes sabores. Bháskara deu as regras para as permutações de $n$ coisas tomadas $r$ a $r$, com ou sem repetição, e o número de combinações de $n$ coisas tomadas $r$ a $r$ sem repetição.

- Smith diz que, no início da Era Cristã, desenvolveu-se uma relação fechada entre a matemática e a ciência mística dos hebreus, conhecida como a Cabala. Isso levou à crença no misticismo dos agrupamentos e, então, ao estudo de permutações e combinações. A primeira fonte judia nesse tópico parece ter tido início com o místico trabalho Sefer Jezira (Livro da Criação), escrito algum tempo antes do oitavo século. Nele, como diz Katz (1993, p.277), o autor desconhecido desse livro, calcula os vários caminhos nos quais as 22 letras do alfabeto hebreu podiam ser arranjadas. Ele estava interessado nesse cálculo porque os místicos judeus acreditavam que essas letras tinham poderes mágicos. Combinações convenientes delas poderiam então dominar os poderes da natureza.

- Assuntos como esses parecem ter atraído a atenção dos escritores árabes e judeus da Idade Média em conexão com a Astronomia. Um estudo mais detalhado de combinações foi levado avante por Rabbi ben Ezra, (1090-1167), que investigou a Astronomia relacionada às conjunções de planetas, acreditando que essas conjunções teriam uma poderosa influência na vida humana. Buscando encontrar o número de maneiras nas quais Saturno pudesse ser combinado com cada um dos outros planetas em particular, e em geral, buscando o número de combinações dos planetas conhecidos tomados dois a dois, três a três, e assim por diante. Ele sabia que o número de combinações de sete coisas tomadas duas a duas era igual ao número tomado cinco a cinco, e, da mesma maneira, para três e quatro e para seis e um. Ele não estabeleceu uma regra geral, mas parece ter tido consciência da regra para encontrar as combinações de $n$ coisas tomadas $r$ a $r$.

- Levi ben Gerson (1288-1344), em sua obra Maassei Choscheb (Trabalho de Cálculo), escrita em 1321, levou esse assunto bastante adiante. Ele deu regras para a permutação de $n$ coisas tomadas todas juntas e também tomadas $r$ a $r$, e para combinação de $n$ coisas tomadas $r$ a $r$.

- Poucos anos depois, Nicole Oresme (1323-1382) escreveu, em 1360, o trabalho Tractatus de figuratione potentiarum et mensurarum difformitatum, no qual ele apresentou a soma dos números que representam as combinações de seis coisas tomadas 1 a 1, 2 a 2, 3 a 3, 4 a 4 e 5 a 5. Ele também apresentou essas combinações em detalhes, tais como ${ }_{2} \mathrm{C}_{6}=15$, lendo-se ${ }_{2} \mathrm{C}_{6}$ combinações de 6 elementos tomados 2 a $2,{ }_{3} \mathrm{C}_{6}=20$, lendo-se ${ }_{3} \mathrm{C}_{6}$ combinações 
de 6 elementos tomados 3 a 3, e assim por diante, é claro que na forma retórica, e parece ter conhecido a lei geral envolvida, embora ele não tenha estabelecido isso.

Katz (1993, p.415) diz que outro matemático que contribuiu para o estudo da Análise Combinatória foi Blaise Pascal (1623-1662), através do desenvolvimento do triângulo aritmético, o triângulo de números que era usado em várias partes do mundo havia mais de 500 anos. Pascal apresentou, em sua obra Triangle Arithmétique, o triângulo aritmético expresso em uma tabela:

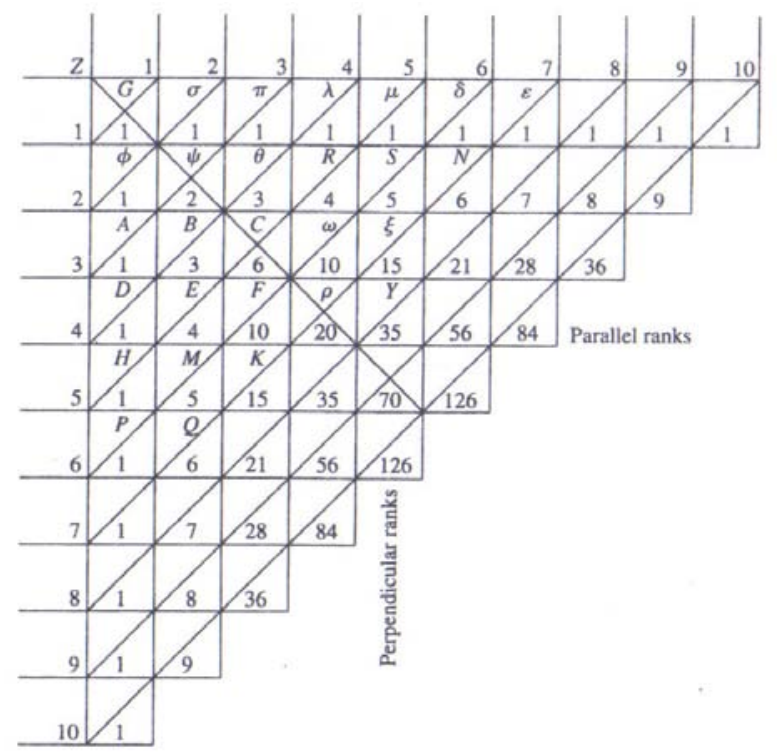

Figura 5: Triângulo Aritmético apresentado por Pascal. Burton, D.M. The History of Mathematics: An Introduction. p.458. McGraw-Hill Companies, 2007.

Na discussão dos resultados de Pascal, entretanto, será mais claro usar uma tabela e notação modernas para identificar as várias entradas no triângulo. O símbolo binomial $\left(\begin{array}{l}n \\ k\end{array}\right)$ será usado para nomear a k-ésima entrada na n-ésima linha (onde a coluna inicial e a linha inicial são ambas numeradas por zero)

O triângulo aritmético, agora geralmente conhecido como Triângulo de Pascal, é uma tabela numérica infinita na forma triangular, onde a n-ésima linha do triângulo lista os coeficientes sucessivos da expansão binomial de $(x+y){ }^{n}$. 
Assim,

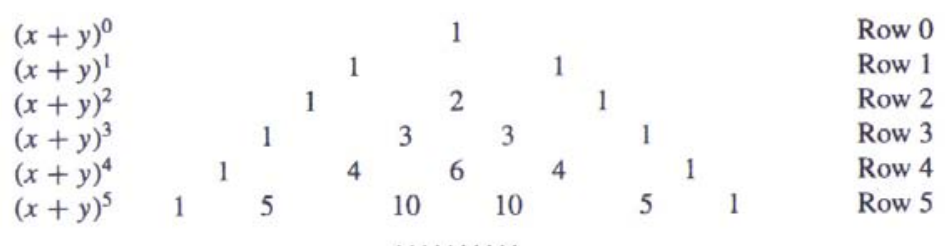

Figura 6: Triângulo Aritmético. Burton, D.M. The History of Mathematics: An Introduction. p.456. McGraw-Hill Companies, 2007.

Por exemplo, os números $1 \quad 5 \quad 10 \quad 5 \quad 1$ na linha 5 são os coeficientes na expansão de $(\mathrm{x}+\mathrm{y})^{5}$. O início dos teoremas binomiais foram encontrados relativamente cedo no desenvolvimento da matemática $-\mathrm{a}$ identidade $(\mathrm{x}+\mathrm{y})^{2}=\mathrm{x}^{2}+2 \mathrm{x} y+\mathrm{y}^{2}$ ocorreu, na linguagem geométrica, seguramente, no livro II dos Elementos de Euclides. Assim as tabelas dos coeficientes binomiais apareceram de uma forma ou de outra muito antes da publicação do famoso Triângulo de Pascal. É largamente um acidente da história que o triângulo aritmético levasse o nome de Blaise Pascal antes que de um dos seus muitos antecessores neste arranjo de números.

Ele mostrou, usando uma notação diferente da apresentada por Nicole Oresme, que o número binomial $\left(\begin{array}{l}n \\ k\end{array}\right)$ é igual ao número de combinações de $n$ elementos tomados $k$ a $k$.

Para resolver certos problemas de matemática, muitas vezes necessitamos do cálculo de potências de somas algébricas, por exemplo, $(a+b)^{n}$, onde $a$ e $b$ são números quaisquer e $\mathrm{n} \in \mathrm{N}$. Assim sabe-se que $(a+b)^{2}=a^{2}+2 a b+b^{2}$ e que $(a+b)^{3}=a^{3}+3 a^{2} b+3 a b^{2}+b^{3}$.

Para desenvolver a potência $(a+b)^{5}$ devemos efetuar, por definição, as seguintes multiplicações: $(a+b) \cdot(a+b) \cdot(a+b) \cdot(a+b) \cdot(a+b)$.

Aplicando a propriedade distributiva, ao fazer a multiplicação, de todas as maneiras possíveis, dos cinco fatores $(a+b)$, um dos termos possíveis seria $a^{3} b^{2}$. Porém, existem variadas possibilidades que resultam no termo $a^{3} b^{2}$. Para saber quantos termos iguais $a^{3} b^{2}$ serão obtidos, depois de efetuadas todas as multiplicações possíveis, devemos calcular o número de modos diferentes de escolher $a$ em três dos cinco fatores $(a+b)$ e $b$ nos outros dois. Note-se que, escolhido $a$ em três fatores, a escolha de $b$ fica automaticamente determinada nos fatores restantes. Assim, basta calcularmos o número de maneiras diferentes de escolher $a$ em três dos cinco fatores. Esse número é $\mathrm{C}_{5,3}$, onde é lido combinações de 5 
elementos tomados 3 a 3. Portanto, o termo $a^{3} b^{2}$ aparecerá $C_{5,3}$ vezes depois de efetuadas todas as multiplicações. Raciocinando de maneira análoga para cada termo, tem-se que:

- O termo $a^{5}$ aparecerá $\mathrm{C}_{5,5}$ vezes.

- O termo $a^{4} b$ aparecerá $\mathrm{C}_{5,4}$ vezes.

- O termo $a^{2} b^{3}$ aparecerá $\mathrm{C}_{5,2}$ vezes.

- O termo $a b^{4}$ aparecerá $\mathrm{C}_{5,1}$ vezes.

- O termo $b^{5}$ aparecerá $\mathrm{C}_{5,0}$ vezes.

Assim, podemos escrever:

$(a+b)^{5}=\mathrm{C}_{5,5} a^{5}+\mathrm{C}_{5,4} a^{4} b+\mathrm{C}_{5,3} a^{3} b^{2}+\mathrm{C}_{5,2} a^{2} b^{3}+\mathrm{C}_{5,1} a b^{4}+\mathrm{C}_{5,0} b^{5}$

$\mathrm{Ou}$ seja, ao comparar esse resultado com a multiplicação dos cinco fatores $(a+b)$ concluí-se que $\mathrm{C}_{5,5}=1, \mathrm{C}_{5,4}=5, \mathrm{C}_{5,2}=10, \mathrm{C}_{5,1}=5, \mathrm{C}_{5,0}=1$.

Então, $(a+b)^{5}=1 a^{5}+5 a^{4} b+10 a^{3} b^{2}+10 a^{2} b^{3}+5 a b^{4}+1 b^{5}$.

O matemático Isaac Newton (1646-1727) demonstrou que:

$$
(a+b)^{n}=\left(\begin{array}{l}
n \\
0
\end{array}\right) a^{0} b^{n}+\left(\begin{array}{l}
n \\
1
\end{array}\right) a^{1} b^{n-1}+\left(\begin{array}{l}
n \\
2
\end{array}\right) a^{2} b^{n-2}+\ldots+\left(\begin{array}{l}
n \\
k
\end{array}\right) a^{k} b^{n-k}+\ldots+\left(\begin{array}{l}
n \\
n
\end{array}\right) a^{n} b^{0}
$$

Sendo que o segundo membro da igualdade é conhecido como o desenvolvimento do binômio de Newton.

Pascal mostrou também que as linhas de entrada no triângulo aritmético são esses mesmos coeficientes binomiais de Newton, isto é, os números na linha $n$ são resultados das expansões de potências de $(a+b)$, em que, na forma geral, se apresenta assim: $(a+b)^{n}=\sum_{i=0}^{n} C_{n}^{i} a^{i} b^{n-i}$

Jacques Bernoulli (1654-1705), em seu Ars Conjectandi, publicado postumamente em 1713, usou a interpretação de Pascal para demonstrar que $(a+b)^{n}=\sum_{i=0}^{n}\left(\begin{array}{l}n \\ i\end{array}\right) a^{n-i} b^{i}$. A segunda parte desse livro foi dedicada à teoria das combinações e permutações. 
Dando valores para $\mathrm{n} \in \mathrm{N}$, tem-se:

$$
\begin{aligned}
& (a+b)^{0}=1 \\
& (a+b)^{1}=a+b \\
& (a+b)^{2}=a^{2}+2 a b+b^{2} \\
& (a+b)^{3}=a^{3}+3 a^{2} b+3 a b^{2}+b^{3} \\
& (a+b)^{4}=a^{4}+4 a^{3} b+6 a^{2} b^{2}+4 a b^{3}+b^{4} \\
& (a+b)^{5}=a^{5}+5 a^{4} b+10 a^{3} b^{2}+10 a^{2} b^{3}+5 a b^{4}+b^{5} \\
& (a+b)^{6}=a^{6}+6 a^{5} b+15 a^{4} b^{2}+20 a^{3} b^{3}+15 a^{2} b^{4}+6 a b^{5}+b^{6}
\end{aligned}
$$

Formando um triângulo com os coeficientes das expansões feitas acima, tem-se:

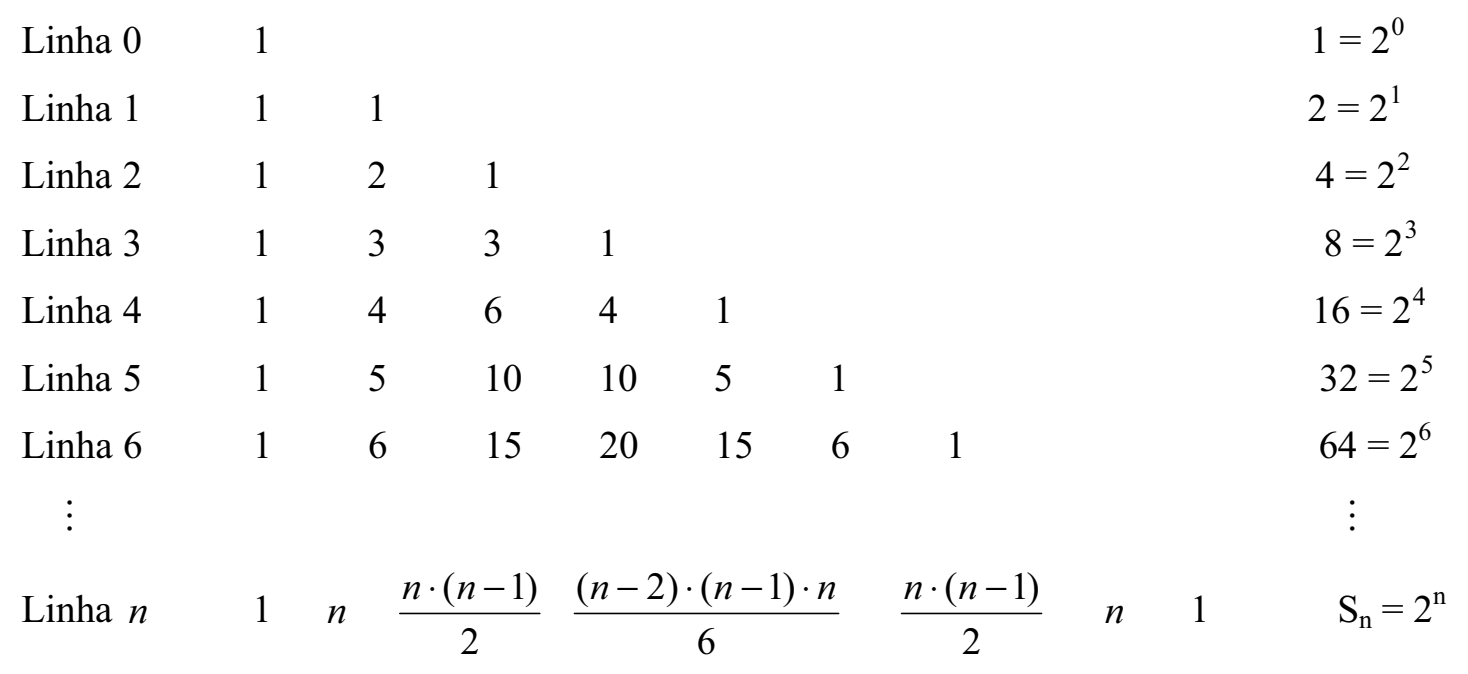

Onde,

$$
\begin{aligned}
& C_{n, 0}=\frac{n !}{0 !(n-0) !}=1 \\
& C_{n, 1}=\frac{n !}{1 !(n-1) !}=n \\
& C_{n, 2}=\frac{n !}{2 !(n-2) !}=\frac{(n-1) \cdot n}{2} \\
& C_{n, 3}=\frac{n !}{3 !(n-3) !}=\frac{(n-2) \cdot(n-1) \cdot n}{6} \\
& C_{n, n-2}=\frac{n !}{(n-2) !(n-n+2) !}=\frac{(n-1) \cdot n}{2}
\end{aligned}
$$

Soma dos elementos de cada linha 


$$
\begin{aligned}
& C_{n, n-1}=\frac{n !}{n !(n-n+1) !}=n \\
& C_{n, n}=\frac{n !}{n !(n-n) !}=1
\end{aligned}
$$

Buscando um padrão para a soma dos elementos de cada linha, podemos conjecturar que a soma dos elementos da n-ésima linha ${ }^{8}$ é igual a $2^{\mathrm{n}}$.

Outra forma de justificar a construção do Triângulo de Pascal é a de fazer uso da Relação de Stifel (1486-1567).

No livro Trotta et al $(1979$, p.44) lê-se a seguinte questão: "Qual é a utilidade da Relação de Stifel na obtenção de desenvolvimento do tipo $(x+a)^{\mathrm{n}}$ ?"

Em seguida, os autores desse livro dizem que: "Na verdade, a Relação de Stifel é utilíssima na construção do Triângulo de Pascal (...). De fato, ela nos informa que no referido "triângulo", a soma de dois elementos consecutivos de uma mesma linha é igual ao elemento da linha seguinte que está abaixo da parcela que se encontra mais a direita:

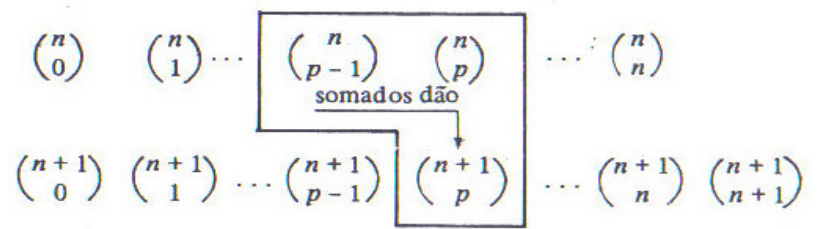

Figura 7: Construção do Triângulo de Pascal 1. Trotta et al Matemática Aplicada: 2, $2^{\circ}$ grau. p.44, São Paulo: Moderna, 1979.

Observando que em qualquer linha do Triângulo de Pascal, o primeiro e o último elementos são iguais a 1, lembrando que após a metade da linha os seus elementos começam a se repetir, e utilizando a relação de Stifel, facilmente se constroem algumas de suas linhas:

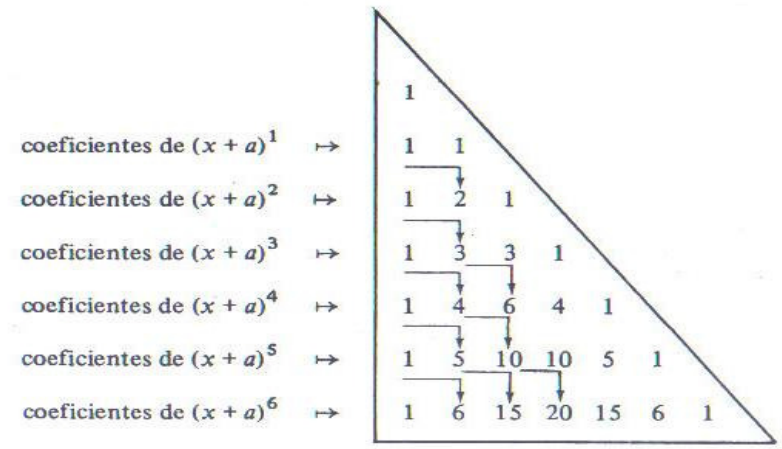

Figura 8: Construção do Triângulo de Pascal 2. Trotta et al Matemática Aplicada: 2, $2^{\circ}$ grau. p.44, São Paulo: Moderna, 1979. 8 Demonstração no livro Introdução à Análise Combinatória, Santos, J.P., Mello, M.P., Murari,
I.T.C.,Campinas,SP: ed. da UNICAMP,1995. 
No livro História da Matemática, de C. Boyer, que se acredita que esse triângulo foi encontrado na China, e era conhecido por Chu Shih-Chieh, por volta de 1300, e, antes deles pelos hindus e árabes. Sabe-se também que o matemático árabe Al-Karaji (fins do século X) conhecia a lei de formação dos elementos do Triângulo de Pascal, $C_{n+1}^{p+1}=C_{n}^{p+1}+C_{n}^{p}$. No entanto ao triângulo aritmético foi dado o nome de Pascal, devido às aplicações feitas por ele na resolução de jogos.
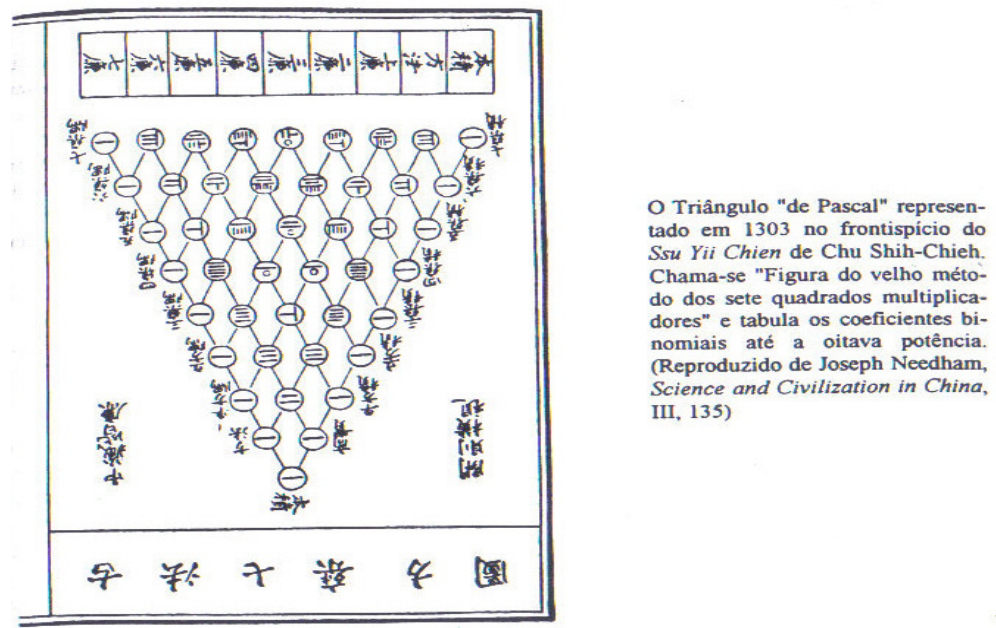

Figura 9: Triângulo de Pascal representado em 1303. Boyer, C. B. História da Matemática. Tradução: Elza F. Gomide. p.141, São Paulo: Edgard Blücher Ltda, 1974.

O primeiro aparecimento do triângulo de Pascal no Ocidente foi no livro Rechnung de Petrus Apianus (1495-1552). Nicolò Fontana (1499-1559), conhecido por Tartaglia, relacionou os elementos do Triângulo de Pascal com as potências de $(\mathrm{x}+\mathrm{y})$. Pascal publicou um tratado em 1654 mostrando como utilizá-lo para achar os coeficientes de desenvolvimento de $(a+b)^{n}$.

Outro matemático do século XVII, Hérigone (1634), realizou um trabalho sobre o Triângulo de Pascal, mostrando a relação entre a formação dos coeficientes binomiais e a teoria das combinações, um assunto também tratado por Fermat e outros.

Segundo Morgado et al (1991, p.3), Isaac Newton (1646-1727) mostrou como calcular diretamente $(1+\mathrm{x})^{\mathrm{n}}$ sem antes calcular $(1+\mathrm{x})^{\mathrm{n}-1}$. Mostrou que cada coeficiente pode ser determinado, usando o anterior, pela fórmula $\left(\begin{array}{l}n \\ r+1\end{array}\right)=\frac{n-r}{r+1}\left(\begin{array}{l}n \\ r\end{array}\right)$. 
Euler (1707-1783) contribuiu para a Análise Combinatória, em particular, para a solução do Problema das Sete Pontes de Königsberg, um teorema da Teoria dos Grafos que é outro tópico da Análise Combinatória.

No século XX, o matemático húngaro George Polya (1887-1985) introduziu uma nova técnica de enumeração, que tem se prestado às mais variadas aplicações, permitindo tratar, de maneira unificada, desde a enumeração de isômeros de uma substância até a enumeração de grafos, principalmente árvores. Um exemplo simples de aplicação da teoria de Polya é o de determinar o número de tetraedros regulares "diferentes" com faces pintadas com duas cores, preto e branco, por exemplo. Podemos ter um tetraedro todo preto, outro todo branco, um com uma face branca e as outras pretas, etc. Dois tetraedros são considerados "diferentes" se um deles não pode ser obtido do outro por meio de rotações (MORGADO et al, 1991, p.05)

O inglês F. P. Ramsey (1903-1930) criou outra teoria importante da Análise Combinatória, que garante a existência de certas configurações ${ }^{9}$, onde se entende por configuração qualquer conjunto formado por pontos, linhas e superfícies.

Como exemplo tem-se o Teorema de Ramsey que afirma: se tivermos no plano um conjunto de $\mathrm{n}$ pontos, $\mathrm{n} \geq 6$, no qual não há três pontos colineares, então, se unirmos todos os pontos, dois a dois, usando duas cores distintas, para traçar os segmentos de reta que unirão os pontos, então, forçosamente teremos formado um triângulo cujos lados são todos da mesma cor.

O primeiro livro sobre permutações foi escrito por Pacioli, Suma, em 1494, onde ele mostra o número de permutações de qualquer número de pessoas sentadas em uma mesa. $\mathrm{Na}$ Inglaterra o assunto foi abordado por W. Buckley em 1540, que mostrou casos especiais de combinações de $n$ coisas tomadas $r$ a $r$.

No século XVI o erudito Rabbi Moses Cordovero escreveu o Pardes Rimmonim (1552), no qual apresenta um interessante tratamento de permutações e combinações, mostrando algum conhecimento sobre leis gerais. Na mesma época Buteo além de discutir a questão do número de possíveis lançamentos com quatro dados, dedicou-se ao problema de uma combinação de um cadeado com vários cilindros móveis (fig.02).

\footnotetext{
${ }^{9}$ Teorema de Ramsey é encontrado no livro Análise Combinatória e Probabilidades, IMPA, Rio de Janeiro, 1991.
} 


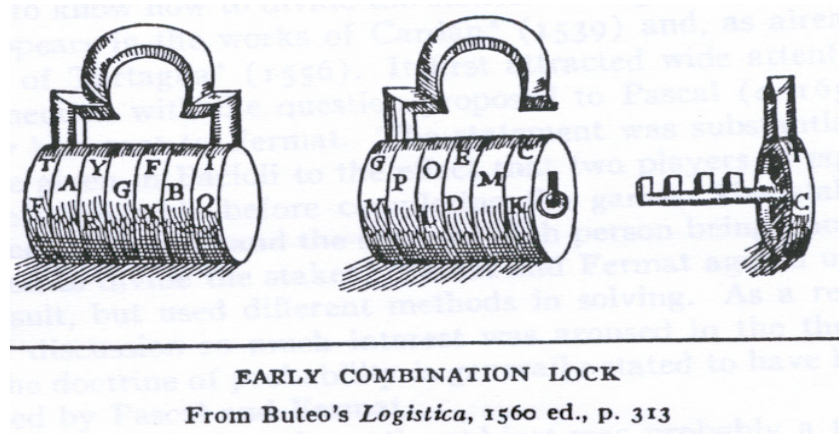

Figura 10: Cadeado com vários cilindros móveis. Smith, D.E., History of Mathematics: Special topics of Elementary Mathematics, v.2. p.527. New York: Dover Publications, 1958.

Outro trabalho do século XVII foi de Harriot, intitulado Artis Analyticae Praxis, onde apresenta casos de combinações, utilizando produto de binomiais ${ }^{10}$.

O primeiro autor a dar a regra geral que ${ }_{n} C_{r}=\frac{n(n-1)(n-2) \ldots(n-r+1)}{r !}$ foi Hérigone no ano de 1634, onde ${ }_{n} C_{r}$ é lido combinações de $n$ elementos tomados $r$ a $r$.

Outros autores sobre a teoria de combinações foram: Huygens, Leibniz (Ars combinatoria, 1666), Frénicle (Abrégé des combinaisons, 1676), Wallis (De combinationibus, alternationibus, et partibus aliqotis, tractatus, 1685), e um breve tratado de Spinoza (16321677).

O primeiro trabalho de grande extensão que é dedicado ao assunto apareceu em Ars Conjectandi (1713) de Jacques Bernoulli (1654-1705). Este trabalho contém a parte essencial da teoria das combinações como conhecida até hoje. Nele aparece pela primeira vez a palavra "permutação". Desta concepção Leibniz usou "variationes" e Wallis adotou "alternationes". A palavra "combinação" foi usada, como atualmente, por Pascal e Wallis. Já Leibniz usou "complexiones" para um termo geral, reservando "combinationes" para grupos de dois elementos e "conternationes" para grupos de três. Generalizou essa ideia escrevendo da seguinte maneira: con2natio, con3natio, e assim por diante.

Segundo Rosa (1998):

A partir de meados do século XVIII, a Análise Combinatória passou a ser utilizada em vários ramos da Matemática como Estatística, Álgebra, Probabilidade, Lógica, etc., e em outras áreas do conhecimento humano como Biologia Molecular, Programação de Computadores, Economia, Teoria da Programação para o Bom Funcionamento da Empresa, etc. (p.04)

\footnotetext{
${ }^{10}$ Um exemplo encontrado dessas combinações está no livro Análise Combinatória e Probabilidades IMPA, Morgado et al, Rio de Janeiro, 1991, p.527.
} 
Dentre os assuntos abordados em combinatória, encontramos os anagramas, os quais são formados utilizando todas as letras de uma mesma palavra, combinando-as de maneiras diferentes, formando outras palavras com ou sem significado. Até o século XVII as revistas científicas quase não existiam e as descobertas que os cientistas faziam eram conhecidas somente através de livros ou correspondências particulares. Mas esse procedimento criava dificuldades enormes na publicação dos resultados originais, pois a impressão de um livro demorava muito tempo e trocar correspondências sobre novas descobertas era perigoso, porque sempre existia a possibilidade de outros estudiosos se apossarem desses trabalhos, assim os anagramas eram utilizados pelos cientistas como códigos para se comunicarem com segurança. Os anagramas também foram amplamente utilizados durante as guerras e trocas de regimes políticos no decorrer da história

Além de todos os trabalhos citados desde a Antiguidade sobre o desenvolvimento da Análise Combinatória, essa teoria se estruturou através do estudo da teoria das probabilidades, como se vê em Morgado et al (1991, p.06), "Em verdade, o desenvolvimento da Análise Combinatória deve-se em grande parte à necessidade de resolver problemas de contagem originados na teoria das probabilidades".

No entanto, considerando a importância da teoria das probabilidades numa melhor sistematização da Análise Combinatória, faremos assim um breve histórico sobre a probabilidade, sendo que alguns matemáticos continuaram seus estudos em combinatória dando sequência ao estudo de probabilidade.

Segundo Domingues (1991, p.57): “A correspondência entre Pascal e Fermat é um dos marcos fundamentais na história da teoria das probabilidades". Pierre Fermat (16011665) e Blaise Pascal (1623-1662) deram o ponto de partida para o desenvolvimento da Teoria das Probabilidades. Eles investigaram e resolveram inúmeros problemas probabilísticos e deram início a um tratamento mais cuidadoso do cálculo combinatório.

Um jogador profissional da época, Antoine Gombaud (1607-1684), o Chevalier de Méré, recorreu a Pascal para examinar alguns problemas sobre os jogos e para explicar certas contradições no seu raciocínio. Pascal se interessou pelo assunto e começou a trocar correspondência com Fermat, que também se interessou por essas questões, discutindo os resultados obtidos por eles.

No século XVI, o italiano de Pávia, Gerolamo Cardano (1501-1576), além de médico, foi um dos grandes matemáticos de todos os tempos. Cardano também gostava de jogar, "em sua autobiografia De propria vita, ele confessa ter jogado diariamente: xadrez por mais de 
quarenta anos e dados por mais de vinte e cinco. Deve-se levar em conta porém que no século XVI o jogo era o passatempo dominante” (DOMINGUES, 1993, p.57)

Ainda sobre os jogos, esse mesmo autor cita em outra obra: "Os jogos praticados nessa época eram os jogos de dados e de cartas. Na Grécia e em Roma o jogo conquistou tanto o povo, de um modo geral, que até leis eram feitas proibindo-o fora de certas épocas" (DOMINGUES, ?, p.155)

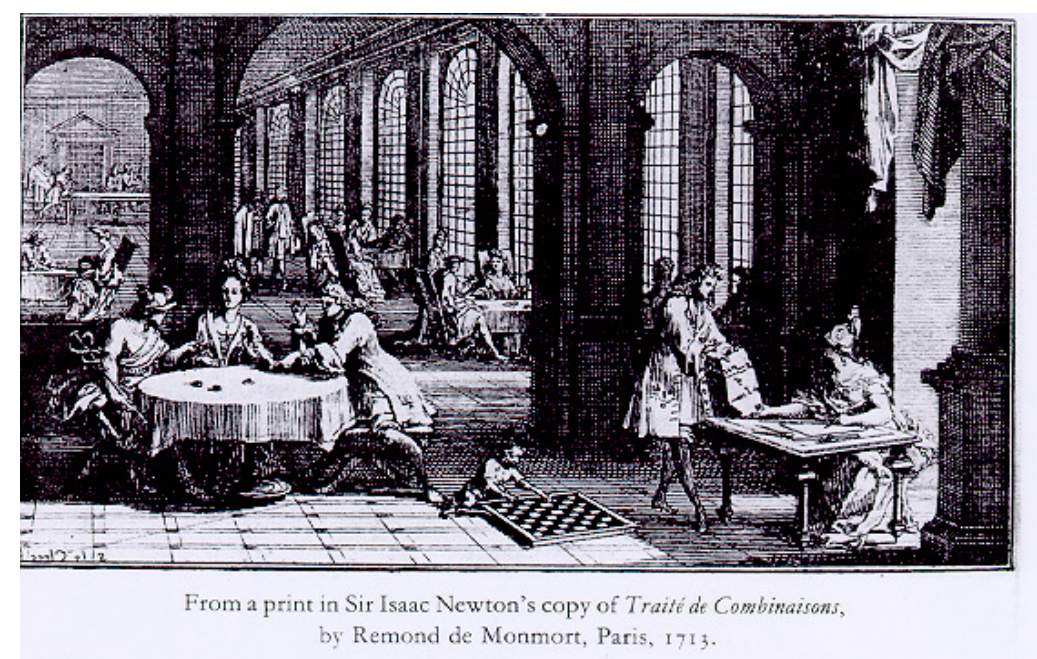

Figura 11: Sala de jogos do século XVIII. Bollobás, B. (contra-capa) Combinatorics. Cambridge, 1986.

Também nessa época jogava-se apostando dinheiro. Cardano gastava seu dinheiro em apostas, desenvolvendo assim, mais profundamente, as técnicas de contagem e combinações, contribuindo principalmente para o cálculo das Probabilidades (ROSA, 1998, p.04). Cardano escreveu um livro sobre a teoria das probabilidades Liber de ludo aleae, Sobre os jogos de azar, (1550, mas publicado em 1663), contendo ironicamente conselhos sobre como trapacear no jogo. No entanto, a Análise Combinatória encontraria suas primeiras sistematizações através de problemas ligados a jogos de azar (cartas, fichas, roletas e dados).

Galileu Galilei (1564-1642) analisou problemas sobre os jogos de dados. Em um dos problemas de combinatória, datados do século XVI, Galileu questionou o porquê da soma dez aparecer tão frequentemente quando se jogam três dados distintos.

O holandês Christian Huygens (1629-1695), também interessado na teoria das probabilidades, publicou em 1657, De Ratiociniis in Ludo Aleae, O raciocínio sobre jogos 
de Azar. Segundo Barbosa (1966, p.19), Huygens foi também o criador do famoso e importante conceito de esperança Matemática ${ }^{11}$.

Outros matemáticos que colaboraram para o desenvolvimento posterior da teoria das probabilidades foram: o suíço Jacques Bernoulli (1654-1705), o alemão Gottfried Wilhellm Leibniz (1646-1716), o suíço Leonhard Euler (1707-1783), os franceses Abraham de Moivre (1667-1754), Pierre Simon de Laplace (1749-1827) com sua Théorie analytique des probabilités; entre outros, como Joseph Lagrange (1736-1813), Thomas Bayes (1702-1761), Bertrand, Poincaré e Borel.

Alguns matemáticos da Rússia deram inúmeras e preciosas contribuições: Tchebycheff, o oficial de artilharia Sabudski, Liapounoff, Andrey Markov (1856-1922), Bernstein, Khintchine, Kolmogoroff (1903-?). Destaca-se também o italiano Guido Castelnuovo (1865-1952), os escandinavos Thiele, Charlier, e o austríaco Czuber. Father Gregor Mendel (1822-1884) relatou probabilidade na genética; Karl Pearson (1857-1936) aplicou probabilidade na Biologia, criando a área de bioestatística; e Norbert Wiener (18941964) relatou que a probabilidade é a ligação entre Física e Matemática.

\subsubsection{Análise Combinatória}

Dentre as diversas definições, do que vem a ser a Análise Combinatória, destaca-se a que está relacionada com o Princípio Fundamental de Contagem, também chamado de Princípio Multiplicativo, que diz: "Se um acontecimento A pode ocorrer de $m$ maneiras diferentes e se, para cada uma das $m$ maneiras possíveis de ocorrências de A, um segundo acontecimento $\mathrm{B}$ pode ocorrer de $n$ maneiras diferentes, então o número de maneiras de ocorrer o acontecimento A seguido do acontecimento B é $m \cdot n^{\prime \prime}{ }^{12}$. Segundo Pitombeira (1986), “A 'Análise Combinatória' poderia ser chamada de 'arte de contar'...” (p.21). Desse modo, a Análise Combinatória está envolvida com o processo de contagem.

Porém, a Análise Combinatória não está relacionada apenas ao processo de simplesmente contar mas, explorando os conceitos de combinação, de arranjo e de

\footnotetext{
${ }^{11}$ Esperança Matemática: de uma variável aleatória discreta, é a soma dos produtos de cada valor da variável por sua respectiva probabilidade; de uma variável aleatória contínua, é a integral do produto da variável por sua densidade de probabilidade.

${ }^{12}$ BACHX, G.C., POPPE, L.M.B., TAVARES, R.N.O., Prelúdio à Análise Combinatória, São Paulo: Nacional, 1975.
} 
permutação, onde o domínio desses conceitos permite resolver os problemas de contagem de certos tipos de subconjuntos de um conjunto finito, sem que seja necessário enumerar seus elementos.

No entanto, verifica-se que a concepção acima citada é parcial. Existem outros tipos de problemas e a Análise Combinatória possui técnicas para resolvê-los: como o princípio da inclusão-exclusão; o princípio das gavetas de Dirichlet; as funções geradoras; e a teoria de Ramsey ${ }^{13}$.

Desse modo, a concepção da Análise Combinatória se torna mais ampla, as combinações, arranjos e permutações são conceitos de uma parte elementar da Análise Combinatória. Assim, de maneira geral, podemos dizer que a Análise Combinatória é a parte da Matemática que analisa estruturas e relações discretas. (MORGADO et al, 1991, p.01)

Outra concepção, agora dada por Ryser (1963, p.02), de Análise Combinatória diz:

Muitos dos problemas estudados no passado para seu divertimento ou apelo estético são de grande valor hoje tanto na ciência pura quanto na aplicada. Não muito tempo atrás, planos projetivos finitos eram considerados como uma curiosidade combinatória. Hoje eles são básicos nos fundamentos da geometria e na análise e planejamento de experimentos. Nossa tecnologia com sua preocupação vital como o discreto tem dado à matemática recreacional do passado uma nova e séria intenção.

Mas, mais importante, a era moderna tem descoberto para as combinatórias uma ampla gama de novos problemas fascinantes. Eles surgiram em álgebra abstrata, topologia, fundamentos da Matemática, teoria dos grafos, teoria dos jogos, programação linear, e em muitas outras áreas. A Análise Combinatória sempre foi diversificada e, durante nossos dias, esta diversificação tem aumentado muito. Nem são seus muitos e variados problemas atacados com sucesso em termos de uma teoria unificada. Muito do que tem-se dito até agora aplica-se com igual força para a Teoria dos Números. De fato, Análise Combinatória e Teoria dos Números são disciplinas irmãs. Elas compartilham uma certa interseção de conhecimento comum e cada uma delas genuinamente enriquece a outra. A Matemática Combinatória apresenta-se como um atalho para muitas subdivisões da Matemática e é isto que torna difícil uma definição formal para ela.

\footnotetext{
${ }^{13}$ Princípio da inclusão-exclusão: é uma fórmula para contar o número de elementos que pertencem à união de vários conjuntos não necessariamente disjuntos. Princípio das gavetas de Dirichlet ou Princípio da Casa dos Pombos: Se forem dados $n$ objetos, a serem colocados em, no máximo, ( $n-1)$ gavetas, então uma delas conterá necessariamente mais do que um objeto. Ou, equivalentemente, se forem dados $n$ objetos, a serem colocados em, no máximo, $(n-1)$ gavetas, então uma delas conterá pelo menos dois objetos. A demonstração e aplicações desse princípio podem ser encontradas na Revista do Professor de Matemática $\mathrm{n}^{\circ} 08$, p.21-26, $1^{\circ}$ semestre de 1986; Teoria de Ramsey: se tivermos no plano um conjunto de $n$ pontos, $n \geq 6$, no qual não há três pontos colineares, então, se unirmos todos os pontos, dois a dois, usando duas cores distintas, para traçar os segmentos de reta que unirão os pontos, então, forçosamente teremos formado um triângulo cujos lados são todos da mesma cor.
} 
Mas, por isso ou aquilo, ela se preocupa com o estudo dos arranjamentos de elementos em conjuntos. Os elementos são usualmente finitos em número e o arranjamento é restrito por certas condições limitantes impostas pelo problema particular tomado pela investigação.

Vimos, então, que a concepção de Análise Combinatória não é tão simples. Mas, recorrendo à História da Matemática, pudemos investigar como surgiu e se desenvolveu, na humanidade, o interesse por ela.

A aprendizagem da Análise Combinatória sempre se mostrou como um obstáculo aos alunos da escola de nível secundário. Trabalhar esse conteúdo, partindo-se de definições e fórmulas, leva os estudantes a um trabalho mecânico que não lhes possibilita chegar à compreensão. A Análise Combinatória é considerada, assim, um tópico difícil de ser abordado na sala de aula, pois geralmente é trabalhada através de "fórmula-aplicação", deixando lacunas na compreensão dos conceitos de arranjo, permutação e combinação. Esse modo de o professor trabalhar Análise Combinatória interfere diretamente na aprendizagem do aluno. Adotar outra metodologia, que permite a participação do aluno na construção desses conceitos, pode contribuir para a aquisição de uma compreensão mais significativa, que procura dar sentido à matemática construída, considerando o cotidiano do aluno e o trabalho com problemas contextualizados. Assim, o papel do professor pode ser visto como fundamental para que isso se efetive, exigindo do professor um planejamento que explicite devidamente os objetivos de cada aula, as estratégias e os procedimentos selecionados para a resolução de problemas e, ainda, a adoção de critérios de avaliação coerentes e justos.

Em geral, numa aula tradicional, onde as fórmulas já foram apresentadas, os alunos procuram identificar, entre elas, aquela que acreditam ser mais conveniente para arranjo, ou permutação ou combinação, com o objetivo de poder resolver um problema. Isso, em geral ocorre por eles não terem participado da construção desses conceitos e apenas os usam para resolver o problema mecanicamente.

Como disse Hariki (1996, p.29)

Problemas combinatórios são usualmente considerados difíceis pela maioria dos alunos e professores de matemática. Talvez a principal dificuldade seja a da conexão correta entre o problema dado e a teoria matemática correspondente. É difícil determinar se o problema combinatório dado é um problema de arranjo, de permutação ou de combinação ou, então, se é suficiente usar diretamente o princípio multiplicativo. 
Faz-se necessário então um estudo que explore os conceitos primitivos da Análise Combinatória, o Princípio Fundamental da Contagem ou os Princípios Multiplicativo e Aditivo, trabalhando de modo intuitivo com o aluno, descrevendo os casos possíveis, formando agrupamentos e contando-os, utilizando técnicas de contagem com o auxílio da árvore de possibilidades ou tabelas de dupla entrada. Na Proposta Curricular, 1992, p.83 ( $1^{\mathrm{a} e d .1986), ~ l e ̂-s e ~ U m a ~ a n a ́ l i s e ~ a d e q u a d a ~ d o s ~ p r o c e s s o s ~ d e ~ f o r m a c ̧ a ̃ o ~ d e ~ a g r u p a m e n t o s, ~ p e l o s ~}$ alunos, evitará defeitos freqüentes entre os iniciantes, decorrentes da tendência de adivinhar a resposta ou o processo de contagem.

Resolvendo os problemas com esse enfoque, dando-se o tempo necessário para resolvê-los, deve se levar o aluno à sistematização da contagem bem como à sistematização dos conceitos de arranjo, permutação e combinação. Os problemas iniciais devem ser elaborados com poucos elementos, através da solução intuitiva e da contagem direta, para destacar quantas e quais são as possibilidades nesse tipo de abordagem. Os alunos poderão observar que a contagem direta é impraticável na maioria dos casos e constatarão que é preciso perceber certas regularidades para desenvolverem técnicas de contagem apropriadas, que generalizem as soluções. Eles perceberão que, ao contar ou fazer os agrupamentos através das técnicas de contagem, estes se diferenciam pela ordem e/ou natureza dos elementos dados no problema.

Técnicas de contagem são um tópico fundamental na matemática discreta e têm aplicações diretas como ferramentas gerais de resolução de problemas. Pensar com um ponto de vista combinatório requer que os alunos explorem criativamente os aspectos estruturais de uma situação-problema, com a esperança de reduzi-la ou a um caso mais simples ou a um problema previamente resolvido. Como um resultado, muitas possibilidades de solução são analisadas sistematicamente, e um conhecimento útil é ganho tanto a partir de tentativas corretas quanto de incorretas. O processo geral é raciocínio combinatório ou "a arte de contar sem contar" (TOWNSEND 1987, apud JOHNSON, 1991, p.128)

Analisando as técnicas de contagem, com relação aos agrupamentos envolvidos nas situações-problema, bem como o processo de formação dos agrupamentos, os alunos estarão preparados para sistematizar os conceitos envolvidos na Análise Combinatória e entender a necessidade do uso de fórmulas, chegando à solução de modo mais rápido, quando o número de elementos envolvidos nos agrupamentos for grande.

Desse modo, a Análise Combinatória está relacionada essencialmente ao processo de contagem de um número de elementos de um conjunto, sem que haja a necessidade de enumerá-los. 
Nesse sentido, Roxo et al (1944, p.81) definem Análise Combinatória assim:

Denomina-se análise combinatória ao estudo da formação, contagem e propriedades dos agrupamentos que podem constituir-se, segundo determinados critérios, com os objetos de uma coleção. Esses agrupamentos distinguem-se, fundamentalmente, em três espécies: arranjos, permutações e combinações, e podem ser formados de objetos distintos ou repetidos.

Ao analisar livros didáticos, pode-se perceber que a maioria deles apresenta o conteúdo de Análise Combinatória, dando ênfase à utilização de fórmulas, sem a preocupação da dedução das mesmas.

Isso já não ocorre no livro de Trotta et al (1979), que apresentam esse conteúdo iniciando-o com a resolução de problemas, de modo que o aluno possa desenvolver seu raciocínio combinatório partindo de processos de contagem. Posteriormente a esse primeiro contato, nesse livro são apresentadas as definições de arranjo, permutação e combinação:

"Dado um conjunto A formado por $\mathrm{n}$ elementos, e sendo $\mathrm{p}$ um número inteiro positivo, chama-se arranjo dos $\mathrm{n}$ elementos dados tomados $\mathrm{p}$ a $\mathrm{p}$, a qualquer seqüência de $\mathrm{p}$ elementos formada com os elementos de A”. (p.11).

"Dado um conjunto A formado por $\mathrm{n}$ elementos, chama-se permutação desses $\mathrm{n}$ elementos, $\mathrm{a}$ qualquer seqüência de n elementos em que compareçam todos os elementos de A". (p.19)

"Dado um conjunto A formado por $\mathrm{n}$ elementos, e sendo $\mathrm{p}$ um número inteiro positivo, chama-se combinação dos $\mathrm{n}$ elementos dados, tomados $\mathrm{p}$ a $\mathrm{p}$, a qualquer subconjunto de $\mathrm{A}$ que possua $\mathrm{p}$ elementos" (p.26)

Na bibliografia de Análise Combinatória, Palangana (2001) cita a Teoria de Piaget, dizendo que o desenvolvimento cognitivo do aluno compreende quatro estágios ou períodos: sensório-motor (do nascimento aos 2 anos); pré-operacional (2 a 7 anos); operações concretas (7 a 12 anos) e operatório-formal (adolescência: 12 anos em diante). Nesse último estágio, Palangana (2001, p.29) afirma que ... o pensamento do adolescente opera através da Análise Combinatória, da correlação e das formas de reversibilidade (inversão e reciprocidade).

Diz também que

A combinatória permite que se estabeleça qualquer classe ou relação, através da reunião dos elementos um a um, dois a dois, três a três, etc. Essa nova e importante habilidade se manifesta na capacidade que o adolescente apresenta de ultrapassar os encaixes hierárquicos ou encadeamentos simples dos agrupamentos e combinar entre si elementos de conjuntos diferentes, a partir dos quais ele constrói um outro conjunto. A combinatória é importante na medida em que possibilita uma nova lógica, significa o raciocínio sobre uma realidade dada em função de todos os aspectos que comporta e de todas as combinações possíveis. Essa capacidade se estende à combinação de objetos e à de proposições. Para tanto, o adolescente utilizase da fórmula "falso" ou "verdadeiro" e de operações que até então não 
dominava, tais como: as relações de implicação, disjunção, exclusão, incompatibilidade e implicação recíproca. (PALANGANA, 2001, p.29).

Os trabalhos "O Pensamento Combinatório no Ensino Fundamental" de Paulo Roberto Câmara de Sousa e "Desmistificando a Análise Combinatória" de Milton Rosa, In: Cassol, 1998, dão uma maior atenção aos conceitos ao invés da mecanização.

No artigo "Razonamiento combinatório em alumnos de secundaria" (Raciocínio combinatório em alunos da escola secundária), Navarro-Pelayo, Batanero e Godino (1996), ressaltam que: a Análise Combinatória é um componente essencial da Matemática Discreta e, como tal, tem um papel importante na matemática escolar (p.26). Esses autores apresentam um questionário sobre a Análise Combinatória, para avaliar o raciocínio combinatório de 720 alunos, de 14 e 15 anos. Mas, apesar de se tratar de uma intervenção na sala de aula, eles, os autores, não trabalham com a metodologia de ensino-aprendizagem-avaliação de Matemática através da Resolução de Problemas, que é nossa linha de trabalho.

A Proposta Curricular, para o Ensino de Matemática do Estado de São Paulo (1992), apresenta, como objetivo geral para o ensino de Análise Combinatória desenvolver o raciocínio combinatório, tendo em vista: a familiarização do aluno com problemas que envolvem contagem; a sistematização da contagem; a sistematização dos conceitos de arranjo, permutação e combinação simples. (Secretaria da Educação, 1992, p.29).

Neste trabalho temos como objetivo central, trabalhar a Análise Combinatória na sala de aula com os alunos, adotando a metodologia de ensino-aprendizagem-avaliação de Matemática através da resolução de problemas. E como objetivos específicos: verificar a potencialidade de um trabalho de investigação, sem depender de fórmulas previamente determinadas (analisando os processos de formação de agrupamentos); explorar situaçõesproblema numa abordagem do cotidiano em sala de aula; permitir ao aluno buscar soluções próprias através de técnicas de contagem; e desenvolver o raciocínio combinatório para a formalização posterior. Em outro momento, trabalhar a Análise Combinatória, fazendo uso da mesma metodologia de trabalho, com professores em formação continuada. Também, em um outro momento, como pesquisadora desenvolver pesquisa nessa área.

Através do desenvolvimento do raciocínio combinatório, pode-se contribuir para que a Análise Combinatória seja um conteúdo significativo para o aluno, para o professor e para o pesquisador, pois esse tipo de raciocínio está presente em muitas situações do cotidiano. Porém, percebem-se as imensas dificuldades que os alunos têm diante desse conteúdo. Este lhes é, geralmente, ensinado através de "fórmula-aplicação", tornando-se um ensino mecanizado onde não são desenvolvidos os conceitos primitivos da Análise Combinatória, 
como o Princípio Multiplicativo, também chamado Princípio Fundamental da Contagem. Desse modo, a necessidade de se buscar caminhos alternativos, para a sala de aula, vem auxiliar o professor em seu trabalho com a Análise Combinatória. É trabalho importante também para o pesquisador que busca caminhos para orientar professores que, por sua vez devem, levar os alunos à compreensão desse conteúdo.

\subsubsection{Análise do tópico Análise Combinatória, nos livros didáticos, em} ordem cronológica

No livro Exame de Textos: Análise de livros de Matemática para o Ensino Médio, organizado por Lima et al (2001), são utilizados alguns critérios para a análise de doze coleções de livros didáticos do Ensino Médio: conceituação (erros, excesso de formalismo, linguagem inadequada, imprecisão, obscuridade, confusão de conceitos, conexões); manipulação; aplicação; qualidade didática; adequação do livro à realidade atual e ao papel educativo da avaliação. Com base nesse livro, estabelecemos alguns critérios para analisar livros didáticos com o objetivo de saber como a Análise Combinatória é neles abordada. Os critérios, por nós selecionados para análise, foram: 1) Se ao trabalhar Análise Combinatória os autores partem ou não de problemas; 2) Se o livro didático motiva e sugere um trabalho colaborativo com os alunos; 3) Se a formalização dos conceitos de Análise Combinatória é feita antes do problema dado, durante a resolução do problema ou depois do problema resolvido; 4) Se o livro é um dos recursos didáticos que pode contribuir para o trabalho do professor em sala de aula.

Os treze livros analisados estão dispostos em ordem cronológica: livros das décadas de 40, 50, 60, 70, 90 e anos 2000. São descritas, no início da análise de cada livro, suas características gerais e aquela que distingue mais fortemente um do outro no trabalho com Análise Combinatória; e as informações obtidas no cumprimento dos critérios, já citados e enumerados de 1 a 4 .

\section{Década de 40}

Matemática $2^{\mathrm{o}}$ ciclo $-2^{\mathrm{a}}$ série

Euclides Roxo, Roberto Peixoto, Haroldo Cunha, Dacorso Netto

Livraria Francisco Alves, $2^{\mathrm{a}}$ ed., São Paulo, 1944. 
Características gerais:

Há mais formalidade e rigor na expressão dos conceitos; e o livro recorre com frequência à demonstração. Faz uso da história da Análise Combinatória. O livro apresenta informações sobre a origem da Análise Combinatória nas notas de rodapé. São notas históricas que descrevem os matemáticos que contribuíram e participaram do desenvolvimento desse conteúdo.

Análise dos critérios estabelecidos:

1) O livro inicia com a definição de Análise Combinatória e não parte de problemas, os quais são apenas encontrados no final do capítulo (50 problemas), como exercícios propostos para ao alunos. Em sua maioria não são problemas relacionados ao cotidiano e envolvem números (número de algarismos, quantidade de números) ou letras (agrupamentos de letras).

2) O livro apresenta notas históricas que podem instigar a curiosidade dos alunos em relação à Análise Combinatória, colaborando para a valorização e a importância desse tópico. Entretanto, não se refere a um trabalho colaborativo entre os alunos em grupos. Apresenta a definição dos conceitos logo no início, o que pode dificultar a aprendizagem.

3) Quanto à ordem da construção dos conceitos de Análise Combinatória, o livro começa com arranjos formados com objetos distintos, definindo-os de início e, através de um exemplo, formaliza o conceito de arranjo, explicitando a fórmula para o cálculo do número de arranjos distintos.

Em seguida, através de uma restrição à definição de arranjo, a de que em todos os agrupamentos os elementos sejam sempre considerados, define permutação e apresenta a fórmula para o cálculo do número de permutações. Apresenta uma formação sistemática ${ }^{14}$ dos arranjos e das permutações e apresenta a fórmula para o cálculo do número de permutações. Faz uma formação sistemática dos arranjos e das permutações, isto é, a partir dos arranjos determinam todas as permutações. A seguir apresenta, formalmente, permutação fundamental, inversão numa permutação, classe de uma permutação, Teorema de Bezout e permutações circulares. Define combinação, seguida da fórmula para o cálculo do número de combinações com objetos distintos, através de um exemplo. Em seguida, apresenta outros exemplos visando à fixação dos conceitos definidos. Apresenta, ainda, o Triângulo Aritmético de Pascal e, por fim, a definição, de arranjos, permutações e combinações com repetição. Esse capítulo finaliza com uma série de exercícios propostos.

\footnotetext{
${ }^{14}$ Sistemática: ordenada, metódica.
} 
Após a apresentação de um exemplo sobre arranjos, é citada, em uma observação, a definição de fatorial, na nota de rodapé. Nessa mesma observação apresenta a notação de fatorial e a convenção de que $0 !=1$ e $1 !=1$.

4) O professor, ao utilizar esse livro, segue o modelo tradicional usado em uma sala de aula onde os conceitos são definidos logo no início, não permitindo a participação dos alunos na construção dos mesmos através de problemas. $\mathrm{O}$ ensino, nesse livro, se apresenta totalmente centrado no professor.

\section{Década de 50}

Matemática $-2^{\mathrm{a}}$ série colegial

Edison Farah, Benedito Castrucci

Editora Brasil S/A, São Paulo, 1956.

Características gerais:

Este livro apresenta características semelhantes às do livro da década de 40 . Entretanto, neste livro não há notas históricas como o de Roxo et al.

Análise dos critérios estabelecidos:

1) Os autores iniciam o conteúdo de Análise Combinatória com a resolução de um problema simples e discutem sobre o modo de resolvê-lo, como se estendessem o problema ao lhe acrescentar mais dados, dando margem à sistematização da definição de Análise Combinatória.

2) Este livro tem uma estrutura bastante semelhante à do livro anterior, mas difere pela maneira que resolve um problema, logo no início, considerando poucos elementos e estendendo a resolução para o caso de ter mais elementos. Acreditamos que, desse modo, o aluno pode compreender melhor os conceitos envolvidos.

3) Para se referir a uma formação sistemática e metódica dos elementos de um conjunto em agrupamentos, os autores deste livro falam em disposição, para expressar a distribuição dos elementos, havendo repetição ou não, seguindo algum critério. Chamam os arranjos, as permutações e as combinações de particulares sistemas de disposições.

Definem arranjos simples e, em seguida, apresentam um exemplo e discutem sobre sua resolução. Depois, a fórmula para o cálculo do número de arranjos é apresentada após sua dedução, onde é explicitado cada passo feito. Há excesso de formalização. A permutação é definida como um caso particular de arranjo, onde o que difere é a ordem dos elementos. A 
partir da definição de permutação, os autores dão a definição de fatorial. Apresentam a seguir: inversões numa permutação, classe de uma permutação, permutação fundamental, Teorema de Bezout. Definem permutações simples com elementos repetidos através de um problema. A seguir é feita a dedução da fórmula, explicitando cada passo formalmente. Por último é definida combinação, seguida de exemplo e da dedução da fórmula. Apresentam também o Triângulo de Pascal. Finalizam o capítulo com oito exercícios resolvidos e dez propostos, a maioria contextualizados.

4) Ensino tradicional e muito parecido ao livro da década de 40, embora não apresente notas históricas.

\section{Década de 60}

Matemática - curso colegial - vol II

School Mathematics Study Group - SMSG

Edição preliminar, Editora - Centro de Publicações Técnicas da Aliança, Rio de Janeiro, 1964

Características gerais:

Neste livro, os autores apresentam a Análise Combinatória evidenciando que o tipo de raciocínio exigido nesse tópico requer do aluno maior amadurecimento em relação aos conteúdos vistos anteriormente.

Ele está apoiado na Matemática Moderna e apresenta bastante formalização. Trabalha com o processo de contagem, fundamentado na Teoria dos Conjuntos, através de três ideias: relação ou correspondência biunívoca, adição e multiplicação. Os conceitos de Análise Combinatória são trabalhados a partir da resolução de problemas contextualizados. Apenas abordam os conceitos de permutações e combinações, deixando as ideias de arranjo como uma conjugação desses dois conceitos.

Análise dos critérios estabelecidos:

1) O capítulo de Análise Combinatória neste livro inicia com uma introdução apresentando três ideias fundamentais sobre o processo de contagem: relação ou correspondência biunívoca, adição e multiplicação e discute essas ideias através de um exemplo: provar que $1+2+3+\ldots+n=\frac{n(n+1)}{2}$. Na sequência, apresenta um conjunto de problemas resolvidos e outros propostos. 
2) Apesar de sempre iniciar com problemas e de apresentar exemplos, o livro, da época do Movimento da Matemática Moderna, tem excesso de formalização, o que, para o aluno, se torna mais complexo quanto à compreensão dos conceitos elaborados.

3) O livro cita algumas situações em que é utilizado o processo de contagem. Seu objetivo é dar ênfase à teoria, aos métodos, e às ideias que eles ilustram e, muito raramente, ao "valor prático" das suas respostas. Os autores citaram que os computadores poderiam resolver os problemas de contagem mas que o seu objetivo nesse livro é o oposto, ou seja, é o de resolver os problemas sem enumerar, de fato, todas as possibilidades de resposta. Eles falam em métodos para resolver problemas.

O livro apresenta problemas contextualizados e, na resolução de um deles, enuncia o Princípio Multiplicativo e na resolução de outro, uma sua extensão, mas sem nomear esse Princípio. No final desse tópico propõe 22 problemas com boas ideias de aplicação.

Para definir permutação, com ou sem repetição, através de uma situação-problema é utilizada uma tabela. Em seguida, é deduzida a fórmula para o cálculo do número de permutações feitas. O conceito de fatorial aparece quando se define permutação e é usado nas aplicações de fórmulas. Seguem vários problemas relacionados à permutação.

Os autores desse livro definem combinação por meio da resolução de um problema. Também, resolvendo um problema, deduzem a fórmula para o cálculo do número de combinações. Esse tópico termina com um conjunto de problemas propostos. Apenas abordam os conceitos de permutações e combinações, deixando as ideias de arranjo como uma mescla dos dois.

4) O livro apresenta o conteúdo de Análise Combinatória de modo diferente do usado no ensino tradicional, explicitando, de início através de exemplos, as ideias fundamentais e importantes relacionadas ao processo de contagem. Agindo assim, o trabalho desse conteúdo realizado pelo professor, torna-se mais significativo pois pode contribuir para um melhor entendimento dos conceitos da Análise Combinatória e os problemas podem despertar a curiosidade dos alunos. Esse livro tem um guia para o professor, um manual que dá orientações sobre o objetivo de cada item trabalhado.

\section{Matemática para o $2^{\circ}$ ano colegial}

Ary Quintella $-4^{\mathrm{a}}$ edição - provavelmente década de 60

\section{Companhia Editora Nacional, São Paulo}


Características gerais:

Neste livro há uma apresentação razoavelmente formal do tópico Análise Combinatória. De início apresenta-se as definições de arranjo, permutação e combinação através de fórmulas. O Teorema Fundamental relativo à construção do número de arranjos é desenvolvido a partir da fórmula dada para arranjos. Diferente do visto nos livros anteriores, estes apresentam três importantes propriedades das combinações que com seu uso facilitam o cálculo das combinações.

Análise dos critérios estabelecidos:

1) O trabalho neste livro não inicia o conteúdo com problemas. Estes aparecem somente no final do capítulo.

2) O livro apresenta uma tabela com fórmulas e às vezes, sua formalização que podem dificultar a compreensão dos conceitos envolvidos na Análise Combinatória. A lista de problemas é apresentada somente no final do capítulo, não favorecendo a participação dos alunos durante a resolução do problema, pois a definição dos conceitos já é apresentada no início.

3) Iniciando com as definições de: Análise Combinatória como estudo de agrupamentos que podem ser formados com os elementos de um conjunto finito, seguindo leis prefixadas; agrupamentos simples: permutação, combinação e arranjo; e com repetição ou completos; taxa ou classe: é o número de elementos do conjunto considerado em cada grupo; fatorial.

A seguir classifica os agrupamentos simples como sendo de três tipos: arranjos ou disposições simples; permutações; e combinações simples. Seguem as definições desses agrupamentos referindo-se à ordem e à natureza dos elementos, de modo bem resumido, iniciando com arranjos, depois permutação e combinação, como casos particulares de arranjo.

Apresenta, no tópico Formação dos arranjos simples, o Teorema Fundamental.

Apresenta, a seguir, fórmula para o cálculo do número de arranjos, de permutações, convencionando $0 !=1$; inversão, classe de uma permutação; Teorema de Bezout com demonstração; permutação com repetição; fórmula do número de combinações simples; e propriedades das combinações simples, $1^{\text {a }}$ ) Duas combinações de taxas complementares são iguais; $2^{\mathrm{a}}$ ) Dado um conjunto de $n$ elementos, o número de combinações de taxa $p$ em que figuram $k$ elementos determinados $(k \leq p)$ é $C_{n-k}^{p-k}$; e $3^{\text {a }}$ ) Dado um conjunto de $n$ elementos, o número de combinações de taxa $p$ em que não figuram $k$ desses elementos é $C_{n-k}^{p}$. 
No final do capítulo, apresenta um quadro com as fórmulas de cada agrupamento seguido de vários exercícios. Cita a definição de fatorial e seu uso aparece no cálculo do número de agrupamentos.

4) O livro apresenta o conteúdo de modo tradicional, iniciando com as definições seguidas por poucos exemplos. Há formalização na demonstração dos teoremas. Para o professor, a dificuldade estaria em selecionar problemas que levassem ao processo de contagem (o que não aparece no livro) e também que os alunos pudessem participar da construção dos conceitos desse tópico.

\section{Década 70}

Prelúdio à Análise Combinatória

Arago de C. Bachx, Luiz M. B. Poppe, Raymundo N. O. Tavares

Editora Nacional, São Paulo, 1975.

\section{Características gerais:}

Este livro trabalha dentro das ideias da Matemática Moderna, na qual sua notação se apóia na linguagem da Teoria dos Conjuntos, uma linguagem universal, concisa e precisa. Um dos autores desse livro, Arago Bachx, foi aluno de Papy no Centro Belga de Pedagogia da Matemática. Na apresentação desse livro há uma reflexão sobre o conceito de Análise Combinatória. Seus autores evidenciam a importância do Princípio Multiplicativo como básico para a conceituação da Análise Combinatória, e dizem que as fórmulas aparecem de modo espontâneo, onde os alunos formam e identificam os grupos de objetos.

O livro apresenta muitos problemas e, como Quintella, demonstra propriedades das combinações. Dentre os livros consultados, esse foi o único a falar em conceitos primitivos para a teoria da Análise Combinatória, chamando-os de termos primitivos e indicando-os por acontecimento, ocorrência de um acontecimento e agrupamento.

Dando início a cada uma das suas atividades, parte de um problema simples, o estende para outras situações e, por fim, define o conceito pretendido. Assim, no prefácio, revelam que Análise Combinatória sempre foi um conteúdo considerado difícil para os alunos. Falam do Princípio Multiplicativo, generalizam problemas, deduzem fórmulas e definem a Análise Combinatória como sendo "o ramo da Matemática que permite resolver problemas em que, basicamente, é necessário "escolher e arrumar" os objetos de um conjunto". Esses autores desenvolvem o estudo da Análise Combinatória com base no Princípio Multiplicativo e nos conceitos primitivos. 
Análise dos critérios estabelecidos:

1) Iniciam com problemas e, em seguida, enunciam o Princípio Multiplicativo. Apresentam novos problemas e, na sequência, a extensão do Princípio Multiplicativo. No final do capítulo, deixam 54 problemas propostos.

2) O livro permite um trabalho colaborativo do professor com os alunos. A partir dos conceitos primitivos apresentados pelo professor, o aluno pode organizar melhor os dados do problema e entender, de modo mais significativo, a construção dos conceitos envolvidos na Análise Combinatória.

3) Inicia com o Princípio Multiplicativo, usa o conceito de fatorial definido e define permutações de objetos distintos apresentando um exemplo. A seguir problemas em diferentes contextos são resolvidos e outros são propostos. Na sequência, apresentam permutações circulares, combinações: definição, exemplo e dedução da fórmula; combinação complementar; novos problemas resolvidos e propostos; permutações com objetos indistinguíveis (repetidos), e faz a dedução da fórmula; equações lineares com coeficientes unitários; propriedades das combinações; Triângulo de Pascal; potência de um binômio Fórmula de Newton com a devida formalização; potenciação de polinômios; cardinalidade da união e combinatória.

Apresentação no apêndice I: Teorema da Indução Matemática; no apêndice II: somatórios; no apêndice III: arranjos simples, arranjos com repetição, combinações com repetição.

Define fatorial no capítulo II e apresenta exercícios resolvidos e exercícios propostos. Nesse capítulo aparece, também, no apêndice III, a definição de fatorial $n !=\left\{\begin{array}{l}1 \text { se } \mathrm{n}=0 \text { ou } \mathrm{n}=1 \\ \mathrm{n} \cdot(\mathrm{n}-1) \cdot \ldots \cdot 3 \cdot 2 \cdot 1, \text { se } \mathrm{n}>1\end{array}\right.$.

4) O livro apresenta uma sequência didática, iniciando com o Princípio Multiplicativo. Há vários problemas úteis ao professor para motivar e incentivar os alunos no estudo da Análise Combinatória. Nesse método de trabalho, o ensino é centrado no professor.

Matemática Aplicada: $2,2^{\circ}$ grau

Fernando Trotta, Luiz Márcio Pereira Imenes, José Jakubovic

Editora Moderna, São Paulo, 1979. 
Características gerais:

Este livro vem acompanhado de um manual para o professor. Faz aplicações práticas dos modelos nele criados; trabalha tópicos da História da Matemática; trabalha com interdisciplinaridade, ou seja, faz a integração com outras disciplinas em aplicações. Os autores acreditam que trabalhar Análise Combinatória é de fundamental importância para a formação matemática do aluno. O capítulo I nesse livro sobre Análise Combinatória, apresenta inicialmente uma coleção de exercícios sobre contagem. Dizem seus autores aos alunos, que a resolução desses exercícios exigirá bastante de seu raciocínio mas que, em compensação, não exigirá conhecimentos anteriores de Matemática.

Os autores dizem acreditar que a melhor e mais rápida maneira de se tomar contato inicial com a Análise Combinatória é resolver o primeiro exercício e deixar outros propostos para serem resolvidos entre os colegas, ao trocarem ideias uns com os outros. O primeiro problema apresentado é resolvido com muitos detalhes e explicações e depois são deixados 9 problemas para serem resolvidos pelos alunos, com o espírito de fixação do conceito.

Nesse livro arranjo é definido, na página 11, por "Dado um conjunto A formado por $n$ elementos, e sendo $p$ um número inteiro positivo, chama-se arranjo dos $n$ elementos dados, tomados $p$ a $p$, a qualquer sequência de $p$ elementos formada com os elementos de A", a combinação é vista como um subconjunto do conjunto dos arranjos e a permutação é vista como qualquer sequência de $\mathrm{n}$ elementos em que comparecem todos os elementos do conjunto A.

Análise dos critérios estabelecidos:

1) O capítulo de Análise Combinatória se inicia com problemas práticos, visando ao desenvolvimento do raciocínio aritmético do aluno, essencial para seu desenvolvimento. Os autores citam que nesses problemas, de início os alunos não estão em condições de resolvêlos. Portanto, deverão ser orientados a efetuar inúmeras observações que servirão de base para a construção dos conceitos e das técnicas para resolver os problemas dados.

2) O livro pode contribuir para um trabalho colaborativo entre professores e alunos, pois apresenta problemas contextualizados que fazem com que os alunos tenham mais interesse pelo assunto e se envolvam com as resoluções dos problemas trocando ideias com seus colegas.

3) Inicialmente será explorado o raciocínio multiplicativo, depois da criação de modelos em Análise Combinatória: arranjos, permutações e combinações. As permutações são apresentadas como um caso particular de arranjos sem repetição e ensejam o aparecimento do fatorial de n. As combinações serão definidas como subconjuntos de um conjunto dado. 
Os autores organizaram a seguinte sequência para o trabalho do tópico Análise Combinatória com os alunos:

a) desenvolver o "raciocínio multiplicativo" nos alunos através da resolução de problemas de contagem, acreditando que nessa fase se deva dar ao aluno tempo para descobertas.

b) os alunos devem perceber que há muita coisa em comum na resolução dos exercícios dados, dando ao professor, condições de apresentar a idéia de criação de modelos em Análise Combinatória.

c) a apresentação dos modelos na seguinte ordem: $1^{\underline{0}}$ ) arranjos - a definição de arranjos em geral e, como caso particular, são definidos os arranjos sem repetição ou simples. Os arranjos são definidos como sequências de elementos e a dedução do número de arranjos surge naturalmente a partir dos raciocínios feitos. $2^{\circ}$ ) permutações - são definidas como um caso particular de arranjos sem repetição e ensejam a oportunidade do aparecimento do conceito de fatorial, n!. Termina esse tópico com exercícios. $3^{\circ}$ ) combinações - são definidas como subconjuntos de um conjunto dado. Posteriormente, é feita a dedução do número de combinações, envolvendo os conceitos de arranjos, permutações e combinações, bem como raciocínios aritméticos essenciais. Após essa dedução são resolvidos e propostos exercícios e os alunos deverão decidir que modelo será usado em cada situação, sendo que em algumas, terá que conjuminar vários modelos conhecidos.

d) Trabalham o Binômio de Newton relacionando-o com o modelo-combinação.

e) A ideia de anagrama é apresentada ensejando a criação das permutações com repetição;

4) Os autores criticam o modelo tradicional, chamado por eles de método axiomáticodedutivo. Os alunos deverão, para resolver um problema dado, fazer observações que servirão de apoio para a criação de conceitos e técnicas que permitam encontrar a solução do problema. Tendo como guia o manual, o professor teria um trabalho mais produtivo na sala de aula pois ele apresenta uma sequência didática de forma clara para se trabalhar.

\section{Década de 90}

\section{$\underline{\text { Fundamentos da Matemática Elementar: combinatória/probabilidade }}$}

Samuel Hazzan

Atual Editora Ltda, 6aed, São Paulo, 1993.

Características gerais:

O livro apresenta muitos e variados exercícios. O Princípio Fundamental de Contagem que é demonstrado com o auxílio de dois lemas (teoremas auxiliares): Lema 1: 
"Consideremos os conjuntos $A=\left\{a_{1}, a_{2}, \ldots, a_{m}\right\}$ e $B=\left\{b_{1}, b_{2}, \ldots, b_{n}\right\}$. Podemos formar $m \cdot n$ pares ordenados $\left(a_{i}, b_{j}\right)$ em que $a_{i} \in A$ e $b_{j} \in B$ " (p.2); Lema 2: “O número de pares ordenados $\left(a_{i}, a_{j}\right)$ tais que $a_{i} \in\left\{a_{1}, a_{2}, \ldots, a_{m}\right\}, a_{j} \in\left\{a_{1}, a_{2}, \ldots, a_{m}\right\}$ e $a_{i} \neq a_{j}$ (para $\left.i \neq j\right) e ́$ $m(m-1)$ " (p.4) $)^{15}$, tem por enunciado, constando de duas partes, A e B, respectivamente: "Consideremos $r$ conjuntos $A=\left\{a_{1}, a_{2}, \ldots, a_{n_{1}}\right\}, B=\left\{b_{1}, b_{2}, \ldots, b_{n_{2}}\right\}, \ldots, Z=\left\{z_{1}, z_{2}, \ldots, z_{n_{r}}\right\}$ com $\# A=n_{1}, \# B=n_{2}, \ldots, \# Z=n_{r}$ então, o número de r-uplas ordenadas (sequências de $r$ elementos) do tipo $\left(a_{1}, b_{j}, \ldots, z_{p}\right)$ em que $a_{i} \in A, b_{j} \in \mathrm{B} \ldots \mathrm{z}_{\mathrm{p}} \in \mathrm{Z}$ é $n_{1} \cdot n_{2} \cdot \ldots \cdot n_{r}$ ” (p.5); "Consideremos um conjunto A com $m(m \geq 2)$ elementos. Então o número de r-uplas ordenadas (sequências com r elementos) formadas com elementos distintos dois a dois de A é: $m \cdot(m-1) \cdot(m-2) \cdot \ldots \cdot[m-(r-1)], r$ fatores. Ou seja, se $A=\left\{a_{1}, a_{2}, \ldots, a_{m}\right\}$, o número de sequências do tipo $\left(a_{j}, a_{l}, \ldots, a_{i}, \ldots, a_{k}\right)$, r elementos e com $a_{i} \in A, \forall i \in\{1,2, \ldots, m\}$ e $a_{i} \neq a_{p}$, para $i \neq p$, é $m \cdot(m-1) \cdot \ldots \cdot[m-(r-1)], r$ fatores (p.7). No início, as fórmulas são trabalhadas a partir do Princípio Fundamental de Contagem, são apresentadas sem fazer uso do conceito de fatorial, que foi, depois, detalhado com a finalidade de simplificar as fórmulas deduzidas para determinar o número de arranjos, de combinações e de permutações.

Análise dos critérios estabelecidos:

1) Esse livro não inicia seu trabalho a partir de problemas. Entretanto, faz uma introdução definindo Análise Combinatória da seguinte forma: a Análise Combinatória visa ao desenvolvimento de métodos que permitem contar o número de elementos de um conjunto, sendo estes elementos agrupamentos formados sob determinadas condições.

2) e 3) Seu início se dá ao enunciar o Princípio Fundamental da Contagem. Seguem dois lemas enunciados que levam à demonstração do Princípio Fundamental da Contagem. Apresenta muitos exercícios. Depois, vem o que o autor chama de "modos de formar agrupamentos" ao definir arranjos, permutações e combinações. Como conseqüência, deduz as fórmulas correspondentes a cada um dos modos classificados: a) arranjos com repetição; b) permutação; c) fatorial; d) combinações simples; e e) permutações com elementos repetidos.

4) O livro se apresenta nos moldes de ensino tradicional. Não parte de problemas, cuja aplicação se dá apenas no final do capítulo. Entretanto, a parte relativa às demonstrações é formal embora com detalhes que permitem levar a certa compreensão mas sem a participação dos alunos. O ensino é centrado no professor.

\footnotetext{
${ }^{15}$ As demonstrações são encontradas nas páginas 2 e 4.
} 
$\underline{\text { Curso de Matemática (volume único) }}$

Edwaldo Bianchini, Herval Paccola

Editora Moderna, 1'ed., São Paulo, 1993.

Características gerais:

O capítulo sobre Análise Combinatória se inicia com uma introdução em que fica evidente que o objetivo principal da Análise Combinatória que é a determinação do número de possibilidades de um dado evento ocorrer. O problema pode ser resolvido descrevendo todas as possibilidades e a seguir contando o número delas. Nesse capítulo são apresentados problemas variados envolvendo situações contextualizadas.

Análise dos critérios estabelecidos:

1) Inicia o capítulo com exemplos, resolvendo-os através da árvore de possibilidades, descrevendo todas as possibilidades possíveis e contando-as posteriormente. Mas, chamam atenção para o fato de que, se o número de possibilidades for muito grande, torna-se necessário encontrar técnicas que permitam contar o número de possibilidades sem descrevêlas. Para isso, usam o Princípio Fundamental de Contagem. Apresentam vários exemplos, resolvendo-os através do Princípio Fundamental de Contagem. Há problemas em variados contextos no final do capítulo.

2) O modo em que o conteúdo é apresentado proporciona aos alunos explorar situaçõesproblema de início. Através da árvore de possibilidades e do Princípio Fundamental de Contagem, o aluno desenvolve técnicas de contagem, sem precisar descrever todos os agrupamentos. Os conceitos são sistematizados e a apresentação das fórmulas é feita posteriormente.

3) A formalização dos conceitos se dá depois do problema resolvido, nomeando os agrupamentos encontrados: arranjos simples, permutações simples e com repetição e combinações simples. Apresenta um modo para reconhecer se o problema dado envolve arranjos ou combinações, trocando as posições dos elementos no agrupamento. Apresentam no final do capítulo 56 problemas.

4) O livro apresenta no início problemas simples e resolvidos através da árvore de possibilidades e usando também o Princípio Multiplicativo. Desse modo, pode facilitar o trabalho inicial do professor com os alunos em Análise Combinatória. Talvez o professor tenha dificuldade na dedução das fórmulas e em seu uso alguns exercícios que enfatizam o uso das fórmulas. Apresenta problemas no final do capítulo. 
$\underline{\text { Matemática para o } 2^{\circ} \text { grau }}$

Nelson Gentil, Carlos Alberto M. dos Santos, Antônio Carlos Greco, Antônio Belloto Filho, $\underline{\text { Sérgio Emílio Greco. }}$

Editora Ática, 1996

Características gerais:

Este livro faz uso de fórmulas desde seu início pondo ênfase no treinamento dos alunos. O capítulo em que inicia Análise Combinatória é dividido nos seguintes tópicos nesta ordem: Fatorial; Princípio Fundamental de Contagem; Arranjo, Combinação e Permutação simples; e Arranjos e Permutação com repetição. Há ênfase no uso de fórmulas na resolução dos problemas.

Análise dos critérios estabelecidos:

1) O livro inicia esse capítulo com a definição de Fatorial, seguido de cinco exercícios resolvidos, usando essa definição, e oito exercícios são propostos. A seguir, apresenta o enunciado do Princípio Fundamental da Contagem, seguido de exercícios resolvidos e propostos. Em nenhum momento são feitas demonstrações das fórmulas usadas.

2) O livro, apesar de mostrar alguns exemplos usando o Princípio Fundamental da Contagem e árvore de possibilidades. São poucos esses exercícios para permitir que o aluno se familiarize com os novos conceitos da Análise Combinatória e adquira condições para resolver os exercícios propostos, agora mais complexos.

3) Na página 229, através de dois exemplos, o autor define arranjo simples e combinação simples dizendo que se a natureza e a ordem dos elementos influem na formação dos grupos, então temos um caso de arranjo. Caso a ordem não influa, isto é, apenas influi nos agrupamentos a natureza dos elementos, então temos um caso de combinação. A seguir, apresenta dois problemas de arranjo, resolvidos através da árvore de possibilidades e, a seguir, deduz a fórmula para arranjos simples generalizando a situação. Define permutação como todo arranjo simples de $\mathrm{n}$ elementos tomados $\mathrm{n}$ a $\mathrm{n}$, isto é, em todos os agrupamentos estão presentes todos os elementos. Apresenta a fórmula e faz aplicações dela.

Formalizam o conceito de combinação simples, na resolução de um problema, usando os conceitos de arranjo e permutação, dizendo que, para cada combinação de $\mathrm{n}$ elementos tomados $\mathrm{p}$ a $\mathrm{p}$, temos $\mathrm{P}_{\mathrm{p}}$ arranjos simples de $\mathrm{n}$ elementos tomados $\mathrm{p}$ a $\mathrm{p}$, ou seja, $A_{n, p}=C_{n, p} . P_{p}$. Seguem exemplos resolvidos com aplicação de fórmulas e 32 exercícios foram propostos. 
No final do capítulo, os autores apresentam a definição de arranjo com repetição e de permutação com repetição. Apresenta uma situação-problema para cada caso e, em seguida, formaliza apresentando a fórmula. Seguem vários exercícios propostos. O capítulo se encerra com 11 exercícios complementares.

4) O livro apresenta Análise Combinatória no modo tradicional. Define os conceitos e os aplica em problemas que são resolvidos com aplicação das fórmulas. Há problemas contextualizados no final do capítulo para o professor trabalhando com os alunos, motivarem a compreensão dos conceitos em situações da prática.

\section{A Matemática no Ensino Médio vol.2}

Elon Lages Lima, Paulo C.P. Carvalho, Eduardo Wagner, Augusto C. Morgado

$\underline{\text { SBM, Rio de Janeiro, } 1998 .}$

\section{Características gerais:}

As explicações exibidas nesse livro são bastante formais e muitos problemas são apresentados no final do capítulo. Não faz uso da árvore de possibilidades, apresenta estratégias para resolver problemas de combinatória, e há sugestões para resolver cada problema proposto. Apresenta o conceito de permutação circular. Não apresenta definição para arranjo. As reflexões sobre o ensino de combinatória são feitas no final do capítulo. Este livro apresenta diferentemente da maioria dos outros livros o conceito de combinação com repetição, através da resolução de um problema.

Análise dos critérios estabelecidos:

1) Os autores iniciam o capítulo com o item Princípios Básicos, apresentando o Princípio Fundamental de Contagem seguido de seis exemplos resolvidos. Não utiliza a árvore de possibilidades. É apresentado um exemplo por meio de um exercício e, logo após, foi apresentada uma fórmula. Em seguida, foram apresentadas as definições de permutação e de combinação, com o registro das correspondentes fórmulas.

Esse livro descreve, na página 86, três estratégias para resolver problemas de combinatória:

a) Postura: o resolvedor deve se colocar no papel da pessoa que deve fazer a ação solicitada pelo problema e ver que decisões devem se tomadas.

b) Divisão: o resolvedor deve, sempre que possível, dividir as decisões a serem tomadas em decisões mais simples. 
Um passo importante em qualquer estratégia adotada para resolver problemas de combinatória é:

c) Não adiar dificuldades: pequenas dificuldades adiadas costumam se transformar em imensas dificuldades.

Os autores descrevem o uso de cada uma das estratégias citadas acima na resolução dos exemplos anteriores. Apresentam 21 exercícios propostos e sugestões de como resolvêlos.

2) O livro apresenta, no início, o Princípio Fundamental de Contagem e isso pode permitir um trabalho colaborativo com os alunos, pois eles podem desenvolver técnicas de contagem sem necessariamente descrever todos os agrupamentos ao resolver os problemas. Assim, o aluno poderia compreender, de modo mais significativo, os conceitos da Análise Combinatória posteriormente apresentados.

3) A formalização dos conceitos de Análise Combinatória se dá durante a resolução do problema. Define permutação simples e com repetição durante a resolução de problemas dados como exemplos e apresenta a fórmula de aplicação. (Obs.: usou fatorial sem antes defini-lo, mas usa esse conceito nas fórmulas apresentadas). Em seguida, define combinação simples através de um exemplo, não explora a resolução mas apresenta a fórmula. Mostra problemas resolvidos com aplicação das fórmulas. Define também permutação circular como sendo o número de modos de colocar n objetos em círculo, de modo que as disposições que possam coincidir por rotação sejam consideradas iguais, isto é, o número de permutações circulares de $\mathrm{n}$ objetos é $(P C)_{n}=\frac{n !}{n}=(n-1)$ !

Propõe 40 exercícios, havendo entre eles exercícios bastante motivadores, explorando outros conceitos da matemática, além da contagem, mas havendo também problemas teóricos, em geral complexos, e deixam sugestões para a resolução de cada um deles. Em seguida, apresenta, na página 107, o Triângulo Aritmético; Relação de Stifel; Teorema das Linhas; Relação das Combinações complementares, e, por fim o Binômio de Newton. Esse capítulo termina com algumas recomendações sugeridas, pelos autores, visando à formação do professor, levando-o a refletir sobre seu possível trabalho, em sala de aula, sobre o ensino de Combinatória.

4) O livro apresenta orientações significativas em relação ao ensino de Combinatória, estratégias e recomendações e também, sugestões de como resolver os exercícios propostos, que podem ajudar os professores, que não souberem como dar início ao trabalho, em sua preparação de aulas. 
Matemática (volume único)

$\underline{\text { Manoel Paiva }}$

Editora Moderna, São Paulo, 1999.

Características gerais:

Esse livro apresenta muitos exercícios, definições claras e objetivas, mas os problemas aparecem somente depois de que as definições são dadas. Apresenta problemas e textos interessantes do cotidiano. Descreve um critério para diferenciar arranjo de combinação e, ainda apresenta o Princípio Aditivo de Contagem. Na resolução de problemas desenvolvidos, o autor põe mais ênfase no processo do que na solução, fazendo esse trabalho com detalhes.

Análise dos critérios estabelecidos:

1) O livro começa resolvendo problemas e, só depois de sua resolução é que ele vai para a formalização. No início do capítulo de Análise Combinatória há uma introdução sobre contagem. Nele é dito que a principal finalidade da Análise Combinatória é a de estabelecer métodos de contagem. Seus problemas se apresentam contextualizados.

2) Sim, pois, por explorar problemas do cotidiano, consegue fazer com que o aluno se envolva nas discussões e possa participar da resolução dos mesmos.

3) A formalização dos conceitos é feita após a resolução dos problemas mas, durante a resolução, o autor apresenta uma organização dos dados do problema que induzem à formalização do conteúdo e é, desse modo, que o Princípio Fundamental da Contagem é trabalhado. Há seis exercícios resolvidos e dez propostos, além dos complementares no final do capítulo. Apresenta também o Princípio Aditivo de Contagem, seguido de exercícios resolvidos e propostos.

No capítulo seguinte intitulado "Classificação dos agrupamentos e Métodos de contagem", ele começa com uma situação-problema que envolve arranjo simples e, posteriormente o define, falando em ordem, sequência e natureza dos elementos. Depois apresenta a fórmula, mas deixa claro, para o aluno que ele pode aplicar o Princípio Fundamental de Contagem, em vez da fórmula, dizendo que "acha até melhor" que faça dessa forma. Seguem exercícios resolvidos e propostos. Há problemas do cotidiano mas há também "exercícios" fundamentados nas fórmulas. Segue a definição de fatorial. Demonstra a propriedade fundamental dos fatoriais e, em seguida, apresenta o cálculo do número de 
arranjos através de fatoriais, com exercícios resolvidos e propostos fazendo uso apenas da aplicação da fórmula. De modo análogo, apresenta a permutação simples. A define como uma sequência de elementos diferentes, formada por todos os elementos do conjunto, dizendo que os agrupamentos se diferenciam apenas pela ordem. Relaciona arranjo e permutação, apresenta as fórmulas e, em seguida, exercícios resolvidos e propostos. Faz o mesmo para permutação com repetição.

Analogamente, trabalha combinação simples, onde os agrupamentos diferem apenas pela natureza dos elementos. Apresenta a fórmula para combinação, deduzindo-a usando os conceitos de arranjo e permutação.

Esse livro apresenta, ainda, um critério prático para diferenciar arranjo de combinação. Seguem exercícios resolvidos e propostos e vários problemas complementares. Apresenta número binomial com exercícios resolvidos, propostos e complementares.

4) O modo que os conceitos de Análise Combinatória são apresentados nesse livro pode contribuir para o trabalho realizado em sala de aula, no qual é explorado, inicialmente, o Princípio Fundamental de Contagem. Problemas do cotidiano podem ajudar os alunos na compreensão desse tópico e até no envolvimento do aluno na resolução do problema dado. Também há, nesse livro, textos contextualizados que evidenciam a importância da Análise Combinatória em situações do mundo real. Como treino, esse livro propõe, um grande número de problemas agrupados depois da definição de cada conceito dado.

\section{ANOS 2000}

Precalculus with limits: a graphing approach $3^{\mathrm{a} e d}$.

Larson, Ron; Hostetler, Robert P.; Edwards, Bruce H.

Boston: Houghton Mifflin Company, 2001

Para poder comparar diferenças de postura entre duas nações, escolhemos este livro para saber como, nos Estados Unidos, se procura trabalhar Análise Combinatória.

Características gerais:

Este livro apresenta muitos problemas trabalhados de modo tradicional. Mas o que se pode perceber de diferente é a forma "do que" trabalhar e "do como" trabalhar esse tópico matemático. Antes de iniciar esse tópico matemático, os autores descrevem alguns itens 
referentes a ele, para auxiliar o professor no trabalho em sala de aula, visando a conhecer “ $\underline{\mathrm{o}}$ que eles devem nele aprender" e "por que eles o devem aprender".

O livro começa falando sobre sequências e séries de elementos e procura posicionar os alunos frente a esses dois itens.

O que você (aluno) deveria aprender:

- Como usar a notação de sequências para escrever os termos de sequências.

- Como usar a notação de fatorial.

- Como usar a notação de somatória para escrever somas.

- Como encontrar somas de séries infinitas.

- Como usar sequências e séries para modelar e resolver problemas da vida real.

Por que você deveria aprender isso:

- Sequências e séries são úteis para modelar conjuntos de valores que identificam um padrão.

Sobre contagem:

$\underline{\text { O que você deveria aprender: }}$

- Como resolver problemas de contagem simples.

- Como usar o Princípio Fundamental de Contagem para resolver problemas mais complicados de contagem.

- Como usar permutações para resolver problemas de contagem.

- Como usar combinações para resolver problemas de contagem.

Por que você deveria aprender isso:

- Você pode usar os princípios de contagem para resolver problemas de contagem que ocorrem na vida real.

O livro, diferente dos outros, apresenta os seguintes tópicos: sequências e séries; sequências aritméticas e somas parciais; sequências e séries geométricas; Indução Matemática; O Teorema Binomial; Princípio de Contagem: permutação e combinação; e Probabilidade.

Os conteúdos anteriores à Análise Combinatória são apresentados do modo tradicional, apresentam a definição, dá exemplos, exercícios e muitos problemas. 
Os tópicos envolvendo a Análise Combinatória são: O Teorema Binomial, O Princípio de Contagem Simples, O Princípio Fundamental de Contagem, a definição de permutação e a definição de combinação. Não aparece o conceito de arranjo.

Análise dos critérios estabelecidos:

1) Não inicia o trabalho com problemas mas apresenta poucos exemplos seguidos pela definição formal e da correspondente fórmula. No final de cada capítulo apresenta uma coleção de problemas contextualizados representando situações do mundo real e relacionados a outros campos da Matemática.

2) O livro apresenta exemplos onde são exploradas estratégias de contagem para cada conceito definido. Apesar de serem poucos exemplos, as estratégias adotadas apresentadas podem contribuir bastante para a posterior formalização dos conceitos.

3) A formalização de cada tópico se dá no início, com a apresentação das fórmulas e posterior aplicação. Interessante, para nós é que o livro não se refere ao conceito de arranjo, muito possivelmente, porque esse conceito está relacionado aos conceitos de combinação e permutação.

4) Os autores, embora apresentando o conteúdo no modo tradicional de ensino, isto é, iniciando com a definição de cada conceito e a seguir desenvolvendo exercícios com aplicação de fórmulas, podem ajudar os professores quando justificam todas as passagens necessárias à resolução completa do problema ao sugerir diferentes estratégias. Apresentam problemas propostos contextualizados para o professor desenvolver o trabalho com os alunos.

Matemática

Luiz Roberto Dante

Editora Ática, São Paulo, 2004.

Características gerais:

Este livro propõe muitos problemas, resolvendo alguns apresentados no início. A linha metodológica para a resolução de problemas, neste livro, segue a idéia de ensinar Matemática para depois resolver problemas, com o trabalho centrado no professor. O que há de diferente neste livro é que, o autor procura sempre dar significado às palavras que dão nome aos conceitos. Buscando sempre para elas um sinônimo mais conhecido. Por exemplo, ele diz que 
permutar é trocar, e combinar, está intuitivamente associado à noção de escolher subconjuntos de conjunto dado, que obedecem a uma condição, a de mudar quando se muda a natureza dos elementos.

Análise dos critérios estabelecidos:

1) Sim, parte de problemas. Apresentando situações-problema do cotidiano, explorando inicialmente a árvore de possibilidades resolvendo o problema em detalhes e formalizando posteriormente.

2) O livro permite um trabalho do professor com os alunos, embora não peça um trabalho entre os alunos em grupos. Os problemas do cotidiano, contextualizados, quando resolvidos, através da árvore de possibilidades, facilita a visualização do aluno na busca da solução.

3) A formalização da teoria é feita no final da resolução de problemas, buscando generalizar que foi explorado anteriormente durante a resolução do problema. A permutação é vista como um agrupamento ordenado. Os arranjos são vistos como agrupamentos ordenados e diferindo pela natureza dos elementos. A combinação é vista como agrupamentos dependendo da escolha dos elementos, isto é, as combinações diferem somente pela natureza de seus elementos. No livro, a permutação com repetição é trabalhada, mas não apresenta arranjo e combinação com repetição. No final do capítulo há problemas com diferentes tipos de agrupamento. Apresenta o Binômio de Newton e o Triângulo de Pascal.

4) Este livro pode contribuir para a aprendizagem do aluno, apesar desse trabalho estar centrado no professor. As justificativas colocadas, ao longo de cada passagem trabalhada na resolução dos problemas, podem mostrar aos alunos porque determinadas ações devem ser feitas.

\section{Minha visão da análise feita nesses livros}

Utilizados os critérios estabelecidos para análise do tópico Análise Combinatória nos livros didáticos, pudemos tirar algumas conclusões ao confrontar as informações e os dados obtidos, visando ao desenvolvimento de um trabalho que adotasse uma metodologia alternativa para a sala de aula e considerando o livro como um dos recursos didáticos mais utilizados pelos professores.

Nos livros que analisamos, apresentados em ordem cronológica, observamos que há mudanças na posição dos autores no tratamento dado ao conteúdo de Análise Combinatória. 
Essas mudanças estão relacionadas às diferentes fases pelas quais a Educação Matemática passou durante o século 20. Essas fases são apresentadas no capítulo 1, do livro The learning of Mathematics - sixty ninth yearbook (NCTM, 2007), intitulado Changes through the Years: Connections between Psychological Learning Theories and School Mathematics Curriculum (Mudanças através dos anos: conexões entre as teorias psicológicas de aprendizagem e o currículo escolar de matemática).

Os autores, Lambdin, D.V. e Walcott, C. mostram seis fases identificáveis com diferentes ênfases: 1) exercício e prática; 2) aritmética significativa; 3) Matemática Moderna; 4) volta às bases; 5) resolução de problemas; e 6) padrão e responsabilidade. Cada uma delas corresponde um período em que a educação americana em geral estava passando por mudanças radicais e fundamentais e introduzia práticas novas e inovadoras na educação matemática. Esses mesmos autores citam, na p.3, que a perspectiva histórica nos ajuda a evitar uma visão afunilada sobre as particularidades dos problemas educacionais que enfrentamos hoje e sugere opções a serem consideradas conforme ponderamos suas soluções.

A tabela a seguir apresenta uma visão geral de cada uma dessas fases, incluindo seus teóricos principais, o foco na sala de aula e os métodos fundamentais de ensino. 


\begin{tabular}{|c|c|c|c|}
\hline Fases & $\begin{array}{c}\text { Principais teorias e } \\
\text { teóricos }\end{array}$ & Foco & $\begin{array}{c}\text { Como foram } \\
\text { realizados }\end{array}$ \\
\hline $\begin{array}{l}\text { Exercício e prática } \\
\text { (Aprox. 1920-1930) }\end{array}$ & $\begin{array}{l}\text { Conexionismo ou } \\
\text { associacionismo. } \\
\text { (Thorndike) }\end{array}$ & $\begin{array}{l}\text { Facilidade com } \\
\text { cálculo. }\end{array}$ & $\begin{array}{l}\text { Rotina: } \\
\cdot \text { - Memorização de } \\
\text { fatos e algoritmos. } \\
\cdot \text { Quebra de todo } \\
\text { trabalho em séries de } \\
\text { pequenos passos. }\end{array}$ \\
\hline $\begin{array}{l}\text { Aritmética } \\
\text { significativa } \\
\text { (Aprox.1930-1950s) }\end{array}$ & $\begin{array}{l}\text { Teoria Guestalt } \\
\text { (Brownell, } \\
\text { Wertheimer, van } \\
\text { Engen, Fehr) }\end{array}$ & $\begin{array}{l}\cdot \text { Compreensão de } \\
\text { ideias e habilidades } \\
\text { aritméticas. } \\
\text { - Aplicações de } \\
\text { matemática a } \\
\text { problemas do mundo } \\
\text { real. }\end{array}$ & $\begin{array}{l}\cdot \text { Ênfase em relações } \\
\text { matemáticas. } \\
\cdot \text { Aprendizagem } \\
\text { incidental. } \\
\cdot \text { Abordagem de uma } \\
\text { atividade orientada. }\end{array}$ \\
\hline $\begin{array}{l}\text { Nova Matemática } \\
\text { (conhecida por nós } \\
\text { como Matemática } \\
\text { Moderna) } \\
\text { (Aprox.1960-1970s) }\end{array}$ & $\begin{array}{l}\text { Psicologia do } \\
\text { desenvolvimento. } \\
\text { - Teoria } \\
\text { sociocultural. } \\
\text { (Bruner, Piaget, } \\
\text { Dienes) }\end{array}$ & $\begin{array}{l}\text { Entender a estrutura } \\
\text { da disciplina. }\end{array}$ & $\begin{array}{l}\cdot \text { Estudo de estruturas } \\
\text { matemáticas. } \\
\text { - Currículo em } \\
\text { espiral. } \\
\text { - Aprendizagem por } \\
\text { descoberta. }\end{array}$ \\
\hline $\begin{array}{l}\text { Volta às bases } \\
\text { (praticamente não foi } \\
\text { considerada no } \\
\text { Brasil) } \\
\text { (Aprox. 1970s) }\end{array}$ & $\begin{array}{l}\text { Volta ao } \\
\text { conexionismo. }\end{array}$ & $\begin{array}{l}\text { Volta a preocupação } \\
\text { pelo conhecimento e } \\
\text { desenvolvimento de } \\
\text { habilidades. }\end{array}$ & $\begin{array}{l}\text { Volta ao aprendizado } \\
\text { de fatos por exercício } \\
\text { e prática. }\end{array}$ \\
\hline $\begin{array}{l}\text { Resolução de } \\
\text { problemas } \\
\text { (Aprox.1980s) }\end{array}$ & $\begin{array}{l}\text { - Construtivismo. } \\
\cdot \text { Psicologia } \\
\text { cognitiva. } \\
\cdot \text { Teoria } \\
\text { sociocultural. } \\
\text { (Vygotsky) }\end{array}$ & $\begin{array}{l}\text { Resolução de } \\
\text { problemas e } \\
\text { processos de } \\
\text { pensamento } \\
\text { matemático. }\end{array}$ & $\begin{array}{l}\cdot \text { Volta ao } \\
\text { aprendizado por } \\
\text { descoberta. } \\
\text { - Aprendizado de } \\
\text { Matemática para } \\
\text { resolução de } \\
\text { problemas. }\end{array}$ \\
\hline $\begin{array}{l}\text { Padrões, avaliação e } \\
\text { responsabilidade } \\
\text { (Aprox. } 1990 \text { até } \\
\text { hoje) }\end{array}$ & $\begin{array}{l}\text { Psicologia cognitiva } \\
\text { e } \\
\text { Teoria sociocultural. } \\
\text { vs } \\
\text { Ênfase renovada na } \\
\text { psicologia } \\
\text { experimental. } \\
\text { NCLB (ato } \\
\text { presidencial: } \\
\text { nenhuma criança } \\
\text { dever ser deixada } \\
\text { para trás). }\end{array}$ & $\begin{array}{l}\text { "guerras } \\
\text { matemáticas" } \\
\text { Preocupação pela } \\
\text { capacidade } \\
\text { matemática } \\
\text { individual. } \\
\text { vs } \\
\text { Preocupação pela } \\
\text { administração de } \\
\text { sistemas } \\
\text { educacionais. }\end{array}$ & $\begin{array}{l}\text { Currículos } \\
\text { desenvolvidos pelo } \\
\text { NSF }^{16} \text { baseados em } \\
\text { padrões orientados } \\
\text { para estudantes. } \\
\text { vs } \\
\text { Foco na preparação } \\
\text { de testes para } \\
\text { expectativas } \\
\text { especificadas pelo } \\
\text { Estado. }\end{array}$ \\
\hline
\end{tabular}

${ }^{16}$ NSF: National Science Foundation (Fundação Nacional de Ciência) 
As reformas pretendidas pelo NCTM continuam a ser trabalhadas embora a publicação Princípios e Padrões, 2000, estejam válidas. Hoje há grande preocupação em se saber como o aluno pensa - teorias cognitivas.

Desse modo, percebemos, ao analisar os livros, que essas mudanças ocorridas na educação americana influenciaram estudiosos brasileiros e consequentemente a Educação Matemática no Brasil.

Esses livros, a maioria deles apresenta Análise Combinatória no modo tradicional de ensino. Ou seja, de início, os conceitos são definidos pelo professor, seguidos de alguns exemplos e com uma possível aplicação num problema a ser resolvido pelo professor, não permitindo a participação dos alunos na construção desses conceitos, uma vez que os problemas para os alunos resolverem são oferecidos somente no final do capítulo. Antes de um problema ser colocado para os alunos, a matemática necessária para resolvê-lo já é trabalhada pelo professor, com a apresentação das fórmulas para posterior aplicação. O ensino é totalmente centrado no professor.

Com os olhares de hoje, percebemos a falta de um trabalho em Análise Combinatória que possibilite a participação dos alunos durante a resolução de uma situação-problema, que os levem "a pensar" e, sob a guia do professor, os faça coconstrutores desses conceitos e que lhes possa permitir a descoberta de uma estratégia adequada à resolução desse problema, levando-os ao processo de contagem dos agrupamentos formados.

Em alguns livros, mudando um pouco o ensino tradicional, há uma sequência didática, que se inicia com o Princípio Multiplicativo. Neles há vários problemas contextualizados, próprios para o professor poder motivar e incentivar seus alunos no estudo da Análise Combinatória.

Foi mais comum encontrar nesses livros o uso das fórmulas apresentadas logo no início do trabalho e com sua aplicação feita a partir delas, entretanto há alguns livros que procuram trabalhar na dedução das fórmulas, tornando o trabalho do professor mais significativo.

Nos livros que apresentam em anexo, um Manual para o professor, acreditamos que poderia haver um trabalho mais produtivo do professor em sua sala de aula, pois ele poderia seguir uma sequência didática construída de forma clara para trabalhar a Análise Combinatória.

No livro de Gentil et al (1996), utilizando-o como recurso didático, o professor poderia selecionar alguns problemas apresentados no final do capítulo, dando um maior 
destaque ao raciocínio combinatório e não somente ao uso da aplicação das fórmulas como apresentada pelos autores.

Observamos que, no livro de Lima et al (1998), não é apresentada a árvore de possibilidades e acreditamos que a ausência do uso dessa estratégia pode dificultar a não compreensão dos conceitos de Análise Combinatória pelos alunos. Os autores poderiam ter explorado de início a construção da árvore de possibilidades, possibilitando aos alunos a visualização dos agrupamentos encontrados. Em seguida, seria apresentado o Princípio Fundamental de Contagem. Desse modo, acreditamos que o aluno poderia compreender de modo mais significativo os conceitos de Análise Combinatória posteriormente apresentados.

Ainda, em Lima et al, as sugestões dos autores, de como resolver os exercícios propostos, podem ajudar os professores, que não souberem dar início ao trabalho, em sua preparação de aulas. Nesse mesmo livro, os autores apresentam estratégias e recomendações interessantes que podem auxiliar o professor no trabalho em sala de aula. Cabe ao professor, tendo o livro como guia, planejar outras estratégias e outros caminhos de resolução. Para um trabalho eficiente, que possa contribuir para uma aprendizagem com compreensão e significado sobre os conceitos de Análise Combinatória, pelos alunos, o professor poderia considerar e explorar estratégias mais simples como, por exemplo, o uso da árvore de possibilidades na resolução dos problemas.

Analisando o livro de Paiva (1999), encontramos muitos problemas contextualizados e motivadores, mas que são apresentados em grupos de mesmo tipo, depois da definição de cada conceito dado, o que evidencia o ensino de Matemática para resolver problemas. $\mathrm{O}$ professor poderia selecionar problemas, que levam a diferentes tipos de agrupamentos, para que o aluno possa perceber a diferença existente entre os diferentes conceitos de Análise Combinatória durante a resolução desses problemas.

No livro do Dante (2004), há vários problemas contextualizados, servindo para o professor motivar seus alunos no estudo dos conceitos de Análise Combinatória. Porém seria interessante que o professor adotasse uma metodologia adequada ao favorecimento do uso do livro didático, explorando a resolução do problema desde o início do tópico Análise Combinatória e não apenas como são deixados, pelo autor, para serem resolvidos pelo aluno no final do capítulo.

Ao adotar um livro como o Precalculus with limits: a graphing approach (2001), o professor poderia encontrar dificuldade em trabalhar pois, na resolução dos problemas, não são exploradas as técnicas de contagem, como, por exemplo, a árvore de possibilidades. A apresentação da fórmula é feita no início, o que pode impedir que o aluno compreenda os 
conceitos e fique apenas na mecanização. Há muitos problemas propostos, mas que são muito mais complexos quando comparados aos exemplos trabalhados no início do capítulo.

Nos livros SMSG ${ }^{17}$ (1964), Lima et al (1998) e Precalculus with limits: a graphing approach (2001), os autores não apresentam o conceito de arranjo, muito possivelmente porque o arranjo seja visto ora como combinação, ora como permutação, deixando a ideia de arranjo como uma conjugação desses dois conceitos.

Poucos desses livros apresentam os conceitos de permutação com repetição e arranjo com repetição. E quanto à combinação com repetição, dos livros analisados, apenas aparece esse conceito no de Lima et al (1998), no apêndice III do livro Prelúdio à Análise Combinatória (1975) e no de Roxo et al (1944). Pensamos que a ausência do conceito de combinação com repetição, na maioria dos livros, se deve ao fato de que ele aparece em situações não muito exploradas no cotidiano mas o não conhecimento desse conceito pode levar o aluno a uma concepção errônea, de que somente é possível pensar em combinação com elementos distintos.

Sobre a definição de Análise Combinatória, citamos algumas de diferentes autores:

- Denomina-se Análise Combinatória ao estudo da formação, contagem e propriedades dos agrupamentos que podem constituir-se, segundo determinados critérios, com os objetos de uma coleção. (ROXO et al, 1944, p.81)

- A Análise Combinatória é o ramo da Matemática que permite resolver problemas em que, basicamente, é necessário "escolher e arrumar" os objetos de um conjunto. (BACHX, POPPE e TAVARES, 1975, p.1)

- A Análise Combinatória visa ao desenvolvimento de métodos que permitem contar o número de elementos de um conjunto, sendo estes elementos agrupamentos formados sob certas condições. (HAZZAN, 1993, p.1)

- Análise Combinatória é o estudo de agrupamentos que podem ser formados com os elementos de um conjunto finito, seguindo leis prefixadas. (QUINTELLA, provavelmente década de 60,p.15)

Ao buscar o objetivo de se trabalhar Análise Combinatória podemos citar dois autores: - O objetivo principal da Análise Combinatória é a determinação do número de possibilidades de um dado evento ocorrer. (BIANCHINI e PACOLLA, 1993, p.321), pois como já foi dito na p.57, além de todos os trabalhos citados desde a Antiguidade sobre o desenvolvimento da Análise Combinatória, essa teoria se estruturou através do estudo da teoria das probabilidades,

${ }^{17}$ SMSG: School Mathematics Study Group (Grupo de Estudo em Matemática escolar). 
como se vê em Morgado et al (1991, p.06), "Em verdade, o desenvolvimento da Análise Combinatória deve-se em grande parte à necessidade de resolver problemas de contagem originados na teoria das probabilidades".

- O objetivo, ou seja, a finalidade principal em trabalhar Análise Combinatória é o de estabelecer métodos de contagem (PAIVA, 1999, p.250). Para nós, esse objetivo colocado se mostra vago, pois na p.59 deste nosso trabalho está escrito que: Porém, a Análise Combinatória não está relacionada apenas ao processo de simplesmente contar mas, explorando os conceitos de combinação, de arranjo e de permutação, onde o domínio desses conceitos permite resolver os problemas de contagem de certos tipos de subconjuntos de um conjunto finito, sem que seja necessário enumerar seus elementos.

Analisando as diferentes concepções dos autores, ao definir Análise Combinatória, percebemos que ela está relacionada com o método de contagem dos elementos de um conjunto, agrupando-os sob determinadas condições, ou seja, se os agrupamentos diferem pela ordem e/ou natureza dos elementos. Os autores usam vocabulários diferentes, mais formais ou não, ao definir Análise Combinatória, e podemos ver com evidência o processo de

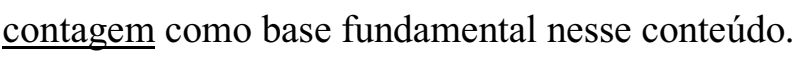

De um modo geral, ao analisar os livros didáticos, segundo nossa concepção de um trabalho significativo em sala de aula, podemos citar algumas dificuldades para isso e o que podemos considerar como contribuição ao trabalho com Análise Combinatória em sala de aula.

Dificuldades: a definição dos conceitos dada logo no início do trabalho; a ênfase atribuída à aplicação de fórmulas para resolver os problemas apresentados; o excesso de formalização, em muitos livros, possivelmente apoiados nas ideias do Movimento da Matemática Moderna; em alguns livros a existência de demonstrações provocando certa dificuldade para alguns professores na dedução das fórmulas.

Contribuições: na maioria dos livros, iniciar com o processo de contagem através do uso da árvore de possibilidades; em muitos livros a existência de problemas contextualizados; o fato de partir de problemas simples para outros mais complexos, buscando facilitar a compreensão dos conceitos da Análise Combinatória; trabalhar inicialmente com o Princípio Fundamental de Contagem, ou Princípio Multiplicativo, evitando o uso precoce de fórmulas; incluir tópicos da História da Matemática, buscando valorizar esse tópico matemático; e, em alguns livros, a apresentação da dedução das fórmulas, possibilitando, com os detalhes desenvolvidos, o entendimento, por parte de alguns alunos, dos passos seguidos durante as demonstrações feitas.. 
Após essa análise e refletindo sobre as informações obtidas, levantamos os seguintes questionamentos:

- Qual seria o livro escolhido para executar meu trabalho de pesquisa em sala de aula?

- Qual dos livros analisados seria possivelmente escolhido pelos professores de escola pública? E da escola particular?

- Seria possível colocar esses livros diretamente nas mãos dos alunos? Como reagiriam? Quão produtivo isso seria?

As respostas a esses questionamentos serão deixadas para reflexão dos leitores e, se possível por ocasião das conclusões que faremos no final desta dissertação.

\subsubsection{Documentos legais: A visão do ensino de Análise Combinatória ao} longo das reformas ocorridas no ensino de Matemática, no século XX.

Sabe-se que, nos últimos anos, a presença da história da Matemática na matemática escolar tem sido frequente, quer nos livros didáticos ou paradidáticos e nas propostas elaboradas por professores, por grupos de professores, por escolas ou por organismos governamentais que respondem pela confecção de diretrizes para os ensinos fundamental, médio e superior.

Como aceitar ou refutar essa inclusão da história na matemática escolar? Há quem a defenda e quem não a aceite. Como essas diferentes posições podem afetar o ensinoaprendizagem da Matemática nas escolas?

Nos Parâmetros Curriculares Nacionais (1998) - 3oe $4^{\circ}$ ciclos do Ensino Fundamental - Matemática, pode-se ler, na página 23:

Apresentada em várias propostas como um dos aspectos importantes da aprendizagem matemática, por propiciar compreensão mais ampla da trajetória dos conceitos e métodos da ciência, a História da Matemática também tem se transformado em assunto específico, um item a mais a ser incorporado ao rol dos conteúdos, que muitas vezes não passa da apresentação de fatos ou biografias de matemáticos famosos.

Fazendo uso da História da Educação Matemática, pode-se notar que Soares et al (2004) apresentam as mudanças ocorridas no século XX, tecnológicas, econômicas, políticas 
e sociais, que atingiram o campo da educação e, em particular, o ensino de Matemática. Essas mudanças tiveram influência no modo de ensinar, nos conteúdos a serem ministrados, na relação entre professor e aluno, entre outros aspectos da educação matemática.

Uma maneira de se ensinar a História da Matemática como um conteúdo específico, contribuiria pouco para o processo de ensino-aprendizagem da Matemática.

No Brasil, de uma maneira forte, essa posição da história da Matemática, fazendo parte de momentos de descontração na sala de aula, foi assumida quando propostas de um movimento de renovação da educação, iniciado nas primeiras décadas do século XX, provocaria o movimento conhecido como "Movimento da Escola Nova".

Nesse momento, encontraríamos, talvez pela primeira vez, uma manifestação explícita em propostas oficiais sobre a importância da História da Matemática para a formação dos alunos das séries do então chamado ensino secundário - o que corresponde, na atualidade, às quatro últimas séries do Ensino Fundamental e às três séries do Ensino Médio. Essa manifestação encontra-se nas instruções pedagógicas da Reforma do Ensino Secundário apresentada pelo Primeiro Ministro do Ministério de Educação e Saúde, Francisco Campos, através do Decreto n.19890 de 18 de abril de 1931, consolidada pelo Decreto n.21241, de 4 de abril de 1932, que contemplaram, no que se refere ao processo de ensino-aprendizagem, o ideário do Movimento da Escola Nova. (MIGUEL; MIORIM, 2004, p.17)

\section{Esses mesmos autores citam também que}

Alguns autores de livros didáticos produzidos, nos últimos anos da década de 1920 e no início da década de 1930, que assumiram as modernas orientações apresentadas pela Reforma Campos, incorporaram elementos de história em suas obras. Uma obra que merece ser destacada é intitulada Mathematica, inicialmente de autoria de Cecil Thiré e Mello e Souza e, posteriormente, também de Euclides Roxo. (p.17)

No artigo Ensino de matemática no século XX - da Reforma Francisco Campos à Matemática Moderna (2004), de Soares et al, referindo-se às atuações de Euclides Roxo, dizem:

As idéias de Euclides Roxo diziam respeito basicamente à fusão dos diferentes ramos da matemática, interligando-os em uma única disciplina à reestruturação de todo o currículo em torno do conceito de função e à introdução de noções de cálculo diferencial e integral para todos os alunos do secundário. $\mathrm{Na}$ verdade, ele estava muito bem informado de todas as discussões sobre o ensino da matemática que ocorriam, em maior ou menor grau, em vários países importantes do mundo. Além disso, estava a par de todas as atividades desenvolvidas pelo $\operatorname{Imuk}^{18}$, criado em abril de 1908 no

\footnotetext{
18 IMUK (Internationale Mathematische Unterrichtskommission/ CIEM: Comissão Internacional de Ensino de Matemática).
} 
Quarto Congresso Internacional de Matemática, visando reunir esforços para a renovação do ensino da matemática. As principais influências sofridas pelo professor Euclides Roxo originaram-se de Felix Klein, com relação às idéias por ele defendidas, e de Ernst Breslich, na elaboração dos compêndios de acordo com as novas diretrizes.

Sintetizando, o professor Euclides Roxo tirou proveito da posição que ocupava na estrutura educacional do país, a qual the proporcionava condições de fazer valer suas idéias, e implementou integralmente, pelo menos na lei, "de cima para baixo" e sem discussões prévias, todas as inovações defendidas por Felix Klein, que havia tentado o mesmo na Alemanha. (2004, p.8)

Ainda sobre as mudanças ocorridas no ensino secundário, Valente (2003) relatou que:

A década de 20 irá viver o clima do 'entusiasmo pela educação', cujo significado é a crença de que, pela multiplicação das instituições escolares, da disseminação da educação escolar, será possível incorporar grandes camadas da população no rumo do progresso nacional; e do 'otimismo pedagógico', representado pela crença de que o escolanovismo daria conta da verdadeira formação do novo homem brasileiro. (NAGLE, 1974, p.99, apud VALENTE, 2003, p.64)

(...)

Mas, o que seria modernizar o ensino de matemática no secundário? Ao que parece, a resposta que procurou ser dada incorre nas mesmas práticas anteriores: adaptar de alhures, dos países considerados referência, dos países que buscaram modernizar a educação, programas de ensino e, sobretudo, livros didáticos. (VALENTE, 2003, p.64)

(...)

Os reformadores incluem também a tarefa de reorganizar os programas de ensino que consideravam sobrecarregados. (VALENTE, 2003, p.65)

Esse mesmo autor relata que, em 1929, as ideias modernizadoras expressam-se no programa de ensino do $1^{\circ}$ ano. Sob o título único de Matemática, o programa busca uma integração de conteúdos da aritmética, álgebra e geometria (Valente, 2003, p.75). A proposta de Roxo - contida no manual de Breslich - rompe então com a apresentação separada dos conteúdos de aritmética, álgebra e geometria e traduz a intenção dos novos programas do Pedro II. (VALENTE, 2000b, apud VALENTE, 2003, p.78)

Assim, as décadas de 20 e 30, do século XX, presenciaram profundas inquietações educacionais e reformas substanciais no ensino brasileiro. Aumentavam as tensões entre uma estrutura voltada para a formação humanista desinteressada das elites e as necessidades de uma sociedade em processo de industrialização e urbanização. É necessário salientar que a atuação bem sucedida de Euclides Roxo, no sentido de implantar seu movimento reformador do ensino de Matemática, dificilmente teria tido sucesso sem um regime centralizador e autoritário no país, de 1930-1945. (VALENTE, 2003, p.94) 
Valente (2003, p.95) cita que, segundo Miorim, a proposta de reforma dos currículos de Matemática do Colégio Pedro II foi homologada pelo Conselho Nacional do Ensino e institucionalizada pelo Decreto 18564 de 15 de janeiro de 1929.

Uma outra mudança no ensino secundário se deu durante a atuação do sucessor de Francisco Campos, o ministro Gustavo Capanema, como é apresentado a seguir:

Em 1934, Gustavo Capanema (1900-1985) assume o Ministério da Educação e Saúde. Em 1936, inicia os trabalhos para a elaboração do Plano Nacional de Educação, previsto pela Constituição de 1934, que seria elaborado pelo Conselho Nacional de Educação e abrangeria todos os graus de ensino. Com o objetivo de recolher informações e estudos para a elaboração desse plano, Gustavo Capanema distribuiu um questionário, em que inquiria sobre aspectos do ensino. Uma questão que despertou interesse dos educadores na época foi sobre a orientação que deveria ser dada ao ensino secundário. Para debater esse problema, a Associação Brasileira de Educação, entre maio e agosto de 1937, promoveu uma série de conferências sobre a temática. Entre os conferencistas estava Euclides Roxo. (SOARES et al, 2004, p.10)

Valente (2003, p.145) relata sobre a importante participação do matemático Euclides Roxo na Reforma Capanema que, ao contrário da Reforma Campos, está abundantemente documentada no Arquivo Gustavo Capanema da Fundação Getúlio Vargas, no Rio de Janeiro, onde se encontra uma pasta dedicada exclusivamente à reforma empreendida por Capanema.

Essa reforma, que ficou conhecida como Reforma Capanema, permaneceu em vigor até 1961, com a aprovação da Lei de Diretrizes Bases da Educação Nacional, lei 4024, de dezembro de 1961. Apenas um reajustamento dos programas foi feito em 1951. E foi também na década de 60 que mudanças significativas ocorreram no ensino de matemática, com a chegada ao Brasil do movimento da "Matemática Moderna"". (SOARES et al, 2004, p.11)

O Movimento da Matemática Moderna não foi implantada por nenhum decreto, ao contrário das reformas anteriores. Mas, esse fato não impediu que fosse adotada nas instituições de ensino. Pelo contrário, é a reforma de ensino mais conhecida e lembrada em todo o território nacional. Uma das principais características dessa reforma foi a ênfase dada à teoria dos conjuntos que, dentre outros fatores, como a não preparação dos professores, teria levado ao fracasso do movimento. Apesar de não ter atingido a melhora no ensino de matemática, houve uma grande mobilização dos professores, pois começaram a refletir sobre sua prática docente e sobre os verdadeiros propósitos do ensino de matemática.

\footnotetext{
19 Para o matemático americano Morris Kline (1976), a adoção da expressão Matemática Moderna era pura propaganda e os termos moderno e novo não se justificavam uma vez que, em geral, os novos currículos ofereciam uma nova abordagem da Matemática Tradicional. Mas, de uma forma ou de outra, a expressão passou a ser largamente usada e divulgada até hoje. (SOARES et al, 2004, p.12)
} 
Com base na experiência malsucedida com a Matemática Moderna, alternativas para o ensino de matemática como os Parâmetros Curriculares Nacionais começaram a surgir, reforçando a importância de se reavaliar os objetivos da disciplina, mas sem propor soluções milagrosas e rápidas para o ensino. (SOARES et al, 2004, p.13)

Como aparece no quadro da página 99 desta nossa pesquisa, após o Movimento da Matemática Moderna, no fim dos anos 70, no mundo inteiro Resolução de Problemas ganhou espaço. Seu objetivo era, ao trabalhar com os alunos, a volta ao aprendizado por descoberta e o aprendizado de Matemática necessária para a resolução de problemas, centrando o ensino no uso de diferentes estratégias. Entretanto, na literatura em Resolução de Problemas, já em 1944 aparecem trabalhos de George Polya. Polya com seu livro How to solve it, começou o movimento a favor do ensino de e com resolução de problemas.

Em 1980 é editada, nos Estados Unidos, uma publicação do NCTM National Council of Teachers of Mathematics - An Agenda for Action: Recommendations for School Mathematics of the 1980's, que chamava todos os interessados, pessoas e grupos, para juntos, num esforço cooperativo massivo, buscar uma melhor educação matemática para todos. (ONUCHIC, 1999, p.204)

E ainda,

No final da década de 1980, a Resolução de Problemas como uma arte e como um objetivo é questionada por pesquisadores do mundo inteiro, Os Parâmetros Curriculares Nacionais chamaram a atenção para o documento "Uma Agenda para a Ação" dizendo que suas idéias influenciaram as reformas ocorridas em todo o mundo e que muitos pontos de convergência foram constatados nas propostas levantadas no período 1980/1995. (ONUCHIC, 1999, p.205)

Dessa forma vamos apresentar como a Análise Combinatória é abordada nos documentos legais no Brasil, cientes de que muito dessas reformas influenciaram na estruturação e na organização desses documentos.

Nos Parâmetros Curriculares Nacionais do Ensino Médio (1999), verificamos a preocupação da integração da Análise Combinatória com aplicações do mundo real:

As habilidades de descrever e analisar um grande número de dados, realizar inferências e fazer predições com base numa amostra de população, aplicar as idéias de probabilidade e combinatória a fenômenos naturais e do cotidiano são aplicações da Matemática em questões do mundo real que tiveram um crescimento muito grande e se tornaram bastante complexas. Técnicas e raciocínios estatísticos e probabilísticos são, sem dúvida, instrumentos tanto das Ciências da Natureza quanto das Ciências Humanas. Isto mostra como será importante uma cuidadosa abordagem dos conteúdos 
de contagem, estatística e probabilidade no Ensino Médio, ampliando a interface entre o aprendizado da Matemática e das demais ciências e áreas. (PCN - Ensino Médio, 1999, p.15)

A seguir, apresentaremos o que consta, nas Propostas Curriculares de Matemática para o $2^{\underline{o}} \operatorname{grau}^{20}$, do estado de São Paulo, sobre o conteúdo Análise Combinatória. A primeira Proposta data de 1986 e tivemos acesso às $2^{\underline{a}}$ e $3^{\underline{a}}$ edições, de 1989 e de 1992 respectivamente, sendo que a segunda Proposta está vigente e foi implementada em 2008.

A Proposta Curricular, de 1989, descreve como ela foi elaborada e conta como ocorreram as mudanças curriculares até então. No final de 1983 implantou-se o ciclo básico, com o Decreto 21833, de 21/12/1983, que dava, às escolas do $2^{\circ}$ grau do Estado, a possibilidade de reformular suas grades curriculares. Tal reformulação deveria ser feita a partir de uma proposta educacional da escola, formulada em consonância com as diretrizes para a implantação da Lei 7044/82, que retirava deste grau de ensino a obrigatoriedade da profissionalização (SÃO PAULO,1989, p.8). Desse modo, as escolas sentiram a necessidade da elaboração de uma nova Proposta Curricular, objetivando reorganizar a distribuição das disciplinas e, em particular, a de Matemática.

A distribuição dos conteúdos nessa Proposta foi feita, separadamente, para as escolas com 2 ou 3 aulas semanais e para aquelas com 4 ou 5 aulas semanais, em cada série. Nos deteremos apenas na $2^{-\mathrm{a}}$ série - EM, onde aparece Análise Combinatória. Como conteúdo proposto para as escolas com 2 ou 3 aulas semanais: Análise Combinatória; Probabilidade; e Geometria; e, para as escolas com 4 ou 5 aulas semanais: Trigonometria; Análise Combinatória; Probabilidade; e Geometria. Os autores dessa proposta chamam a atenção dizendo que o aprofundamento dos conteúdos propostos, bem como a introdução de novos conteúdos dependerá sempre da disponibilidade e da necessidade da clientela (1989, p.16).

O objetivo geral ao trabalhar Análise Combinatória, apresentado por essa proposta, é o de desenvolver o raciocínio combinatório, tendo em vista: a familiarização do aluno com problemas que envolvem contagem; a sistematização da contagem; a sistematização dos conceitos de Arranjo, Permutação e Combinação Simples. Nela são apresentadas algumas sugestões, na página 29 , com o trabalho a ser desenvolvido com os alunos:

- os primeiros contatos com o raciocínio combinatório deverão ser intuitivos, com discussões livres, proporcionando ao aluno oportunidade de apontar caminhos para solucionar os problemas, que o motive a desenvolver técnicas sistematizadas para a descrição dos casos possíveis, bem como para sua contagem.

\footnotetext{
${ }^{20}$ Atual Ensino Médio
} 
- a introdução de sistemáticas para a formação de agrupamentos, bem como para sua contagem, sem necessidade da descrição de cada caso. A árvore de possibilidades ou tabelas de dupla entrada são instrumentos cujo apelo visual favorece a compreensão do processo da construção dos agrupamentos, esse processo deve preceder o problema da contagem, uma vez que não se recomenda quantificar uma variedade de situações sem o domínio claro de seu processo de criação. Decorrente desse processo, o aluno terá indicações para o desenvolvimento de técnicas como o Princípio Multiplicativo, que no início deverá se apreendido intuitivamente e não de forma memorizada.

- O Princípio Multiplicativo ocupa posição de extrema importância em qualquer técnica de contagem, estando quase sempre associado a situações do tipo "cada elemento de um conjunto A pode ser combinado com todos os elementos de um conjunto B". Ao trabalhar desse modo com os alunos, esse fato favorece a ampliação do conceito de multiplicação. Nessa fase, os alunos se apropriam das ideias que compõem os conceitos de Arranjos, Permutações e Combinações Simples, sem formalizar qualquer um deles.

- a sistematização desses conceitos tem como base as ideias de sequência e subconjunto, subjacentes aos conceitos de Arranjos e Combinações, respectivamente.

Os autores da proposta apresentam problemas, no início do trabalho, com diferentes resoluções para cada um e com explicações dadas com detalhes. A dedução das fórmulas, para permutação, arranjo e combinação, é apresentada durante a resolução dos problemas. $\mathrm{O}$ documento Subsídios para a implementação da proposta curricular de Matemática para o $2^{\circ}$ grau diz que o hábito de adivinhar a fórmula adequada, para resolver um problema de combinatória, deve ser, portanto, substituído por um trabalho de análise e sintese. (SÃO PAULO, 1980, p.81).

Na Proposta Curricular do Estado de São Paulo (2008, p.58), consta o conteúdo de Análise Combinatória no $3^{\mathrm{o}}$ bimestre da $2^{\mathrm{a}}$ série do Ensino Médio. É apresentado, junto com o de probabilidade, em um quadro: 


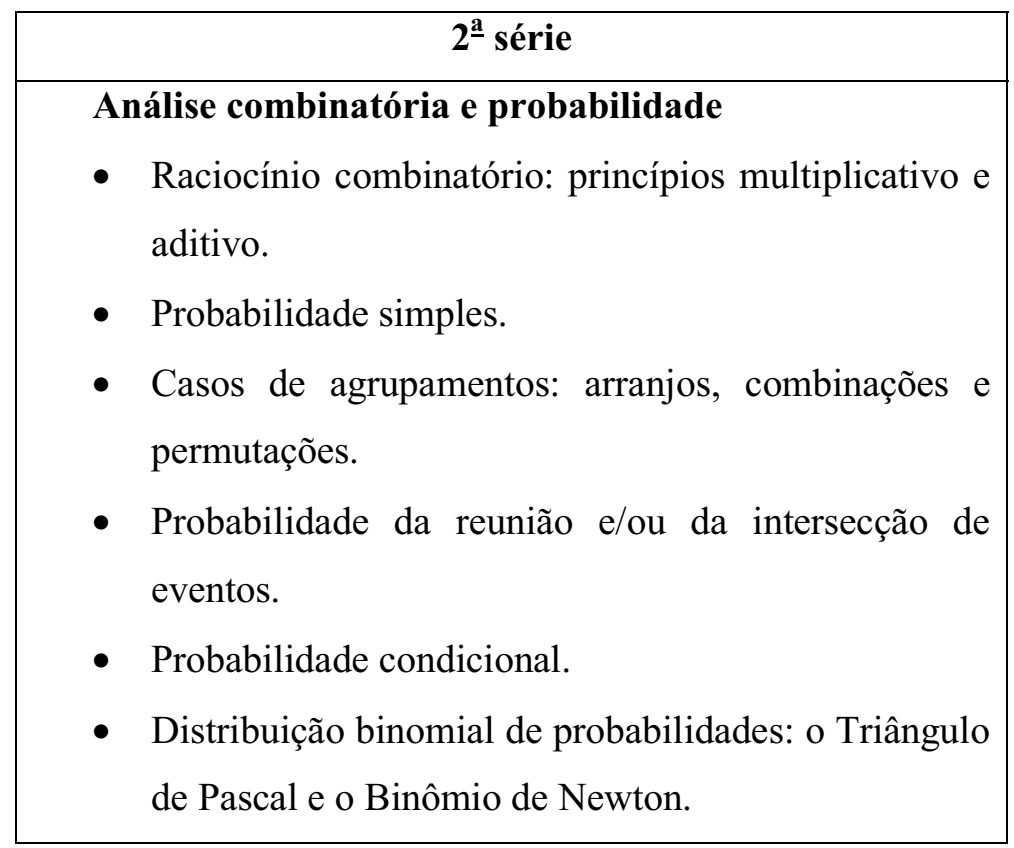

O Caderno do Professor - Matemática, da $2^{\underline{a}}$ série do Ensino Médio, do $3^{\underline{o}}$ bimestre de 2008, apresenta uma orientação geral para o professor sobre os conteúdos acima propostos. São divididos em quatro situações de aprendizagem: Probabilidade e proporcionalidade: no início era um jogo...; Análise Combinatória: raciocínios aditivo e multiplicativo; Probabilidades e raciocínio combinatório; e Probabilidades e raciocínio combinatório: o binômio de Newton e o triângulo de Pascal.

Na segunda situação de aprendizagem destacamos o seguinte:

A solução de situações-problema envolvendo simultaneamente raciocínio combinatório e o cálculo de probabilidades costuma acarretar dificuldades maiores do que aquelas em que se aplicam esses conteúdos de maneira independente. Dentre as diversas justificativas possíveis, podemos enunciar o fato de que as características conjuntas desses conteúdos impedem que os problemas possam ser facilmente agrupados em tipos-padrão, de maneira que resolver um deles sempre passe pela mobilização da estratégia de raciocínio que o associa a algum anteriormente resolvido e compreendido, como ocorre, mais facilmente, com problemas de outros grupos de conteúdos matemáticos. Essa impossibilidade de padronização exige, mais do que em outros casos, que os alunos mobilizem diversas estratégias de raciocínio. Cabe, portanto, ao professor estimular a resolução de diversos problemas de Análise Combinatória e Probabilidade com o foco voltado para o tipo de raciocínio exigido, em vez da clássica separação em problemas típicos, baseada no tipo de operação matemática envolvida. (SÃO PAULO, 2008, p.10) 
Os autores dizem, na página 22, que a Análise Combinatória trata dos problemas que envolvem a contagem de casos em situações de agrupamentos de determinado número de elementos. Citam que para resolver os problemas são necessárias uma ou mais operações elementares entre números naturais: adição, subtração, multiplicação e divisão. Chamam a atenção para a importância da representação da resolução do problema por intermédio de desenho e/ou diagramas e/ou tabelas. Por exemplo, a árvore de possibilidades em que, através dela, os alunos podem ilustrar os dois principais tipos de raciocínio envolvidos na Análise Combinatória: o raciocínio aditivo e o raciocínio multiplicativo. Priorizam a resolução de problemas logo ao iniciar o conteúdo, ao invés de fazer uso da aplicação de fórmulas. A dedução das fórmulas é realizada durante a resolução de alguns problemas. Apresentam poucos problemas e esses são simples e contextualizados, visando à compreensão dos alunos.

Um critério é adotado para a apresentação dos conceitos: o fato de que há agrupamentos em que a ordem entre seus elementos deve ser respeitada; e há agrupamentos onde, num agrupamento formado, em que a ordem dos elementos pode ser alterada sem que, por isso, conduza a um novo agrupamento, diferente do anterior, referindo-se respectivamente aos conceitos de arranjos e de combinações simples. Trabalham, ainda, o conceito permutação com uma apresentação de problemas da categoria denominada "formação de filas", ou seja, problemas que envolvem agrupamentos ordenados de elementos. Por um lado, reforçar a mobilização do raciocínio multiplicativo e, por outro, apresentação do número fatorial (n!) como o fator que nos dá a quantidade das diferentes ordenações em um agrupamento de $n$ elementos.

Neste ano de 2009, foi dada continuidade ao trabalho previsto nesta proposta nas escolas públicas. Diferentemente do ano anterior, os alunos receberam, em cada bimestre, o Caderno do aluno, com todas as atividades propostas a serem desenvolvidas em sala de aula e também atividades extraclasse. 


\subsubsection{Resolução de Problemas}

Desde a Antiguidade até o tempo presente, a Matemática desempenhou um papel importante no desenvolvimento da sociedade. Sem dúvida, o papel que ela desempenha hoje é muito mais significativo do que em qualquer época anterior e promete se tornar muito mais significativo no futuro.

Estamos vivendo numa sociedade do conhecimento. Manda mais aquele que detém esse conhecimento e nele está incluído fortemente o conhecimento matemático. Assim, a Educação Matemática tornou-se questão de grande interesse e, em muitos espaços, a Educação Matemática é debatida acaloradamente. Entretanto, muitos dos argumentos e práticas que pedem atenção hoje se parecem muito àqueles do passado.

O mundo está se tornando mais matemático. Decisões, frequentemente tomadas, tentam ser benéficas aos trabalhos desenvolvidos pela Educação Matemática. Mas falhas no processo de ensino-aprendizagem de Matemática não permitem obter, com sucesso, um bom ensino e consequentemente uma boa aprendizagem.

O objetivo dos professores de matemática deveria ser o de ajudar as pessoas a compreender a matemática e encorajá-las a acreditar que é tão natural quanto agradável saber usar e compreendê-la. Assim, é importante que a forma de ensinar Matemática deveria proporcionar aos estudantes um modo natural e agradável de ver a Matemática.

A quantidade de matemática que os alunos devem aprender durante sua vida escolar cresce sem parar e o desenvolvimento dessa ciência também. A ideia de que estudar matemática torna as pessoas mais lógicas vem desde o tempo de Platão. Outros filósofos também foram responsáveis pelas mudanças ocorridas em educação no mundo.

O quadro, apresentado por nós na página 86 , mostrou quantas reformas no ensino de Matemática ocorreram no século XX, desde um excesso de repetição até a resolução de problemas como metodologias de ensino.

Problemas têm ocupado um lugar central no currículo da matemática escolar desde a Antiguidade, mas resolução de problemas não. Somente recentemente, educadores matemáticos têm aceitado a ideia de que o desenvolvimento da habilidade em resolver problemas merece atenção especial. (STANIC, KILPATRICK, 1989, p.01)

Onuchic (1999, p.203) ressalta que a importância dada à Resolução de Problemas é recente e somente nas últimas décadas é que os educadores matemáticos passaram a aceitar a 
ideia de que o desenvolvimento da capacidade de se resolver problemas merecia mais atenção.

Apresentaremos, a partir do que entendemos por problema, um panorama sobre resolução de problemas, destacando a gênese da pesquisa em resolução de problemas; as diferentes concepções sobre resolução de problemas no processo de ensino-aprendizagem de Matemática; e a resolução de problemas como metodologia de ensino.

Diante desse quadro teórico, teremos respaldo para justificar e mostrar a importância da resolução de problemas nesta pesquisa e apresentar nossa concepção sobre resolução de problemas adotada para este trabalho.

\subsubsection{História da Pesquisa em Resolução de Problemas}

A existência de problemas emerge desde as antigas civilizações. Problemas matemáticos, encontrados na história antiga: egípcia, chinesa e grega, são ainda apresentados, da mesma forma, em livros-texto de matemática dos séculos XIX e XX, com a mesma ênfase. A ideia é a mesma. Alguém cria um problema, resolve-o, apresenta sua solução e oferece uma lista de problemas do mesmo tipo para serem resolvidos da mesma forma. Com essa abordagem, não se exige do resolvedor a criação de estratégias para a resolução do problema, ele "aprende" mecanicamente o que lhe é "ensinado", não aprende a pensar.

Da antiga civilização egípcia, é conhecido um famoso documento que contém uma coleção de problemas, o Papiro de Rhind ou de $\mathrm{Ahmes}^{21}$ que mede $5 \mathrm{~m}$ de comprimento e $0,30 \mathrm{~m}$ de largura. Para a resolução dos problemas, os egípcios utilizavam regras, como aquela do conhecido "método da falsa posição". Por exemplo, no problema 25 do Papiro de Ahmes constava o seguinte enunciado: "Um número mais sua metade somam 16. Qual é esse número?".

Como eles teriam resolvido esse problema?

Usando o método da falsa posição, eles devem ter pensado: se o número fosse 2, a soma dele mais sua metade daria 3. Mas a soma do número mais sua metade, no problema dado, dá 16.

\footnotetext{
${ }^{21}$ Ahmes é o nome do escriba que encontrou um antigo documento em 1650 a.C.. Sabe-se que Henry Rhind, um escocês que o comprou em 1858.
} 
Então, supunham um valor para esse número desconhecido: $\mathrm{x}$, tal que, na metade do número ficasse um número inteiro para facilitar os cálculos. Assim, no caso de $\mathrm{x}=2$, obtinham como resultado 3. Mas, para o valor suposto $\mathrm{x}, \mathrm{x}$ mais sua metade, teria que ser igual a 16. Desde que já conheciam proporcionalidade, os valores de x e 2 e os valores dos resultados 16 e 3 , permitiam-lhes pensar que $\frac{2}{x}=\frac{3}{16}$ e, então $3 x=32, x=\frac{32}{3}$ que é a solução do problema.

Com recursos atuais, o problema se apresenta assim: $x+\frac{x}{2}=16$.

$$
\begin{aligned}
& \text { Se } x=2,2+\frac{2}{2}=2+1=3 \\
& \text { e, para } x=x, \quad x+\frac{x}{2}=16,
\end{aligned}
$$

Então a igualdade $\frac{2}{x}=\frac{3}{16}$ pode ser identificada como uma proporção onde vale o princípio do produto cruzado. Assim, $3 x=32, x=\frac{32}{3}$.

Os problemas encontrados no documento "Qui Chang suan Shu" ("Nove Capítulos sobre a arte matemática"), de 250 a.C., referem-se à agricultura, mensuração de terras, sociedades, engenharia, impostos, cálculos, solução de equações e propriedades do triângulo retângulo. Como exemplo, pode-se apresentar o seguinte problema, tirado do trabalho de Baraldi (1994, p.4): Aquele que tem 10 áreas de plantio, 2 filhos e colheu 20 sacos de arroz pagará 1 de imposto, enquanto que aquele que tem 20 áreas de plantio, 4 filhos e colheu 30 sacos de arroz pagará ...

Esse caso não é de proporcionalidade pois uma proporção é uma igualdade entre duas razões e uma razão é uma comparação multiplicativa entre duas grandezas e o artifício da regra de três, ou produto cruzado, não se aplica.

Na obra de Diofanto ( \pm 250 d.C.) há uma coleção de 150 problemas. Um deles pede para

Encontrar dois números tais que sua soma seja 20 e a soma dos quadrados desses números seja 208.

Uma resolução para esse problema, com recursos de hoje, seria:

Designando esses números por $(10+x)$ e $(10-x)$, uma vez que sua soma é 20, tem-se: 
$(10+x)^{2}+(10-x)^{2}=208$

Resolvendo essa equação, chega-se a $x^{2}=4$ e, então, $x=2$ ou $x=-2$.

Os gregos consideravam apenas o valor positivo pois, na época, não se conheciam os negativos. Então, para eles só valia $\mathrm{x}=2$. Não havia outro valor.

Assim, os números procurados são $10+2=12$ e $10-2=8$.

Outro método que poderia ser utilizado para resolver esse problema seria, por exemplo, montar o sistema de equações $\left\{\begin{array}{l}x+y=20 \\ x^{2}+y^{2}=208\end{array}\right.$ e resolvê-lo pelo processo de adição, substituição, ou comparação.

Usando o processo de substituição: tirando, da primeira equação, $x=20-y$ e substituindo na segunda $(20-y)^{2}+y^{2}=208$, chegando-se a $\quad x=12$ e $\quad y=8$.

Mas, o que é um problema?

Para Polya (1962),

a palavra "problema" será considerada num significado bastante abrangente (...) Ter fome não é usualmente um problema na vida moderna. Se tenho fome em casa, pego alguma coisa na geladeira, ou vou a uma lanchonete, ou a algum outro lugar se estou na cidade. É uma questão diferente, entretanto, quando a geladeira está vazia ou acontece de eu estar na cidade sem dinheiro; nesse caso, ter fome torna-se um problema. Em geral, um desejo pode ou não levar a um problema. Se o desejo traz à minha mente imediatamente, sem qualquer dificuldade, alguma ação óbvia que seja provavelmente a de alcançar o objeto desejado, não há problema. Se, entretanto, nenhuma ação me ocorre, há um problema. Assim, ter um problema significa: procurar conscienciosamente alguma ação apropriada para atingir um fim claramente concebido, mas não imediatamente atingivel. Resolver um problema significa achar tal ação. (p.117)

As autoras Vale e Pimentel (2004) apresentam uma concepção de problema, relatando uma ideia semelhante àquela apresentada por Polya,

Definir problema é um propósito difícil, já que uma determinada situação pode ser um problema para um dado indivíduo, num dado momento, e para o mesmo indivíduo, num outro momento, ser apenas um exercício ou um fato específico. Podemos assim concluir que existe um conjunto de fatores inerentes ao indivíduo e à própria tarefa, além de outros, que vão condicionar quer à sua caracterização quer ao seu desempenho. Das várias definições de problema podemos retirar que um problema é uma situação para a qual não se dispõe, à partida, de um procedimento que nos permita 
determinar a solução, sendo a resolução de problemas o conjunto de ações tomadas para resolver essa situação. (VALE; PIMENTEL, 2004, p.12)

Já Marincek (2001) apresenta a concepção de que

Problema é toda situação em que os alunos necessitam pôr em jogo tudo o que sabem, mas que contém também algo novo, para o qual ainda não tem resposta e que exige a busca de soluções. É nesse movimento de busca de soluções que se estabelecem novas relações e se constroem conhecimentos que modificam os anteriores. (p.15)

Onuchic (2004) mostra a definição de problema dada por Van de Walle e também sua concepção

Para Van de Walle (2001), muitas vezes se fala em trabalhar com problemas para se ensinar Matemática sem ter uma idéia clara do que é um problema. Há muitas diferentes concepções de problema. Para nós, é tudo aquilo que não sabemos fazer mas que estamos interessados em fazer. Para ele, um problema é definido como qualquer tarefa ou atividade para a qual os estudantes não têm métodos ou regras prescritas ou memorizadas, nem a percepção de que haja um método específico para chegar à solução correta. (p.221)

No livro Teaching Mathematics through Problem Solving, grades K-6, NCTM (2003), a autora Lambdin, num artigo desse livro, na página 7, diz que um problema é, por definição, uma situação que causa desequilíbrio e perplexidade.

Para Dante (1989, p.9), problema é qualquer situação que exija o pensar do indivíduo para solucioná-la. Para nós, numa ampliação dessa colocação, dizemos que além de não saber resolver o problema, o aluno deve estar interessado em resolvê-lo.

Ao falar sobre os problemas na Antiguidade e sobre a maneira de se trabalhar com eles desde essa época até hoje, são encontrados, em livros-texto de Matemática dos séculos XIX e XX, problemas tratados com o mesmo enfoque. Stanic e Kilpatrick (1989) disseram que o ponto importante a ser considerado, nos exemplos desses livros-texto, é que neles é assumida uma visão bastante limitada de aprendizagem em resolução de problemas. Até hoje, podemos perceber nos livros atuais que ensinar com resolução de problemas significa apresentar problemas, talvez incluindo uma técnica especifica para a busca da solução, como modelo a ser seguido para a resolução de outros problemas do mesmo tipo. Stanic e Kilpatrick (1989) citam um problema, num livro de 1987, que, ao tentar mostrar habilidades de alunos com resolução de problemas, mostra, utilizando como estratégia: fazer uma figura onde, 
procurando analisar as informações dessa figura e marcando cuidadosamente os dados do problema, poder depois perceber as operações necessárias para a sua resolução. Após todo esse trabalho, apresentar novos problemas semelhantes para serem resolvidos.

Os primeiros indícios de reflexão sobre o processo de resolução de problemas apareceram com o trabalho de Pappus, por volta de 300 d.C., em sua obra "Collectiones" (no livro VII), onde ele descreve sobre a heurística, que chamou de analyomenos, que quer dizer a arte de investigar, de descobrir. No século XVII surgem tentativas de sistematização da heurística: a de Descartes e a de Leibniz; no século XVIII a de Clairaut e ainda a de Bolzano, até meados do século XIX. Porém, tais tentativas nunca se aproximaram da sala de aula. (BARALDI, 1994, p.6)

Concordando com Onuchic (1999), resolver problemas parece que sempre foi um desafio para alunos e professores, devido aos métodos utilizados enfatizarem a repetição e a mecanização da resolução de problemas. Embora as reformas de ensino propostas no século XX: o ensino de matemática por repetição, o ensino de matemática com compreensão, a Matemática Moderna e a Resolução de Problemas, em suas três vertentes, tenham proposto novos rumos de um trabalho mais produtivo, o professor nunca foi chamado a participar da elaboração dessas reformas. Mostra-se o que os professores devem fazer somente na hora de sua implementação, não os deixando preparados para atender bem suas recomendações.

As primeiras pesquisas sobre Resolução de Problemas iniciaram-se sob a influência de George Polya (1888-1983), da Universidade de Stanford-EUA, que discutiam sobre heurísticas, de modo a que os professores pudessem entender e saber usar corretamente o processo de resolução de problemas. No livro How to Solve It (traduzido por A Arte de Resolver Problemas), 1994, com $1^{\text {a }}$ ed. em 1945, Polya apresenta um método de trabalho desenvolvido em quatro etapas para a resolução de problemas: $1^{\circ}$ ) compreender o problema, lendo-o e interpretando-o; $2^{\circ}$ ) elaborar um plano, $3^{\circ}$ ) executar o plano, $4^{\circ}$ ) fazer o retrospecto ou verificação da solução encontrada no problema original. Polya desenvolve um processo heurístico ao longo da resolução de problemas. Chegar à solução de um problema não é o único objetivo que ele propõe. O aluno deveria, ao longo do processo de resolução do problema, descobrir por si mesmo, com ajuda e guia do professor, o significado dos conceitos matemáticos envolvidos. Para ele, era fundamental "ensinar o aluno a pensar". Baraldi (1994, p.6) cita que Polya acreditava que o ensino da Matemática deveria abarcar os aspectos principais do pensamento envolvido na descoberta da Matemática e isso se deve ao fato do grande interesse em discutir-se sobre as condições do descobrimento científico. Mas o 
trabalho, desse autor, procura fixar algumas regras, apresentando estratégias que podem levar à solução do problema.

Entretanto, esse não é o enfoque dado à nossa pesquisa, pois nela pretendemos ensinar matemática através da resolução de problemas, isto é, enquanto os alunos estão envolvidos com a busca de uma estratégia que os leve à solução.

A reforma pretendida com Resolução de Problemas passou por várias modificações, sendo que o NCTM apresentou, em 1980, o documento "An Agenda for Action" (Uma Agenda para Ação), constando nela, na página 2, recomendações para a matemática escolar a ser desenvolvida nos anos oitenta. A primeira dessas recomendações era: Resolução de problemas deve ser o foco da matemática escolar nos anos oitenta, dizendo, também, que

O desenvolvimento da habilidade em resolução de problemas deveria direcionar os esforços dos educadores matemáticos ao longo dessa década. O desempenho em resolução de problemas avaliará a eficácia de nossa posse pessoal e nacional de competência matemática. (NCTM, 1980, p.02)

Durante essa década, foram desenvolvidos materiais instrucionais para auxiliar o professor em sala de aula, com a resolução de problemas passando a ser o ponto central de seu trabalho.

Entretanto, esse tipo de trabalho, não deu o tipo de coerência e a direção necessária a um bom resultado porque havia pouca concordância na forma pela qual esse objetivo era encarado. Essa falta de concordância ocorreu, possivelmente, pelas grandes diferenças existentes entre as concepções que pessoas e grupos tinham sobre o significado de "resolução de problemas ser o foco da matemática escolar" (ONUCHIC, 1999, p.206)

Desse modo, nessa década, apareceram diferentes formas de se conceber resolução de problemas no processo de ensino-aprendizagem de Matemática.

No trabalho de Gazire (1988) são apresentadas perspectivas em Educação Matemática para a Resolução de Problemas: 1) como um novo conteúdo, 2) como aplicação do conteúdo, e 3) como um meio de se ensinar matemática. Nossa pesquisa se identifica com sua última perspectiva: ver Resolução de Problemas como um meio de se ensinar Matemática, sendo o problema o gerador do processo de ensino-aprendizagem. Gazire apresenta a principal característica dessa perspectiva: Se todo conteúdo a ser aprendido for iniciado numa situação de aprendizagem, através de um problema desafio, ocorrerá uma construção interiorizada do conhecimento a ser adquirido. (GAZIRE, 1988, p.124) 
Como já vimos, em Lambdin, D.V. e Walcott, C. (2007), a matemática escolar passou por várias mudanças no século XX. Depois da reforma "Back to Basics" ("Volta às bases"), ocorrida nos Estados Unidos nos anos setenta. A Resolução de problemas passou a ter destaque nos anos oitenta, tendo como teorias de aprendizagem psicológica o construtivismo; a psicologia cognitiva; e a teoria sociocultural (Vygotsky). $O$ foco estava na resolução de problemas e nos processos de pensamento matemático, e o aprendizado se dava por descoberta e através da resolução de problemas.

Schroeder \& Lester (1989) identificaram, na década de oitenta, dois modos distintos de conceber Resolução de Problemas: 1) ensinar sobre resolução de problemas matemáticos (teorizando); e 2) ensinar matemática para resolver problemas.

Ao ensinar sobre resolução de problemas, tem-se um trabalho com o modelo de ensino proposto por Polya ou variações dele, dividido em quatro etapas: compreender o problema, criar um plano, executar o plano e fazer a verificação ou o retrospecto da solução levada ao problema original.

Já o trabalho de ensinar Matemática para poder resolver problemas enfatiza as estratégias a fim de resolver o problema. Tem a resolução de problemas como um fim, ou seja, a Matemática foi ensinada para resolver problemas, e a ênfase é dada na aplicação dos conteúdos matemáticos vistos anteriormente.

Os materiais instrucionais, da década de oitenta, ou abordavam os quatro passos de Polya ou usavam estratégias ou heurísticas para a resolução de problemas. Schroeder \& Lester sentiram uma falta de consenso, entre os pesquisadores, na interpretação da primeira recomendação do documento "Uma Agenda para Ação": resolução de problemas deve ser o foco da matemática escolar nos anos oitenta. E, também, como outros pesquisadores, questionaram sobre os resultados obtidos do ensino de Matemática com o uso de modelos e de estratégias. Assim, no final de 1989, começam a admitir a possibilidade de ver a resolução de problemas como uma metodologia, isto é, dentro de uma perspectiva didático-pedagógica, apresentando, então, um novo modo de trabalhar com a resolução de problemas: ensinar Matemática via (por meio) da resolução de problemas.

Mendonça (1993) apresenta três interpretações para a Resolução de Problemas: 1) como um objetivo, significando que se ensina Matemática para resolver problemas e a resolução de problemas é a meta final; 2) como um processo, significando que a resolução de problemas é um meio para desenvolver o potencial heurístico do aluno ao fazer uso de diferentes estratégias. Dirige-se ao desempenho do indivíduo como resolvedor; e 3) como um ponto de partida, significando olhar o problema como um elemento que pode disparar um 
processo de construção do conhecimento matemático, cujo foco está na ação por parte do educando.

No final da década de 1980, começo dos anos noventa, houve uma volta às ideias construtivistas e a pesquisa em resolução de problemas ficou ameaçada. Assim, pesquisadores passaram a questionar o ensino e o efeito de estratégias e modelos. Começaram a discutir as perspectivas didático-pedagógicas da resolução de problemas. Na década de 90, assume-se a Resolução de Problemas como uma metodologia, onde o problema é visto como um ponto de partida e a metodologia um veículo para o ensino e a aprendizagem de Matemática, sob a guia do professor.

Nos PCN (1999) a Resolução de Problemas mostra-se, também, presente como um caminho para o ensino de Matemática, aproximando-se do enfoque dado nesta pesquisa.

\subsubsection{Metodologia de Ensino-Aprendizagem-Avaliação de}

\section{Matemática através da Resolução de Problemas}

É importante reconhecer que a Matemática deve ser trabalhada através da Resolução de Problemas, ou seja, que tarefas envolvendo problemas ou atividades sejam o veículo pelo qual um currículo deva ser desenvolvido. A aprendizagem será uma conseqüência do processo de Resolução de Problemas. (ONUCHIC, 2004, p.221)

O que a pesquisa nos diz sobre ensinar Matemática através da resolução de problemas?

A partir de 1990, que a abordagem "ensinar via resolução de problemas" (Teaching via Problem Solving) passou a ser "ensinar através da resolução de problemas" (Teaching through Problem Solving) que é uma metodologia bastante nova na história da pesquisa em resolução de problemas no currículo de Matemática. A diferença entre essas duas abordagens é que a expressão "através de" significa do começo ao fim, inteiramente, ao longo da resolução do problema e não simplesmente um recurso para se resolver o problema dado como pedia a expressão "via" que significa "por meio de".

Jinfa Cai (2003, p.241) diz que

o ensino de resolução de problemas tem uma longa história na matemática escolar. Nas últimas décadas houve avanços significativos em nossa compreensão dos processos complexos envolvidos em resolução de problemas (Lester 1994; Schoenfeld 1992; Silver 1985). Também, uma considerável discussão tem acontecido sobre ensino de Matemática com um foco sobre resolução de problemas (Hembree e Marsh 1993; Henningsen e Stein 1997; Hiebert et al 1997; Kroll e Miller 1993; Stein, Smith e Silver 1999). Entretanto, ensinar através da resolução de problemas é uma ideia 
relativamente nova na história da resolução de problemas no currículo de matemática (Lester, 1994). De fato, porque ensinar matemática através da resolução de problemas é antes de tudo um conceito novo, ele não tem sido assunto de muita pesquisa.

Embora pouco se conheça sobre os mecanismos atuais que os estudantes usam para aprender e dar sentido à matemática através da resolução de problemas, os pesquisadores concordam que ensinar através da resolução de problemas permanece a promessa de aprendizagem nos estudantes. Muitas das ideias tipicamente associadas com essa abordagem (mudança nos papéis do professor, projetar e selecionar problemas para o ensino, aprendizagem colaborativa, e problematizar o currículo) têm sido extensivamente estudadas, resultando em respostas baseadas em pesquisa para as várias questões frequentemente levantadas sobre o ensino com resolução de problemas.

A metodologia adotada para o trabalho em sala de aula nesta pesquisa é a Metodologia de Ensino-Aprendizagem-Avaliação de Matemática através da Resolução de Problemas. A palavra composta ensino-aprendizagem-avaliação significa que o ensino e a aprendizagem devem ocorrer simultaneamente, durante o processo de construção de um determinado conceito. E a avaliação, integrada ao ensino, contribui para a melhora da aprendizagem.

Nesse sentido Van de Walle (2001) coloca que

Os professores de Matemática, para serem realmente eficientes, devem envolver quatro componentes básicos em suas atividades: gostar da disciplina Matemática, o que significa fazer Matemática com prazer; compreender como os alunos aprendem e constroem suas idéias; ter habilidades em planejar e selecionar tarefas e, assim, fazer com que os alunos aprendam Matemática num ambiente de Resolução de Problemas; ter habilidade em integrar diariamente a avaliação com o processo de ensino a fim de melhorar esse processo e aumentar a aprendizagem. (apud ONUCHIC, 2004, p.219)

Nessa metodologia, concebemos problema matemático como algo que não sabemos resolver mas que há interesse em resolvê-lo (ONUCHIC, 1999). O problema é o ponto de partida no processo de ensino-aprendizagem-avaliação de Matemática.

Desse modo, temos que a Metodologia de Ensino-Aprendizagem-Avaliação de Matemática é um meio de se aprender Matemática através da resolução de problemas.

Essa metodologia tem por meta ajudar os alunos a se tornarem investigadores diante de uma situação desafiadora, um problema, de forma a compreender e questionar os conceitos de que irão necessitar para resolvê-lo. O papel do professor muda de "comunicador de conhecimento" para o de observador, organizador, consultor, mediador, controlador, incentivador da aprendizagem. Sendo assim, exige-se bastante do professor, “... o professor terá que enfrentar situações inesperadas em sala de aula e, em algumas oportunidades, deverá 
alterar aquilo que tinha planejado, ainda mais, terá que estar atento às dificuldades apresentadas pelos alunos...” (RODRIGUES, 1992, p.29).

Ao colocar em prática o trabalho com esta metodologia, Onuchic (1998), trabalhando com um grupo de professores de um Curso de Educação Continuada, redigiu um roteiro de atividades para orientar os professores no trabalho em sala de aula.

Atendendo a solicitações e com a participação dos professores, procuramos esquematizar uma aula na qual um objeto matemático fosse trabalhado, visando a um ensino-aprendizagem acompanhado de compreensão e significado, através da resolução de problemas. Apoiados na literatura consultada e aproveitando experiências anteriores, chegamos a uma proposta básica:

- Formar grupos - entregar uma atividade

Lembrar que, no mundo real, aprender é muitas vezes um processo compartilhado e que o progresso em direção a um objetivo vem através de esforços combinados de muita gente. É preciso que os estudantes experimentem este processo cooperativo e que se lhes dê a oportunidade de aprender uns com os outros. Sentimos que muito da aprendizagem em sala de aula será feita no contexto de pequenos grupos.

- O papel do professor

Dentro desse trabalho, o papel do professor muda de comunicador de conhecimento para o de observador, organizador, consultor, mediador, interventor, controlador e incentivador da aprendizagem. O professor lança questões desafiadoras e ajuda os alunos a se apoiarem, uns nos outros, para atravessar as dificuldades. O professor faz a intermediação, leva os alunos a pensar, espera que eles pensem, dá tempo para isso, acompanha suas explorações e resolve, quando necessário, problemas secundários.

- Resultados na lousa

Com o trabalho dos alunos terminado, o professor anota na lousa os resultados obtidos pelos diferentes grupos. Anota resultados certos, errados e aqueles feitos por diferentes caminhos.

- Plenária

Chama os alunos todos, de todos os grupos, para uma assembléia plena. Como todos trabalharam sobre o problema dado, estão ansiosos quanto a seus resultados. Procuram defender seus pontos de vista e participam.

- $\quad$ Análise dos resultados

Nesta fase, os pontos de dificuldade encontrados pelos alunos são novamente trabalhados. Surgem, outra vez, problemas secundários que, se não resolvidos, poderão impedir que se leve o trabalho à frente. $\mathrm{O}$ aspecto exploração é bastante importante nesta análise.

- Consenso

A partir da análise feita, com a devida retirada das dúvidas, busca-se um consenso sobre o resultado pretendido.

- $\quad$ Formalização

Num trabalho conjunto de professor e alunos, com o professor dirigindo o trabalho, é feita uma síntese do que se objetivava aprender a partir do problema dado. São colocadas as devidas definições, identificadas as propriedades e feitas as demonstrações. É importante destacar, nesse momento, o que de matemática nova se construiu, usando a terminologia própria ao assunto. (ONUCHIC, 1999, p.215) 
Com a prática ao longo do tempo, algumas coisas pediam por mudança nesse roteiro e outros passos lhe foram adicionados, passando a ser visto nas seguintes etapas:

1) Formar grupos e entregar a atividade. - O professor apresenta o problema aos alunos que, distribuídos em pequenos grupos, lêem e tentam interpretar e compreender o problema. Ressalte-se que o conteúdo necessário, ou mais indicado, para a resolução do problema ainda não foi trabalhado em sala de aula. O problema proposto aos alunos, que chamamos problema gerador, é que conduzirá ao conteúdo que o professor planejou construir naquela aula.

2) Observar e incentivar. - O professor não mais tem o papel de transmissor do conhecimento. Enquanto os alunos tentam resolver o problema, o professor observa, analisa o comportamento dos alunos e estimula o trabalho colaborativo. O professor faz a intermediação no sentido de levar os alunos a pensar, dando-lhes tempo para tal, e incentivando a troca de idéias entre os alunos.

3) Auxiliar nos problemas secundários. - O professor incentiva os alunos a utilizarem seus conhecimentos prévios ou técnicas já conhecidas para resolver o problema; estimula-os a escolher diferentes estratégias a partir dos próprios recursos de que dispõem. Entretanto, é necessário que o professor atenda os alunos em suas dificuldades, colocando-se como um interventor e questionador, acompanhando suas explorações e ajudando-os, quando necessário, a resolver problemas secundários. Tratam-se de dúvidas apresentadas pelos alunos no contexto do vocabulário presente no enunciado; no contexto da leitura e interpretação; além daqueles que podem surgir por ocasião da resolução do problema: notação, passagem da linguagem vernácula para a linguagem matemática, conceitos relacionados, técnicas operatórias, a fim dar prosseguimento ao trabalho.

4) Registrar as resoluções na lousa. - Representantes dos grupos são convidados a registrar suas resoluções na lousa. Resoluções certas e erradas ou feitas por diferentes processos devem ser apresentadas para que todos os alunos as analisem e discutam.

5) Realizar uma Plenária. - O professor chama todos os alunos para discutirem as resoluções realizadas pelos colegas, para defenderem seus pontos de vista e esclarecerem suas dúvidas. O professor se coloca como guia e mediador das discussões, incentivando a participação ativa e efetiva de todos os alunos, pois este é um momento bastante rico para a aprendizagem.

6) Buscar um consenso. - Após sanadas as dúvidas e analisadas as resoluções e soluções obtidas para o problema, o professor tenta, com toda a classe, chegar a um consenso sobre o resultado correto.

7) Formalizar o conteúdo. - Neste momento, denominado "formalização", o professor registra na lousa uma apresentação formal dos novos conceitos e conteúdos construídos, destacando as diferentes técnicas operatórias e as propriedades qualificadas para o assunto. (ALLEVATO; ONUCHIC, 2006; ONUCHIC, 2004, apud ONUCHIC; ALLEVATO, 2008, p.2).

Algumas questões dirigidas aos professores ao adotar essa metodologia poderiam estar entre as colocadas abaixo:

- Para que séries você acredita ser este problema adequado? 
- Que tópicos de Matemática poderiam ser iniciados com este problema?

- Haveria necessidade de se considerar problemas menores (secundários) associados a ele?

- Que grau de dificuldade você acredita que seu aluno possa ter diante deste problema?

- Como relacionar o problema dado com aspectos sociais e culturais?

Van de Walle (2001) apresenta um modo de encaminhar as aulas, trabalhando com o ensino através da resolução de problemas. Sugere que as aulas sejam planejadas em três fases importantes: antes, durante e depois, como explicitamos abaixo:

Antes (fora da sala de aula)

Nessa fase, o professor deve levar em consideração o conhecimento prévio dos alunos, necessário à construção de novo conhecimento matemático. Além disso, o professor deve fazer todo o planejamento da aula, organizando-a assim: o foco da aula - ou seja, ter em mente o que de novo se pretende construir em Matemática, com o problema dado; o problema - selecionar um problema que permita chegar à construção de novos conceitos e conteúdos pretendidos; $\underline{\text { as estratégias }}$ - devem ser selecionadas para o encaminhamento e o desenvolvimento da aula; a resolução do problema - o problema deve ser resolvido detalhadamente, pelo professor, selecionando diferentes caminhos para se chegar à solução; $\underline{\mathrm{a}}$ plenária - levantar questões para estimular os alunos à discussão e à exploração do problema durante a plenária; e a formalização - é o momento em que o professor, sob sua inteira responsabilidade, faz o fechamento da aula, apresentando, por escrito, as definições dos novos conceitos construídos e todo o conteúdo matemático decorrente desse trabalho.

Durante (na sala de aula)

Nessa fase, o professor é um observador e avaliador do trabalho dos alunos. Inicialmente, entrega a cada aluno, uma cópia da atividade que deve ser lida por ele. Em seguida, formam-se os grupos, e nesse ambiente, há a socialização do trabalho onde, seus participantes passam a trabalhar cooperativamente na busca de possíveis estratégias que poderão levar o grupo a busca da solução, num trabalho colaborativo.

É importante dar aos alunos o tempo que o professor considera suficiente para desenvolver esse trabalho. Após a leitura do problema, é possível que alguns alunos, em seus grupos, façam perguntas a respeito do enunciado. Se necessário, o professor poderá interferir no processo, desde que essa situação se apresente como uma dúvida (problema secundário) pois, se não esclarecida, o trabalho poderá não ir para a frente. Também seria considerado um 
problema secundário se alguns alunos ou alguns grupos não conseguissem fazer a leitura correta do problema, falhando em sua interpretação. Considerado pelo professor o tempo esgotado, será solicitada a colocação das resoluções de alguns grupos, na lousa, esperando-se que, na plenária, suas dúvidas fiquem esclarecidas.

\section{Depois (na sala de aula)}

Para esta fase, o professor congrega todos os alunos de todos os grupos para uma atividade participativa - professor e alunos.

Nela, o professor considera as soluções apresentadas pelos grupos, sem avaliá-las, e dirige uma discussão exploratória enquanto os alunos defendem suas resoluções e dão justificativas. Professor e alunos, socialmente analisam as resoluções colocadas na lousa: as estratégias escolhidas, os resultados corretos ou não, e, com as dúvidas esclarecidas, chega-se a um consenso acerca da solução obtida. O professor termina com a formalização, totalmente de responsabilidade do professor, escrevendo na lousa os novos conceitos e conteúdos construídos e com os alunos anotando em seus cadernos toda a teoria construída.

Este é um tempo de muita exploração, tanto da parte do professor quanto da dos alunos. Aproveita-se esse tempo também, para levar os alunos a entenderem como os membros de uma comunidade devem proceder, quando estão num ambiente de formação de um cidadão: saber ouvir, saber falar e saber agir num ambiente onde o respeito pelo outro, quer seja colega ou professor, deve acontecer.

Dúvidas esclarecidas, questionamentos levantados e discutidos, conscientização do que se queria buscar nos dados do problema e em sua resolução fazem parte dessa fase.

O professor, como um veículo que conduz os alunos durante todo esse trabalho, deve usar terminologia e notação adequadas de acordo com a construção Matemática dos conceitos e nos conteúdos pretendidos.

\section{4 - A identificação do Problema da Pesquisa}

Para nós, depois de termos caminhado pelas atividades 1, 2 e 3, muitas questões, como previa Romberg, surgiram e as que mais nos provocaram referiam-se a uma mescla dos três eixos trabalhados. Depois, de muito pensar, como num vai e vem, surgiu a primeira questão:

1) Qual seria a contribuição da Metodologia de Ensino-Aprendizagem-Avaliação de Matemática através da Resolução de Problemas para uma nova abordagem, em sala de aula, do ensino de Análise Combinatória? 
Mas, também, com ela aparecia uma outra forte questão:

2) Como se desenvolve a formação de conceitos de Análise Combinatória, adotandose a Resolução de Problemas como uma metodologia de ensino? de aprendizagem? de avaliação?

Parece-nos que essas duas perguntas tinham algo em comum, pareciam-nos complementares. Mas, nos questionando ainda, perguntávamos: há alguma diferença essencial entre as duas?

A primeira, envolvendo mais a força da metodologia adotada, poderia contribuir para a elaboração de uma nova abordagem de trabalho com a Análise Combinatória, ou seja, uma linha alternativa de trabalho para o professor.

A segunda se mostrava mais preocupada com a aprendizagem dos alunos, buscando um caminho para a construção de novos conceitos e novos conteúdos, tendo os alunos como coconstrutores desse conhecimento e o professor como um veículo para conduzir essa construção.

Como essas duas colocações parecem se ajustar uma à outra, decidimos que a pergunta diretriz de nossa pesquisa poderia surgir numa sequência em que, a primeira, quando respondida, poderia levar à resposta da segunda.

Sentimos que essas duas questões podem ser prolongadas para o processo de Educação Continuada, como para o prosseguimento da pesquisa sobre Análise Combinatória como parte da Matemática Discreta. 


\title{
CAPÍTULO 3 - Dando continuidade à pesquisa ( $2^{\underline{0}}$ bloco de Romberg)
}

\author{
3.1 - Selecionar Estratégias e Procedimentos de Pesquisa \\ 3.2 - Projeto $1-\mathrm{P}_{1}$ \\ 3.3 - Projeto $2-\mathrm{P}_{2}$ \\ $3.4-$ Projeto $3-\mathrm{P}_{3}$
}




\section{CAPÍTULO 3 - Dando continuidade à pesquisa \\ ( $2^{\circ}$ bloco de Romberg)}

\subsection{Selecionar Estratégias e Procedimentos de Pesquisa}

A decisão sobre que métodos utilizar segue diretamente das questões que se seleciona; da visão de mundo na qual as questões estão situadas; do Modelo que foi construído a fim de explicar o "fenômeno de interesse"; e da conjectura que se faz sobre a evidência necessária. (ROMBERG, 2007, p.102)

Dando início à continuação de nossa pesquisa, nos demos conta das muitas contribuições que recebemos de nossos "outros", percebendo que ela, a nossa pesquisa, pedia mais. Nela nós poderíamos aparecer:

1) Como uma professora-pesquisadora, trabalhando em sua própria sala de aula, com seus próprios alunos, construindo os importantes conceitos da Análise Combinatória, um ramo da Matemática Discreta, utilizando a Metodologia de Ensino-Aprendizagem-Avaliação de Matemática através da Resolução de Problemas.

2) Como uma pesquisadora que, ministrando minicursos e oficinas de trabalho, em encontros de Educação Matemática, num processo de Educação Continuada, trabalhasse, usando como alternativa de trabalho a Metodologia de Ensino-Aprendizagem-Avaliação de Matemática através da Resolução de Problemas, atividades de Análise Combinatória com professores, educadores matemáticos e até alunos da Licenciatura em Matemática.

3) Como uma pesquisadora que se apresentasse, em Congressos e Encontros de Educação Matemática, oferecendo suas próprias pesquisas, para conhecimento e divulgação delas a outros pesquisadores, para discussão e análise. 
Para poder enfrentar essa linha de trabalho, o Problema da pesquisa pedia, também, mais uma modificação do Modelo que deveria reger a continuação de nossa pesquisa. Assim, o Modelo Modificado, apresentado na página 44, passou a chamar-se Modelo Modificado $1-\mathrm{MM}_{1}-$ e, a partir dele, e das ideias acima colocadas, seria criado o Modelo Modificado $2-\mathrm{MM}_{2}$.

$\mathrm{OMM}_{2}$ será construído em três diferentes partes: o Projeto $1-\mathbf{P}_{\mathbf{1}}-$, o Projeto $2-\mathbf{P}_{\mathbf{2}}$ - e o Projeto $3-\mathbf{P}_{\mathbf{3}}$-, cada um deles destinado a atender à postura da pesquisadora em cada uma das visões acima.

De posse do problema instalado para a pesquisa, o que se deve fazer é buscar sua solução. Desse modo, dando continuidade à pesquisa, descreveremos as duas atividades do $2^{\mathrm{o}}$ bloco, apresentadas no fluxograma de Romberg: selecionar uma Estratégia Geral e seu correspondente procedimento, o Procedimento Geral.

Como Estratégia Geral de nossa Pesquisa, imaginamos criar os três projetos $\mathbf{P}_{\mathbf{1}}, \mathbf{P}_{\mathbf{2}} \mathrm{e}$ $\mathbf{P}_{\mathbf{3}}$, adotando, para os três, a Metodologia de Ensino-Aprendizagem-Avaliação de Matemática através da Resolução de Problemas, com o objetivo de responder à Pergunta da Pesquisa segundo três visões diferentes. Como Procedimento Geral, teremos a criação desses três projetos que serão trabalhados separadamente.

\subsection{Projeto $1-\mathbf{P}_{1}$}

$\mathrm{O} \quad \mathrm{MM}_{1}$ será utilizado integralmente para o desenvolvimento de $\mathbf{P}_{\mathbf{1}}$, cujo desenvolvimento atenderá, de perto, o esquema abaixo.

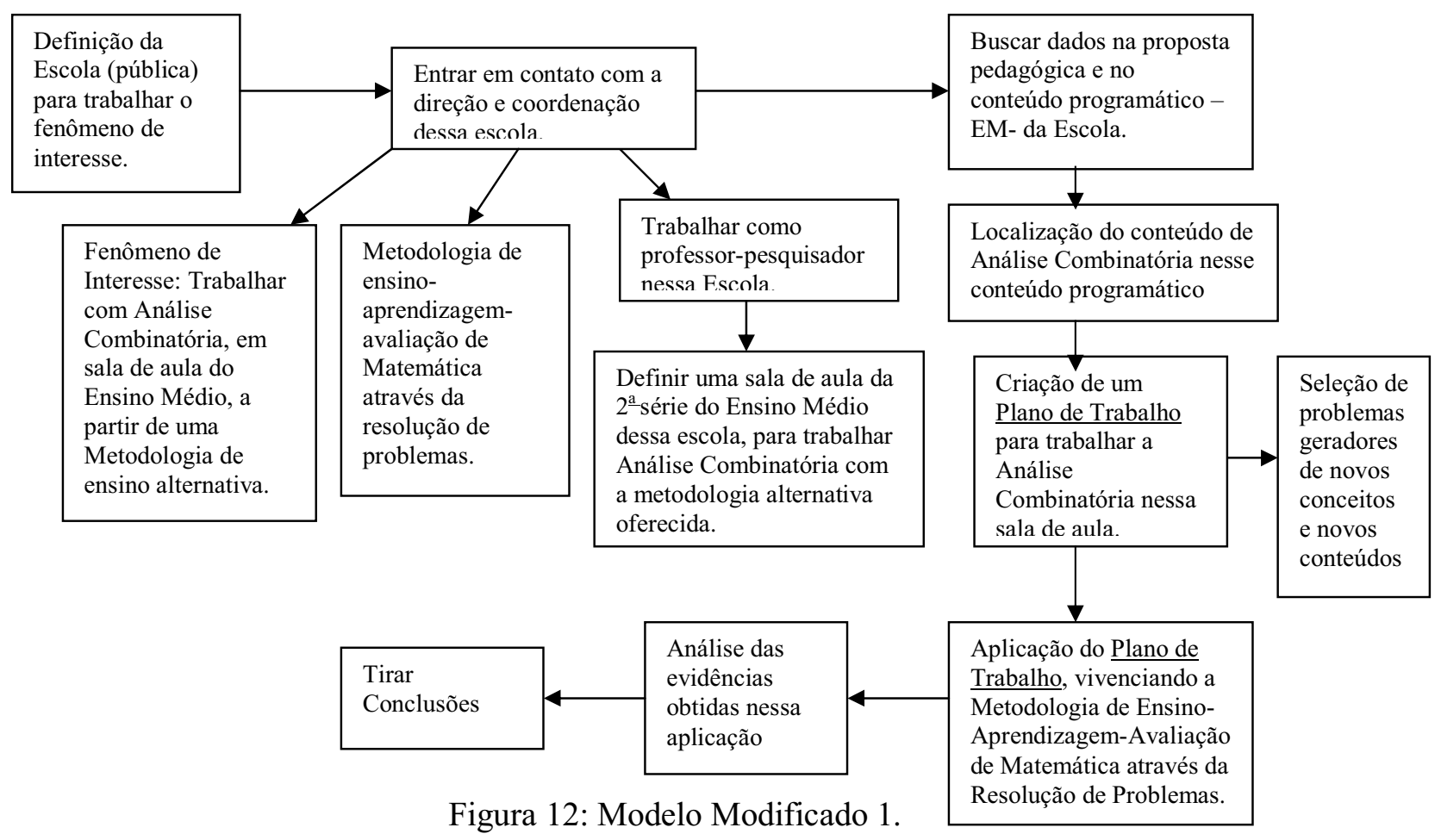


O objetivo de $\mathbf{P}_{1}$ é o de trabalhar com alunos, em uma sala de aula, com a pesquisadora como professora da turma, visando à construção de conceitos da Análise Combinatória, fazendo uso da Metodologia de Ensino-Aprendizagem-Avaliação de Matemática através da resolução de problemas.

A Estratégia Geral selecionada para $\mathbf{P}_{1}$ é a de Criar um Plano de Trabalho e, como Procedimento Geral correspondente, a Criação desse Plano de Trabalho.

A definição da escola para o desenvolvimento desta Pesquisa decorreu de nossa vinda para Rio Claro através da transferência de nossa função de professora efetiva do Estado de São Paulo, permitida pelo artigo 22 da Lei Complementar $n^{-}$444/85, regulamentado pelo Decreto 24.948 de 03/04/1986, que permite que os docentes efetivos do magistério oficial afastados, por qualquer razão, de suas atividades sejam substituídos por pessoas legalmente habilitadas, inclusive por outros efetivos. Fato já descrito no capítulo 1. Desse modo, iniciamos nosso trabalho na Escola Estadual Professora Oscália Góes Correa Santos que, na ocasião, contava com uma $2^{\mathrm{a}}$ série do Ensino Médio, turma que nos interessava para pesquisa. Seguem alguns dados da unidade escolar, no ano de 2007 :

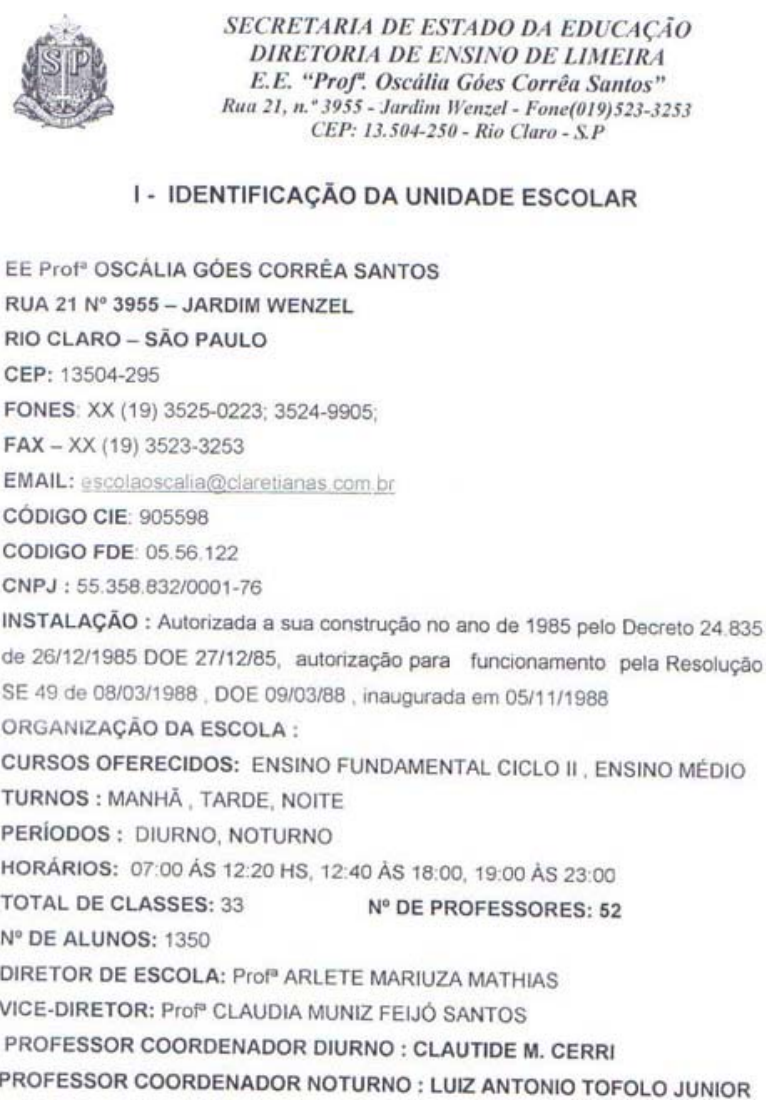


Durante o planejamento escolar realizado nessa escola no início do ano de 2007, momento em que os professores tiveram o primeiro contato com a escola, falamos, com a Diretora e o Coordenador do período noturno, sobre nossa pretensão de realizar uma pesquisa durante nossas aulas, dizendo que queríamos trabalhar Análise Combinatória, em uma sala de aula de Ensino Médio, a partir de uma metodologia alternativa, com a qual estávamos trabalhando há algum tempo, em nosso Grupo de trabalho na UNESP: Metodologia de Ensino-Aprendizagem-Avaliação de Matemática através da Resolução de Problemas. Tanto a Coordenação como a Direção aceitaram a proposta que lhes foi apresentada e que seria adotada para o trabalho em sala de aula e não tivemos problemas. Mas, foi-nos colocada a condição de que não se deixasse de cumprir as normas contidas no contrato pedagógico, entregue no início das aulas, onde constam os direitos e deveres dos professores e dos alunos.

Visto que iríamos trabalhar como professora-pesquisadora, com essa turma, sobre o tópico matemático Análise Combinatória, fazendo uso da metodologia oferecida, fomos em busca da proposta pedagógica e do conteúdo programático da escola.

A proposta pedagógica de 2007 apresentava o perfil dos alunos, a realização do trabalho com esses alunos e a meta principal da escola como sendo a melhoria da qualidade de ensino e as possíveis soluções para os problemas identificados. Apresentamos a seguir essa proposta pedagógica: 


\section{B - Projeto Pedagógico}

De acordo com levantamentos realizados anualmente pela equipe escolar, juntos aos alunos, cerca de $30 \%$ do total de nossos alunos são oriundos das regiões norte, nordeste do pais, cujos responsáveis vêm para o Estado de São Paulo em busca de melhores condições de vida.

Partindo-se dos resultados obtidos nos vários setores de atuação da escola, destacam-se como pontos a serem melhorados: (plano de melhoria)

- O trabalho coletivo e interdisciplinar de um pequeno $n^{\circ}$ de professores, que ainda não se enquadram nos moldes;

- Valorização por alguns docentes de avaliação de forma classificatória em detrimento da diagnóstica;

- Mudança de postura de uma minoria de docentes em relação a sua condição de educador;

- Relacionamento escola - comunidade, melhorou muito, mas podemos melhorar mais.

- Com o início do ensino médio, mudou o perfil estudantil, e a estrutura física do prédio tornou-se precária, falta ambiente físico, como laboratórios, biblioteca, quadra de esportes coberta

De posse de todos esses dados, a Unidade Escolar, promove reuniões com os diversos segmentos, professores, funcionários, pais, alunos e equipe de gestores, mais a comunidade de entorno, que elaboraram presente proposta que tem como missão proporcionar um ensino de qualidade que vise a aquisição de conhecimento, desenvolvendo habilidades e atitudes na formação de cidadãos responsáveis perante a sociedade. A escola tem o desejo de formar cidadãos capacitados, respeitados autoconfiantes e inovadores. A escola terá seus objetivos centrados nos alunos, para que os mesmos desenvolvam valores políticos e culturais. Seu plano de curso segue objetivos gerais do ensino fundamental e médio dos Parâmetros curriculares Nacionais e a LDB ou seja:

Compreender a cidadania como participação social e política

Construir o conhecimento

Posicionar-se de maneira a respeitar as diferenças

Conhecer as características sociais e culturais dos paises

Ser agente transformador do ambiente para a melhoria do mesmo

Desenvolver sua auto estima, desenvolver hábitos de higiene e saúde Utilizar diferentes linguagens, verbal, musical,matemática,

Usar tecnologia diversificada para construir o conhecimento

Sistematizar os conhecimentos apreendidos.

Com base no diagnóstico da escola, nossa meta principal, continua sendo a melhoria da qualidade de ensino dando ênfase:

a) soluções dos problemas de defasagens na aprendizagem apresentadas pelos alunos;

b) Trabalho coletivo

c) Ensino médio

Para solucionar a defasagem de aprendizagem, pretendemos diagnosticar de imediato as séries ingressantes, no ciclo II, bem como investir nos projetos de correção como PR, recuperação paralela, usando laboratório de

informática com os recursos existentes no mesmo, biblioteca, livros PNLD, materiais disponiveis na escola. A avaliação interna estará de acordo com o estabelecido pelo regimento da escola, a externa dar-se á através do Saresp, Enem.Quanto ao trabalho coletivo, queremos ação comum da comunidade escolar em relação as atividades dentro da escola, com base num consenso geral, através de reunião de pais, festas etc.

Com relação ao ensino médio: pretendemos encaminhar pedido para a Secretaria de Educação para adequação da estrutura física do prédio, com a nova realidade. Ė necessário que os órgãos colegiados da escola se comprometam para assegurar a melhoria da infra estrutura física do prédio, facilitando assim melhor acomodação para os recursos tecnológicos, e também para dar maior tranqüilidade ao acesso de portadores de necessidades especiais. Organizar espaços para atividades artísticoculturais, esportivas, recreativas.

Para realização das ações prioritárias e ou de rotina, a escola conta com recursos da FDE, MEC/FNDE, recursos próprios da APM e ainda fornecimento da Merenda escolar convênio municipal / Secretaria estadual, contamos também com algumas parcerias realizadas entre pais (mão de obra) e material ( comercio).Estando a Unidade Escolar localizada em região periférica tem características próprias. Diante disso a proposta pedagógica visa a adaptação dos conteúdos com a realidade de nossos alunos, através da prática interdisciplinar, com a intenção de integrar todos os segmentos da Unidade Escolar. 
No planejamento feito, nessa escola, estavam citadas, pelos coordenadores, a existência de algumas atividades de socialização entre os alunos a serem realizadas durante o ano letivo: Festa Junina, Jogos Interclasse, Sarau Cultural, Semana de Artes e Meio Ambiente (Efeito estufa).

No planejamento escolar, realizado nos dias 21, 22 e 23 de fevereiro de 2007, em uma das atividades do dia 23, os professores foram divididos em grupos, por disciplina, com o objetivo de organizar os conteúdos a serem trabalhados nesse ano letivo. Analisamos os planos de curso de 2006, onde constavam os conteúdos abaixo expostos, para a $2^{\mathrm{a}}$ série do Ensino Médio, no período noturno:

Revisão: Equações do $1^{\underline{o}}$ e $2^{2}$ graus; sistema de equações do $2^{\underline{o}}$ grau; funções de $1^{\underline{o}}$ e $2^{\underline{o}}$ graus (gráficos); equação irracional.

Conteúdos: Relações Métricas no triângulo retângulo; Razões trigonométricas no triângulo retângulo; Arcos e ângulos; Equações trigonométricas no triângulo retângulo; Matrizes (noção); Probabilidade; Estatística (noção), gráficos; Áreas de figuras planas; áreas do círculo e de suas partes; polígonos regulares; geometria espacial de posição: conceitos relativos às retas.

Para nossa surpresa e decepção, não constava o conteúdo de Análise Combinatória no plano de curso da escola do ano de 2006.

Questionamos o coordenador, querendo saber se seria possível acrescentar o conteúdo de Análise Combinatória ao plano de curso de 2007. Não houve objeção. Os professores poderiam fazer as modificações que achassem necessárias. Os outros professores concordaram com a solicitação feita e, então, vimos que haveria a oportunidade de fazer nossa pesquisa sobre esse conteúdo definido. Após algumas alterações serem feitas ao plano de curso de 2007, para a $2^{\mathrm{a}}$ série do Ensino Médio, ele se apresentou assim:

Revisão: Equações do $1^{\underline{o}}$ e $2^{\underline{o}}$ graus; sistema de equações do $2^{\underline{o}}$ grau; funções de $1^{\underline{o}}$ e $2^{\circ}$ graus (gráficos); equação irracional.

Conteúdos: Trigonometria (introdução); Matriz; Determinante; Sistemas Lineares; Análise Combinatória e Probabilidade.

Nos planos de ensino deveriam constar também, além do conteúdo programático, dos critérios de avaliação, das metodologias e das habilidades, os projetos e as atividades culturais a serem desenvolvidos; Festa Junina, Jogos Interclasses, Sarau Cultural, Semana de Artes, Meio Ambiente (efeito estufa), Jogos Pan Americanos (a serem realizados em julho no Rio de Janeiro). 
$\mathrm{Na}$ primeira aula dada para essa turma apresentamos aos alunos o Contrato Pedagógico proposto pela escola tanto para o professor como para os alunos. Ele foi lido com cautela e lhes chamamos a atenção para o cumprimento dessas regras, dizendo que, como eles, nós também deveríamos cumpri-las.

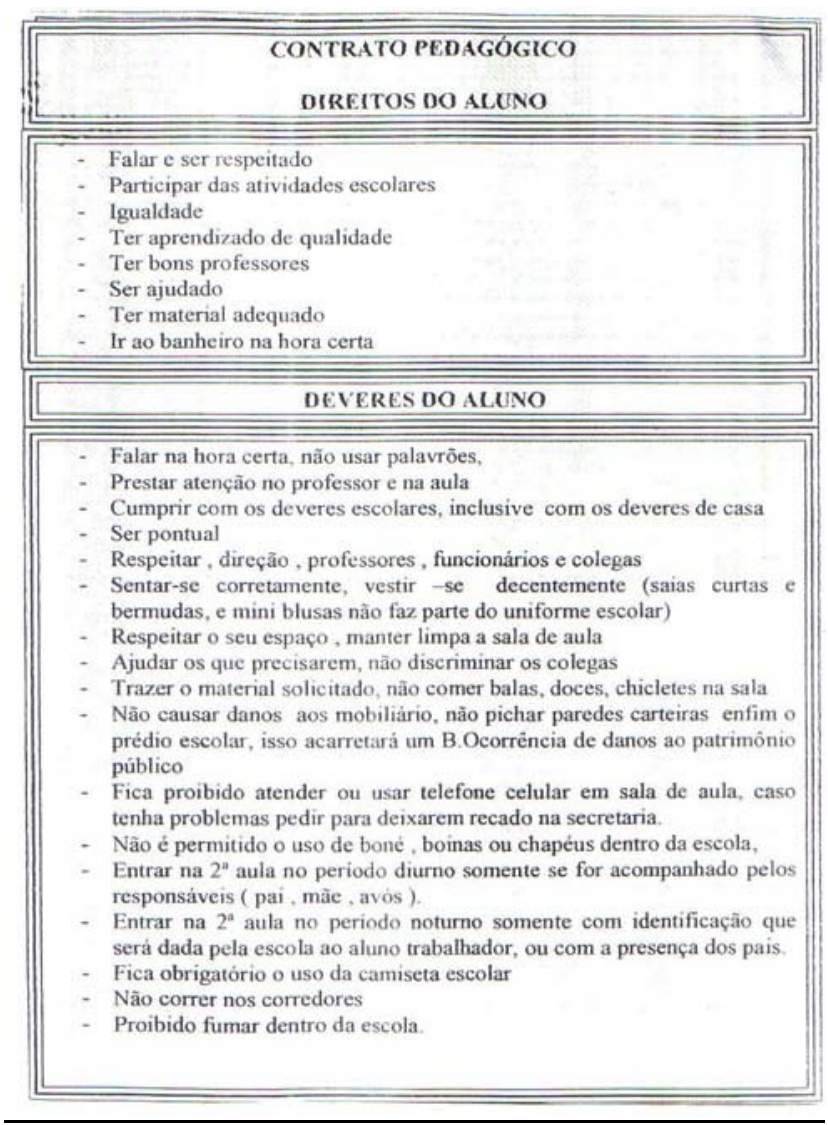

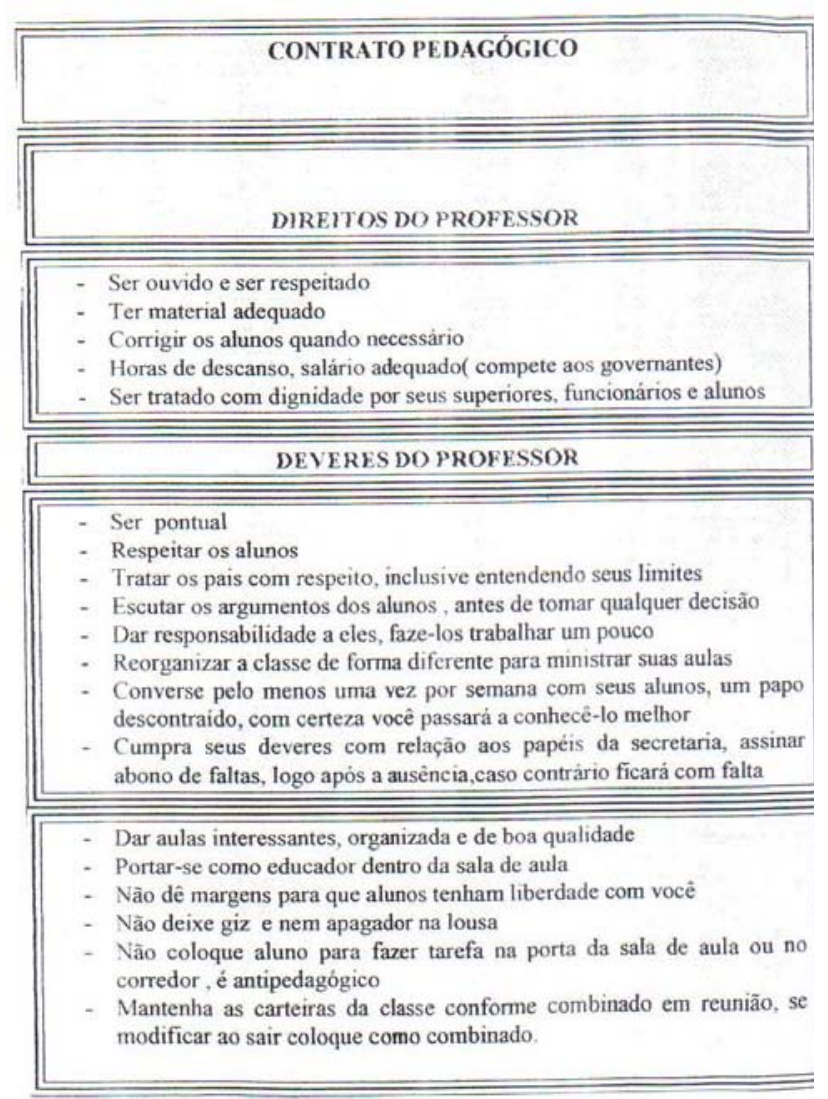

Para o trabalho em sala de aula, professora e alunos elaboraram juntos um Termo de Compromisso no qual constariam regras para organizar e desenvolver um trabalho eficiente durante as atividades em sala de aula.

Propusemos que se discutisse e se elaborasse esse Termo de Compromisso que, sem violar as regras já colocadas pela escola, deveria vigorar em todas as atividades de nossa disciplina, dizendo que, com ele, iríamos direcionar melhor nosso trabalho durante nossas aulas.

Não foi tão simples essa discussão pois alguns alunos, que não aceitam facilmente limites, mostraram-se contrários a qualquer outra regra, o que poderia levar-nos a prever sua posição de não cumpri-las. 


\section{$\underline{\text { Termo de Compromisso }}$}

Introdução:

Este Termo de Compromisso tem por objetivo estabelecer parâmetros para nortear o desenvolvimento e a organização de um trabalho diferenciado em Matemática, apontando as responsabilidades e os direitos dos alunos e da professora. O trabalho será realizado na disciplina de Matemática na $2^{\mathrm{a}}$ série do Ensino Médio, na Escola Estadual Prof ${ }^{\mathrm{a}}$. Oscália Góes Corrêa Santos, localizada na cidade de Rio Claro/SP.

\section{Conteúdo e Metodologia:}

Será desenvolvido o conteúdo matemático pertinente à $2^{\text {a }}$ série do Ensino Médio, proposto pela instituição, cujo trabalho será aplicado pela professora Analucia Castro Pimenta de Souza, utilizando a Metodologia de Ensino-Aprendizagem-Avaliação de Matemática através da Resolução de Problemas.

\section{Normas:}

- O trabalho será desenvolvido de forma cooperativa e colaborativa. Os estudantes trabalharão em pequenos grupos, com o objetivo de resolver problemas visando à construção de novos conceitos e novos conteúdos matemáticos;

- Todos deverão engajar-se na discussão dos problemas apresentados;

- Os grupos serão formados por quatro alunos, aceitando-se três na impossibilidade de um quarto elemento juntar-se ao grupo, devido à insuficiência do número de alunos na sala de aula;

- O trabalho individual de cada membro terá um efeito direto sobre o sucesso do grupo.

$\underline{\text { Avaliação: }}$

Cada aluno será avaliado individualmente, de acordo com o artigo 24, inciso V-a, da L.D.B. da Educação Nacional, lei no 9394 de 20/12/1996, nos seguintes itens:

- FREQUÊNCIA (Peso 1): "Todos deverão estar presentes no local e horário estipulados."

- TAREFA (Peso 1): “As tarefas extraclasse serão recolhidas no início de cada aula." 
- TRABALHO DE GRUPO (Peso 1): “Os trabalhos de grupo serão observados e avaliados pela professora durante as atividades em classe."

- PARTICIPAÇÃO (Peso 1): "Participação nas discussões e no desenvolvimento de atividades propostas."

- DISCIPLINA (Peso 1): "Será observada a disciplina em sala de aula em todos os momentos da aula de Matemática."

- PROVA (Peso 5): “A avaliação escrita terá a validade de 5 pontos.”

Outras resoluções:

Questões e problemas surgidos durante o desenvolvimento do trabalho serão discutidos por todos, alunos e professora, afim de chegar-se a um comum acordo, ficando estabelecido que as normas deverão ser cumpridas pelos alunos e pela professora.

Ciente dessas normas, de pleno acordo com todas as condições estabelecidas, assinam abaixo.

Rio Claro, de de 2007.

Para a seleção dos problemas, foram utilizados e analisados diferentes livros didáticos do Ensino Médio. Diante de uma grande quantidade de problemas, não é tão simples selecioná-los. Cabe ao professor, tendo anteriormente diagnosticado o conhecimento prévio dos alunos, escolher problemas que os levem a chegar ao objetivo da construção de novos conceitos e conteúdos.

A metodologia de trabalho em sala de aula é a Metodologia de Ensino-AprendizagemAvaliação de Matemática através da Resolução de Problemas, apresentada no capítulo 2, p.121. Ao adotar essa metodologia, assume-se que o problema é o ponto de partida para a construção do novo conhecimento pretendido e considerando o ensino centrado no aluno. A formalização dos conceitos trabalhados deve ocorrer no final de cada problema resolvido. 


\title{
Procedimento Geral em ação - A Criação do Plano de Trabalho
}

\begin{abstract}
Ao criar-se um projeto de trabalho, para a sala de aula, necessita-se de harmonia, pois se passa por uma série de situações diversas. Deve-se analisar o conteúdo matemático proposto para a série pesquisada e observar a realidade dos alunos; propor problemas geradores de novos conceitos e novos conteúdos matemáticos, a partir do conteúdo programático correspondente à série; obter um espaço físico; preparar materiais instrucionais; e administrar o tempo destinado à sua aplicação. Além disso, aplicar um projeto para um trabalho diferenciado, em sala de aula, envolve trabalhar com diferentes personalidades e situações em seu transcorrer, ou seja, não é uma tarefa fácil. (PEREIRA, 2004, p.75)
\end{abstract}

No início do ano letivo de 2007, trabalhando com os alunos com quem, no $4^{\circ}$ bimestre, deveria aplicar nosso Projeto, visando ao traçar o perfil da turma, propusemos aos alunos algumas questões matemáticas com o propósito de conhecê-los melhor, já que era a primeira vez que iríamos trabalhar com eles. As questões, apresentadas abaixo, eram relacionadas à disciplina Matemática e uma delas destinava-se ao seu futuro profissional.

1) O que é Matemática para você?

2) Dê alguns exemplos que mostrem onde se utiliza a Matemática.

3) Você gosta de Matemática? Por quê?

4) De que conteúdos matemáticos você se lembra ter estudado até o momento?

5) Que curso você gostaria de fazer depois de concluir o Ensino Médio?

A maioria dos alunos definiu a Matemática como sendo teoria, recurso, estudo, disciplina ou matéria que envolve números e contas. Alguns relatos: "Matemática é tudo que envolve números"; "Matemática é tudo o que se relaciona com contas".

Alguns alunos reconheceram a importância da Matemática, dizendo que é "algo fundamental para o dia-a-dia". Os exemplos apresentados por eles sobre a utilização da Matemática foram, a maior parte, relacionados ao comércio, ou seja, mercado, compras, supermercado, padaria, etc. Também alguns citaram contas de casa, pagamento, coisas do cotidiano.

Em relação se gostam ou não de Matemática, responderam que gostam quando entendem ou se entendem a matéria, passam a gostar de Matemática. Ou também por ter facilidade em fazer em contas, outros conseguem relacionar a Matemática com o cotidiano, ressaltando sua importância então a recebem de modo positivo. Alguns alunos falaram do papel do professor que se explica bem o conteúdo ou se é um professor legal então, acham que fica mais fácil de entender e de gostar de Matemática. 
Os alunos que afirmaram não gostar de Matemática apontaram os seguintes fatores que os levaram a esse fato: disciplina complicada; não entende; é considerada difícil; tem dúvidas em conteúdos anteriores; dificuldade em aprender.

Em relação aos conteúdos que eles lembraram ter estudado foram: Teorema de Pitágoras; fórmula de Bháskara; "delta”; equações do $1^{\underline{0}}$ e $2^{\underline{0}}$ graus; as quatro operações fundamentais; regra de três.

Os cursos escolhidos para fazer após o término do Ensino Médio foram variados, de diferentes áreas, tais como: psicologia; secretariado; computação; turismo; pedagogia; mecânica; computação; medicina; enfermagem; nutrição; direito; administração; entre outros.

Encontra-se na Proposta Pedagógica, em nossa Escola, que a meta principal da escola é a melhoria do ensino, atividade que diz respeito ao professor. Mas, para a pesquisadora, interessa uma consequente melhoria da aprendizagem, fato que depende da ação dos alunos, sob a condução do professor.

O livro "Como as pessoas aprendem: cérebro, mente, experiência e escola", de autoria de Bransford et al (2007), publicado pela União do Comitê de Desenvolvimento da Ciência da Aprendizagem; do Comitê de Pesquisa da Aprendizagem e da Prática Educacional; da Comissão de Educação e Ciências Sociais e do Comportamento; e do Conselho Nacional de Pesquisa, dos Estados Unidos, tem como propósito ajudar professores e escolas a criarem uma ponte entre o processo de aprendizagem e as atividades concretas utilizadas em sala de aula, aperfeiçoando o sistema de ensino e valorizando a cidadania.

Conhecer a forma como ocorre o processo de aprendizagem é fundamental para a existência de um bom planejamento pedagógico e um resultado positivo entre os alunos. Assim, ao planejar nosso trabalho sobre Análise Combinatória, com alunos da $2^{\mathrm{a}}$ série do Ensino Médio, refletindo sobre tudo o que se poderia fazer e utilizando certos conhecimentos considerados essenciais para isso, procuramos conhecer as bases para executar esse plano de trabalho.

1) Onde seria realizado?

2) Quem seriam os alunos com os quais se trabalharia?

3) Em que período do ano o professor trabalharia, com essa classe, o tópico Análise Combinatória?

4) Que conhecimento matemático prévio deveriam ter esses alunos para poder trabalhar Análise Combinatória?

5) Quais são as "grandes ideias" que devem, com segurança, ser exploradas dentro da Análise Combinatória? 
6) Como bem distribuir conceitos e conteúdos de Análise Combinatória, a partir da resolução de problemas, dentro um determinado tempo para sua execução?

7) Trabalhar Análise Combinatória, a partir de fórmulas, levam os alunos à compreensão de conceitos e técnicas operatórias?

Como já foi dito, o trabalho seria realizado na Escola onde éramos professora e que tinha uma sala de aula com alunos da $2^{\text {a }}$ série do Ensino Médio. A sala escolhida, tinha, no início do ano, 38 alunos, sendo que três deles foram transferidos durante o ano letivo. Essa classe era do período noturno, com 4 aulas semanais de 45 minutos cada, assim distribuídas: 2 aulas simples ( $3^{\mathrm{a}}$ feira- $1^{\mathrm{a}}$ aula e $4^{\mathrm{a}}$ feira- $3^{\mathrm{a}}$ aula) e 1 aula dupla ( $5^{\mathrm{a}}$ feira- $2^{\mathrm{a}}$ e $3^{\mathrm{a}}$ aulas), com um trabalho a ser realizado em 12 aulas.

De acordo com o planejamento proposto no início do ano, ficou decidido, entre os professores, o coordenador e a direção da Escola, o plano de ensino para cada disciplina. O tópico Análise Combinatória, dentro da disciplina Matemática, seria, então, trabalhado no $4^{\mathrm{O}}$ bimestre do ano letivo de 2007. Sabíamos que o tempo seria pouco para desenvolver esse trabalho e além disso que muito possivelmente nem todos os alunos trariam consigo todo o conhecimento construído durante o Ensino Fundamental, necessário para poder operar em Análise Combinatória, durante a resolução dos problemas propostos.

Durante o trabalho com os alunos, poderíamos explorar as "grandes ideias" existentes dentro da Análise Combinatória e, por "grandes ideias" entendemos os conceitos importantes a serem construídos e os modos de agir dentro de uma teoria. A Análise Combinatória é o ramo da Matemática Discreta que trabalha com contagem e a formação de agrupamentos de objetos de um conjunto em conjuntos menores. O processo de contagem é essencial para se obter esses agrupamentos e é uma das "grandes ideias" dessa teoria. A busca por um padrão também é uma "grande ideia". Ao explorar e observar os grupos formados, através do processo de contagem, pode-se chegar a um padrão, uma regularidade, ou seja, algo que se repete sempre, um modelo. Na Análise Combinatória, encontram-se padrões para três tipos de agrupamentos diferentes, vinculados a três diferentes ideias contidas: permutação, arranjo e combinação, sendo que os grupos podem ser formados com ou sem repetição de elementos.

Para o trabalho a partir de problemas, em sala de aula, dentro de um curto espaço de tempo, poderíamos ter dificuldade para construir conceitos importantes da Análise Combinatória: Princípio Fundamental de Contagem, Permutação, Arranjo e Combinação. Para poder trabalhar bem, torna-se importante fazer um planejamento das aulas, tendo-se, antes, diagnosticado o perfil dos alunos, como, por exemplo, conhecer a realidade em que vivem, seu conhecimento prévio e seu interesse pelo trabalho proposto para a sala de aula. 
Como se pode perceber, não seria fácil chegar à maioria das respostas às perguntas feitas, uma vez que, a partir dos dados obtidos delas, novas perguntas poderiam ser levantadas.

Iríamos trabalhar numa escola pública, de periferia; no período noturno, onde a maioria dos alunos iria para a sala de aula depois de um dia de trabalho; que possivelmente teriam dificuldade de cumprir integralmente os deveres estipulados no Termo de Compromisso; com uma formação matemática um tanto duvidosa quanto ao conteúdo necessário para o desenvolvimento do tópico Análise Combinatória. Como fazer para trabalhar esse tópico, fazendo uso da Metodologia de Ensino-Aprendizagem-Avaliação de Matemática através da Resolução de Problemas. E, até onde poderíamos chegar?

\begin{abstract}
Um dos marcos da nova ciência da aprendizagem é a ênfase na aprendizagem com entendimento. Intuitivamente, o entendimento é bom, mas é difícil estudá-lo do ponto de vista científico. Ao mesmo tempo, os estudantes geralmente têm poucas oportunidades de entender ou de dar sentido a certos tópicos, pois diversos currículos enfatizam mais a memória que o entendimento. Os livros são repletos de fatos que os estudantes têm de memorizar, e a maior parte dos testes avalia sua capacidade de recordar os fatos. (BRANSFORD et al, p.25, 2007)
\end{abstract}

Apesar de sentir que poderíamos ter bastante dificuldade, resolvemos enfrentar o problema e montar um planejamento capaz de atender a esse trabalho pretendido.

Dentro de nossa pretensão, a de dar mais atenção à aprendizagem dos alunos do que lhes impor uma forma de ensino, menos preocupada com a transmissão de saberes do que reconhecer como os alunos podem aprender, resolvemos adotar uma metodologia alternativa, trabalhando a partir de problemas, que deveriam ser resolvidos pelos alunos em grupos cooperativos e colaborativos.

Por termos consultado diferentes livros didáticos e conhecido diferentes linhas metodológicas, como professora-pesquisadora resolvemos fazer um planejamento visando à aprendizagem das importantes ideias da Análise Combinatória e, se possível, chegar aos padrões que definem os conceitos de arranjos, permutações e combinações. 
$\underline{\text { Planejamento das aulas }}$

Para uma boa condução das aulas, senti-nos necessidade de elaborar um bom planejamento. Isso é importante para que o professor possa organizar suas aulas de modo a atingir, quando possível, seus objetivos propostos.

Consideramos importantes, para trabalhar o tópico matemático Análise Combinatória, os seguintes conceitos: padrão; contagem; Princípio Fundamental de Contagem (ou Princípio Multiplicativo); permutação; combinação e arranjo.

Para trabalhar esses conceitos, foram selecionados, em livros didáticos existentes, alguns problemas para serem explorados com a Metodologia de Ensino-AprendizagemAvaliação de Matemática através da resolução de problemas. Desse modo, iniciariam o trabalho em sala de aula com esses problemas, com o objetivo de construir novos conceitos e novos conteúdos na área de Análise Combinatória. Os alunos desde o início do ano já trabalhavam em grupos e com a metodologia adotada para o trabalho em sala de aula.

$\mathrm{Na}$ tabela abaixo apresentamos a sequência de aulas a serem desenvolvidas nesse projeto. Para cada aula fazemos corresponder o conteúdo a ser trabalhado sendo que os problemas geradores desses conteúdos obedecerão a mesma sequência proposta.

\begin{tabular}{|c|c|}
\hline Aulas & Conteúdo \\
\hline 1 e 2 & Padrão \\
\hline 3,4 e 5 & $\begin{array}{c}\text { Contagem } \\
\text { Árvore de possibilidades } \\
\text { Representação por meio de tabelas }\end{array}$ \\
\hline 6 e 7 & Contagem/Combinação \\
\hline 8,9 e 10 & $\begin{array}{c}\text { Contagem/Combinação - construção da } \\
\text { fórmula (padrão) }\end{array}$ \\
\hline 11 & $\begin{array}{c}\text { Contagem/Arranjo - } \\
\text { construção da fórmula (padrão) }\end{array}$ \\
\hline 12 & $\begin{array}{l}\text { Contagem/Permutação/Pesquisa - } \\
\text { construção da fórmula (padrão) }\end{array}$ \\
\hline
\end{tabular}

$\left(^{*}\right)$ Pesquisa solicitada para discorrer sobre diferentes temas: anagrama, senhas, código de barras, código Morse. 
Para a preparação de cada aula ou conjunto de aulas, o professor deve, para cada problema selecionado, estar ciente dos objetivos pretendidos para o problema; a justificativa para sua escolha; apresentar estratégias convenientes para sua resolução; criar diferentes possibilidades para sua resolução; idealizar a plenária com seus questionamentos; e a formalização da nova teoria construída.

\section{Roteiro de atividades}

Introdução

Com os alunos em grupos, iríamos fazer a leitura de um texto motivador para chegar ao conceito de padrão. O texto escolhido foi "Enchente no rio Nilo" e, a partir dessa leitura, esperar que os alunos se deparassem com uma primeira ideia sobre o conceito de "padrão", o que poderia acontecer através da interpretação das informações contidas no texto. Ainda mais, os alunos poderiam ter a oportunidade de conhecer um pouco da cultura antiga egípcia.

Texto: "Enchente no rio Nilo"

O Egito é banhado pelo Nilo, imenso rio que fertiliza as suas margens.

Para poderem plantar na época certa e assim garantir seus alimentos, os egípcios precisavam saber quando haveria inundação. Havia, portanto, a necessidade de se conhecer o padrão desse acontecimento.

Eles observaram que o rio subia logo depois que a estrela Sirius se levantava a leste, um pouco antes do Sol. Notando que isso acontecia a cada 365 dias, os egípcios criaram um calendário solar composto de doze meses, de 30 dias cada mês e mais cinco dias de festas, dedicados aos deuses Osíris, Hórus, Seth, Ísis e Nephthys.

Os egípcios dividiram ainda os doze meses em três estações de quatro meses cada uma: período de semear, período de crescimento e período de colheita. Leitura e discussão do texto.

Entregar aos grupos uma cópia do conjunto de atividades 1 a 6 . 
1) Qual é o próximo símbolo?

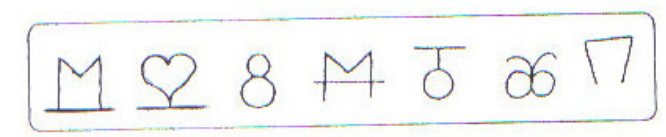

2) Quando o médico nos receita um remédio para ser tomado de três em três horas, e começamos a tomá-lo às 6 horas da manhã, quais serão os horários seguintes neste dia?

3) Situação: As estações do ano se repetem obedecendo a um padrão: de três em três meses temos uma nova estação.

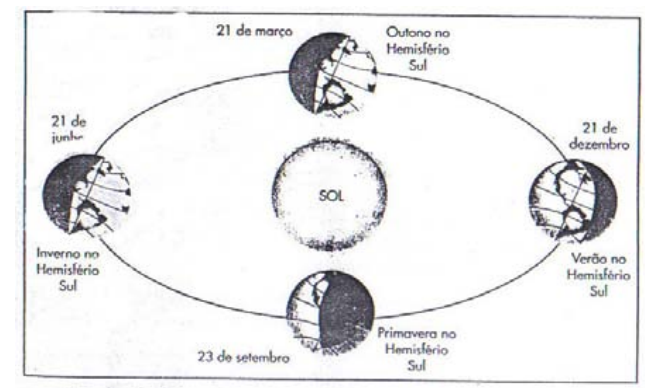

Discuta no grupo sobre a situação acima. Dê exemplos de outros padrões encontrados no dia a dia.

4) Observe a tabela retirada de uma propaganda de venda de madeiras.

\begin{tabular}{|l|l|}
\hline \multicolumn{2}{|c|}{ Cedrinho } \\
\hline $\begin{array}{l}\text { Comprimento da } \\
\text { tábua }\end{array}$ & Preço \\
\hline $30 \mathrm{~cm}$ & $\mathrm{R} \$ 1,80$ \\
\hline $25 \mathrm{~cm}$ & $\mathrm{R} \$ 1,50$ \\
\hline $20 \mathrm{~cm}$ & $\mathrm{R} \$ 1,20$ \\
\hline $15 \mathrm{~cm}$ & $\mathrm{R} \$ 0,90$ \\
\hline $10 \mathrm{~cm}$ & $\mathrm{R} \$ 0,60$ \\
\hline $5 \mathrm{~cm}$ & $\mathrm{R} \$ 0,30$ \\
\hline
\end{tabular}

Qual é o padrão existente na coluna do comprimento das tábuas? E o padrão apresentado na coluna do preço?

5) Observe as figuras abaixo e descubra, na sequência, qual é a próxima.

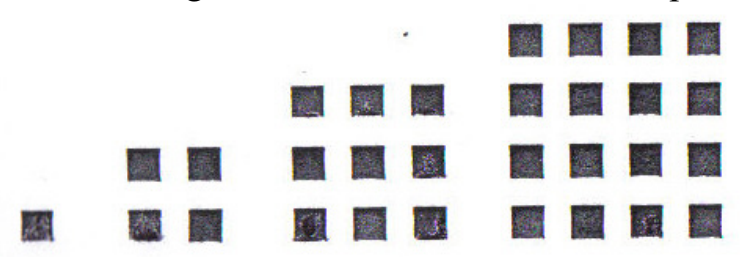

6) Problema: Estude a sequência abaixo e descubra seu padrão:

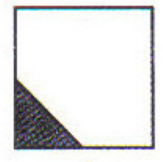

1

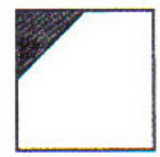

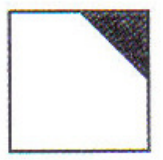

3

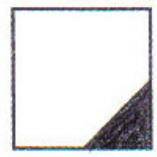

4

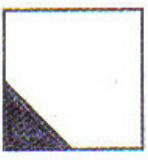

5

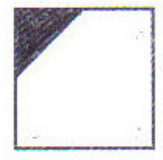

6

a) Desenhe as próximas três figuras seguindo o padrão.

b) Desenhe o $35^{\circ}$ quadrado da sequência seguindo o padrão. 


\section{Objetivos:}

- Identificar, ou não, padrões em situações do cotidiano.

- Fazer com que os alunos, através da observação, encontrem identifiquem um padrão em cada caso.

\section{Justificativa:}

O conceito de padrão é importante. Faz com que o aluno possa perceber que esse conceito pode ser usado para estender sequências, encontrar um termo da sequência sem precisar enumerá-lo, e é, também, uma boa estratégia para resolver determinados problemas.

Para a $1^{\mathbf{a}}$ atividade, uma boa estratégia seria:

a) Buscar por um padrão por meio de observação.

b) Usar simetria.

Com a primeira estratégia, observando o formato de cada símbolo da sequência, o grupo poderia chegar a perceber que seus termos da sequência são os números 1, 2, 3, 4, 5, 6 e 7, desenhados aos pares especularmente:

\section{MIS 8 M $26 \Pi$}

Assim, o próximo símbolo seria 88.

Com a segunda estratégia, traçando uma reta pontilhada, perpendicular à linha que contém esses símbolos, passando pelo ponto médio de cada símbolo, teríamos:

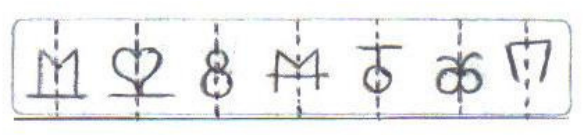

Essa estratégia facilitaria a visualização dos números que compõem cada símbolo. Então, sendo eles 1, 2, 3, 4, 5, 6, 7, o próximo símbolo será 88 .

$\mathrm{Na}$ plenária, pretendemos que os alunos possam observar e perceber como obter a sequência.

Para a $2^{\mathbf{a}}$ atividade, uma estratégia conveniente é fazer uma tabela e buscar um padrão. 


\begin{tabular}{|c|c|c|}
\cline { 2 - 3 } \multicolumn{1}{c|}{} & $\begin{array}{c}\text { hora de tomar o } \\
\text { remédio }\end{array}$ & $\begin{array}{c}\text { próximo horário a } \\
\text { tomar o remédio }\end{array}$ \\
\hline início & $6 \mathrm{~h}$ & $9 \mathrm{~h}$ \\
\hline $2^{\mathrm{o}}$ horário & $9 \mathrm{~h}$ & $12 \mathrm{~h}$ \\
\hline $3^{\mathrm{o}}$ horário & $12 \mathrm{~h}$ & $15 \mathrm{~h}$ \\
\hline $4^{\circ}$ horário & $15 \mathrm{~h}$ & $18 \mathrm{~h}$ \\
\hline $5^{\circ}$ horário & $18 \mathrm{~h}$ & $21 \mathrm{~h}$ \\
\hline $6^{-}$horário & $21 \mathrm{~h}$ & $24 \mathrm{~h}$ \\
\hline
\end{tabular}

Para encontrar os horários seguintes, a começar às $6 \mathrm{~h}$, basta adicionar $3 \mathrm{~h}$ a cada horário em que tomou o remédio. Portanto os próximos horários são 9h, 12h, 15h, 18h, $21 \mathrm{~h}$ e $24 h$.

Na plenária, espera-se que, mesmo considerando um problema simples, o aluno possa observar e reconhecer um padrão.

Para a $3^{\mathbf{a}}$ atividade, a estratégia escolhida foi: observar a figura, discutir em grupo e interpretar o movimento da Terra em torno do Sol, mostrando quanto da Terra está exposto frente ao Sol, exibindo as datas do início de cada estação do ano.

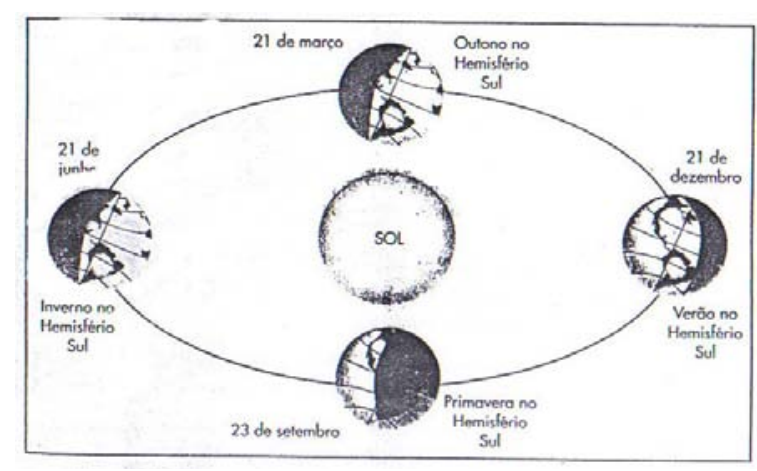

Exemplos de padrões encontrados no dia a dia: fases da Lua; formação da semana (7 em 7 dias); formação do ano (12 em 12 meses); outros padrões podem ser observados em ornamentos e peças de decoração.

Na plenária, espera-se que os alunos possam discutir, em seus grupos e citar padrões do cotidiano, compartilhando seus exemplos, um com os outros.

Para a $4^{\mathbf{a}}$ atividade utilizamos a seguinte estratégia: buscar por um padrão, ao observar uma tabela: 


\begin{tabular}{|l|l|}
\hline \multicolumn{2}{|c|}{ Cedrinho } \\
\hline $\begin{array}{l}\text { Comprimento da } \\
\text { tábua }\end{array}$ & Preço \\
\hline $30 \mathrm{~cm}$ & $\mathrm{R} \$ 1,80$ \\
\hline $25 \mathrm{~cm}$ & $\mathrm{R} \$ 1,50$ \\
\hline $20 \mathrm{~cm}$ & $\mathrm{R} \$ 1,20$ \\
\hline $15 \mathrm{~cm}$ & $\mathrm{R} \$ 0,90$ \\
\hline $10 \mathrm{~cm}$ & $\mathrm{R} \$ 0,60$ \\
\hline $5 \mathrm{~cm}$ & $\mathrm{R} \$ 0,30$ \\
\hline
\end{tabular}

Observando cada coluna pode-se perceber que na coluna que se refere ao comprimento das tábuas, de uma para a outra, o comprimento vai diminuindo $5 \mathrm{~cm}$. Na coluna do preço, o valor de cada tábua vai diminuindo, de uma para a outra 30 centavos.

Plenária: analisar os valores dispostos nas colunas da tabela e buscar um padrão. Discutir que, no comércio, nem sempre aparece um padrão como esse. Mas, nesse caso, o padrão seria dado por uma relação funcional, descrevendo a variação do preço em função do número de vezes que ocorreria a variação do comprimento da tábua.

Para a $5^{\mathbf{a}}$ atividade foi escolhida a estratégia que pedia, ao desenhar a figura, nela buscar um padrão de continuidade.

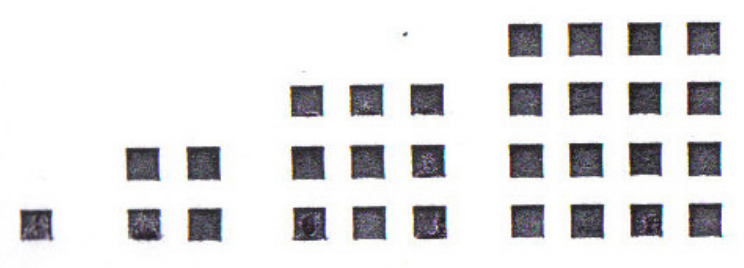

A sequência é formada por figuras de quadrados formados por outros quadrados menores e ampliando cada figura chegar a quadrados maiores. Observando cada sequência apresentada, teremos que a próxima será:

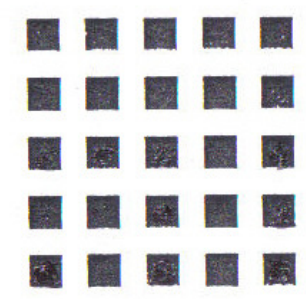

Na plenária, em discussão, esperamos que os grupos identifiquem a figura seguinte através da observação do número de quadrados iguais ao primeiro na sequência dada. $\mathrm{O}$ 
número de quadrados menores de cada figura da sequência forma uma sequência de números quadrados.

Seja $n$ o número de quadrados menores para formar o lado do quadrado maior.

Para $n=1$, temos em relação à área que $1^{2}=1$; para $n=2$, temos $2^{2}=4$; para $\mathrm{n}=3$, temos $3^{2}=9$. Seguindo esse mesmo raciocínio, para $n=n$, temos $n^{2}$.

Observando o significado do expoente colocado sobre o número $n$ de quadrados menores utilizados para formar os quadrados maiores, os alunos poderiam perceber que $\forall n \in N$, o número de quadrados necessários para formar o quadrado de lado $n$ é $n^{2}$. Assim, pode-se obter a sequência de números quadrados: $1,4,9,16,25, \ldots, n^{2}, \ldots$

Para a $6^{\mathbf{a}}$ atividade uma boa estratégia é a de buscar um padrão desenhando e observando o movimento das figuras, no sentido horário, do canto sombreado ao longo da sequência.

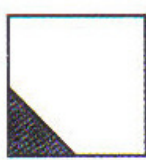

1

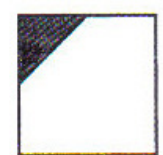

2

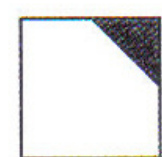

3

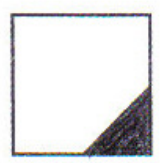

4

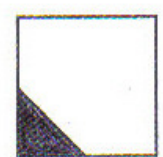

5

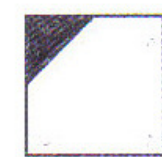

6

a) Esse padrão consiste da sequência de quadrados desenhados com um canto sombreado. $\mathrm{O}$ canto sombreado é determinado, pela rotação no sentido horário. Então as próximas três figuras perdidas seriam as desenhadas abaixo:

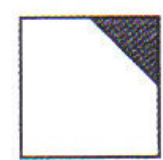

7

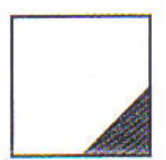

8

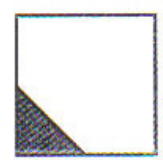

9

Outro possível caminho para se chegar à solução dessa atividade: observa-se que o padrão se repete a cada 4 desenhos, então o sétimo quadrado será a mesma forma que a do $3^{0}$ quadrado; o oitavo será igual ao quarto quadrado; e o nono será o mesmo que o quinto.

b) O padrão se repete depois de quatro desenhos e continua se repetindo de quatro em quatro.

Sabe-se que 32 é o maior número, menor que 35 , que é divisível por 4 , então o $33^{\circ}$ quadrado terá a mesma forma que a do primeiro quadrado. Então temos: 


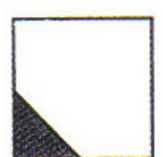

33

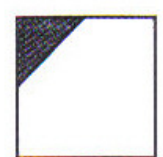

34

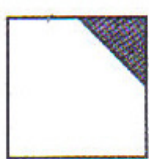

35

O $35^{\underline{0}}$ tem a mesma forma que o $3^{\circ}$ quadrado.

Outra maneira de ver seria esta:

Basta, neste caso, fazer $35 \bigsqcup 4$ e isto significa que haveria na sequência, oito 38

blocos de quatro quadrados e sobrariam três quadrados: o primeiro correspondendo ao $33^{\circ}$, o segundo, ao $34^{\circ}$ e o terceiro ao $35^{\circ}$.

$\mathrm{Na}$ plenária, pretende-se que os alunos busquem um padrão observando que, nessa sequência de quadrados, há um período que se repete: o bloco formado pelas quatro primeiras figuras. Desse modo, para encontrar um quadrado de numeração maior, não é necessário desenhá-lo, basta entender o padrão e reconhecer o período.

\section{$\underline{\text { Formalização }}$}

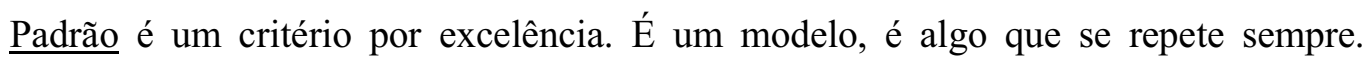
Podemos encontrar padrões numa sequência numérica; numa sequência de figuras; em ornamentos (decoração), na natureza, nas fórmulas deduzidas, nas proposições demonstradas, nas rotinas da escola, etc.

Nestas atividades, foram utilizadas diferentes estratégias para encontrar a solução, então, a formalização pode ser trabalhada de diferentes modos durante a resolução do problema.

Por exemplo, na $2^{\underline{a}}$ atividade, a formalização pode ser feita através da construção e da discussão da tabela. $\mathrm{Na}^{3}$ atividade, durante a discussão, os grupos poderiam citar padrões do cotidiano, compartilhando seus exemplos, um com os outros. $\mathrm{Na} 4^{\underline{a}}$ atividade, pode-se observar os dados da tabela e concluir que o padrão é expresso por uma proporcionalidade.

A formalização deve ser expressa como uma ação essencialmente desenvolvida pelo professor depois que uma plenária permitiu a participação de todos. O professor poderia ter feito esse trabalho resumindo o que foi trabalhado pelos alunos, com sua guia, durante a Plenária, desde a análise das resoluções, das soluções obtidas pelos alunos e dos diferentes caminhos assumidos. 
A formalização de toda Matemática nova construída a partir dessas duas aulas deve estar apoiada no trabalho realizado por professor e alunos em cada atividade dando destaque ao objetivo geral: buscar padrão e aos objetivos específicos para cada uma das atividades propostas.

Tarefa extraclasse:

1) a) Dê os próximos dois itens na sequencia:
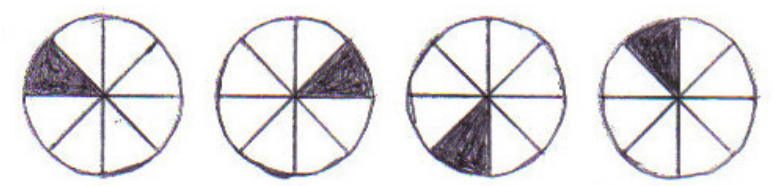

b) Qual é o padrão encontrado nessa sequência?

2) Encontrar os próximos três termos de cada sequência:

a) $7,13,19,25, \ldots$

b) $243,81,27,9, \ldots$ 
Para as aulas 3 e 4 (aula dupla) e 5 (aula simples)

\section{- Contagem}

- Árvore de possibilidades

\section{- Representação por meio de tabelas}

\section{$7^{\mathbf{a}}$ atividade}

Apresentar o problema, entregando, para cada grupo, uma cópia dele:

Agenda de aulas: Eliane quer escolher o seu horário para a natação. Ela quer ir a duas aulas por semana, uma de manhã e a outra de tarde, não sendo no mesmo dia nem em dias seguidos. De manhã, há aulas de natação de segunda-feira a sábado, às $9 \mathrm{~h}$, às $10 \mathrm{~h}$ e às $11 \mathrm{~h} \mathrm{e}$, de tarde, de segunda-feira a sexta-feira, às $17 \mathrm{~h}$ e às $18 \mathrm{~h}$. De quantas maneiras distintas Eliane pode escolher seu horário?

Objetivos:

- Projetamos trabalhar com o processo de contagem, através do uso da metodologia adotada, a partir de um problema, visando à construção de conceitos e conteúdos relativos à Análise Combinatória.

- Proporcionar aos alunos "ver" (visualizar) o processo de contagem.

Para atingir os objetivos colocados, a partir da resolução de problemas, dar-se-á tempo aos grupos para que eles possam "ver" um caminho e chegar à solução.

Como estratégias convenientes para desenvolver esse trabalho podemos citar: fazer uma lista organizada, usar o Princípio Fundamental de Contagem; expressar em ações; ou também utilizar a árvore de possibilidades.

Possíveis maneiras de resolução:

a) Extraída do livro "Banco de Questões" para a $3^{\text {a }}$ Olimpíada Brasileira de Matemática das Escolas Públicas (2007).

Se a aula da manhã é segunda ou sexta (em qualquer dos três horários), então o dia da aula de tarde pode ser escolhida de três formas diferentes (em qualquer dos dois horários), assim temos 2 × 3 × 3 × $2=36$ formas diferentes de escolher o horário. No caso em que a aula de manhã seja sábado então o dia da aula da tarde pode ser qualquer dia de segunda a quinta, assim temos $3 \times 4 \times 2=24$ possíveis formas. Por último, se a aula da manhã é terça, quarta ou quinta, então a aula da tarde só poder ser escolhida de duas formas, assim temos $3 \times 3 \times 2 \times 2$ $=36$ formas. Logo a Eliane pode escolher seu horário de $36+24+36=96$ formas distintas. 
b) Estratégia - lista organizada

Dispondo em uma tabela os dias da semana possíveis e os horários das aulas de natação do modo solicitado por Eliane:

\begin{tabular}{|l|l|c|}
\hline Manhã, às 9h, às 10h ou às 11h & Tarde, às 17h ou às 18h & Possibilidades de horários \\
\hline Segunda-feira & Quarta-feira & 6 \\
\hline Segunda-feira & Quinta-feira & 6 \\
\hline Segunda-feira & Sexta-feira & 6 \\
\hline Terça-feira & Quinta-feira & 6 \\
\hline Terça-feira & Sexta-feira & 6 \\
\hline Quarta-feira & Sexta-feira & 6 \\
\hline Quarta-feira & Segunda-feira & 6 \\
\hline Quinta-feira & Segunda-feira & 6 \\
\hline Quinta-feira & Terça-feira & 6 \\
\hline Sexta-feira & Segunda-feira & 6 \\
\hline Sexta-feira & Terça-feira & 6 \\
\hline Sexta-feira & Quarta-feira & 6 \\
\hline Sábado & Segunda-feira & 6 \\
\hline Sábado & Terça-feira & 6 \\
\hline Sábado & Quarta-feira & 6 \\
\hline Sábado & Quinta-feira & \\
\hline
\end{tabular}

Tomando a $1^{\underline{a}}$ linha da tabela, temos 1 aula na segunda de manhã e a outra aula na quarta de tarde. De manhã há 3 horários (às 9h, às 10 h ou às 11 h) e de tarde, 2 horários (às $17 \mathrm{~h}$ ou às $18 \mathrm{~h}$ ). Pelo Princípio Fundamental de Contagem temos $3 \cdot 2$ possibilidades de horários, ou seja, 6 maneiras distintas de fazer natação de segunda de manhã e quarta de tarde. Analogamente, para os outros dias disponíveis na tabela. Totalizando 96 maneiras distintas de Eliane escolher o horário para aula de natação.

Obs.: Há 96 maneiras distintas de escolher o horário, o que corresponde a 96 semanas de aula com horários diferentes. Isso corresponde a 24 meses ou 2 anos fazendo aula de natação sem repetir os horários. 
c) Estratégia - expressar em ações

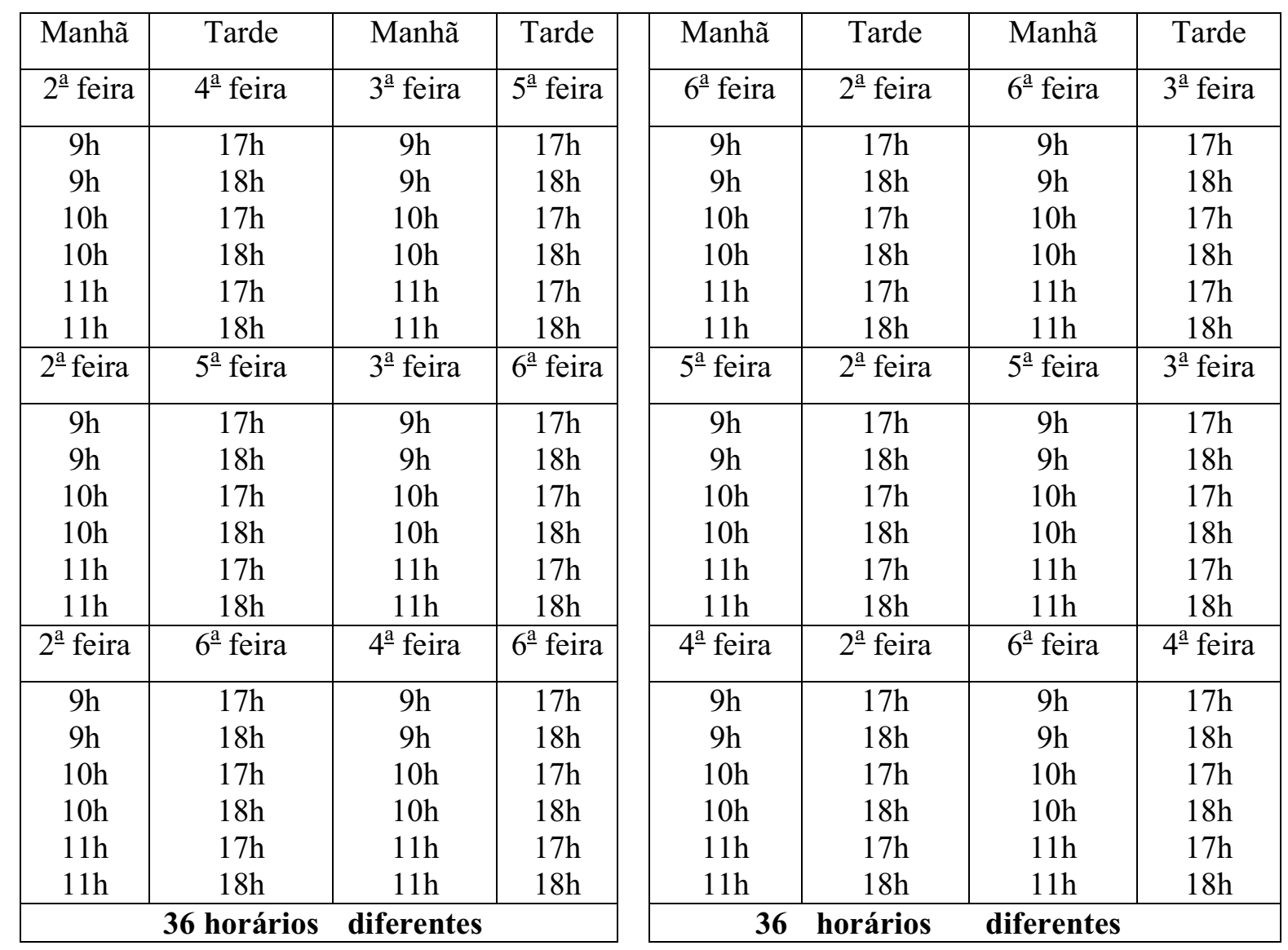

\begin{tabular}{|c|c|c|c|}
\hline Manhã & Tarde & Manhã & Tarde \\
\hline sábado & $2^{\mathrm{a}}$ feira & sábado & $3^{\mathrm{a}}$ feira \\
\hline $9 \mathrm{~h}$ & $17 \mathrm{~h}$ & $9 \mathrm{~h}$ & $17 \mathrm{~h}$ \\
$9 \mathrm{~h}$ & $18 \mathrm{~h}$ & $9 \mathrm{~h}$ & $18 \mathrm{~h}$ \\
$10 \mathrm{~h}$ & $17 \mathrm{~h}$ & $10 \mathrm{~h}$ & $17 \mathrm{~h}$ \\
$10 \mathrm{~h}$ & $18 \mathrm{~h}$ & $10 \mathrm{~h}$ & $18 \mathrm{~h}$ \\
$11 \mathrm{~h}$ & $17 \mathrm{~h}$ & $11 \mathrm{~h}$ & $17 \mathrm{~h}$ \\
$11 \mathrm{~h}$ & $18 \mathrm{~h}$ & $11 \mathrm{~h}$ & $18 \mathrm{~h}$ \\
\hline sábado & $4^{\mathrm{a}}$ feira & sábado & $5^{-}$feira \\
\hline $9 \mathrm{~h}$ & $17 \mathrm{~h}$ & $9 \mathrm{~h}$ & $17 \mathrm{~h}$ \\
$9 \mathrm{~h}$ & $18 \mathrm{~h}$ & $9 \mathrm{~h}$ & $18 \mathrm{~h}$ \\
$10 \mathrm{~h}$ & $17 \mathrm{~h}$ & $10 \mathrm{~h}$ & $17 \mathrm{~h}$ \\
$10 \mathrm{~h}$ & $18 \mathrm{~h}$ & $10 \mathrm{~h}$ & $18 \mathrm{~h}$ \\
$11 \mathrm{~h}$ & $17 \mathrm{~h}$ & $11 \mathrm{~h}$ & $17 \mathrm{~h}$ \\
$11 \mathrm{~h}$ & $18 \mathrm{~h}$ & $11 \mathrm{~h}$ & $18 \mathrm{~h}$ \\
\hline $\mathbf{2 4}$ & horários diferentes \\
\hline
\end{tabular}

Tem-se então $36+36+24=96$ horários diferentes.

Logo, Eliane pode escolher o horário para a natação de 96 maneiras diferentes. 


\section{Para as aulas 6 e 7 (aulas simples)}

\section{- Contagem}

\section{- Combinação}

\section{$\mathbf{8}^{\mathbf{a}}$ atividade}

Apresentar o problema, entregando para cada grupo, uma cópia dele:

Cumprimente antes de você festejar: Dez finalistas de diferentes estados foram convidados para uma confraternização. Antes de iniciar a festa, cada finalista cumprimentará, com as mãos, todos os outros finalistas. Quantos cumprimentos haverá ao todo?

(Retirado e traduzido do livro Problem- Driven Math: applying the mathematics beyond solutions Krulik, S.; Rudnick, J.A (2005).)

Objetivos:

- Projetamos trabalhar com o processo de contagem, através do uso da metodologia adotada, a partir de um problema, visando à construção de conceitos e conteúdos relativos à Análise Combinatória.

- Trabalhar com o conceito de Combinação simples e fazer a construção da respectiva fórmula.

Estratégias:

a) Considerar um problema mais simples.

b) Fazer uma tabela e buscar um padrão.

c) Usar o raciocínio lógico.

Possíveis maneiras de resolução:

a) Supor que se tivesse, ao invés de 10, somente 3 finalistas.

Nomear por A, B e C os três finalistas.

Não importa quem seja o primeiro a chegar, se A, B ou C. Suponhamos que seja A. Logo, não há nenhum aperto de mãos. Se B for o segundo a chegar, então, haverá o aperto de mãos de B e A. Logo um aperto de mão. Quando chegar C, ele encontrará A e B e, portanto C cumprimentará B e A. Logo, dois cumprimentos. 
No total, se apenas 3 são os convidados para a confraternização, nesse encontro haverá 3 apertos de mãos.

Justificativas:

Neste problema o que importa é a ordem de chegada dos convidados, não importando quem ele seja.

Outro aspecto a notar é que quando um deles chega ele deve cumprimentar os que já haviam chegado, notando-se que quando um cumprimenta o outro, esse aperto de mão entre eles não mais será dado.

Assim, se A tiver chegado em primeiro lugar, B em segundo e, consequentemente, C em terceiro, quando o finalista $B$ cumprimenta o finalista $A$, houve um único cumprimento.

Quando C chega, já encontra A e B e haverá dois cumprimentos. Totalizando, nessa confraternização três apertos de mãos entre os três.

b) Podemos usar como estratégia, para a resolução desse problema, buscar um padrão através de uma representação geométrica, representando cada finalista por um ponto e uma linha para representar o cumprimento entre dois finalistas. Somente uma linha representa cada par, porque quando o finalista A cumprimenta o finalista B, é o mesmo que B cumprimentar A.

\begin{tabular}{|c|c|c|c|}
\hline $\begin{array}{c}\text { Número de } \\
\text { finalistas }\end{array}$ & $\begin{array}{c}\text { Representação } \\
\text { geométrica }\end{array}$ & $\begin{array}{c}\text { Número de } \\
\text { cumprimentos }\end{array}$ & $\begin{array}{c}\text { Diferença no número } \\
\text { de cumprimentos }\end{array}$ \\
\hline 1 & - & 0 \\
\hline 2 & 10 & 3 \\
\hline 3 & &
\end{tabular}

Observando essa tabela, vemos que a diferença no número de cumprimentos aumenta sempre 1 , isto é, as diferenças são $1,2,3,4, \ldots$ Continuando o padrão e adicionando sobre o número anterior do número de cumprimentos, temos: 


\begin{tabular}{|c|c|}
\hline Número de finalistas & Número de cumprimentos \\
\hline 6 & $10+5=15$ \\
\hline 7 & $15+6=21$ \\
\hline 8 & $21+7=28$ \\
\hline 9 & $28+8=36$ \\
\hline 10 & $36+9=45$ \\
\hline
\end{tabular}

Assim, teremos o total de 45 cumprimentos entre os 10 finalistas.

E se tivéssemos mais que dez finalistas, 20, 30, 100, 350, 2000? Não seria tão fácil continuar o mesmo raciocínio, adicionar a diferença do número de cumprimentos ao número anterior. E também, através da representação geométrica, o aluno poderia perceber que se torna difícil a visualização quando o número de finalistas é grande.

Então, poderíamos estender a resolução do problema montando uma tabela da seguinte maneira:

\begin{tabular}{|c|c|c|c|}
\hline $\begin{array}{c}\text { Número de } \\
\text { finalistas } \\
(n)\end{array}$ & $\begin{array}{c}\text { Número de } \\
\text { cumprimentos } \\
(\mathrm{N})\end{array}$ & $\begin{array}{c}\text { Soma indicada do total de cumprimentos } \\
(\mathrm{S})\end{array}$ & $\begin{array}{c}\text { Total de } \\
\text { cumprimentos } \\
(T)\end{array}$ \\
\hline 1 & 0 & 0 & 0 \\
\hline 2 & 1 & $0+1$ & 1 \\
\hline 3 & 2 & $0+1+2$ & 3 \\
\hline 4 & 3 & $0+1+2+3$ & 10 \\
\hline 5 & 4 & $0+1+2+3+4$ & 21 \\
\hline 6 & 5 & $0+1+2+3+4+5+6$ & 28 \\
\hline 7 & 6 & $0+1+2+3+4+5+6+7$ & 36 \\
\hline 8 & 7 & $0+1+2+3+4+5+6+7+8$ & 45 \\
\hline 9 & 8 & $0+1+2+3+4+5+6+7+8+9$ & $\vdots$ \\
\hline 10 & 9 & $\vdots$ & $\frac{n \cdot(n-1)}{2}$ \\
\hline$\vdots$ & $\vdots$ & $0+1+2+3+4+\ldots+(n-2)+(n-1)$ & \\
\hline$n$ & $n-1$ & & \\
\hline
\end{tabular}


Pode-se observar na tabela que o número de cumprimentos é uma unidade a menos do número de finalistas. Então, se temos $n$ finalistas, teremos $(n-1)$ cumprimentos. Na segunda coluna, a visualização da soma indicada do total de cumprimentos ajuda a encontrar o número de cumprimentos, adicionando o número de finalistas menos uma unidade. Assim, para $n$ finalistas, temos $n \cdot(n-1)$ cumprimentos, mas entre duas pessoas contamos apenas um cumprimento, então dividimos por dois. Então, na terceira coluna, vemos que o total de finalistas é indicado por $\frac{n \cdot(n-1)}{2}$. Na terceira coluna, podemos ver que $\mathrm{T}=\frac{n \cdot(n-1)}{2}$, essa fórmula é um padrão, que relaciona as grandezas: número de finalistas e o total do número de cumprimentos. Assim, podemos encontrar o número total de cumprimentos para qualquer valor de $n$, ou seja, sendo $n$ o número de pessoas. Teríamos que provar, tendo como recurso o Princípio de Indução Finita, a validade dessa fórmula e ter assim como garantia

Ao observar essa tabela, podemos explorar também o conceito de função, relacionando as variáveis envolvidas:

$n$ : variável independente

$\mathrm{N}$ : variável dependente

T: total de cumprimentos

$T(n)=\frac{n \cdot(n-1)}{2} \quad$ e $\quad \mathrm{N}(n)=n-1$

Podemos observar ainda que a sequência do número de cumprimentos forma uma progressão aritmética de razão 1 . O primeiro termo da sequência $\left(a_{1}\right)$ é 0 , o último termo $\left(a_{n}\right)$ é $(n-1)$, o número de termos é $n$. A soma dos elementos de uma Progressão Aritmética é dada por $\frac{\left(a_{1}+a_{n}\right) \cdot n}{2}$.

Substituindo pelos dados do problema, temos $\frac{[0+(n-1)] \cdot n}{2}=\frac{(n-1) \cdot n}{2}$, total de cumprimentos para $n$ pessoas.

Para $n=10$, temos $\frac{[0+(10-1)] \cdot 10}{2}=\frac{[0+9] \cdot 10}{2}=\frac{9 \cdot 10}{2}=\frac{90}{2}=45$. 
c) Usando o raciocínio lógico

Cada finalista deve cumprimentar todos os outros nove. Então há $9 \cdot 10=90$ cumprimentos. O cumprimento de A com B é o mesmo de B com A, então o cumprimento de um pelo outro deve ser considerado apenas uma vez, quer ele cumprimente ou quer seja cumprimentado. Assim, dividimos 90 por 2, então temos no final 45 cumprimentos no total.

A situação que aparece nesse problema, cumprimento com as mãos, há uma ação de que ocorre simultaneamente de dois em dois - duas pessoas. Essa ação é um ato de combinar que significa co: junto e binar: binário, de dois.

Questões-chave que poderiam ser exploradas durante a plenária:

a) Quantos finalistas estão na confraternização? Como se sabe isso?

b) Depois que o finalista $\mathrm{A}$ cumprimentar o finalista $\mathrm{B}$, há um outro cumprimento entre B e A?

c) Se você representar cada finalista com um ponto, como você pode representar cada cumprimento?

d) Como cada polígono representa a questão de quantos são os cumprimentos?

e) Como você pode encontrar um padrão para o número de cumprimentos para cada finalista e, também para o total de cumprimentos?

f) Que padrão você observa? 
Para as aulas 8 (aula simples); 9 e 10 (aula dupla)

- Contagem

- Combinação

- Construção da fórmula

\section{9' atividade}

Apresentar o problema, entregando para cada grupo uma cópia dele:

Sobre uma circunferência marcam-se 6 pontos distintos. Determine quantos quadriláteros convexos podem ser formados com vértices nesses pontos.

Objetivos:

- Explorar o processo de contagem, fazendo uso da geometria.

- Trabalhar as ideias básicas de combinação, percebendo a necessidade de que os grupos formados diferem somente pela natureza dos elementos.

- Construção da fórmula de Combinação simples.

Em geral os livros-texto dão início, ao trabalho com Análise Combinatória, a partir do conceito de Arranjo, que envolve como critérios de mudança nos agrupamentos: a natureza dos elementos e sua ordem.

Preferimos iniciar o trabalho de Análise Combinatória com combinações, por acreditar que, para os alunos seria mais compreensível, a partir do Princípio Multiplicativo, representado pela árvore de possibilidades, o reconhecimento de combinações.

Estratégias:

a) Faça uma lista organizada.

b) Expresse em ações - represente geometricamente essas ações.

Possíveis maneiras de resolução:

a) Utilizando a primeira estratégia.

Desenhar uma circunferência.

Representar por A, B, C, D, E e F os seis pontos distintos dados, marcados na circunferência. 
Para determinar os quadriláteros, precisamos de apenas quatro dos seis pontos marcados, que serão seus vértices. Organizando em uma lista os vértices, e iniciando com o vértice $\mathrm{A}$ e terminando também em $\mathrm{A}$, encontramos as seguintes possibilidades:

$\begin{array}{ll}\text { ABCD } & \text { ABEF } \\ \text { ABCE } & \text { ACDE } \\ \text { ABCF } & \text { ACDF } \\ \text { ABDE } & \text { ACEF } \\ \text { ABDF } & \text { ADEF }\end{array}$

Obtendo, então, 10 quadriláteros.

Ao iniciar com o vértice $B$ e terminando em $B$, não será mais considerado o vértice $A$. Nesse caso os quadriláteros possíveis serão:

\section{BCDE BCEF \\ BCDF BDEF}

Obtendo, então, 4 quadriláteros.

Ao iniciar com o vértice $\mathrm{C}$ e terminando em $\mathrm{C}$, não são mais considerados os vértices A e B.

Então, CDEF é o único quadrilátero possível.

Assim, pelo Princípio Aditivo, podem ser formados $10+4+1=15$ quadriláteros, com os seis pontos distintos marcados na circunferência.

Observa-se que começar com qualquer um dos vértices é irrelevante, isto é, este resultado independe do vértice escolhido para começar a formação dos quadriláteros.

b) Expresse em ações - represente geometricamente

Dispondo os seis pontos distintos sobre uma circunferência, poderíamos representá-los de variadas maneiras ao longo dela. Entretanto, depois que uma ordem seja estabelecida, deve-se trabalhar sempre sobre ela.

Um dos possíveis caminhos para descrever os quadriláteros seria o de "tentativa e erro", onde seria possível chegar à essa mesma resposta. Seria fácil haver, com tentativa e erro com falta de ou repetição de quadriláteros. 


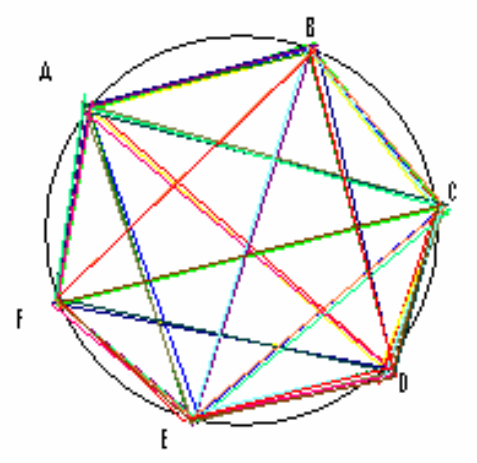

Um outro caminho, para facilitar a visualização dos quadriláteros, seria o de construir separadamente os diferentes quadriláteros.
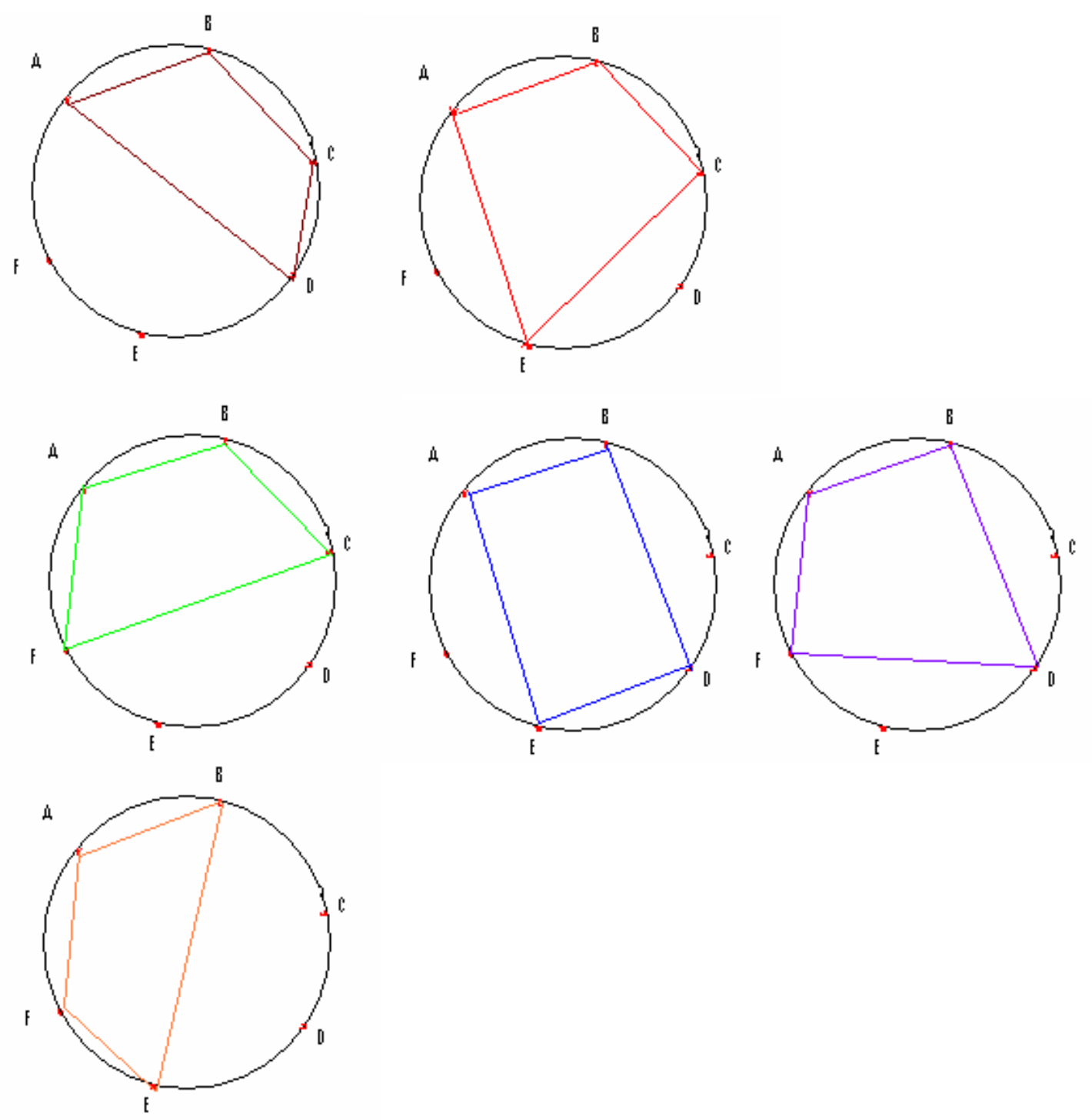

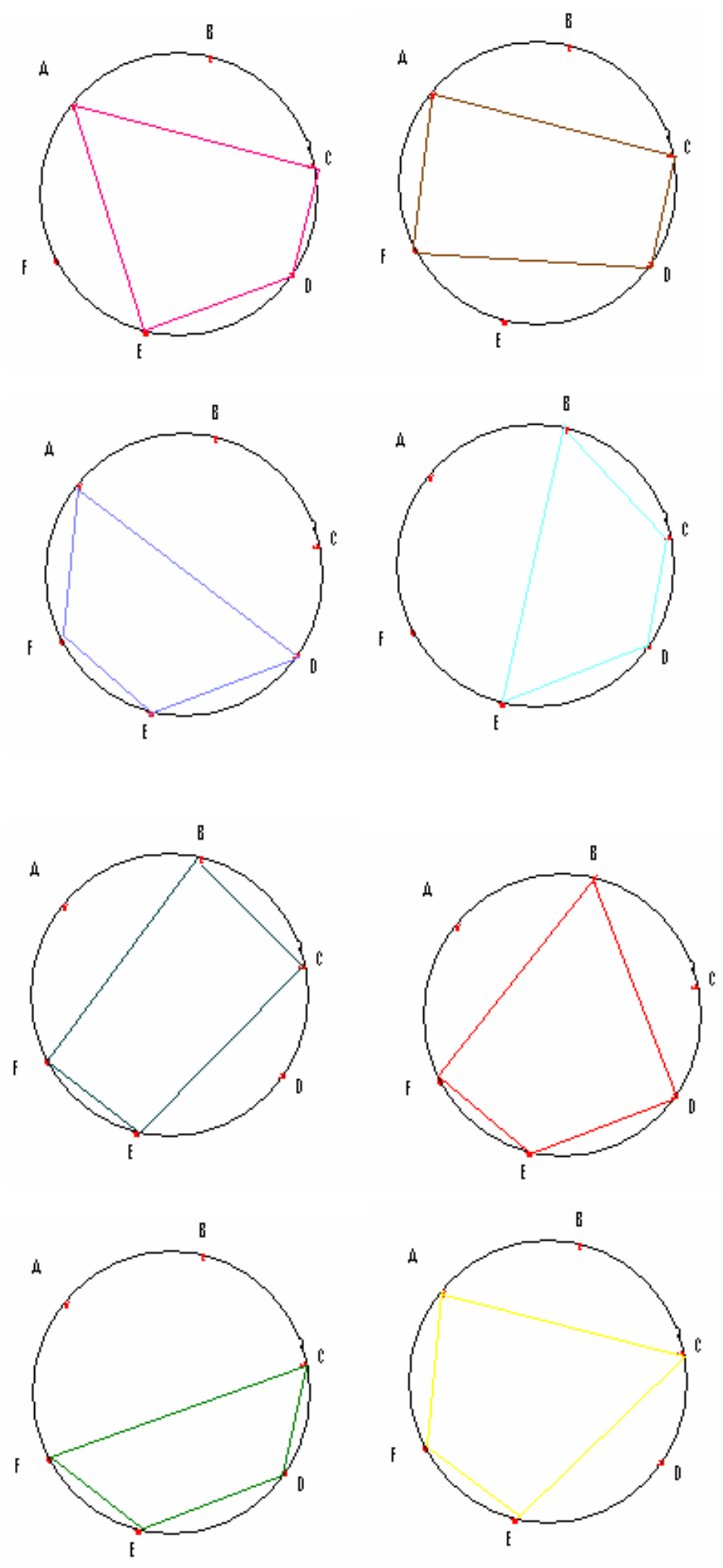


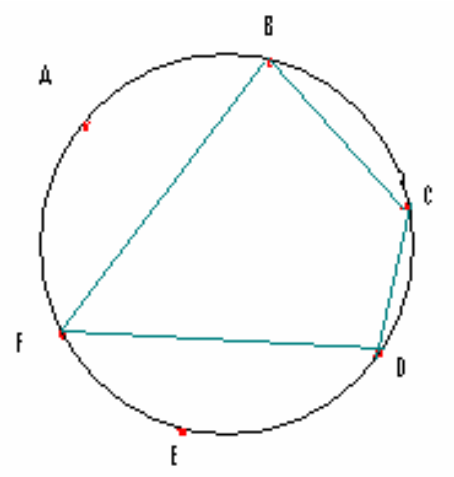

$\mathrm{Na}$ plenária, pretende-se que os alunos percebam que um quadrilátero, quando mudamos o início e o fim dos vértices para sua construção, permanece o mesmo. Por exemplo, iniciando no vértice $\mathrm{B}$ e obedecendo a uma ordem já estabelecida - por exemplo, o sentido horário -, então teríamos $\mathrm{BCDE}$. Se iniciarmos no vértice $\mathrm{C}$, teríamos $\mathrm{CDEB}$, onde BCDE e CDEB representam o mesmo quadrilátero. 


\section{Para a aula 11 (aula simples)}

- Contagem

- Arranjo

- Construção da fórmula

\section{$10^{\mathrm{a}}$ atividade}

Apresentar o problema, entregando para os grupos uma cópia dele:

Com os algarismos 1, 2 e 7, quantos números com 3 algarismos distintos podemos formar?

Objetivos:

- Durante o processo de contagem, observar a ordem dos elementos e verificar se o fato de mudar a ordem influencia ou não o resultado.

- Trabalhar as ideias básicas de Arranjo, percebendo que os grupos formados diferem pela ordem e pela natureza dos elementos.

- Construção das fórmulas de Arranjo e Combinação simples.

\section{Estratégias}

a) Faça uma lista organizada.

b) Faça a árvore de possibilidades.

a) Com os algarismos 1, 2, e 7, façamos uma lista organizada, iniciando-a primeiro com o algarismo 1, depois com o 2 e, em seguida, com o 7.

$$
\begin{array}{lll}
127 & 217 & 712 \\
172 & 271 & 721
\end{array}
$$

Há portanto seis números diferentes com três algarismos distintos.

b) Através da árvore de possibilidades:

A árvore de possibilidades é um recurso útil para a sistematização da contagem de casos possíveis. Ela representa os principais tipos de raciocínio envolvidos nos problemas de Análise Combinatória: o raciocínio aditivo e o raciocínio multiplicativo. Os alunos deveriam aprender que a árvore de possibilidades representa o número de possibilidades e que tem uma estrutura multiplicativa. 
Para sua construção, podemos imaginar uma árvore com vários troncos (ramos principais). Cada tronco com vários galhos (ramos secundários), e cada galho com vários ramos (ramos terciários).

Nesse problema, temos que os troncos representam a casa das centenas, os ramos secundários, a casa das dezenas e os ramos terciários, a casa das unidades. Assim, temos três troncos, 1, 2 ou 7; dois ramos secundários pois, escolhido um tronco, restam duas possibilidades para formar esses ramos; e um ramo terciário correspondente a cada ramo secundário. Desse modo formam-se seis números de três algarismos distintos.

Representamos a árvore de possibilidades desse problema a seguir:

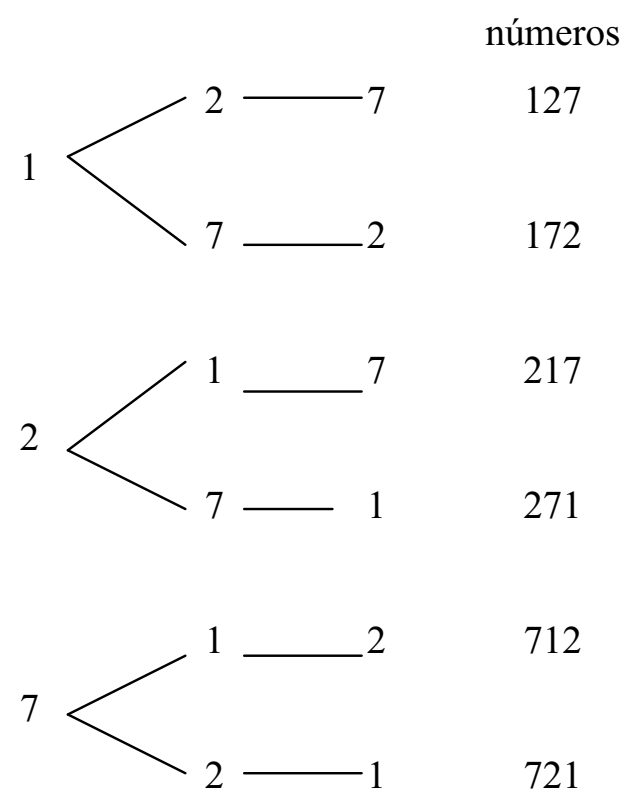

Algumas questões que poderiam ser feitas durante a plenária:

a) Quantas são as possibilidades para o algarismo das centenas?

b) Uma vez escolhido o algarismo das centenas, quantas possibilidades há para o algarismo das dezenas?

c) Escolhido os algarismos das centenas e das dezenas, quantas possibilidades há para o algarismo das unidades?

d) E se aumentássemos o número de algarismos para 4, quantos números teríamos formado? 
e) Poderíamos generalizar essa observação feita, de modo a torná-la um padrão que valesse para qualquer número de algarismos?

\section{Tarefa extraclasse:}

Quantos números de 4 algarismos distintos podemos formar com os algarismos 2, 4, 5 e 7 ?

\section{Construção das fórmulas:}

Se, ao invés de números de três algarismos, tivéssemos números com 9 algarismos, a árvore de possibilidades não seria tão facilmente representativa. Quantos números de 9 algarismos distintos poderíamos formar?

Assim, temos a necessidade da construção da fórmula que represente o número de arranjos formados.

Nesses agrupamentos, além da exigência que se faz quanto à natureza dos elementos, também se exige, para formar grupos, que seja obedecida a ordem dos elementos considerados.

Essa forma de agrupar recebe o nome de arranjo.

\section{Arranjos simples}

Seja $I=\left\{a_{1}, a_{2}, a_{3}, \ldots, a_{n}\right\}$ um conjunto formado por $n$ elementos e seja $p$ um número natural não nulo, $p \leq n$. O número de arranjos simples dos $n$ elementos de I tomados $p$ a $p$, isto é, $A_{n, p}$, pode ser calculado pelo Princípio Fundamental de Contagem:

Para o $1^{\mathrm{o}}$ elemento, há $n$ possibilidades de assumir um lugar na sequência dos elementos;

para o $2^{\underline{0}}$ elemento, $(n-1)$ possibilidades;

para o $3^{\circ}$ elemento, $(n-2)$ possibilidades;

para o $4^{\circ}$ elemento, $(n-3)$ possibilidades;

e, para o p-ésimo elemento, $[n-(\mathrm{p}-1)]$ possibilidades.

Assim, temos que:

$A_{n, p}=n(n-1)(n-2)(n-3) \cdot \ldots \cdot[n-(p-1)]$

ou

$A_{n, p}=n(n-1)(n-2)(n-3) \cdot \ldots \cdot(n-p+1)$ 
Para chegar ao fatorial de $n$, precisamos multiplicar por $(n-\mathrm{p})$ !.

Mas para não alterar a igualdade, devemos dividir o segundo membro dessa igualdade também por $(n-p)$ !. Além de facilitar os cálculos, utilizando o conceito de fatorial, o fato de multiplicar por $(n-p)$ ! decorre do número de agrupamentos que se repete utilizando os mesmos elementos, ou seja, há $(n-p)$ ! agrupamentos formados pelos mesmos elementos.

Desse modo, temos:

$$
\begin{aligned}
& A_{n, p}=n(n-1)(n-2)(n-3) \cdot \ldots \cdot(n-p+1) \cdot \frac{(n-\mathrm{p}) !}{(n-\mathrm{p}) !} \\
& A_{n, p}=\frac{n(n-1)(n-2)(n-3) \cdot \ldots \cdot(n-p+1)(n-\mathrm{p}) !}{(n-\mathrm{p}) !} \\
& \therefore A_{n, p}=\frac{n !}{(n-p) !}
\end{aligned}
$$

\section{Teorema 1}

Seja $\mathrm{I}=\left\{\mathrm{a}_{1}, \mathrm{a}_{2}, \mathrm{a}_{3}, \ldots, \mathrm{a}_{\mathrm{n}}\right\}$ um conjunto formado por $n$ elementos e seja $p$ um número natural não nulo tal que $p \leq n$. Chama-se arranjo simples de $\boldsymbol{p}$ elementos distintos de I a toda sequência formada por $p$ elementos de I distintos.

O número de arranjos simples de $n$ elementos distintos tomados $p$ a $p$ é dado pela fórmula $A_{n, p}=\frac{n !}{(n-p) !}$.

\section{Combinações simples}

Conhecidas as ideias de arranjos simples, as ideias de combinações surgiriam como um consequente caso particular, e não dependeriam da ordem dos elementos mas, somente da natureza desses elementos.

A cada combinação de $\mathbf{n}$ elementos tomados $\mathbf{p}$ a $\mathbf{p}$ correspondem $\mathbf{p}$ ! arranjos que são obtidos permutando-se os elementos da combinação, ou seja: 


$$
\begin{aligned}
& A_{n, p}=C_{n, p} \cdot P_{p} \Rightarrow C_{n, p}=\frac{A_{n, p}}{P_{p}} \Rightarrow C_{n, p}=\frac{n \cdot(n-1) \cdot \ldots \cdot(n-p+1)}{p !}=\frac{n(n-1) \cdot \ldots \cdot(n-p+1)}{p !} \cdot \frac{(n-p) !}{(n-p) !}= \\
& =\frac{n !}{p !(n-p) !}
\end{aligned}
$$

\section{Teorema 2}

Sendo $A=\left\{a_{1}, a_{2}, a_{3}, \ldots, a_{n}\right\}$ um conjunto formado com $\mathbf{n}$ elementos e $\mathbf{p}$ um número natural, tal que $\mathrm{p} \leq \mathrm{n}$, chamamos de combinação simples dos $\mathbf{n}$ elementos de A, tomados $\mathbf{p}$ a $\mathbf{p}$, a todo subconjunto de A com $\mathbf{p}$ elementos, onde o número de combinações é dado por $C_{n, p}=\frac{n !}{p !(n-p) !}$, sendop $\leq \mathrm{n}$. 
Para a aula 12 (aula simples)

- Contagem

- Permutação

- Construção da fórmula

- Pesquisa

$11^{\mathrm{a}}$ atividade

Pedir aos alunos, formados em grupos, para realizarem pesquisas sobre os temas: anagrama, senhas, código de barras, código Morse.

Objetivos:

- Trabalhar as ideias básicas de Permutação percebendo que os grupos formados diferem apenas pela ordem dos elementos envolvidos.

- Verificar a importância desse tópico matemático na realidade em que vivem através da realização da pesquisa.

- Compartilhar em grupo as informações obtidas na pesquisa.

A pesquisa deve ser realizada em grupos, abordando um ou mais dos temas propostos. Os alunos poderiam consultar sites, revistas e livros sobre o tema escolhido.

Após feita a discussão sobre os diferentes temas pesquisados, serão explorados em particular os anagramas, a fim de que os alunos possam trabalhar as ideias básicas de Permutação.

\section{Construção da fórmula}

\section{Permutação simples}

Consideremos os $n$ elementos $a_{1}, a_{2}, a_{3}, \ldots, a_{n}$ e as $n$ posições $P_{i}(i=1,2, \ldots, n)$ da sequência $\left(P_{1}, P_{2}, \ldots, P_{n}\right)$ que esses elementos podem assumir. 


\begin{tabular}{|c|c|}
\hline Acontecimentos & Número de possibilidades \\
\hline Preenchimento da $1^{\underline{a}}$ posição & $n-1$ \\
\hline $\begin{array}{c}\text { Preenchimento da } 2^{\underline{a}} \text { posição, após o } \\
\text { preenchimento da } 1^{\underline{a}}\end{array}$ & $\vdots$ \\
\hline$\vdots$ & 1 \\
\hline $\begin{array}{c}\text { Preenchimento da } n \text {-ésima posição, após o } \\
\text { preenchimento das anteriores }\end{array}$ & \\
\hline
\end{tabular}

Logo, pelo Princípio Multiplicativo, temos:

$P_{n}=n(n-1)(n-2) \ldots 1=n !$

$\therefore P_{n}=n$ !

\section{Teorema}

Seja E um conjunto de $n$ elementos. chama-se permutação simples de $n$ elementos, qualquer sequência de $n$ elementos distintos de E. O número de permutações de $n$ elementos distintos é dado por $P_{n}=n$ !. 
Problema proposto (Código de barras): As embalagens dos produtos vendidos por uma empresa apresentam uma seqüência formada por barras verticais: quatro de largura 1,5mm; três de largura $0,5 \mathrm{~mm}$ e duas de largura $0,25 \mathrm{~mm}$, como no exemplo abaixo. Cada seqüência indica o preço de um produto. Quantos preços diferentes podem ser indicados por essas nove barras? (Retirado e adaptado do livro Matemática volume único, Manoel Paiva (1999).)

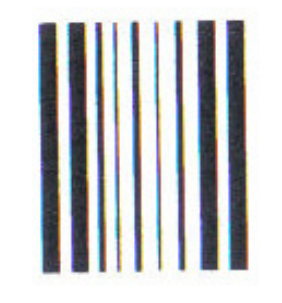

Para calcular o número de preços, temos:

4 barras de largura 1,5mm, indicaremos por: $\mathrm{x}_{1}, \mathrm{x}_{2}, \mathrm{x}_{3} \mathrm{e} \mathrm{x}_{4}$;

3 barras de largura $0,5 \mathrm{~mm}$, indicaremos por: $\mathrm{y}_{1}, \mathrm{y}_{2}$ e $\mathrm{y}_{3}$;

2 barras de largura $0,25 \mathrm{~mm}$ indicaremos por: $\mathrm{z}_{1}$ e $\mathrm{z}_{2}$.

Cada sequência formada por essas nove barras indica o preço de um produto.

Se todas as nove barras fossem diferentes (na largura), teríamos 9! preços diferentes, ou seja, 362880 .

Neste problema temos as nove barras com o mesmo comprimento, mas nem todas com a mesma largura (4 de largura 1,5mm; 3 de largura $0,5 \mathrm{~mm}$ e 2 de largura $0,25 \mathrm{~mm}$ ). Quando permutamos barras de mesma largura entre si, a sequência não se altera, isto é, o preço é o mesmo. Então teremos, assim, menos que 362880 preços diferentes. Mas quanto menos?

Para responder esta pergunta, tomemos como exemplo a sequência $\mathrm{x}_{1} \mathrm{x}_{2} \mathrm{x}_{3} \mathrm{x}_{4} \mathrm{y}_{1} \mathrm{z}_{1} \mathrm{y}_{2} \mathrm{y}_{3}$ $\mathrm{z}_{2}$. Permutando as barras, temos 4 ! (permutação das barras $\mathrm{x}_{1}, \mathrm{x}_{2}, \mathrm{x}_{3} \mathrm{e} \mathrm{x}_{4}$ ); 3 ! (permutação das barras $\mathrm{y}_{1}, \mathrm{y}_{2}$ e $\mathrm{y}_{3}$ ) e 2 ! (permutação das barras $\mathrm{z}_{1}$ e $\mathrm{z}_{2}$ ), promovendo os códigos das diferentes sequências.

Pelo Princípio Fundamental de Contagem temos 4 ! . 3! . $2 !=24.6 .2=288$ sequências que indicam o mesmo preço quando a máquina converte os códigos para preços.

Analogamente, se tivéssemos a sequência $\mathrm{x}_{1} \mathrm{x}_{3} \mathrm{x}_{2} \mathrm{x}_{4} \mathrm{y}_{1} \mathrm{y}_{2} \mathrm{z}_{1} \mathrm{y}_{3} \mathrm{z}_{2}$, teríamos também 4 ! . 3 ! . 2! sequências que indicam o mesmo preço.

Assim das 362880 sequências (calculadas anteriormente). Ao dividir esse número por 288, para não contar as sequências repetidas, isto é, $\frac{362880}{288}$ ou $\frac{9 !}{4 ! 3 ! 2 !}$. Então, obtemos $\frac{362880}{288}=1260$ preços diferentes. 
Portanto, podem ser indicados por essa máquina, no código de nove barras, 1260 preços diferentes.

Obs.: Pode-se estender esse problema, pedindo para pesquisar onde mais se encontra o código de barras, além do caso de indicar o preço de produtos. Como é feita a sua leitura? O número de barras que aparece é necessariamente sempre o mesmo?

\section{Formalização:}

Esse problema pode ser generalizado.

Consideremos:

n: número total de barras

$\mathrm{n}_{1}$ : número de barras de $1,5 \mathrm{~mm}$

$\mathrm{n}_{2}$ : número de barras de $0,5 \mathrm{~mm}$

$\mathrm{n}_{3}$ : número de barras de $0,25 \mathrm{~mm}$

Assim,

\section{Teorema:}

Seja o conjunto $\left\{a_{1}, a_{2}, a_{3}, \ldots, a_{n}\right\}$ um conjunto formado por $n$ elementos.

Permutação com repetição desses $n$ elementos é dado por $P R_{n}^{\left(n_{1}, n_{2}, \ldots, n_{k}\right)}=\frac{n !}{n_{1} ! \cdot n_{2} ! \cdot \ldots \cdot n_{k} !}$, sendo $\mathrm{n}_{\mathrm{i}}$ elementos iguais a $\mathrm{a}_{\mathrm{i}}, \operatorname{com} \mathrm{i}=1,2,3, \ldots, \mathrm{k}$. 


\section{Outros problemas que poderiam ser trabalhados:}

Resolva os problemas abaixo e verifique se a ordem dos elementos envolvidos altera o resultado ou não.

1) De quantos modos diferentes podemos ordenar 2 livros de Matemática, 3 de Português e 4 de Física, de modo que os livros de uma mesma matéria fiquem sempre juntos e, além disso, os de Física, entre si, fiquem sempre na mesma ordem?

2) (Retas e triângulos) a) Quantos triângulos ficam determinados por nove pontos distintos, sendo que cinco deles pertencem a uma reta $s$ paralela a $r ?^{22}$

b) Quantas retas ficam determinadas por nove pontos distintos, sendo que cinco deles pertencem a uma reta $\mathrm{r}$ e os outros quatro pertencem a uma reta $s$ paralela a $r$ ?

Resolução:

Sejam os pontos A, B, C, D, E, F, G, H e I, sendo os cinco primeiros dispostos na reta $s$ e os outros dispostos na reta $r$.

a)

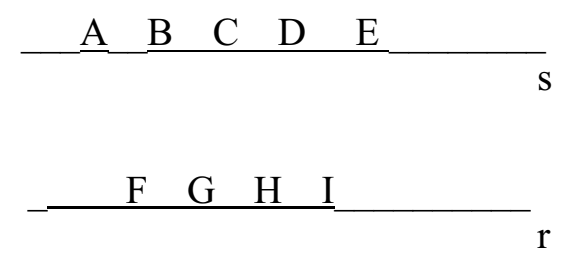

Um triângulo fica determinado por três pontos não-colineares. Assim sendo, faremos combinações de três dos nove pontos. Algumas combinações determinam um triângulo, outras não. Por exemplo, a combinação $\mathrm{BCH}$ determina um triângulo, enquanto a combinação $\mathrm{BCD}$ não determina um triângulo (pois $\mathrm{B}, \mathrm{C}$ e D são pontos colineares).

Podemos resolver esse problema de dois modos diferentes:

\section{1ำ modo:}

Um triângulo fica determinado se escolhermos dois pontos numa reta e um ponto na outra, sendo:

i) dois pontos em $r$ e um ponto em $s$

ou

ii) um ponto em $r$ e 2 pontos em $s$.

i) para cada dois pontos tomados em $r$ e um em $s$ ficam determinados 4 triângulos.

\footnotetext{
${ }^{22}$ Retirado e adaptado do livro Matemática volume único, Manoel Paiva (1999).
} 
Por exemplo, seja o par A, B. É possível com eles formar triângulos com F, G, H e I, resultando 4 triângulos.

Vamos determinar o número de pares de pontos possíveis em $r$.

A, B; A,C; A, D; A, E; B, C; B, D; B, E; C, D; C, E e D, E, totalizando 10 pares de pontos em $r$.

Observar que os pares de pontos A, B e B, A representam o mesmo lado de um triângulo. Então os pares de pontos diferem apenas pela natureza dos elementos, por exemplo o par A, B é diferente do par A, C.

Como, para cada par de pontos em $r$ e um ponto em s são gerados 4 triângulos, temos que os 10 pares considerados geram $10 \cdot 4$ triângulos $=40$ triângulos. $\mathrm{O}$ que pode ser visto em Análise Combinatória, como um caso de combinação simples. Ou seja, combinando os 5 pontos de $s$ tomados 2 a 2 e os 4 pontos de $r$ tomados 1 a 1 nos levam $C_{5,2}=10$ e $C_{4,1}=4$, visto que são duas ações ocorridas simultaneamente e então com o Princípio Multiplicativo chega-se a $C_{5,2} \cdot C_{4,1}=10 \cdot 4=40$

ii) cada dois pontos em $r$ e um em $s$ são determinados 5 triângulos.

Por exemplo, o par F, G, pode formar triângulos com A, B, C, D e E, resultando 5 triângulos.

Em $r$, quantos pares de pontos podemos formar?

F, G; F, H; F, I; G, H; G, I e H, I totalizando 6 pares de pontos em $r$.

Cada par de pontos em $r$ e um ponto em $s$ geram 5 triângulos. Então, os 6 pares geram $6 \cdot 5$ triângulos $=30$ triângulos. $O$ que pode levar, pela mesma razão anterior a $C_{4,2} \cdot C_{5,1}=6 \cdot 5=30$.

Logo, o número total de triângulos determinados é $40+30=70$ ou, numa linguagem combinatorial, onde o Princípio Aditivo comparece chega-se a

$C_{4,2} \cdot C_{5,1}+C_{5,2} \cdot C_{4,1}=30+40=70$.

\section{2- modo:}

Podemos calcular todas as combinações possíveis dos nove pontos três a três, subtraindo desse resultado o total de combinações que não determinam os triângulos.

De modo análogo ao que foi feito nos itens i) e ii) do $\mathbf{1}^{\mathbf{0}}$ modo, mas considerando que os lados AB e BA são considerados duas vezes, o total de combinações é 84 . 
Ma, tomando três pontos em $s$, temos, A, B, C; A, B, D; A, B, E; A, C, D; A, C, E; A, D, E; B, C, D; B, C, E; B, D, E e C, D, E, 10 possibilidades que não determinam triângulos.

Se três pontos tomados em $r$ tem-se, F, G, H; F, G, I; F, H, I e G, H, I, 4 possibilidades que não determinam triângulos. Assim, ao todo, tem-se $10+4=14$ possibilidades que não são triângulos.

Subtraindo 14 do total 84 , tem-se 70 triângulos determinados pelos nove pontos, ou seja, $C_{9,3}-C_{5,3}-C_{4,3}=84-10-4=70$.

b) Dois pontos distintos determinam uma única reta que passa por eles.

Podemos resolver esse problema de dois modos diferentes:

\section{$1^{\mathbf{0}}$ modo}

i) Tomando um ponto em cada reta, um ponto em $r$ e um ponto em $s$.

Então os pares de pontos que determinam uma reta são: A, F; A, G; A, H; A, I; B, F; B, G; B, H; B, I; C, F; C, G; C, H; C, I; D, F; D, G; D, H; D, I; E, F; E, G; E, H e E, I, ou seja, totalizando 20 retas.

Se mudarmos a ordem dos pontos, como por exemplo, F, A; G, A; ... teremos a mesma reta, então a ordem dos pontos não interfere na determinação da reta.

\section{$2^{\mathbf{0}}$ modo}

ii) as retas $r$ e $s$, ou seja, 2 retas.

$\therefore$ por i) e ii) tem-se 20 retas +2 retas $=22$ retas, ou seja, $4 \cdot C_{5,1}+2$ ou $5 \cdot \mathrm{C}_{4,1}$.

Observações:

a) Ao determinar os triângulos, temo-se que, por exemplo, $\triangle B C H=\triangle H B C$, então, a ordem das letras não altera o resultado (triângulo). Então tem-se agrupamentos que diferem apenas pela natureza dos elementos.

b) $\mathrm{O}$ mesmo ocorre quando se determinam as retas. Por exemplo, as retas $\overleftrightarrow{A F}$ e $\overleftrightarrow{\mathrm{FA}}$ são coincidentes, então tem-se uma única reta, ou seja, não importa a ordem em que são tomados esses pontos.

c) Pode ser utilizada a árvore de possibilidades para a determinação de todos os casos possíveis. 
d) Foram utilizados o Princípio Fundamental de Contagem (PFC) (ou Princípio Multiplicativo) e o Princípio Aditivo (PA) para dar sentido ao processo de contagem levando aos resultados.

e) Conteúdos trabalhados no processo da resolução do problema: contagem, combinação, geometria (triângulo, reta).

f) Resumindo, tomou-se um conjunto de elementos (nove pontos distintos), com os quais se fizeram agrupamentos, de acordo com os dados apresentados no problema (formar triângulos e retas com os nove pontos sendo que 5 estão em uma reta e 4 em outra). Ao fazer os agrupamentos, observou-se que a ordem estabelecida para os pontos não alterava a determinação dos triângulos ou das retas. Desse modo, contaram-se os agrupamentos, sem ter necessidade de contá-los todos, utilizando-se o PFC e/ou PA para encontrar o total de soluções.

g) As retas $r$ e $s$ não precisam ser paralelas. Nesse caso, muda o problema, desde que se concorrentes, haverá um ponto em comum. 
Neste projeto, através da apresentação das atividades em sala de aula com os problemas sendo dados como ponto de partida, pretende-se trabalhar, com os alunos, as ideias importantes presentes na formação de diferentes agrupamentos de um conjunto finito de elementos dados.

Os subconjuntos desse conjunto dado podem ser categorizados do seguinte modo:

a) Quando todos os elementos do conjunto são utilizados para formar os subconjuntos (agrupamentos), o que difere de um para outro é apenas a ordem dos elementos, caracterizando uma permutação.

b) Quando nem todos os elementos do conjunto são utilizados, e seus subconjuntos são diferenciados apenas pela natureza dos elementos, eles caracterizam um caso de combinação.

c) Outros subconjuntos, também no caso em que nem todos os elementos do conjunto são utilizados, podem se diferenciar tanto pela ordem como pela natureza dos elementos, eles caracterizam um caso de arranjo.

Pretende-se em sala de aula que essas três ideias diferentes sejam bem compreendidas pelos alunos. O conceito de padrão está presente pois sua importância se mostra na generalização dessas três ideias, que fazem parte da Matemática Discreta, onde se estuda a Análise Combinatória. Assim, o trabalho realizado abordando as três ideias acima leva à construção dos conceitos de permutação, combinação e arranjo. 


\subsection{Projeto $2-\mathbf{P}_{2}$}

Como relatamos no início deste capítulo, o $\mathbf{P}_{\mathbf{2}}$ refere-se à postura da pesquisadora ao ministrar uma oficina trabalhando o tópico Análise Combinatória. Planejamos um modelo para esboçar esse trabalho:

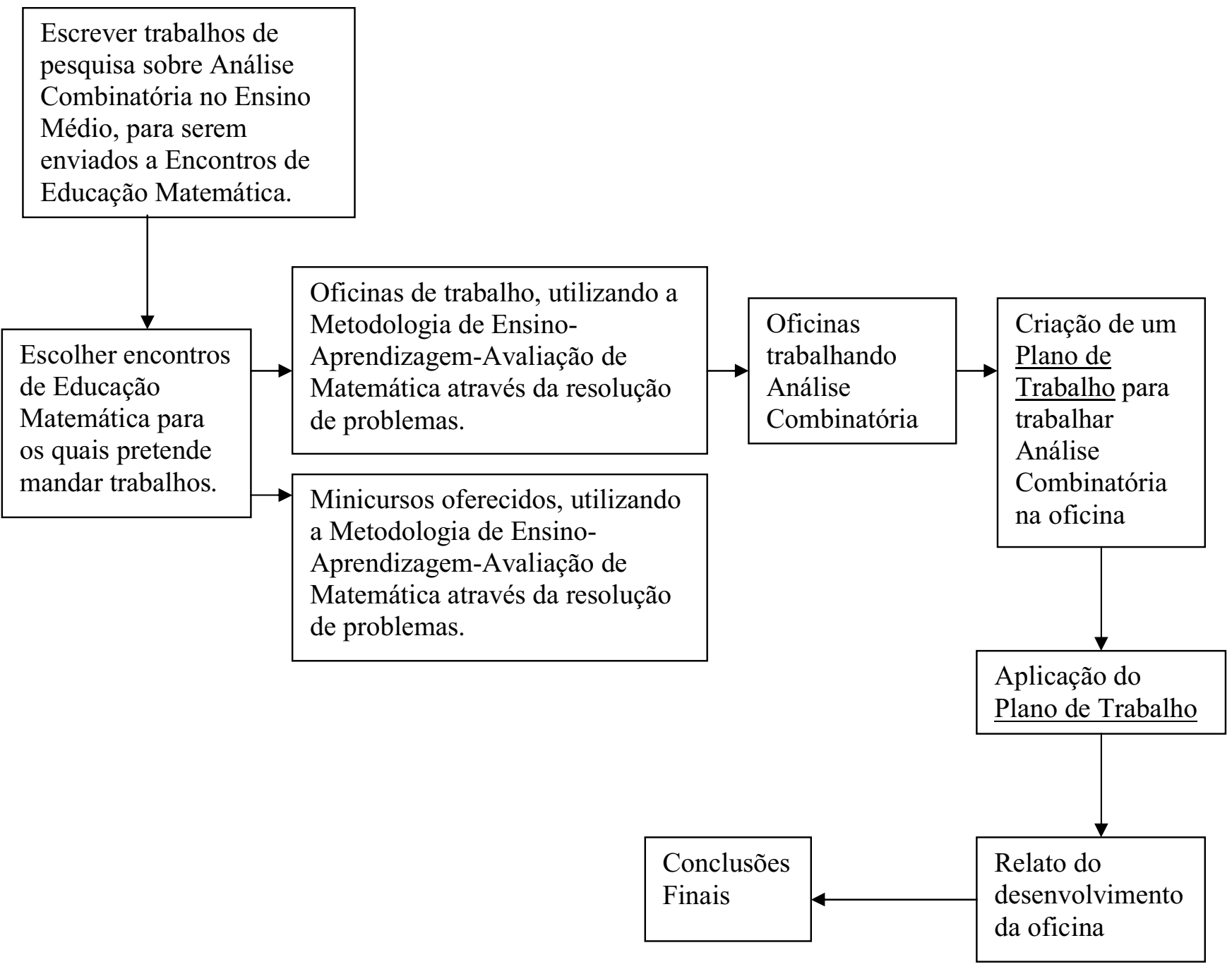

Figura 13: Modelo $-\mathrm{P}_{2}$

O objetivo de $\mathbf{P}_{2}$ é o de ministrar uma oficina de trabalho, com a autora desta pesquisa atuando como pesquisadora, para professores de Matemática, educadores matemáticos e até alunos da Licenciatura em Matemática, usando como alternativa de trabalho a Metodologia de Ensino-Aprendizagem-Avaliação de Matemática através da resolução de problemas. 
A Estratégia Geral selecionada para $\mathbf{P}_{2}$ é a de Criar um Plano de Trabalho e, como Procedimento Geral correspondente, a Criação desse Plano de Trabalho.

Confrontando com os eixos de nossa pesquisa, Resolução de Problemas e Análise Combinatória, inserida na Matemática Discreta, sentimos a necessidade de relatar nossa experiência de uma oficina, visando a apresentar uma outra abordagem de trabalhar Análise Combinatória, em um Encontro de Educação Matemática.

Escolhemos participar do II Seminário de Histórias e Investigações de/em Aulas de Matemática (IISHIAM), realizado na FE-UNICAMP no período de 24 a 26 de julho de 2008. Dentre as atividades oferecidas nesse Seminário, decidimos ministrar uma oficina que envolvesse o conteúdo Análise Combinatória, adotando uma metodologia de ensino alternativa.

Enviamos o resumo do trabalho para ser realizado na oficina, intitulado Análise Combinatória: uma abordagem com compreensão apoiada na Metodologia de EnsinoAprendizagem-Avaliação de Matemática através da resolução de problemas. $\mathrm{O}$ trabalho foi aceito e a oficina foi realizada no dia 25 de julho de 2008, das $8 \mathrm{~h} 00$ às $12 \mathrm{~h} 30 \mathrm{~min}$, com duração de 4 horas além de meia hora de intervalo.

\section{Procedimento Geral em ação - A Criação do Plano de Trabalho}

Os objetivos dessa oficina foram: apresentar uma proposta de trabalho para abordar a Análise Combinatória em sala de aula, segundo a Metodologia de Ensino-AprendizagemAvaliação de Matemática através da resolução de problemas; vivenciar essa metodologia através da dinâmica em grupo; evidenciar a importância de um trabalho investigativo, em aulas de matemática, através da resolução de problemas, que pode contribuir para a formação do professor e promover uma aprendizagem com compreensão nos alunos.

Planejamos desenvolver a oficina em dois momentos:

$\left.1^{\underline{0}}\right)$ Apresentar, aos participantes, os objetivos da oficina e da fundamentação teórica do tema proposto.

$2^{\underline{a}}$ ) Realizar uma dinâmica em grupos com o objetivo de vivenciar a Metodologia de EnsinoAprendizagem-Avaliação de Matemática através da resolução de problemas. 
Após organizar os participantes em grupos, seria entregue pela pesquisadora, aos grupos, os três problemas ${ }^{23}$ a seguir:

1) Há quatro bolinhas de gude numeradas numa caixa; elas estão numeradas pelos números 2 , 4, 7 e 9. Peguei uma das bolinha e anotei seu número. Depois, coloquei a bolinha de volta na caixa. Repeti esse processo até formar um número de três dígitos. Quantos números diferentes de três dígitos posso ter formado?

2) Tenho três letras idênticas que desejo colocar dentro de quatro envelopes de cores diferentes, azul, rosa, laranja e verde. Posso colocar apenas uma letra em cada envelope. De quantos modos as três letras idênticas podem ser colocadas dentro dos quatro envelopes diferentes?

3) Suzie e Sam têm quatro adesivos numerados de 1 a 4 . Eles decidiram dividir os adesivos, dois para cada um. De quantos modos diferentes eles podem dividir os adesivos?

Objetivos:

- Projetamos trabalhar com o processo de contagem fazendo uso da metodologia adotada, a partir de um problema, visando à construção de conceitos e conteúdos relativos à Análise Combinatória.

- Proporcionar aos participantes "ver" (visualizar) o processo de contagem e usar o Princípio Fundamental de Contagem (ou Princípio Multiplicativo).

- Trabalhar, durante a resolução dos problemas, com os conceitos de Combinação, Arranjo e Permutação e fazer a construção das respectivas fórmulas.

Justificativa:

Para atingir os objetivos pretendidos, a partir da resolução de problemas, dar-se-á tempo aos grupos para que eles possam "ver" um caminho e chegar à solução.

${ }^{23}$ Retirados e traduzidos da Revista Mathematics Teacher vol.98, n³. October2004. 
Problema 1: Há quatro bolinhas de gude numeradas numa caixa; elas estão numeradas pelos números 2, 4, 7 e 9. Peguei uma das bolinha e anotei seu número. Depois, coloquei a bolinha de volta na caixa. Repeti esse processo até formar um número de três dígitos. Quantos números diferentes de três dígitos posso ter formado?

\section{Estratégias selecionadas:}

a) Faça uma lista organizada;

b) Construa a árvore de possibilidades.

Possíveis maneiras de resolução:

a) Lista organizada

Adotar o seguinte critério: o primeiro número a ser retirado da caixa será o algarismo das centenas, o segundo número retirado será o algarismo das dezenas e o terceiro número retirado será o algarismo das unidades. Temos, que se retirarmos primeiro da caixa o número 2 e o colocarmos de volta na caixa, então, para o algarismo das dezenas, há quatro possibilidades, 2, 4, 7 e 9 e, por fim, para o algarismo das unidades, há também quatro possibilidades, 2, 4, 7 e 9. Formamos assim 16 números diferentes de três algarismos, como mostra a lista a seguir:

$\begin{array}{llll}222 & 242 & 272 & 292 \\ 224 & 244 & 274 & 294 \\ 227 & 247 & 277 & 297 \\ 229 & 249 & 279 & 299\end{array}$

Seguindo a mesma estratégia, teremos 16 números diferentes para os outros números que retirarmos da caixa primeiro, 4, 7 e 9. Então, como temos quatro algarismos, resultam $4 \cdot 16=64$ números diferentes de três algarismos. 
b) Árvore de possibilidades.

Temos quatro possibilidades para a casa das centenas, 2, 4, 7 e 9; para a casa das dezenas, quatro possibilidades, 2, 4, 7 e 9 e, também para a casa das unidades temos quatro possibilidades, 2, 4, 7 e 9. Iniciando com o algarismo 2, representamos a árvore de possibilidades a seguir:

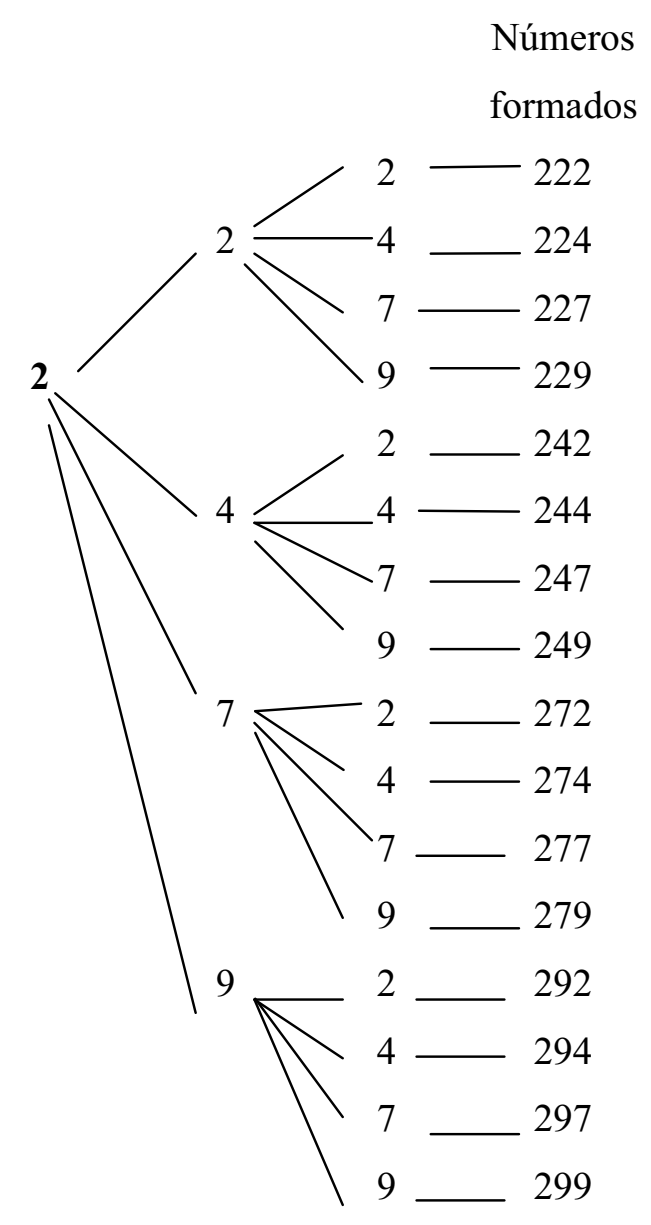

Obtemos então 16 números iniciando com o algarismo 2. Analogamente, ao iniciar com os demais algarismos, 4, 7, e 9, teremos esses mesmos ramos. Assim, teremos 16 números diferentes ao iniciar com 2 , com 4 , com 7 e com 9. Ou seja, 4·16=64 números diferentes de três algarismos.

A árvore de possibilidades permite visualizar as possibilidades para cada ordem da classe a que pertence o número a ser formado e também, através do Princípio Fundamental de Contagem ou Princípio Multiplicativo e calcular o total de números formados. 
Assim, temos 4 possibilidades para a casa das centenas, 4 possibilidades para a casa das dezenas e 4 possibilidades para a casa das unidades. Pelo Princípio Multiplicativo, resulta $4 \cdot 4 \cdot 4=64$ números diferentes de três algarismos.

$\mathrm{Na}$ Plenária, pretende-se que os alunos percebam e analisem que os números de três algarismos formados pelos algarismos 2, 4, 7 e 9 diferem quer pela ordem, quer pela natureza dos elementos.

Ao analisar, por exemplo, os números 247 e 274. Percebe-se que esses dois números são formados pelos mesmos algarismos (2, 4 e 7), e que, quando trocamos de posição os algarismos 4 e 7, do número 247, obtém-se um número diferente, 274. Então, considerar a ordem dos algarismos foi importante. Assim, os números 247 e 274 diferem pela ordem dos algarismos. Já, ao analisar os números 247 e 249, percebe-se que são diferentes por apresentarem algarismos diferentes na sua formação. Nesse caso, não foi a ordem dos algarismos que os fizeram diferentes, mas a natureza de seus elementos. Ou seja, para obter todos os números de três algarismos, formados com os algarismos 2, 4, 7 e 9, foi importante observar se os números formados diferiam pela ordem dos elementos e/ou pela natureza dos elementos. Os agrupamentos formados, obedecendo a ordem e a natureza dos elementos do conjunto dado, recebem o nome de arranjo e como, neste problema, podemos repetir o mesmo algarismo para formar o número, então, temos o caso de arranjo com repetição.

\section{$\underline{\text { Construção da fórmula }}$}

\section{Arranjo com repetição}

Seja $n \in N^{*}, p \in N^{*}$ e $p \leq n$.

Designando por $A R_{n, p}$ o número de arranjos, com repetição, de $n$ elementos tomados $p$ a $p$, é claro que $A R_{n, 1}=n$. Esta expressão é chamada de arranjo com repetição de $1^{\underline{a}}$ ordem. Pode-se dizer que os arranjos com repetição de $n$ elementos tomados 2 a 2 diferem do arranjo com repetição de $1^{\underline{a}}$ ordem, de onde provieram ou, se deduzidos do mesmo, da seguinte forma $A R_{n, 2}=n \cdot A R_{n, 1}=n \cdot n=n^{2}$.

De um modo geral cada $A R_{n, p-1}$ pode ser prolongado sucessivamente com os $n$ elementos, dando $\operatorname{assim} n$ arranjos de ordem $p$, ou seja, $A R_{n, p}=n \cdot n^{p-1}=n^{p}$, o que caracteriza um princípio de indução.

Segue a demonstração fazendo uso do Princípio de Indução Finita: 
- Verificar para $p=1$

$A R_{n, 1}=n$

- Aceita-se como verdadeira, a hipótese de indução:

$A R_{n, p-1}=n^{p-1}$

Temos que provar que $A R_{n, p}=n^{p}$

Como temos $n$ elementos e, a cada prolongamento, aparecem $n$ vezes o anterior

$$
\begin{aligned}
& A R_{n, p}=n \cdot A R_{n, p-1}=n \cdot n^{p-1}=n^{p} \\
& \therefore A R_{n, p}=n^{p}
\end{aligned}
$$

De fato, fazendo na fórmula $A R_{n, p}=n \cdot A R_{n, p-1}$, sucessivamente $p=2,3, \ldots, \mathrm{n}, \ldots$, e atendendo que arranjo de $n$ elementos tomados 1 a 1 é igual a $n$, vem:

$$
\begin{aligned}
& A R_{n, 2}=n \cdot A R_{n, 1}=n \cdot n=n^{2} \\
& A R_{n, 3}=n \cdot A R_{n, 2}=n \cdot n^{2}=n^{3} \\
& A R_{n, p}=n \cdot A R_{n, p-1}=n \cdot n^{p-1}=n^{p}
\end{aligned}
$$

Daíse conclui :

$$
A R_{n, p}=n^{p}
$$

Formalizando, podemos definir arranjos com repetição assim:

Seja $\mathrm{I}=\left\{\mathrm{a}_{1}, \mathrm{a}_{2}, \mathrm{a}_{3}, \ldots, \mathrm{a}_{\mathrm{n}}\right\}$ um conjunto formado por $n$ elementos e seja $p$ um número natural não nulo tal que $p \leq n$. Chama-se arranjo com repetição de $p$ elementos de I a toda sequência formada por $p$ elementos de I.

$\mathrm{O}$ número de arranjos com repetição de $n$ elementos tomados $p$ a $p$ é dado por $A R_{n, p}=n^{p}$ 
Problema 2: Tenho três letras idênticas que desejo colocar dentro de quatro envelopes de cores diferentes, azul, rosa, laranja e verde. Posso colocar apenas uma letra em cada envelope. De quantos modos as três letras idênticas podem ser colocadas dentro dos quatro envelopes diferentes?

Podemos usar, como estratégia, a montagem de uma tabela para visualizar a distribuição das três letras nos quatro envelopes.

O problema tem, como restrição, colocar apenas uma letra em cada envelope. Entendemos como letras idênticas, letra do mesmo tamanho e forma. Escolhemos a letra $a$ para representá-la na tabela.

\begin{tabular}{|c|c|c|c|c|}
\cline { 2 - 5 } \multicolumn{1}{c|}{} & azul & rosa & laranja & verde \\
\hline $1^{\underline{0}}$ modo & $a$ & $a$ & $a$ & vazio \\
\hline $2^{-}$modo & $a$ & $a$ & vazio & $a$ \\
\hline $3^{\mathrm{o}}$ modo & $a$ & vazio & $a$ & $a$ \\
\hline $4^{\mathbf{0}}$ modo & vazio & $a$ & $a$ & $a$ \\
\hline
\end{tabular}

A tabela foi organizada do seguinte modo, as colunas apresentam os quatro envelopes colocados na seguinte ordem, azul, rosa, laranja e verde e, em cada linha, foram distribuídas as letras, deixando consequentemente um envelope vazio. Resultando então quatro modos diferentes de distribuir as três letras idênticas nos diferentes envelopes.

Na Plenária espera-se uma discussão sobre a solução encontrada. Uma análise sobre a ordem e a natureza dos elementos envolvidos leva a uma importante construção dos conceitos matemáticos durante a resolução do problema.

Um início de discussão seria o de considerar, por exemplo, o $1^{\underline{0}}$ modo de distribuição das letras:

\begin{tabular}{|c|c|c|c|c|}
\cline { 2 - 5 } \multicolumn{1}{c|}{} & azul & rosa & laranja & verde \\
\hline $1^{\underline{\underline{o}}}$ modo & $a$ & $a$ & $a$ & vazio \\
\hline
\end{tabular}

O que aconteceria se mudassem as letras de lugar, passando a letra do envelope azul para o envelope rosa e do rosa para o azul? 
Não haverá alteração no resultado se mudarmos a ordem das letras dessa maneira. $\mathrm{Ou}$ seja, os envelopes azul, rosa e laranja continuariam com uma letra e o envelope verde, vazio. É irrelevante fazer essa mudança: azul e rosa, pois temos letras idênticas.

E se mudarmos agora a letra do envelope azul para o envelope verde?

Como o envelope verde está vazio, então teríamos outro resultado, ou seja, outro modo de distribuir as três letras. Então, nesse caso, a ordem interfere no resultado.

Tem-se então que ter preocupação com os modos de distribuição das três letras. Como já discutimos, no $1^{\circ}$ modo acima, mudar as letras de lugar não altera o resultado e, então, haverá seis vezes o mesmo modo, pois as letras são idênticas (elementos repetidos). Logo, é necessário desconsiderar os modos repetidos. Mas, quando mudamos uma das letras para o envelope verde, aparece um outro modo de distribuição, um segundo modo, e assim sucessivamente até o quarto modo de distribuição. A ordem aqui altera o modo de distribuição. Temos, pois, quatro modos diferentes.

Considerando o esquema:

\begin{tabular}{|c|c|c|c|}
\hline azul & rosa & laranja & verde \\
\hline
\end{tabular}

Há 4 possibilidades para o envelope azul (três letras disponíveis ou ficar vazio), 3 possibilidades para o rosa (duas letras restantes ou o vazio), 2 possibilidades para o laranja (uma letra restante ou o vazio) e 1 possibilidade para o verde (vazio). Pelo Princípio Fundamental de Contagem, temos $4 \cdot 3 \cdot 2 \cdot 1=24$ modos de distribuição. Mas como temos elementos repetidos que resultam em seis vezes o mesmo modo (permutando as letras de um mesmo modo), então tem-se que dividir por 6. E divide-se por um também, pois o envelope vazio aparece sempre trocando de lugar. Ficando: $\frac{24}{6 \cdot 1}$. Obtemos 24 fazendo $4 \cdot 3 \cdot 2 \cdot 1$, ou seja 4 !, e 6 , permutando as 3 letras, $3 \cdot 2 \cdot 1$, ou seja, 3 !. Tem-se então $\frac{4 !}{3 ! 1 !}$. Essa expressão representa o agrupamento definido como permutação com repetição.

Outra questão a considerar, a da diferença entre arranjo (arranjo com repetição) e permutação (permutação com repetição) é que, neste problema, estão sendo utilizados todos os elementos (envelopes) para determinar os modos de distribuição das letras, enquanto que, no primeiro problema, dos 4 elementos dados (algarismos 2, 4, 7 e 9), foram utilizados apenas três para obter os agrupamentos pretendidos (números de três algarismos). É verdade que, 
quando se trata de permutação, todos os elementos do conjunto devem ser utilizados para formar os agrupamentos, o que não acontece no caso de arranjo.

\section{Construção da fórmula}

\section{Permutação com repetição}

Neste caso, indicando por:

n: número total de elementos

$\mathrm{n}_{1}$ : número de letras

$\mathrm{n}_{2}$ : vazio

Na resolução desse problema, vimos que o número de modos de distribuição das três letras nos quatro envelopes foi dado por:

$$
\frac{4 !}{3 ! 1 !}=\frac{4 !}{3 !}=\frac{1 \cdot 2 \cdot 3 \cdot 4}{1 \cdot 2 \cdot 3}=4
$$

Pode-se conjecturar, então, que generalizando: que o número total de elementos, o número de letras e o número de envelopes vazios produziriam a expressão $\frac{n !}{n_{1} ! \cdot \mathrm{n}_{2} !}$.

Pode-se imaginar que se houvesse $n$ elementos a serem distribuídos, com repetição, em $k$ conjuntos diferentes, essa fórmula poderia se apresentar assim

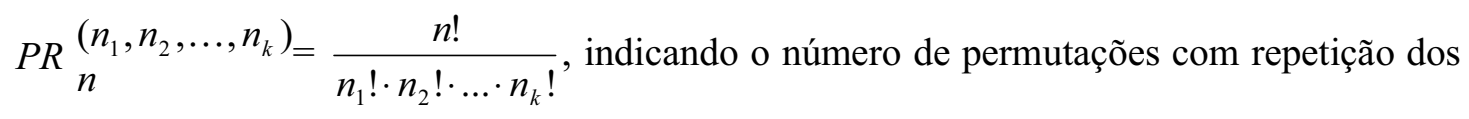
elementos envolvidos.

Será que vale sempre?

Indicando o número de permutações com repetição dos elementos envolvidos,

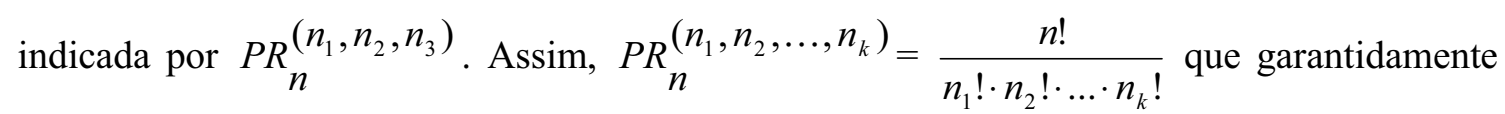
será um padrão verdadeiro quando provado pelo Teorema do Princípio de Indução Finita.

Considerando o caso de $n$ elementos com $n \in N^{*}$. Entre esses $n$ elementos, sejam $n_{1}$

\begin{tabular}{|c|c|c|}
\hline \multicolumn{3}{|c|}{$n$ elementos } \\
\hline$a_{1}, a_{1}, \ldots, a$ & $, a_{2}, \ldots, a_{2}$ & $a_{k}, a_{k}, \ldots, a_{k}$ \\
\hline
\end{tabular}
deles iguais a $a_{1}, n_{2}$ deles iguais a $a_{2}, \ldots, n_{k}$ deles iguais a $a_{k}$.

onde $a_{1}, a_{2}, a_{3}, \ldots, a_{k}$ são distintos entre si. 
Esse é um caso de permutação com repetição que será indicado por $P R_{n}^{\left(n_{1}, n_{2}, \ldots, n_{k}\right)}$.

Como calcular esse número?

Temos um conjunto de $n$ elementos.

Iniciamos, permutando todos os $n$ elementos, $a_{1}, a_{2}, \ldots, a_{k}$. Obtemos assim todas as permutações com esses $n$ elementos ( $n$ !). Mas, há elementos repetidos nesse conjunto.

$n_{1}$ : número de elementos iguais a $a_{1}$

$n_{2}$ : número de elementos iguais a $a_{2}$

$n_{k}$ : número de elementos iguais a $a_{k}$

com $n_{1}+n_{2}+\ldots+n_{k}=n$

Os elementos iguais a $a_{1}$, quando permutados, não alteram a sequência formada. $\mathrm{O}$ mesmo ocorre com os elementos iguais a $a_{2}, a_{3}, \ldots, a_{k}$. Assim, dividimos por $n_{1}$ ! referentes a $a_{1}, n_{2}$ ! referentes a $a_{2}, \ldots$, e $n_{k}$ ! referentes a $a_{k}$ para não contar o mesmo número de agrupamentos que se repete utilizando os mesmos elementos. Então, dividimos $n$ ! por $n_{1}$ !, $n_{2} !, \ldots, n_{k}$ !

Logo

$$
P R_{n}^{\left(n_{1}, n_{2}, \ldots, n_{k}\right)}=\frac{n !}{n_{1} ! \cdot n_{2} ! \ldots \cdot n_{k} !}
$$

Uma vez que os elementos fossem diferentes entrariam na totalidade das permutações, como se fossem permutações simples.

Uma vez que provado matematicamente esse resultado, ele passou a valer sempre e tornou-se um padrão.

\section{Teorema:}

Seja o conjunto $\left\{a_{1}, a_{2}, a_{3}, \ldots, a_{n}\right\}$ um conjunto formado por $n$ elementos. Permutação com repetição desses $n$ elementos é dado por $P R_{n}^{\left(n_{1}, n_{2}, \ldots, n_{k}\right)}=\frac{n !}{n_{1} ! \cdot n_{2} ! \cdot \ldots \cdot n_{k} !}$, sendo $\mathrm{n}_{\mathrm{i}}$ elementos iguais a $\mathrm{a}_{\mathrm{i}}, \operatorname{com} \mathrm{i}=1,2,3, \ldots, \mathrm{k}$. 
Problema 3: Suzie e Sam têm quatro adesivos numerados de 1 a 4. Eles decidiram repartir igualmente os adesivos, dois para cada um. De quantos modos eles podem dividir os quatro adesivos entre eles?

Neste problema, podemos usar como estratégia fazer uma lista organizada para melhor visualizar a distribuição dos adesivos.

Há quatro adesivos 1, 2, 3 e 4 para serem distribuídos igualmente para Suzie e Sam.

De quantos modos diferentes posso distribuir o adesivo 1? De 6 modos. Idem para os adesivos 2, 3 e 4. Então teríamos 6 modos multiplicado por 4 (pois temos 4 adesivos), totalizando 24 modos de distribuição. Como são dois adesivos para cada um, dividimos por 2 , resultando 12 modos. Como são duas pessoas, dividimos 12 por 2, resultando 6 modos de dividir os adesivos entre Suzie e Sam.

Observando a tabela, temos os seis modos de distribuir cada adesivo:

\begin{tabular}{|c|c|}
\hline Suzie & Sam \\
\hline $1-2$ & $3-4$ \\
$1-3$ & $2-4$ \\
$1-4$ & $2-3$ \\
$2-3$ & $1-4$ \\
$2-4$ & $1-3$ \\
$3-4$ & $1-2$ \\
\hline $2-1$ & $3-4$ \\
$2-3$ & $1-4$ \\
$2-4$ & $1-3$ \\
$3-1$ & $2-4$ \\
$3-2$ & $1-4$ \\
$3-4$ & $1-2$ \\
\hline $3-1$ & $2-4$ \\
$3-2$ & $1-4$ \\
$3-4$ & $1-2$ \\
$4-1$ & $2-3$ \\
$4-2$ & $1-3$ \\
$4-3$ & $1-2$ \\
\hline $4-1$ & $2-3$ \\
$4-2$ & $1-3$ \\
$4-3$ & $1-2$ \\
$1-2$ & $3-4$ \\
$1-3$ & $2-4$ \\
$1-4$ & $2-3$ \\
\hline 24 & modos \\
\hline & \\
\hline
\end{tabular}

\begin{tabular}{|c|c|}
\hline Suzie & Sam \\
\hline $1-2$ & $3-4$ \\
$1-3$ & $2-4$ \\
$1-4$ & $2-3$ \\
$2-1$ & $3-4$ \\
$2-3$ & $1-4$ \\
$2-4$ & $1-3$ \\
$3-1$ & $2-4$ \\
$3-2$ & $1-4$ \\
$3-4$ & $1-2$ \\
$4-1$ & $2-3$ \\
$4-2$ & $1-3$ \\
$4-3$ & $1-2$ \\
\hline 12 & modos \\
\hline
\end{tabular}

\begin{tabular}{|c|c|}
\hline Suzie & Sam \\
\hline $1-2$ & $3-4$ \\
\hline $1-3$ & $2-4$ \\
\hline $1-4$ & $2-3$ \\
\hline $2-3$ & $1-4$ \\
\hline $2-4$ & $1-3$ \\
\hline $3-4$ & $1-2$ \\
\hline
\end{tabular}


Na Plenária, o aluno deve perceber que a ordem em que os adesivos são distribuídos não altera o resultado final, ou seja, os dois adesivos que Suzie e Sam receberam. Por exemplo, quando Suzie recebeu os adesivos 1 e 2, não importa se ela recebeu o adesivo 1 primeiro ou o adesivo 2 primeiro, pois isso não mudará os adesivos que ela tem em mãos que continuam sendo os adesivos 1 e 2 . Mas, se fossem entregues os adesivos 1 e 2 para Suzie, restariam apenas os adesivos 3 e 4 para Sam. Esse modo de distribuição fica diferente se fossem entregues os adesivos 1 e 2 para Sam e o 3 e 4 para Suzie, alterando assim a natureza dos elementos recebidos pelos envolvidos no problema e, consequentemente, o modo de distribuição.

Assim, a ordem em que os adesivos são distribuídos não altera o resultado, mas muda a natureza dos elementos envolvidos. Um agrupamento que se diferencia de outros apenas pela natureza de seus elementos é chamado de combinação e indicada por $C_{n, p}$.

Neste problema temos 4 elementos (adesivos 1, 2, 3 e 4). Pelo Princípio Multiplicativo, teremos 4.3.2.1=24 modos de distribuir esses adesivos. Como são dois adesivos para cada um, divide-se por 2, tendo então 12 desses modos. Mas como são duas pessoas, divide-se novamente por 2, resultando 6 modos de distribuir os quatro adesivos entre Suzie e Sam.

Então

$$
C_{4,2}=\frac{4 !}{2 !(4-2) !}=\frac{4 !}{2 ! 2 !}=\frac{1 \cdot 2 \cdot 3 \cdot 4}{1 \cdot 2 \cdot 1 \cdot 2}=\frac{12}{2}=6
$$

Conjecturando, isto é, indo em busca de um padrão e considerando:

$n$ : número total de elementos

$p$ : número de adesivos para cada um: Suzie e Sam.

Poderíamos escrever $C_{n, p}=\frac{n !}{p !(\mathrm{n}-\mathrm{p}) !}$.

Será que vale sempre?

\section{Construção da fórmula}

Para a construção da fórmula de combinação simples, partimos da construção da fórmula para arranjo simples.

Como já demonstrado na página 166 a fórmula encontrada para arranjos simples é 


$$
A_{n, p}=\frac{n !}{(n-p) !} \text {. Mas para essa fórmula eram considerados a ordem e a natureza dos }
$$
elementos.

Como, para este nosso caso, a ordem não é relevante mas apenas a natureza dos elementos, e p! é o número das possíveis ordenações iguais, a fórmula gera para combinações é dada por $C_{n, p}=\frac{n !}{p !(n-p) !}$, sendop $\leq \mathrm{n}$.

\section{Combinações simples}

Conhecidas as ideias de arranjos simples, as ideias de combinações surgiriam como um consequente caso particular, e não dependeriam da ordem dos elementos mas, somente da natureza desses elementos.

A cada combinação de $\mathbf{n}$ elementos tomados $\mathbf{p}$ a $\mathbf{p}$ correspondem $\mathbf{p}$ ! arranjos que são obtidos permutando-se os elementos da combinação, ou seja:

$$
\begin{aligned}
& A_{n, p}=C_{n, p} \cdot P_{p} \Rightarrow C_{n, p}=\frac{A_{n, p}}{P_{p}} \Rightarrow C_{n, p}=\frac{n \cdot(n-1) \cdot \ldots \cdot(n-p+1)}{p !}=\frac{n(n-1) \cdot \ldots \cdot(n-p+1)}{p !} \cdot \frac{(n-p) !}{(n-p) !}= \\
& =\frac{n !}{p !(n-p) !}
\end{aligned}
$$

\section{Teorema}

Sendo $A=\left\{a_{1}, a_{2}, a_{3}, \ldots, a_{n}\right\}$ um conjunto formado com $\mathbf{n}$ elementos e $\mathbf{p}$ um número natural, tal que $\mathrm{p} \leq \mathrm{n}$, chamamos de combinação simples dos $\mathbf{n}$ elementos de A, tomados $\mathbf{p}$ a $\mathbf{p}$, a todo subconjunto de A com $\mathbf{p}$ elementos, onde o número de combinações é dado por $C_{n, p}=\frac{n !}{p !(n-p) !}$, sendop $\leq \mathrm{n}$. 


\section{Combinação com repetição}

Motivados pela pergunta de um dos participantes da oficina: "E se no problema dos adesivos houvesse adesivos iguais, como seria resolvido esse problema?", sentimos então a necessidade de explorar o conceito matemático envolvido nessa situação apontada pelo aluno.

Essa pergunta seria equivalente a perguntar: "Há combinações com repetição?"

Como foi citado no capítulo 2, o conceito de combinação com repetição, ou também denominada por alguns autores de combinação completa, aparece apenas em três dos treze livros analisados: Prelúdio à Análise Combinatória, de Arago de C. Bachx, Luiz M. B. Poppe, Raymundo N. O. Tavares (1975); Matemática $2^{\underline{o}}$ ciclo - $2^{\underline{a}}$ série, de Euclides Roxo, Roberto Peixoto, Haroldo Cunha, Dacorso Netto (1944); e A Matemática no Ensino Médio, vol.2, de Elon Lages Lima, Paulo C.P. Carvalho, Eduardo Wagner, Augusto C. Morgado (1998).

Consideramos relevante apresentar esse conceito para preencher essa lacuna existente na maioria dos livros didáticos que analisamos. Desse modo, buscamos mostrar a importância de saber da existência de um novo tipo de agrupamento e evitar que o aluno tenha uma concepção errônea, de que somente é possível pensar em combinação simples, ou seja, combinação com elementos distintos. E saber que há problemas de aparência simples que envolve o conceito de combinação com repetição.

Através da resolução de um problema, mostraremos como se dá a construção do conceito de combinação com repetição, bem como a construção da respectiva fórmula.

Deixamos, como sugestão de trabalho, o problema abaixo, apresentado no livro $A$ Matemática no Ensino Médio, vol.2, p.99, de Elon Lages Lima, Paulo C.P. Carvalho, Eduardo Wagner Augusto C. Morgado, SBM, Rio de Janeiro, 1998.

De quantos modos podemos comprar 3 sorvetes em um bar que os oferece em 6 sabores distintos?

\section{$\underline{\text { Resolução apresentada pelo livro: }}$}

A resposta não é $C_{6}^{3}=20 . C_{6}^{3}$ seria o número de modos de comprar 3 sorvetes diferentes. 
Chamamos de $\mathrm{x}_{\mathrm{k}}$ o número de sorvetes do k-ésimo sabor que vamos comprar, devemos determinar valores inteiros e não-negativos para $\mathrm{x}_{\mathrm{k}}, \mathrm{k}=1,2,3,4,5,6$, tais que $\mathrm{x}_{1}+\mathrm{x}_{2}+\mathrm{x}_{3}+\ldots+\mathrm{x}_{6}=3$. A solução apresentada anteriormente consiste em determinar as soluções dessa equação.

Isso pode ser feito por meio de $C R_{6}^{3}=C_{8}^{3}=56$ modos, uma vez que $C R_{n}^{p}=C_{n+p-1}^{p}$, onde $C R_{n}^{p}$ é a combinação com repetição de n elementos tomados $p$ a $p$.

\section{Nossa resolução:}

Representamos por A, B, C, D, E e F os seis diferentes sabores.

Para contar o número de modos de comprar os três sorvetes com esses sabores, iniciamos com o sabor A. Organizamos, numa tabela, todos os modos de comprar os três sorvetes:

\begin{tabular}{|c|c|c|c|c|c|c|}
\hline \multirow{2}{*}{\multicolumn{2}{|c|}{\begin{tabular}{|c|}
$\mathbf{A}$ \\
\cline { 2 - 2 }
\end{tabular}}} & B & $\mathbf{C}$ & D & $\mathbf{E}$ & $\mathbf{F}$ \\
\hline & & BBB & $\mathrm{CCC}$ & DDD & EEE & FFF \\
\hline \multirow{21}{*}{ 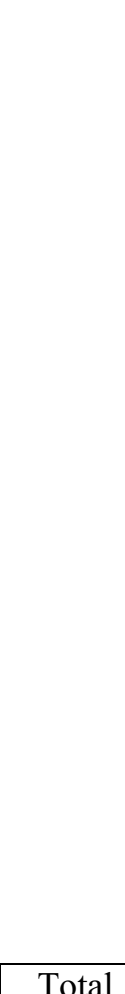 } & $\mathrm{AAB}$ & BBC & $\mathrm{CCD}$ & DDE & EEF & \\
\hline & AAC & BBD & $\mathrm{CCE}$ & DDF & EFF & \\
\hline & $\mathrm{AAD}$ & BBE & $\mathrm{CCF}$ & DEE & & \\
\hline & AAE & BBF & CDD & DEF & & \\
\hline & AAF & $\mathrm{BCC}$ & $\mathrm{CDE}$ & DFF & & \\
\hline & ABB & $\mathrm{BCD}$ & $\mathrm{CDF}$ & & & \\
\hline & $\mathrm{ABC}$ & $\mathrm{BCE}$ & CEE & & & \\
\hline & ABD & $\mathrm{BCF}$ & CEF & & & \\
\hline & ABE & BDD & CFF & & & \\
\hline & $\mathrm{ABF}$ & BDE & & & & \\
\hline & ACC & BDF & & & & \\
\hline & ACD & BEE & & & & \\
\hline & ACE & BEF & & & & \\
\hline & ACF & BFF & & & & \\
\hline & ADD & & & & & \\
\hline & ADE & & & & & \\
\hline & ADF & & & & & \\
\hline & AEE & & & & & \\
\hline & AEF & & & & & \\
\hline & $\mathrm{AFF}$ & & & & & \\
\hline & 21 & 15 & 10 & 6 & 3 & 1 \\
\hline
\end{tabular}

Obtemos então $21+15+10+6+3+1=56$ modos de escolher os três sorvetes. 
Ao observar o total dos sabores atribuídos aos sorvetes pode-se notar a presença dos coeficientes binomiais.

Pode-se relacionar a solução encontrada nesse problema com o Triângulo de Pascal.

\section{Triângulo de Pascal}

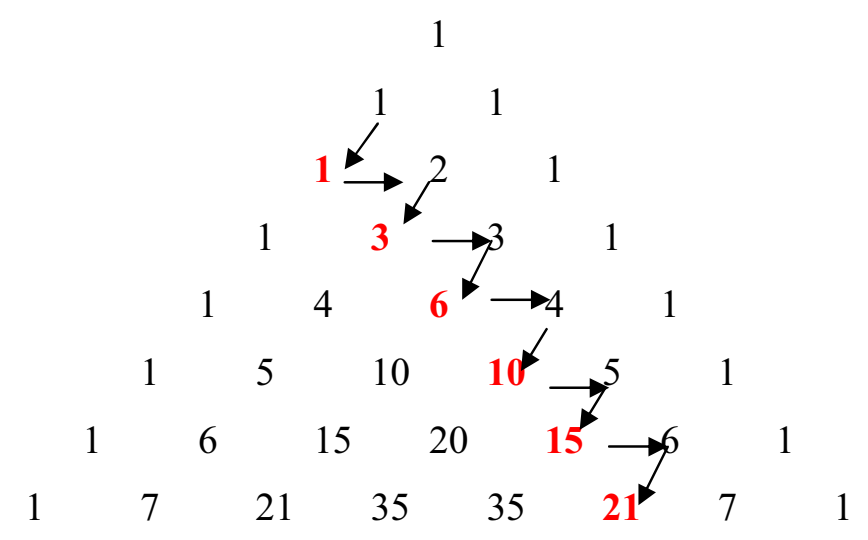

Os elementos da diagonal, assinalada em vermelho, são exatamente o número de modos de escolher os três sorvetes encontrados anteriormente e que somam 56 modos.

\section{Construção da fórmula}

\section{Combinação com repetição}

\section{Teorema}

Seja $\mathrm{I}=\left\{\mathrm{a}_{1}, \mathrm{a}_{2}, \mathrm{a}_{3}, \ldots, \mathrm{a}_{\mathrm{n}}\right\}$ um conjunto formado por $n$ elementos e seja $p$ um número natural não nulo tal que $p \leq n$. Chama-se combinação com repetição de $\boldsymbol{p}$ elementos de I a toda sequência formada por $p$ elementos de I.

O número de combinações com repetição de $n$ elementos tomados $p$ a $p$ é dado por $C R_{n}^{p}=C_{n+p-1}^{p}$

Demonstração: Alves, 1944)

(ROXO, E. et al. Matemática $\mathbf{2}^{\mathbf{o}}$ ciclo, $\mathbf{2}^{\mathbf{a}}$ série. $2^{\mathrm{a}}$ ed. Rio de Janeiro: Livraria Francisco

Suponhamos formadas as combinações, com repetição $\mathrm{p}$ a $\mathrm{p}$, das $n$ letras: 
$\mathrm{a}_{1}, \mathrm{a}_{2}, \mathrm{a}_{3}, \ldots, \mathrm{a}_{\mathrm{n}} \mathrm{e}$ admitamos ordenadas, em relação aos índices, as letras de cada agrupamento.

Somando-se, nessas combinações, ao índice de cada letra o número de letras que a precedem no agrupamento, a combinação:

$\begin{array}{lllllllllll}a_{2} & a_{2} & a_{4} & a_{5} & a_{5} & a_{5} & a_{6} & \ldots & a_{n}\end{array}$

por exemplo, passa a ser escrita:

$b_{2} \quad b_{3} \quad b_{6} \quad b_{8} \quad b_{9} \quad b_{10} \quad b_{12 \ldots} \ldots b_{n+p-1}$

e, desse modo, cada agrupamento com repetição se transforma numa combinação simples, também de ordem $p$, das letras: $b_{1}, b_{2}, b_{3}, \ldots, b_{n+p-1}$.

Reciprocamente, qualquer combinação, de ordem $p$, destas $n+p-1$ letras, ordenadas em relação aos índices em cada agrupamento, determina uma combinação com repetição, de ordem $\mathrm{p}$, das letras $\mathrm{a}_{1}, \mathrm{a}_{2}, \mathrm{a}_{3}, \ldots, \mathrm{a}_{\mathrm{n}}$ desde que se diminuam os índices sucessivos de $0,1,2, \ldots$, $\mathrm{p}-1$ unidades.

Assim, o número de combinações com repetição, de ordem p, de n objetos é igual ao número de combinações simples, de ordem $p$, de $\mathrm{n}+\mathrm{p}-1$ objetos, isto é, $C R_{n}^{p}=C_{n+p-1}^{p}$.

Talvez trabalhar com esse raciocínio poderia parecer muito difícil com alunos e professores em formação. Então, lançamos mão de outros dois livros que, trabalhando com casos particulares, deixam essas ideias mais claras.

No livro Prelúdio à Análise Combinatória (1975), Bachx, Poppe e Tavares apresentam que o número de combinações com repetição, de ordem $p$, de $n$ objetos distintos é representado por $(C R)_{n}^{p}$ ou $(C R)_{n, p}$. Este número é igual ao número de soluções inteiras não negativas da equação: $x_{1}+x_{2}+x_{3}+\ldots+x_{n}=p$

Logo, $(C R)_{n}^{p}=C_{p+n-1}^{n-1} \quad$ ou $\quad(\mathrm{CR})_{\mathrm{n}}^{\mathrm{p}}=C_{n+p-1}^{p}$.

Para esclarecer melhor como os autores chegaram nesse resultado, consideramos necessário recordar como se dá a resolução de uma equação linear.

Nesse mesmo livro, os autores iniciam o assunto com equações lineares na página 96.

Seja a equação $x_{1}+x_{2}+x_{3}+\ldots+x_{p}=n$, sendo $n$ natural.

Chama-se solução inteira dessa equação a toda p-upla de números inteiros $\left(\alpha_{1}, \alpha_{2}, \ldots, \alpha_{p}\right)$ tal que $\alpha_{1}+\alpha_{2}+\ldots+\alpha_{p}=n$.

$\mathrm{Na}$ sequência, os autores apresentam como calcular o número de soluções inteiras positivas e o número de soluções inteiras não negativas de equações lineares. 
Iniciam considerando a seguinte equação

$x+y+z+w=12$

Identificam o cálculo do número de soluções inteiras positivas dessa equação com o seguinte problema:

Escrevendo-se em fila 12 algarismos iguais a 1, de quantos modos podemos separar esses algarismos em 4 grupos, onde cada grupo contém pelo menos um algarismo?

$\begin{array}{lllllllllllllllll}1 & 1 & 1 & 1 & 1 & 1 & 1 & 1 & 1 & 1 & 1 & 1\end{array}$

Observemos que entre os 12 algarismos há 11 espaços; se colocarmos elementos de separação (como barras verticais) em 3 desses espaços, obteremos uma disposição correspondente a uma solução da equação dada. Assim, por exemplo, a disposição:

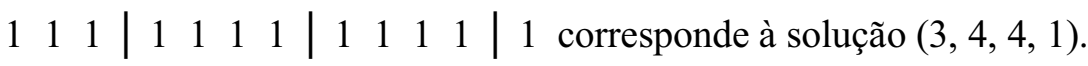

Reciprocamente, cada solução inteira positiva da equação corresponde a um modo de se colocar as 3 barras em 3 dos 11 espaços.

Por exemplo, a solução $(2,3,5,2)$ corresponde à disposição:

\begin{tabular}{ll|lll|lllll|ll|l}
1 & 1 & 1 & 1 & 1 & 1 & 1 & 1 & 1 & 1 & 1 & 1
\end{tabular}

Então, o número de soluções inteiras positivas da equação $x+y+z+w=12$ é igual ao número de modos de se escolher 3 dos 11 espaços, para se colocar as 3 barras, isto é: $C_{11,3}=\frac{11 !}{3 ! \cdot(11-3) !}=\frac{11 !}{3 ! \cdot 8 !}=165$. Assim, a equação $x+y+z+w=12$ tem 165 soluções inteiras positivas.

Um raciocínio análogo para a equação $x_{1}+x_{2}+x_{3}+\ldots+x_{p}=n$, sendo $n$ natural, nos fornece o número de soluções inteiras positivas: $C_{n-1, p-1}$. De fato, supondo escritos em fila $n$ algarismos iguais a 1 , devemos separá-los em $p$ grupos, tendo cada grupo pelo menos um algarismo.

\section{$\begin{array}{lllllllllll}1 & 1 & 1 & 1 & 1 & 1 & \ldots & 1 & \text { ( } n \text { algarismos) }\end{array}$}

Basta, então, escolher $p-1$ dos $n-1$ espaços entre os algarismos para se colocar as $\mathrm{p}-1$ barras, o que pode ser feito de $C_{n-1, p-1}$ modos. Se $p=n$, a equação $x_{1}+x_{2}+x_{3}+\ldots+x_{p}=n$ possui uma única solução, e se $p>n$ a equação não possui solução inteira positiva.

Para o cálculo do número de soluções inteiras não negativas (maiores ou iguais a zero), consideram a mesma equação do exemplo feito acima, $x+y+z+w=12$. Apresentam algumas soluções inteiras não negativas para essa equação: 
$(12,0,0,0),(9,1,1,1),(6,5,1,0),(0,2,0,10)$, etc

Supuseram que todas essas soluções sejam escritas em uma mesma coluna, e somaram uma unidade a cada inteiro dessas soluções, obtendo, assim, soluções inteiras positivas de uma nova equação $x+y+z+w=16$.

$$
\begin{aligned}
&(12,0,0,0) \Leftrightarrow(13,1,1,1) \\
&(9,1,1,1) \Leftrightarrow(10,2,2,2) \\
&(6,5,1,0) \Leftrightarrow(7,6,2,1) \\
&(0,2,0,10) \Leftrightarrow(1,3,1,11)
\end{aligned}
$$

Desse modo, a cada solução inteira não negativa da equação $x+y+z+w=12$ corresponde uma única solução inteira positiva da equação $x+y+z+w=16$ e, reciprocamente, a cada solução inteira positiva da equação $x+y+z+w=16$ corresponde uma única solução inteira não negativa da equação $x+y+z+w=12$, pois basta subtrair uma unidade de cada inteiro das soluções da coluna da direita para obter as soluções correspondentes na coluna da esquerda.

Portanto, o número de soluções inteiras não negativas da equação $x+y+z+w=12$ é igual ao número de soluções inteiras positivas da equação $x+y+z+w=16$, e este número é, como vimos no exemplo anterior $C_{16-1}^{4-1}=C_{15}^{3}$.

Generalizando para uma equação com $p$ variáveis $x_{1}+x_{2}+x_{3}+\ldots+x_{p}=n$.

Somando uma unidade a cada inteiro de uma solução inteira não negativa $\left(\alpha_{1}, \alpha_{2}, \ldots, \alpha_{p}\right)$ da equação $x_{1}+x_{2}+x_{3}+\ldots+x_{p}=n$, obtemos uma solução inteira positiva da equação $x_{1}+x_{2}+x_{3}+\ldots+x_{p}=n+p, \operatorname{com}\left(\alpha_{1}, \alpha_{2}, \ldots, \alpha_{p}\right) \rightarrow\left(\alpha_{1}+1, \alpha_{2}+1, \ldots, \alpha_{p}+1\right)$.

Reciprocamente, subtraindo uma unidade de cada inteiro de uma solução inteira positiva da equação $x_{1}+x_{2}+x_{3}+\ldots+x_{p}=n+p$ obtemos uma solução inteira não negativa da equação $x_{1}+x_{2}+x_{3}+\ldots+x_{p}=n$.

Portanto, o número de soluções inteiras não negativas da equação $x_{1}+x_{2}+x_{3}+\ldots+x_{p}=n$ é igual ao número de soluções inteiras positivas da equação $x_{1}+x_{2}+x_{3}+\ldots+x_{p}=n+p$, e este número é, como vimos anteriormente, $C_{n+p-1}^{p-1}$. 
Os autores definiram, na página 230 desse livro, combinação com repetição, ou também chamadas por eles de completa, de $n$ objetos distintos, a todo agrupamento de $p$ objetos (distintos ou não) selecionados dos $n$ objetos dados, sem levar em conta a ordem.

Apresentaram ainda que o número de combinações com repetição, de ordem $p$, de $n$ objetos distintos é representado por $(C R)_{n}^{p}$ ou $(C R)_{n, p}$. Este número é igual ao número de soluções inteiras não negativas da equação $x_{1}+x_{2}+x_{3}+\ldots+x_{n}=p$.

Logo, $(C R)_{n}^{p}=C_{p+n-1}^{n-1}$ ou $(C R)_{n}^{p}=C_{n+p-1}^{p}$. Observemos que para o cálculo de $(C R)_{n}^{p}$ pode-se ter $p \leq n$ ou $p>n$.

De modo semelhante, no livro Análise Combinatória e Probabilidade (1991), Morgado et al chamam combinações com repetição de combinações completas. Definem, na página 48, como sendo o número de modos de escolher $p$ objetos distintos ou não entre $n$ objetos distintos dados, denotado por $C R_{n}^{p}$ e, também, como sendo o número de soluções da equação $x_{1}+x_{2}+x_{3}+\ldots+x_{n}=p$ em inteiros não negativos.

Apresentam o problema da compra dos sorvetes: De quantos modos é possivel comprar 4 sorvetes em uma loja que os oferece em 7 sabores?

Esse problema é bem parecido com o problema que apresentamos na página 192 deste trabalho.

A equação linear para esse problema ficaria assim

$x_{1}+x_{2}+x_{3}+x_{4}+x_{5}+x_{6}+x_{7}=4$, sendo $x_{i}(\mathrm{i}=1,2,3,4,5,6$ e 7$)$ a quantidade de sorvetes de cada sabor.

Os autores usaram o mesmo raciocínio apresentado no livro Prelúdio, mas usaram o esquema bola-traço (cada bola representa uma unidade no valor da incógnita; cada traço é usado para separar duas incógnitas). Por exemplo:

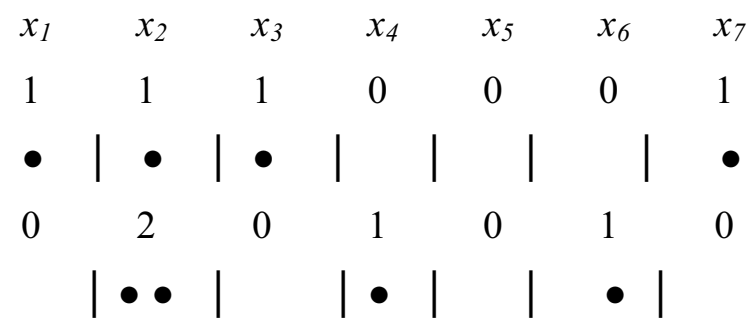


Assim, para formar uma representação devemos arrumar em fila 4 bolas (pois em cada solução o total de unidades nas incógnitas é 4 já que $\left.x_{1}+x_{2}+x_{3}+x_{4}+x_{5}+x_{6}+x_{7}=4\right)$ e 6 traços (para separar 7 incógnitas, usamos 6 traços). Os autores apresentam uma relação de permutação com repetição com combinação simples.

O número de modos de fazer isso é $P_{4+6}^{4,6}=\frac{10 !}{4 ! \cdot 6 !}=C_{10}^{4}$. Observe que os autores não usam $P R$ como notação para permutação com repetição.

Logo, $C R_{7}^{4}=C_{10}^{4}=210$.

Os autores apresentam ainda que no caso geral, para calcular $C R_{n}^{p}$, isto é, para determinar o número de soluções inteiras e não negativas de $x_{1}+x_{2}+x_{3}+\ldots+x_{n}=p$ teríamos $p$ bolas e $(n-1)$ traços. Logo,

$$
C R_{n}^{p}=P_{p+n-1}^{p, n-1}=\frac{(n+p-1) !}{p ! \cdot(\mathrm{n}-1) !}=C_{n+p-1}^{p}
$$

Portanto, $C R_{n}^{p}=C_{n+p-1}^{p}$.

Concluindo, vimos nesses dois livros que, ao achar o número de combinações com repetição, os autores apresentam uma equivalência entre combinação com repetição, combinação simples e permutação com repetição. Podemos mostrar essa equivalência através das expressões apresentadas por eles.

$$
C R_{n}^{p}=C_{n+p-1}^{n-1}, \quad C R_{n}^{p}=C_{n+p-1}^{p} \quad \text { e } \quad C R_{n}^{p}=P_{p+n-1}^{p, n-1}=\frac{(n+p-1) !}{p ! \cdot(\mathrm{n}-1) !}=C_{n+p-1}^{p}
$$


Outra observação interessante, nascida de um questionamento com um outro participante da oficina, foi a seguinte: utilizei, para resolver o problema proposto, o Princípio Multiplicativo (ou Princípio Fundamental de Contagem), uma vez que me foi dito que ele se aplicava nesse caso. Mas, na verdade não sei justificar por que multiplico as possibilidades encontradas.

Assim, se houvesse mais tempo, poderia trabalhar com os participantes da oficina, visando a responder a questão levantada da seguinte maneira, que foi apresentada no livro Prelúdio à Análise Combinatória (BACHX; POPPE; TAVARES, 1975, p.3).

\section{Enunciado do Princípio Fundamental de Contagem (ou Princípio Multiplicativo)}

Se um acontecimento A pode ocorrer de $m$ maneiras diferentes e se, para cada uma das $m$ maneiras possíveis de ocorrências de A, um segundo acontecimento B pode ocorrer de $n$ maneiras diferentes, então o número de maneiras de ocorrer o acontecimento A seguido do acontecimento B é $m \cdot n$.

De uma maneira intuitiva podemos analisar o comportamento da ocorrência desses acontecimentos como indicados no enunciado, fazendo uso de uma tabela dos possíveis pares ordenados $\left(\mathrm{a}_{\mathrm{i}}, \mathrm{b}_{\mathrm{j}}\right)$.

Designemos por:

$\mathrm{a}_{1}, \mathrm{a}_{2}, \ldots, \mathrm{a}_{\mathrm{m}}, \quad$ as $m$ maneiras de ocorrências de $\mathrm{A}$

e por $\mathrm{b}_{1}, \mathrm{~b}_{2}, \ldots, \mathrm{b}_{\mathrm{n}}$, as $n$ maneiras de ocorrências de $\mathrm{B}$,

após A ter-se concretizado da maneira $\mathrm{a}_{\mathrm{i}}($ onde $\mathrm{i}=1,2, \ldots, m)$, e $\mathrm{B}$ ter-se concretizado da maneira $b_{\mathrm{j}}$ (onde $\mathrm{j}=1,2, \ldots, n$ )

Construamos o seguinte quadro:

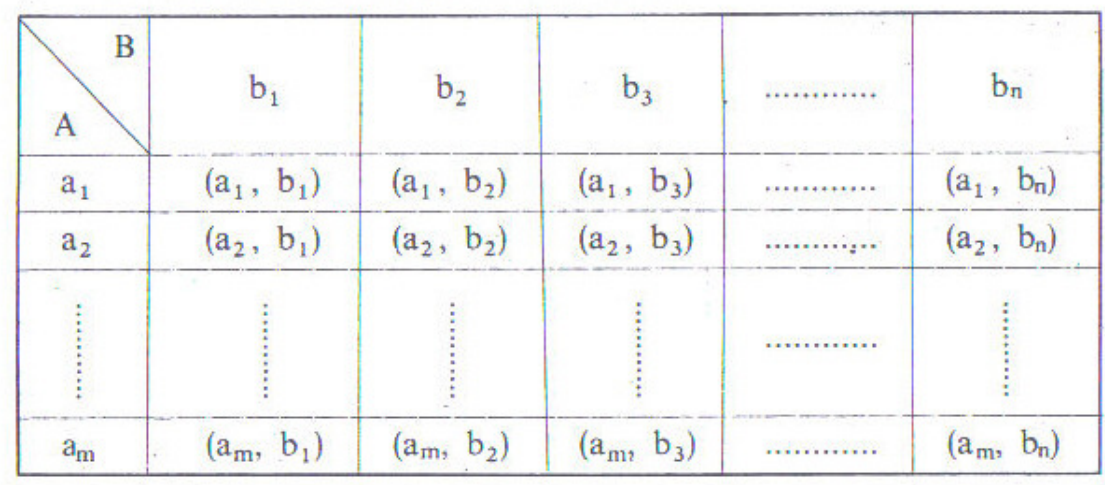

Este quadro nos mostra que: 
1) Existem $m \cdot n$ pares ordenados;

2) Em cada par ordenado $\left(a_{i}, b_{j}\right)$,

$\mathrm{a}_{\mathrm{i}}$ representa uma das $m$ possíveis ocorrências do acontecimento A

e $b_{\mathrm{j}}$ representa uma das $n$ possíveis ocorrências do acontecimento B.

Daí ser imediata a constatação da existência de $m \cdot n$ possibilidades de ocorrer o acontecimento A seguido do acontecimento B.

Esse é o chamado Princípio Multiplicativo ou Princípio Fundamental de Contagem.

\section{Extensão do Princípio Multiplicativo}

Se um acontecimento $A_{i}$ pode ocorrer de $m_{i}$ maneiras diferentes para $(i=1,2, \ldots, n)$, então a sequência $\left(A_{1}, A_{2}, \ldots, A_{n}\right)$ de $n$ acontecimentos sucessivos pode ocorrer de $\mathrm{m}_{1} \cdot \mathrm{m}_{2} \cdot \ldots \cdot \mathrm{m}_{\mathrm{n}}$ maneiras diferentes.

Demonstração por indução:

i) Para $\mathrm{n}=2$ o teorema recai no Princípio Multiplicativo.

ii) Suponhamos que o teorema seja verdadeiro para $n=k(k \geq 2)$, isto é, a sequência de acontecimentos sucessivos $\left(\mathrm{A}_{1}, \mathrm{~A}_{2}, \mathrm{~A}_{3}, \ldots, \mathrm{A}_{\mathrm{k}}\right)$ pode ocorrer de $m_{1} \cdot m_{2} \cdot \ldots \cdot m_{k}$ maneiras diferentes (hipótese de indução).

Queremos provar que esse teorema vale para $n=k+1$ e se vale para $k+1$, então vale sempre, ou seja, para qualquer valor de $n$.

iii) Seja agora a sequência de acontecimentos sucessivos $\left(A_{1}, A_{2}, A_{3}, \ldots, A_{k}, A_{k+1}\right)$, onde $A_{k+1}$ pode ocorrer de $m_{k+1}$ maneiras diferentes.

iv) Seja $x^{*}=\left(x_{1}, x_{2}, x_{3}, \ldots, x_{k}\right)$ uma sequência de ocorrências, onde $\mathrm{x}_{\mathrm{i}}$ é uma das $\mathrm{m}_{\mathrm{i}}$ possíveis ocorrências de $A_{i}(i=1,2,3, \ldots, k)$ 


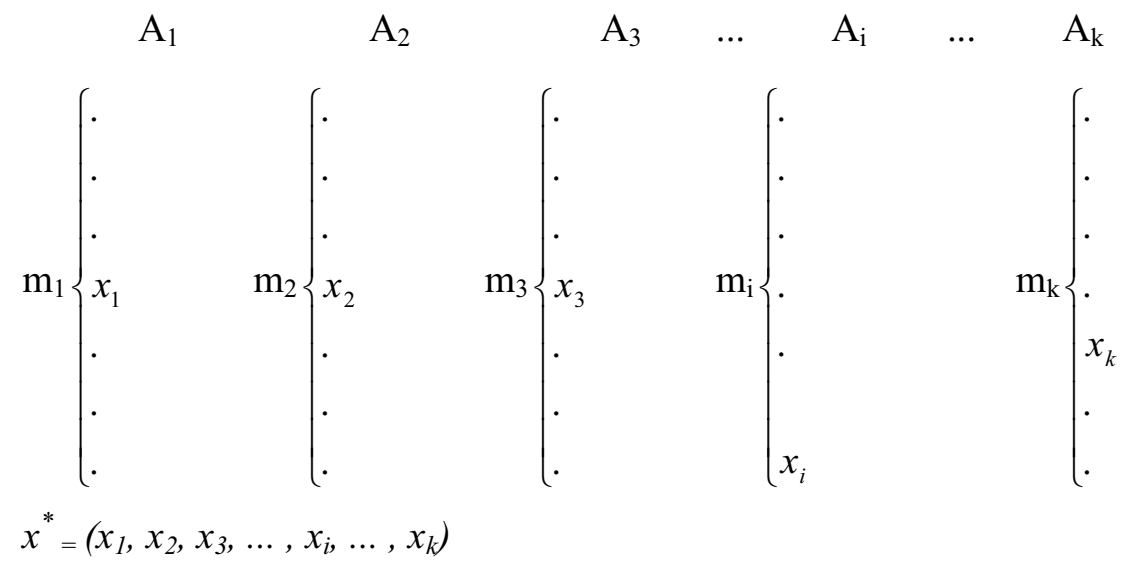

Pela hipótese de indução, $x^{*}$ pode ser determinada de $m=m_{1} \cdot m_{2} \cdot m_{3} \cdot \ldots m_{k}$ maneiras diferentes.

v) Seja $\mathrm{x}_{\mathrm{k}+1}$ uma das $\mathrm{m}_{\mathrm{k}+1}$ maneiras pelas quais $A_{k+1}$ pode ocorrer. Como, por (iv), $x^{*}$ pode ser determinada de $m_{\mathrm{i}}$ maneiras diferentes, e $x_{k+1}$ de $m_{k+1}$ maneiras diferentes, segue-se pelo Princípio Multiplicativo, que $x^{*}$ e $x_{k+1}$ podem ser determinadas de $m_{i} \cdot m_{k+1}=\left(m_{1} \cdot m_{2} \cdot m_{3} \cdot \ldots m_{k}\right) \cdot m_{k+1}$ modos diferentes.

Todavia, determinar $x^{*}$ e $x_{k+1}$ equivale a determinar a sequência de ocorrências $\left(x_{1}, x_{2}, x_{3}, \ldots, x_{k}, x_{k+1}\right)$.

vi) Assim, a determinação das ocorrências $x_{1}, x_{2}, x_{3}, \ldots, x_{k}, x_{k+1}$ pode ser efetuada de $m_{1} \cdot m_{2} \cdot m_{3} \cdot \ldots m_{k} \cdot m_{k+1}$ maneiras diferentes, e a demonstração, por indução, está completa. 


\subsection{Projeto 3}

Como relatamos no início deste capítulo, o $\mathbf{P}_{\mathbf{3}}$ refere-se à postura da pesquisadora ao apresentar sua pesquisa em Congressos e Encontros de Educação Matemática.

Planejamos um modelo para esboçar esse trabalho:

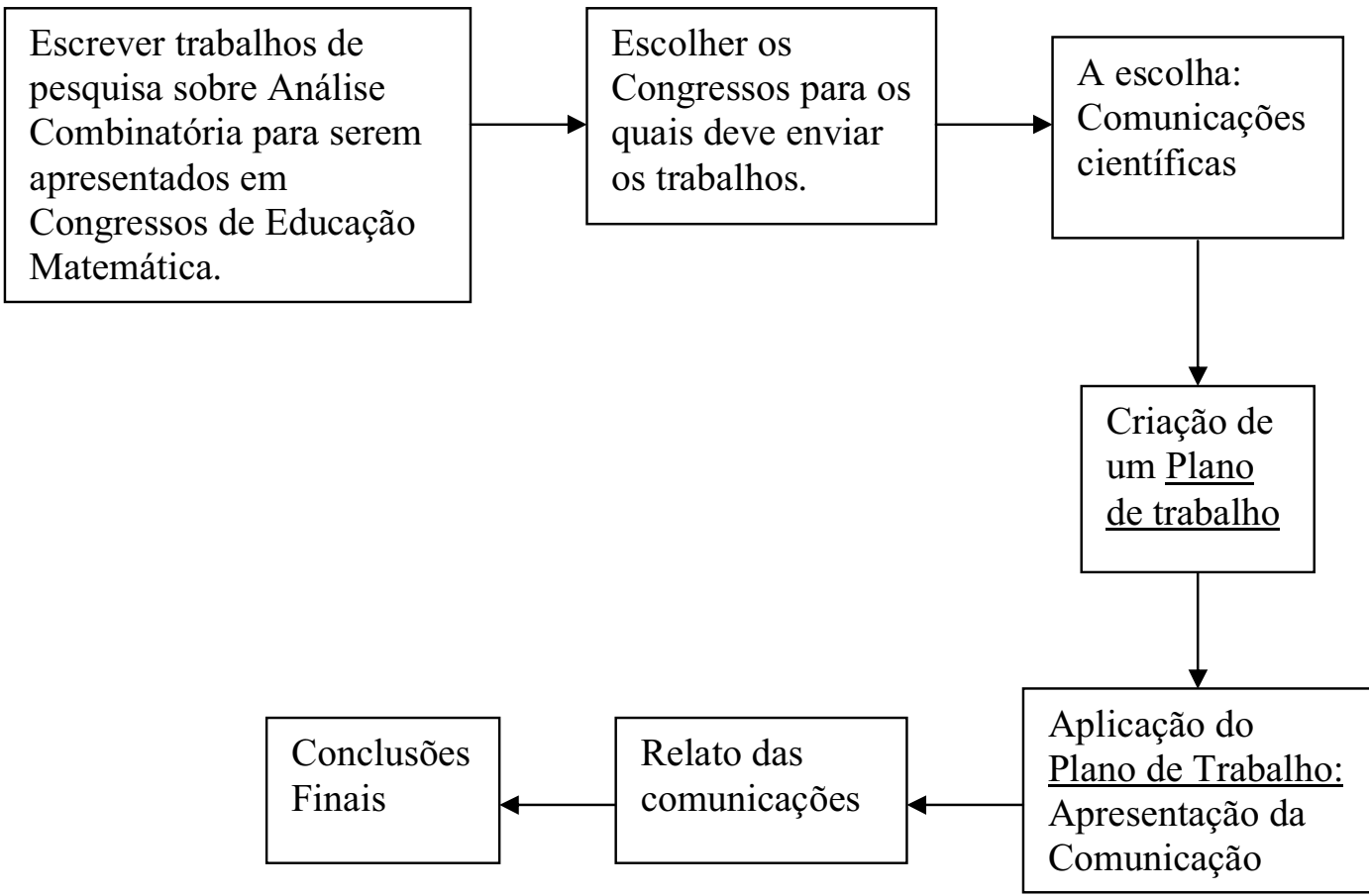

Figura 14: Modelo $-\mathrm{P}_{3}$

$\mathrm{O}$ projeto $\mathbf{P}_{3}$ tem como objetivo enviar, a Encontros de Educação Matemática, trabalhos científicos da pesquisadora para frente à Comunidade Científica, serem analisados e discutidos o ensino e a aprendizagem de tópicos relativos à Análise Combinatória, fazendo uso da Metodologia de Ensino-Aprendizagem-Avaliação de Matemática através da resolução de problemas.

A Estratégia Geral selecionada para $\mathbf{P}_{3}$ é a de Criar um Plano de Trabalho e, como Procedimento Geral correspondente, a Criação desse Plano de Trabalho.

\section{Procedimento Geral em ação - A Criação do Plano de Trabalho}

Selecionamos dois eventos em que participamos através de comunicação científica do trabalho: I Congresso Nacional das Licenciaturas: Ciência, Ensino e Aprendizagem 
(2007) e XII EBRAPEM -XII Encontro Brasileiro de Estudantes de Pós-Graduação em Educação Matemática (2008), cujos trabalhos apresentados serão relatados a seguir.

Para o I Congresso Nacional das Licenciaturas: Ciência, Ensino e Aprendizagem, realizado na Universidade Presbiteriana Mackenzie, São Paulo-SP, no período de 24 a 28 de setembro de 2007, enviamos o trabalho, de dez páginas, intitulado Análise Combinatória no Ensino Médio Apoiada na Metodologia de Ensino-Aprendizagem-Avaliação de Matemática através da Resolução de Problemas. O trabalho foi aceito e sua comunicação científica seria realizada no dia 28 de setembro de 2007. Apresentamos abaixo o texto enviado para esse Congresso, com algumas modificações.

\section{Análise Combinatória no Ensino Médio Apoiada na Metodologia de Ensino- Aprendizagem-Avaliação de Matemática através da Resolução de Problemas}

\section{ENSINO DE MATEMÁTICA ATRAVÉS DA RESOLUÇÃO DE PROBLEMAS}

Problemas matemáticos, do tipo que são encontrados na história antiga: egípcia, chinesa e grega, são apresentados em livros-texto de matemática nos séculos XIX e XX com a mesma ênfase. A idéia é a mesma. Alguém cria um problema, resolve-o, apresenta sua solução e oferece a outros uma lista de problemas do mesmo tipo para serem resolvidos da mesma forma. Assim não se exige do aluno criar estratégias para a resolução do problema, o aluno "aprende" mecanicamente o que lhe é "ensinado", não aprende a pensar, não raciocina.

Resolver problemas sempre foi um desafio para alunos e professores, devido aos métodos enfatizarem a repetição e a mecanização da resolução de problemas. Embora as reformas de ensino propostas no século XX: o ensino de matemática por repetição, o ensino de matemática com compreensão, a Matemática Moderna e a Resolução de Problemas, tenham proposto novos rumos de trabalho mais produtivo, o professor, nunca chamado a participar delas, mostra-se, na hora da aplicação, não preparado para empregá-las.

As primeiras pesquisas sobre o Ensino de Matemática através da Resolução de Problemas iniciou-se sob a influência de George Polya (Universidade de Stanford-EUA), que propõe, no livro A Arte de Resolver Problemas (1994) $1^{\mathrm{a}}$ ed. em 1945, um método em quatro etapas para a resolução de problemas: $1^{\circ}$ ) compreender o problema, $2^{\circ}$ ) elaborar um plano, $3^{\circ}$ ) executar o plano, $4^{\circ}$ ) fazer o retrospecto ou verificação da solução do problema original. Desenvolve um 
processo heurístico ao longo da resolução de problemas. Alan H. Schoenfeld apresentou, a partir de 1978, trabalhos semelhantes ao de Polya.

Mas o trabalho desses autores procura fixar algumas regras, apresentando estratégias que podem levar à solução do problema. Este não é o enfoque dado à minha pesquisa, pois, nela, pretendo ensinar matemática através da resolução de problemas.

Desde os anos 80, a orientação de Polya faz parte da discussão da comunidade brasileira de Educação Matemática. A proposta de Resolução de Problemas passou por várias modificações, sendo que o NCTM (Conselho Nacional de Professores de Matemática), entidade norte-americana, apresentou um documento "An Agenda for Action" (Uma Agenda para Ação), recomendando que os professores de Matemática deveriam criar situações nas salas de aula onde a Resolução de Problemas pudesse desabrochar.

$\mathrm{Na}$ década de 90, assume-se a Resolução de Problemas como o foco da matemática escolar e um meio de se ensinar Matemática, sendo o problema um ponto de partida e o desencadeador ou gerador do processo de construção do conhecimento.

Para Dante, "problema é qualquer situação que exija o pensar do indivíduo para “solucioná-la"(apud Rodrigues, 1992, 27) e que o aluno esteja interessado em resolvê-la. O trabalho de Mendonça, (1993), apresenta três interpretações para a Resolução de Problemas: 1) como um objetivo, significa que se ensina Matemática para resolver problemas, Resolução de Problemas é a meta final, 2) como um processo, significa que a Resolução de Problemas é um meio para desenvolver o potencial heurístico do aluno, dirige-se ao desempenho do indivíduo como resolvedor, ou 3) como um ponto de partida, significa olhar o problema como um elemento que pode disparar um processo de construção do conhecimento matemático.

No trabalho de Gazire (1988) são apresentadas perspectivas em Educação Matemática para a Resolução de Problemas: 1) um novo conteúdo, 2) aplicação do conteúdo, e 3) um meio de se Ensinar Matemática.

Temos três temas gerais relacionados ao trabalho com resolução de problemas em Stanic \& Kilpatrick (1990): a) A resolução de problemas como contexto, que é dividido em cinco subtemas: como justificativa, como motivação, como recreação, como veículo e como prática. b) A resolução de problemas como habilidade: a resolução de problema é vista como muitas habilidades a serem ensinadas no currículo matemático; resolve problemas rotineiros. c) A resolução de problemas como arte: emerge do trabalho de Polya, que revive a idéia da heurística, a de levar os estudantes a compreenderem como a Matemática foi descoberta e como fazer suas próprias descobertas. 
Schroeder e Lester (1989, p.31) descrevem situações em relação à resolução de problemas:

- Ensinar sobre resolução de problemas: o professor trabalha com variações do modelo de Polya.

- Ensinar a resolver problemas: concentra-se na maneira como a Matemática é ensinada e o que dela pode ser aplicada. Dá-se relevância ao uso do conhecimento adquirido anteriormente em problemas rotineiros e não rotineiros.

- Ensinar Matemática via resolução de problemas: a resolução de problemas é vista como uma forma de ensino, o problema como um ponto de partida e um meio de se fazer matemática. $\mathrm{O}$ ensino está centrado no professor.

- Ensinar Matemática através da resolução de problemas: o problema é olhado como um elemento que pode disparar um processo de construção do conhecimento. O ensino está centrado no aluno, que participa da construção dos conceitos e conteúdos matemáticos durante a resolução de um problema que, a seguir, são formalizados pelo professor.

Minha pesquisa se identifica com a última perspectiva: ensino de Matemática através da resolução de problemas, como um meio de se ensinar Matemática, uma metodologia, sendo o problema o gerador do processo de ensino-aprendizagem.

Ainda,

$O$ ponto central de nosso interesse em trabalhar o ensinoaprendizagem de matemática através da resolução de problemas baseia-se na crença de que a razão mais importante para esse tipo de ensino é a de ajudar os alunos a compreenderem os conceitos, os processos e as técnicas operatórias necessárias dentro do trabalho feito em cada unidade temática. (ONUCHIC, 1999, 208).

Nos PCN (1999), a Resolução de Problemas está presente como um caminho para o ensino de Matemática, identificando-se parcialmente com o enfoque assumido nesta pesquisa.

A metodologia de ensino de Matemática através da Resolução de Problemas tem, por meta, ajudar os alunos a se tornarem investigadores diante de uma situação desafiadora, um problema, de forma a buscar compreender e questionar os conceitos de que irão necessitar. O papel do professor muda de "comunicador de conhecimento" para o de observador, organizador, consultor, mediador, controlador, incentivador da aprendizagem. Sendo assim, exige-se bastante do professor, “... o professor terá que enfrentar situações inesperadas em sala de aula e, em algumas oportunidades, deverá alterar aquilo que tinha planejado e, ainda mais, terá que estar atento às dificuldades apresentadas pelos alunos...” (Rodrigues, 1992, 29). 
Em relação à aprendizagem do aluno pode-se ouvir que

Em nossa visão, a compreensão de Matemática, por parte dos alunos envolve a idéia de que compreender é essencialmente relacionar. Esta posição baseia-se na observação de que a compreensão aumenta quando o aluno é capaz de: relacionar uma determinada idéia matemática a um grande número ou a uma variedade de contextos, relacionar um dado problema a um grande número de idéias matemáticas implícitas nele, construir relações entre as várias idéias matemáticas contidas num problema. Ressalte-se que as indicações de que um estudante entende, interpreta mal ou não entende idéias matemáticas específicas surgem, com freqüência, quando ele resolve um problema. (ONUCHIC e ALLEVATO, 2004, 222)

\section{ANÁLISE COMBINATÓRIA}

A Análise Combinatória é considerada um conteúdo difícil de ser abordado na sala de aula, pois geralmente é vista através de "fórmula-aplicação", deixando lacunas na compreensão dos conceitos de arranjo, permutação e combinação.

O modo que o professor trabalha com a Análise Combinatória interfere diretamente na aprendizagem do aluno. Adotar uma metodologia que permita a participação do aluno na construção desses conceitos contribui para uma compreensão significativa, dando sentido à Matemática, e também levando em consideração o cotidiano do aluno, trabalhando com problemas contextualizados. Assim, o papel do professor é fundamental para que isso se efetive. Desse modo, exige do professor planejar a aula, explicitando: os objetivos de cada aula; as estratégias e procedimentos na resolução de problemas e os critérios de avaliação.

Geralmente os alunos procuram identificar a fórmula correta (para arranjo, permutação ou combinação) ao resolver um problema. Isso ocorre pois eles não participaram da construção desses conceitos apenas o resolveram de modo mecânico.

Faz-se necessário então um estudo explorando os conceitos primitivos da Análise Combinatória, o Princípio Fundamental de Contagem ou Princípio Multiplicativo e o Princípio Aditivo, trabalhando de modo intuitivo com o aluno, descrevendo os casos possíveis, formando agrupamentos e contando-os, utilizando técnicas de contagem com o auxílio da árvore de possibilidades ou tabelas de dupla entrada. "Uma análise adequada dos processos de formação de agrupamentos, pelos alunos, evitará defeitos freqüentes entre os iniciantes, decorrente da tendência de adivinhar a resposta ou o processo de contagem" (Proposta Curricular, 1992, 104) 
Resolver os problemas com esse enfoque, dando o tempo necessário, deve levar o aluno à sistematização da contagem bem como à sistematização dos conceitos de arranjo, permutação e combinação. Os problemas iniciais devem ser elaborados com poucos elementos, solução intuitiva e contagem direta, para destacar quantas e quais são as possibilidades neste tipo de abordagem. Os alunos poderão observar que a contagem direta é impraticável na maioria dos casos e constatarão que é preciso perceber certas regularidades, para desenvolverem técnicas de contagem apropriadas, que generalizem as soluções. Os alunos perceberão que ao contar ou fazer os agrupamentos, através das técnicas de contagem, estes se diferenciam pela ordem e/ou natureza dos elementos dados no problema.

Analisando as técnicas de contagem com relação aos agrupamentos envolvidos nas situações-problema, bem como o processo de formação dos agrupamentos, os alunos estarão preparados para sistematizar os conceitos envolvidos na Análise Combinatória e entender a necessidade do uso de fórmulas, chegando à solução de forma mais rápida, quando o número de elementos envolvidos nos agrupamentos for grande.

Desse modo, a Análise Combinatória está relacionada essencialmente com o processo de contagem de um número de elementos de um conjunto, sem que haja a necessidade de enumerá-los.

Nesse sentido, Roxo et al (1944) descreve:

Denomina-se análise combinatória ao estudo da formação, contagem e propriedades dos agrupamentos que podem constituir-se, segundo determinados critérios, com os objetos de uma coleção. Esses agrupamentos distinguem-se, fundamentalmente, em três espécies: arranjos, permutações e combinações, e podem ser formados de objetos distintos ou repetidos. (81)

Analisando os livros didáticos, percebe-se que a maioria apresenta o conteúdo de Análise Combinatória dando ênfase à utilização de fórmulas, sem a preocupação da dedução das mesmas. O que não ocorre no livro de Trotta et al (1979), que apresenta o conteúdo iniciando com a resolução de problemas, de modo que o aluno desenvolva o raciocínio combinatório partindo de processos de contagem. Posteriormente a esse primeiro contato, são apresentadas as definições de arranjo, permutação e combinação. Os arranjos são definidos como seqüências de elementos; as permutações são apresentadas como um caso particular de arranjos sem repetição e as combinações são definidas como subconjuntos de um conjunto dado. 
É discutido, na bibliografia, como se dá o desenvolvimento do raciocínio combinatório nos alunos. Palangana (2001) cita a teoria de Piaget em que o desenvolvimento cognitivo compreende quatro estágios ou períodos: sensório-motor (do nascimento aos 2 anos); préoperacional (2 a 7 anos); operações concretas ( 7 a 12 anos) e operatório-formal (adolescência: 12 anos em diante). Nesse último estágio “... o pensamento do adolescente opera através da Análise Combinatória, da correlação e das formas de reversibilidade (inversão e reciprocidade) "(Palangana, 2001, 29).

A combinatória permite que se estabeleça qualquer classe ou relação, através da reunião dos elementos um a um, dois a dois, três a três, etc. Essa nova e importante habilidade se manifesta na capacidade que o adolescente apresenta de ultrapassar os encaixes hierárquicos ou encadeamentos simples dos agrupamentos e combinar entre si elementos de conjuntos diferentes, a partir dos quais ele constrói um outro conjunto. A combinatória é importante na medida em que possibilita uma nova lógica, significa o raciocínio sobre uma realidade dada em função de todos os aspectos que comporta e de todas as combinações possíveis. Essa capacidade se estende à combinação de objetos e à de proposições. Para tanto, o adolescente utiliza-se da fórmula "falso" ou "verdadeiro" e de operações que até então não dominava, tais como: as relações de implicação, disjunção, exclusão, incompatibilidade e implicação recíproca. (Palangana, 2001, 29).

Alguns trabalhos enfatizam o aprendizado da Análise Combinatória: O Pensamento Combinatório no Ensino Fundamental e Desmistificando a Análise Combinatória (Cassol, 1998), realizam esses trabalhos dando uma maior atenção aos conceitos ao invés da mecanização.

No artigo de Navarro-Pelayo, Batanero e Godino (1996), ressalta que: “a Análise Combinatória é um componente essencial da Matemática Discreta e, como tal, tem um papel importante na matemática escolar"(p.26). Estes autores apresentam um questionário sobre a Análise Combinatória para avaliar o raciocínio combinatório de 720 alunos, de 14 e 15 anos. Apesar de se tratar de uma intervenção na sala de aula, eles não trabalham com a metodologia de ensino-aprendizagem-avaliação de Matemática através da Resolução de Problemas.

Outros referenciais teóricos que nortearão o desenvolvimento desta pesquisa são: a Proposta Curricular para o Ensino de Matemática do Estado de São Paulo (1992), sendo que o objetivo geral dessa proposta para o ensino de Análise Combinatória é o de desenvolver o raciocínio combinatório, tendo em vista: a familiarização do aluno com problemas que envolvem contagem; a sistematização da contagem; a sistematização dos conceitos de arranjo, 
permutação e combinação simples. (Secretaria da Educação, 1992, 29); e também os Parâmetros Curriculares Nacionais do Ensino Médio (1999) que apontam

As habilidades de descrever e analisar um grande número de dados, realizar inferências e fazer predições com base numa amostra de população, aplicar as idéias de probabilidade e combinatória a fenômenos naturais e do cotidiano são aplicações da Matemática em questões do mundo real que tiveram um crescimento muito grande e se tornaram bastante complexas. Técnicas e raciocínios estatísticos e probabilísticos são, sem dúvida, instrumentos tanto das Ciências da Natureza quanto das Ciências Humanas. Isto mostra como será importante uma cuidadosa abordagem dos conteúdos de contagem, estatística e probabilidade no Ensino Médio, ampliando a interface entre o aprendizado da Matemática e das demais ciências e áreas. (PCN-Ensino Médio, 1999, 15)

Este trabalho, para esse Congresso, tem como objetivo central apresentar uma proposta de trabalho para ensinar Análise Combinatória, na sala de aula, adotando a metodologia de ensino-aprendizagem-avaliação de Matemática através da resolução de problemas. São objetivos específicos para as atividades nela sugeridas, verificar a necessidade de um trabalho de investigação, sem depender de fórmulas previamente determinadas (analisando os processos de formação de agrupamentos); explorar situações-problema numa abordagem do cotidiano em sala de aula; permitir ao aluno buscar soluções próprias através de técnicas de contagem; e desenvolver o raciocínio combinatório necessário para uma formalização posterior.

Sendo o objetivo deste estudo apresentar uma proposta para trabalhar Análise Combinatória na sala de aula, segundo a metodologia adotada, pretendo com essa proposta procurar evitar a utilização inicial de fórmulas prontas, incentivando os alunos a buscarem soluções próprias, que deverão levar o professor, posteriormente, à formalização de conceitos e conteúdos novos. As situações-problema serão um gerador do processo ensinoaprendizagem de Matemática. Trabalhando com essa metodologia, proponho um trabalho diferenciado em sala de aula.

\section{PROBLEMA PROPOSTO}

Proponho a seguir, por meio deste trabalho, a resolução de um problema para iniciar o conteúdo de Análise Combinatória na sala de aula nos moldes citados por mim, de forma significativa e com compreensão, a fim de contribuir para o processo de ensino- 
aprendizagem-avaliação de Matemática no Ensino Médio. Deixo outros problemas como sugestão para serem explorados por professores na sala de aula.

Problema: Numa urna foram colocadas 5 bolas de cores diferentes: vermelha, preta, amarela, cinza e branca. De quantas maneiras distintas poderemos retirar 3 bolas da urna? ${ }^{24}$

Resolução: Vamos representar as cores das bolas por: vermelha (v), preta (p), amarela (a), cinza (c) e branca (b).

Ao interpretar o enunciado do problema, podem aparecer soluções diferentes. Analisaremos a seguir as possíveis soluções:

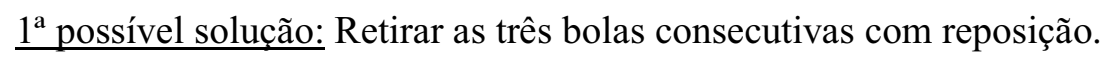

Temos 5 possibilidades de retirada da $1^{\mathrm{a}}$ bola (v, p, a, c ou b). Como vamos repô-la, então temos também 5 possibilidades de retirada para a $2^{\mathrm{a}}$ bola. $\mathrm{O}$ mesmo ocorrendo para a $3^{\mathrm{a}}$ bola a ser retirada, como se ilustra abaixo:

$1^{\text {a }}$ bola retirada: 5 possibilidades, $2^{\text {a }}$ bola retirada: 5 possibilidades e $3^{\text {a }}$ bola retirada: 5 possibilidades.

Pelo Princípio Fundamental de Contagem, temos: $5 \cdot 5 \cdot 5=125$. Temos então 125 maneiras distintas de retirar as três bolas da urna.

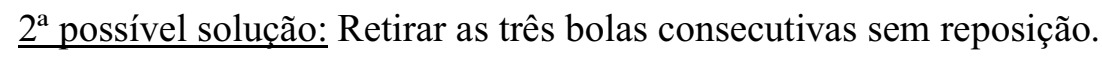

Temos 5 possibilidades de retirada da $1^{\mathrm{a}}$ bola (v, p, a, c ou b). Como não vamos repô-la, então temos 4 possibilidades de retirada para a $2^{\text {a }}$ bola, e para $3^{\text {a }}$ bola a ser retirada restam 3 possibilidades, como se ilustra abaixo:

$1^{\text {a }}$ bola retirada: 5 possibilidades, $2^{\text {a }}$ bola retirada: 4 possibilidades e $3^{\text {a }}$ bola retirada: 3 possibilidades.

Pelo Princípio Fundamental de Contagem, temos: 5·4 $3=60$. Temos então 60 maneiras distintas de retirar as três bolas da urna.

Analisando a segunda solução, temos que foi estabelecida a ordem da retirada das bolas, pois a retirada da $2^{\mathrm{a}}$ bola dependia da $1^{\mathrm{a}}$, assim como a $3^{\mathrm{a}}$ dependia da retirada da $2^{\mathrm{a}}$. Então, as possibilidades, por exemplo, cav e cva são distintas, diferem pela ordem. Também diferem pela natureza dos elementos, por exemplo, cap e cav.

\footnotetext{
${ }^{24}$ Retirado da Proposta Curricular para o Ensino de Matemática 2o grau (Matemática), (1992).
} 


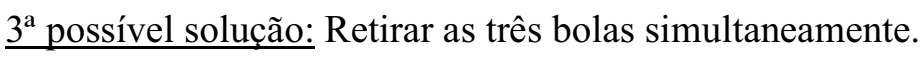

Ao retirar as bolas simultaneamente, fica impossível distinguir entre as possibilidades, por exemplo: cav, cva, vac, vca, avc e acv. Então, cada uma das 6 possibilidades fica reduzida a uma só. Analogamente, na retirada das bolas cap; cab; cvp; cpb; avp; avb; apb e vpb.

Assim, das 60 maneiras diferentes de retirar as três bolas (calculado anteriormente), dividimos por 6 para não contar as possibilidades repetidas. Então temos $\frac{60}{6}=10$ maneiras distintas de retirar três bolas simultaneamente.

\section{Análise do problema:}

a) $\mathrm{Na}^{\mathrm{a}}$ possível solução só importa a natureza dos elementos em cada agrupamento. Denominamos esse agrupamento de combinação. Assim, das 60 maneiras diferentes de retirar as três bolas, foi necessário dividir 60 por 6 para não contar as possibilidades repetidas.

Neste caso $\frac{60}{6}=\frac{60}{3 !}=\frac{60}{3 \cdot 2 \cdot 1}=10$. Assim há 10 maneiras distintas de se retirar as três bolas simultaneamente.

Podemos fazer $\frac{60}{3 !}=\frac{5 \cdot 4 \cdot 3}{3 !}$. Multiplicando numerador e denominador por 2!, temos:

$\frac{5 \cdot 4 \cdot 3 \cdot 2 !}{3 ! 2 !}=\frac{5 !}{3 ! 2 !}, C_{5,3}=\frac{5 !}{3 ! 2 !}=10$. Generalizando, considerando $n$ : número de elementos, e $p$ : o número de elementos de cada agrupamento, então $C_{n, p}=\frac{n !}{p !(n-p) !}$ que indica o número de combinações simples de $n$ elementos tomados $p$ a $p$.

b) Mas, caso a ordem também importasse, isto é, a retirada das bolas estivesse ligada às mesmas cores, estaríamos tratando de outra forma de agrupamento, onde a natureza dos elementos e a ordem deles são necessárias, o que ocorre nas $1^{\mathrm{a}}$ e $2^{\mathrm{a}}$ possíveis soluções. Denominamos ao agrupamento com essas características de arranjo.

c) $\mathrm{Na} 1^{a}$ possível solução, temos uma seqüência na retirada das bolas, mas com repetição, ou seja, podemos, por exemplo, ter duas bolas amarelas e uma preta (aap) ou (apa) ou (paa), que diferem pela ordem. Mas, se ainda houvesse mudança na natureza dos elementos, isto é, se 
mudasse pelo menos uma cor (por ex, avp), então, na $1^{\text {a }}$ possível solução teríamos arranjos com repetição.

É importante que, na sala de aula, os alunos descrevam, através da árvore de possibilidades, todos os casos possíveis.

$\mathrm{Na} 1^{\mathrm{a}}$ solução possível tem-se $\mathrm{n}=5(\mathrm{v}, \mathrm{p}, \mathrm{c}, \mathrm{a}, \mathrm{b})$ e $\mathrm{p}=3$ (o número de bolas retiradas a cada vez).

Iniciando com a bola $\mathrm{v}$, representamos a árvore de possibilidades a seguir

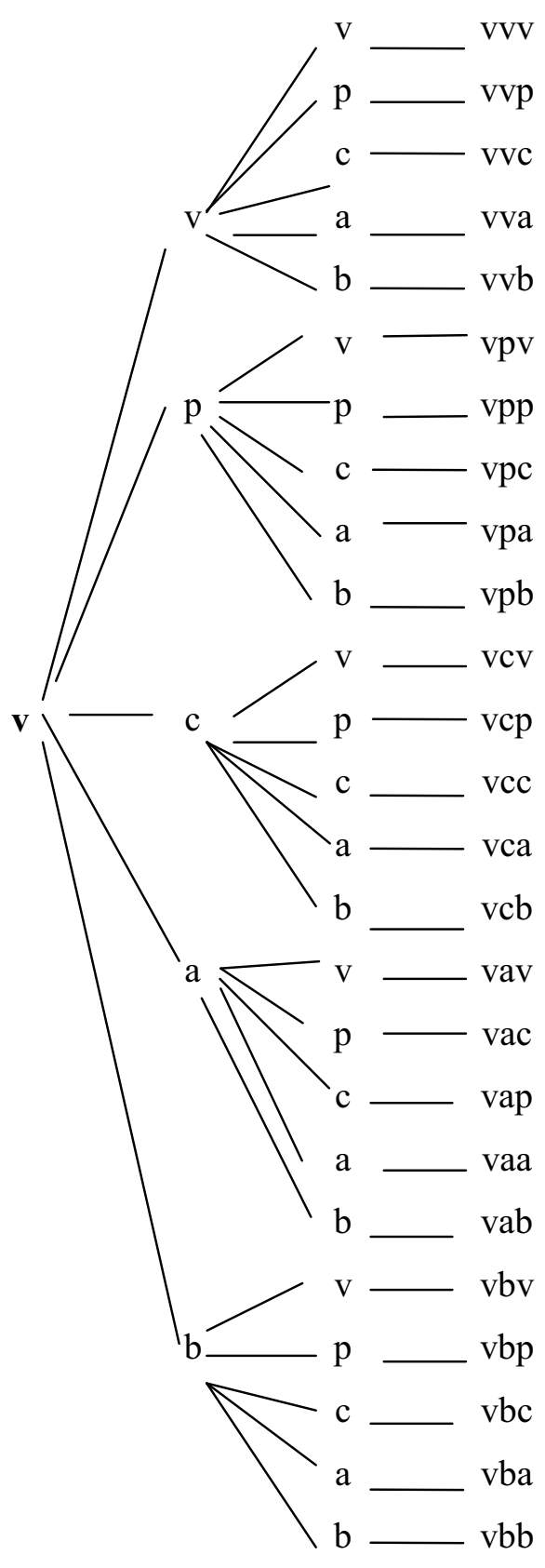


Contam-se então 25 possibilidades nesse ramo, iniciando com a retirada da bola vermelha. De modo análogo para início com p, c, a e b. Assim, tem-se 5·25=125 possibilidades de retirar as três bolas da urna.

Esse resultado poderia ser confirmado com o Princípio Multiplicativo: $5 \cdot 5 \cdot 5=125$ possibilidades.

Generalizando, se $n$ é o número de elementos do conjunto e $p$ é o número de retirada de bolas, então, pelo Princípio Multiplicativo ter-se-ia $\underbrace{n \cdot n \cdot \ldots \cdot n}_{p \text { vezes }}=n^{p}$. Então, o número de arranjos com repetição será dado por: $A R_{n, p}=n^{p}$ (arranjo com repetição).

d) $\mathrm{Na} 2^{\mathrm{a}}$ possível solução estamos tratando de arranjo, indicado por $\mathrm{A}_{\mathrm{n}, \mathrm{p}}$, arranjo de $\mathrm{n}$ elementos tomados p a p. Cada combinação, por exemplo, cav, gera 6 ou 3! possibilidades. Assim, no caso, temos $\mathrm{C}_{5,3} \cdot 3 !=\mathrm{A}_{5,3}$. Generalizando tem-se $A_{\mathrm{n}, \mathrm{p}}=\mathrm{C}_{\mathrm{n}, \mathrm{p}} \cdot \mathrm{p}$ !, substituindo $\mathrm{C}_{\mathrm{n}, \mathrm{p}}$ por $\frac{n !}{p !(n-p) !}$, resulta que $\mathrm{A}_{\mathrm{n}, \mathrm{p}}=\frac{n !}{(n-p) !}$ (arranjo simples).

Analisando a resolução desse problema, pode-se deduzir as fórmulas que generalizam o número de combinações e arranjos. Mas, anterior a isso, é importante que o aluno se familiarize com o processo de contagem e sistematize os conceitos envolvidos na Análise Combinatória, sentindo a necessidade da utilização da fórmula quando, por exemplo, a contagem dos casos se torna difícil. Desse modo, adotando a metodologia de ensinoaprendizagem-avaliação de Matemática através da resolução de problemas, o professor pode proporcionar ao aluno uma oportunidade de aprendizagem com significado e compreensão.

Como sugestão, poderiam ser indicados dois problemas para serem trabalhados na mesm linha adotada para esse.

\section{Problema 1:}

a) Quantos triângulos ficam determinados por nove pontos distintos, sendo que cinco deles pertencem a uma reta $\mathrm{s}(\mathrm{s} \equiv \mathrm{z})$ paralela a $\mathrm{r}^{25}$

b) Quantas retas ficam determinadas por nove pontos distintos, sendo que cinco deles pertencem a uma reta $\mathrm{r}$ e os outros quatro pertencem a uma reta $\mathrm{s}(\mathrm{s} \equiv \mathrm{z})$ paralela a $\mathrm{r}$ ?

\footnotetext{
${ }^{25}$ Retirado e adaptado do livro Matemática volume único, Paiva (1999).
} 
Problema 2: Cumprimente antes de você festejar.

Dez finalistas de diferentes estados foram convidados para uma confraternização. Antes de iniciar a festa, cada finalista cumprimentará com as mãos a todos os outros finalistas. Quantos cumprimentos haverá ao todo ${ }^{26}$

${ }^{26}$ Retirado e traduzido do livro Problem- Driven Math: applying the mathematics beyond solutions Krulik, S.; Rudnick, J.A (2005). 
Para o XII EBRAPEM - XII Encontro Brasileiro de Estudantes de PósGraduação em Educação Matemática - Educação Matemática: possibilidades de interlocução, realizado na UNESP, Rio Claro-SP, no período de 05 a 07 de setembro de 2008, enviamos o trabalho Comunicação científica intitulado Análise Combinatória apoiada na metodologia de ensino-aprendizagem-avaliação de matemática através da resolução de problemas. Para esse encontro enviamos esse trabalho, que foi aceito e publicado nos Anais na forma impressa e em CD.

O objetivo do EBRAPEM é, principalmente, o do debate científico sobre processos teórico-metodológicos de pesquisas ainda em construção e, também, para a divulgação de pesquisas concluídas, sendo aceitas até um ano após a conclusão.

O XII EBRAPEM foi estruturado como um espaço que privilegia a interlocução entre linhas de pesquisa em Educação Matemática e outras áreas de conhecimento. Nesse evento ocorre a dinâmica dos Grupos de trabalho - GTs - que têm por objetivo proporcionar aos participantes um espaço interativo de discussão de seus trabalhos, visando trazer colaborações tanto ao processo de formação de pesquisadores quanto ao do desenvolvimento de suas pesquisas.

A dinâmica dos GTs, nesse encontro, foi estruturada da seguinte forma:

1) Cada GT foi dividido em sessões de discussão.

2) Cada sessão teve um momento de discussão para cada trabalho ali presente.

3) Cada trabalho foi discutido durante 25 minutos pelos comentadores.

4) Os demais autores de trabalho e o coordenador da sessão são os comentadores de cada momento de discussão.

5) Neste momento, cada autor poderá utilizar os 5 minutos iniciais para expor as considerações introdutórias, caso entenda a necessidade de fazê-las. Ao final de todos os momentos de discussão de cada sessão, o debate é aberto ao público.

Nessa comunicação científica apresentei o desenvolvimento de minha pesquisa, apoiada na Metodologia de Thomas A. Romberg, já apresentada no início deste trabalho de pesquisa.

Seguindo as etapas das atividades 1,2 e 3 dessa Metodologia, identificamos, no $1^{\text {o }}$ bloco, a atividade 4 - o Problema da Pesquisa.

Identificado o problema da pesquisa, deu-se início o $2^{\mathrm{o}}$ bloco, atividades 5 e 6 , mostrando como resolver o problema levantado através da seleção de estratégias e procedimentos de pesquisa. 
Esta comunicação não fez referência ao $3^{0}$ bloco de Romberg, que foi trabalhado somente após a qualificação do professor-pesquisador.

Desse modo, decidimos não colocar esse trabalho no corpo do texto desta pesquisa, pois ele é parte importante de nossa pesquisa. Já constam no trabalho, nos capítulos anteriores, todos os itens abordados por nós nesta comunicação científica. Após a qualificação, foram realizadas correções e também foram acrescentadas mais informações em relação ao tema proposto. Assim, o trabalho encontra-se no Anexo desta pesquisa, apresentado na versão em que foi enviada, na época, para o Encontro. 


\section{CAPÍTULO 4 - Procedimento Geral em ação - Aplicação dos três projetos}

Introdução
4.1 - A aplicação do Projeto 1
4.2 - A aplicação do Projeto 2
4.3 - A aplicação do Projeto 3 


\section{CAPÍTULO 4 - Procedimento Geral em ação - Aplicação dos três projetos}

Introdução

No capítulo anterior, apresentamos as estratégias selecionadas e os selecionados procedimentos correspondentes a elas que nos levem à solução do Problema da Pesquisa, caracterizado por duas perguntas que se complementam: 1) Qual seria a contribuição da Metodologia de Ensino-Aprendizagem-Avaliação de Matemática através da Resolução de Problemas em uma nova abordagem, em sala de aula, da Análise Combinatória? E também: 2) Como se desenvolve a formação de conceitos de Análise Combinatória, adotando-se a Resolução de Problemas como uma metodologia de ensino? de aprendizagem? de avaliação?

Tínhamos como Estratégia Geral criar os três projetos $\mathrm{P}_{1}, \mathrm{P}_{2}$ e $\mathrm{P}_{3}$. E, como Procedimento Geral correspondente, a criação desses projetos. Criamos os projetos e descrevemos, no capítulo 3 todas as atividades a serem neles desenvolvidas.

Assim, apresentamos todo o planejamento, ou seja, a estrutura de cada projeto: o tema a ser desenvolvido; os objetivos pretendidos; as atividades idealizadas (como seriam as aulas); e os resultados que poderiam surgir durante sua aplicação. Essa fase de planejamento se identifica com uma das três fases apresentadas por Van de Walle (2001), a fase "antes", momento em que ainda não há interação do professor com os alunos. Na página 125 deste trabalho consta que:

Nessa fase, o professor deve levar em consideração o conhecimento prévio dos alunos, necessário à construção de novo conhecimento matemático. Além disso, o professor deve fazer todo o planejamento da aula, organizando-a assim: o foco da aula - ou seja, ter 
em mente o que de novo se pretende construir em Matemática, com o problema dado; $\underline{o}$ problema - selecionar um problema que permita chegar à construção de novos conceitos e conteúdos pretendidos; as estratégias - devem ser selecionadas para o encaminhamento e o desenvolvimento da aula; a resolução do problema - o problema deve ser resolvido detalhadamente, pelo professor, selecionando diferentes caminhos para se chegar à solução; a plenária - levantar questões para estimular os alunos à discussão e à exploração do problema durante a plenária; e a formalização - é o momento em que o professor, sob sua inteira responsabilidade, faz o fechamento da aula, apresentando, por escrito, as definições dos novos conceitos construídos e todo o conteúdo matemático decorrente desse trabalho.

Neste capítulo descreveremos o que ocorreu quando o Procedimento Geral foi posto em ação, ou seja, o que aconteceu nas aplicações dos projetos $\mathrm{P}_{1}, \mathrm{P}_{2}$ e $\mathrm{P}_{3}$, reconhecendo que há uma diferença entre criar um projeto e aplicar um projeto. Por exemplo, o tempo destinado para aplicação pode não ser suficiente como foi planejado.

Desse modo, na descrição dos dados, que apresentaremos a seguir, nem sempre se atinge à idealização almejada durante a elaboração do projeto, devido às dificuldades e aos imprevistos decorrentes de sua aplicação.

Nos três projetos evidenciamos o trabalho em sala de aula, adotando a Metodologia de Ensino-Aprendizagem-Avaliação de Matemática através da Resolução de Problemas, uma metodologia de ensino alternativa que mostra a importância de proporcionar aos alunos uma aprendizagem com significado e com compreensão. O problema é o ponto de partida no processo de ensino-aprendizagem-avaliação de Matemática. Assim, temos que essa metodologia é um meio de se aprender Matemática através da resolução de problemas. Como colocamos, na página 122: Essa metodologia tem por meta ajudar os alunos a se tornarem investigadores diante de uma situação desafiadora, um problema, de forma a compreender e questionar os conceitos de que irão necessitar para resolvê-lo.

Como relatamos nas páginas 123 a 125, Onuchic (1998) apresenta um roteiro para direcionar o trabalho em sala de aula. Mas, ao longo do tempo, fruto da prática em sala de aula, Onuchic e Allevato (2008) apresentam um novo roteiro com algumas alterações, que foram necessárias para um melhor encaminhamento das aulas.

Durante a aplicação de $\mathrm{P}_{1}$ e $\mathrm{P}_{2}$, utilizamos o primeiro roteiro apresentado por Onuchic. Fazer uso desse roteiro pode proporcionar ao professor e aos alunos uma melhor organização no desenrolar das aulas. Sempre que possível, utilizamos o roteiro mas, se necessário, o adaptamos, pois outros fatores podem causar mudanças que não estão descritos nele. 
Em busca de evidências para responder o Problema de Pesquisa, que leva ao $3^{\circ}$ bloco de Romberg, descreveremos como ocorreu a aplicação de $\mathrm{P}_{1}, \mathrm{P}_{2}$ e $\mathrm{P}_{3}$. Lembrando que os três projetos foram aplicados separadamente em diferentes cenários: $\mathrm{P}_{1}$ (na sala de aula), $\mathrm{P}_{2}$ (oficina em congresso) e $\mathrm{P}_{3}$ (apresentação de pesquisa em congresso).

Ao realizar a análise dos dados obtidos, pretendemos identificar as evidências que respondam ao Problema de Pesquisa e relatar seus resultados a quem possa interessar. 


\subsection{A aplicação do Projeto $1-P_{1}$}

Introdução

O objetivo de $\mathbf{P}_{1}$ é o de trabalhar com alunos, em uma sala de aula, com a pesquisadora como professora da turma, visando à construção de conceitos da Análise Combinatória, fazendo uso da Metodologia de Ensino-Aprendizagem-Avaliação de Matemática através da resolução de problemas.

Quando estava próximo o período para a aplicação do projeto, conversei com os alunos sobre a pesquisa que estava fazendo. Eles se interessaram mas não entendiam muito bem o que era um curso de Mestrado, Pós-Graduação, Graduação, etc. Então expliquei para eles como ocorria todo o processo, desde o $2^{\underline{0}}$ grau até chegar à Pós-Graduação. Esse momento foi importante pois houve interação da professora com os alunos e mostrou-se propício para conhecê-los melhor.

Assim, achei conveniente esse momento para conversarmos sobre o tema da minha pesquisa mesmo antes de as atividades serem propostas. Comentei sobre Matemática Discreta, sem lhe dar esse nome, falando das matrizes, conteúdo que já havíamos trabalhado no bimestre anterior. Então, revisamos esse assunto falando sobre a tela de um computador, de uma televisão e da câmera digital que, por mais que tenha milhares de linhas e colunas, tem um número finito de pontos. Comentei, também, que quanto maior o número de pontos, maior é a precisão da imagem, ou seja, ela fica mais nítida mas, enfatizando que por mais pontos que tenha, esse número é sempre finito, acaba.

Como já foi citado na página 138, a maioria dos alunos tinha a concepção de que Matemática está relacionada a números e a fazer contas. E quando os questionei quanto aos conteúdos matemáticos de que se lembravam, citaram conteúdos distantes daqueles da série que estavam cursando. Assim, tínhamos a preocupação de fazer um planejamento visando à aprendizagem das "grandes ideias" da Análise Combinatória e, se possível, chegar aos padrões que definem os conceitos de arranjos, permutações e combinações. Essas "grandes ideias" seriam o processo de contagem e a busca por um padrão.

Conhecer a realidade do aluno, seu conhecimento prévio, e seu interesse durante o trabalho em sala de aula, seria importante para lá se iniciar esse trabalho. Sabia-se que se teria pouco tempo para desenvolver esse projeto, então, a dificuldade para a construção dos conceitos de arranjo, permutação e combinação já era prevista. Desse modo, surgiu uma 
insegurança para a professora e principalmente para a pesquisadora que, almejando o esperado, nem sempre alcançaria os objetivos pretendidos pela pesquisa.

Além disso, como já comentamos no planejamento, iria-se trabalhar numa escola pública, de periferia; no período noturno, onde a maioria dos alunos iria para a sala de aula depois de um dia de trabalho; que possivelmente teriam dificuldade para cumprir integralmente os deveres estipulados no Termo de Compromisso; com uma formação matemática um tanto duvidosa quanto ao conteúdo matemático necessário para o desenvolvimento do tópico Análise Combinatória.

Para a turma da $2^{-a}$ série do Ensino Médio escolhida para realização da pesquisa, os alunos eram do período noturno, com 4 aulas semanais de 45 minutos cada, assim distribuídas: 2 aulas simples ( $3^{\mathrm{a}}$ feira- $1^{\mathrm{a}}$ aula e $4^{\mathrm{a}}$ feira- $3^{\mathrm{a}}$ aula) e 1 aula dupla ( $5^{\mathrm{a}}$ feira- $2^{\mathrm{a}}$ e $3^{\mathrm{a}}$ aulas). Como se sabia que o tempo seria pouco para trabalhar os conceitos que envolvem Análise Combinatória, as 12 aulas planejadas seriam ministradas no $4^{\circ}$ bimestre, como já havia sido proposto no planejamento escolar no início do ano. A quantidade de aulas, o conteúdo a elas destinado e as atividades correspondentes para cada aula estão dispostos na tabela abaixo:

\begin{tabular}{|c|c|c|}
\hline Aulas & Conteúdo & Atividades \\
\hline 1 e 2 & Padrão & 1 a 6 \\
\hline 3,4 e 5 & $\begin{array}{c}\text { Contagem } \\
\text { Aepresentação pors meio de tabelas }\end{array}$ & 7 \\
\hline 6 e 7 & $\begin{array}{c}\text { Contagem/Combinação } \\
\text { Contagem/Combinação - } \\
\text { construção da fórmula } \\
8,9 \text { e } 10\end{array}$ & $\begin{array}{c}\text { Contagem/Arranjo - } \\
\text { construção da fórmula }\end{array}$ \\
\hline 11 & $\begin{array}{c}\text { Contagem/Permutação/Pesquisa }- \\
\text { construção da fórmula }\end{array}$ & 10 \\
\hline 12 &
\end{tabular}




\section{Aulas 1 e 2}

Como os alunos já conheciam o Termo de compromisso, não foi gasto muito tempo sobre isso, apenas foram reforçados alguns pontos, pedindo-se a colaboração dos alunos. Também foi lido novamente o Contrato Pedagógico proposto pela escola.

A professora-pesquisadora organizou os alunos em grupos e entregou, a cada grupo, uma cópia das atividades 1 a 6 . Na mesma folha em que estavam as atividades, constava um pequeno texto para motivar os alunos a iniciar uma discussão sobre padrões.

\section{Texto: "Enchente no rio Nilo"}

O Egito é banhado pelo Nilo, imenso rio que fertiliza as suas margens.

Para poderem plantar na época certa e assim garantir seus alimentos, os egípcios precisavam saber quando haveria inundação. Havia, portanto, a necessidade de se conhecer o padrão desse acontecimento.

Eles observaram que o rio subia logo depois que a estrela Sirius se levantava a leste, um pouco antes do Sol. Notando que isso acontecia a cada 365 dias, os egípcios criaram um calendário solar composto de doze meses, de 30 dias cada mês e mais cinco dias de festas, dedicados aos deuses Osíris, Hórus, Seth, Ísis e Nephthys.

Os egípcios dividiram ainda os doze meses em três estações de quatro meses cada uma: período de semear, período de crescimento e período de colheita.

Leitura e discussão do texto.

Foi dado um tempo para que os alunos lessem e discutissem o texto. Não tiveram dificuldade, pois o texto era curto e as informações não eram muito complexas. Acharam interessante o modo como os egípcios observavam a natureza para decidir quando poderiam plantar e, também, com a organização do calendário solar. Este pequeno texto motivou e instigou a curiosidade dos alunos, promovendo uma socialização do conhecimento. $\mathrm{O}$ conceito de padrão foi discutido a partir desse texto.

Após esse momento, os alunos começaram a resolver em grupo as atividades de 1 a 6 . Nas atividades realizadas por eles, apresentadas depois da descrição das aulas, os alunos enumeraram de 1 a 7 pois eles contaram o texto como primeira atividade. Essas atividades, consideradas simples, tinham como objetivo, fazer com que os alunos se familiarizassem com o conceito de padrão. 
1) Qual é o próximo símbolo?

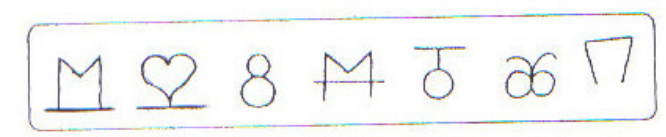

2) Quando o médico nos receita um remédio para ser tomado de três em três horas, e começamos a tomá-lo às 6 horas da manhã, quais serão os horários seguintes nesse dia?

3) Situação: As estações do ano se repetem obedecendo a um padrão: de três em três meses temos uma nova estação.

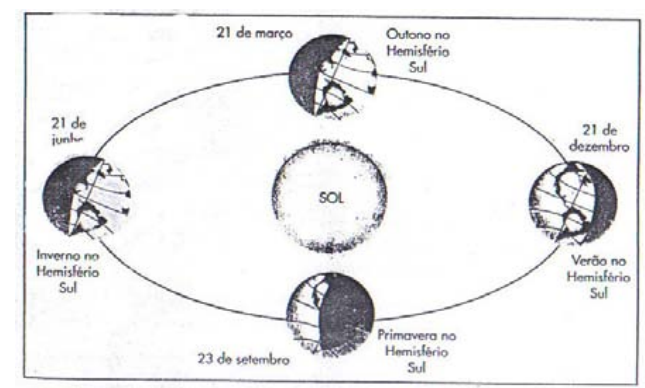

Discuta no grupo sobre a situação acima.

Dê exemplos de outros padrões encontrados no dia a dia.

4) Observe a tabela retirada de uma propaganda de venda de madeiras.

\begin{tabular}{|l|l|}
\hline \multicolumn{2}{|c|}{ Cedrinho } \\
\hline $\begin{array}{l}\text { Comprimento } \\
\text { tábua }\end{array}$ & Preço \\
\hline $30 \mathrm{~cm}$ & $\mathrm{R} \$ 1,80$ \\
\hline $25 \mathrm{~cm}$ & $\mathrm{R} \$ 1,50$ \\
\hline $20 \mathrm{~cm}$ & $\mathrm{R} \$ 1,20$ \\
\hline $15 \mathrm{~cm}$ & $\mathrm{R} \$ 0,90$ \\
\hline $10 \mathrm{~cm}$ & $\mathrm{R} \$ 0,60$ \\
\hline $5 \mathrm{~cm}$ & $\mathrm{R} \$ 0,30$ \\
\hline
\end{tabular}

Qual é o padrão existente na coluna do comprimento das tábuas? E o padrão apresentado na coluna do preço?

5) Observe as figuras abaixo e descubra, na sequência, qual é a próxima.

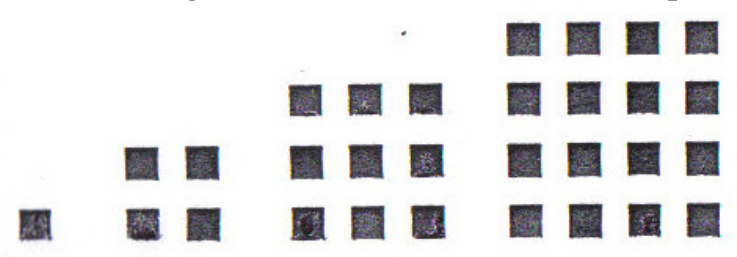

6) Problema: Estude a sequência abaixo e descubra seu padrão:

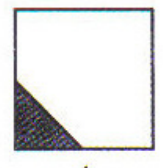

1

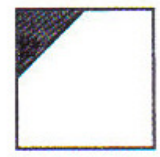

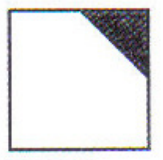

3

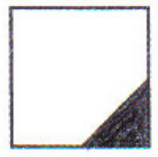

4

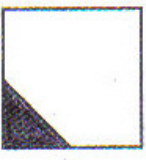

5

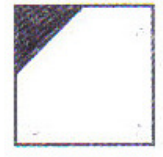

6

a) Desenhe as próximas três figuras seguindo o padrão.

b) Desenhe o $35^{\circ}$ quadrado da sequência seguindo o padrão. 
A pesquisadora observava os grupos para poder perceber a reação deles com as primeiras atividades do projeto. Mesmo já tendo trabalhado em grupos durante o ano letivo, alguns ficavam preocupados com a resolução de outros colegas. Ela teve que chamar atenção, algumas vezes, para que os integrantes de um dos grupos não atrapalhassem os de outro grupo, com perguntas ou conversas que não eram referentes ao assunto das atividades.

Depois de um tempo, a professora-pesquisadora solicitou que os grupos se manifestassem sobre a resolução das atividades propostas.

Logo na primeira atividade, os alunos tiveram bastante dificuldade. Foi uma surpresa para a pesquisadora que precisou intervir dizendo: “- Observem as figuras atentamente. O que essa sequência diz? Procurem identificar um padrão". Mas como continuavam a ter dificuldade, ela pediu para que resolvessem os outros e que depois retornassem ao primeiro problema.

Nessa atividade, por meio da observação, eles não conseguiam encontrar o padrão esperado. Mas, outros padrões, elaborados por eles, foram descobertos.

O Grupo 1 apresentou uma solução muito interessante e curiosa, relacionando os símbolos dispostos na sequência com a geometria.

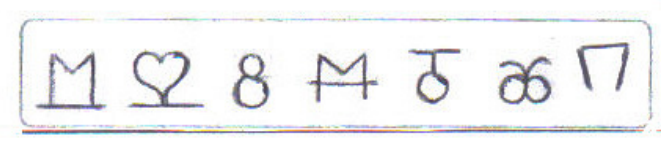

Relataram o seguinte:

- A primeira figura é formada somente por "linhas". A segunda figura é formada por "linhas" e curvas. A terceira figura é formada somente por curvas. Então o mesmo ocorre para as próximas.

E aí concluíram que o mesmo ocorria com as próximas três figuras. Nomearam de 1, a figura formada apenas por "linhas"; de 2, a figura formada por "linhas" e curvas. Então a figura seguinte da sequência seria formada por linhas e curvas. Mas não conseguiram fazer nenhuma representação geométrica dessa figura.

O Grupo 2 não conseguiu fazer a primeira atividade, esses alunos ficaram apenas observando e não encontraram nenhum padrão.

O Grupo 3 apresentou o seguinte: como a sequência é formada por sete símbolos, relacionaram com os sete dias da semana, e disseram que como não há dias da semana repetidos então volta ao primeiro símbolo. Foi também interessante a solução apresentada por esse grupo, pois não tínhamos imaginado esse possível padrão. 
Para suprir as dificuldades da maioria desses alunos que não conseguiam encontrar nenhum padrão, a professora-pesquisadora decidiu mostrar, como estratégia, o uso do conceito de simetria nos símbolos da sequência e, traçando uma reta pontilhada, perpendicular à linha inferior do quadro que contém os símbolos, passando pelo ponto médio de cada símbolo ela disse: - Vejam

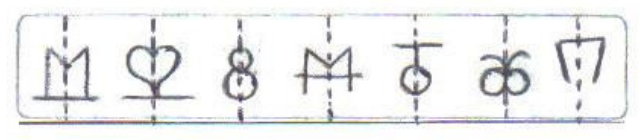

Logo que foi traçada a reta pontilhada, alguns alunos já conseguiam visualizar como eram constituídos os símbolos. E antes de falar, já deram a resposta 88 , ou seja, perceberam que os símbolos que formavam a sequência eram os números $1,2,3,4,5,6,7$, e suas imagens refletidas pelo eixo de simetria. Assim, o próximo termo da sequência seria constituído do número 8 e sua imagem, ficando 88 .

Depois dessa descoberta, foi chamada a atenção dos alunos relatando a importância de reconhecer o padrão em uma determinada sequência: " - Se vocês conhecem o padrão então podem encontrar o próximo termo da sequência, sem precisar enumerá-lo e isso, nós conseguimos inicialmente por meio da observação e de uma posterior análise sobre formação da sequência".

$\mathrm{Na}$ segunda atividade os alunos não tiveram dificuldades. Todos resolveram corretamente e não apresentaram dúvida durante a resolução. Identificaram o padrão para encontrar os horários seguintes para tomar o remédio. Ou seja, para encontrar os horários seguintes, a começar às $6 \mathrm{~h}$, bastaria adicionar $3 \mathrm{~h}$ a cada horário em que tomou o remédio. Portanto esses horários são $9 \mathrm{~h}, 12 \mathrm{~h}, 15 \mathrm{~h}, 18 \mathrm{~h}, 21 \mathrm{~h}$ e $24 \mathrm{~h}$.

A professora-pesquisadora lhes apresentou uma outra estratégia para resolver esse problema. Seria a de fazer uma tabela e então buscar um padrão.

\begin{tabular}{|c|c|c|}
\cline { 2 - 3 } \multicolumn{1}{c|}{} & $\begin{array}{c}\text { hora de tomar o } \\
\text { remédio }\end{array}$ & $\begin{array}{c}\text { próximo horário a } \\
\text { tomar o remédio }\end{array}$ \\
\hline início & $6 \mathrm{~h}$ & $9 \mathrm{~h}$ \\
\hline $2^{\mathrm{o}}$ horário & $9 \mathrm{~h}$ & $12 \mathrm{~h}$ \\
\hline $3^{\mathrm{o}}$ horário & $12 \mathrm{~h}$ & $15 \mathrm{~h}$ \\
\hline $4^{\mathrm{o}}$ horário & $15 \mathrm{~h}$ & $18 \mathrm{~h}$ \\
\hline $5^{\mathrm{o}}$ horário & $18 \mathrm{~h}$ & $21 \mathrm{~h}$ \\
\hline $6^{\mathrm{o}}$ horário & $21 \mathrm{~h}$ & $24 \mathrm{~h}$ \\
\hline
\end{tabular}


Para a terceira atividade, o objetivo era o de observar a figura, discutir em grupos as observações feitas e interpretar o movimento da Terra em torno do Sol, mostrando quanto da Terra está exposto frente ao Sol, exibindo as datas do início de cada estação do ano.

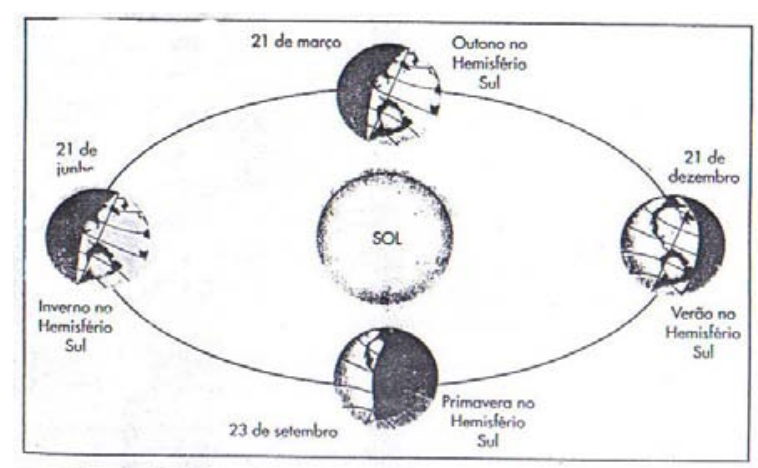

Os alunos citaram padrões do cotidiano e compartilharam seus exemplos, um com os outros. Não houve necessidade de ajuda durante a resolução.

Na quarta atividade, os alunos tinham que descobrir qual era o padrão existente ao observar a tabela:

\begin{tabular}{|l|l|}
\hline \multicolumn{2}{|c|}{ Cedrinho } \\
\hline $\begin{array}{l}\text { Comprimento da } \\
\text { tábua }\end{array}$ & Preço \\
\hline $30 \mathrm{~cm}$ & $\mathrm{R} \$ 1,80$ \\
\hline $25 \mathrm{~cm}$ & $\mathrm{R} \$ 1,50$ \\
\hline $20 \mathrm{~cm}$ & $\mathrm{R} \$ 1,20$ \\
\hline $15 \mathrm{~cm}$ & $\mathrm{R} \$ 0,90$ \\
\hline $10 \mathrm{~cm}$ & $\mathrm{R} \$ 0,60$ \\
\hline $5 \mathrm{~cm}$ & $\mathrm{R} \$ 0,30$ \\
\hline
\end{tabular}

O Grupo 2 não compreendeu essa atividade e somou os valores da coluna do comprimento das tábuas, $105 \mathrm{~cm}$, e somou também os preços, resultando $\mathrm{R} \$ 6,30$. Os demais grupos responderam corretamente. O Grupo 1, por exemplo, respondeu: - O padrão do comprimento, o tamanho diminui de 5 em $5 \mathrm{~cm}$ e no preço diminui de $\mathrm{R} \$ 0,30$ em $\mathrm{R} \$ 0,30$ centavos.

Durante a plenária, num contexto social foi discutido, com os alunos que, no comércio, nem sempre aparece um padrão como esse, pois, há promoções ou juros que alteram o valor da mercadoria e pode também depender da quantidade que o consumidor irá comprar. 
Na quinta atividade, o objetivo era o de descobrir qual era a próxima figura da sequência dada:

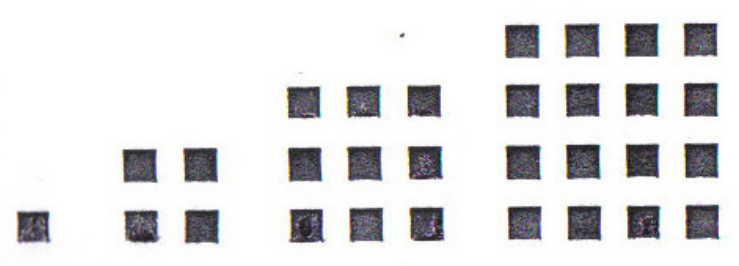

Os alunos perceberam que a primeira figura era um quadrado $1 \times 1$, a segunda figura era um quadrado formado por quatro quadrados menores (cada um igual à primeira figura), formando um quadrado maior $2 \times 2$. A terceira figura era um quadrado $3 \times 3$ e a quarta figura um quadrado $4 \times 4$, então, a próxima figura seria um quadrado $5 \times 5$ e desenharam essa figura.

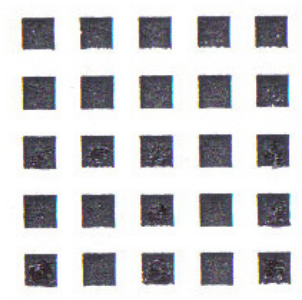

O grupo 3 justificou sua resolução do seguinte modo: “- pois aumenta uma fileira do lado e outra em cima com um quadrado a mais".

Os grupos não identificaram que o número de quadrados menores de cada figura da sequência forma uma sequência de números quadrados. Não houve tempo para que se pudesse mostrar essa relação, mas deixamos aqui uma sugestão de resolução.

Seja $n$ o número de quadrados menores para formar o lado do quadrado maior.

Para $n=1$, temos em relação à área que $1^{2}=1$; para $n=2$, temos $2^{2}=4$; para $\mathrm{n}=3$, temos $3^{2}=9$. Seguindo esse mesmo raciocínio, para $n=n$, temos $n^{2}$.

Observando o significado do expoente colocado sobre o número $n$ de quadrados menores utilizados para formar os quadrados maiores, os alunos poderiam perceber que $\forall n \in N$, o número de quadrados menores necessários para formar o quadrado de lado $n$ é $n^{2}$. Assim, pode-se obter a sequência de números quadrados: $1,4,9,16,25, \ldots, n^{2}, \ldots$

Na sexta atividade, os alunos teriam que, no item a), desenhar as próximas três figuras seguindo o padrão descoberto por eles. Foi observado que eles ficaram olhando e 
analisando a sequência de figuras dadas, quando um aluno disse: - Professora, a cada passo tem um canto pintado. Resposta: - Como os cantos aparecem em cada figura?

Então, esse aluno mostrou, no papel, na primeira figura, indicando num movimento circular, o sentido horário. Assim, percebeu-se que ele havia encontrado um padrão.

Os grupos não tiveram muita dificuldade em encontrar o padrão e desenhar as três figuras seguintes da sequência. Apenas o grupo 1 que, pela resolução entregue, apresentava correção.

No item b) dessa atividade, o Grupo 3 apresentou a solução correta e justificou do seguinte modo: - pois se contarmos os quatro cantos sucessivamente o $35^{\circ}$ será o mesmo de A, querendo identificar com A, a primeira das três figuras seguintes encontrada no item a).

Já estava no final da aula, mas pude comentar que haveria outra estratégia além da observação para resolver a atividade. Observando que o padrão se repete a cada 4 desenhos, então o sétimo quadrado terá a mesma forma que a do $3^{\mathrm{o}}$ quadrado; o oitavo será igual ao quarto quadrado; e o nono será o mesmo que o quinto. Desse modo, o padrão se repete depois de quatro desenhos e continua se repetindo de quatro em quatro.

Sabe-se que 32 é o maior número, menor que 35 , que é divisível por 4 , então o $33^{\circ}$ quadrado terá a mesma forma que a do primeiro quadrado. Então temos:

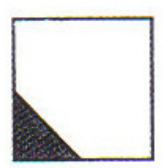

33

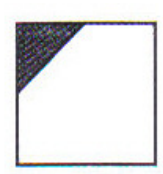

34

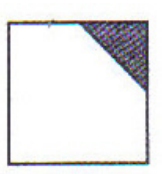

35

O $35^{\circ}$ tem a mesma forma que o $3^{\circ}$ quadrado da sequência dada.

Se houvesse mais tempo, seria também interessante mostrar uma outra maneira de resolver, apresentada a seguir:

Basta, neste caso, fazer $\frac{35}{3} \frac{4}{8}$ e isto significa que haveria na sequência, oito blocos de quatro quadrados e sobrariam três quadrados: o primeiro correspondendo ao $33^{\circ}$, o segundo, ao $34^{\circ}$ e o terceiro ao $35^{\circ}$.

Após a discussão das resoluções apresentadas pelos grupos e a correção das atividades, alguns alunos disseram que padrão é alguma coisa que se repete, vai repetindo. A professora-pesquisadora confirmou a definição dada pelos alunos e disse que padrão é um critério por excelência. É um modelo, é algo que se repete sempre. Podemos encontrar 
padrões numa sequência numérica; numa sequência de figuras; em ornamentos (decoração), na natureza, nas fórmulas deduzidas, nas proposições demonstradas, nas rotinas da escola, etc.

Seguem as soluções de cada atividade apresentadas por quatro grupos:

\section{Grupo 1:}
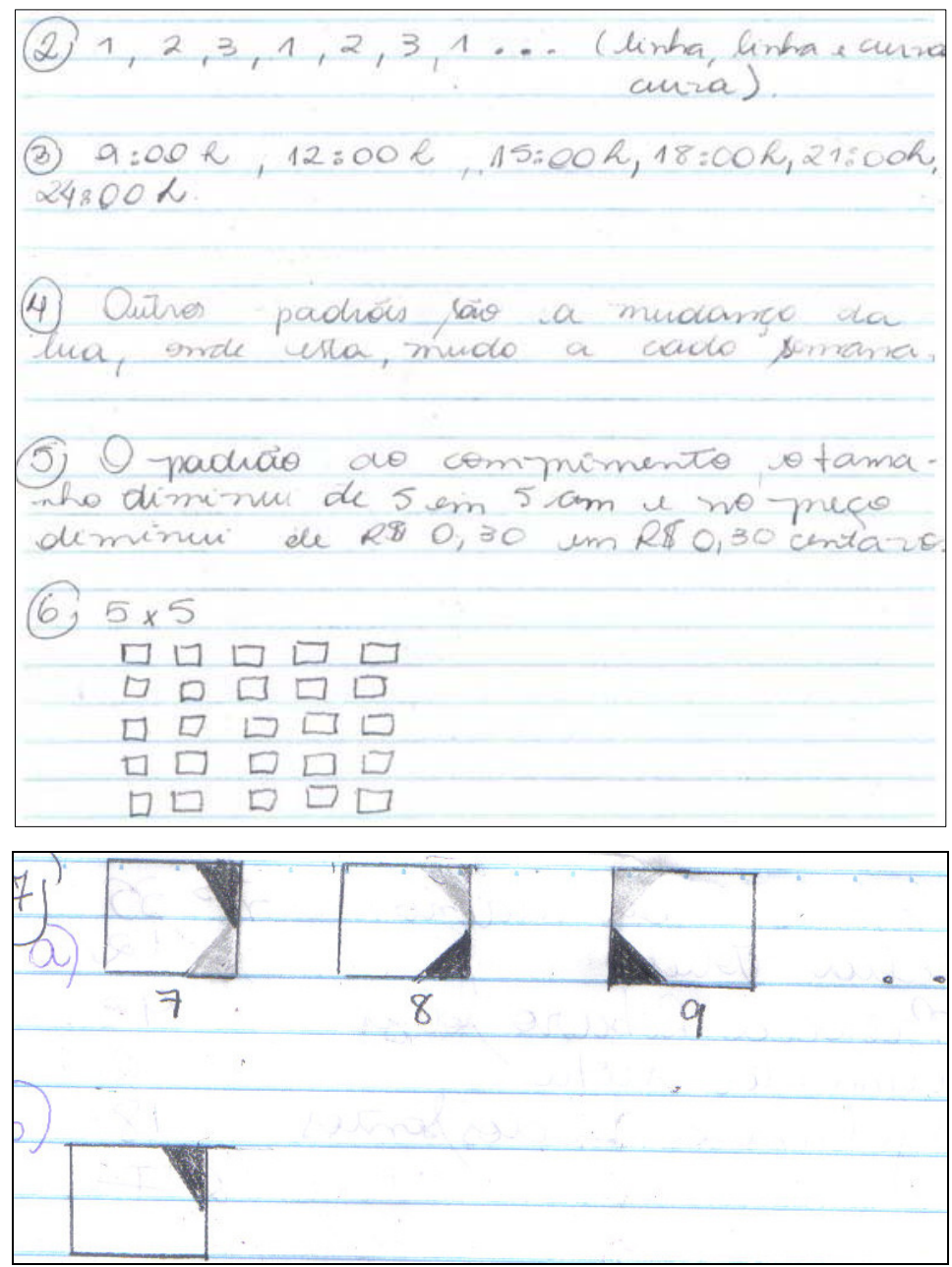
Grupo 2:

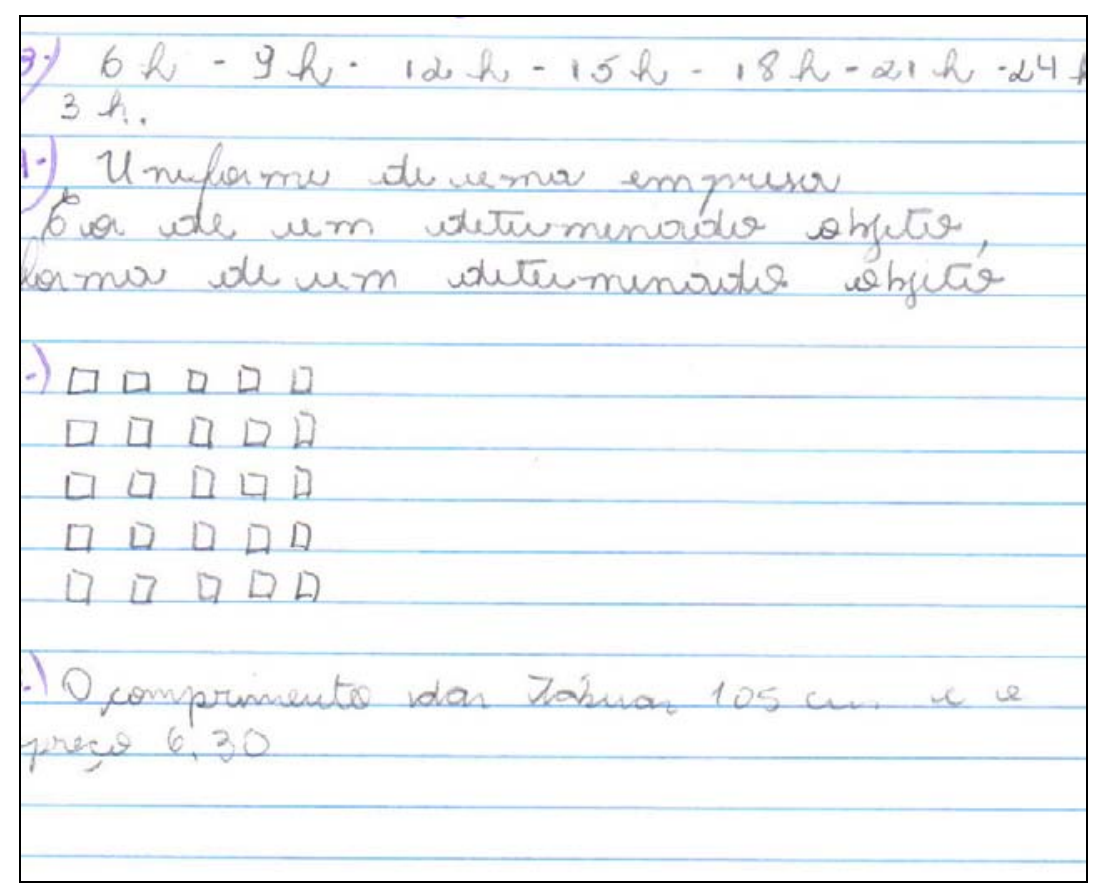


Grupo 3:

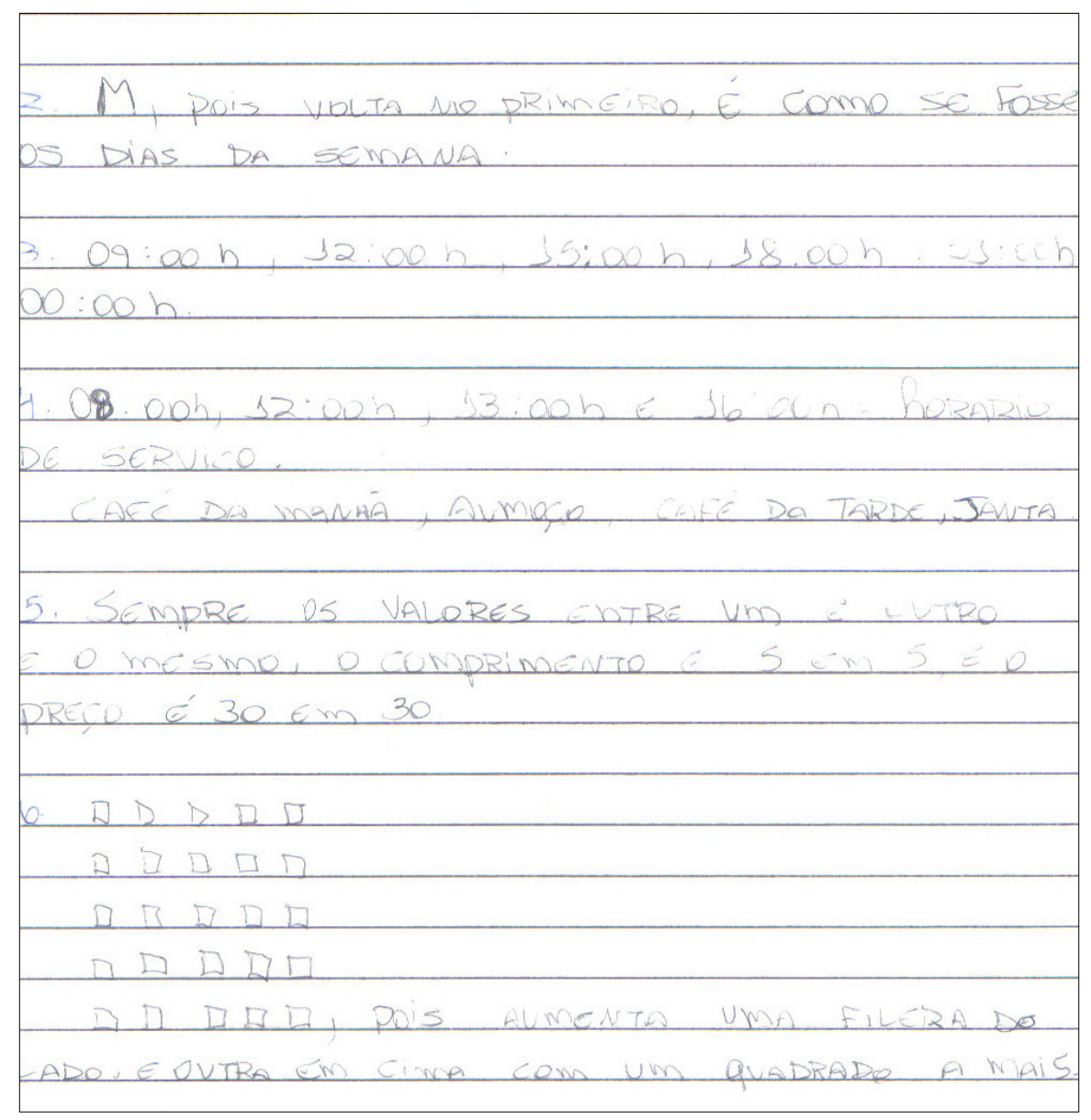

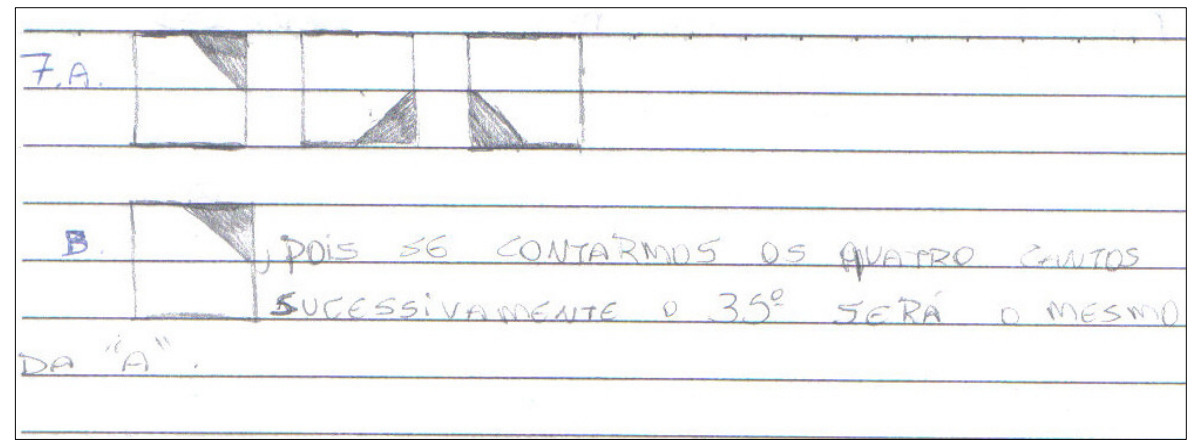


Grupo 4:

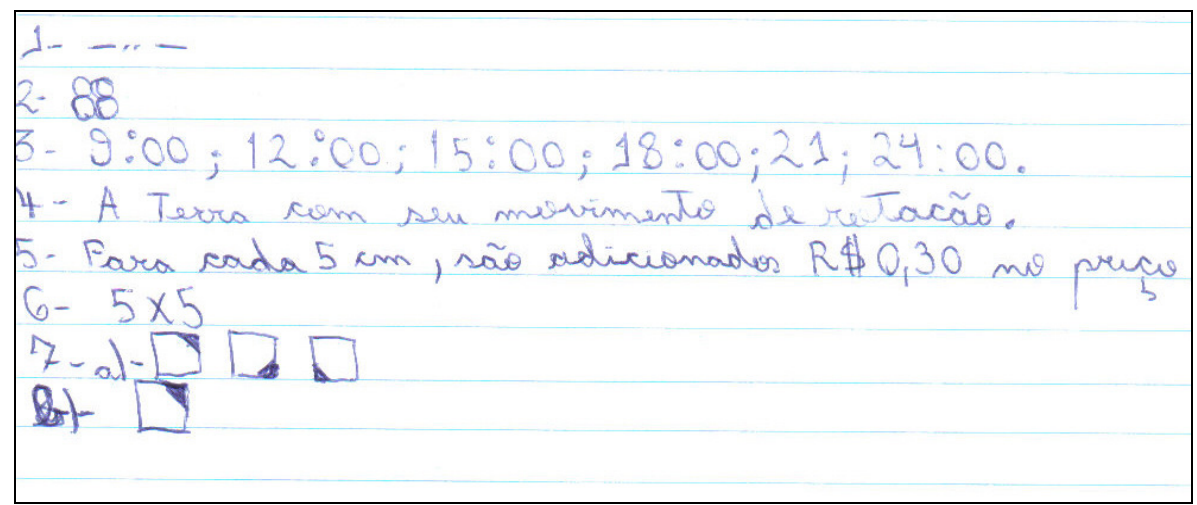




\section{Aulas 3 e 4 (aula dupla)}

Para essas aulas, o objetivo era o de trabalhar com o processo de contagem, focando o Princípio Fundamental de Contagem e buscando estratégias que proporcionem aos alunos a visualização desse processo.

Foi entregue, por escrito, a cada um dos grupos a sétima atividade do projeto, o problema intitulado Agenda de aulas:

Agenda de aulas: Eliane quer escolher o seu horário para a natação. Ela quer ir a duas aulas por semana, uma de manhã e a outra de tarde, não sendo no mesmo dia nem em dias seguidos. De manhã, há aulas de natação de segunda-feira a sábado, às $9 \mathrm{~h}$, às $10 \mathrm{~h}$ e às $11 \mathrm{~h}$ $\mathrm{e}$, de tarde, de segunda-feira a sexta-feira, às $17 \mathrm{~h}$ e às $18 \mathrm{~h}$. De quantas maneiras distintas Eliane pode escolher seu horário?

Após a entrega do problema, os grupos iniciaram a leitura do problema. Foi observado que, em alguns grupos, os alunos copiaram o problema no caderno justificando que ficaria mais fácil para fazer a leitura.

Como a aula era dupla, então teríamos mais tempo para explorar e discutir a resolução do problema, sem interrupção. Assim, a professora-pesquisadora, num primeiro momento, apenas observou de que modo os grupos buscaram estratégias para ir em busca da solução. Para a organização do problema, percebeu que eles voltavam ao enunciado várias vezes para tentar esclarecer quais eram seus dados. De fato, esse problema exigia atenção dos alunos em relação às restrições oferecidas para escolher o horário de natação para Eliane: ela queria duas aulas por semana, uma de manhã e outra de tarde, não sendo no mesmo dia nem em dias seguidos.

A maioria dos alunos iniciou a resolução através da organização de tabelas, explorando os dias da semana e os horários oferecidos. Outros fizeram uma lista organizada ou, também, foi observada a representação dos possíveis horários através de uma estrutura parecida com a da árvore de possibilidades que é um esquema ou diagrama que mostra todas as possibilidades de um acontecimento e que por meio dos Princípios Multiplicativo e Aditivo, chega-se ao total de possibilidades. Assim, a representação feita pelos alunos não é considerada uma árvore de possibilidades. Em alguns momentos a professora-pesquisadora, quando solicitada pelos grupos, intervinha para orientá-los diante da estratégia escolhida por eles. Um grupo levantou a questão para o seguinte: se sábado e segunda-feira poderiam ser considerados dias seguidos, então foi tirada essa dúvida respondendo que não, pois há o 
domingo entre esses dias, então viram que poderiam encontrar mais possibilidades de horários. Outros grupos, atentos a esse comentário, aproveitaram a explicação da professora e continuaram a resolução. A maioria dos grupos apresentou a resolução correta, alguns com uma boa apresentação e organização de tabela, outros, que também resolveram corretamente, apresentaram uma resolução não muito organizada, mas foi o modo com que conseguiram explicitar seu raciocínio. Poucos grupos chegaram a uma solução parcial do problema mas, após a explicação da professora, as dúvidas ficaram mais esclarecidas e puderam chegar à resposta correta. Esse problema foi bem explorado pelos alunos, mas não foi tão fácil para alguns fazer a contagem das possibilidades dos horários de natação, devido talvez à má interpretação e organização dos dados do problema.

Apresentamos a resolução do problema realizada por alguns grupos:

O Grupo 2 apresentou sua resolução através de uma lista organizada e chegou à solução do problema. Separaram em manhã e tarde e, para cada um desses períodos, foram colocando os possíveis dias da semana. Assim, escreveram o número de possibilidades para cada par de dias da semana e fizeram a contagem para chegar ao resultado final, 96 horários diferentes. Analisando a solução apresentada, percebe-se que eles inverteram alguns pares de dias e encontraram outras possibilidades para escolher as aulas, e que isso não seria possível quando tinha o sábado pois, nesse dia, só era possível aula no período da manhã.
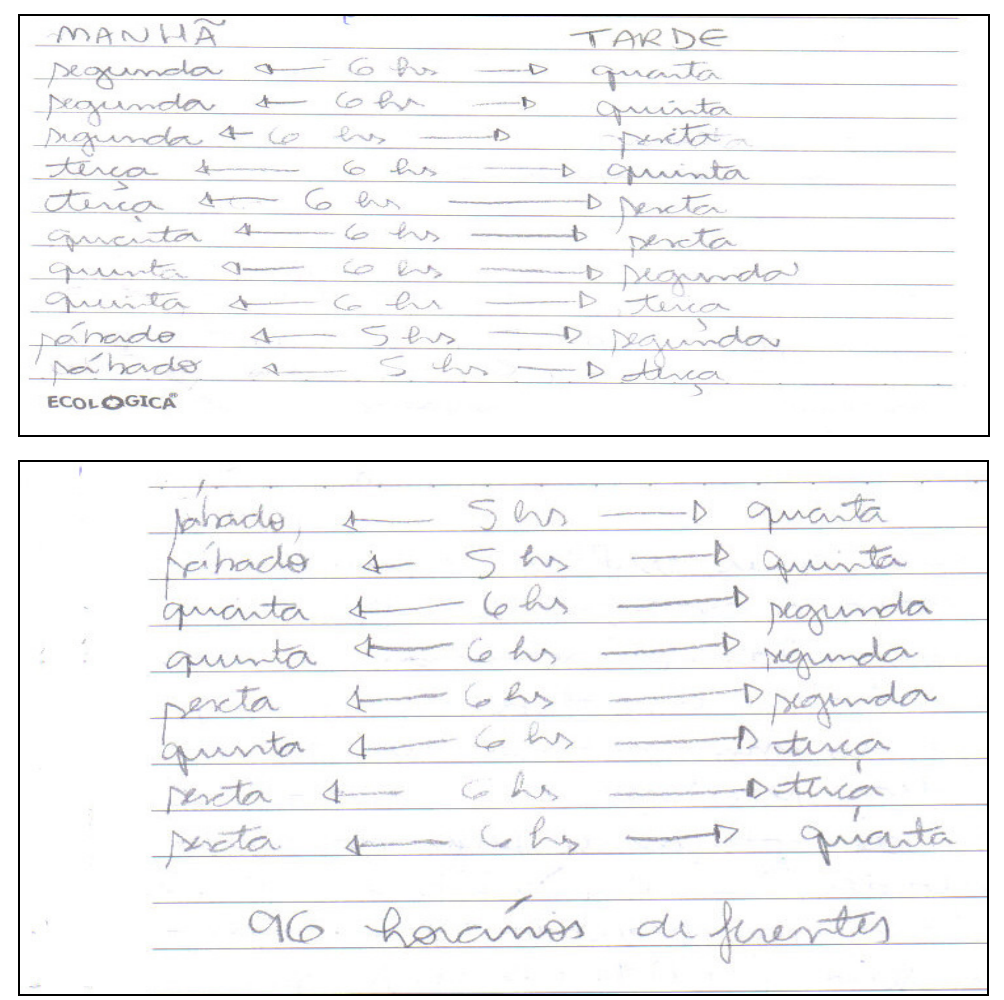
O Grupo 3 teve dificuldade em encontrar uma estratégia para resolver o problema. Então, a professora-pesquisadora, quando solicitada pelo grupo, teve que intervir e ajudá-los, sugerindo que fizessem uma tabela. Encontraram um resultado parcial, como o apresentado abaixo:

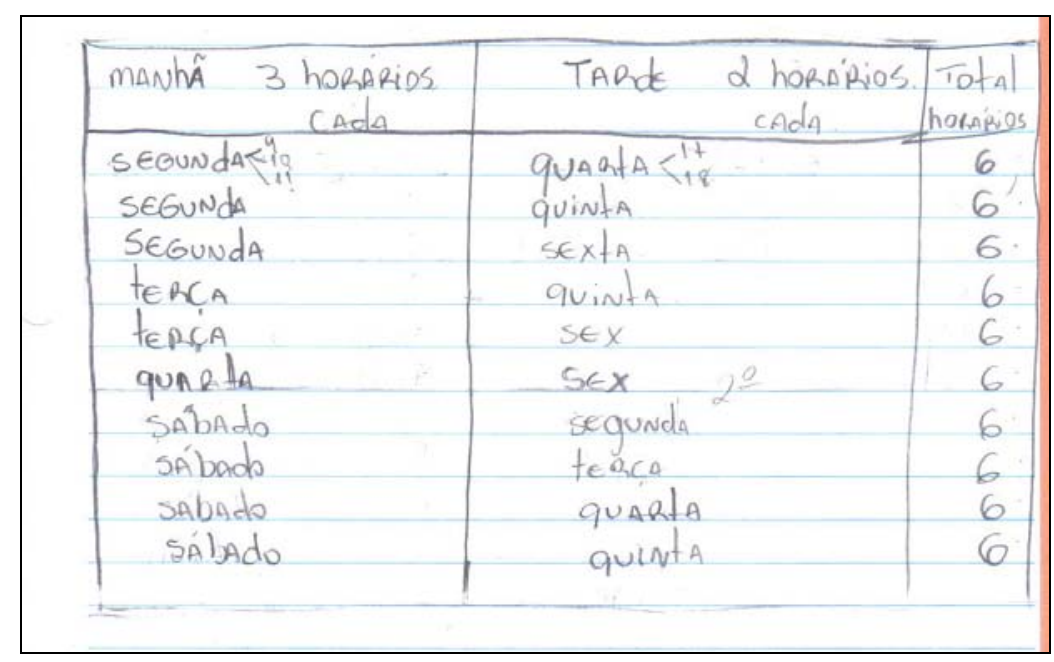

Esse grupo não conseguiu pensar que poderia haver troca em manhã e tarde ou tarde e manhã. Reconhecendo que aos sábados a aula poderia ser pela manhã, ao trocar nos demais casos os dias da semana, eles encontrariam mais 36 horários, totalizando a possibilidade de 96 horários.

Já, no Grupo 4, os alunos foram muito bem organizados e chegaram à solução do problema. A tabela apresentada por eles mostra, com detalhes, os dias da semana e os respectivos horários das aulas. E o mais enriquecedor foi que eles usaram tanto o princípio multiplicativo como o aditivo. 


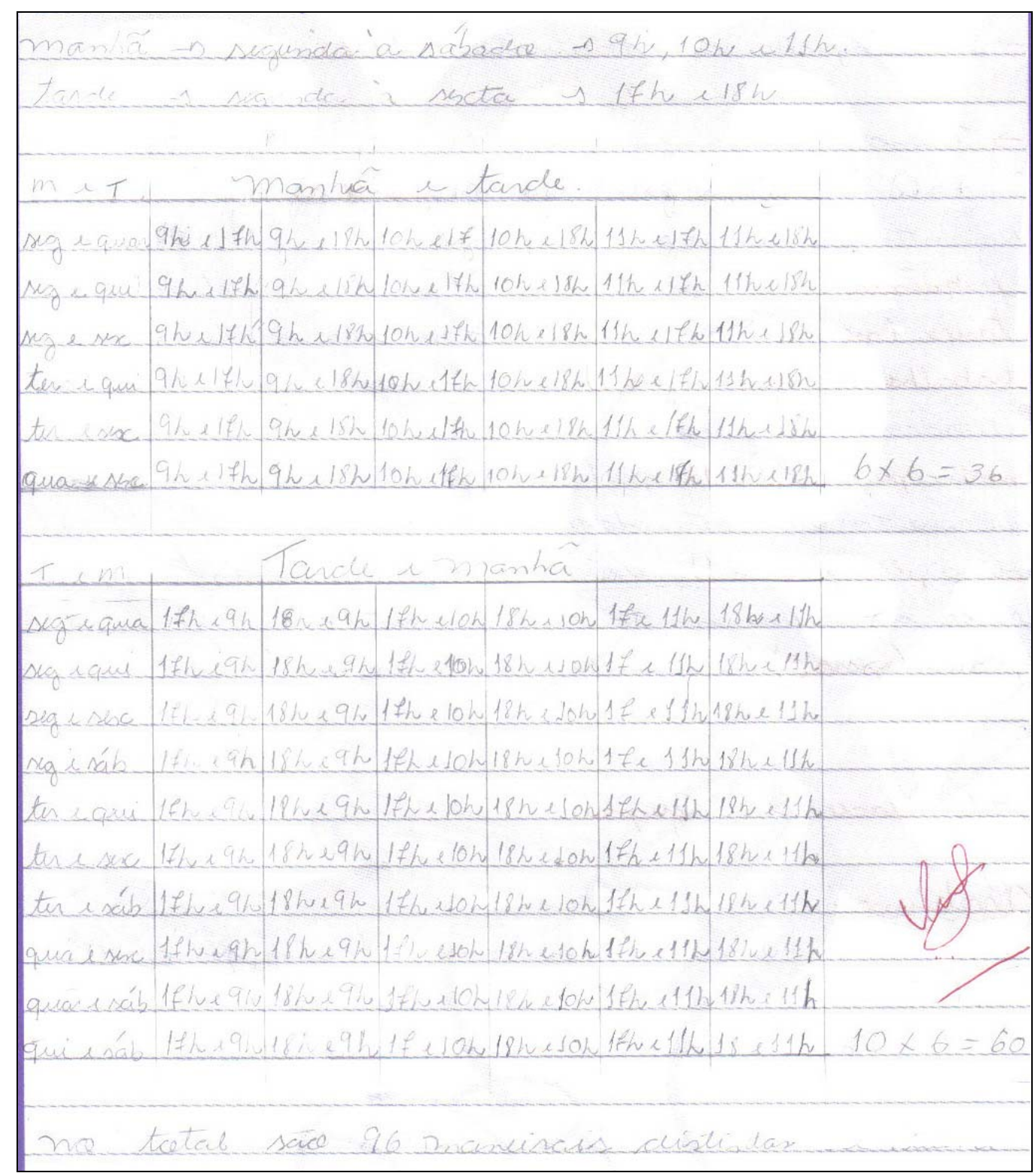

O Grupo 5 foi o que resolveu o problema esquematizando os dados em uma estrutura em que, usando o princípio aditivo, puderam chegar ao resultado desejado. Explicaram do seguinte modo, de segunda a sexta há aulas no período da tarde. Iniciaram com a segunda, restavam então quarta, quinta, sexta e sábado no período da manhã. Contaram o total dos possíveis horários para essa primeira situação e o anotaram do lado da árvore. Usando esse mesmo raciocínio, trabalharam para os outros dias e adicionaram todas as possibilidades, totalizando 96 horários para a Eliane fazer as aulas de natação desejadas. 


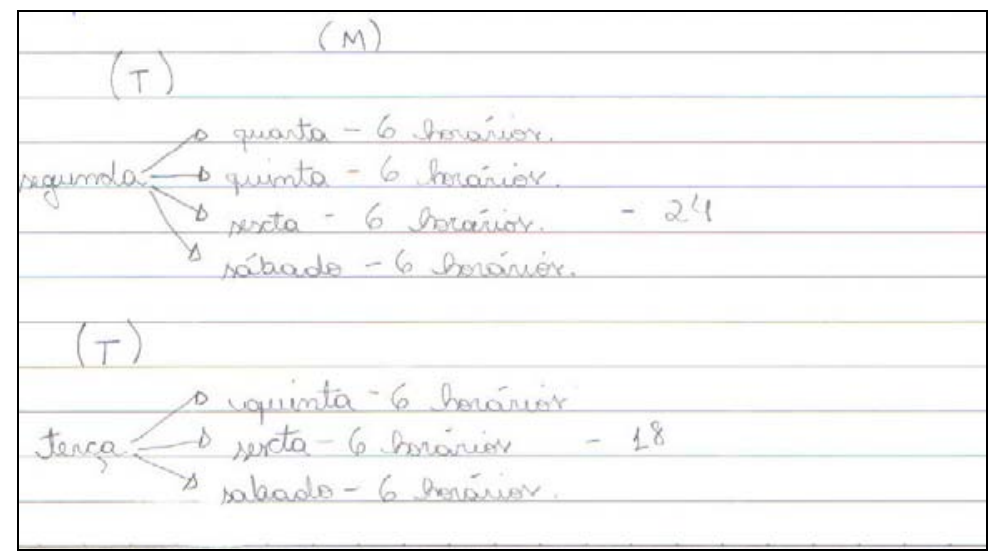

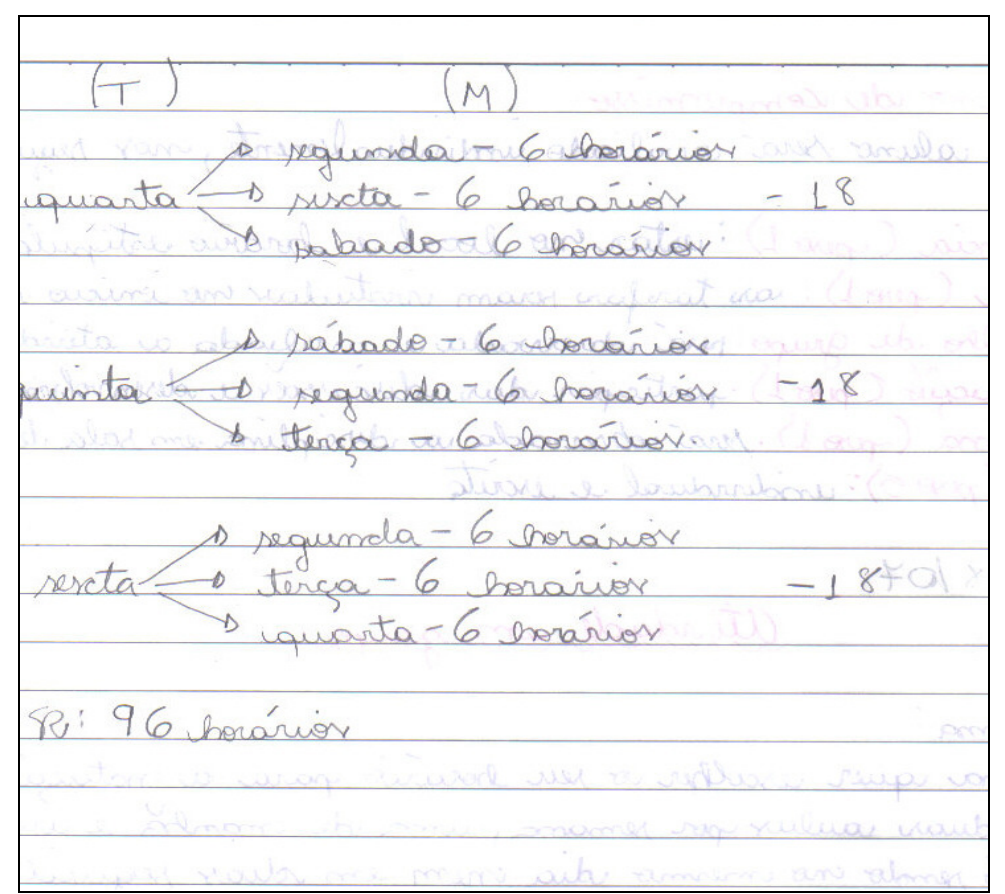

O Grupo 6 encontrou, numa solução parcial, 42 possíveis horários para a Eliane fazer natação. Fizeram uma lista, apresentando de modo um pouco desorganizado, ou melhor, não estabelecendo um critério para fazer a lista e, assim, não perceberam que ainda faltavam encontrar algumas outras possibilidades. 

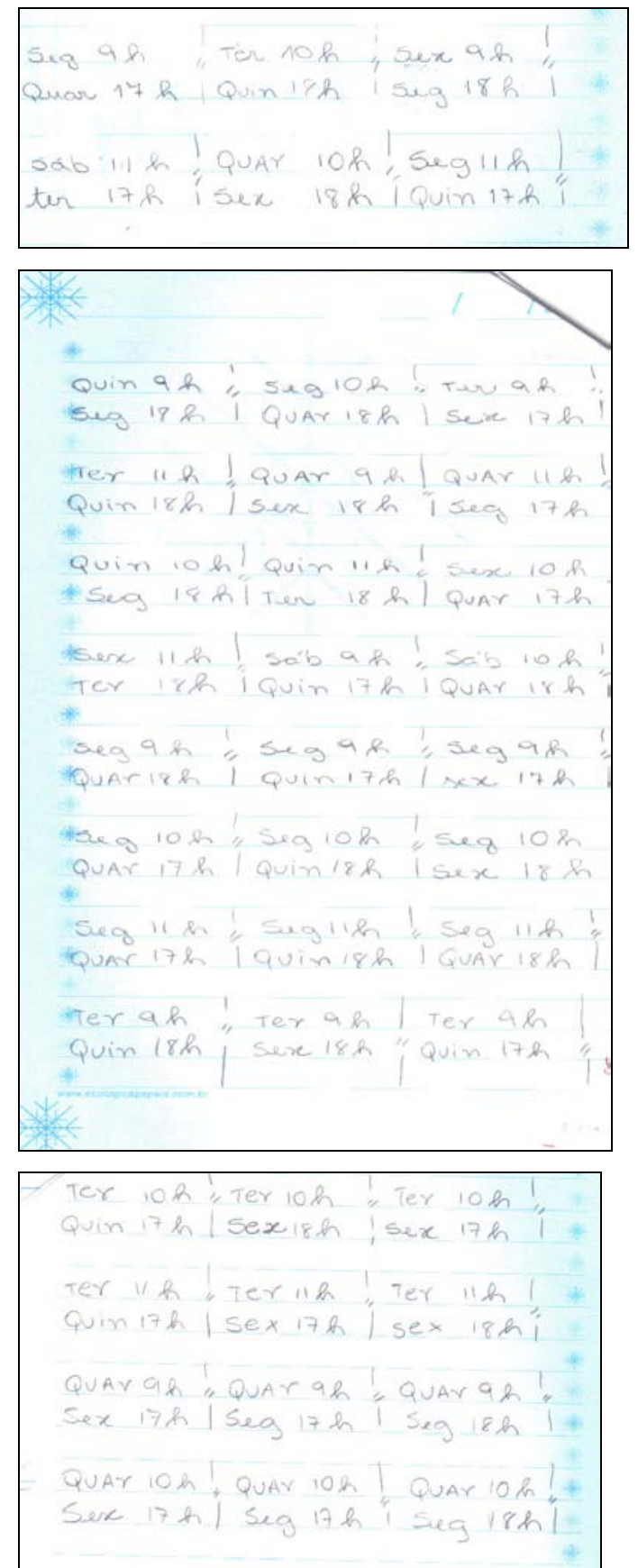

O Grupo 7 era formado por alguns alunos um tanto dispersos e não muito interessados. Questionei-os sobre a maneira como estavam resolvendo o problema pois ele estava um pouco confuso de se entender. A notação que estavam usando, como está esboçada a seguir, não era adequada. Quando queriam combinar os horários, usaram o sinal de igual, na verdade estavam querendo explicar que era um horário para a manhã e outro para a tarde. Mas, 
mostraram seu raciocínio e, talvez por falta de organização, ainda ficaram faltando algumas possibilidades de horários.

\begin{tabular}{|c|c|c|c|c|c|}
\hline $\operatorname{seg} \in q^{V}$ R $=m$ & month $E$ TARde & & & & \\
\hline Sege quin $=$ TAS & TARDE 6 month & 24 & & & \\
\hline 11 e $56 x=11$ & 11,11 & & & & \\
\hline i) $e 548=$ & 11,11 & & & & \\
\hline$r_{1}$ & 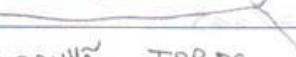 & & & & \\
\hline$T \in R \in q u i=m$ & MANHA, TPRDE & & & & \\
\hline$T \in R \in S 6 x=T R$ & $\begin{array}{c}\text { TARDE, MANHA } \\
11,11\end{array}$ & 18 & & & \\
\hline$T \in R \in S A B=1$ & 11,11 & & & & \\
\hline 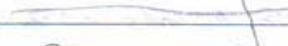 & MANHE TARDE & & & & \\
\hline QUA $E \operatorname{sex}=$ & $\begin{array}{l}\text { MANHE, TARDE } \\
\text { TARDE, MANHÃ }\end{array}$ & & & & \\
\hline$Q \cup A \& S A B=$ & TARDE, MANHÃ & 12 & $9=17$ & $17=9$ & \\
\hline Qua $\& \operatorname{seg}=$ & $, 1,11$ & & $9=18$ & $17=10$ & \\
\hline$x^{2} \cdot x^{2}$ & +2 & -2 & $10=17$ & $17=11$ & $=12$ \\
\hline qui $\in \operatorname{sA}^{\prime} B=$ & $\Rightarrow$ Tards mant & 6 & $10=18$ & $18=9$ & \\
\hline $1<$ & & & $11=17$ & $18=10$ & \\
\hline & 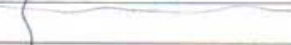 & 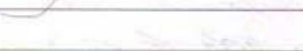 & $11=18$ & $18=11$ & \\
\hline & - & & +- & +2 & \\
\hline $9=17$ & $17=9$ & & $17=9$ & & \\
\hline $9=18$ & $17=10$ & & $17=10$ & & \\
\hline $10=17$ & $17=11$ & $=24$ & $17=11$ & $=6$ & \\
\hline $10=18$ & $18=9$ & $x^{2}$ & $18=9$ & & \\
\hline $11=17$ & $18=10$ & & $18=10$ & & \\
\hline $11=1 \gamma$ & $18=11$ & & $18=11$ & & \\
\hline+2 & 16 & 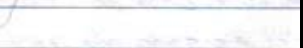 & & & \\
\hline $9=17$ & $17=9$ & & 54 & & \\
\hline $9=18$ & $17=10$ & 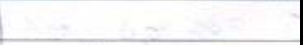 & 18 & & \\
\hline $10=12$ & $17-11$ & $=18$ & 12 & & \\
\hline $10=18$ & $10=9$ & 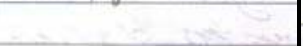 & $b$ & & \\
\hline $11=17$ & $k=10$ & & 160 & & \\
\hline $111=12$ & $x=11$ & & & & \\
\hline
\end{tabular}

Assim como o anterior, o Grupo 8 também não mostrou uma boa organização durante a resolução do problema, mas chegaram à solução correta. Fizeram uma lista com todas as possibilidades de horários, iniciando pelo período da manhã, considerando então de segundafeira a sábado. Para cada horário da manhã, relacionavam um horário disponível de tarde. Desse modo, realizaram a contagem e encontraram um total de 96 possibilidades de horários. 

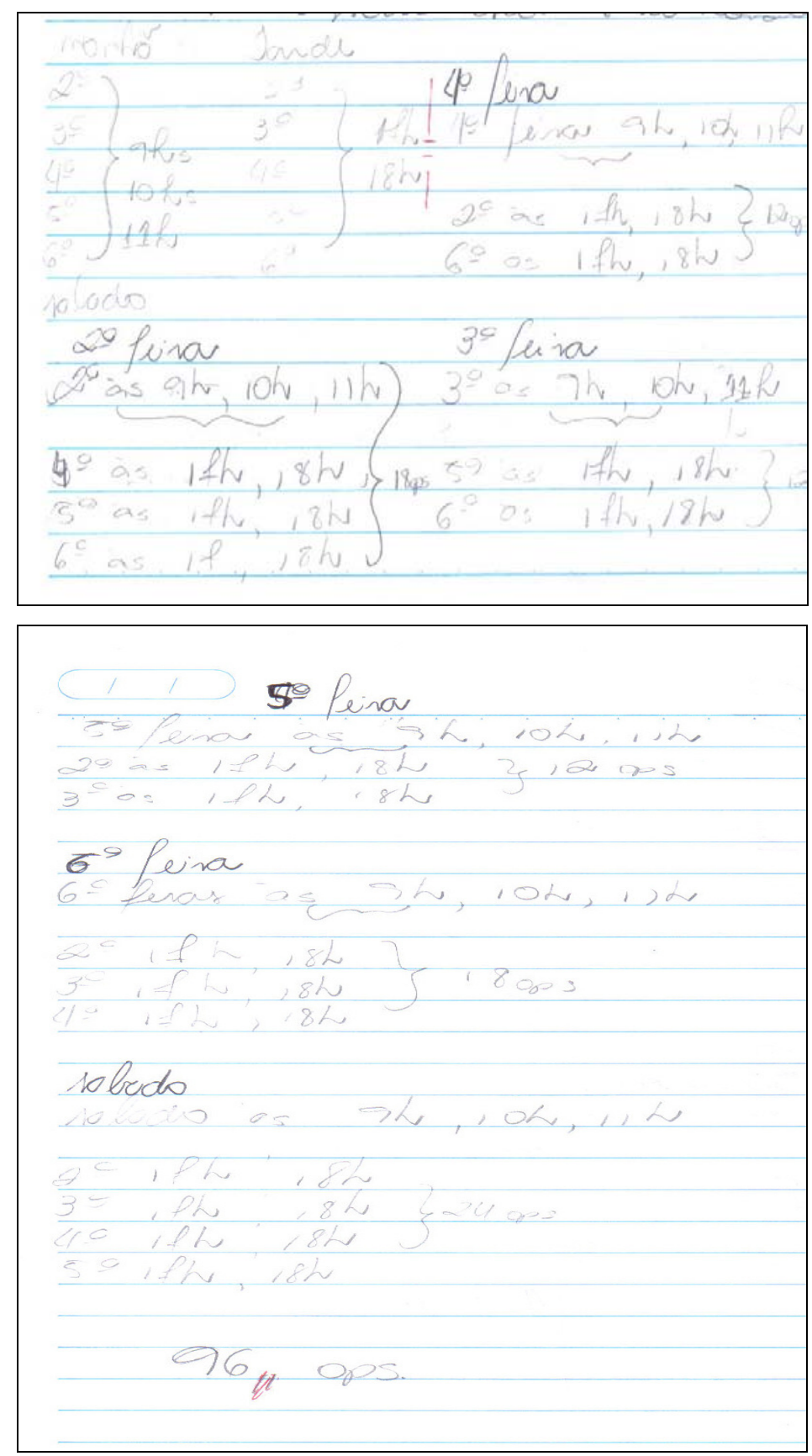

Como não haveria tempo suficiente para que todos os grupos colocassem suas resoluções na lousa, apenas três grupos foram à lousa e compartilharam suas resoluções com os outros. Durante a plenária, alguns alunos manifestaram que não imaginavam ter tantas possibilidades de horários (96). A professora pesquisadora alertou que dependendo da estratégia escolhida para a resolução, tem-se uma melhor visualização do processo de contagem, o que eles podiam ver nas diferentes resoluções apresentadas pelos grupos. Como a aula estava no fim, combinamos deixar a discussão para a próxima aula. 


\section{Aula 5 (aula simples)}

Como era a primeira aula do horário dos alunos, muitos chegaram atrasados e, pelo fato de que a direção permitia sua entrada. A justificativa dada para isso é que a maioria dos alunos trabalhava e, como muitos moravam longe do local do trabalho, não sobrava muito tempo para ir até em casa e depois para a escola. A aula começava às 19horas, e esses alunos chegavam por volta das $19 \mathrm{~h} 20 \mathrm{~min}$. Quando chegavam, dispersavam a atenção da sala e se levava um certo tempo para reorganizar os grupos. Como o tempo destinado à aula era de 45 minutos então restavam apenas 25 minutos da aula. Esse fato ocorria diariamente nas primeiras aulas. Como professora, percebi que não podia intervir na decisão da direção da escola e, portanto, tinha que acatar. Então, quando tinha a primeira aula com eles, o desenvolvimento do projeto ficava prejudicado.

Desse modo, essa aula não foi muito produtiva. Fizemos o fechamento das resoluções do problema apresentadas pelos grupos.

Os alunos mostraram, em suas resoluções, o uso do Princípio Fundamental de Contagem ou Princípio Multiplicativo. Então a partir daí foi possível formalizar esse conceito. A professora-pesquisadora mostrou a tabela abaixo, que mostra um dos modos de se resolver o problema dado, bem semelhante ao que os alunos apresentaram durante as aulas. A tabela explicita os dias da semana possíveis e os horários das aulas de natação do modo solicitado por Eliane:

\begin{tabular}{|l|l|c|}
\hline $\begin{array}{l}\text { Manhã } \\
\text { às 9h, às 10h ou às 11h }\end{array}$ & $\begin{array}{l}\text { Tarde } \\
\text { às 17h ou às 18h }\end{array}$ & $\begin{array}{l}\text { Possibilidades } \\
\text { de horários }\end{array}$ \\
\hline Segunda-feira & Quarta-feira & 6 \\
\hline Segunda-feira & Quinta-feira & 6 \\
\hline Segunda-feira & Sexta-feira & 6 \\
\hline Terça-feira & Quinta-feira & 6 \\
\hline Terça-feira & Sexta-feira & 6 \\
\hline Quarta-feira & Sexta-feira & 6 \\
\hline Quarta-feira & Segunda-feira & 6 \\
\hline Quinta-feira & Segunda-feira & 6 \\
\hline Quinta-feira & Terça-feira & 6 \\
\hline Sexta-feira & Segunda-feira & 6 \\
\hline Sexta-feira & Terça-feira & 6 \\
\hline Sexta-feira & Quarta-feira & 6 \\
\hline Sábado & Segunda-feira & 6 \\
\hline Sábado & Terça-feira & 6 \\
\hline Sábado & Quarta-feira & 6 \\
\hline Sábado & Quinta-feira & 6 \\
\hline
\end{tabular}


Tomando a $1^{\underline{a}}$ linha da tabela, temos 1 aula na segunda de manhã e a outra aula na quarta de tarde. De manhã há 3 horários (às $9 \mathrm{~h}$, às $10 \mathrm{~h}$ ou às $11 \mathrm{~h}$ ) e de tarde, 2 horários (às $17 \mathrm{~h}$ ou às $18 \mathrm{~h}$ ). Pelo Princípio Fundamental de Contagem temos $3 \cdot 2$ possibilidades de horários, ou seja, 6 maneiras distintas de fazer natação de segunda de manhã e quarta de tarde. Analogamente, para os outros dias disponíveis na tabela. Totalizando 96 maneiras distintas de Eliane escolher o horário para aulas de natação.

Para finalizar, a professora-pesquisadora, estendeu o problema perguntando: - Se Eliane fizesse um horário diferente para cada semana, durante quanto tempo ela usaria esse esquema sem repetir os horários?

Começou-se a discussão a partir da resposta do problema, 96 maneiras distintas de escolher o horário. Esse valor corresponde a 96 semanas de aula com horários diferentes. Para saber quantos meses terão, divide-se 96 por 4 (pois em um mês há 4 semanas), obtém-se então 24 meses, que correspondem a 2 anos fazendo aula de natação semanais sem repetir os possíveis horários, em situações ideais. 


\section{Aulas 6 e 7 (aulas simples)}

Para essas aulas objetivava-se que os alunos trabalhassem com o processo de contagem, através do uso da metodologia adotada pela pesquisadora, visando à construção do conceito de Combinação simples e chegar à construção da respectiva fórmula. Seriam observadas atentamente pela pesquisadora as estratégias escolhidas pelos grupos para encaminhar a resolução do problema.

Foi entregue, a cada grupo, a oitava atividade do projeto, o problema a seguir:

Cumprimente antes de você festejar: Dez finalistas de diferentes estados foram convidados para uma confraternização. Antes de iniciar a festa, cada finalista cumprimentará, com as mãos, todos os outros finalistas. Quantos cumprimentos haverá ao todo?

(Retirado e traduzido do livro Problem- Driven Math: applying the mathematics beyond solutions Krulik, S.; Rudnick, J.A (2005).)

Foi dado um tempo para que os grupos lessem e interpretassem o problema. Num primeiro momento, foi notado que o contexto do problema era bem familiar para eles. Não tiveram dificuldade na interpretação e logo iniciaram o processo de contagem. Ao analisar o material entregue pelos grupos, observou-se que fizeram uma boa resolução e que apareceram diferentes estratégias utilizadas tais como: fazer uma lista organizada; fazer uma representação desses dados; e usar uma tabela de dupla entrada.

Descreveremos a seguir a resolução de alguns grupos acompanhada do material entregue por eles.

O Grupo 1 selecionou os nomes dos integrantes do grupo e completou com outros da sala para compor os dez finalistas referentes ao problema dado. Foi interessante, pois eles se envolveram mais com a resolução, vivenciando a situação colocada no problema. Iniciaram sua resolução do seguinte modo: escreveram o nome de um dos integrantes e a partir dele, indicaram com flechas os nomes daqueles que ele cumprimentou, representando-os pelas iniciais de seus nomes. Para cada finalista seguinte, diminuíam um aperto de mãos. Perceberam também que, quando uma pessoa cumprimenta outra, esta já está sendo cumprimentada pelo primeiro, então no total, não são contados dois cumprimentos a cada 
aperto de mãos, mas apenas um. Seguindo o mesmo raciocínio, finalizaram contando, no total, 45 cumprimentos.

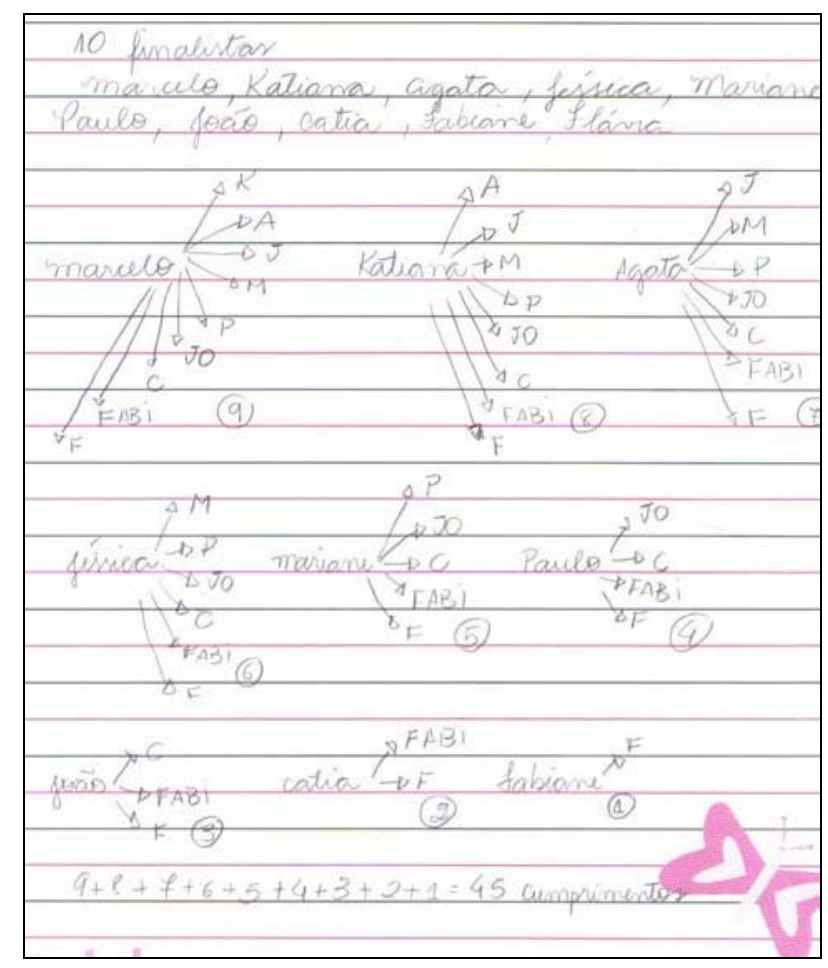

O Grupo 4 resolveu de modo semelhante ao grupo 1. Mas, ao invés de nomes, nomearam os finalistas por números de 1 a 10. Foram contando o número de cumprimentos, chegando à solução correta, 45 cumprimentos dados entre todos os dez finalistas.

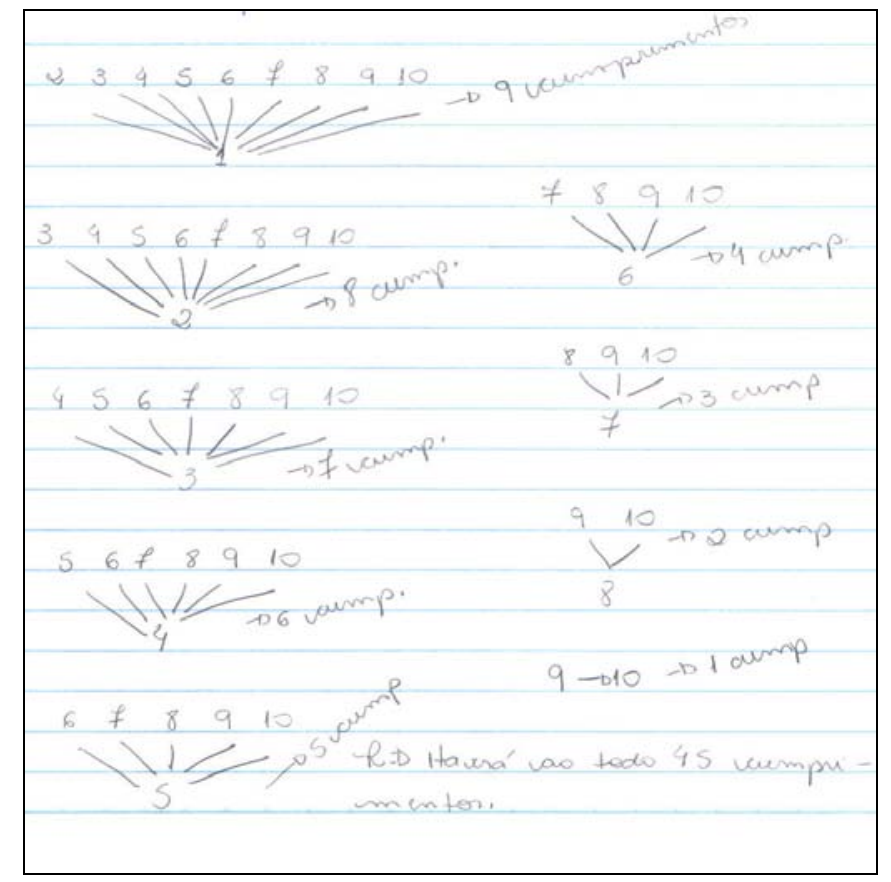


Uma outra estratégia utilizada foi a de fazer uma lista organizada. Esta estratégia foi observada nos Grupos 3 e 2.

O Grupo 3 nomeou os dez finalistas pelos números de 1 a 10 . Partiu do finalista 1 que cumprimentaria todos os outros, do finalista 2 ao finalista 10. A seguir, iniciou com o finalista 2, que cumprimentaria do finalista 3 ao finalista 10 , e, usando esse mesmo raciocínio, chegaria até o finalista 9 cumprimentaria apenas o finalista 10, e representou assim

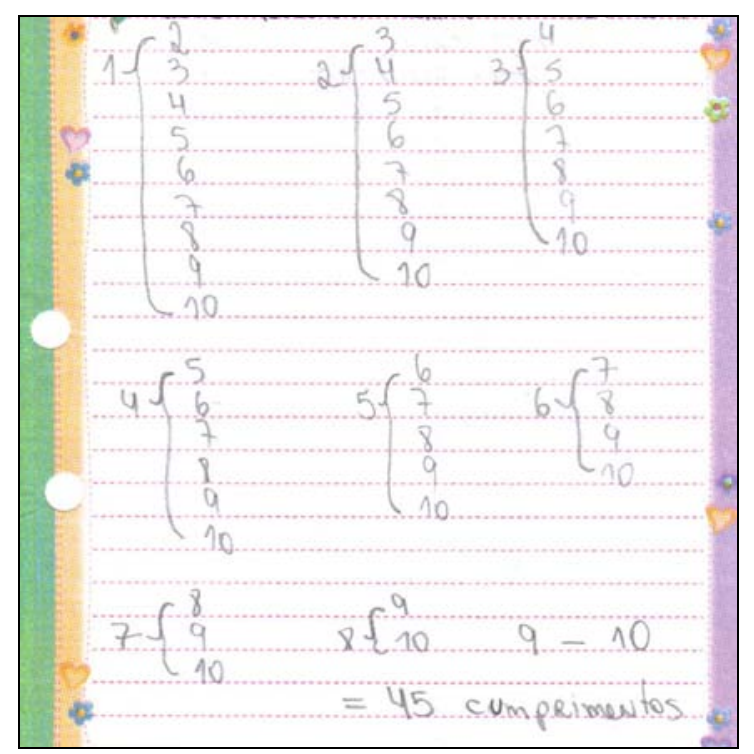

O Grupo 2, fez uso dessa mesma estratégia, mudando apenas os números de 1 a 10 para as letras do alfabeto A, B, C, D, E, F, G, H, I e J para nomear os dez finalistas. Mas, deixando de observar que quando A cumprimenta B, B já foi cumprimentado por A, então só há um aperto de mãos entre $\mathrm{A}$ e $\mathrm{B}$, totalizaram 90 cumprimentos e não obtiveram a resposta correta que seria $90 \div 2=45$ cumprimentos.

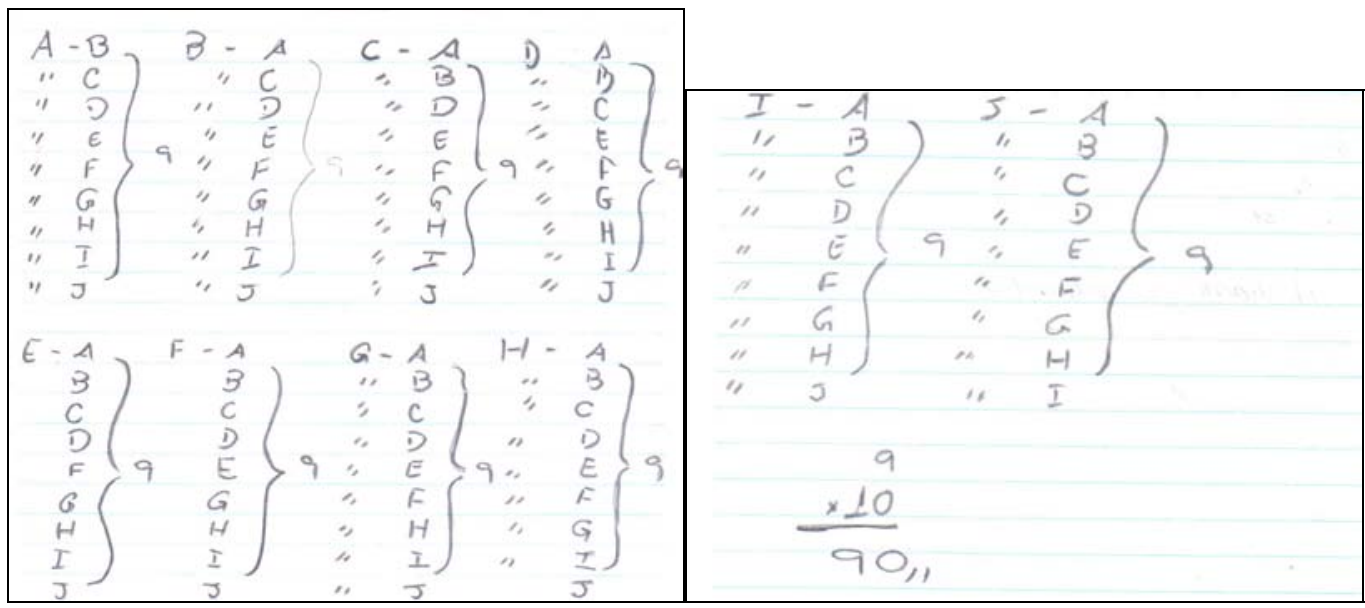


Foi-me surpreendente a organização do Grupo 6 ao resolver esse problema. Fizeram uma tabela de dupla entrada, exibindo os dez finalistas pelas letras A, B, C, D, E, F, G, H, I e $\mathrm{J}$, nessa ordem, na primeira linha e na primeira coluna. Então, fazendo o cruzamento de todas as linhas e todas colunas, foram escrevendo os pares de finalistas que estavam, entre si, se cumprimentando. Depois de discutirem entre os integrantes do grupo, perceberam que havia pares repetidos, como, por exemplo, $\mathrm{BD}$ e $\mathrm{DB}$, e como se tratavam dos mesmos finalistas, então não teriam dois cumprimentos entre B e D, mas apenas um. Perceberam que a ordem em que os finalistas apareciam nos pares não importava, pois seria contado apenas um cumprimento entre eles. Foram, então, identificando os pares repetidos e os eliminando da tabela e, através da contagem direta, obtiveram 45 cumprimentos no total.

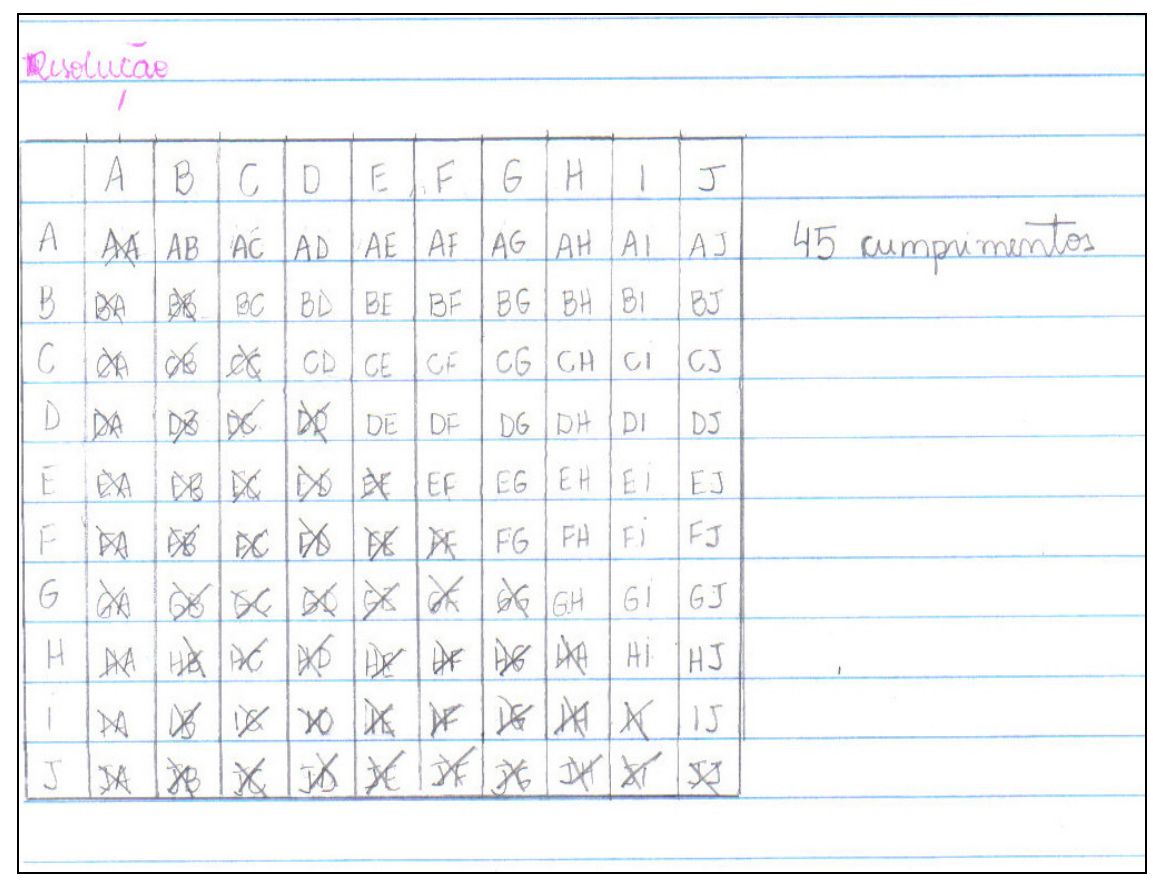

O Grupo 8 apresentou uma estratégia para resolver o problema em duas formas diferentes, partindo nas duas de uma lista organizada. Como pode se ver no material entregue pelos alunos, numa representação, eles também usaram as letras a, b, c, d, e, f, g, h, i, j. De forma recorrente, o segundo: $b$, seria cumprimentado por $c, d, e, f, g, h, i, j$ até que o finalista $i$ seria cumprimentado apenas por $\mathrm{j}$. 


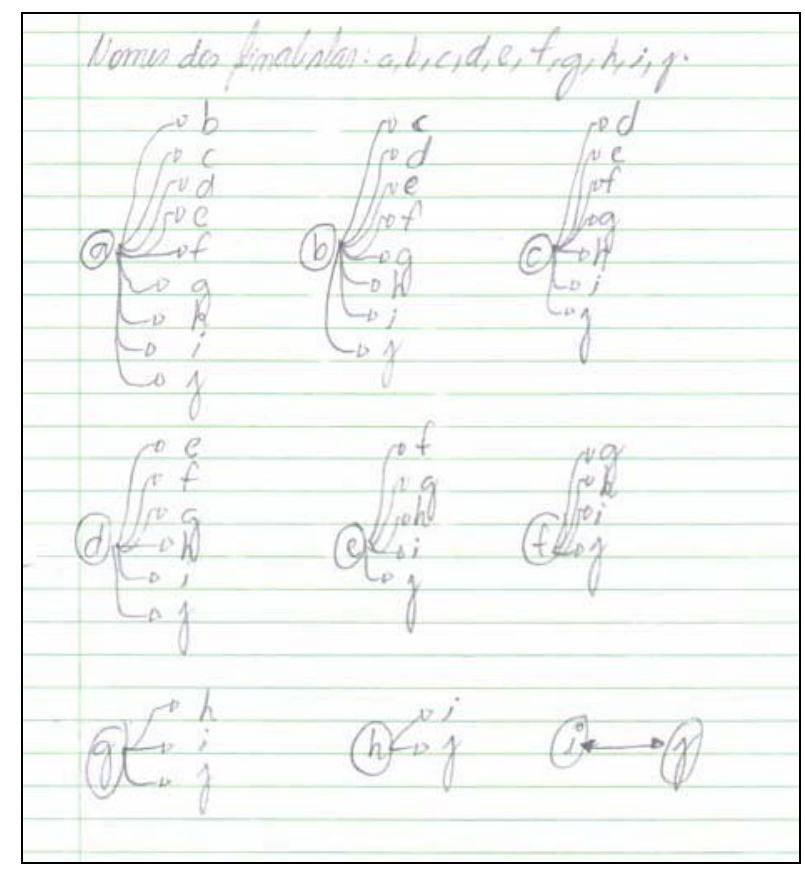

Em outra representação para sua, usando números, o Grupo 8 fez uma apresentação, a partir de cada finalista, exibindo todos os outros que o cumprimentaram. Nesta representação eles, adicionando, mostraram que foram dados 45 apertos de mãos.

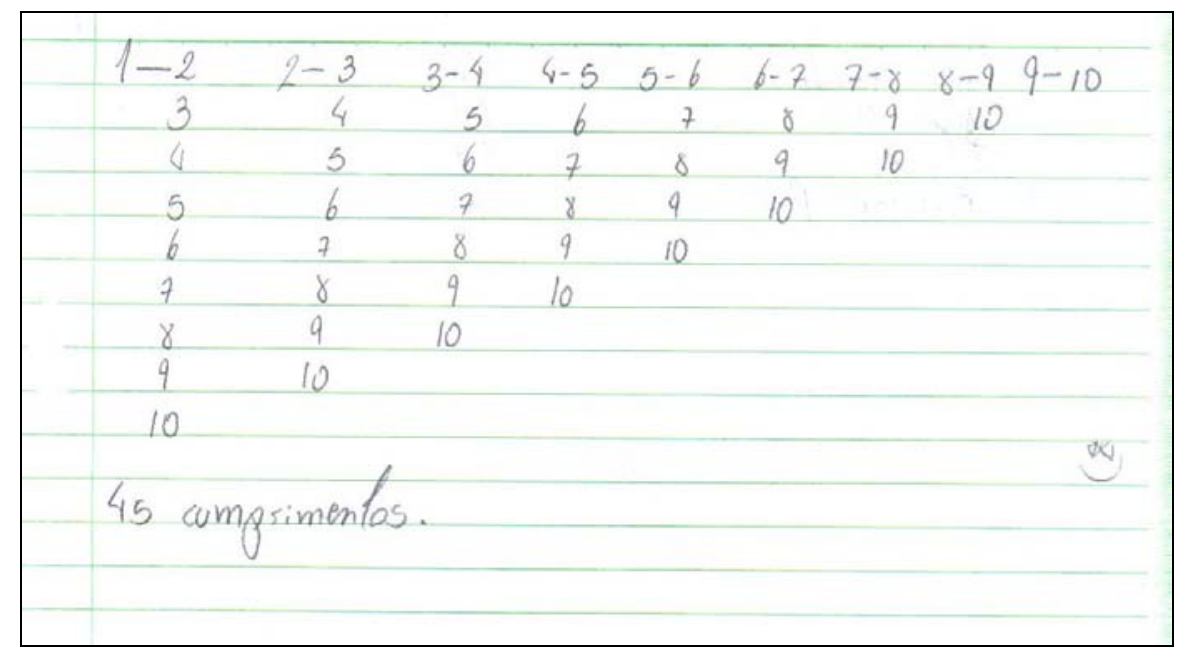

Durante a Plenária, devido ao fato de ter havido um grupo que errou o problema, a discussão sobre o aperto de mãos entre dois finalistas ser contado apenas uma vez foi importante pois, isso já era um indício da construção do conceito de combinação. 
Assim, a professora-pesquisadora querendo fixar esse fato perguntou: - Se tivéssemos, ao invés de 10, somente 3 finalistas, chamando-os de A, B e C, como vocês contariam os apertos de mãos? E disse: - Não importa quem fosse o primeiro a chegar, se A, B ou C. Suponham que fosse A. Logo, não haveria nenhum aperto de mãos. Se B fosse o segundo, então, haveria o aperto de mãos de B e A. Logo um aperto de mãos. Quando chegasse C, ele encontraria A e B e, portanto C cumprimentaria B e A. Logo, dois cumprimentos. No total, se apenas 3 fossem os convidados para a confraternização, nesse encontro haveria 3 apertos de mãos.

Nesse problema o que importa é a ordem de chegada dos convidados, não importando quem ele seja. E outro aspecto a notar é que quando um deles chegasse ele deveria cumprimentar os que já haviam chegado, notando-se que quando um cumprimenta o outro, esse aperto de mão entre eles não mais será dado.

Uma outra estratégia possível, apresentada pela professora-pesquisadora, foi a de buscar um padrão através de uma representação geométrica, representando cada finalista por um ponto e cada cumprimento entre dois finalistas por um segmento de reta. Foi colocada na lousa a tabela abaixo:

\begin{tabular}{|c|c|c|c|}
\hline $\begin{array}{c}\text { Número de } \\
\text { finalistas }\end{array}$ & $\begin{array}{c}\text { Representação } \\
\text { geométrica }\end{array}$ & $\begin{array}{c}\text { Número de } \\
\text { cumprimentos }\end{array}$ & $\begin{array}{c}\text { Diferença no número } \\
\text { de cumprimentos }\end{array}$ \\
\hline 1 & & 0 \\
\hline 2 & & 1 \\
\hline 3 & $\vdots$ & 3 & $\vdots$ \\
\hline 5 & & $\vdots$ & \\
\hline
\end{tabular}

Observando essa tabela, podemos ver que a diferença entre casos sucessivos cresce por uma unidade, isto é, as diferenças são $1,2,3,4, \ldots$ Continuando esse padrão e adicionando a diferença sobre o número anterior de cumprimentos, tem-se: 


\begin{tabular}{|c|c|}
\hline Número de finalistas & Número de cumprimentos \\
\hline 6 & $10+5=15$ \\
\hline 7 & $15+6=21$ \\
\hline 8 & $21+7=28$ \\
\hline 9 & $28+8=36$ \\
\hline 10 & $36+9=45$ \\
\hline
\end{tabular}

Assim, o número o total de cumprimentos entre os 10 finalistas é 45 .

E se tivéssemos mais que dez finalistas, 20, 30, 100, 350, 2000? Não seria tão fácil continuar o mesmo raciocínio, adicionar a diferença nos casos sucessivos ao número anterior de cumprimentos. E também, através da representação geométrica, o aluno poderia perceber que se torna difícil a visualização quando o número de finalistas é grande.

Não houve tempo, mas, se houvesse, o professor poderia estender esse problema, mostrando e discutindo os outros modos de resolvê-lo como indicado no planejamento na página 156. 


\section{Aula 8 (aula simples)}

Essa aula era a primeira do horário dos alunos e, como já foi dito, muitos chegavam atrasados, não tendo então um bom rendimento no desenvolvimento das atividades propostas.

Nessa aula, o objetivo era o de explorar o processo de contagem, fazendo uso da geometria; trabalhar o conceito de combinação e a construção da respectiva fórmula.

Então, foi entregue, por escrito, a cada um dos grupos a oitava atividade do projeto, com o problema a seguir:

Sobre uma circunferência marcam-se 6 pontos distintos. Determine quantos quadriláteros convexos podem ser formados com vértices nesses pontos.

Os grupos iniciaram a leitura do problema e, logo, já solicitaram à professorapesquisadora para tirar algumas dúvidas. Todos os alunos estavam com dificuldade na interpretação do problema, pois não se lembravam de o que era quadrilátero convexo. Aliás, muitos sabiam o que era quadrilátero, mas nenhum dos alunos sabia explicar o que significava a palavra convexo. Nesse momento, os alunos estavam diante de um problema secundário referente à geometria e ao significado da palavra. Foi preciso então, por causa dessa dificuldade, que a professora-pesquisadora interviesse para sanar as dúvidas dos alunos, senão não seria possível dar continuidade à resolução do problema.

A professora iniciou essa explicação desenhando na lousa vários quadriláteros, tanto côncavos como convexos e perguntou: - $\mathrm{O}$ que essas figuras têm em comum?

Alguns alunos responderam: - Todas têm quatro lados.

Então a professora pesquisadora disse: - Essas figuras são chamadas de quadriláteros, desde que elas sejam figuras fechadas. Mas há algo que não é comum a elas, o quê?

Os alunos ficaram observando as figuras até que um deles disse: - Tem algumas figuras que têm um bico voltado para dentro dela. Ele estava se referindo a um quadrilátero côncavo.

A partir dessa resposta, dada por esse aluno, os outros rapidamente identificaram os demais quadriláteros com essa característica. E os outros quadriláteros eram denominados convexos, de acordo com a observação feita por eles. Desse modo, parece que ficou esclarecida qual era a diferença entre um quadrilátero côncavo e um quadrilátero convexo. Mas, com um pouco mais de rigor, teria sido possível dizer que um polígono é côncavo 
quando ao traçar o prolongamento de alguns de seus lados, ele intercepta pontos interiores desse polígono, o que não acontece com os polígonos convexos.

Depois dessa discussão, os alunos voltaram a trabalhar em seus grupos.

Ao observar os grupos, a professora-pesquisadora notou que um deles desenhou os vértices do quadrilátero fora da circunferência. Essa foi outra dificuldade que eles tiveram na interpretação do enunciado. Então, a professora corrigiu essa colocação dando a definição de circunferência: - "Circunferência é o conjunto de todos os pontos de um plano equidistantes de um ponto fixo, denominado centro da circunferência”. Então, eles não poderiam colocar os vértices em outro lugar, pois o enunciado dizia para colocar os pontos sobre a circunferência.

A maioria dos alunos iniciou a resolução do problema representando os quadriláteros em uma mesma circunferência, alguns encontraram o número total de quadriláteros, mas outros desanimaram, pois sentiram dificuldade em visualizar alguns quadriláteros sobrepostos a outros. Mostraremos como o Grupo 1 resolveu o problema, da mesma forma que a maioria dos outros grupos o resolveu. A professora-pesquisadora percebeu que, entre os integrantes do grupo, um desenhava e os outros iam orientando na contagem. Acharam no total 15 quadriláteros.

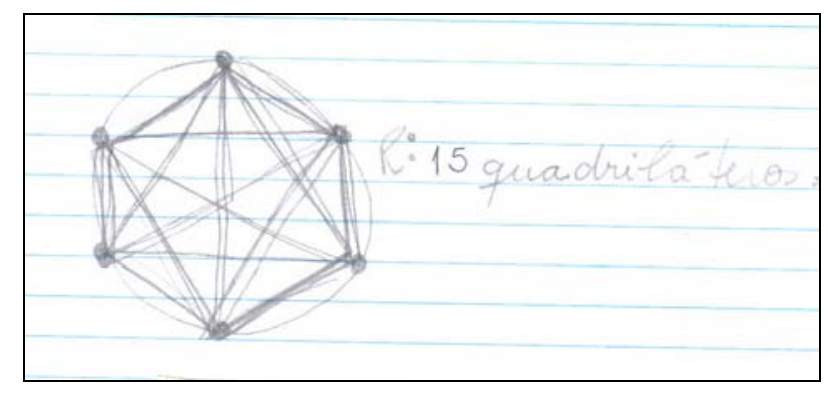

Já o Grupo 2 havia feito a circunferência em um rascunho mas não o entregou. Entregou somente as anotações feitas como aqui mostramos:

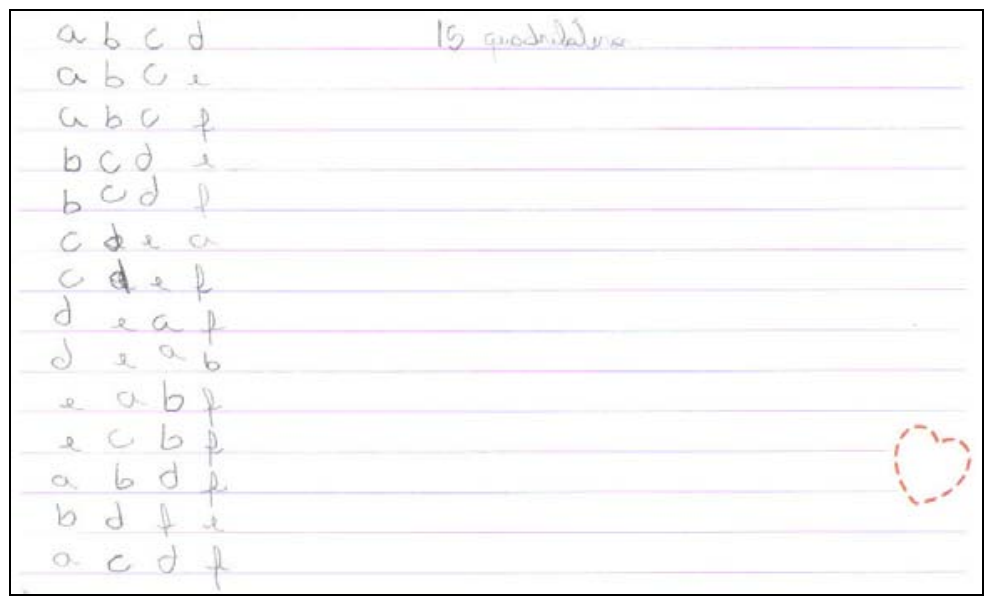


Esse grupo nomeou os vértices por $a, b, c, d, e, f$ e foi anotando os quatro vértices do modo que apareciam nas figuras. Encontraram 15 quadriláteros convexos. Pode-se perceber que iniciaram com o vértice $a$, em seguida com o vértice $b, c, d, e$, ou seja, estabeleceram uma ordem para iniciar os vértices do quadrilátero. Porém, no final, perceberam que faltavam alguns quadriláteros. Então, os três últimos saíram da ordem estabelecida no início. Além disso, em deaf, eabf, bdfe houve uma inversão na ordem dos vértices, e isso pode aparecer confuso na construção do quadrilátero.

O Grupo 5 apresentou resolução, como a maioria dos alunos, desenhando todos os quadriláteros numa mesma circunferência, e nomeando os vértices por 1, 2, 3, 4, 5 e 6. Quando já estava quase terminando a aula, um dos integrantes desse grupo questionou:

- Posso desenhar os quadriláteros separadamente? Essa aluna quis dizer com isso, desenhar cada um dos quadriláteros em uma circunferência própria. Respondi que sim e lhe pedi que trouxesse seu trabalho na aula seguinte.

Não houve tempo, nessa aula, para discutir as resoluções dos problemas feitos pelos grupos. Isso seria feito na aula seguinte. 


\section{Aulas 9 e 10 (aula dupla)}

Nessa aula continuamos a discussão do problema trabalhado na aula anterior. Retomamos seu enunciado para revisar seus dados e verificar se ainda havia ficado alguma dúvida.

A professora-pesquisadora solicitou o Grupo 2 que apresentasse, na lousa, sua resolução. Juntos, professora e alunos, recordaram a solução apresentada por esse grupo. Comentando-se, então, sobre, por exemplo, a solução deaf, pediu-se para que se desenhasse na circunferência o quadrilátero com esses vértices, na ordem apresentada. Acharam esquisito pois não conseguiam fechar o quadrilátero se seguissem a ordem deaf. Então, perceberam os alunos que teriam que mudar a ordem de $a$ e $f$, para que houvesse uma sequência ordenada dos lados do quadrilátero. O mesmo fato ocorria com eabf e bdfe. Chamou-se a atenção para a notação dos vértices de uma figura onde, usualmente, é utilizada a letra maiúscula do alfabeto para pontos.

O Grupo 5 trouxe duas soluções trabalhadas por ele. Pediu-se que esse grupo apresentasse aos demais o que fizeram. O Grupo 5 utilizou, em um computador, o programa Paint para resolver o problema. Mas, anteriormente, eles haviam iniciado a resolução desenhando os quadriláteros no caderno e só depois é que fizeram o trabalho com a ajuda do computador.

Trouxeram impressa a solução, feita no programa Paint no computador, com todos os quadriláteros desenhados. Pediu-se que reproduzissem, na lousa, o desenho feito no computador.

Nesta solução foram desenhados os quadriláteros mas não foi apresentado o número de quadriláteros formados.

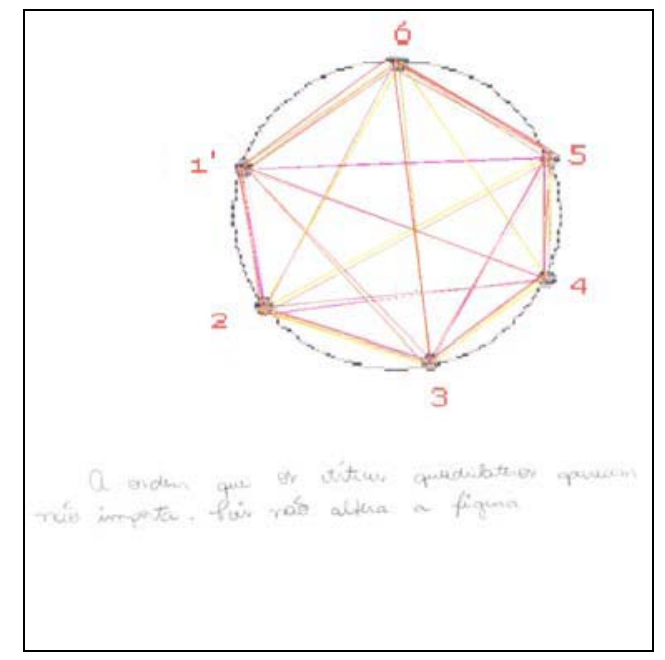


A seguir, apresentaram a outra solução.

Da mesma forma, esse grupo apresentou o trabalho feito no Programa Paint e, depois, fez sua representação na lousa a fim de possibilitar a discussão com os membros de outros grupos. Essa ação demandou mais tempo. Aqui, nesta folha, todas as possibilidades são ordenadamente expostas em cinco colunas, a começar de 1234 e indo até 3456. Respeitando uma melhor visão pede-se que o leitor veja a representação girando a folha $90^{\circ}$.
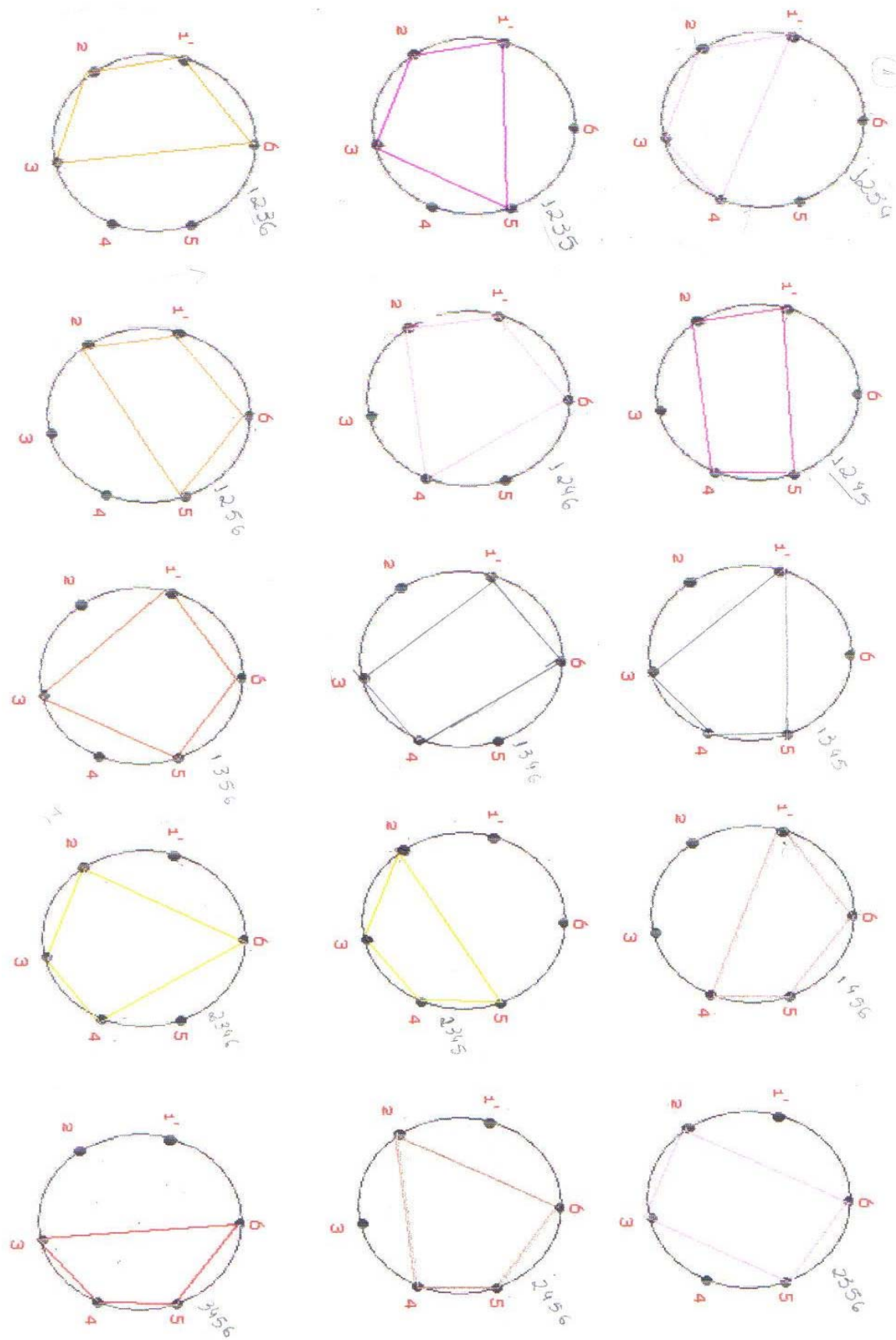
O fato de desenhar os quadriláteros em circunferências separadas foi justificado pelos alunos. Alegaram que a visualização se torna confusa ao tentar identificar os 15 quadriláteros e, então, pensaram em um outro meio que pudesse levar à solução do problema.

Assim, adotaram um método para organizar a descrição dos quadriláteros nas circunferências. Iniciaram, traçando várias circunferências. Em seguida, marcaram os seis pontos dados nos mesmos lugares, em todas as circunferências traçadas. Nomearam os pontos escolhidos por 1,2,3,4,5,6 e escolheram a ordem crescente dos números lidos em sentido anti-horário. Adotaram o seguinte critério: o vértice inicial de cada quadrilátero, desenhado em cada circunferência, deveria terminar nele também, fechando a figura.

Desse modo, começaram a traçar os quadriláteros, sem lançar mão de tentativa e erro, assim: partindo do vértice $1 \mathrm{em}$ ordem crescente, varrendo todas as possibilidades: 1234 , $1235,1236,1245,1246,1256,1345,1346,1356$ e 1456, notação que se encontra ao lado de cada circunferência desenhada. Obtendo-se então 10 quadriláteros. Ao iniciar com o vértice 2 obteve-se analogamente 2345, 2346, 2356 e 2456, um total de 4 quadriláteros. E, iniciando-se com o vértice 3,3456 , um quadrilátero. No total, encontraram-se 15 quadriláteros convexos.

A professora-pesquisadora perguntou: - A ordem em que os vértices foram marcados alteraria o número de soluções (quadriláteros)?

Os alunos responderam: - Não.

- Haveria uma outra figura utilizando, por exemplo, os vértices 1234 ?

- A figura aberta 1423; e também a figura aberta 1324.

Observando que a figura não fechou pois não terminou no vértice inicial.

Foram questionados pela professora-pesquisadora: - Se mudassem a posição dos vértices do quadrilátero, o que aconteceria? e, como resposta, perceberam que a figura não se alteraria.

O Grupo 7 começou com a estratégia de "tentativa e erro", que pode ocasionar falta ou repetição de quadriláteros. Representaram os quadriláteros com lápis de diferentes cores e não encontraram o total de quadriláteros formados com os seis vértices dispostos sobre a circunferência, como mostramos abaixo:

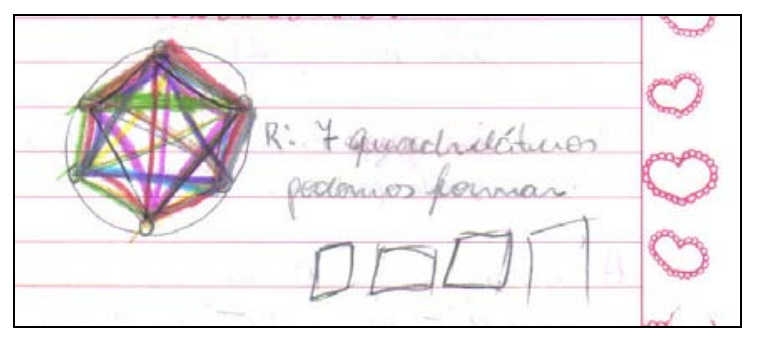


Como podemos ver no material entregue por esses alunos, a contagem dos quadriláteros foi anotada corretamente, 15 quadriláteros, mas se confundiram e responderam 7 quadriláteros.

Após a plenária, a professora-pesquisadora apresentou à classe, a estratégia de fazer uma lista organizada.

Desenhar uma circunferência. Representar por A, B, C, D, E e F os seis pontos distintos dados, marcados na circunferência.

Para determinar os quadriláteros, precisa-se de apenas quatro dos seis pontos marcados, que serão seus vértices. Para organizar uma lista, é importante que depois que uma ordem seja estabelecida, deve-se trabalhar sempre com ela. Iniciando-se com o vértice A e terminando também em A, encontram-se as seguintes possibilidades:

$\mathrm{ABCD} \quad \mathrm{ABEF}$

ABCE ACDE

$\mathrm{ABCF} \quad \mathrm{ACDF}$

ABDE ACEF

ABDF ADEF

Obtendo, então, 10 quadriláteros.

Ao iniciar-se com o vértice $B$ e terminando em $B$, não será mais considerado o vértice A.

Nesse caso os quadriláteros possíveis serão:

$$
\begin{array}{ll}
\text { BCDE } & \text { BCEF } \\
\text { BCDF } & \text { BDEF }
\end{array}
$$

Obtendo, então, 4 quadriláteros.

Ao iniciar-se com o vértice $\mathrm{C}$ e terminando em $\mathrm{C}$, não são mais considerados os vértices $\mathrm{A}$ e $\mathrm{B}$.

Então, CDEF é o único quadrilátero possível.

Assim, pelo Princípio Aditivo, podem ser formados 10quadriláteros + 4quadriláteros + 1 quadrilátero $=15$ quadriláteros, com os seis pontos distintos marcados na circunferência.

Observa-se que começar com qualquer um dos vértices é irrelevante, isto é, este resultado independe do vértice escolhido para começar a formação dos quadriláteros.

Para uma pergunta de um aluno que buscava, na Matemática, uma forma mais fácil de resolver esse problema, nesse momento, a professora-pesquisadora tentando dar início ao conceito de "combinação", disse aos alunos que o problema dado poderia ser visto assim: 
- Foram tomados 6 pontos na circunferência;

- Com esses seis pontos queremos formar um certo número de quadriláteros;

- Cada quadrilátero vai usar, como vértices, somente quatro desses seis pontos.

Então, disse a professora-pesquisadora, o que se tem a fazer é ajustar quatro desses seis pontos formando diferentes quadriláteros.

Esse é um problema do ramo da Matemática chamado Análise Combinatória e a Matemática vai permitir que se encontre um padrão, aquele que se repete sempre, e que pode ser expresso por uma fórmula, que é uma relação entre grandezas.

Não houve tempo para fazer a construção dessa fórmula para o cálculo do número de combinações. Se tivesse havido tempo chegar-se-ia à $C_{6,4}=\frac{6 !}{(6-4) ! 4 !}=15$, onde $C_{6,4}$ é lido como combinação de 6 elementos tomados 4 a 4. Essa fórmula representa uma relação entre grandezas. Neste caso as grandezas são: os vértices e os quadriláteros, isto é combinando os vértices: $1,2,3,4,5$ e 6 , tomados quatro a quatro para obter os quadriláteros, que são polígonos convexos fechados de quatro lados onde o ponto final coincide com o ponto inicial.

Mas vamos fazer subconjuntos de 4 elementos diferentes construídos a partir do 6 elementos dados.

É importante notar que um subconjunto difere do outro pela natureza dos elementos, os vértices. Mas para chegar a todos os subgrupos e não haver confusão em sua determinação foi necessária a utilização de uma ordem estabelecida. E numa expressão geral chegaríamos a combinação de $n$ elementos tomados $p$ a $p, \operatorname{com} n \leq p, n>0, C_{n, p}=\frac{n !}{(n-p) ! \mathrm{p} !}$. 


\section{Aula 11 (aula simples)}

Os objetivos para trabalhar a décima atividade do projeto eram: durante o processo de contagem, observar a ordem dos elementos e verificar se o fato de mudar a ordem influencia ou não o resultado; trabalhar as ideias básicas de Arranjo, percebendo que os grupos formados diferem pela ordem e pela natureza dos elementos; e fazer a construção das fórmulas de Arranjo e de Combinação simples.

Foi entregue, a cada grupo, uma cópia do problema:

Com os algarismos 1, 2 e 7, quantos números com 3 algarismos distintos podemos formar?

Este problema foi resolvido por todos os grupos. Não tiveram dificuldade durante a resolução e apresentaram como estratégia: fazer uma lista organizada.

A seguir registramos as resoluções de quatro grupos e, em seguida as discussões.

Os Grupos 1, 3 e 2 apresentaram, como estratégia, para resolver o problema, uma lista organizada. Iniciando com o algarismo 1 para o algarismo das centenas, restaram então os algarismos 2 ou 7 para o algarismo das dezenas e para o algarismo das unidades. Seguindo o mesmo raciocínio, iniciaram com o algarismo 2 e depois com o 7 para o algarismo das centenas. Chegando, usando diferentes representações, a:

\section{Grupo 1}

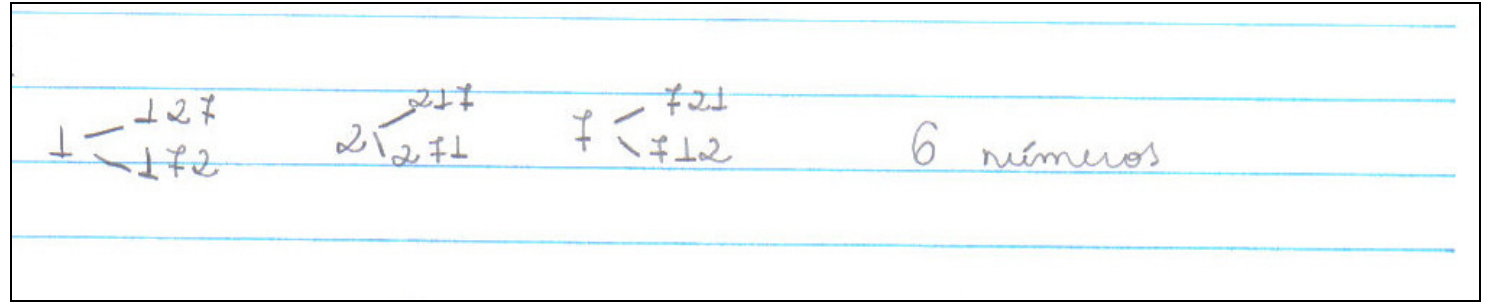


Da mesma forma,

Grupo 3

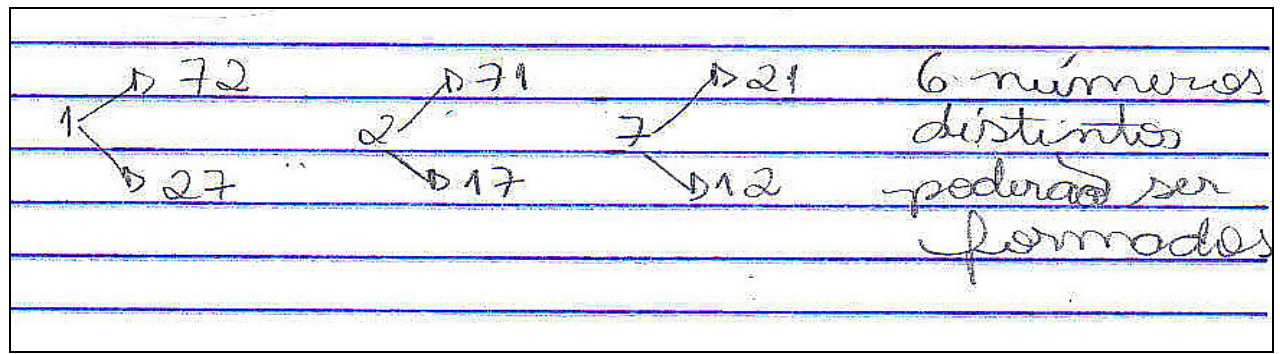

Grupo 2

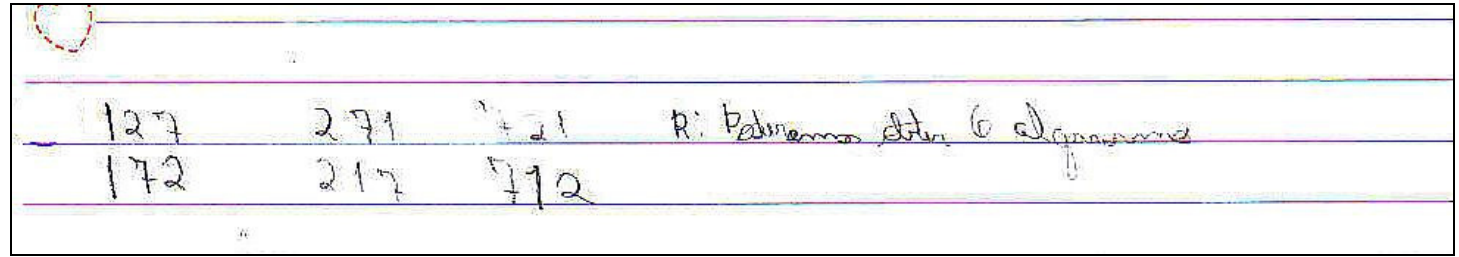

O Grupo 7 apresentou um novo modo de resolver esse problema, fazendo uso da ideia do Princípio Multiplicativo ou Princípio Fundamental de Contagem. Para cada algarismo, colocaram o número de possibilidades, iniciando pelas unidades, com três possibilidades (1, 2 ou 7), nas unidades; como o número é formado com algarismos distintos, então restam duas possibilidades para as dezenas, e para as centenas então só resta uma possibilidade. Pelo Princípio Multiplicativo, são formados $1 \cdot 2 \cdot 3=6$ possibilidades, ou seja, há 6 números com os três algarismos dados, embora tenha deixado de apresentar esses seis números.

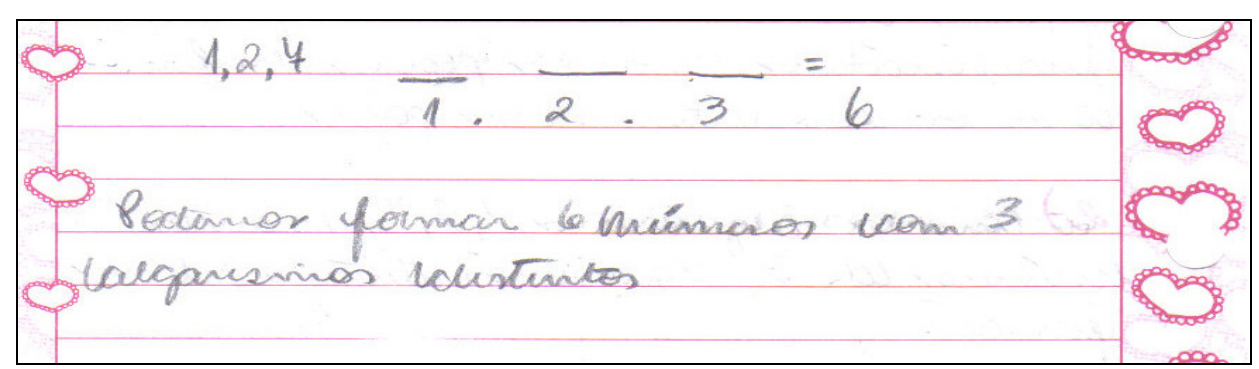


A professora-pesquisadora assumiu a direção dos trabalhos e disse que, para a construção da árvore de possibilidades, podemos imaginar uma árvore com vários troncos (ramos principais). Cada tronco com vários galhos (ramos secundários), e cada galho com outros ramos (ramos terciários). Assim, nesse problema, tem-se que os troncos representam a casa das centenas, os ramos secundários, a casa das dezenas e os ramos terciários, a casa das unidades. Assim, temos três troncos, 1, 2 e 7; dois ramos secundários, pois escolhido um tronco, restam duas possibilidades para formar esses ramos; e um ramo terciário correspondente a cada ramo secundário. Desse modo formam-se seis números de três algarismos distintos.

Representamos a árvore de possibilidades desse problema a seguir:

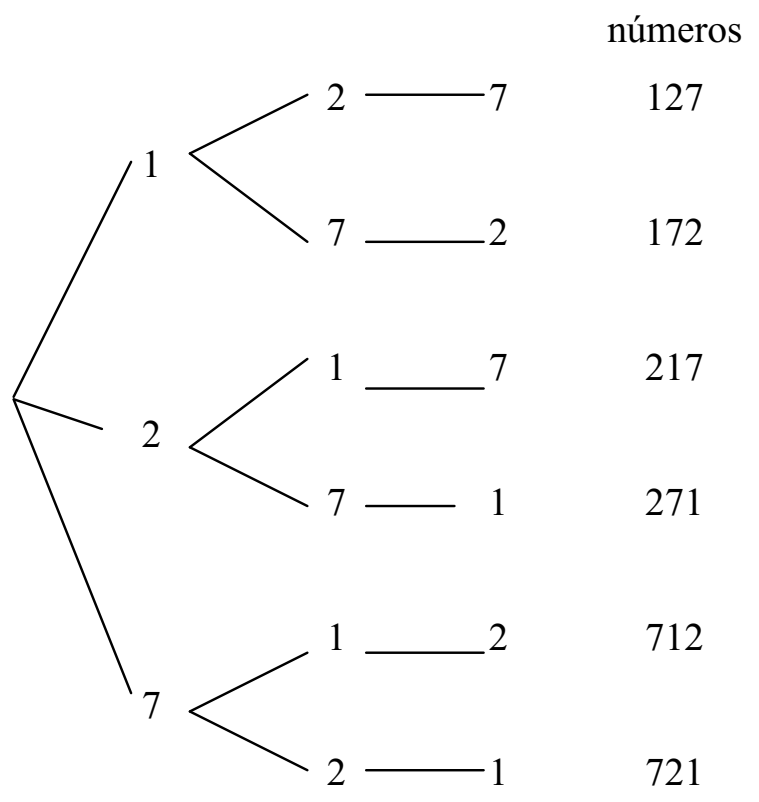

Então, pelo Princípio Multiplicativo, tem-se que o número de números de três algarismos distintos pôde ser obtido assim:

$$
m_{1} \cdot m_{2} \cdot m_{3} \text {, onde } m_{1}=3 ; m_{2}=2 ; \cdot m_{3}=1 . \operatorname{Logo} 3 \cdot 2 \cdot 1=6 \text {. }
$$

A professora-pesquisadora pediu a atenção de modo que pudessem observar a ordem dos algarismos dos números encontrados pelos grupos. Por exemplo, nos números 217 e 271 , temos que eles são formados pelos mesmos algarismos, mas ao mudar a ordem dos algarismos 1 e 7 , o que ocorre?

- São formados números diferentes.

- Então, a ordem é importante para a formação dos números? 
Prontamente responderam que sim.

Aproveitando a discussão sobre a ordem entre os elementos de um conjunto para formar os agrupamentos, a professora-pesquisadora retomou o problema da aula anterior, o problema dos quadriláteros convexos. Recordou com os alunos que quando mudamos a ordem dos vértices de um quadrilátero, ele permanece o mesmo e, então, a ordem nesse caso é irrelevante. Desse modo, estamos diante de agrupamentos diferentes, onde a ordem é irrelevante, e temos, então, um caso de combinação.

Se, nesse problema, além da ordem, fosse também exigida a diferença pela natureza dos elementos, ter-se-ia um caso de arranjo.

Não houve tempo para a construção das fórmulas de arranjo e de combinação com esta classe, mas deixamos, no planejamento deste projeto, essa construção para que o professor que for trabalhar em sala de aula e tiver oportunidade, faça a construção das fórmulas, de modo que os alunos convencidos da verdade dessas relações possam usa-las com mais familiaridade, mesmo quando o número de elementos do conjunto seja bastante grande. 


\section{Aula 12 (aula simples)}

Nesta aula, trabalhamos a décima primeira atividade e última do projeto, deixada na aula anterior como tarefa.

Os objetivos centrais dessa aula eram: o de trabalhar as ideias básicas de Permutação, percebendo que os grupos formados diferem apenas pela ordem dos elementos envolvidos; o de verificar a importância desse tópico matemático na realidade em que vivem os alunos, através da realização de uma pesquisa e de compartilhar em grupo as informações nela obtidas que, como dito, essa pesquisa havia sido solicitada pela professora na aula anterior. Foi pedido aos alunos, formados em grupos, que pesquisassem sobre um ou mais dos seguintes temas: anagrama, senhas, código de barras e código Morse. Os alunos poderiam consultar sites, revistas e livros sobre o tema escolhido.

Os grupos entregaram por escrito as pesquisas realizadas. A principal fonte de pesquisa foi a internet e, mais especificamente, no banco de dados pt.wikipedia.org.

Os principais pontos descritos no trabalho dos grupos, dentro dos temas solicitados foram:

\section{Código Morse}

É um sistema de representação de letras, números e sinais de pontuação através de um sinal codificado, enviado intermitentemente apenas com uma sequência de pontos, traços e espaços. Foi desenvolvido por Samuel Morse e Alfred Vail em 1835, criadores do telégrafo elétrico, dispositivo que utiliza correntes elétricas para controlar eletroímãs que funcionam para emissão ou recepção de sinais. Era muito usado antigamente mas atualmente não se usa muito pois existem outros aparelhos mais modernos que transmitem as nossas mensagens de forma mais rápida e eficaz. Ainda aparece nos faróis. Uma mensagem codificada em Morse pode ser transmitida de várias maneiras em pulsos (ou tons) curtos e longos: pulsos elétricos transmitidos em um cabo; ondas mecânicas (perturbações sonoras); sinais visuais (luzes acendendo e apagando) e ondas eletromagnéticas (sinais de rádio). O código Morse é transmitido usando apenas dois estados, ligado e desligado.

\section{Senhas}

Os alunos citaram alguns exemplos onde são utilizadas as senhas: no caixa eletrônico, na compra com cartão de crédito ou débito, no atendimento personalizado no telefone e na internet ao cadastrar o email. Descreveram que há uma senha para cada situação e que é difícil 
uma pessoa não precisar de senha no cotidiano. Podem-se usar apenas letras, apenas números ou uma mescla de letras e números, e também acrescentar pontuação para formar uma senha. Um grupo definiu senha, ou também palavra-chave, como uma palavra ou uma ação secreta previamente convencionada entre duas partes como forma de reconhecimento.

\section{Anagramas}

Sobre os Anagramas, os alunos o definiram e apresentaram alguns tipos de anagramas.

Escreveram que anagrama é uma palavra de origem grega que significa ana = "voltar" ou "repetir" e graphein = "escrever". Assim, anagrama é uma espécie de jogo de palavras resultando do rearranjo das letras de uma palavra ou frase para produzir outras palavras ou frases, utilizando todas as letras originais exatamente uma vez.

Os tipos de anagramas apresentados foram:

- Pangrama: é uma sentença que usa todas as letras do alfabeto. Apresentaram o exemplo: "Um pequeno jabuti xereta viu dez cegonhas felizes".

- Anigrama: é um anagrama que se anima sozinho embaralhando as letras numa animação gif ou flash.

- Anugrama: é uma sentença em que seu anagrama tem o mesmo significado, em inglês, da sentença original. Apresentaram o seguinte exemplo: "Eleven plus two" ("Onze mais dois") tem o mesmo significado que "Twelve plus one" ("Doze mais um") e foram usadas as mesmas letras e rearranjadas de forma que as duas sentenças tivessem o mesmo significado.

Na plenária, a professora-pesquisadora chamou a atenção para os anagramas, com o objetivo de que os alunos pudessem iniciar um estudo sobre as ideias básicas de Permutação.

Foi apresentada na lousa a palavra ESCOLA e foi pedido que encontrassem os anagramas dessa palavra.

Foi dado um tempo para que os grupos fizessem essa atividade. Eles perceberam que seriam muitas as possibilidades de anagramas para essa palavra. Então, a professora colocou na lousa uma sugestão, resolver esse problema através da construção da árvore de possibilidades, 


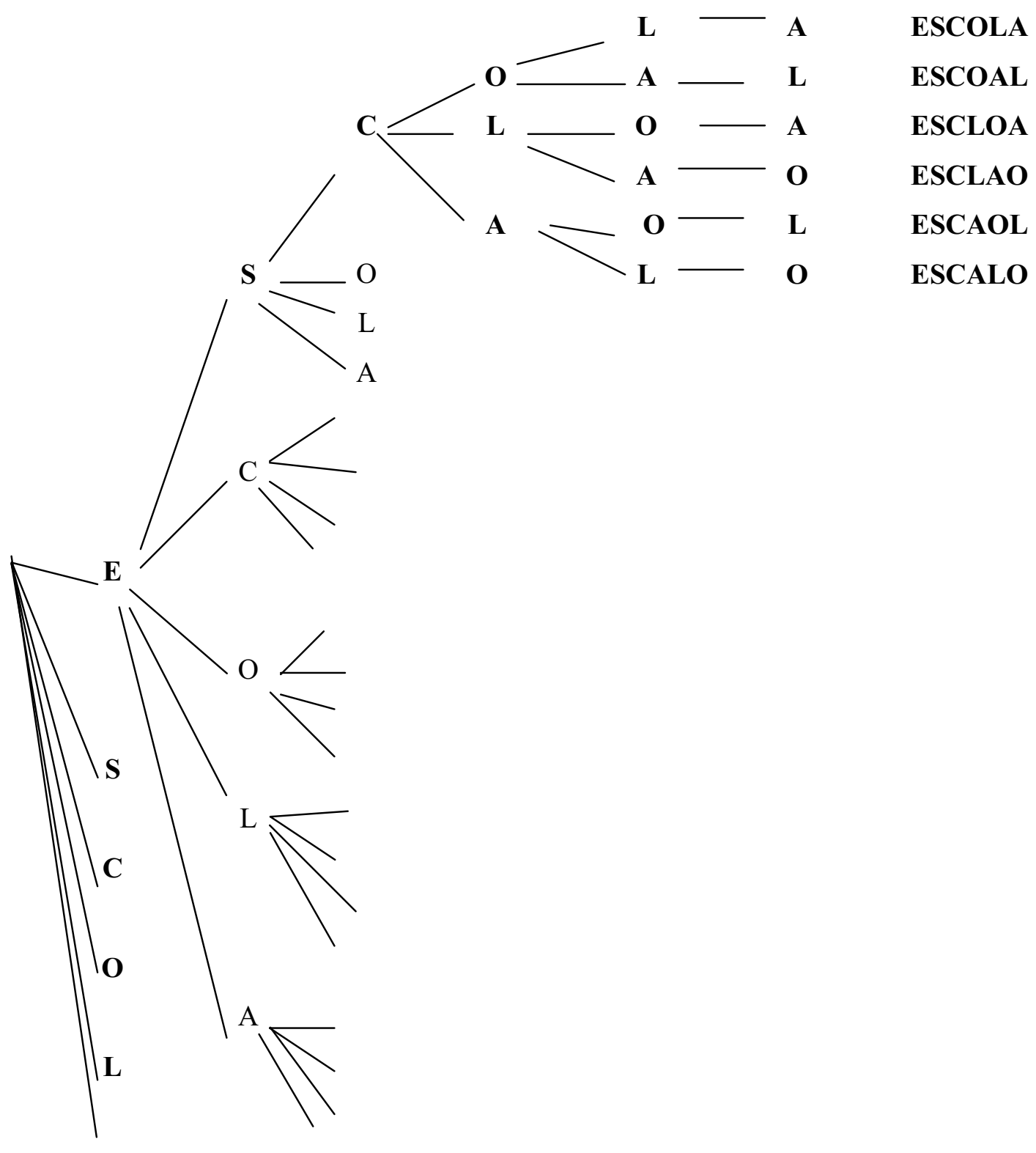

$\mathbf{A}$

que permitirá, ao partir de cada letra: E, S, C, O, L, A, encontrar todas as possibilidades. Iniciando com a letra $\mathrm{E}$, então as possibilidades para a segunda letra são: $\mathrm{S}, \mathrm{C}, \mathrm{O}, \mathrm{L}$ e $\mathrm{A}$. Partindo da letra S, têm-se quatro possibilidades para a terceira letra: C, O, L e A. A seguir, partindo de C, como a terceira letra, têm-se três possibilidades para a quarta letra: $\mathrm{O}, \mathrm{L}$ e A. Para a quinta letra, partindo de $\mathrm{O}$, têm-se duas possibilidades: L e A e, para a última letra, a partir de L, há uma única possibilidade, A. No primeiro ramo, a partir de C, temos então 6 palavras. Do mesmo modo ocorre com as letras O, L e A. Totalizando então $4 \cdot 6=24$ 
possibilidades, ou, pelo Princípio Multiplicativo, faz-se $4 \cdot 6=24$. Partindo-se de $\mathrm{C}$, de $\mathrm{O}$, de L e de A como sendo a segunda letra, então temos $5 \cdot 24=120$ possibilidades iniciando com a letra E, ou seja, $5 \cdot 4 \cdot 3 \cdot 2 \cdot 1=120$. Como essa palavra tem seis letras, E, S, C, O, L e A, então temos $6 \cdot 120=720$, ou seja, $6 \cdot 5 \cdot 4 \cdot 3 \cdot 2 \cdot 1=720$ anagramas com as letras da palavra escola.

Os alunos ficaram surpresos com o número possível de anagramas usando apenas seis letras. Também, através da árvore de possibilidades, ficou mais fácil para eles entenderem a importância da ordem das letras ao formar os anagramas e observaram ainda que cada palavra formada, com significado ou não, é formada por todas as letras da palavra dada. A esse agrupamento denominamos permutação simples, pois as letras não são repetidas.

O tempo da aula não foi suficiente para a construção da fórmula da permutação, mas pedi para prestarem atenção no produto $6 \cdot 5 \cdot 4 \cdot 3 \cdot 2 \cdot 1=720$, e disse, também que esse produto $6 \cdot 5 \cdot 4 \cdot 3 \cdot 2 \cdot 1$ é chamado fatorial de 6 e denotado por 6 !.

Na decomposição de 720 , em fatores primos, encontramos:

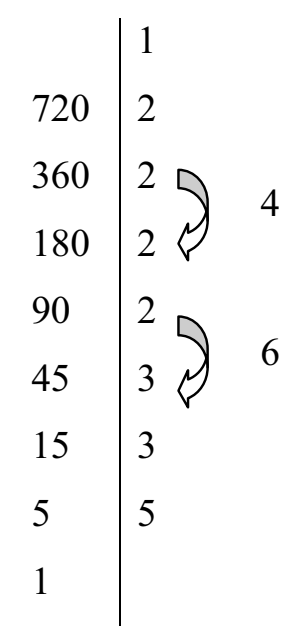

E podemos explicitar $1 \cdot 2 \cdot 3 \cdot 4 \cdot 5 \cdot 6=720$.

Conjecturamos, então, que tendo $n$ elementos em um conjunto, o cálculo do número de permutações simples desses $n$ elementos é dado por $n$ !, lembrando que nas permutações entram todos os elementos sempre. A mudança entre as permutações ocorre apenas na ordem dos elementos.

\section{Código de barras}

No trabalho pedido, houve alunos que pesquisaram também sobre o código de barras. Seguem alguns registros constantes neles.

- O código de barras é uma representação gráfica de dados que podem ser numéricos ou alfanuméricos (letras e números) dependendo do tipo de código de barras empregado. 
- As linhas paralelas e verticais e os espaços entre elas têm diferentes larguras em função das várias técnicas de codificação de dados empregados.

- No Brasil, o código de barras foi implantado no começo dos anos 90, no governo de Fernando Collor de Mello. O código de barras para nosso país é "789" (lê-se no início do código), enquanto que, em Portugal, o código de país de origem é " 560 ”.

- O código de barras é uma forma de representar a numeração, que viabiliza a captura automática dos dados por meio de leitura óptica nas operações automatizadas. É feito através de um scanner, dotado de uma fonte luminosa vermelha que, por contraste das barras e seus espaços, convertem a representação gráfica em bits (sequências de 0 ou 1) compreendidos pelo computador, que por sua vez converte-os em letras ou números legíveis para nós.

- Não é qualquer scanner que consegue ler qualquer tipo de código de barras, os leitores ópticos devem estar habilitados para leitura a fim de poderem interpretar um código de barras.

O problema proposto abaixo não foi trabalhado por não haver tempo suficiente para resolvê-lo, mas fica como sugestão de trabalho para os professores que irão abordar esse conteúdo.

Problema proposto (Código de barras): As embalagens dos produtos vendidos por uma empresa apresentam uma seqüência formada por barras verticais: quatro de largura 1,5mm; três de largura $0,5 \mathrm{~mm}$ e duas de largura $0,25 \mathrm{~mm}$, como no exemplo abaixo. Cada seqüência indica o preço de um produto. Quantos preços diferentes podem ser indicados por essas nove barras? (Retirado e adaptado do livro Matemática volume único, Manoel Paiva -1999.)

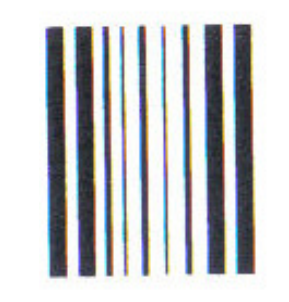

Nesse problema, seria trabalhado o conceito de permutação com repetição, estendendo o conceito de permutação simples. Sua resolução e a construção da fórmula para o cálculo do número de permutações com repetição se encontram no planejamento deste projeto. 


\subsection{A aplicação do Projeto $2-P_{2}$}

Introdução

O objetivo de $\mathbf{P}_{2}$ é o de ministrar uma oficina de trabalho, com a autora desta pesquisa atuando como pesquisadora, para professores de Matemática, educadores matemáticos e até alunos da Licenciatura em Matemática, usando como alternativa de trabalho a Metodologia de Ensino-Aprendizagem-Avaliação de Matemática através da resolução de problemas.

A Estratégia Geral selecionada para $\mathbf{P}_{\mathbf{2}}$ é a de Criar um Plano de Trabalho e, como Procedimento Geral correspondente, a Criação desse Plano de Trabalho. Esse plano é constituído pelas atividades a serem trabalhadas na oficina escolhida. Relataremos como foi o desenvolvimento da oficina ministrada pela pesquisadora.

Como já foi dito no planejamento, escolhemos participar do II Seminário de Histórias e Investigações delem Aulas de Matemática (IISHIAM), realizado na FE-UNICAMP no período de 24 a 26 de julho de 2008. Enviamos o resumo do trabalho para ser realizado na oficina, intitulado Análise Combinatória: uma abordagem com compreensão apoiada na Metodologia de Ensino-Aprendizagem-Avaliação de Matemática através da resolução de problemas. O trabalho foi aceito e a oficina seria realizada no dia 25 de julho de 2008, das $8 \mathrm{~h} 00$ às $12 \mathrm{~h} 30 \mathrm{~min}$, com duração de 4 horas além de meia hora de intervalo.

Havia 10 pessoas participando da oficina. Entre elas, professores do Ensino Fundamental e Médio, professores do Ensino Superior, alunos de Graduação e um aluno concluinte do curso de Licenciatura em Matemática.

No primeiro momento da oficina apresentamos aos participantes, usando o data show com o Powerpoint, treze slides constando os objetivos da oficina e também a fundamentação teórica do tema proposto.

Os objetivos dessa oficina foram: apresentar uma proposta de trabalho para abordar a Análise Combinatória em sala de aula, segundo a Metodologia de Ensino-AprendizagemAvaliação de Matemática através da resolução de problemas; vivenciar essa metodologia através da dinâmica em grupo; evidenciar a importância de um trabalho investigativo, em aulas de matemática, através da resolução de problemas, que pode contribuir para a formação do professor e promover uma aprendizagem com compreensão nos alunos.

Falamos resumidamente sobre Resolução de problemas, Matemática Discreta e Análise Combinatória. Em relação à Resolução de Problema, destacamos três concepções 
diferentes, ensinar sobre resolução de problemas, ensinar matemática para resolver problemas e ensinar matemática através da resolução de problemas, sendo esta última a concepção considerada para nossa pesquisa. Falamos então da Metodologia de Ensino-AprendizagemAvaliação de Matemática através da Resolução de Problemas, quais são seus objetivos, o papel do aluno, do professor e a avaliação. E também apresentamos, como sugestão, um roteiro para o trabalho em sala de aula ao adotar essa metodologia.

Quanto à Matemática Discreta, apresentamos sua definição e em seguida, sobre o ensino de Análise Combinatória, comentando sobre as dificuldades de trabalhar esse tópico. Desse modo, a oficina seria um momento de trabalhar Análise Combinatória fazendo uso de uma metodologia alternativa, visando a uma melhor compreensão.

Num segundo momento, iniciou-se a dinâmica em grupos, com o objetivo de vivenciar a Metodologia de Ensino-Aprendizagem-Avaliação de Matemática através da resolução de problemas. Como não havia um número grande de participantes, decidiu-se formar dois grupos para resolver os problemas propostos e depois discuti-los.

Os grupos foram participativos durante todo o transcorrer da oficina. Foram propostos três problemas para que vivenciassem a metodologia adotada. Integrantes de um mesmo grupo apresentaram, colaborativamente, diferentes caminhos para resolver um mesmo problema, possivelmente devido à diversidade quanto à formação dos integrantes. Alguns membros dos grupos foram à lousa e relataram o que haviam discutido no grupo. Não surgiram erros durante a resolução. Todos chegaram à mesma solução. Em seguida questionamos os participantes sobre a ordem e a natureza dos elementos envolvidos em cada um dos problemas. Esse foi um passo importante nessa discussão para dar encaminhamento à formalização dos conceitos de Análise Combinatória. 
Os problemas propostos ${ }^{27}$ foram entregues para os grupos:

1) Há quatro bolinhas de gude numeradas numa caixa; elas estão numeradas pelos números 2, 4, 7 e 9. Peguei uma das bolinha e anotei seu número. Depois, coloquei a bolinha de volta na caixa. Repeti esse processo até formar um número de três dígitos. Quantos números diferentes de três dígitos posso ter formado?

2) Tenho três letras idênticas que desejo colocar dentro de quatro envelopes de cores diferentes, azul, rosa, laranja e verde. Posso colocar apenas uma letra em cada envelope. De quantos modos as três letras idênticas podem ser colocadas dentro dos quatro envelopes diferentes?

3) Suzie e Sam têm quatro adesivos numerados de 1 a 4 . Eles decidiram repartir igualmente os adesivos, dois para cada um. De quantos modos eles podem dividir os quatro adesivos entre eles?

Os objetivos, ao resolver esses problemas, eram: trabalhar com o processo de contagem fazendo uso da metodologia adotada, visando à construção de conceitos e conteúdos relativos à Análise Combinatória; proporcionar aos participantes visualizar o processo de contagem e usar o Princípio Fundamental de Contagem (ou Princípio Multiplicativo); e trabalhar, durante a resolução dos problemas, com os conceitos de Combinação, Arranjo e Permutação e fazer a construção das respectivas fórmulas.

Os participantes, dez, reuniram-se em dois grupos. Deram início à resolução dos problemas. Foram discutidos os diferentes caminhos encontrados por eles. Um membro de cada grupo colocou na lousa os resultados de seu grupo. Nesse momento, os grupos compartilharam seus diferentes modos de resolver o mesmo problema.

\section{Solucões encontradas para o Problema 1:}

Um dos participantes, de início, disse que estava tentando lembrar-se das fórmulas, coisa que nem passava pela cabeça de professores de $1^{\mathrm{a}}$ a $4^{\mathrm{a}}$ séries.

\footnotetext{
${ }^{27}$ Retirados e traduzidos da Revista Mathematics Teacher vol.98, nº3. October2004.
} 
a) Alguns deles lançaram mão da árvore de possibilidades.

Consideraram para a casa das centenas as quatro possibilidades, 2, 4, 7 e 9; para a casa das dezenas, quatro possibilidades, 2, 4, 7 e 9 e, também para a casa das unidades quatro possibilidades, 2, 4, 7 e 9, desde que o problema exigia reposição das bolinhas retiradas.

Iniciando com o algarismo 2, foi representado o seguinte:

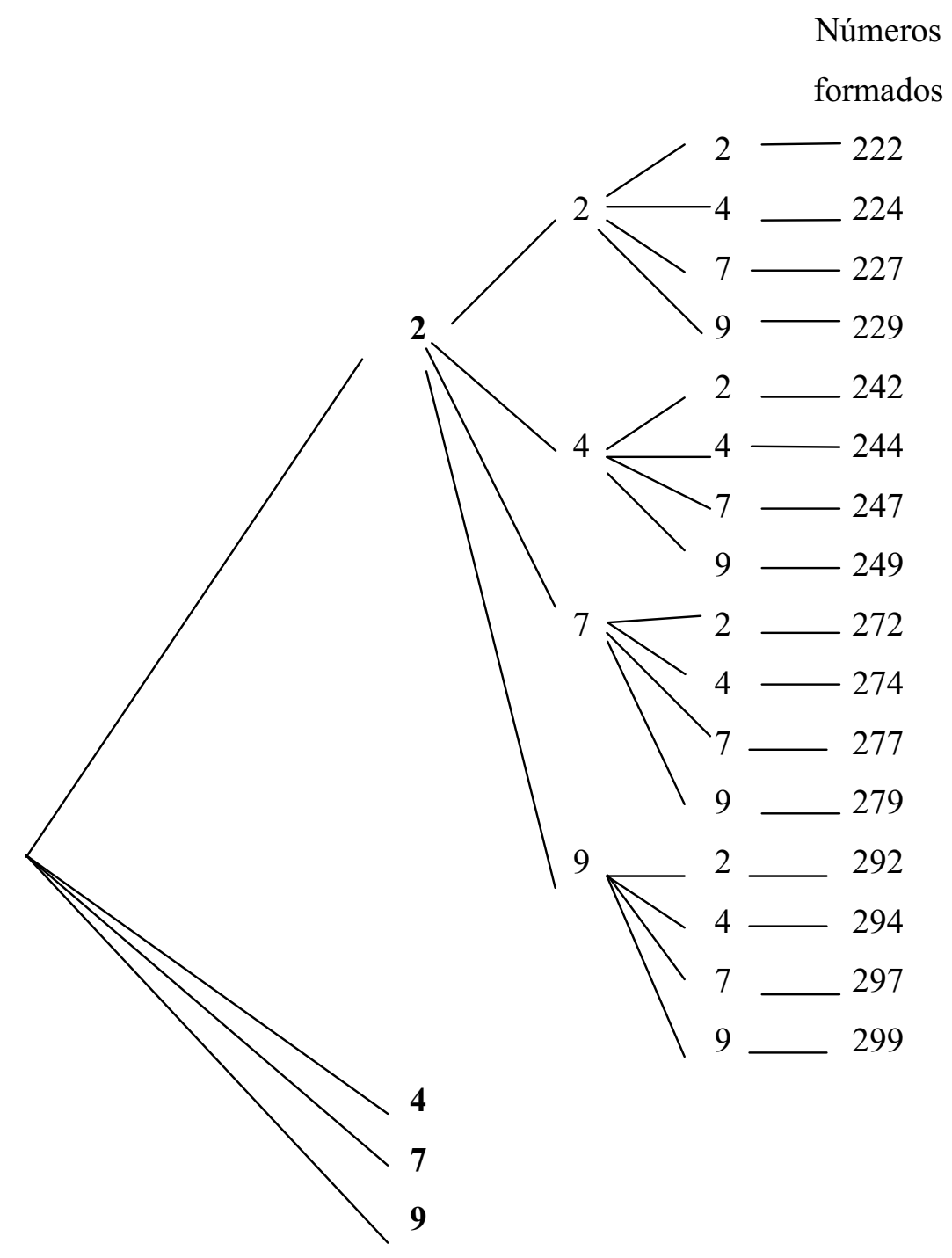

Obtiveram então 16 números iniciando com o algarismo 2. Analogamente, ao iniciar com os demais algarismos, 4, 7, e 9, tiveram esses mesmos ramos. Assim, houve 16 números diferentes ao iniciar com 2, com 4, com 7 e com 9. Ou seja, 4·16 =64 números diferentes de três algarismos. 
b) Outros grupos formaram os números de três dígitos fazendo uma lista organizada, iniciando com o 2, iniciando com o 4, e assim sucessivamente, com o 7 e com o 9. Iniciando com o 2, listaram dezesseis números de três dígitos.

$\begin{array}{llll}222 & 242 & 272 & 292 \\ 224 & 244 & 274 & 294 \\ 227 & 247 & 277 & 297 \\ 229 & 249 & 279 & 299\end{array}$

Analogamente, começando com o 4, também encontraram dezesseis números de três dígitos. Como no total, são quatro algarismos iniciantes, então, multiplicaram 16 por 4 , dizendo que eram 64 números diferentes de três dígitos. Algumas alunas que seguiram esse caminho, durante a plenária perceberam que haviam se esquecido de alguns números quando compararam com a solução de outros colegas. Sentiram necessidade de uma melhor organização para formar os números diferentes de três dígitos pedidos.

c) Alguns alunos, dentro de seu grupo, usaram o Princípio Multiplicativo (ou Princípio Fundamental de Contagem). Explicitaram: 4 possibilidades para o algarismo da centena, 4 possibilidades para o algarismo da dezena e 4 possibilidades para o algarismo da unidade. Usando o Princípio Multiplicativo, fizeram 4·4 4 = 64 e obtiveram 64 números diferentes de três dígitos.

Depois de colocadas na lousa as resoluções dos grupos, iniciou-se a Plenária. A professora instigou os participantes para que observassem e analisassem as resoluções obtidas por eles e os questionou: - Como todos os números são formados com os algarismos 2, 4,7 e 9, o que os diferenciam entre si?

Então iniciou-se uma discussão, através de alguns exemplos.

Ao analisar, por exemplo, os números 247 e 274, percebe-se que esses dois números são formados pelos mesmos algarismos (2, 4 e 7), e que, quando trocamos de posição os algarismos 4 e 7, do número 247, obtém-se um número diferente, 274. Então, considerar a ordem dos algarismos foi importante. Assim, os números 247 e 274 diferem pela ordem dos algarismos. Já, ao analisar os números 247 e 249, percebe-se que são diferentes por apresentarem pelo menos um algarismo diferente na sua formação. Nesse caso, não foi a ordem dos algarismos que os fizeram diferentes, mas a natureza de seus elementos. Ou seja, para obter todos os números de três algarismos, formados com os algarismos $2,4,7$ e 9 , foi 
importante observar se os números formados diferiam pela ordem dos elementos e/ou pela natureza dos elementos. A professora então mostrou a definição desse tipo de agrupamento, que recebe o nome de arranjo e como, neste problema, podemos repetir o mesmo algarismo para formar o número, então, tem-se o caso de arranjo com repetição.

Através do Princípio Multiplicativo, temos $4.4 .4=4^{3}=64$ agrupamentos, que é a quantidade de números de três dígitos que o problema pede, embora, nesse caminho, não se tivessem apresentado os diferentes números.

Conjecturando assim, poderiam imaginar que um Arranjo com repetição é dado pela fórmula $\mathrm{n}^{\mathrm{p}}$, sendo $\mathrm{n}$ : o número de elementos disponíveis e $\mathrm{p}$ : a quantidade de elementos solicitada para formar os agrupamentos. Notação: $A_{n, p}=n^{p}$.

Embora tenha sido facilmente aceita a fórmula $\mathrm{AR}_{\mathrm{n}, \mathrm{p}}=\mathrm{n}^{\mathrm{p}}$, em uma reflexão sobre a ação feita, pudemos perceber com que facilidade isso foi aceito.

É verdade que, numa oficina de trabalho, o tempo disponível para o trabalho é pequeno. Mas, pudemos sentir como teria sido importante chegar a essa fórmula, como apresentamos no planejamento deste projeto, e não somente ter feito uso dela.

\section{Solucões encontradas para o Problema 2:}

Na resolução do Problema 2, foi discutida bastante a importância de se considerar ou não as cores dos envelopes e também a questão do envelope vazio.

a) Professoras do "Primário":

As professoras, que trabalhavam de $1^{\underline{a}}$ a $4^{\underline{a}}$ séries, antigamente chamadas professoras do Primário, comentaram que poderiam utilizar material concreto, fazendo os envelopes coloridos e as três letras escritas em um pedaço de papel.
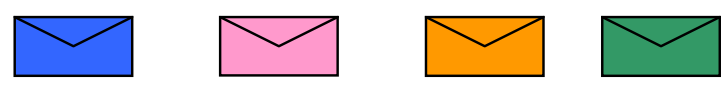

Consideraram que três envelopes já estivessem com uma letra. E foram, então, numa representação, organizando os trios:

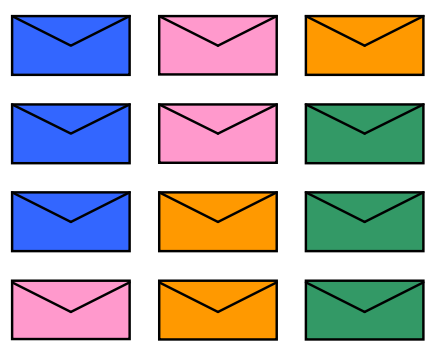


Encontraram então 4 modos de distribuir as três letras, já que tinham suposto que elas estavam nos envelopes. Comentaram também que o trio azul, rosa e laranja seria o mesmo que rosa, azul e laranja, ou seja, se mudassem a ordem dos envelopes haveria o mesmo trio (e as letras continuariam em cada envelope). Não pensaram no envelope vazio.

b) Um aluno da graduação resolveu do seguinte modo, fazendo esta representação:

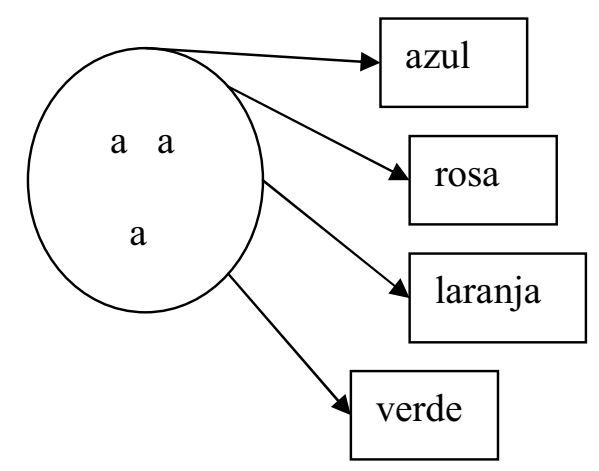

Esse aluno explicou o esquema feito dizendo que, como se tem três letras para serem distribuídas, representadas dentro do balão, nos quatro envelopes (azul, rosa, laranja e verde), apontando, indicava as flechas ao fazer a distribuição. Assim, disse que se tem quatro modos de distribuir as três letras idênticas nos quatro envelopes. Também deixou de falar na existência de um envelope vazio.

c) Outro aluno desenhou uma tabela e fixou a primeira linha com os envelopes na ordem, azul, rosa, laranja e verde, e foi distribuindo as letras, deixando consequentemente um envelope vazio. Encontrou quatro modos de distribuir as três letras idênticas. Esse aluno comentou que não haveria necessidade de considerar as cores dos envelopes, pois não alteraria o modo de distribuir as letras, mas desde que se fixe no início uma ordem para os envelopes dados. Segue o esquema apresentado por ele:

$\begin{array}{lcccc} & \text { azul } & \text { rosa } & \text { laranja } & \text { verde } \\ 1^{{ }^{\circ} \text { modo }} & \text { a } & \text { a } & \text { a } & \text { vazio } \\ 2^{\circ} \text { modo } & \text { a } & \text { a } & \text { vazio } & \text { a } \\ 3^{\circ} \text { modo } & \text { a } & \text { vazio } & \text { a } & \text { a } \\ 4^{\circ} \text { modo } & \text { vazio } & \text { a } & \text { a } & \text { a }\end{array}$


Na Plenária discutiu-se sobre a solução encontrada. Como, no problema anterior, foi pedido que os participantes observassem sobre a ordem e a natureza dos elementos envolvidos, a professora-pesquisadora, ao iniciar a discussão, pediu que se considerasse, por exemplo, o $1^{\underline{0}}$ modo de distribuição das letras feita por um dos alunos.

\begin{tabular}{|c|c|c|c|c|}
\cline { 2 - 5 } \multicolumn{1}{c|}{} & azul & rosa & laranja & verde \\
\hline $1^{\underline{0}}$ modo & $a$ & $a$ & $a$ & vazio \\
\hline
\end{tabular}

E questionou: - O que aconteceria se mudasse as letras de lugar, passando a letra do envelope azul para o envelope rosa e do rosa para o azul?

Os alunos prontamente responderam que não haveria mudança pois as letras são idênticas. E também, esses envelopes continuariam com uma letra, atendendo à restrição do problema.

A pesquisadora fez outra pergunta: - E se mudarmos agora a letra do envelope azul para o envelope verde?

Nesse caso, os alunos responderam que, como o envelope verde está vazio, então teríamos outro resultado, ou seja, outro modo de distribuir as três letras. Então, nesse caso, a ordem interfere no resultado.

A pesquisadora prosseguiu com a seguinte explicação. Tem-se então que ter preocupação com os modos de distribuição das três letras. Como já discutimos, no $1^{\underline{0}}$ modo acima, mudar as letras de lugar não altera o resultado e, então, haverá seis vezes o mesmo modo, pois as letras são idênticas (elementos repetidos). Logo, é necessário desconsiderar os modos repetidos. Mas, quando mudamos uma das letras para o envelope verde, aparece um outro modo de distribuição, um segundo modo, e assim sucessivamente até o quarto modo de distribuição. A ordem aqui altera o modo de distribuição. Temos, pois, quatro modos diferentes.

Considerando o esquema:

\begin{tabular}{|l|l|l|l|}
\hline azul & rosa & laranja & verde \\
\hline
\end{tabular}

Há 4 possibilidades para o envelope azul (três letras disponíveis ou ficar vazio), 3 possibilidades para o rosa (duas letras restantes ou o vazio), 2 possibilidades para o laranja (uma letra restante ou o vazio) e 1 possibilidade para o verde (vazio). Pelo Princípio 
Fundamental de Contagem, temos $4 \cdot 3 \cdot 2 \cdot 1=24$ modos de distribuição. Mas como temos elementos repetidos que resultam em seis vezes o mesmo modo (permutando as letras de um mesmo modo), então tem-se que dividir por 6 . E divide-se por um também, pois o envelope vazio aparece sempre trocando de lugar. Ficando: $\frac{24}{6 \cdot 1}$. Obtemos 24 fazendo $4 \cdot 3 \cdot 2 \cdot 1$, ou seja 4 !, e 6 , permutando as 3 letras, $3 \cdot 2 \cdot 1$, ou seja, 3 !. Tem-se então $\frac{4 !}{3 ! 1 !}$. Essa expressão representa o agrupamento definido como permutação com repetição.

Outra questão a considerar, a da diferença entre arranjo (arranjo com repetição) e permutação (permutação com repetição) é que, neste problema, estão sendo utilizados todos os elementos (envelopes) para determinar os modos de distribuição das letras, enquanto que, no primeiro problema, dos 4 elementos dados (algarismos 2, 4, 7 e 9), foram utilizados apenas três para obter os agrupamentos pretendidos (números de três algarismos). É verdade que, quando se trata de permutação, todos os elementos do conjunto devem ser utilizados para formar os agrupamentos, o que não acontece no caso de arranjo.

Nesse caso, indicando por:

n: número total de elementos

$\mathrm{n}_{1}$ : número de letras

$\mathrm{n}_{2}$ : vazio

Substituindo-se na expressão anterior, temos:

$$
\frac{4 !}{3 ! 1 !}=\frac{4 !}{3 !}=\frac{1 \cdot 2 \cdot 3 \cdot 4}{1 \cdot 2 \cdot 3}=4
$$

Então, pode-se conjecturar que $\frac{n !}{n_{1} ! \cdot \mathrm{n}_{2} !}$ seria a expressão geral para permutações com repetição.

Pode-se imaginar que se houvesse $n$ elementos a serem distribuídos, com repetição, em $k$ conjuntos diferentes, essa fórmula poderia se apresentar assim

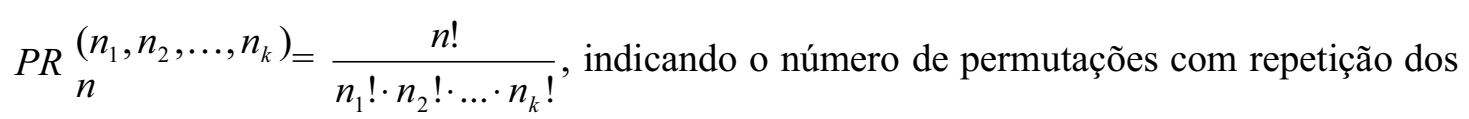
elementos envolvidos.

Mais uma vez, não houve tempo disponível para desenvolver essa fórmula. Mas a construção dessa fórmula está no planejamento deste projeto. 


\section{Soluç̃es encontradas para o Problema 3:}

a) Professoras do "Primário":

Disseram essas professoras que trabalhariam esse problema com material concreto, confeccionando os adesivos e dividindo-os com os alunos. Encontrando então seis modos de dividir esses adesivos, entre os dois colegas. Não houve registro escrito desse grupo.

b) Alguns alunos determinaram os possíveis pares de adesivos para distribuir entre Suzie e Sam, respectivamente: $1-2$ e $3-4,1-3$ e $2-4,1-4$ e $2-3$. Para encontrar os outros modos de dividir esses adesivos, bastava inverter a ordem dos pares entre Suzie e Sam. Resultando então em 6 modos de dividir os adesivos entre eles.

\begin{tabular}{|c|c|}
\hline Suzie & Sam \\
\hline $1-2$ & $3-4$ \\
\hline $1-3$ & $2-4$ \\
\hline $1-4$ & $2-3$ \\
\hline $3-4$ & $1-2$ \\
\hline $2-4$ & $1-3$ \\
\hline $2-3$ & $1-4$ \\
\hline
\end{tabular}

c) Aluno da graduação:

Tem-se quatro adesivos: 1, 2, 3 e 4. Das quatro possibilidades, retiro um adesivo, restando 3 possibilidades; retiro outro; restando duas possibilidades. No final, resta apenas uma possibilidade. Pelo Princípio Multiplicativo temos: $4 \cdot 3 \cdot 2 \cdot 1=24$ modos de repartir os adesivos. Como são dois adesivos para cada um, divido por 2, tendo então 12 modos. Mas como são duas pessoas, divido por 2 novamente, resultando 6 modos de repartir os adesivos, como se pode ver abaixo.

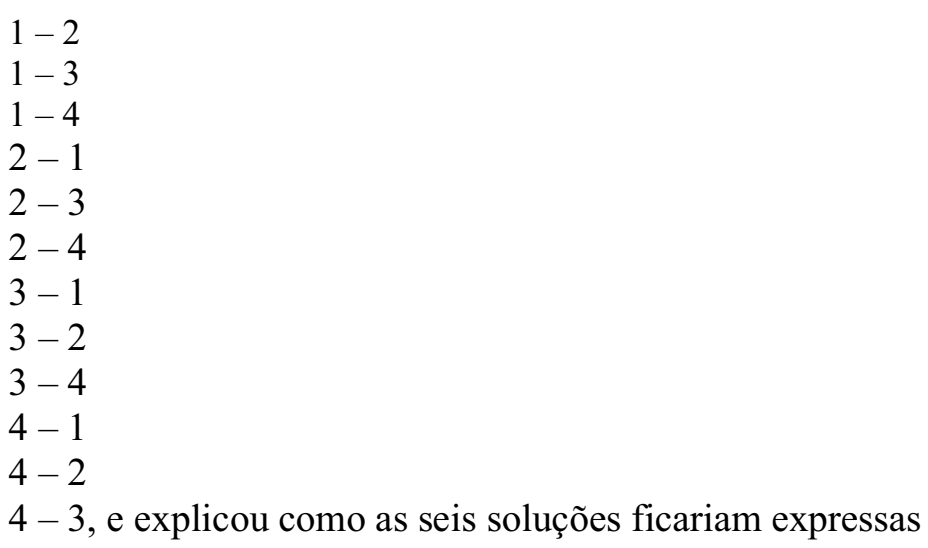




\begin{tabular}{|l|l|}
\hline $1-2$ & $3-4$ \\
\hline $1-3$ & $2-4$ \\
\hline $1-4$ & $2-3$ \\
\hline $3-4$ & $2-1$ \\
\hline $4-2$ & $1-3$ \\
\hline $2-3$ & $4-1$ \\
\hline
\end{tabular}

De quantos modos posso distribuir o adesivo 1 ? 6 modos. Idem para os adesivos 2, 3 e 4. Então teríamos 6 modos multiplicado por 4 (pois temos 4 adesivos), totalizando 24 modos de distribuição. Como são dois adesivos para cada um, dividimos por 2, resultando 12 modos. Como são duas pessoas, dividimos 12 por 2 , resultando 6 modos de dividir os adesivos entre Suzie e Sam. Observando a tabela, uma aluna visualizou os seis modos de distribuir cada adesivo, representando as diferentes situações.

\begin{tabular}{|c|c|c|c|c|c|}
\hline Suzie & Sam & & & & \\
\hline $1-2$ & $3-4$ & & & & \\
\hline $1-3$ & $2-4$ & & & & \\
\hline $1-4$ & $2-3$ & & & & \\
\hline $2-3$ & $1-4$ & & & & \\
\hline $2-4$ & $1-3$ & & & & \\
\hline $3-4$ & $1-2$ & & & & \\
\hline $2-1$ & $3-4$ & & & & \\
\hline $2-3$ & $1-4$ & & & & \\
\hline $2-4$ & $1-3$ & & & & \\
\hline $3-1$ & $2-4$ & & & & \\
\hline $3-2$ & $1-4$ & Suzie & Sam & & \\
\hline $3-4$ & $1-2$ & & & & \\
\hline $3-1$ & $2-4$ & $1-2$ & $3-4$ & & \\
\hline $3-2$ & $1-4$ & $1-3$ & $2-4$ & & \\
\hline $3-4$ & $1-2$ & $1-4$ & $2-3$ & & \\
\hline $4-1$ & $2-3$ & $2-1$ & $3-4$ & & \\
\hline $4-2$ & $1-3$ & $2-3$ & $1-4$ & Suzie & Sam \\
\hline $4-3$ & $1-2$ & $2-4$ & $1-3$ & & \\
\hline $4-1$ & $2-3$ & $3-1$ & $2-4$ & $1-2$ & $3-4$ \\
\hline $4-2$ & $1-3$ & $3-2$ & $1-4$ & $1-3$ & $2-4$ \\
\hline 4-3 & $1-2$ & $3-4$ & $1-2$ & $1-4$ & $2-3$ \\
\hline $1-2$ & $3-4$ & $4-1$ & $2-3$ & $2-3$ & $1-4$ \\
\hline $1-3$ & $2-4$ & 4-2 & $1-3$ & $2-4$ & $1-3$ \\
\hline $1-4$ & $2-3$ & $4-3$ & $1-2$ & $3-4$ & $1-2$ \\
\hline 24 & modos & \multicolumn{2}{|c|}{12 modos } & 6 & modos \\
\hline
\end{tabular}


A pesquisadora chamou a atenção quanto ao enunciado do problema: De quantos modos diferentes eles podem dividir os adesivos? Foi chamada a atenção quanto à ordem e à natureza dos elementos nesse problema.

Pede-se para determinar o número de modos que Suzie e Sam podem distribuir os adesivos. Os alunos perceberam que a ordem em que os adesivos são distribuídos não altera o resultado final, ou seja, os dois adesivos que Suzie e Sam receberam. Por exemplo, quando Suzie recebeu os adesivos 1 e 2, não importava se ela havia recebido o adesivo 1 primeiro ou o adesivo 2 primeiro, pois isso não mudaria os adesivos que ela tem em mãos, que continuam sendo os adesivos 1 e 2 . Mas, se fossem entregues os adesivos 1 e 2 para Suzie, restariam apenas os adesivos 3 e 4 para Sam. Esse modo de distribuição fica diferente se fossem entregues os adesivos 1 e 2 para Sam e o 3 e 4 para Suzie, alterando assim a natureza dos elementos recebidos pelos envolvidos no problema e, consequentemente, o modo de distribuição.Assim, a ordem em que os adesivos são distribuídos não altera o resultado, mas muda a natureza dos elementos envolvidos. Foi, então, definido que um agrupamento que se diferencia de outros apenas pela natureza de seus elementos é chamado combinação.

Insistindo, a professora-pesquisadora disse que, nesse problema, há 4 elementos (adesivos 1, 2, 3 e 4) e que pelo Princípio Multiplicativo, há 4.3.2.1 = 24 modos de distribuir esses adesivos. Como são dois adesivos para cada um, divide-se por 2, tendo, então, 12 desses modos. Mas, como são duas pessoas, divide-se novamente por 2, resultando 6 modos de distribuir os quatro adesivos entre Suzie e Sam.

Então, como chegar à fórmula de combinação simples?

Buscando um padrão na forma de trabalhar esse problema, levantou-se a seguinte expressão $\frac{\frac{24}{2}}{2}$ que pode ser escrita assim $\quad C_{4,2}=\frac{4 !}{2 !(4-2) !}=\frac{4 !}{2 ! 2 !}=\frac{1 \cdot 2 \cdot 3 \cdot 4}{1 \cdot 2 \cdot 1 \cdot 2}=\frac{12}{2}=6$.

Conjecturando, isto é, indo em busca de um padrão geral e considerando:

$n$ : número total de elementos

$p$ : número de adesivos para cada um: Suzie e Sam.

Poderíamos escrever $C_{n, p}=\frac{n !}{p !(\mathrm{n}-\mathrm{p}) !}$.

Como essa fórmula já era conhecida por alguns dos participantes, o assunto terminou aí, com a pesquisadora dizendo que há uma maneira de demonstrar a verdade dessa fórmula, como se pode ver no planejamento, na página 167. 
Já no final, um aluno questionou sobre o problema e perguntou: - E se houvesse adesivos repetidos? Como seria?

Esse seria um problema novo e não houve comentários sobre ele. Porém, apresentamos, no planejamento deste projeto, uma situação onde se tem elementos repetidos em um caso de combinação, bem como a construção da respectiva fórmula.

Algumas situações dessa oficina foram discutidas no GTERP, onde outros pesquisadores puderam, de acordo com seus pontos de vista sobre os problemas, relacionar o trabalho à metodologia adotada. Essa troca de experiências enriquece a formação e o desenvolvimento profissional do professor, e, também, da comunidade de pesquisa.

Vimos como o professor da sala de aula pode, através do desenvolvimento de prática reflexiva, engajar-se no processo de pesquisa. Ele toma consciência de que essa ação pode contribuir, não somente para o desenvolvimento de conhecimento de sua prática em sala de aula mas, também, para acumular o conhecimento recebido da comunidade de pesquisa. Além disso, o professor, ao escrever sobre os registros das aulas ministradas, pode oferecer aos colegas um meio possível de realizar suas próprias pesquisas. Enfim, se a educação matemática é um empreendimento profissional, então é essencial que aqueles professores engajados nessa prática, envolvidos numa série de trabalhos, possam contribuir para o crescimento do conhecimento profissional através da sua própria pesquisa praticante e a reflexão sobre ela.

Quando alguém reflete na ação torna-se um pesquisador no contexto da prática. Ele não depende das categorias de teorias e técnicas estabelecidas, mas constroi uma nova teoria sobre esse caso. Sua investigação não está limitada a uma deliberação sobre meios que depende de um acordo anterior sobre os fins. Ele não mantem os fins e os meios separados, mas os define interativamente enquanto estrutura uma situação problemática. Ele não separa o pensar do fazer, argumentando seu modo de fazer a uma decisão que precisa, mais tarde, converter em ação. Porque sua experimentação é um tipo de ação e a implementação é construir na sua investigação. (SCHÖN, 1983, p.68, apud HATCH; SHIU, 1998, p.298)

Ao refletir sobre a ação realizada nessa oficina, com um tempo programado para ser desempenhada, pudemos perceber que os três problemas apresentados foram resolvidos visando à construção dos conceitos de arranjo com repetição, permutação com repetição e combinação simples. 


\subsection{A aplicação do Projeto $3-P_{3}$}

Introdução

$\mathrm{O}$ Projeto $\mathbf{P}_{3}$ refere-se à postura da pesquisadora ao apresentar sua pesquisa em Congressos e Encontros de Educação Matemática. Este projeto tem como objetivo enviar, a Encontros de Educação Matemática, trabalhos científicos da pesquisadora para, frente à Comunidade Científica, serem analisados e discutidos o ensino e a aprendizagem de tópicos relativos à Análise Combinatória, fazendo uso da Metodologia de Ensino-AprendizagemAvaliação de Matemática através da resolução de problemas.

Como já foi dito, a Estratégia Geral selecionada para $\mathbf{P}_{\mathbf{3}}$ é a de Criar um Plano de Trabalho e, como Procedimento Geral correspondente, a Criação desse Plano de Trabalho. Esse plano refere-se à apresentação de comunicação científica em eventos relacionados à Educação Matemática. Desse modo, relataremos como se deu a participação da pesquisadora em dois desses eventos: I Congresso Nacional das Licenciaturas: Ciência, Ensino e Aprendizagem (2007) e XII EBRAPEM - XII Encontro Brasileiro de Estudantes de PósGraduação em Educação Matemática (2008).

Este projeto se distingue dos outros pelo fato de que a pesquisadora irá agora interagir com pesquisadores em Educação Matemática e não com alunos do Ensino Médio, como no Projeto 1, ou com professores e com alunos de graduação, como no Projeto 2. Isso mostra que, ao expor sua pesquisa, a pesquisadora será avaliada no meio acadêmico de modo a aprofundar seu trabalho com diferentes pontos de vista de outros pesquisadores e que possam contribuir para o prosseguimento da pesquisa. Outro fator que o diferencia dos outros é que, neste projeto, foi acrescentada, com maior profundidade, a Matemática Discreta e, como parte desse ramo matemático, a Análise Combinatória. Decidimos dar um maior destaque à Matemática Discreta e à Análise Combinatória em uma Comunidade Científica, pela falta de referência na bibliografia consultada por nós e também por considerar importante para buscar uma melhor compreensão dos conceitos abordados nesse tópico matemático. 


\section{Congresso Nacional das Licenciaturas: Ciência, Ensino e Aprendizagem}

Esse Congresso foi realizado na Universidade Presbiteriana Mackenzie, São Paulo-SP, no período de 24 a 28 de setembro de 2007. Como já foi dito no planejamento deste projeto, enviamos o trabalho intitulado Análise Combinatória no Ensino Médio Apoiada na Metodologia de Ensino-Aprendizagem-Avaliação de Matemática através da Resolução de Problemas. O trabalho foi aceito e sua comunicação científica seria realizada no dia 28 de setembro de 2007. O objetivo desse Congresso era o de divulgar a produção científica e acadêmica de pesquisadores (docentes e discentes) e estabelecer o diálogo entre pares, privilegiando uma reflexão científica e crítica sobre as licenciaturas e a reforma do pensamento, no que tange à questão sobre quem formará os educadores e de que forma.

Em cada apresentação, o participante teria 30 minutos, sendo de 15 a 20 minutos para expor o trabalho e o tempo restante para a discussão com a plateia.

A Comunicação foi realizada no dia 28 de setembro de 2007, às $10 \mathrm{~h} 30 \mathrm{~min}$, no Auditório João Calvino, com os coordenadores: Vera Lúcia A. Azevedo e Wagner Borges. Em seguida, outros três pesquisadores apresentaram seus trabalhos.

Apresentamos, aos participantes, usando o data show com o Powerpoint, treze slides constando a fundamentação teórica referente ao tema proposto e um problema resolvido visando ao uso da metodologia de ensino adotada.

No primeiro da apresentação, a pesquisadora mostrou um pouco da sua formação acadêmica e o que atualmente investiga na área de Educação Matemática. A seguir, apresentou, de forma resumida, a fundamentação teórica do tema proposto, ou seja, o ensino de Matemática através da resolução de problemas, a Matemática Discreta e a Análise Combinatória. Em relação à Resolução de Problema foram destacadas três concepções diferentes: teorizar sobre resolução de problemas, ensinar matemática para resolver problemas e ensinar matemática através da resolução de problemas, sendo esta última a concepção considerada em nossa pesquisa. Falamos então de nossa Metodologia, destacando quais são seus objetivos, qual é o papel do aluno e do professor e sobre a avaliação que, continuamente, deve estar integrada ao ensino para melhorar a aprendizagem. Também apresentamos, como sugestão, um roteiro para o trabalho em sala de aula ao adotar essa metodologia.

Quanto à Matemática Discreta que, segundo Dossey, é chamada "a Matemática de nosso tempo", um ramo da Matemática que cresceu rapidamente em importância na década de 80 do século passado. A Matemática Discreta envolve o estudo de objetos e de ideias que podem ser divididos em partes "separadas" ou "descontínuas". 
A Matemática Discreta cresceu muito das ciências matemáticas, pela necessidade de uma melhor compreensão das bases combinatórias da matemática usada no desenvolvimento de algoritmos computacionais eficientes; da criação de novas abordagens para problemas de pesquisa operacionais, e do estudo das heurísticas subjacentes às abordagens de tais problemas.

Para a Análise Combinatória, apresentamos a definição dada por Roxo et al (1944), os conceitos primitivos (não definidos): acontecimento, ocorrência e agrupamento apresentados por Bachx, Poppe e Tavares (1975), e os conceitos definidos: Princípio Fundamental de Contagem ou Princípio Multiplicativo; Princípio Aditivo; Arranjo, permutação e combinação, agrupamentos que diferem pela ordem e/ou natureza dos elementos envolvidos.

A fim de propor um trabalho em sala de aula, adotando a Metodologia de EnsinoAprendizagem-Avaliação de Matemática através da Resolução de Problemas, foi apresentado o problema abaixo, discutindo sua forma de resolução:

"Numa urna foram colocadas 5 bolas de cores diferentes: vermelha, preta, amarela, cinza e branca. De quantas maneiras distintas poderemos retirar 3 bolas da urna? ${ }^{28, "}$

A sugestão de resolução desse problema foi apresentada no planejamento deste projeto.

Após a apresentação da comunicação, o próprio coordenador da sessão fez alguns comentários. Disse que nos faltou falar, ao definir os conceitos de Análise Combinatória, sobre a ideia de sequência, que julgava ser importante quando se considera a ordem dos elementos envolvidos em um conjunto. Quanto à resolução do problema, o coordenador disse que poderia haver alguma confusão para o aluno que talvez não conseguisse considerar as três situações descritas: retirar as três bolas da urna com reposição, sem reposição ou simultaneamente. Sobre a Matemática Discreta, por nós abordada, não tivemos contribuições nem questionamentos da plateia. Percebe-se, então, um certo desconhecimento desse ramo matemático no meio acadêmico, mesmo que, recentemente, esteja sendo abordado em várias disciplinas.

No II Congresso Nacional de Licenciaturas: Ciência, Ensino, Aprendizagem na Formação de Professores, realizado no período de 28 de setembro a 01 de outubro de 2009 , foram lançados dois livros da Coleção Licenciaturas em Debate: Ciências, Ensino e Aprendizagem, com alguns trabalhos do I Congresso. Nosso trabalho foi publicado nessa

\footnotetext{
${ }^{28}$ Retirado da Proposta Curricular para o Ensino de Matemática $2^{\circ}$ grau (Matemática), (1992).
} 
Coleção, no volume 1, nas p.139 a 148, com o mesmo título do trabalho apresentado na comunicação.

\section{EBRAPEM - XII Encontro Brasileiro de Estudantes de Pós-Graduação em \\ Educação Matemática - Educação Matemática: possibilidades de interlocução}

Como já foi dito no planejamento deste projeto, esse encontro foi realizado na UNESP, campus de Rio Claro-SP, no período de 05 a 07 de setembro de 2008. Seu objetivo principal era o do debate científico sobre processos teórico-metodológicos de pesquisas ainda em construção, em um ambiente que privilegia a interlocução entre linhas de pesquisa em Educação Matemática e outras áreas de conhecimento.

A apresentação da Comunicação científica intitulada Análise Combinatória apoiada na metodologia de ensino-aprendizagem-avaliação de matemática através da resolução de problemas, enviada por nós, foi realizada no dia 06 de setembro no período da tarde, na sala 21-C, como mostra o quadro, tirado do site do evento, abaixo:

\begin{tabular}{|c|c|c|c|c|}
\hline $\begin{array}{l}21 / \\
\text { Sala } \\
21-C\end{array}$ & $\begin{array}{l}\text { 06/09/2008/ } \\
14: 00 \text { às } 16: 00\end{array}$ & $\begin{array}{l}\text { Rosa } \\
\text { Monteiro } \\
\text { Paulo }\end{array}$ & José Felice & $\begin{array}{l}\text { Uma Organização Didática para Ensinar } \\
\underline{\text { Conteúdos Matemáticos por meio de }} \\
\text { Situações Problematizadoras }\end{array}$ \\
\hline $\begin{array}{l}21 / \\
\text { Sala } \\
21-\mathrm{C}\end{array}$ & $\begin{array}{l}06 / 09 / 2008 / \\
14: 00 \text { às } 16: 00\end{array}$ & $\begin{array}{l}\text { Rosa } \\
\text { Monteiro } \\
\text { Paulo }\end{array}$ & $\begin{array}{l}\text { JULIANA DE LIMA } \\
\text { GREGORUTTI }\end{array}$ & $\begin{array}{l}\text { Critérios de divisibilidade: estudo por meio } \\
\text { de uma seqüência didática. }\end{array}$ \\
\hline
\end{tabular}

\begin{tabular}{|c|c|c|c|c|}
\hline $\begin{array}{l}21 / \\
\text { Sala } \\
21-C\end{array}$ & $\begin{array}{l}06 / 09 / 2008 / \\
14: 00 \text { às } 16: 00\end{array}$ & $\begin{array}{l}\text { Rosa } \\
\text { Monteiro } \\
\text { Paulo }\end{array}$ & $\begin{array}{l}\text { Analucia Castro } \\
\text { Pimenta de } \\
\text { Souza }\end{array}$ & $\begin{array}{l}\text { Análise combinatória apoiada na } \\
\text { metodologia de ensino-aprendizagem- } \\
\text { avaliação de matemática através da } \\
\text { resolução de problemas }\end{array}$ \\
\hline $\begin{array}{l}21 / \\
\text { Sala } \\
21-C\end{array}$ & $\begin{array}{l}\text { 06/09/2008 / } \\
\text { 14:00 às 16:00 }\end{array}$ & $\begin{array}{l}\text { Rosa } \\
\text { Monteiro } \\
\text { Paulo }\end{array}$ & $\begin{array}{l}\text { Bruno Tadeu } \\
\text { Garcia }\end{array}$ & $\begin{array}{l}\text { A Implementação da Edição Especial do } \\
\text { Programa São Paulo Faz Escola com Vistas à } \\
\text { Resolução de Problemas e aos Níveis de } \\
\text { Conhecimento Esperados. }\end{array}$ \\
\hline
\end{tabular}

Como podemos observar no quadro, havia outros três participantes para apresentar suas pesquisas. $\mathrm{O}$ nome da coordenadora da sessão de comunicação das pesquisas consta na terceira coluna, que já havia coordenado uma sessão, no período da manhã, com sete trabalhos.

Participamos do Grupo 08 cujo tema era Investigação em Sala de Aula e Formulação de Problemas e, na dinâmica, cada autor teve 25 minutos para discutir sobre seu trabalho, 
sendo que os 5 minutos iniciais seriam utilizados para a exposição do trabalho e o tempo restante para discussão. Os comentadores do debate eram o coordenador da sessão e os demais autores de trabalho. Ao final de todos os momentos de discussão de cada sessão, o debate foi aberto ao público.

Foram utilizados cinco minutos para a apresentação. E, como o tempo disponível para a exposição do trabalho era curto, selecionamos apresentar a estrutura do trabalho seguindo as dez atividades da Metodologia de Pesquisa, apresentadas por Thomas A. Romberg, que delineia o desenvolvimento da pesquisa. Essas dez atividades estão divididas em três blocos: o $1^{\underline{o}}$ bloco (atividades 1, 2, 3 e 4), tem por objetivo identificar o Problema da Pesquisa; o $2^{\text {o }}$ bloco (atividades 5 e 6), apresenta estratégias e procedimentos destinados à busca da resolução do problema levantado; e no $3^{\circ}$ bloco (atividades 7, 8, 9 e 10), busca-se evidências nas informações obtidas na aplicação do Procedimento Geral, levando à resposta do problema da pesquisa. Nessa comunicação não fizemos referência ao $3^{\circ}$ bloco de Romberg, que foi trabalhado somente após a qualificação do professor-pesquisador, o que ocorreu no ano seguinte desse evento.

Apresentamos então o foco de nossa pesquisa, trabalhar com uma metodologia alternativa para o ensino de Análise Combinatória em sala de aula do Ensino Médio, a Metodologia de Ensino-Aprendizagem-Avaliação de Matemática através da Resolução de Problemas. Falamos da dificuldade em encontrar na bibliografia existente o conteúdo Análise Combinatória. Os autores consultados, sempre se referem a esse assunto como um conteúdo difícil de ser abordado na sala de aula devido, por exemplo, ao fato de ser trabalhado geralmente através de "fórmula-aplicação", não contribuindo para uma aprendizagem com compreensão. Assim, discorremos sobre a importância de se trabalhar com uma metodologia que pudesse levar os alunos à construção dos conceitos envolvidos em Análise Combinatória.

Outro assunto, citado por nós, foi a Matemática Discreta, ramo matemático do qual a Análise Combinatória faz parte. Relatamos que foi um referencial novo para nossa pesquisa e que, também, não é muito encontrado facilmente na bibliografia nacional. A importância da Matemática Discreta se revela ao perceber que se trata de um trabalho que fez uso do conjunto dos números naturais e que o seu cerne está no processo de contagem dos agrupamentos formados. Quando este encontro aconteceu ainda não tínhamos nos aprofundado muito sobre Matemática Discreta e consideramos importante falar sobre ela de modo a poder enriquecer nossa pesquisa ao apresentá-la, já que há pouca referência a ela em nossos meios acadêmicos. 
Falamos resumidamente como se dá o trabalho em sala de aula usando a metodologia adotada por nós, seguindo o roteiro apresentado por Onuchic (1999). Iniciando a aula com um problema, que seria o gerador do processo de ensino-aprendizagem de Matemática. O papel do professor é o de observador, organizador, incentivador, consultor e mediador da aprendizagem. É realizada uma Plenária, momento de discussão das resoluções do problema feitas pelos alunos, trabalhando em grupos. E, por fim, a formalização da construção de novos conceitos e novos conteúdos é feita exclusivamente pelo professor, mostrando para os alunos as notações e a terminologia adequadas, as definições e suas propriedades e as demonstrações necessárias.

Após nossa apresentação, iniciou-se a discussão do trabalho.

Foram levantados questionamentos relacionados à construção dos conceitos de Análise Combinatória e do uso das fórmulas. A pesquisadora os respondeu dizendo que a metodologia de ensino adotada para o trabalho em sala de aula visa à construção dos novos conceitos, com os alunos como coconstrutores, enquanto se resolvem os problemas. Deixa-se claro que é o problema o gerador do processo de ensino-aprendizagem e que a compreensão dos conceitos construídos se dá enquanto o aluno resolve o problema. Quanto às questões levantadas sobre o uso das fórmulas, a pesquisadora respondeu que, a partir da compreensão dos conceitos é que se cuidará da construção das fórmulas correspondentes e que, para isso, os alunos deveriam ter percebido o padrão envolvido nos diferentes agrupamentos formados. Desse modo, seria feita então a construção das fórmulas para o cálculo do número de arranjos, de permutações e de combinações simples e com repetição.

Um dos participantes, comentando sobre a metodologia de ensino adotada, disse que sentia a importância de se trabalhar através da resolução do problema, uma vez que o aluno aprende Matemática enquanto resolve o problema. Nesse momento, a pesquisadora comentou sobre sua experiência com alunos durante a aplicação do projeto.

A coordenadora considerou importante falar-se sobre a Matemática Discreta, pois é algo novo na bibliografia existente sobre esse tema. Questionou sobre a avaliação, se iríamos considerá-la no trabalho. A pesquisadora respondeu que é elaborado, antes do início do trabalho em sala de aula, um termo de compromisso professor-alunos. Nele constam os critérios de avaliação dos alunos no que se refere ao desenvolvimento do trabalho. Também, a pesquisadora disse da importância de uma avaliação contínua, que ocorre durante todas as atividades da aula.

Depois de terminada essa discussão, a coordenadora entregou sua cópia do trabalho para a pesquisadora, onde nela constavam alguns comentários feitos por ela: 
1) O interesse na pesquisa é o de trabalhar com a Análise Combinatória em sala de aula do Ensino Médio a partir da metodologia de ensino-aprendizagem-avaliação de Matemática através da Resolução de Problemas.

2) Os passos (etapas) da pesquisa estão bem definidos e apresentados.

3) A ideia de Matemática Discreta, trazida no texto, será objeto de discussão no trabalho? Pretende-se exemplificar os modos de o professor lidar com ela na Educação Básica, por exemplo?

4) Na página 15 é feita a seguinte afirmação "a resolução de problemas, como metodologia, favorece a investigação matemática". Comentar.

5) Comente a Avaliação vista nessa metodologia.

6) Comente o modo de como pretende-se coletar os dados do trabalho de campo e analisá-los.

7) Os trabalhos de Celi Lopes Espasandim (especialmente sobre análise combinatória) são de interesse da pesquisadora? Há, no site da UNICAMP, CENPEC, alguns artigos disponíveis.

Questão para reflexão: como a metodologia da resolução de problemas, aliada à postura investigativa, pode auxiliar na construção do conhecimento matemático?

Como já havia terminado o tempo para a discussão, então as respostas para essas questões e as sugestões feitas pela coordenadora ficaram para a reflexão da pesquisadora ao dar continuidade à sua pesquisa. 


\section{CAPÍTULO 5 - Resultados e Reflexões}

(3ํㅡㅁoco de Romberg)

5.1 - Coletar, Interpretar e Relatar as evidências coletadas diante do Problema da Pesquisa

5.1.1 - Projeto 1

5.1.2 - Projeto 2

5.1.3 - Entrevista

5.1.4 - Projeto 3

5.2 - Antecipar as Ações de Outros

5.2.1 - Reflexões e posições da professora-pesquisadora pós-pesquisa 


\section{CAPÍTULO 5 - Reflexões e Resultados - (3ํㅡㅁoco de Romberg)}

\section{Introdução}

Dando sentido às evidências coletadas na aplicação do Procedimento Geral, buscamos selecioná-las e relacioná-las ao Problema da Pesquisa, relatando os resultados e antecipando ações de outros.

No terceiro e último bloco do fluxograma de Romberg - Dar sentido às evidências coletadas e relatar os resultados para outros -, são apresentadas as atividades 7, 8, 9 e 10. Nesse bloco, fazemos uma análise das informações obtidas após o Procedimento Geral ser posto em ação, ou seja, na aplicação dos projetos $\mathbf{P}_{1}, \mathbf{P}_{2}$ e $\mathbf{P}_{3}$, buscando tudo o que fícou evidente diante das questões levantadas. Refletindo sobre as ações feitas durante a aplicação, relataremos os resultados obtidos. Por fim, serão apresentadas as conclusões e sugestões a fim de antecipar as ações de outros pesquisadores.

\subsection{Coletar, Interpretar e Relatar as evidências coletadas diante do Problema da}

\section{Pesquisa}

Os projetos, como descritos no capítulo anterior, foram aplicados em diferentes cenários: sala de aula; oficina de trabalho em um Congresso; e apresentação de pesquisa em um encontro com pesquisadores. Objetivamos mostrar, nesta análise, o que há em comum aos três projetos: a importância do tema da pesquisa - Análise Combinatória contida na Matemática Discreta; a importância da Metodologia de Ensino-Aprendizagem-Avaliação de 
Matemática através da Resolução de Problemas; o envolvimento, cada um a seu modo, dos participantes de cada projeto; e a importância da pesquisadora no desenvolvimento de cada projeto e sua reflexão na ação e sobre a ação realizada.

Para essas atividades foram selecionados e colocados em ação diferentes procedimentos. Alguns foram selecionados para o ato da coleta de dados: observações diretas; diário de campo; Entrevista com um professor; e os trabalhos dos alunos entregues, por escrito, no final de cada aula. As anotações que fiz no diário de campo, juntamente com a observação direta dos acontecimentos, fizeram-se necessárias para se ter um número consistente de dados sobre o desenvolvimento das aplicações dos projetos.

\subsubsection{Projeto 1}

No $\mathbf{P}_{\mathbf{1}}$ foram utilizados todos os procedimentos, exceto a Entrevista com um professor.

Durante a aplicação do $\mathrm{P}_{1}$, solicitamos, a cada grupo, que entregasse, por escrito, a resolução dos problemas propostos em todas as aulas. Essas resoluções se mostraram como um documento importante para nos ajudar na análise do desempenho dos alunos. Consideramos importante, também, levar em conta a produção escrita, como elemento de comunicação por meio da linguagem vernácula ligada à linguagem matemática, pois os alunos, em geral, tentam explicitar seu modo de raciocinar durante o processo da resolução do problema, procurando indicar as possíveis estratégias assumidas para sua resolução.

Apesar de termos um tempo disponível curto para a aplicação do projeto pretendido, percebemos que houve condições de crescimento na aprendizagem dos alunos, no que se refere às ideias centrais dos conceitos da Análise Combinatória. A maioria dos alunos, em seus grupos, conseguiu representar, de diferentes formas, usando diferentes estratégias para expressar a resolução dos problemas, chegando a encontrar sua solução correta. A bem da verdade, houve exceção, pois alguns alunos em seus grupos apenas o resolveram parcialmente ou até cometeram erros na escolha da estratégia ou na busca da solução. Desse modo, podemos dizer que atingimos alguns dos objetivos específicos de nossa pesquisa, que são o de verificar a necessidade de um trabalho de investigação, sem depender da apresentação de fórmulas previamente dadas; e construir, professora e alunos juntos, conceitos de Análise Combinatória através da resolução de problemas. Consideramos importante para a construção dos conceitos pretendidos: arranjo, combinação e permutação, a organização da 
resolução dos problemas por meio de tabelas, da árvore de possibilidades e de listas organizadas.

A construção das fórmulas não pôde ser trabalhada, mas, mesmo sem o uso delas, foi possível que os alunos chegassem ao resultado esperado. Esse fato foi importante para mostrar o desenvolvimento do raciocínio combinatório, explorando o processo de contagem e o conceito de padrão, sendo estas as grandes ideias da Análise Combinatória. Mas, mesmo assim, um passo posterior e importante, que não podemos descartar, é o do rigor matemático, ou seja, mostrar a validação das conjecturas levantadas durante a resolução dos problemas. Desse modo, apesar de não ter sido dado esse passo, durante a aplicação do projeto, não podemos considerar irrelevante a construção das fórmulas correspondentes aos conceitos trabalhados, para o cálculo do número de arranjos, combinações e permutações, pois, por meio dela, os alunos teriam uma melhor formalização desses conceitos. Se houvesse mais tempo para a aplicação de nosso projeto, acreditamos que, então, poderia ser feita uma extensão dos problemas propostos e partir para o trabalho da construção das fórmulas.

Para mim, professora-pesquisadora, foi um desafio lidar com o tempo escasso para desenvolver o projeto construído e, também, com a insegurança de trabalhar conceitos que não haviam sido devidamente compreendidos, durante minha formação escolar, em que o trabalho fora feito apenas a partir de fórmulas. Além disso, fazer uso de uma metodologia de trabalho alternativa, bem diferente da tradicional, pela primeira vez, visando a provocar interesse, motivação e, consequentemente, crescimento no conhecimento dos alunos, mostrouse positivo. Houve momentos em que meus papéis de professora e de pesquisadora se misturavam. Como professora, consegui desenvolver as grandes ideias envolvidas na Análise Combinatória, mas como pesquisadora, senti que poderia ter sido feito mais, a partir da resolução de mais problemas, e com a análise das estratégias selecionadas pelos alunos, e da minha nova postura no trabalho com os alunos. Como professora, se eu tivesse tido mais tempo para desenvolver o projeto, poderia, de fato, ter avançado mais? Como pesquisadora, eu poderia considerar que o tempo é um fator que pode influenciar no andamento da aplicação de um projeto, mas outros fatores também interferem no rendimento dos alunos, como o insuficiente conhecimento prévio dos alunos, o número excessivo de alunos em sala de aula, e, em particular, no nosso caso e naquele ano, o fato de Análise Combinatória não ter feito parte do conteúdo programático da escola. Uma outra limitação para o desenvolvimento completo do projeto decorreu de uma norma estabelecida pela direção de que os alunos de curso noturno pudessem chegar com atraso para a primeira aula. 
Essa reflexão sobre a ação que realizei e aqui descrevi pode permitir ao professor desenvolver sua formação profissional, em que a reflexão sobre sua prática o conduz, após ação feita na sala de aula, a uma flexibilidade de modificar o trabalho pretendido com seus alunos.

Retomando os teóricos consultados por nós, realçamos o que Perez (2004) afirmou sobre a formação docente:

Cabe aqui lembrar que, segundo Ponte, muitos professores continuam achando que o seu papel é o de receber formação, não se assumindo ainda como os protagonistas que deveriam ser nesse processo. A formação 'formal' continua a ser um suporte fundamental do desenvolvimento profissional. Investigar sobre sua própria prática de formação é uma condição para o progresso profissional. É, também, a única forma de ser coerente no seu discurso e na sua ação. (p.251)

E, como fruto de nossa vivência, destacamos que o papel do professor no processo de ensino-aprendizagem é de fundamental importância para promover nos alunos uma aprendizagem significativa. Esse fato envolve a postura do professor diante de suas ações no trabalho em sala de aula, relacionando-o à sua própria formação e às transformações que os alunos sofrem por estarem envolvidos na sociedade. Suas crenças, suas experiências com os alunos, uma possível articulação entre a escola e a universidade (pesquisa), entre a escola e a sociedade, são questões que podem influenciar bastante a formação do professor.

Durante o trabalho realizado em sala de aula, o professor tem a oportunidade de vivenciar momentos que merecem atenção, pois lhe possibilitam fazer uma autoavaliação de sua prática, refletir sobre questões relacionadas ao ensino, ao currículo, à aprendizagem dos alunos e às metodologias subjacentes à sua prática. Desse modo, a reflexão do professor deve contribuir para seu sucesso profissional.

\subsubsection{Projeto 2}

Para este projeto foram selecionados os seguintes procedimentos: observações diretas e anotações feitas por mim durante a oficina. Sua aplicação foi realizada no ano posterior ao trabalho feito com os alunos. A minha experiência como pesquisadora, ao trabalhar com alunos do Ensino Médio, foi importante e levada em consideração para o planejamento e a execução deste projeto. Em $\mathrm{P}_{1}$, desempenhei meu papel como professora da turma e fui responsável pelo aprendizado dos alunos de conceitos da Análise Combinatória. O fato de eu 
poder viver junto com os alunos essa construção fez com que eu pudesse sentir os resultados e refletir sobre eles durante sua aplicação.

Neste Projeto 2, minha postura de pesquisadora foi outra. Agora, como professorapesquisadora, que já havia vivido a sala de aula, já me ambientara com a nova metodologia, teria como participantes dessa oficina professores de Matemática já formados e em pleno exercício. Alguns eram alunos concluintes do curso de Licenciatura em Matemática. Assim, a minha expectativa de pesquisadora era diferente daquela que havia tido quando trabalhara diretamente com alunos. Desta vez, iria lidar com professores que, supostamente, em seus cursos, já haviam estudado Análise Combinatória e, como procuraram nossa oficina, pareciam estar interessados sobre esse tema.

No início da oficina, falei sobre Matemática Discreta e, como parte importante desse novo ramo da Matemática, ofereci aos participantes, numa breve exposição, fundamentos da Análise Combinatória.

Assim, nosso objetivo principal em $\mathrm{P}_{2}$ era o de oferecer uma metodologia de ensino alternativa, a Metodologia de Ensino-Aprendizagem-Avaliação de Matemática através da Resolução de Problemas, trabalhando conceitos e conteúdos da Análise Combinatória. Foi importante vivenciar a reação desses participantes, ao trabalharem com resolução de problemas fazendo uso dessa nova metodologia.

O envolvimento de todos participantes foi muito enriquecedor. Todos se envolveram na resolução dos problemas que lhes propus. O número de participantes foi vantajoso para a realização deste projeto. Eram apenas 10, o que possibilitou um melhor aproveitamento do tempo destinado para a oficina, 4 horas, e foi possível ouvi-los, com atenção, durante a Plenária.

Outro fator que contribuiu para as discussões sobre as resoluções dos problemas foi a diversidade da formação dos participantes que pôde nos proporcionar um trabalho cooperativo e colaborativo.

Ao trabalhar com professores, como era de se esperar, uma certa resistência a mudanças surgiria, principalmente para aqueles que já, há algum tempo, estavam em exercício. Durante a oficina, pudemos perceber que alguns professores tinham a ansiedade de encontrar logo a solução do problema proposto e que não havia neles muita preocupação em discutir o processo de resolução. Identificamos, nos participantes, essa postura, comumente enraizada no modo tradicional de agir na sala de aula. Diante desse fato, eu buscava levar os participantes da oficina, que viam o ensino, a aprendizagem e a avaliação naquele modelo em que estavam acostumados a trabalhar, a um novo modo de atuar em sala de aula, fazendo uso 
da metodologia de ensino adotada por mim. Dialogando com os participantes, eu conduzia o trabalho para que fosse atingido o objetivo pretendido na oficina.

Apesar dessa intenção, pôde-se perceber que um aluno da graduação resistia à nova metodologia apresentada, buscando se lembrar das fórmulas existentes para a Análise Combinatória. Inicialmente, não se interessou em entender, de fato, o modo como os integrantes do seu grupo estavam procurando resolver os problemas. Posteriormente, juntando-se ao grupo, começou a perceber que havia um caminho diferente de se trabalhar esse tópico.

No final da oficina, alguns professores mostraram-se interessados em saber mais sobre a Matemática Discreta. Mostrei-lhes o livro Discrete Mathematics across the Curriculum, $\mathrm{K}$ 12, de Kenney, M.J. e Hirsch, C.R., Yearbook (1991), NCTM, que havia levado. Eles desanimaram um pouco, justificando-se que infelizmente esse livro é escrito em inglês e que tinham dificuldade nessa língua.

Como ocorreu com o Projeto 1, não nos foi possível chegar à demonstração das fórmulas correspondentes aos conceitos da Análise Combinatória. Entretanto, durante a Plenária, foram levantadas as conjecturas para o cálculo do número de arranjos, de combinações e de permutações, mas não as demonstramos. Falei da importância de validar as conjecturas por meio de demonstrações. Disse também da dificuldade que tivera com meus alunos do Ensino Médio ao abordar os conceitos em Análise Combinatória e que, também, devido ao pouco tempo disponível para o projeto, não havia sido possível chegar às fórmulas. No papel de pesquisadora, vemos que, como já dissemos no planejamento dos projetos, não é tão simples para o professor demonstrá-las, pois algumas exigem certa engenhosidade e até artifícios que não são tão corriqueiros no cotidiano do professor.

O objetivo proposto na oficina foi atingido, pois os participantes, de fato, vivenciaram a dinâmica da metodologia oferecida. Um fato auspicioso foi o de, partindo dos participantes, conhecer outras estratégias que conduziram à resolução dos problemas propostos, não previstas por mim, como, por exemplo, fazendo uso de material concreto, apresentado por duas professoras atuantes na 4⿳⺈冂䒑 série do Ensino Fundamental.

Ao refletir sobre a ação feita nessa oficina, senti que deveria ter solicitado aos participantes que entregassem suas resoluções, pois por meio desse material, os dados obtidos se mostrariam mais completos para análise. Considerar apenas as anotações e observações que fiz pode não ser suficiente para uma análise mais detalhada e completa. 


\subsubsection{Entrevista}

Foi elaborado um questionário exploratório, para entrevistar um professor de matemática, atuante no Ensino Médio, efetivo na rede pública de ensino do Estado de São Paulo, com o propósito de coletar outras informações que, posteriormente, poderiam contribuir com a análise feita nos projetos, possibilitando a articulação entre os pressupostos teóricos do estudo. Para efeito de nossa pesquisa, consideramos importante conhecer outro ponto de vista, o de um entrevistado que não conhecesse a metodologia adotada, que não tivesse participado da aplicação dos Projetos 1 e 2 e que estivesse atuante na $2^{-a}$ série do Ensino Médio, na qual a Análise Combinatória é trabalhada.

Os objetivos dessa Entrevista eram o de evidenciar a importância do ensino de Análise Combinatória; o de descrever como esse conteúdo é trabalhado pelo professor e poder identificar as principais dificuldades que professor e alunos enfrentam ao trabalhar esse tópico matemático. A Entrevista feita foi do tipo semiestruturada, ou seja, com algumas perguntaschave que guiariam a Entrevista, mas que permitiriam o surgimento de outros questionamentos, à medida que se recebem as respostas do entrevistado. Assim, uma entrevista desse tipo garante uma maior flexibilidade para o entrevistador e o entrevistado. A Entrevista foi gravada e realizada no mês de setembro de 2008 e durou cerca de 25 minutos.

\section{1) Você já ouviu falar sobre Matemática Discreta? Não.}

2) Você conhece a Proposta Curricular para o ensino de Matemática (Estado de São Paulo) de 1986? Acredita que ela pode contribuir para melhorar sua prática de ensino em Análise Combinatória?

Não a conheço.

3) Você conhece a Proposta Curricular vigente (2008)? Acredita que ela pode contribuir para melhorar sua prática de ensino em Análise Combinatória?

Esta eu conheço porque eu trabalhei com ela melhor em sala de aula. Eu acredito que ela pode contribuir uma vez que ela deu uma modernizada no ensino de Análise Combinatória, colocou uma nova roupagem, vamos dizer assim na de Análise Combinatória, apesar de que em alguns aspectos eu achei que ficou um pouco obscuro. Eles quiseram generalizar muito e acabou ficando meio embaraçoso para o aluno entender.

4) Em que sentido ficou obscuro, como você falou? 
Por exemplo, algumas fórmulas são omitidas nessa proposta e eles tentam levar mais para o lado teórico. Acho que isso é complicado para o aluno entender, porque precisa estar dando alguns exemplos, usando outras propostas, etc, para clarear mais a mente do aluno.

5) Como você inicia o tópico Análise Combinatória em sua sala de aula? Independente da proposta ou não, como você fazia antes?

Sempre com exercícios bem práticos. Eu costumo, por exemplo, trabalhar aqueles exercícios que falam sobre placas de automóveis, de números aleatórios de celulares, por exemplo, ou de telefone fixo, para aguçar, para inflamar a curiosidade dos alunos. Dessa forma, prender a atenção deles.

6) Você trabalha com o Princípio Multiplicativo de início ou já utiliza as fórmulas para trabalhar a Análise Combinatória?

Primeiramente, eu começo utilizando o diagrama de árvores, depois que eu vejo que os alunos entenderam bem como funciona a idéia central, então eu passo para o Princípio Multiplicativo juntamente com o diagrama de árvores. Eu já coloco lá embaixo. Quando eu faço o diagrama de árvores, eu coloco aquelas quantidades para que o aluno vá entendendo e relacionando as duas coisas. As fórmulas eu deixo para trabalhar mais adiante, mas eu trabalho todas elas.

7) Quais as principais dificuldades que você encontra para trabalhar esse tópico?

Na questão das repetições onde a ordem importa e a ordem não importa eu acho que aí começa a haver um pouco de confusão entre os alunos. Quando que a ordem importa, quando não importa. Nesse momento eu acho que é um meio confuso e, também, se você pensar a fórmula do arranjo é muito semelhante com a fórmula da permutação. Acho que o aluno fica um pouco confuso. Nesse momento é importante você fazer vários exercícios, muitos exercícios para que eles consigam distinguir uma coisa da outra.

\section{8) Quais as dificuldades dos alunos ao estudar Análise Combinatória?}

As dificuldades no geral, você pergunta assim?

Sim, as dificuldades no geral, as que eles têm ao trabalhar Análise Combinatória.

Eu percebo que os alunos encontram muitas dificuldades em relação às fórmulas $A$ fórmula do arranjo simples e da combinação simples elas são semelhantes. Tem aluno que quer aplicar uma e aplica a outra. Sem contar também que a ordem no arranjo simples importa e na combinação simples não importa. Quando se trata da permutação simples eu vejo que eles 'pegam muito rápido', porque é só aplicar o fatorial... Aliás eles amam esse conteúdo... eu percebo que eles adoram mesmo, amam de paixão. Mas essas 
fórmulas são necessárias... ter cuidado com elas, principalmente quando você fala antes o binômio de Newton, se você falar o binômio de Newton primeiro eu acho que embaralha mais ainda a cabeça deles, vai formando uma 'bola de neve'. O aluno se pergunta: - e agora qual daquelas fórmulas eu vou utilizar? Se não tiver bem claro pra ele o que é arranjo, o que é permutação e o que é permutação com elementos repetidos, etc fica muito confuso.

9) Você acha necessário apresentar as fórmulas? E se não apresentasse as fórmulas, só trabalhando com o Princípio Multiplicativo, o que você perceberia, como professor, se os alunos sentiriam essa necessidade?

Eu próprio, como professor, não me sinto seguro sem apresentar as fórmulas porque querendo ou não, a fórmula funciona como se fosse uma tabuada. Tipo, o aluno tenta agarrar aquilo com as duas mãos e não soltar mais. No entanto, dependendo da forma que são explicadas, ou passadas, ou provadas as fórmulas, cria-se uma ..., vamos dizer assim..., um terrorismo na cabeça deles mesmo, eles ficam perdidos vendo aquelas fórmulas todas e sem saber realmente quando e de que forma utilizá-las. Mas eu, pessoalmente, prefiro aplicar as fórmulas. Eu não vejo um aluno saindo do Ensino Médio saber bastante Análise Combinatória sem falar das fórmulas, até porque, no vestibular, ele vai usar essas fórmulas como uma garantia, fica mais fácil para ele memorizar o conteúdo, na aplicabilidade do conteúdo de Análise Combinatória.

10) Você acha importante trabalhar Análise Combinatória? Para quem é isso importante?

É muito importante o ensino de Análise Combinatória. Como professor, eu acredito que é aquele conteúdo que você pensa ... que delícia ... chegou a hora de trabalhar com Análise Combinatória. Porque parece que esse conteúdo oferece uma certa flexibilidade tanto para o professor quanto para o aluno e, além do quê, ele é muito atrativo, muito prático, muito aplicável. Quando você fala daqueles exercícios envolvendo tipo de roupa, combinações de roupa, de meia ou de calçado, etc., eu percebo que o aluno gosta... se interessa muito e acaba vendo ali uma aplicação de tudo que ele aprendeu. Talvez é o único conteúdo que abre a cabeça do aluno na segunda série do Ensino Médio, parece que dá neles aquela ansiedade de desvendar cada vez mais o conteúdo.

11) Seu aluno, como um cidadão útil à sociedade, cresce com a aprendizagem desse tópico?

Cresce bastante sem dúvida.

12) Em que sentido? 
Esse é um conteúdo que desperta o interesse no aluno e, a partir do momento, é que a gente como professor sabe disso, que o mais importante, o mais gostoso de ser professor é quando você tem uma correspondência do aluno, quando você vê um "feed back" dos alunos e esse assunto especificamente desperta desejo, envolvimento nos alunos. Da forma que se envolve com o conteúdo, logicamente que contribui para um cidadão útil, um cidadão que você tem a certeza absoluta que lá fora, ou seja, no dia a dia dele, ele é muito prático e fácil para ser aplicado.

13) Livros teóricos e livros didáticos colaboram para a prática docente, refletindo-se na aprendizagem dos alunos. Como você os usa?

Sem dúvida que os livros teóricos e didáticos colaboram, porque se você observar todos os livros que falam sobre Análise Combinatória, em geral aquele básico não muda, todos tocam a parte de filas, a parte com roupas, combinação com roupas ou sorteio nas urnas, tem tantas bolas numa urna, de várias cores, etc. Então eles trazem de forma bem objetiva. Eu uso bastante os livros nessas ocasiões e também acredito que ficaria bem mais difícil dar um curso de Análise Combinatória sem explorar diversos livros, diversos materiais didáticos. Eu uso mais para aplicação de exercícios mesmo. Eu formulo algumas ideias da minha cabeça e, na hora de explorar os exercícios, eu utilizo vários livros.

14) Com relação aos livros ainda, você falou que os utiliza para os exercícios. Você falou também que inicia esse conteúdo com a árvore de possibilidades. Então, você usa os exercícios do livro como auxílio, como exercício de fixação?

Para mim seria uma complementação, seria um material de apoio, um material onde existem ali vários problemas já pensados, bem trabalhados e por que não utilizar, né? Então eu uso mais como uma ferramenta, apesar que esse assunto permite você elaborar de próprio punho diversos tipos de exercícios, atividades ou até práticos mesmo. Na sala de aula, por exemplo, quando fala das filas eu peço para os alunos sentarem em linha indiana nas carteiras e vou fazendo as permutações, dá pra você trabalhar de várias maneiras esse conteúdo. Mas seria mais um material de apoio mesmo.

15) Em relação à avaliação, como você avalia os alunos, através de provas, trabalhos, observações?

A avaliação eu faço de várias maneiras. Com exercícios principalmente eu faço muitas perguntas para o aluno e vou dando ponto positivo de participação conforme as respostas dos alunos. Se elas forem objetivas, se forem respostas convincentes... eles ganham pontos. Também peço que eles façam pesquisas sobre o assunto. 


\section{6) Como avaliar todo esse processo?}

Em geral, na avaliação que eu tenho feito, quando a gente faz a pergunta em relação a esse conteúdo, se ficou bem trabalhado, se as estratégias que você utilizou deram certo, eu fico bastante satisfeito, e percebo que é um trabalho que normalmente dá certo e preenche as nossas expectativas enquanto professor. As respostas dos alunos deixam isso claro pra gente.

17) Você acredita que trabalhar com Resolução de Problemas poderia ajudar na compreensão dos conceitos de Análise Combinatória?

Sem dúvida ... porque a resolução de problemas ..., existe um trabalho publicado sobre isso, agora, me perdoe que eu não vou lembrar qual foi o matemático que escreveu isso. Mas eu sei que foram feitas muitas pesquisas a respeito e a resolução de problemas seria o carro chefe para entender Análise Combinatória. É ela que mostra a prática e faz com que o aluno se interesse mais pelo conteúdo.

\section{8) Você já iniciou esse conteúdo através de um problema?}

Já, quando fiz o meu estágio eu comecei com a placa de automóveis que eu tinha visto uma vez num livro antes mesmo de ser professor. No Ensino Médio eu tentei entender mas não consegui. Mas após o término do meu estágio, eu fiquei bastante convencido de que a aplicação desse problema, logo no início, no primeiro dia, foi muito útil. Eu peguei uma placa de automóveis e falei pra eles, inclusive, que há um tempo atrás eram três algarismos e duas letras e, depois, foi para quatro algarismos e três letras. Eu levantei a seguinte questão: se você fosse trabalhar naquele órgão, no Departamento Nacional de Trânsito, e se colocasse pra você a questão de que não tinha mais como confeccionar nenhuma placa, pois haveria repetição, como você resolveria esse problema? E dai, eu disse, a Análise Combinatória ajuda você a responder em fração de segundos e deixei algum tempo os alunos pensarem sobre isso. Em seguida, eu disse você vai lá e aumenta um algarismo ou aumenta uma letra. Se você quiser milhões de placas a mais você aumenta uma letra e um algarismo. Se você quiser mais ainda, aumente duas letras e dois algarismos e assim por diante. Eu iniciei meu estágio no Ensino Médio uma vez que eu trabalhei esse conteúdo com o problema da placa de automóveis e eu vi que foi muito útil.

19) E os alunos corresponderam a esse trabalho? Como você formalizou o conceito trabalhado de Análise Combinatória nesse problema? Você iniciou com o problema, trabalhou sobre ele e depois você formalizou?

Exatamente, depois que eu fiz a colocação do problema e sugeri, em seguida, que eles fizessem de forma que não houvesse nenhuma repetição de letras nem de números, enfim 
eu explorei bastante esse problema, de várias formas. Em seguida, eu fui tentando ligá-lo a outros problemas semelhantes.

Ao analisar a Entrevista realizada com o professor do Ensino Médio, pudemos perceber que ele trabalha o conteúdo Análise Combinatória para resolver problemas, e não através da resolução de problemas, enfatizando, então, a aplicabilidade dos conceitos. Em alguns momentos, o professor descreveu alguns episódios que exploram a construção dos conceitos, por meio de dinâmicas e problemas contextualizados. O professor se mostrou um tanto confuso quanto à utilização das fórmulas. Relatou que as utiliza após ter resolvido vários exercícios, mas que não se sente seguro em aplicá-las, o que pode revelar a dificuldade que seus alunos tiveram ao tentar trabalhar com elas na resolução dos problemas.

\subsubsection{Projeto 3}

No projeto $\mathbf{P}_{3}$, participei como pesquisadora em Congressos de Educação Matemática, tendo como objetivo principal oferecer a outros pesquisadores minha pesquisa para discussão e análise.

A minha expectativa, ao participar dos dois congressos, era conhecer outros pesquisadores que pudessem compartilhar suas vivências com o tema proposto e contribuir com nossa pesquisa, ainda em andamento, na época da apresentação.

Na participação do I Congresso Nacional das Licenciaturas: Ciência, Ensino e Aprendizagem (2007), parece que houve desconhecimento do público sobre o tema proposto. Houve apenas comentários de um dos coordenadores da sessão de comunicação. Ele mostrouse interessado e fez também algumas críticas, sendo que uma delas foi a de eu não ter citado a questão de sequência na definição dos conceitos de Análise Combinatória. Esse fato foi identificado, posteriormente, por nós, ao realizarmos a análise de livros didáticos. No livro Matemática Aplicada: 2, $2^{\circ}$ grau (1979), os autores Fernando Trotta, Luiz Márcio Pereira Imenes e José Jakubovic referiram-se à sequência ao definirem os conceitos de arranjo, combinação e permutação ao trabalhar Análise Combinatória. Desse modo, essa crítica trouxe contribuição à nossa pesquisa. Quanto ao uso da metodologia adotada, para resolver o problema proposto, nada foi discutido.

Já, no XII EBRAPEM - XII Encontro Brasileiro de Estudantes de Pós-Graduação em Educação Matemática (2008), houve maior envolvimento dos participantes durante as 
comunicações científicas. Isso, talvez pelo fato de ser esse um encontro cujos pesquisadores estão numa mesma fase de desenvolvimento de pesquisa e, também, por fazerem parte de uma mesma comunidade de pesquisa, no caso, a Educação Matemática.

Para Romberg (1992, p.53), ser membro de uma comunidade de pesquisa implica uma responsabilidade em informar a outros membros sobre a investigação completa e ir em busca de seus comentários e críticas. Muito frequentemente, os pesquisadores relatam somente os procedimentos e as descobertas e não o modelo ou a visão de mundo que têm. Assim, nesse encontro, senti-me mais à vontade para expor e envolver minha pesquisa em um debate científico. Pudemos verificar o envolvimento dos participantes durante o debate. Em relação ao tema proposto, houve comentários e sugestões de outras referências bibliográficas.

Como já foi dito, durante a aplicação desse projeto, a coordenadora da sessão nos entregou algumas questões para reflexão. Algumas delas foram respondidas por ocasião do debate. Outras, na medida do possível, serão respondidas aqui.

A ideia de Matemática Discreta, trazida no texto, será objeto de discussão no trabalho? Pretende-se exemplificar os modos de o professor lidar com ela na Educação Básica, por exemplo?

Podemos responder que de fato nosso trabalho aborda a Matemática Discreta, explorando parte dela na Análise Combinatória. O trabalho realizado com os alunos do Ensino Médio, feito durante a aplicação do Projeto 1, mostra, por meio da metodologia adotada, como trabalhar a Matemática Discreta na Educação Básica.

Na página 15 de seu trabalho é feita a seguinte afirmação "a resolução de problemas, como metodologia, favorece a investigação matemática”. Comentar.

$\mathrm{Na}$ Metodologia de Ensino-Aprendizagem-Avaliação de Matemática através da Resolução de Problemas, adotada para nossa pesquisa em sala de aula, o problema é o ponto de partida e orientação para a aprendizagem de novos conceitos e novos conteúdos, permitindo o avanço no conhecimento matemático. Na resolução de cada problema, a Matemática vai sendo construída. Assim, essa metodologia mostra sua força no processo ensino-aprendizagem e há, portanto, um trabalho de investigação matemática.

Questão para reflexão: como a metodologia da resolução de problemas (sic), aliada à postura investigativa, pode auxiliar na construção do conhecimento matemático? 
Esta questão como está proposta mostra como alguns educadores matemáticos estão longe de compreender a Metodologia de Ensino-Aprendizagem-Avaliação de Matemática através da Resolução de Problemas, adotada por nossa comunidade de pesquisa.

A coordenadora dessa sessão, nesse encontro, perguntou sobre a metodologia da resolução de problemas, parecendo querer se referir à nossa metodologia.

Nossa metodologia é destinada a ensinar, aprender e avaliar conhecimentos matemáticos construídos a partir da resolução de um problema. Seu nome faz uso da palavra através querendo dizer que os alunos, sob a guia e direção do professor, são coconstrutores de novos conceitos e novos conteúdos oriundos de um problema gerador.

Quando se fala em metodologia da resolução de problemas, é notório perceber que esses educadores estão se referindo ou a Polya ou a alguma variante do método de Polya.

Os livros didáticos que partem de problemas, em geral, apresentam antes os conteúdos matemáticos necessários à resolução deles. Então, a partir do problema dado e ensinando a Matemática necessária para o problema, resolvem-no em seus detalhes, mostrando aos alunos o que devem fazer. Nossa metodologia, ao contrário, conduz os alunos à construção desse conhecimento novo.

Como foi respondida a questão anterior, a metodologia adotada por nossa comunidade permite que o aluno aprenda Matemática enquanto resolve o problema. No entanto, é importante que haja um ambiente favorável para a construção dos conceitos envolvidos no problema, tendo o professor como condutor do processo de ensino-aprendizagem. Podemos afirmar, a partir das aplicações realizadas em nossa pesquisa, que a postura investigativa, tanto do professor quanto dos alunos, durante todo esse processo, auxilia e contribui na construção do novo conhecimento matemático.

Em relação à Matemática Discreta, pudemos verificar, mais uma vez, que se trata de um assunto novo no meio acadêmico, pois, apesar de ouvirmos ser interessante o assunto, não houve colaboração alguma para crescimento de nossa pesquisa.

\subsection{Antecipar as Ações de Outros}

Os membros de uma comunidade de pesquisa discutem suas ideias uns com os outros, confrontam ideias de uns com as de outros e sugerem novos passos, modificações de estudos prévios, elaborações de procedimentos e assim por diante. Os pesquisadores tentam situar cada um de seus estudos numa cadeia de investigação. (Romberg, 1992, p.53) 
Após eu coletar, interpretar as evidências e refletir sobre a ação realizada nas aplicações dos três projetos, fez-se necessário inter-relacionar as conclusões obtidas nessas aplicações para que tivéssemos condições de responder ao Problema de nossa Pesquisa, colocado, na página 126 deste trabalho, do seguinte modo:

1) Qual seria a contribuição da Metodologia de Ensino-Aprendizagem-Avaliação de Matemática através da Resolução de Problemas em uma nova abordagem, em sala de aula, da Análise Combinatória?

Mas também aparecia uma forte questão:

2) Como se desenvolve a formação de conceitos de Análise Combinatória, adotandose a Resolução de Problemas como uma metodologia de ensino? de aprendizagem? de avaliação?

Parecia-nos que essas duas perguntas tinham algo em comum, que eram complementares. Mas, questionando-nos ainda, perguntávamos: há alguma diferença essencial entre as duas?

A primeira, envolvendo mais a força da metodologia adotada, poderia contribuir para a construção de uma nova abordagem para trabalhar Análise Combinatória, uma linha de trabalho para o professor.

A segunda apresentava mais preocupação com a aprendizagem dos alunos, buscando um caminho para a construção de novos conceitos e novos conteúdos, tendo os alunos como coconstrutores desse conhecimento e o professor como um veículo para conduzir essa construção.

Como essas duas colocações parecem se ajustar uma à outra, decidimos que a pergunta diretriz de nossa pesquisa poderia surgir numa sequência em que a primeira, quando respondida, poderia levar à resposta da segunda.

O objetivo central de nossa pesquisa é o de apresentar uma proposta de trabalho para abordar Análise Combinatória em sala de aula, utilizando a Metodologia de EnsinoAprendizagem-Avaliação de Matemática através da Resolução de Problemas.

Analisamos o que há em comum aos três projetos: a importância do tema da pesquisa - Análise Combinatória contida na Matemática Discreta; a importância da Metodologia de Ensino-Aprendizagem-Avaliação de Matemática através da Resolução de Problemas; o envolvimento, cada um a seu modo, dos participantes de cada projeto; e a importância da pesquisadora no desenvolvimento de cada projeto e sua reflexão na e sobre a ação realizada. 
Consideramos importante um trabalho diferenciado ao adotar a Metodologia de Ensino-Aprendizagem-Avaliação de Matemática através da Resolução de Problemas, por proporcionar aos alunos a participação ativa na construção dos conceitos de Análise Combinatória, ao resolver um problema. Em nossa pesquisa, percebemos que essa metodologia, na aplicação dos três projetos, ainda não é muito conhecida por alunos e professores, mas que motiva e entusiasma a participação dos envolvidos no processo ensinoaprendizagem.

Refletindo sobre nossa prática e relacionando-a com nossos referenciais teóricos, percebemos que, em geral, a Análise Combinatória é trabalhada em sala de aula no modo tradicional, enfatizando o uso de fórmulas para a resolução dos problemas que pudemos observar. Os alunos as usam sem significado e não chegam a compreender os conceitos envolvidos nesse conteúdo. Assim, fica difícil responder às questões que levantamos na p.104. Apresentamos nossa definição de Análise Combinatória como sendo o ramo da Matemática que permite que se escolha, arrume e principalmente se conte o número de agrupamentos formados com os elementos de um determinado conjunto, sem que haja necessidade de se enumerarem tais elementos.

Apontamos algumas diferenças importantes entre a Matemática Contínua e a Matemática Discreta.

1 - Na Matemática Contínua, todos os pontos são de acumulação, portanto, qualquer vizinhança desse ponto contém infinitos pontos diferentes dele. Já na Matemática Discreta, todos os pontos são isolados, isto é, há vizinhanças desse ponto que não contêm nenhum ponto do conjunto diferente dele.

2 - A Matemática Contínua é subjacente à maioria dos problemas de Álgebra e do Cálculo. A Matemática Discreta é necessária para a investigação de cenários em que as funções são definidas sobre conjuntos de números discretos ou finitos, tais como os inteiros positivos.

3 - A Matemática Contínua é apropriada para situações cujo objetivo principal é a medida de uma quantidade. Na Matemática Discreta, o foco está em determinar uma contagem.

4 - Os ramos da Matemática Contínua e Matemática Discreta complementam-se nas aplicações do mundo real. As abordagens discretas dão aproximações para o tamanho de algumas medidas, enquanto que métodos contínuos permitem o estabelecimento de alguns limites para o número de passos ao calcular algoritmos, que são finitos na natureza. 
Percebemos que o desconhecimento dos professores e pesquisadores do ramo da Matemática Discreta, no qual a Análise Combinatória está inserida, foi um fato marcante. Como consequência desse fato, o aluno trabalha esse conteúdo sem the dar significado e ganhar compreensão.

Podemos afirmar que a metodologia de ensino adotada pôde proporcionar aos participantes um crescimento em sua aprendizagem. Quando trabalhamos com os alunos, em sala de aula, e com os professores, na oficina, pudemos sentir que vivenciaram essa metodologia, e que ela colaborou com parte da formação continuada desses professores. Com os pesquisadores, em Congressos, foi importante a divulgação e a discussão dessa metodologia, diferente da tradicional, que muitos não conheciam. Uma limitação, encontrada por nós, foi o tempo, pois, como relatamos, não conseguimos trabalhar a construção das fórmulas. Usamos quase que todo o tempo para que os participantes explorassem mais o processo de contagem e atuassem como coconstrutores dos conceitos envolvidos nos problemas, durante sua resolução.

Trabalhar partindo de problemas, com a preocupação inicial de abordar as grandes ideias dos conceitos da Análise Combinatória, foi essencial, pois pudemos perceber que os alunos e os professores resolveram os problemas sem fazer uso das fórmulas. Para mim, como pesquisadora, foi uma conquista, pois pude vivenciar, junto com eles, um novo modo de estudar esse conteúdo, diferente daquele que tinha visto quando estudante. $\mathrm{O}$ uso de diferentes representações pelos participantes na resolução dos problemas, ou seja, por meio de tabelas, diagramas e listas organizadas, mostrou-se relevante, pois eles explicitaram seu raciocínio por meio dessas estratégias ao resolver os problemas. Podemos afirmar que mostrar o raciocínio combinatório, explorar o processo de contagem e o conceito de padrão foram passos importantes para a construção dos conceitos envolvidos em Análise Combinatória. E ainda, como disseram Correia e Fernandes (2009, p.12), ... os problemas de Combinatória facilitam $o$ desenvolvimento de processos de enumeração, de realização de conjecturas, de generalização e o pensamento sistemático, essenciais para a aprendizagem da matemática em todos os níveis de ensino. Além da inter-relação da Análise Combinatória com outras áreas, como ocorreu nos problemas trabalhados por nós, como a Geometria e a Álgebra. Desse modo, consideramos importante que Análise Combinatória deve ser um tópico presente no ensino de Matemática e também que a escolha do problema esteja relacionada à postura da pessoa que vai ministrar a aula e à formação dos participantes.

Ressaltamos que a Metodologia de Ensino-Aprendizagem-Avaliação de Matemática através da Resolução de Problemas pressupõe aspectos epistemológicos. Assim, a Resolução 
de Problemas é mais que uma metodologia, é uma filosofia de educação, pois ela abrange um aspecto teórico-metodológico, que conduz os alunos criarem caminhos para aprender Matemática enquanto resolvem problemas.

A Metodologia de Ensino-Aprendizagem-Avaliação de Matemática através da Resolução de Problemas, trabalhando com Análise Combinatória, contribuiu para um trabalho significativo tanto para os alunos como para o professor.

Desse modo, quando colocamos o objetivo central de nossa pesquisa - apresentar uma proposta de trabalho para abordar Análise Combinatória em sala de aula, utilizando a Metodologia de Ensino-Aprendizagem-Avaliação de Matemática através da Resolução de Problemas - pretendíamos mostrar que essa proposta de trabalho é fruto das reflexões feitas sobre a minha prática como professora, professora-pesquisadora e pesquisadora, ao interrelacionar as conclusões obtidas nas aplicações dos três projetos. Esta pesquisa pode colaborar na formação do professor que, ao ler este trabalho, pode refletir sobre o que ocorreu além da sala de aula ao se trabalhar Análise Combinatória e, com sua prática, buscar um trabalho diferenciado.

Como bem expõem Correia e Fernandes (2009) sobre as implicações para o ensino de Análise Combinatória,

As dificuldades dos alunos em estabelecer conexões entre as operações combinatórias, nomeadamente entre arranjos e combinações, enfatizam a importância que os problemas de Combinatória podem ter no desenvolvimento de processos de raciocínio analógico. Segundo English (2005), o raciocínio analógico reveste-se de grande importância, já que um dos objetivos da educação matemática é que os alunos identifiquem conexões entre as ideias matemáticas e apliquem esta compreensão na construção de novas ideias e na resolução de novos problemas. (p.17)

Desse modo, a importância dada ao raciocínio analógico, apresentada pelos autores, mostra a abrangência dada à Análise Combinatória e a relevância de abordar esse conteúdo, estendendo para a construção de novo conhecimento matemático. Mostram, assim, a contribuição dada aos pesquisadores que fazem parte da comunidade de Educação Matemática.

\subsubsection{Reflexões e posições da professora-pesquisadora pós-pesquisa}

O grande desafio para a educação é pôr em prática hoje o que vai servir para o amanhã. Pôr em prática significa levar pressupostos teóricos, isto é, um 
saber/fazer acumulado, ao longo de tempos passados, ao presente. Os efeitos da prática de hoje vão se manifestar no futuro. Se essa prática foi correta ou equivocada só será notada após o processo e servirá como subsídio para uma reflexão sobre os pressupostos teóricos que ajudarão a rever, reformular, aprimorar o saber/fazer que orienta nossa prática. (D'AMBROSIO, 1996, p.80)

Neste trabalho, tive o papel de professora reflexiva que poderá dirigir-se a outros professores no que se refere às suas formações. Este trabalho dirige-se para o professor visto nas três situações: na sala de aula; na oficina de trabalho, em formação continuada, discutindo entre seus pares; e na ligação de pesquisa da educação matemática destinada aos professores na formação inicial, na formação continuada e na formação de pesquisador.

As três posturas diferentes que assumi surgiram durante o desenvolvimento desta pesquisa. Assim, o crescimento e o amadurecimento da pesquisadora, com certeza, revelaramse importantes para o prosseguimento do trabalho. Senti uma necessidade de enriquecer minha pesquisa, ampliando meu conhecimento sobre Análise Combinatória contida na Matemática Discreta e a força da Metodologia de Ensino-Aprendizagem-Avaliação de Matemática através da Resolução de Problemas. Assumir essas três diferentes posturas não foi tão fácil, pois na aplicação os projetos foram planejados para diferentes cenários e, para cada um deles, havia uma expectativa.

Assim, ao fazer a reflexão sobre essas diferentes posturas e responder ao problema da pesquisa, algumas questões surgiram:

- Este trabalho visa à formação do professor na sua sala de aula? na participação em oficinas de trabalho? na leitura de trabalhos de pesquisa?

Este trabalho não visava diretamente à formação de professores. Entretanto, implicitamente, ele cuidava disso.

- Como não se referir ao trabalho do professor, em sua formação continuada, na necessidade de ser um professor reflexivo?

É claro que, com este trabalho concluído e com a pergunta de pesquisa já respondida, fica aqui a pretensão, ao buscar as respostas para essas duas questões, de uma reflexão para um novo trabalho que visasse, com mais profundidade, à formação do professor.

Neste momento, abordaremos alguns pontos relevantes, em relação a um professor que reflete sobre sua própria prática: o desenvolvimento profissional, a formação do professor, a reflexão do professor na ação e a reflexão do professor sobre a ação.

No início de 1989, uma comissão sobre Padrões Profissionais de Ensino foi estabelecida pelo comitê de diretores do NCTM (Nacional Council of Teachers of 
Mathematics-USA). A comissão foi encarregada de produzir um conjunto de padrões que promovesse uma visão do ensino de Matemática; da avaliação do ensino de Matemática; do desenvolvimento profissional dos professores de Matemática; e das responsabilidades para o desenvolvimento e o apoio profissional, que viriam a contribuir para a melhora da educação matemática como pretendida no Curriculum and Evaluation Standards for School Mathematics-USA (1989 - Padrões de Currículo e Avaliação para a matemática escolar Estados Unidos).

Os Professional Standards for Teaching Mathematics (1991-Padrões Profissionais para o Ensino da Matemática) foram projetados, apoiados no Curriculum and Evaluation Standards for School Mathematics, a fim de estabelecer uma ampla estrutura para guiar a reforma na matemática escolar na década de noventa. Em particular, esses Padrões apresentam uma visão de que tipo de ensino seria requerido para apoiar as mudanças no currículo exibidas no documento de 1989. O documento de 1991 explica, com detalhes, o que os professores precisam saber para ensinar Matemática, visando aos novos objetivos da educação matemática, e como o ensino deveria ser avaliado para o propósito de melhora.

Outro problema se colocava: como os professores poderiam atender a essas mudanças pretendidas?

Para compreender a questão altamente complexa do desenvolvimento profissional dos professores de Matemática, disseram Kathryn Castle e Douglas B. Aichele (1994) que os professores precisavam levantar algumas questões:

1) Como chegamos até onde estamos hoje?

2) Que forças, tanto internas quanto externas à comunidade de educação matemática, influenciam o desenvolvimento profissional dos professores de matemática?

3) Como podem essas forças ser redirecionadas, de modo que elas estejam facilitando seu trabalho, e enfocadas definitivamente?

Em seu artigo intitulado Prática reflexiva do professor de Matemática, Perez (2004), diz:

Diante de uma crescente conscientização da profissionalização do magistério, que reflete uma profunda insatisfação e descontentamento pela baixa aprendizagem, por parte dos alunos, somos levados a sonhar com uma nova educação, que vise a criar novos ambientes, e que proporcione mudanças em posturas e formação pré-serviço e continuada de professores de Matemática, com características de pesquisadores em seu ambiente de trabalho.

O que nos leva a essa intenção está focalizado nas dissertações e teses que temos orientado no Programa de Pós-Graduação em Educação Matemática 
na UNESP - campus de Rio Claro-SP - nos últimos anos, nas quais algumas questões relevantes têm sido levantadas:

1. por que a sugestão de o professor desenvolver papel de pesquisador em sala de aula?

2. a existência de novos ambientes pode coincidir com a criação de laboratórios de Educação Matemática tanto na formação pré-serviço como na formação continuada do professor de Matemática?

3. o que significa desenvolver cidadania através da sala de aula de Matemática a fim de formar o homem como um todo e não apenas como mais um aluno, ou seja, transformando o aluno em sujeito da educação?

4. qual o significado para o desenvolvimento profissional? (p.250)

João Pedro da Ponte, pesquisador português, inicia seu texto $D a$ formação ao Desenvolvimento Profissional, 1998, alertando-nos que falar de formação é um terrivel desafio (...) porque a formação é um daqueles domínios em que todos se sentem à vontade para emitir opiniões, de onde resulta a estranha impressão de que nunca se avança. (apud PEREZ, 2004, p.251)

Perez (2004, p.252) define reflexão como um processo em que o professor analisa sua própria prática, compila dados, descreve situações, elabora teorias, implementa e avalia projetos e partilha suas ideias com colegas e alunos, estimulando discussões em grupo. E, ainda, conclui que, para isso, o professor precisa ter ausência de preconceitos e disposição para aceitar e implementar novas idéias, ter atitudes de responsabilidade baseadas em princípios éticos e ter entusiasmo e coragem para adotar atitudes novas. Já, em 1967, falando sobre a mudança de atitude do professor, Montessori referia-se a ela enfatizando que nada é mais dificil para um professor do que desistir de seus velhos hábitos e preconceitos. (apud WEISSGLASS, 1994, p.67)

Lorenzato (2006, p.127) expõe que

A falta de reflexão do professor sobre sua prática pedagógica pode garantir a repetição de um ensino destituído de significado para os alunos, mesmo porque somos um país de dimensões continentais que, como tal, apresenta diferentes demandas regionais.

Assim, ser reflexivo é uma exigência ao professor que persegue uma melhor postura profissional (...) e,

para assumir uma melhor postura, é preciso reflexão sobre as aulas dadas e uma constante atualização para a formação.

A reflexão pode ser realizada em duas vertentes de como o conhecimento em ação é desenvolvido e adquirido, explicitadas por Schön (1995), apud Perez (1999), como reflexão na ação e reflexão sobre a ação.

Reflexão na ação é a que ocorre simultaneamente à prática, na interação com as experiências, permitindo ao professor dialogar com a situação, elaborar um diagnóstico 
rápido, improvisar e tomar decisões diante da ambiguidade, do inesperado e das condições efetivas do momento.

Reflexão sobre a ação refere-se ao pensamento deliberado e sistemático, ocorrendo após a ação, quando o professor faz uma pausa para refletir sobre o que acredita ter acontecido em situações vividas em sua prática.

A primeira vertente mostra a postura do professor durante o trabalho em sala de aula, preocupa-se com as situações imediatas que ocorrem, investiga suas ações e as dos alunos e procura resolver os problemas que eventualmente possam ocorrer. A reflexão sobre a ação, por sua vez, requer do professor uma postura de pesquisador sobre as aulas realizadas onde ele assume o papel de professor pesquisador. Assim, o professor tem uma visão crítica sobre seu trabalho, tornando-se consciente de suas ações e, desse modo, assume uma prática reflexiva.

Em Castle e Aichele (1994), podemos notar uma visão semelhante sobre a prática

\begin{abstract}
Através da reflexão sobre práticas de ensino, os professores desenvolvem autonomia. A prática reflexiva engaja os professores ao pensar sobre bom ensino e refletir sobre significados que o ensino tem para os seus alunos. Um exemplo de prática reflexiva é o uso de um diário escrito no qual os professores escrevem sobre suas vivenciadas experiências de ensino. Escrever e refletir sobre experiências ajuda os professores a desenvolver percepções em seus próprios comportamentos e reconhecer como eles, professores, afetam seus alunos através de suas práticas de ensino. Percepções reflexivas dão uma mais profunda e mais rica compreensão do que significa ensinar, assim contribuindo para que com o conhecimento profissional usado tome decisões autônomas. (p.05)
\end{abstract}

Concordando com Perez (1999, p.274), consideramos importante a reflexão na prática e sobre ela para o desenvolvimento profissional do professor e para uma nova cultura profissional.

Ponte apresenta algumas diferenças entre desenvolvimento profissional e formação:

A formação está muito associada à idéia de "freqüentar" cursos, numa lógica mais ou menos "escolar"; o desenvolvimento profissional processa-se através de múltiplas formas e processos, que inclui a freqüência de cursos mas também outras atividades, como projetos, troca de experiências, leituras, reflexões (...). Na formação, o movimento é essencialmente de fora para dentro, cabendo-lhe absorver os conhecimentos e a informação que lhe são transmitidos; com o desenvolvimento profissional se está a pensar num movimento de dentro para fora, na medida em que toma as decisões fundamentais relativamente às questões que quer considerar, aos projetos que quer empreender e ao modo como os quer executar; ou seja: o professor é o objeto de formação mas é sujeito no desenvolvimento profissional. $\mathrm{Na}$ formação atende-se principalmente (se não exclusivamente) aquilo em que o professor é carente; no desenvolvimento profissional parte-se dos aspectos 
que o professor já tem mas que podem ser desenvolvidos (...). A formação tende a ser vista de modo compartimentado, por assuntos ou por disciplinas, como a formação inicial (...); faz-se formação em avaliação, em MS-DOS, em cultura islâmica; o desenvolvimento profissional, embora possa incidir em cada momento num ou noutro aspecto, tende sempre a implicar a pessoa do professor como um todo. A formação parte invariavelmente da teoria e muitas vezes (talvez na maior parte) não chega a sair da teoria; o desenvolvimento profissional tanto pode partir da teoria como da prática; e, em qualquer caso, tende a considerar a teoria e a prática interligadas. (PONTE, 1996, p.194 apud PEREZ, 2004, p.254)

Como vimos, Ponte menciona que uma das formas em que se dá o desenvolvimento profissional é por meio da troca de experiências. Em nossas escolas públicas, há um momento reservado para as discussões sobre o desenvolvimento das aulas, é o Horário de Trabalho Pedagógico Coletivo (HTPC). Os professores têm a oportunidade de relatar sobre o que ocorreu em suas aulas, os sucessos e os fracassos. Conhecer diferentes pontos de vista e aceitar as sugestões de outros colegas enriquece a postura do professor diante da sala de aula, fato que o leva a uma autonomia profissional.

Segundo Castle e Aichele (1994, p.05), a autonomia profissional é desenvolvida quando professores têm oportunidades de dividir suas opiniões com outros, bem como ouvir e debater as opiniões dos outros. Discussões, debates e seminários dão oportunidades de dividir suas opiniões com as dos outros. Por meio do cruzamento de opiniões, os professores tornamse melhores em saber expressar e esclarecer seu próprio raciocínio sobre as questões levantadas. Quando os professores estão questionando sobre suas ideias e se lhes pedem para explicá-las, eles chegam a novas profundidades de compreensão sobre essas questões. Conhecendo pontos de vista alternativos sobre uma questão, começam eles a pensar sobre a questão levantada em caminhos novos e mais compreensíveis.

Mediante a troca de pontos de vista, os professores desenvolvem uma apreciação da diversidade de pensamento. Eles se tornam melhores em ver a perspectiva do outro, que os leva a uma melhor tomada de decisão. Considerar uma questão de ponto de vista múltiplo ajuda na decisão do que é melhor para a maioria daqueles envolvidos.

Em estudos de caso, trocar pontos de vista pode promover aos professores discussões em grupo e debate de questões mais urgentes. Tais discussões, no que se refere à resolução dos problemas levantados, ajudam os professores a decidir sobre os melhores modos de manipular o ensino de problemas. Os professores podem ser encorajados a escrever e a apresentar seus próprios estudos de caso ou situações em que eles tenham experienciado um 
problema difícil. Escrever narrativas pessoais e compartilhá-las com outros ajuda na apreciação da complexidade do ensino e da individualidade de cada professor.

Um outro exemplo de troca de pontos de vista seria o da participação num projeto colaborativo. Um membro do grupo faz concessões para discussão e debate dentro de um ambiente seguro no qual ele se sente aceito, "pertinente", e com o sentido de uma contribuição pessoal para o grupo. Por meio de tal participação, os professores formam redes de apoio de um para o outro e trabalham cooperativamente sobre objetivos, tarefas e projetos mútuos.

Fatos como esse, de troca de pontos de vista, ocorrem frequentemente no Grupo de Trabalho e Estudos em Resolução de Problemas (GTERP), do qual sou integrante, realizado na UNESP - Rio Claro-SP. Mestrandos, doutorandos e professores pesquisadores levam até o grupo relatos vividos em sala de aula, todos participam, discutem e debatem, enriquecendo situações apresentadas com sugestões para o trabalho com os alunos.

O crescimento dos professores, ao pensar reflexivamente sobre seu ensino, fica evidenciado não somente em sua participação no grupo mas, também no grande número de comentários analíticos que aparecem em seus diários de aula e na qualidade das questões que estão sendo levantadas em suas salas de aula. O que temos aprendido é que para nossos professores, exatamente como jovens estudantes, "menos pode ser mais" se eles tomam responsabilidade para o seu próprio desenvolvimento profissional e se tornam ativamente envolvidos como produtores ao invés de somente consumidores. (SCHIELACK; CHANCELLOR, 1994, p.307)

O professor é responsável por sua prática docente, pela aprendizagem dos alunos e deveria enriquecer sua prática construindo suas próprias teorias, como apontam Castle e Aichele (1994):

Professores autônomos promovem autonomia em crianças e jovens. Professores autônomos são aprendizes autodirigidos que questionam, estudam e buscam respostas a uma necessidade de saber. Eles podem articular com outros suas visões sobre questões educacionais e construir suas próprias teorias que constituem um bom ensino. Através das interações com outros, eles esclarecem suas idéias e reconstroem o que significa ser um professor profissional. Este processo de reconstrução leva a novas e melhores abordagens do ensino. Professores autônomos constroem pessoalmente um conhecimento profissional significativo resistente às modas da educação ou ordens externas. Eles constroem seu conhecimento profissional, não o emprestam de especialistas, e ficam então mais confiantes naquilo que sabem. Eles apreciam o processo construtivo e são mais capazes de cultivá-lo em crianças e jovens. (p.05)

Cabe ao professor acreditar no seu potencial, realizar reflexão na ação e na reflexão sobre a ação, compartilhar suas experiências num grupo de discussão e assim contribuir com o 
seu desenvolvimento profissional e o da comunidade (escolar ou de pesquisa) em que está inserido. Acreditamos que não basta ter apenas formação, é preciso interiorizar suas ações, refletir sobre elas e construir sua própria teoria sobre a prática docente, concebendo assim seu desenvolvimento profissional. Como bem apresenta Ponte (1996, apud PEREZ, 2004), a formação é um movimento que se dá de fora para dentro e o desenvolvimento profissional, de dentro para fora.

Esta visão, fruto de nossas ações e reflexões, tem como consequência contribuições para o trabalho do professor e pesquisador sobre o tema abordado e se resume, então, em uma proposta de trabalho. Esta proposta não é constituída por meio das aplicações, mas ela se apresenta como consequência dessas aplicações. Ela só será efetivada quando outros pesquisadores a adotarem e provocarem mudanças em suas práticas docentes. 
REFERÊNCIAS 


\section{Referências}

ABRANTES, P. Contagens, Grafos e Matrizes nos nossos programas? Talvez um dia... Revista Educação e Matemática, n³0, $2^{\circ}$ trimestre de 1994 (Portugal).

Allevato, N. S. G. Associando o Computador à Resolução de Problemas: Análise de uma Experiência, 2005. Tese (Doutorado em Educação Matemática) UNESP- Rio Claro.

APEOSP. www.apeosp.org.br/direitos_prof/direitos.htm, acesso em: 28 de agosto de 2008.

BACHX, G.C., POPPE, L.M.B., TAVARES, R.N.O., Prelúdio à Análise Combinatória, São Paulo: Nacional, 1975.

BARALDI, I. Um pouco de história dos problemas... e da resolução de problemas, PGEM, UNESP: Rio Claro/SP, $2^{\circ}$ sem. 1994.

BARbOSA, R. M. Combinatória e Probabilidades. Série Professor n ${ }^{\circ} 05$, São Paulo: Livraria Nollel, 1966.

BIANCHINI, E., Paccola, H. Curso de Matemática. 1ed., volume único. São Paulo: Ed. Moderna, 1993.

BOLLOBÁS, B. Combinatorics. Cambridge, 1986.

BOYER, C. B. História da Matemática. Tradução: Elza F. Gomide. São Paulo: Edgard Blücher Ltda, 1974.

BRANSFORD, J.D.; BROWN, A.L.; COCKING, R.R. Como as pessoas aprendem: cérebro, mente, experiência e escola. Tradução: SZLAK, C.D. São Paulo: Editora Senac, 2007.

BRASIL, Ministério da Educação e da Secretaria de Educação Média e Tecnológica. Parâmetros Curriculares Nacionais $-3^{0}$ e $4^{\underline{0}}$ ciclos do Ensino Fundamental (Matemática). Brasília: MEC, 1998.

BRASIL, Ministério da Educação e da Secretaria de Educação Média e Tecnológica. Parâmetros Curriculares Nacionais para o Ensino Médio (Matemática). Brasília: MEC, 1999.

BURTON, D.M. The History of Mathematics: An Introduction. McGraw-Hill Companies, 2007.

CAI, J. What Research tells us about Teaching Mathematics through Problem Solving In: LESTER, F.; CHARLES, R. Teaching Mathematics through Problem Solving: prekindergarten - grade 6. Reston: NCTM, p.241-253, 2003.

CASSOL, A. (coord. geral). VI Encontro Nacional de Educação Matemática. Anais. São Leopoldo-RS: [s.n.] , v-1, 1998. 
CASTLE, K.; AICHELE, D.B. Professional Development and Teacher Autonomy. In: AICHELE, D.B.; COXFORD, A.F. Professional Development for Teachers of Mathematics. Reston: NCTM, p.01-08, 1994.

CORREIA, P.F.; FERNANDES, J.A. Estratégias espontâneas de alunos do $9^{\underline{0}}$ ano em Combinatória. In: Revista Educação e Matemática. nº 102, março/abril de 2009 (Portugal).

D’AMBROSIO, U. Educação Matemática: da teoria à prática. Campinas, SP: Papirus, 1996.

Prefácio In: BORBA, M.; ARAÚJO, J.L. (orgs.) Pesquisa Qualitativa em Educação Matemática, Belo Horizonte: Autêntica, 2006

DANTE, L.R. Didática da Resolução de Problemas de Matemática. São Paulo: Ática, 1989.

Matemática. São Paulo: Editora Ática, 2004.

DOMINGUES, H.H. A Matemática e os jogos de azar In: HAZZAN, S. Fundamentos da Matemática Elementar (Combinatória/Probabilidade). São Paulo: Atual Editora, 6 ed., vol.05, 1993.

A gênese da teoria das probabilidades In: MORGADO, A. C. O.; CARVALHO, J.B.P.; CARVALHO, P.C.P.; FENANDEZ, P. Análise Combinatória e Probabilidade. Rio de Janeiro: IMPA/VITAE, 1991.

DOSSEY, J.A. The Math for Our Time. In: Kenney, M.J.; Hirsch, C.R. Discrete Mathematics across the Curriculum, K-12: 1991, Yearbook. NCTM, 1-9, 1991.

FARAH, E.; CASTRUCCI, B. Matemática - $\mathbf{2}^{\mathbf{a}}$ série colegial, São Paulo: Editora Brasil S/A, 1956.

FIORENTINI, D.; LORENZATO, S. Investigação em educação matemática: percursos teóricos e metodológicos, Campinas, SP: Autores Associados, 2006.

GARDINER, A.D. A Cautionary Note. In: Kenney, M.J.; Hirsch, C.R. Discrete Mathematics across the Curriculum, K-12: 1991, Yearbook. NCTM, 10-17, 1991.

GAZIRE, E.S. Resolução de Problemas: Perspectivas em Educação Matemática. 1988. Dissertação (Mestrado em Educação Matemática), Rio Claro: UNESP.

GENTIL, N.; SANTOS, C.A.M.; GRECO, A. C.; FILHO, A.B.; GRECO, S. E. Matemática para $02^{\circ}$ grau. $5^{\text {a }}$ ed. v.02. São Paulo: Ed. Ática, 1996.

HARIKI, S. Conectar problemas: uma nova estratégia de resolução de problemas combinatórios. Revista Educação e Matemática, n³7, $1^{\circ}$ trimestre de 1996 (Portugal).

HATCH, G.; SHIU, C. Practitioner research and the construction of knowledge in mathematics education. In: SIERPINSKA, A.; KILPATRICK, J., Mathematics Education as 
a Research Domain: A Search for Identity. Kluwer Academic Publishers, p. 297-315, 1998.

HAZZAN, S. Fundamentos da Matemática Elementar: Combinatória/ Probabilidade. 6ed, v.05, São Paulo: Atual Editora Ltda, 1993.

HOUAISS, A. Dicionário Houaiss da Língua Portuguesa. 1ªed. Rio de Janeiro: Objetiva, 2001, 2925p.

JOHNSON, J. Using dominoes to introduce combinatorial reasoning. In: Kenney, M.J.; Hirsch, C.R. Discrete Mathematics across the Curriculum, K-12: 1991, Yearbook. NCTM, 128-136, 1991.

KENNEY, M.J.; HIRSCH, C.R. Discrete Mathematics across the Curriculum, K-12: Yearbook. NCTM, 1991.

KILPATRICK, J. A History of Research in Mathematics Education. In: D.A. Grows (ed.), Handbook of Research on Mathematics Teaching and Learning, Macmillan: New York, p.3-38., 1992.

Fincando estacas: uma tentativa de demarcar a Educação Matemática como campo profissional e científico. Tradução: MISKULIN, R.G.S.; PASSOS, C.L.B.; GRANDO, R.C.; ARAÚJO, E.A. In: Zetetiké, v.4, n5, janeiro/junho, Campinas, SP: UNICAMP, p.99120, 1996.

KRULIK, S.; RUDNICK, J.A. Problem- Driven Math: applying the mathematics beyond solutions. Chicago, IL: Wright group/McGraw-Hill, 2005.

LAMBDIN, D.V.; WALCOTT, C. Changes through the years: Connections between Psychological Learning Theories and the School Mathematics Curriculum. In: The Learning Mathematics, sixty-ninth yearbook, NCTM, 2007.

LAMBDIN, D.V. Benefits of Teaching through Problem Solving In: LESTER, F.; CHARLES, R. Teaching Mathematics through Problem Solving: prekindergarten grade 6. Reston: NCTM, p.3-13, 2003.

LARSON, R.; HOSTETLER, R.P., EDWARDS, B.H. Precalculus with limits: a graphing approach $3^{\text {a }}$ d. Boston: Houghton Mifflin Company, 2001

LIMA, E.L.; CARVALHO, P.C.P.; MORGADO, E.W.A. A Matemática no Ensino Médio vol.2. Rio de Janeiro: SBM, 1998.

LARSEN, R.J.; MARX, M.L. An Introduction to Mathematical Statistics and Its Application. Fourth Edition. Publisher: Pearson Prentice Hall. Upper Saddle River, NJ, 2006.

LIMA, E. L. (editor) Exame de Textos: Análise de livros de Matemática para o Ensino Médio, Rio de Janeiro: SBM, 2001.

LORENZATO, S. Para aprender matemática. (Coleção Formação de Professores). Campinas-SP: Autores Associados, 2006. 
MARINCEK, V. Algumas contribuições da didática da Matemática: a resolução de problemas e o papel do professor. In: MARINCEK, V. (coord.) Aprender Matemática resolvendo problemas. Porto Alegre: Artmed, p.13 -17, 2001.

MATHEMATICS FRAMEWORK FOR CALIFORNIA PUBLIC SCHOOLS kindergarten through grade twelve, 1985.

MATHEMATICS FRAMEWORK FOR CALIFORNIA PUBLIC SCHOOLS kindergarten through grade twelve, 1992.

MENDONÇA, M.C.D. Problematização: um caminho a ser percorrido em Educação Matemática. 1993. Tese (Doutorado em Educação). Campinas: UNICAMP.

MIGUEL, A.; MIORIM, M.A. História na Educação Matemática: propostas e desafios, Belo Horizonte: Autêntica, 2004.

MORGAdO, A. C. O.; CARVALHO, J.B.P.; CARVALHO, P.C.P.; FENANDEZ, P. Análise Combinatória e Probabilidade. Rio de Janeiro: IMPA, 1991.

NATIONAL COUNCIL OF TEACHERS OF MATHEMATICS. An Agenda for Action: Recommendations for School Mathematics of the 1980's. Reston, VA: NCTM, 1980.

Curriculum and Evaluation Standards for School Mathematics. Reston: Library of Congress Cataloguing, NCTM, 1989.

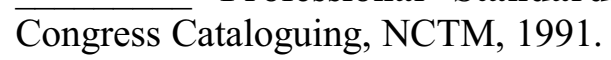

Professional Standards for Teaching Mathematics. Reston: Library of

Principles and Standards for School Mathematics. Reston: Library of Congress Cataloguing, NCTM, 2000.

ROBINSON, E.E.; ROBINSON, M.F.; MACELI, J.C. The Impact of Standards - Based Instructional Materials in Mathematics in the Classroom. In: Learning Mathematics for New Century. Yearbook. NCTM, p.112-126, 2000.

ONUCHIC, L.R. Ensino-aprendizagem de Matemática através da resolução de problemas. In: Bicudo, M.A.V. (org.) Pesquisa em Educação Matemática: concepções e perspectivas (Seminários e Debates). São Paulo: UNESP, p.199-218, 1999.

ONUCHIC, L.R.; ALLEVATO, N.S.G. Novas reflexões sobre o ensino-aprendizagem de matemática através da resolução de problemas. In: BICUDO, M. A.; BORBA, M. (orgs) Educação Matemática - pesquisa em movimento, São Paulo: Cortez, p.213-231, 2004.

ONUCHIC, L. R.; ALLEVATO, N. S. G. 1ํㅡㄹ Escola de Inverno de Educação Matemática de Santa Maria. Anais. Ensino-Aprendizagem-Avaliação de Matemática através da Resolução de Problemas - Aritmética, Álgebra e Geometria. Universidade Federal de Santa Maria/RS, 2008.

PAIVA, M. Matemática volume único. São Paulo: Moderna, 1999. 
PALANGANA, I.C. Desenvolvimento e aprendizagem Piaget e Vygotsky: a relevância social. $3^{\mathrm{a}}$ ed. São Paulo: Summus, 2001.

PELAYO, V. N., BATANERO, C., GODINO, J.D., Razionamiento combinatorio en alumnos de secundaria. Educación Matemática, México, 8 (1), p.26-39, abril, 1996.

PEREIRA, M. O ensino-aprendizagem de matemática através da resolução de problemas no $3^{0}$ ciclo do ensino fundamental. 2004. 262 f. Dissertação (Mestrado em Educação Matemática) - Instituto de Geociências e Ciências Exatas, Universidade Estadual Paulista, Rio Claro, 2004.

PEREZ, G. Prática reflexiva do professor de matemática. In: BICUDO, M. A.; BORBA, M. (orgs.) Educação Matemática - pesquisa em movimento, São Paulo: Cortez, p.250-263, 2004.

Formação de Professores de Matemática sob a Perspectiva do Desenvolvimento Profissional. In: Bicudo, M.A.V. (org.) Pesquisa em Educação Matemática: concepções e perspectivas (Seminários e Debates). São Paulo: UNESP, p.263-282, 1999.

PITOMBEIRA, J.B. Princípio da casa dos pombos. Revista do Professor de Matemática, 8 , p. 21-26, São Paulo: SBM, 1986.

POLYA, G. A arte de resolver problemas. Primeira reimpressão. Tradução e adaptação de Heitor Lisboa de Araújo. Rio de Janeiro: Interciências, 1986.

Mathematical Discovery: on understanding, learning, and teaching problem solving. vol.01, Jonh Wiley \& Sons, 1962.

QUINTELLA, A. Matemática para o $2^{\circ}$ ano colegial. $4^{\mathrm{a}}$ ed., São Paulo: Companhia Editora Nacional, $196 ?$.

RODRIGUES, V. Resolução de Problemas como estratégia par incentivar e desenvolver a criatividade dos alunos na prática educativa matemática. 1992. Dissertação (Mestrado em Educação Matemática) Rio Claro: UNESP.

ROMBERG, T. A. Perspectives on Scholarship and Research Methods. In: Grouws, D. A. (ed.) Handbook of Research on Mathematics Teaching and Learning, p.49-64. NCTM, New York: Simon \& Schuster, 1992.

Perspectivas sobre o Conhecimento e Métodos de Pesquisa. Tradução: ONUCHIC, L.; BOERO, M.L. In: BOLEMA - Boletim de Educação Matemática. Rio Claro: UNESP, n.27, p.93-139, 2007.

The social Organization of Research Programs in Mathematical Scienses Education. In: KILPATRICK, J.; SIERPINSKA, A. (ed.) Mathematics Education as a Research Domain: A Search for Identity, Kluwer Academic Publishers, 1997.

ROSA, M. VI ENEM. Anais. Desmistificando a Análise Combinatória. São Leopoldo-RS, 1998. 
ROXO, E.; PEIXOTO, R.; CUNHA, H.; NETTO, D. Matemática $2^{\mathbf{0}}$ ciclo, $2^{\mathbf{a}}$ série. $2^{\mathrm{a}}$ ed. Rio de Janeiro: Livraria Francisco Alves, 1944.

RYSER, H.J. Combinatorial Mathematics: the carus mathematical monograph, New York, 1963.

SÃO PAULO, estado. Secretaria da Educação, Coordenadoria de Estudos e Normas Pedagógicas. Proposta Curricular para o Ensino de Matemática $2^{\circ}$ grau (Matemática). $3^{\text {a }}$ ed.. São Paulo: SE/CENP, 1992.

SÃO PAULO, estado. Secretaria da Educação, Coordenadoria de Estudos e Normas Pedagógicas, Fundação para o Desenvolvimento da Educação. Proposta Curricular do Estado de São Paulo: Matemática. Fini, M. I. (coord.) São Paulo: SEE, 2008.

Caderno do professor: matemática, ensino médio $-2^{a}$ série, $3^{\circ}$ bimestre/ Secretaria da Educação; Fini, M. I. (coord.), Machado, N.J.; Granja, C.E.S.C.; Mello, J.L.P.; Moisés, R.P.; Spinelli, W. (equipe) São Paulo: SEE, 2008.

SANTOS, J.P.O., MELLO, M.P., MURARI, I.T.C., Introdução à Análise Combinatória. Campinas, SP: UNICAMP, 1995.

SCHIELACK, J.F.; CHANCELLOR, D. Stop, Look, Listen: Building Reflection into Continuing Professional Development. In: AICHELE, D.B.; COXFORD, A.F. Professional Development for Teachers of Mathematics. Reston: NCTM, p.304-307, 1994.

SCHOOL MATHEMATICS STUDY GROUP (org.), Matemática-curso colegial. v.02. Rio de Janeiro: Centro de Publicações Técnicas da Aliança, 1964.

SCHROEDER, T.L., LESTER Jr., F.K. Developing Understanding in Mathematics via Problem Solving, TRAFTON, P.R., SHULTE, A.P. (Ed.) New Directions for Elementary School Mathematics. Reston, VA: National Council of Teachers of Mathematics, p.31-42, 1989. (Yearbook).

SMITH, D.E. History of Mathematics-Special Topics of Elementary Mathematics, New York: Dover Publications, Inc., v. 02, 1958.

SOARES, F.S., DASSIE, B.A., ROCHA, J.L. Ensino de matemática no século XX - da Reforma Francisco Campos à Matemática Moderna. Horizontes, Bragança Paulista, v.22, n.1, p.7-15, jan.jun. 2004.

SOUZA, A.C.P. I Congresso Nacional das Licenciaturas. Anais. Análise Combinatória no Ensino Médio Apoiada na Metodologia de Ensino-Aprendizagem-Avaliação de Matemática através da Resolução de Problemas. Mackenzie - São Paulo-SP, 2007.

II Seminário de Histórias e Investigações de/em Aulas de Matemática. Anais. Análise Combinatória: uma abordagem com compreensão apoiada na metodologia de ensinoaprendizagem-avaliação de matemática através da resolução de problemas, FE: UNICAMP Campinas - SP, 2008. 
SRIRAMAN, B.; ENGLISH, L. D. Combinatorial Mathematics: Research into Practice. Mathematics Teacher, vol.98, 182-191, NCTM, outubro 2004.

STANIC, G. M. A.; KILPATRICK, J. Historical Perspectives on Problem Solving in the Mathematics Curriculum. In: Charles, R. I.; Silver, E. A. (Eds.) The Teaching and Assessing of Mathematical Problem Solving. Reston: NCTM, p. 1-22, 1989.

TINOCO, L. Quando e como um professor está fazendo Educação Matemática. In: BOLEMA - Boletim de Educação Matemática. Rio Claro: UNESP, n.07, p.68-77, 1991.

TROTTA, F., IMENES, L.M.P., JAKUBOVIC, J., Matemática Aplicada $2^{\mathbf{0}}$ grau, São Paulo: Moderna, 1979.

VALE, I.; PIMENTEL, T. Resolução de problemas In: PALHARES, P. Elementos de Matemática para professores do Ensino Básico. Lisboa: Lidel, p.6-51, 2004.

VALENTE, W.R. (org.) Euclides Roxo e a modernização do ensino de Matemática no Brasil, São Paulo: SBEM, 2003.

VAN DE WALLE, J.A. Elementary and Middle School Mathematics. New York: Longman, 2001.

VELOSO, G. Matemática Discreta: relações de recorrência num contexto de resolução de problemas. Revista Educação e Matemática, nº43, Maio/Junho de 1997 (Portugal).

WEISSGLASS, J. Changing Mathematics Teaching Means Changing Ourselves: Implications for Professional Development. In: AICHELE, D.B.; COXFORD, A.F. Professional Development for Teachers of Mathematics. Reston: NCTM, p.67-78, 1994.

\section{Bibliografia Complementar}

CARPENTER, T.P., Teaching as Problem Solving In: Charles, R.I.; Silver, E.A., The Teaching and Assessing of Mathematical Problem Solving, NCTM, 1989.

KATZ, V. J. A History of mathematics - An Introduction. Harper Collins College Publishers, 1993.

KILPATRICK, J.; SILVER, E.A., Unfinished Business: Challenges for Mathematics Educators in the Next Decads. In: BURKE, M.J. and CURCIO, F. (Org.) Learning Mathematics for a New Century, National Council of Teachers of Mathematics, Reston, Virginia, 2000. p. 223-235.

LOUREIRO, C. Multiplicação, combinatória e desafios. Revista Educação e Matemática, Lisboa-Portugal, número 44, 14-20, 1997.

MATHEMATICAL SCIENSES EDUCATION BOARD (MSEB). Everybody counts: A report to the nation on the future of mathematics education. Washington, DC: National Academy Press, 1989. 
SOUZA, A.C.P. Análise Combinatória no Ensino Médio Apoiada na Metodologia de Ensino de Matemática via Resolução de Problemas. UNORP - São José do Rio Preto-SP, 2001.

SOUZA, A.C.P.; NUNES, C.B. IX Encontro Nacional de Educação. Anais. A Resolução de problemas como metodologia de ensino-aprendizagem-avaliação de Matemática em sala de aula. Belo Horizonte - MG, 2007.

SOUZA, A.C.P. I Seminário de Histórias e Investigações de/em Aulas de Matemática. Anais. A Resolução de Problemas como metodologia no processo ensino-aprendizagem de Matemática. FE: UNICAMP, Campinas - SP, 2006.

XII Encontro Brasileiro de Estudantes de Pós-Graduação em Educação Matemática. Anais. Análise Combinatória apoiada na Metodologia de Ensino-AprendizagemAvaliação de Matemática através da Resolução de Problemas. Rio Claro - São Paulo-SP, 2008.

STURM, W. As possibilidades de um Ensino de Análise Combinatória sob uma Abordagem Alternativa. 1999. Dissertação (Mestrado em Educação) Campinas: UNICAMP.

VAN DE WALLE, J.A.; LOVIN, L.H. Teaching Student-Centered Mathematics - grades 5-8. New York, USA: Pearson, 2006.

VILENKIN, N.I.A. Combinatorics. New York e London: Academic Press, (?). 
ANEXO 


\section{EBRAPEM - XII Encontro Brasileiro de Estudantes de Pós-Graduação em} Educação Matemática, realizado na UNESP, Rio Claro-SP, no período de 05 a 07 de setembro de 2008, enviamos o trabalho Comunicação científica intitulado Análise Combinatória apoiada na metodologia de ensino-aprendizagem-avaliação de matemática através da resolução de problemas.

\section{Análise Combinatória apoiada na Metodologia de Ensino-Aprendizagem-Avaliação de Matemática através da resolução de problemas}

Analucia Castro Pimenta de Souza

Orientadora: Lourdes de la Rosa Onuchic

Programa de Pós-Graduação em Educação Matemática

UNESP- Rio Claro

\section{Metodologia da Pesquisa}

\subsection{Metodologia de Thomas A. Romberg}

O objetivo da pesquisa em educação matemática deveria produzir novo conhecimento sobre o ensino e a aprendizagem de matemática, porque os alunos aprendem a maior parte de sua matemática nas salas de aula, na escola. Acredito que a principal missão de um programa de pesquisa seria o de identificar a maioria dos componentes das salas de aula que promovem compreensão matemática e esclarecem algumas das características organizacionais que contribuem para ou impedem a operação de tais salas de aula. (ROMBERG, 1997, p. 379)

Thomas A. Romberg (1992), matemático e professor da Universidade de WisconsinMadison-USA, descreve, no artigo intitulado "Perspectives on Scholarship and Research Methods" (Perspectivas sobre o Conhecimento e Métodos de Pesquisa) no Handbook of Research on Mathematics Teaching and Learning”, Grows, D. (Ed.), NCTM, 1992 (Manual de Pesquisa em Ensino e Aprendizagem Matemática), a Educação Matemática como um campo de estudo; as atividades dos pesquisadores; os métodos de pesquisa usados pelos pesquisadores e por fim apresenta cinco tendências gerais de pesquisa e suas relações com estudos em Educação Matemática.

1.1.1 Educação Matemática como um campo de estudo. 
Romberg (1992) considera a Educação Matemática como um campo de estudo no qual se investigam questões relacionadas aos processos envolvidos no ensino e na aprendizagem de Matemática nas escolas. E ainda, as perspectivas e procedimentos de investigação escolar. O diagrama abaixo (de E.G. Begle, apud Romberg, 1992, p.95) elucida como os componentes do processo da educação escolar (escola, professores, alunos, Matemática) estão interrelacionados.

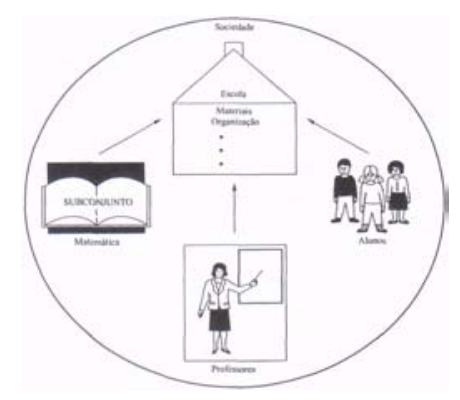

\section{Identificando a pesquisa no modelo proposto por Romberg.}

A relação do pesquisador com o objeto de estudo:

Pesquisa em educação matemática tem que lidar inicialmente com problemas de ensinamento e aprendizagem, como é definido por pesquisadores. Eles se submetem às pesquisas porque conhecem práticas que deveriam ser melhores e têm uma visão de como tal melhora pode ser alcançada. Eles tendem a fazer pesquisa aplicada e não pura. (KILPATRICK, 1992, p.02)

Para o desenvolvimento deste trabalho, adotamos a metodologia de pesquisa de Romberg, a ser apresentada num fluxograma constituído de dez atividades divididas em três blocos. Passamos agora a identificar nossa pesquisa inserida nos moldes propostos por Romberg.

1.1.2 As atividades dos pesquisadores

O termo pesquisa refere-se a processos - as coisas que se faz, não os objetos que alguém pode tocar e ver. Além disso, fazer pesquisa não pode ser visto como uma ação mecânica ou como um conjunto de atividades que indivíduos seguem de uma maneira prescrita ou predeterminada. (Romberg, 2007, p.97) 
Romberg ressalta que as atividades envolvidas em fazer pesquisa incorporam mais características de uma arte do que de uma disciplina puramente técnica, atividades estas que dão respaldo aos pesquisadores e explicitam o desenvolvimento da pesquisa.

Desse modo, Romberg descreve dez atividades, organizadas num fluxograma, que são distribuídas em três blocos: o primeiro bloco trata da identificação do problema (atividades 1 , 2, 3, e 4); o segundo bloco vê de que modo pode-se resolver o problema, onde estratégias e procedimentos de trabalho são levantados e selecionados (atividades 5 e 6); e o terceiro e último bloco, após o Procedimento geral ser posto em ação, trata da análise das informações obtidas, buscando tudo o que ficou evidente frente à questão ou conjectura levantada. Romberg justifica esse modelo dizendo que estas atividades são importantes pois esclarecem alguns problemas comuns que pessoas, não familiarizadas com pesquisa, enfrentam na compreensão do processo. Ainda o autor ressalta que as atividades descritas não precisam ser seguidas necessariamente na ordem apresentada, e afirma que:

A interação entre fatores tais como a intenção do pesquisador, as suposições, as conjecturas, a disponibilidade de informações, os métodos e, assim por diante, não podem ser separados na prática tão nitidamente. (Romberg, 2007, p.98)

A seguir, são apresentadas abaixo as atividades de pesquisa e como elas estão relacionadas. Essa seqüência de atividades, denominada por nós Metodologia de Romberg, será adotada neste trabalho de pesquisa. 


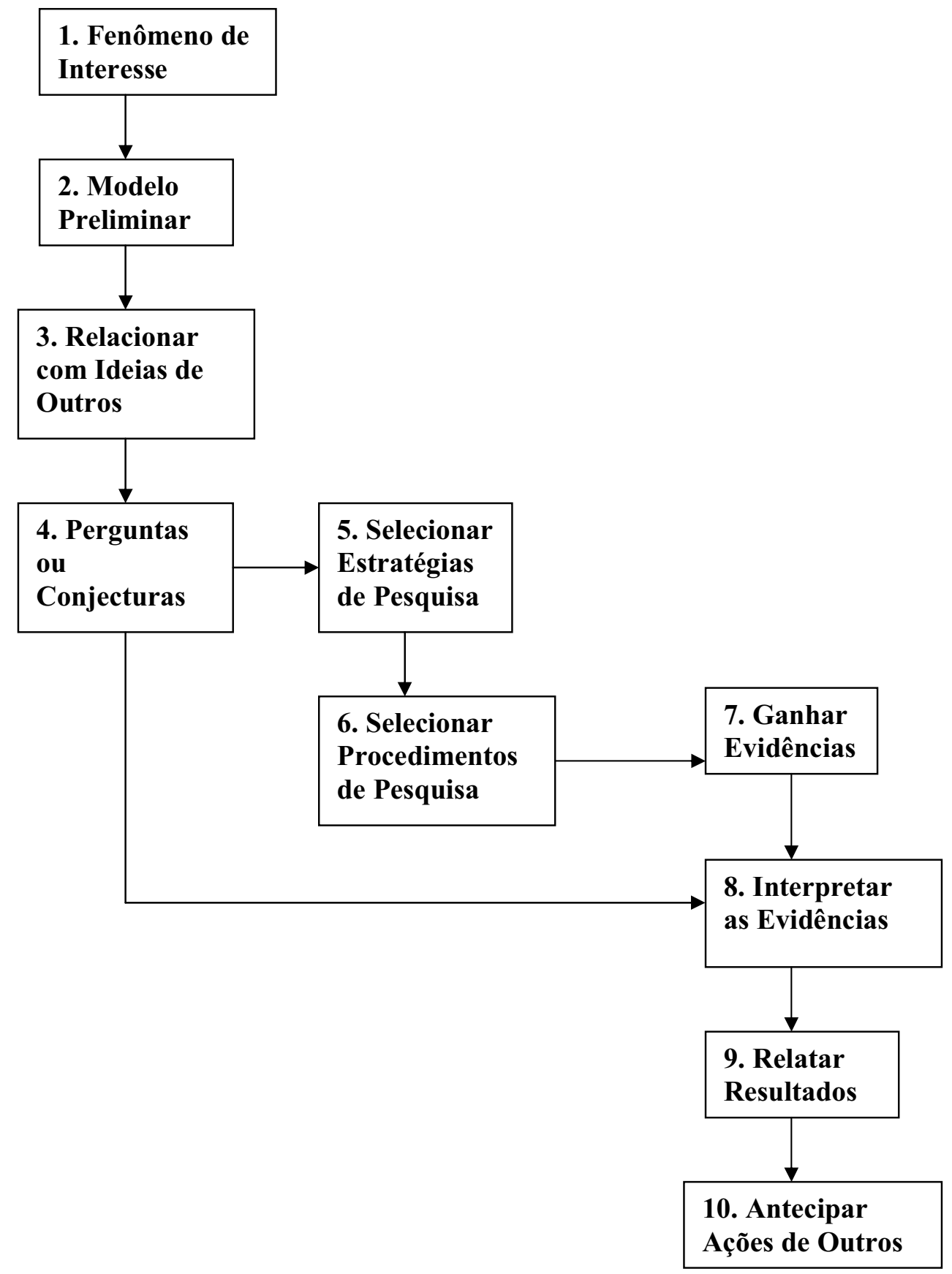

$1^{\circ}$ bloco: Identificação do problema da pesquisa

As quatro primeiras atividades são as mais importantes, pois elas estão envolvidas com o situar as idéias de alguém sobre um particular problema no trabalho de outros estudiosos e decidir o que se quer investigar. (Romberg, 2007, p.98) 


\section{$\underline{1^{\mathrm{a}} \text { atividade: Identificar um fenômeno de interesse }}$}

Romberg diz que o fenômeno de interesse de toda e qualquer pesquisa começa com uma curiosidade sobre um fenômeno particular do mundo real. Conceituamos fenômeno como sendo um fato escrito de interesse científico que pode ser descrito e explicado cientificamente.

A definição do meu fenômeno de interesse deu-se através do Curso de Especialização em Educação Matemática (UNORP - São José do Rio Preto-SP), Pós graduação - lato-sensu; pela participação no GTERP (Grupo de trabalho e estudos em Resolução de Problemas); e a reflexão sobre minha prática docente. No final do curso de Especialização, foi redigida uma monografia como parte da avaliação. O tema escolhido foi Análise Combinatória e a busca de uma metodologia alternativa para o trabalho em sala de aula. Isso se deu por minha reflexão como aluna pois, nesse tempo, tive dificuldade em entender os conceitos envolvidos na Análise Combinatória, onde estes foram trabalhados sempre através de fórmula-aplicação. Também, como professora, tive dificuldade em trabalhá-los pois era um grande desafio trabalhar Análise Combinatória de modo a conseguir proporcionar aos alunos sucesso no aprendizado desse conteúdo. Minha participação no GTERP foi de suma importância para estruturar melhor meu projeto de pesquisa na UNESP e amadurecer a idéia de pesquisar esse tema. Desse modo, foi definido meu fenômeno de interesse: Trabalhar com Análise Combinatória, em sala de aula do Ensino Médio, a partir da Metodologia de ensinoaprendizagem-avaliação de Matemática através da resolução de problemas.

\section{$\underline{2^{\mathrm{a}} \text { atividade: Construir um modelo preliminar }}$}

Nesta atividade é construído um modelo formado pelas variáveis-chave do fenômeno de interesse e as relações implícitas entre elas.

Ao recomendar a construção de um modelo preliminar como uma das atividades (atividade2) que os pesquisadores devem realizar, Romberg (1992) se distingue de outros autores que tratam do assunto, tornando seu trabalho, neste aspecto, original.

[...] ele consiste num esquema onde se indicam as variáveis componentes do fenômeno e as relações entre elas. Variáveis são os elementos que compõem e interferem no fenômeno de interesse. (ALLEVATO, 2005, p.20)

O modelo preliminar serve como um ponto de partida e mostra como as variáveis identificadas pelo pesquisador possivelmente estão operando. 


\section{Modelo Preliminar}

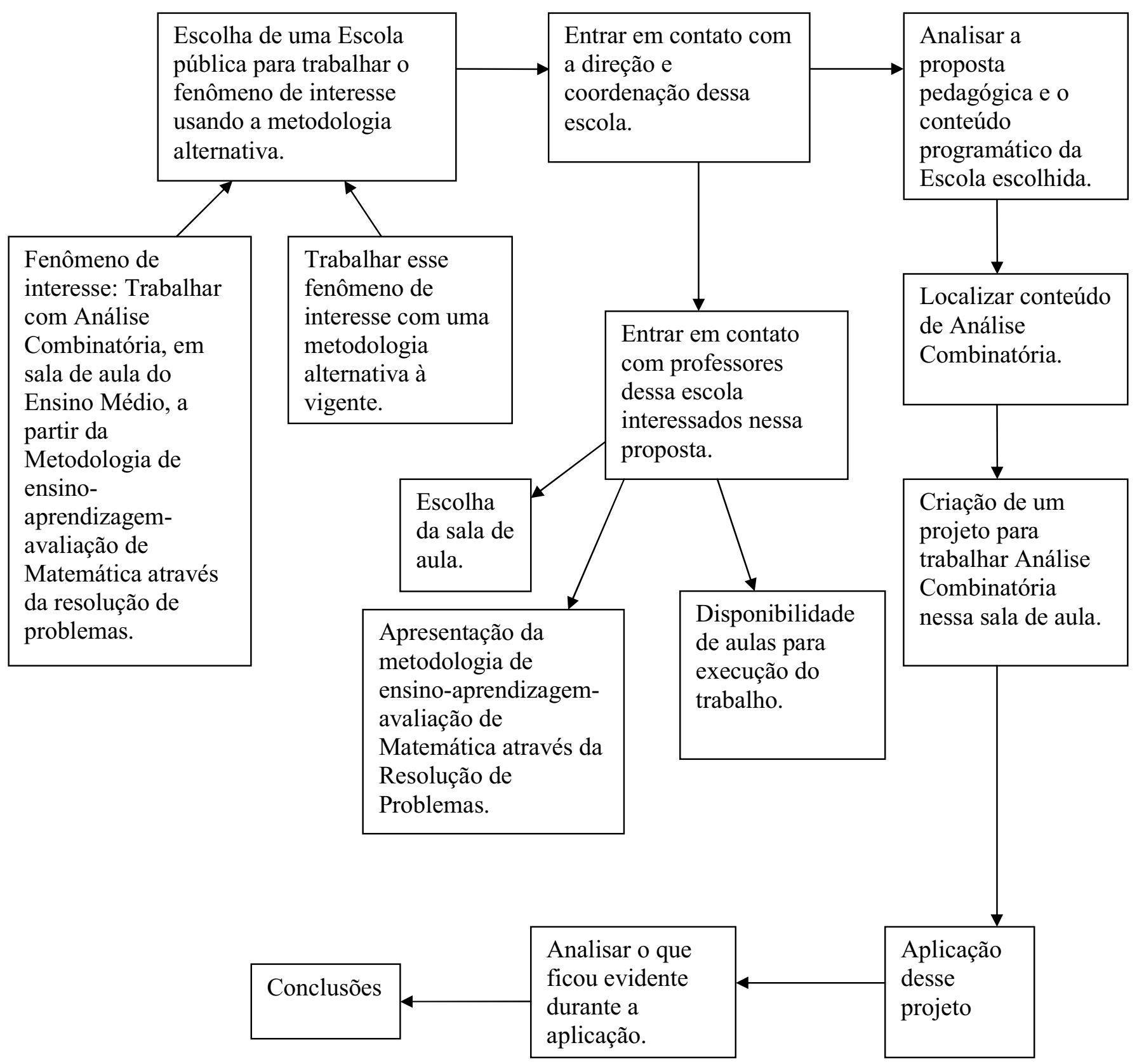

Esse Modelo Preliminar apresenta uma organização dos passos a serem seguidos para o desenvolvimento da pesquisa pretendida. Construído o Modelo Preliminar, percebemos que relacionando-o com o Fenômeno de Interesse, poderíamos trabalhar Análise Combinatória, 
em sala de aula do Ensino Médio, a partir da metodologia de ensino-aprendizagem-avaliação de Matemática através da resolução de problemas, de modo a visualizar o percurso do trabalho desta pesquisa. Foram delineados os seguintes passos: definição da escola para trabalhar o fenômeno de interesse; entrar em contato com a direção e a coordenação da escola para obter permissão de aplicar um projeto novo; entrar em contato com professores dessa escola interessados nessa proposta; apresentação da Metodologia de Ensino-AprendizagemAvaliação de Matemática através da Resolução de Problemas; Escolha de uma sala de aula para aplicação do projeto; disponibilidade de aulas para a execução do trabalho; analisar a proposta pedagógica e o conteúdo programático da Escola escolhida; localizar o conteúdo de Análise Combinatória dentro do planejamento escolar; a criação de um projeto para trabalhar Análise Combinatória nessa sala de aula; a aplicação desse projeto; analisar o que ficou evidente durante sua aplicação; e tirar conclusões.

Mas, antes de iniciar esta pesquisa, eu estava como professora efetiva da rede estadual de ensino do Estado de São Paulo com cargo na cidade de Olímpia - SP. Como ingressei no Mestrado, fiz a inscrição para concorrer a um cargo substituto em Rio Claro para poder cursar o Mestrado e desenvolver esta pesquisa. O artigo 22 da Lei Complementar $n^{\circ} 444 / 85$, regulamentado pelo Decreto 24.948 de 03/04/1986 que permite que o professor ocupe um cargo em outra escola, assumindo aulas livres ou aulas de um professor em afastamento. Desse modo, fui transferida para uma escola em Rio Claro, a Escola Professora Oscália Góes Correa Santos que, na ocasião, tinha algumas salas da $2^{\mathrm{a}}$ série do Ensino Médio, turma que interessava à minha pesquisa.

Uma das variáveis do Modelo Preliminar foi modificada. Ao invés de procurar um professor da escola para fazer a pesquisa, passei a ser professora da $2^{\mathrm{a}}$ série do Ensino Médio, sala pretendida para desenvolver a pesquisa e, então, meu Modelo Preliminar sofreu uma importante mudança e, a seguir, meu Modelo Preliminar passou para um Modelo Modificado: 


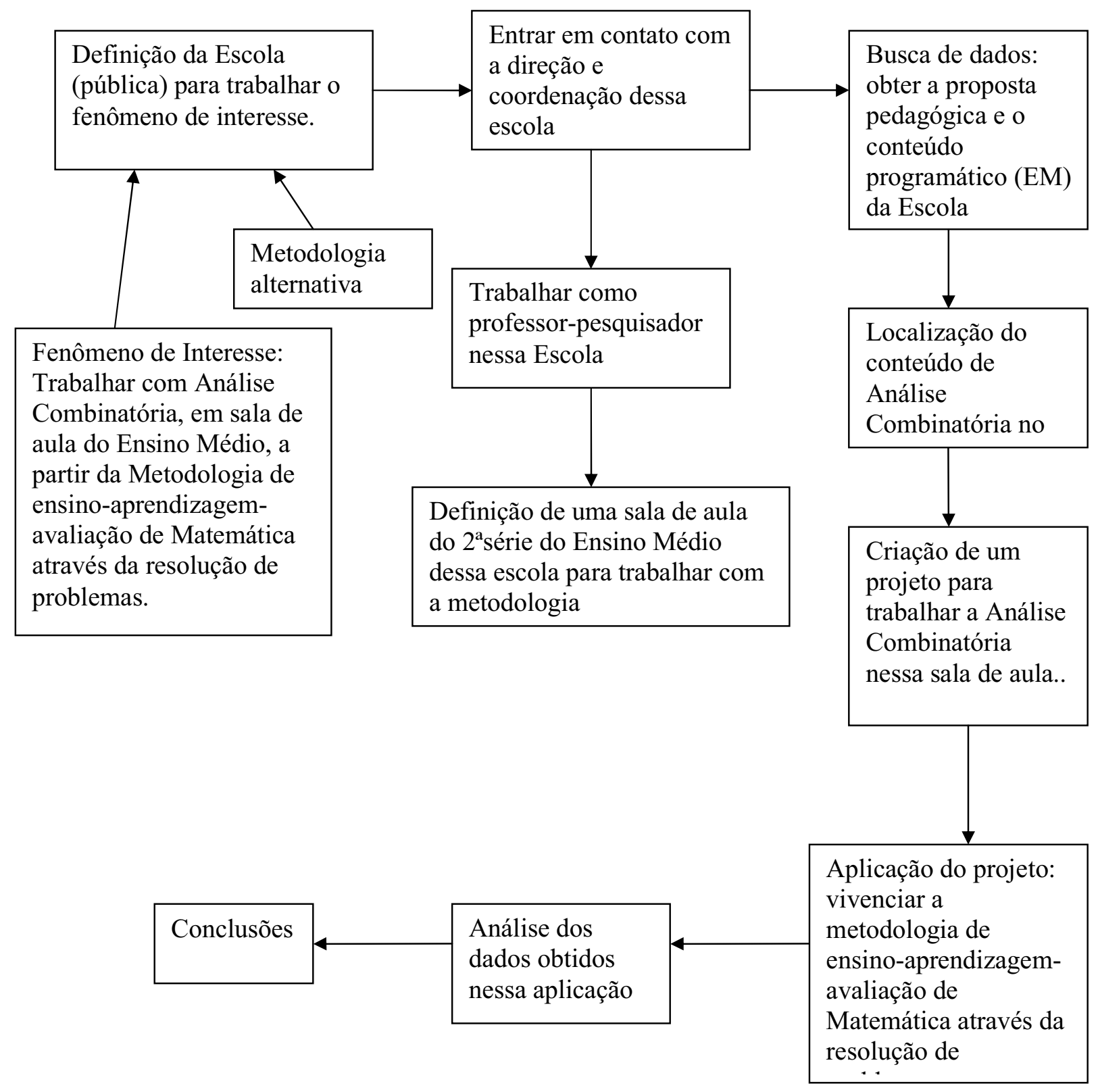

$\underline{3^{a}}$ atividade: Relacionar o fenômeno e o modelo com idéias de outros.

Esta atividade consiste em examinar o que outros pensam sobre o fenômeno de interesse e também em determinar se outras idéias podem explicar, ampliar ou modificar o modelo proposto. Romberg ressalta que o pesquisador deve reconhecer que cada investigador é um membro de um particular grupo de pesquisa que tem defendido uma determinada "visão de mundo" (2007, p.100). Desse modo, o pesquisador deve tomar cuidado para não optar por 
um autor que não esteja trabalhando sobre a linha de interesse do fenômeno escolhido e dentro da linha de resolução de problemas.

Definido nosso Fenômeno de Interesse e construído o Modelo Modificado, serão realizadas leituras relacionadas ao Fenômeno de Interesse, ou seja, queremos saber o que outros autores escreveram sobre Matemática Discreta, Análise Combinatória, Resolução de Problemas e a prática de um professor-reflexivo. Conhecer o que outros autores pensam e quais são suas idéias em pesquisas desenvolvidas relacionadas ao tema proporciona referências teóricas relevantes para o trabalho, pois dá a possibilidade de se ampliarem as investigações durante a pesquisa. Um vasto conhecimento de estudos relacionados ao seu tema de investigação permitirá ao pesquisador ter parâmetros para o estudo do fenômeno, particularmente para a interpretação das evidências (ALLEVATO, 2005, p.22)

Nesta atividade, delineamos a fundamentação teórica do trabalho. As principais fontes de pesquisa serão: livros didáticos, acadêmicos, PCN (Parâmetros Curriculares Nacionais Ensino Médio - de Matemática), a Proposta Curricular do Estado de São Paulo; artigos em revistas; teses e dissertações. Serão aplicadas entrevistas a professores de Matemática do Ensino Médio, em particular os que trabalham ou deveriam trabalhar com Análise Combinatória.

\section{- Matemática Discreta}

Para os Standards (1989/1991), a Matemática Discreta diz respeito às propriedades matemáticas de conjuntos e sistemas numeráveis, e o seu estudo é indispensável no mundo do processamento da informação e na resolução de problemas que envolvem métodos computacionais. O NCTM argumenta que "os computadores são essencialmente máquinas finitas e discretas" que vêm exercendo uma influência crescente nos modos de criar e usar a Matemática. (ABRANTES, 1994, p.17)

Trataremos sobre a Matemática Discreta, ramo da matemática do qual a Análise Combinatória faz parte e que é abordada neste trabalho. Descreveremos o que é Matemática Discreta, falaremos sobre sua importância, sua forma de ensino e de quando se deu sua inserção no currículo da matemática escolar.

Suponha que apresentássemos aos alunos o seguinte problema: "Quantos números de dois algarismos distintos podemos formar com os algarismos $1,2,3,4,5,6,7$, 8, e 9?" $\mathrm{O}$ objetivo do problema é determinar a quantidade de números formados com os algarismos dados. Os alunos poderiam iniciar sua resolução, por exemplo, do seguinte modo: começando com o algarismo 1 para a dezena, teríamos como algarismo das unidades o 2,3, 4, 5, 6, 7, 8 e 9 
então temos 8 números; começando com o algarismo 2, temos também 8 números, seguindo o mesmo raciocínio temos o total de 72 números.

E se um aluno respondesse: “encontrei 71 números e meio!” Seria possível? Sabemos que não, pois estamos tratando de entes discretos, ou seja, objetos separados (descontínuos) , consistindo de partes distintas. Estamos trabalhando com conjunto finito de números, então seria absurdo considerar que um aluno encontrasse 71 números e meio.

O professor poderia comentar, por exemplo, sobre a tela de uma televisão ou um computador, que são formados por milhares de linhas e colunas (matriz) definindo muitos pontos e que não formam um conjunto contínuo.

As situações acima retratam exemplos da Matemática Discreta. Seu estudo tem destaque na área da informática. Temos que o computador é uma estrutura finita, e muitas das suas propriedades podem ser entendidas dentro do universo da Matemática Discreta.

Mas o que é Matemática Discreta?

No livro Discrete Mathematics across the Curriculum, k-2, 1991 Yearbook, Margaret J. Kenney e Christian R. Hirsch (NCTM), apresentam, em seus capítulos, relevâncias sobre a Matemática Discreta tais como: por que é importante; o que consta sobre ela nos vários níveis escolares; onde aparece no currículo; e algumas idéias sobre seu ensino. Atende às recomendações apresentadas nos Standards, tais como: Matemática Discreta permite fazer conexões matemáticas; Matemática Discreta proporciona um conjunto de resoluções de problemas com aplicações no mundo real; Matemática Discreta aproveita-se de cenários tecnológicos; Matemática Discreta promove pensamento crítico e raciocínio matemático.

No capítulo 1, Dossey define a Matemática Discreta como a Matemática de nosso tempo dizendo que ela é um ramo da matemática que cresceu rapidamente em importância na década passada. Este crescimento é devido em grande parte às muitas aplicações de seus princípios em negócios e para seus vínculos próximos à ciência da computação. Os teoremas e as estratégias de resolução de problemas centrais à matemática discreta, combinados com o aumento crescente computacional dos computadores, abriram áreas de investigação e aplicações inteiramente novas. Entretanto, cidadãos comuns, e muitos professores de matemática, nunca ouviram falar sobre matemática discreta. O que é isso, perguntam?

O dicionário define discreto como "distinto de outros; separado; consistindo de partes distintas; descontínuas". Matemática discreta, então, envolve o estudo de objetos e idéias que podem ser divididas em partes “separadas" ou "descontínuas". Então Matemática Discreta pode ser contrastada com a noção clássica de matemática contínua, que é a matemática subjacente à maioria da álgebra e do cálculo. Esses dois tópicos tipicamente usam números 
reais ou complexos como um domínio para suas funções. A Matemática Discreta, por contraste, é necessária para a investigação de cenários onde as funções são definidas sobre conjuntos de números discretos ou finitos tais como partes dos inteiros positivos.

Na Matemática Discreta há uma grande quantidade de idéias relacionadas. Por exemplo o Princípio de Contagem, arranjos de objetos discretos (permutações, combinações, seleções), outros princípios de contagem (princípio de inclusão/exclusão, o princípio da casa dos pombos); algumas idéias básicas e úteis da teoria dos conjuntos (união e interseção); o estudo de estruturas discretas (rede de comunicação e grafos).

Os problemas de Matemática Discreta podem ser classificados em três amplas categorias: $1^{\text {a }}$ ) Problemas de existência: tratam de saber se um problema dado tem uma solução ou não; $2^{\mathrm{a}}$ ) Problemas de contagem: investigam quantas soluções podem existir em problemas com soluções conhecidas e $3^{\text {a }}$ ) Problemas de otimização: focalizam encontrar uma melhor solução para um problema particular.

\section{- Análise Combinatória}

Análise Combinatória é considerada um tópico difícil de ser abordado na sala de aula, pois geralmente é trabalhada através de "fórmula-aplicação", deixando lacunas na compreensão dos conceitos de arranjo, permutação e combinação.

O modo como o professor trabalha com a Análise Combinatória interfere diretamente na aprendizagem do aluno. Adotar uma metodologia que permita a participação do aluno na construção desses conceitos pode contribuir para uma compreensão mais significativa, considerando o dar sentido à matemática e, também, levando em conta o cotidiano do aluno ao trabalhar com problemas contextualizados. Assim, o papel do professor é fundamental para que isso se efetive. Desse modo, exige do professor planejar, explicitando devidamente os objetivos de cada aula, as estratégias e os procedimentos na resolução de problemas dados e fazendo uso de critérios de avaliação.

Em geral numa aula tradicional, alunos procuram identificar a fórmula correta para arranjo, permutação ou combinação ao resolver um problema. Isso ocorre por eles não terem participado da construção desses conceitos, apenas o resolveram de modo mecânico.

Problemas combinatórios são usualmente considerados difíceis pela maioria dos alunos e professores de matemática. Talvez a principal dificuldade seja a da conexão correta entre o problema dado e a teoria matemática correspondente. É difícil determinar se o problema combinatório dado é um problema de arranjo, de permutação ou de combinação, ou então se é suficiente usar diretamente o princípio multiplicativo. (HARIKI, 1996, p.29) 
Faz-se necessário então um estudo que explore os conceitos primitivos da Análise Combinatória, o Princípio Fundamental da Contagem ou os Princípio Multiplicativo e Aditivo, trabalhando de modo intuitivo com o aluno, descrevendo os casos possíveis, formando agrupamentos e contando-os, utilizando técnicas de contagem com o auxílio da árvore de possibilidades ou tabelas de dupla entrada. "Uma análise adequada dos processos de formação de agrupamentos, pelos alunos, evitará defeitos freqüentes entre os iniciantes, decorrente da tendência de adivinhar a resposta ou o processo de contagem" (Proposta Curricular, 1992, p.83) (1 $1^{\mathrm{a} e d .1986)}$

Resolvendo os problemas com esse enfoque, dando-se o tempo necessário, deve se levar o aluno à sistematização da contagem bem como à sistematização dos conceitos de arranjo, permutação e combinação. Os problemas iniciais devem ser elaborados com poucos elementos, através da solução intuitiva e da contagem direta, para destacar quantas e quais são as possibilidades neste tipo de abordagem. Os alunos poderão observar que a contagem direta é impraticável na maioria dos casos e constatarão que é preciso perceber certas regularidades para desenvolverem técnicas de contagem apropriadas, que generalizem as soluções. Os alunos perceberão que, ao contar ou fazer os agrupamentos através das técnicas de contagem, estes se diferenciam pela ordem e/ou natureza dos elementos dados no problema.

Técnicas de contagem é um tópico fundamental em Matemática Discreta e tem aplicações direta como ferramentas na resolução de problema geral. Pensar sob um ponto de vista combinatório requer que os alunos explorem criativamente os aspectos estruturais de uma situação problema, com o desejo de reduzi-lo a cada caso mais simples ou a um problema previamente resolvido. Como resultado, muitas possibilidades de solução são analisadas sistematicamente, e um conhecimento útil é ganho a partir de certas tentativas corretas e incorretas. O processo geral é o raciocínio combinatório ou "a arte de contar sem contar" (Townsend 1987, apud Johnson, 1991, p.128)

Analisando as técnicas de contagem com relação aos agrupamentos envolvidos nas situações-problema, bem como o processo de formação dos agrupamentos, os alunos estarão preparados para sistematizar os conceitos envolvidos na Análise Combinatória e entender a necessidade do uso de fórmulas, chegando à solução de forma mais rápida, quando o número de elementos envolvidos nos agrupamentos for grande.

Desse modo, a Análise Combinatória está relacionada essencialmente com o processo de contagem de um número de elementos de um conjunto, sem que haja a necessidade de enumerá-los. 
Nesse sentido, Roxo et al (1944) descrevem:

Denomina-se análise combinatória ao estudo da formação, contagem e propriedades dos agrupamentos que podem constituir-se, segundo determinados critérios, com os objetos de uma coleção. Esses agrupamentos distinguem-se, fundamentalmente, em três espécies: arranjos, permutações e combinações, e podem ser formados de objetos distintos ou repetidos. (p.81)

Analisando os livros didáticos, percebe-se que a maioria apresenta o conteúdo de Análise Combinatória dando ênfase à utilização de fórmulas, sem a preocupação da dedução das mesmas. O que não ocorre no livro de Trotta et al (1979), que apresenta o conteúdo iniciando com a resolução de problemas de modo que o aluno desenvolva o raciocínio combinatório partindo de processos de contagem. Posteriormente a esse primeiro contato, são apresentadas as definições de arranjo, permutação e combinação. Os arranjos são definidos como seqüências de elementos; as permutações são apresentadas como um caso particular de arranjos sem repetição e as combinações são definidas como subconjuntos de um conjunto dado.

\section{Análise dos livros didáticos em ordem cronológica}

No livro Exame de Textos: Análise de livros de Matemática para o Ensino Médio (2001), organizado por Elon, são utilizados alguns critérios para a análise de doze coleções de livros didáticos do Ensino Médio: conceituação (erros, excesso de formalismo, linguagem inadequada, imprecisão, obscuridade, confusão de conceitos, conexões); manipulação; aplicação; qualidade didática; adequação do livro à realidade atual e papel educativo da avaliação. Baseado nesse livro, estabelecemos alguns critérios para analisar livros didáticos com o objetivo de saber como a Análise Combinatória é abordada nesses livros. Os critérios para análise foram: 1) Se partem ou não de problemas; 2) O livro didático permite um trabalho colaborativo com os alunos?; 3) Formalização dos conceitos de Análise Combinatória se dá no início, durante a resolução do problema ou depois do problema resolvido?; 4) É um dos recursos didáticos que contribui para o trabalho do professor em sala de aula?

Livros analisados: Décadas de 40,50 e 60: Matemática $2^{\circ}$ ciclo $-2^{\mathrm{a}}$ série (1944), Euclides Roxo, Roberto Peixoto, Haroldo Cunha, Dacorso Netto; Matemática $-2^{\text {a }}$ série colegial (1956), Edison Farah, Benedito Castrucci; Matemática - curso colegial - vol II (1964), School Mathematics Study Group. Década de 70: Matemática para o $2^{\circ}$ ano colegial (1975), Ary Quintella; Prelúdio à Análise Combinatória (1975), Arago de C. Bachx, Luiz M. B. Poppe, Raymundo N. O. Tavares; Matemática Aplicada: 2, 2º grau (1979), Fernando 
Trotta, Luiz Márcio Pereira Imenes, José Jakubovic. Década de 90: Análise Combinatória e Probabilidade (1991), Augusto César de Oliveira Morgado et al; Fundamentos da Matemática Elementar: combinatória/probabilidade (1993), Samuel Hazzan; A Matemática no Ensino Médio vol.2 (1998), Elon Lages Lima et al; Matemática (volume único) (1999), Manoel

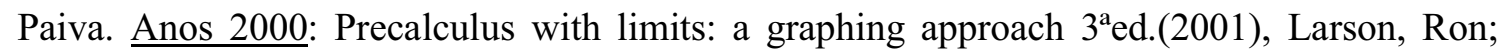
Hostetler, Robert P.; Edwards, Bruce H.; Matemática (2004), Luiz Roberto Dante. Os livros apresentam uma abordagem centrada no professor e não no aluno

\section{- Resolução de Problemas}

Problemas matemáticos, do tipo que são encontrados na história antiga: egípcia, chinesa e grega, são apresentados em livros-texto de matemática nos séculos XIX e XX com a mesma ênfase. A idéia é a mesma. Alguém cria um problema, resolve-o, apresenta sua solução e oferece aos outros uma lista de problemas do mesmo tipo para serem resolvidos da mesma forma. Assim não se exige do aluno criar estratégias para a resolução do problema, o aluno "aprende" mecanicamente o que lhe é "ensinado", não aprende a pensar, não raciocina.

Resolver problemas sempre foi um desafio para alunos e professores, devido aos métodos enfatizarem a repetição e a mecanização da resolução de problemas. Embora as reformas de ensino propostas no século XX: o ensino de matemática por repetição, o ensino de matemática com compreensão, a Matemática Moderna e a Resolução de Problemas, tenham proposto novos rumos de trabalho mais produtivo, o professor, nunca chamado a participar delas, mostra-se, na hora da aplicação, não preparado para empregá-las.

As primeiras pesquisas sobre o Ensino de Matemática através da Resolução de Problemas iniciou-se sob a influência de George Polya (Universidade de Stanford-EUA), que propõe, no livro A Arte de Resolver Problemas (1994) 1ª ed. em 1945, um método em quatro etapas para a resolução de problemas: $1^{\circ}$ ) compreender o problema, $2^{\circ}$ ) elaborar um plano, $3^{\circ}$ ) executar o plano, $4^{\circ}$ ) fazer o retrospecto ou verificação da solução do problema original. Desenvolve um processo heurístico ao longo da resolução de problemas. Alan H. Schoenfeld apresentou, a partir de 1978, trabalhos semelhantes ao de Polya.

Mas o trabalho desses autores procura fixar algumas regras, apresentando estratégias que podem levar à solução do problema. Este não é o enfoque dado à nossa pesquisa, pois, nela, pretendemos ensinar matemática através da resolução de problemas.

Desde os anos 80, a orientação de Polya faz parte da discussão da comunidade brasileira de Educação Matemática. A proposta de Resolução de Problemas passou por várias modificações, sendo que o NCTM (Conselho Nacional de Professores de Matemática), entidade norte-americana, apresentou um documento "An Agenda for Action" (Uma Agenda 
para Ação), recomendando que os professores de Matemática deveriam criar situações nas salas de aula onde a Resolução de Problemas pudesse desabrochar.

Na década de 90, assume-se a Resolução de Problemas como um ponto de partida e um meio de se ensinar Matemática, sendo o problema um ponto de partida e o desencadeador ou gerador do processo de construção do conhecimento. Para Dante, "problema é qualquer situação que exija o pensar do indivíduo para "solucioná-la"(apud Rodrigues, 1992, p.27). Ampliamos essa colocação dizendo que é muito importante, também, que o indivíduo esteja interessado em resolvê-lo.

O trabalho de Mendonça, (1993), apresenta três interpretações para a Resolução de Problemas: 1) como um objetivo, significa que se ensina Matemática para resolver problemas, Resolução de Problemas é a meta final, 2) como um processo, significa que a Resolução de Problemas é um meio para desenvolver o potencial heurístico do aluno, dirige-se ao desempenho do indivíduo como resolvedor, ou 3) como um ponto de partida, significa olhar o problema como um elemento que pode disparar um processo de construção do conhecimento matemático.

Já no trabalho de Gazire (1988) são apresentadas perspectivas em Educação Matemática para a Resolução de Problemas: 1) um novo conteúdo, 2) aplicação do conteúdo, e 3) um meio de se Ensinar Matemática. Nossa pesquisa se identifica com a última perspectiva: Resolução de Problemas como um meio de se ensinar Matemática, sendo o problema o gerador do processo de ensino-aprendizagem. Gazire apresenta a principal característica dessa perspectiva: "Se todo conteúdo a ser aprendido for iniciado numa situação de aprendizagem, através de um problema desafio, ocorrerá uma construção interiorizada do conhecimento a ser adquirido" (Gazire, 1988, p.124)

Nos PCN (1999) a Resolução de Problemas está presente como um caminho para o ensino de Matemática, identificando com o enfoque pretendido nesta pesquisa.

A metodologia de ensino de Matemática através da Resolução de Problemas tem por meta ajudar os alunos a se tornarem investigadores diante de uma situação desafiadora, um problema, de forma a compreender e questionar os conceitos de que irão necessitar. O papel do professor muda de "comunicador de conhecimento" para o de observador, organizador, consultor, mediador, controlador, incentivador da aprendizagem. Sendo assim, exige-se bastante do professor, “... o professor terá que enfrentar situações inesperadas em sala de aula e, em algumas oportunidades, deverá alterar aquilo que tinha planejado, ainda mais, terá que estar atento às dificuldades, apresentadas pelos alunos...” (RODRIGUES, 1992, p.29). 
$\underline{4^{\mathrm{a}} \text { atividade: Levantar questões específicas ou fazer uma conjectura baseada na razão }}$

Romberg considera essa atividade o passo-chave da pesquisa porque uma grande quantidade de perguntas possíveis aparece ao examinar-se um fenômeno particular, e decidir que perguntas examinar não é fácil (2007, p.100). O autor diz que as perguntas podem assumir uma das seguintes formas: caráter descritivo: quando orientadas no passado, questiona-se "Como as coisas chegaram a ser desta maneira?"e quando orientadas no presente, "Qual é a condição das coisas?”; caráter preditivo: quando orientadas no futuro, “O que acontecerá se eu fizer o seguinte?”

Romberg prefere as conjecturas às perguntas, as conjecturas estão baseadas em algumas relações entre as variáveis que caracterizam o fenômeno e nas idéias sobre aquelas variáveis-chave e suas relações com o esboçado no modelo (2007, p.100).

Diante do Fenômeno de Interesse e a preocupação com o ensino de Análise Combinatória, que desafia alunos e professores diante à dificuldade em trabalhá-la em sala de aula, temos algumas perguntas que nortearão a pesquisa:

- Como trabalhar com a Análise Combinatória através da metodologia de ensinoaprendizagem-avaliação de Matemática através da Resolução de Problemas?

- Qual seria a contribuição da metodologia de ensino-aprendizagem-avaliação de Matemática através da resolução de problemas na abordagem da Análise Combinatória?

- Como se mostra a formação dos conceitos de Análise Combinatória adotando a resolução de problemas como metodologia de ensino?

\section{$2^{\circ}$ bloco: Como resolver o problema levantado}

\section{$\underline{5^{a} \text { atividade: Selecionar uma estratégia geral de pesquisa. }}$}

Nesta atividade, o pesquisador deve decidir o que fazer para responder as questões que foram levantadas, ou seja, que métodos serão utilizados. Romberg diz que as estratégias selecionadas estão relacionadas às questões ou conjecturas que seleciona da visão de mundo, do modelo preliminar e da conjectura que se faz sobre a evidência necessária.

De posse do problema instalado para a pesquisa, o que segue é resolvê-lo. Como esse problema depende de muitos passos para chegar à solução, serão criadas além de uma estratégia geral, tantas estratégias auxiliares quantas sejam as variáveis do modelo modificado. Para cada estratégia selecionada há um correspondente procedimento a ser selecionado. Assim, haverá um Procedimento Geral e tantos procedimentos auxiliares necessários às estratégias selecionadas.

$\underline{6^{a} \text { atividade: Selecionar um procedimento geral para a pesquisa. }}$ 
Esta atividade mostra como fazer para coletar os dados, como selecionar uma amostra, como coletar uma informação (entrevista, pergunta, observação, teste), como organizar a informação uma vez que ela tenha sido coletada, e assim por diante. (2007, p.102)

\begin{tabular}{|c|c|}
\hline $\begin{array}{c}\mathbf{5}^{\mathrm{a}} \text { atividade. Selecionar Estratégias de } \\
\text { Pesquisa }\end{array}$ & $\begin{array}{c}6^{a} \text { atividade. Selecionar Procedimentos de } \\
\text { Pesquisa }\end{array}$ \\
\hline $\begin{array}{l}\text { Estratégia Geral (EG): Criar um Projeto } \\
\text { para ser aplicado na sala de aula. }\end{array}$ & $\begin{array}{c}\text { Procedimento Geral (PG): A criação do } \\
\text { Projeto }\end{array}$ \\
\hline $\begin{array}{l}\text { E1: Descrever como é a escola definida } \\
\text { para a realização da pesquisa }\end{array}$ & P1: Descrição da escola (documentos) \\
\hline $\begin{array}{l}\text { E2: Falar sobre a pesquisa pretendida para a } \\
\text { coordenação e direção da escola } \\
\text { direcionando ao uso de uma metodologia } \\
\text { alternativa. }\end{array}$ & $\begin{array}{l}\text { P2: Conversar com a Coordenação e Direção } \\
\text { da escola sobre a pesquisa pretendida. }\end{array}$ \\
\hline $\begin{array}{l}\text { E3: Apresentar para a direção } \\
\text { coordenação a metodologia a ser adotada } \\
\text { para a sala de aula }\end{array}$ & $\begin{array}{l}\text { P3: Explicitar para a Coordenação e Direção } \\
\text { a metodologia a ser adotada para a sala de } \\
\text { aula. }\end{array}$ \\
\hline $\begin{array}{l}\text { E4: Obter a proposta pedagógica da Escola } \\
\text { da Secretaria da Educação visando a análise } \\
\text { do conteúdo programático do Ensino Médio }\end{array}$ & $\begin{array}{l}\text { P4: Analisar a proposta pedagógica e seu } \\
\text { conteúdo programático. }\end{array}$ \\
\hline \begin{tabular}{|llll} 
E5: & Identificar e analisar & o & tópico \\
matemático A.C. nos documentos da escola.
\end{tabular} & $\begin{array}{l}\text { P5: Descrever a análise do tópico A.C. } \\
\text { encontrado nos documentos da escola. }\end{array}$ \\
\hline $\begin{array}{l}\text { E6: Elaborar um termo de compromisso } \\
\text { com os alunos. }\end{array}$ & $\begin{array}{l}\text { P6: Elaboração do termo de compromisso } \\
\text { juntamente com os alunos. }\end{array}$ \\
\hline $\begin{array}{l}\text { E7: Selecionar problemas para desenvolver } \\
\text { a A.C., utilizando a metodologia de } \\
\text { trabalho adotada. }\end{array}$ & $\begin{array}{l}\text { P7: Organização dos problemas selecionados } \\
\text { para trabalhar com a metodologia adotada. }\end{array}$ \\
\hline
\end{tabular}

Posto o Procedimento Geral em ação, coletam-se as informações e tiram-se as evidências relevantes para o trabalho. Parte-se então para o terceiro bloco proposto por Romberg, que é dar sentido às informações coletadas e relatar resultados para outros. 
$3^{\circ}$ bloco: Dar sentido às informações coletadas e relatar os resultados para outros.

\section{$\underline{7^{\mathrm{a}} \text { atividade: Coletar informações. }}$}

Quando colocamos os procedimentos em ação, obtêm-se informações que serão necessárias para responder às perguntas ou conjecturas levantadas. Os procedimentos podem ser totalmente planejados ou serem redefinidos durante a coleta, dependendo de como se conduz a pesquisa.

$\underline{8^{\mathrm{a}} \text { atividade: Interpretar as informações coletadas. }}$

Nesta atividade as informações coletadas são selecionadas, organizadas e interpretadas. O pesquisador pode utilizar os métodos quantitativos, onde se atribui números às informações e os métodos qualitativos, quando os números não forem utilizados. Dentre as informações coletadas, parte delas é relevante, parte é irrelevante e parte não é compreensível, cabe ao pesquisador selecionar aquelas que são importantes para a pesquisa e que ajudam responder às perguntas ou conjecturas levantadas. Romberg ressalta que tentar encontrar informação importante dentre todas que estejam disponíveis é uma arte na qual certas pessoas são melhores do que outras.(2007, p.103)

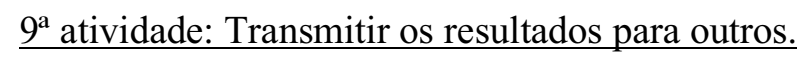

Romberg fala da importância de relatar aos outros membros de pesquisa sobre uma investigação terminada e buscar seus comentários e críticas. Além dessa responsabilidade, é importante que o pesquisador situe sua visão de mundo, pois as descobertas são interpretadas segundo essa visão, senão os leitores usarão suas próprias noções para interpretar o estudo. $\underline{10^{\mathrm{a}} \text { atividade: Antecipar ação de outros. }}$

Os pesquisadores tentam situar cada estudo em uma cadeia de investigações. Coisas que vieram antes e coisas que vêm após qualquer particular estudo são importantes. (2007, p.103)

O pesquisador nesse passo está interessado no que acontecerá depois e deveria antecipar ações posteriores. Desse modo, membros de uma comunidade discutem idéias entre si, dão sugestões de novos passos, modificações de estudos anteriores, elaboração de propostas, etc.

\section{"Onde estou na pesquisa?"}

$3^{\circ}$ bloco: Dar sentido às informações coletadas e relatar os resultados para outros.

\section{7: Ganhar Evidências}

\section{8: Interpretar as Evidências}




\section{9: Relatar Resultados}

\section{0: Antecipar as Ações dos Outros}

Assim, o objetivo central desta pesquisa é apresentar uma proposta de trabalho para abordar Análise Combinatória em sala de aula, utilizando a Metodologia de EnsinoAprendizagem-Avaliação de Matemática através da Resolução de Problemas. Constituem-se como objetivos específicos: verificar a necessidade de um trabalho de investigação sem depender de fórmulas previamente determinadas; discutir conceitos de Análise Combinatória através da resolução de problemas; explorar situações-problema, numa abordagem do cotidiano em sala de aula, visando à construção desses conceitos pelos próprios alunos, como co-construtores desse conhecimento sob a guia do professor. 